OECD Reviews of Migrant Education The Resilience of Students with an Immigrant Background FACTORS THAT SHAPE WELL-BEING

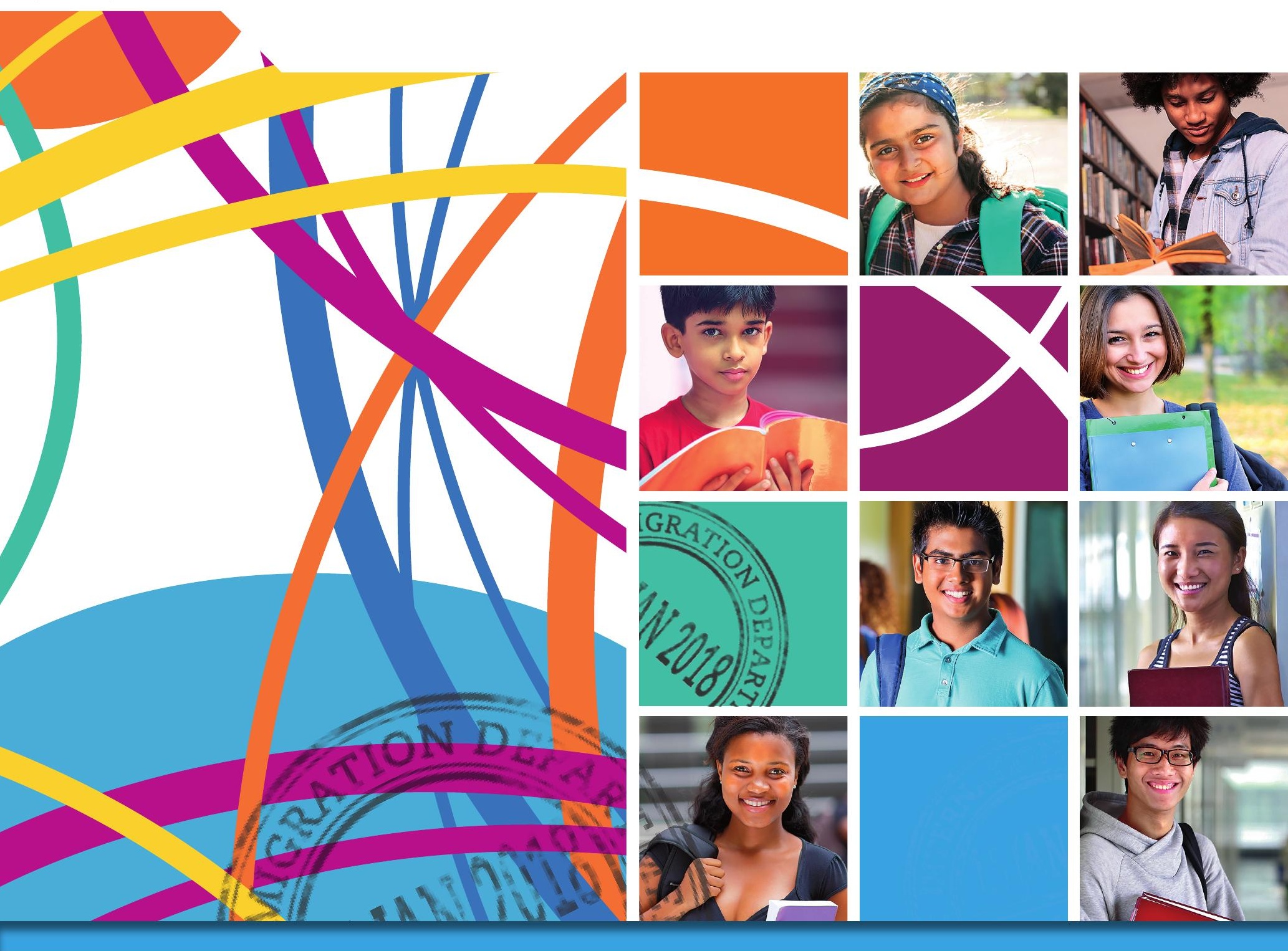

0) OECD 

OECD Reviews of Migrant Education

\section{The Resilience of Students with \\ an Immigrant Background}

FACTORS THAT SHAPE WELL-BEING

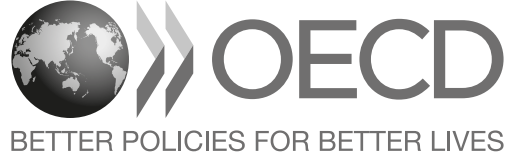


This work is published under the responsibility of the Secretary-General of the OECD. The opinions expressed and arguments employed herein do not necessarily reflect the official views of the OECD member countries.

This document, as well as any data and any map included herein, are without prejudice to the status of or sovereignty over any territory, to the delimitation of international frontiers and boundaries and to the name of any territory, city or area.

Please cite this publication as:

OECD (2018), The resilience of students with an immigrant background: Factors that shape well-being,

OECD Publishing, Paris.

http://dx.doi.org/10.1787/9789264292093-en

ISBN (print) 978-92-64-20090-6

ISBN (PDF) 978-92-64-29209-3

Series: OECD Reviews of Migrant Education

ISSN: 20776802 (print)

ISSN: 20776829 (online)

The statistical data for Israel are supplied by and under the responsibility of the relevant Israeli authorities. The use of such data by the OECD is without prejudice to the status of the Golan Heights, East Jerusalem and Israeli settlements in the West Bank under the terms of international law.

Photo credits:

() bo1982/iStock

(c) Bo1982/Shutterstock

(c) Jacob Lund/Shutterstock

( ) kate_sept2004/iStock

(c) michaeljung/Shutterstock

(c) Muralinath/iStock

() Steve Debenport/iStock

(c) tommaso79/Shutterstock

Corrigenda to OECD publications may be found on line at: www.oecd.org/publishing/corrigenda.

(c) OECD 2018

You can copy, download or print OECD content for your own use, and you can include excerpts from OECD publications, databases and multimedia products in your own documents, presentations, blogs, websites and teaching materials, provided that suitable acknowledgment of the source and copyright owner is given. All requests for public or commercial use and translation rights should be submitted to rights@oecd.org. Requests for permission to photocopy portions of this material for public or commercial use shall be addressed directly to the Copyright Clearance Center (CCC) at info@copyright.com or the Centre français d'exploitation du droit de copie (CFC) at contact@cfcopies.com. 


\section{Foreword}

Migration flows are profoundly changing the composition of classrooms. Whatever the history and context in each country, data from the Programme for International Student Assessment (PISA) reveals growing social, cultural and linguistic diversity. The ability of societies to preserve and promote social cohesion in the presence of large migration flows depends on their capacity to integrate immigrants.

While migration flows pose challenges for host communities, they also represent opportunities. Diversity has always been at the heart of human progress. Beyond that, migration can facilitate the adjustment in ageing socieities. But to unlock the benefits of migration, effective education and social policies are necessary to integrate migrant children successfully into society. Education systems shape immigrants' ability to eventually participate in the labour markets of host countries, contribute to welfare arrangements, and feel part of their communities. The growing share of children among those fleeing conflict has led to a re-examination of how best to integrate foreign-born children into their new communities. This is particularly important given the high likelihood that a large number of young migrants will settle permanently in their country of destination.

Education can help immigrants acquire skills and contribute to the host-country economy; it can also foster immigrants' social and emotional well-being and sustain their motivation to join others in work and life in their new communities - and, by doing so, help them integrate more easily. But ensuring that students with an immigrant background have positive well-being outcomes represents a significant challenge, because many immigrant or mixed-heritage students must overcome the adversities associated with displacement, socio-economic disadvantage, language barriers and the difficulty of forging a new identity all at the same time.

This report looks at the issue from a new angle, by examining the resilience of students with an immigrant background, from academic, social and emotional perspectives. It draws on data from PISA and the European Social Survey (ESS) to identify both the risk factors that prevent immigrant students from successfully integrating and the protective factors that enable these students to thrive. The report paints a detailed picture of the diversity of circumstances that arise as the face and nature of international migration changes. It illustrates how institutional and social features play a key role in reducing the vulnerability of students with an immigrant background to the adverse circumstances that accompany migration, and how education systems should therefore be held accountable for the opportunities they create for students to overcome adversity.

The growing diversity that arises from international migration can be a great opportunity for education systems, forcing teachers to rethink their pedagogical approaches and teaching styles to address the needs of highly diverse student populations. Doing so will better equip them to cater to the needs of each individual student, whether this student has an immigrant background or not. At the same time, if teachers and educators are left without the right support they may not be able to adapt and, as a result, all students may suffer.

The OECD, with its Strength through Diversity project, stands ready to support countries develop education systems that promote the academic, social, and emotional resilience of students with an immigrant background.

The development of this report was guided by Andreas Schleicher and Yuri Belfali and was overseen by the Education Policy Committee. The report was drafted by Francesca Borgonovi with Alessandro Ferrara. 
Lucie Cerna, Jose Marquez and Özge Bilgili drafted materials for specific chapters of the report. Marilyn Achiron edited the report and Henri Pearson co-ordinated its production. Fung Kwan Tam designed the publication. Cécile Bily, François Keslair and Diana Tramontano provided editorial, statistical and administrative support. The report benefited from substantive input from the study's Steering Committee at the European Commission, led by Susanne von Below, with Kristina Cunningham, Vladimir Garkov, Geir Ottestad, Emanuela Tassa and Margie Waters. Finally, the report was enriched by the thoughtful contributions provided by the many participants in the policy fora organised in the context of the Strength through Diversity project and, in particular, by the Education Counsellors. 


\section{Table of Contents}

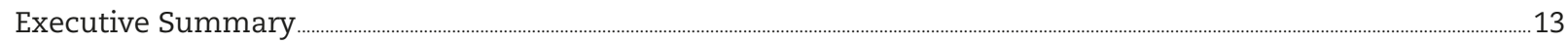

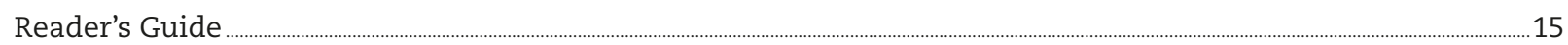

Chapter 1

Overview - The resilience of students with an immigrant background: Factors that shape well-being .............17

A profile of students with an immigrant background in OECD and EU countries ................................................................... 18

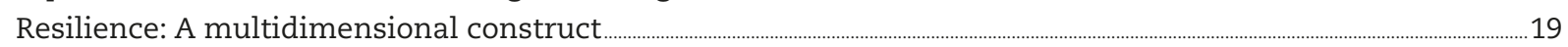

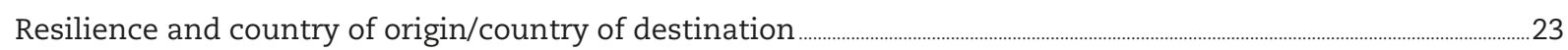

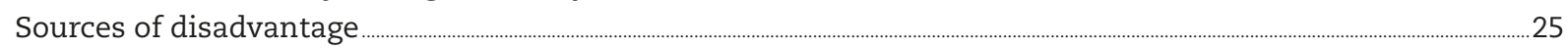

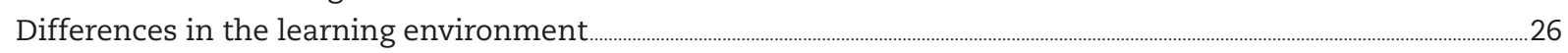

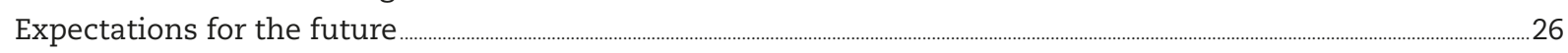

What can education policy do to help immigrant students become more resilient? ..................................................................27

Chapter 2

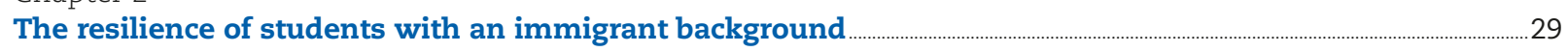

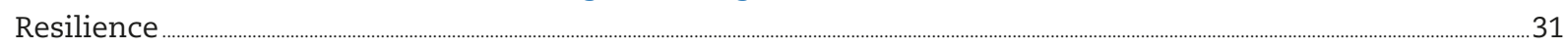

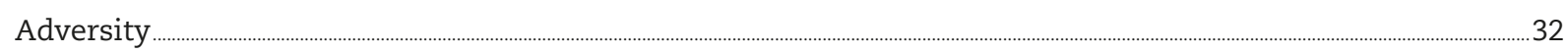

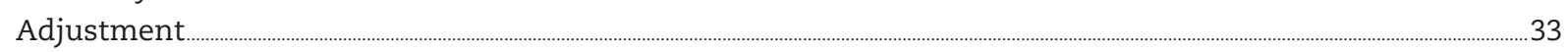

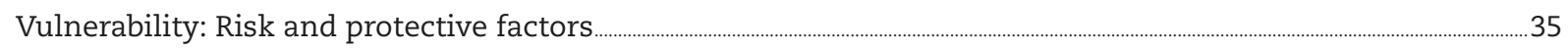

Analytical choices taken in this report to study the resilience of students with an immigrant background...........36

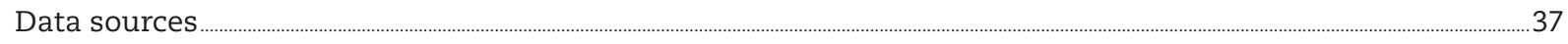

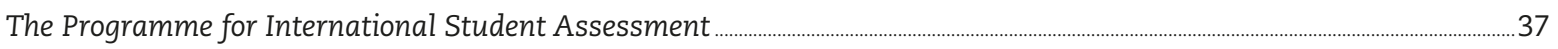

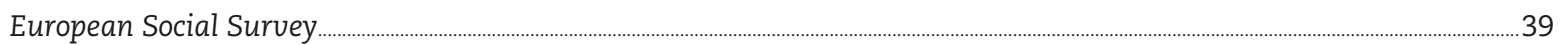

Chapter 3

Adversity and adjustment: The resilience of students with an immigrant background .....................................................45

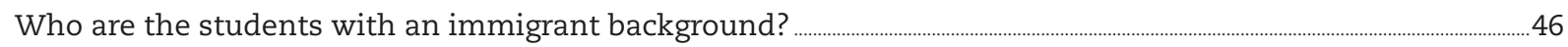

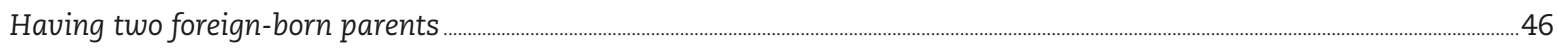

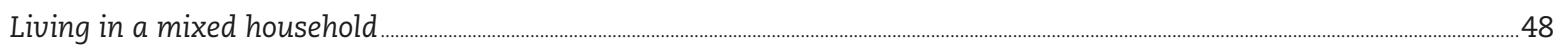

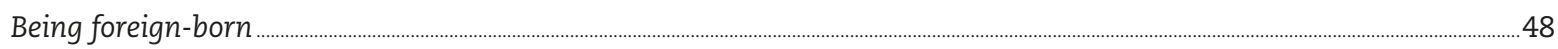

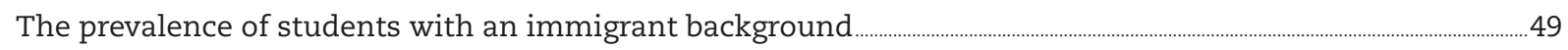

First-generation immigrant students: Differences related to the age at arrival ……....................................................................5

The academic resilience of students with an immigrant background .......................................................................................................... 58

The social and emotional resilience of students with an immigrant background .........................................................................64

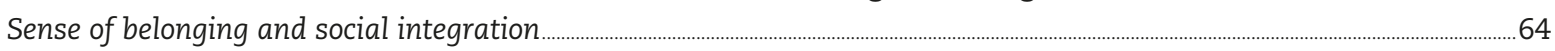

Life satisfaction ............................................................................................................................................................................................................. 70

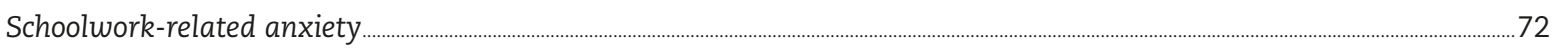

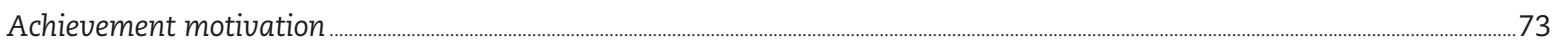

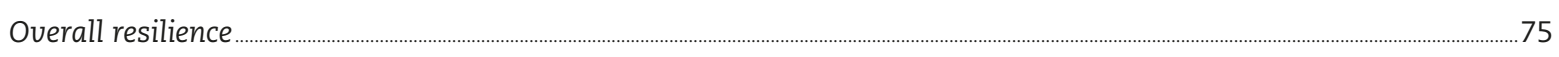

Annex 3.A1 - Unaccompanied children .................................................................................................................................................................................... 83

Spotlight on social outcomes among native and immigrant young adults in Europe: Evidence from

the European Social Survey. 
Chapter 4

Individual characteristics and the resilience of students with an immigrant background .......................................99

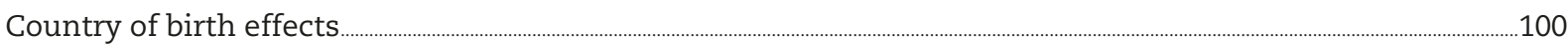

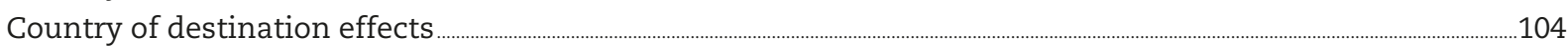

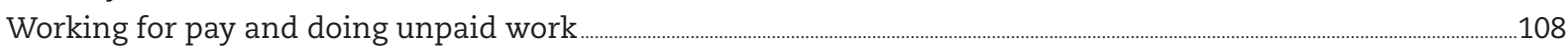

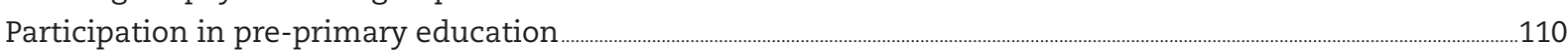

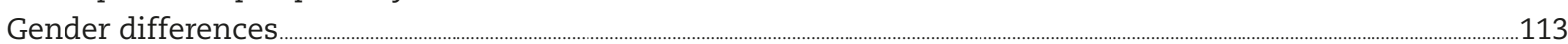

Chapter 5

Language barriers and the resilience of students with an immigrant background ........................................................117

Individual characteristics and use of the host-country language at home ...........................................................................................122

Immigrant background and languages spoken at home: An overview ....................................................................................................... 123

Language barriers and the academic performance of students with an immigrant background ..............................127

Attaining baseline levels of proficiency in the core PISA subjects ....................................................................................................................129

Language barriers and the well-being of students with an immigrant background ................................................................133

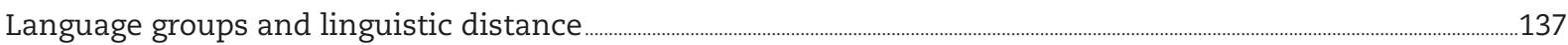

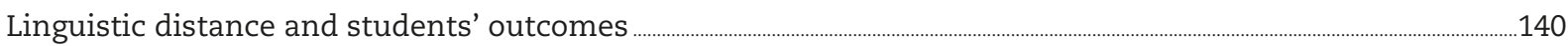

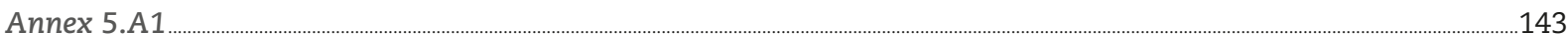

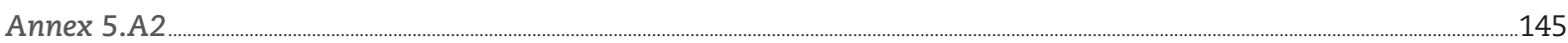

Chapter 6

Resilience and the socio-economic status of students with an immigrant background ..............................................149

The socio-economic status of students with an immigrant background …........................................................................................154

Socio-economic status and the academic, social and emotional resilience of students

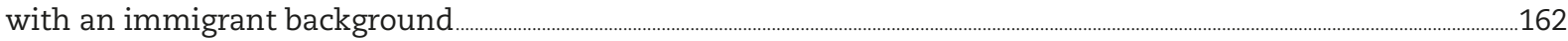

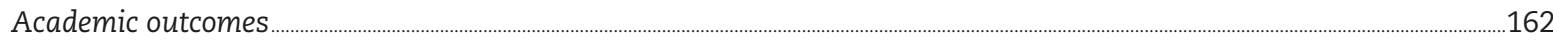

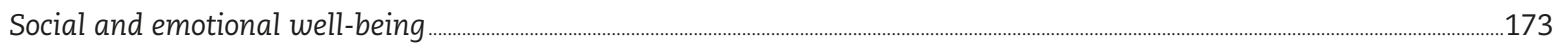

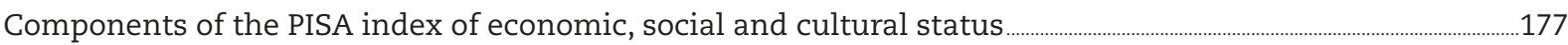

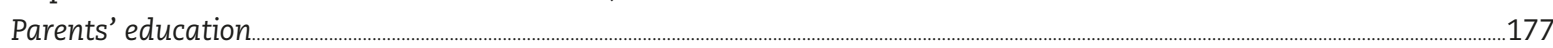

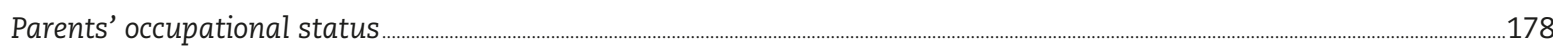

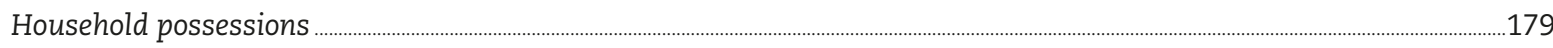

Socio-economic status and the disadvantage of students with an immigrant background .......................................181

Chapter 7

How schools and education policy support or undermine student resilience

The learning environment and the academic, social, emotional and motivational resilience

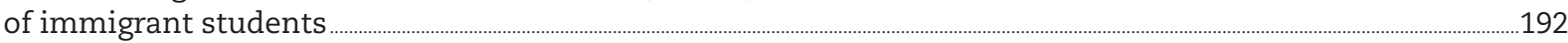

School composition ..................................................................................................................................................................................................................193

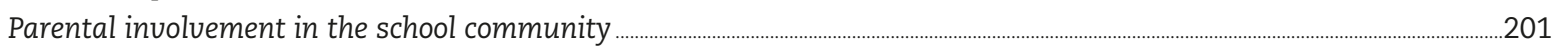

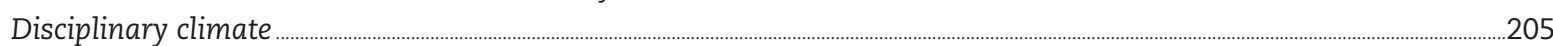

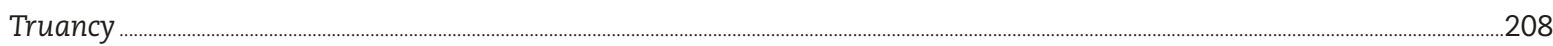

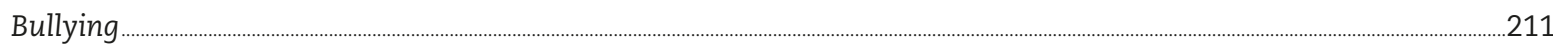

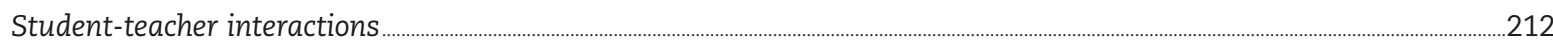

School resources and the academic, social, emotional and motivational resilience of immigrant students .........221

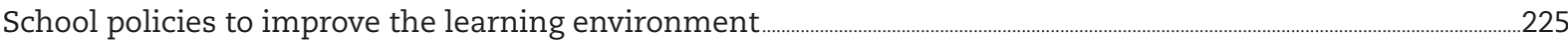

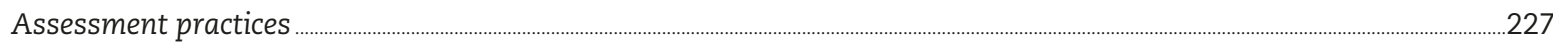

Selecting and grouping students: Vertical and horizontal stratification …......................................................................................................227

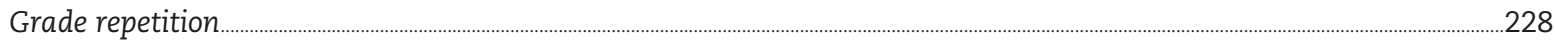

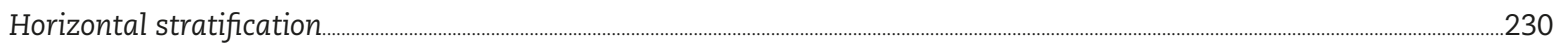

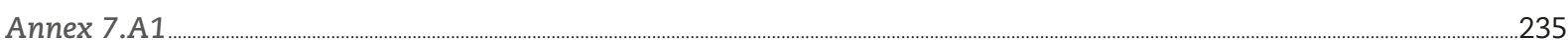

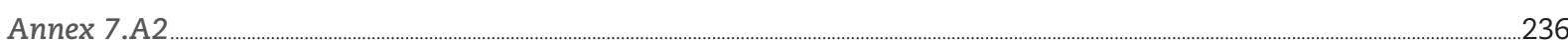


Chapter 8

What students with an immigrant background expect in their future ….........................................................................................243

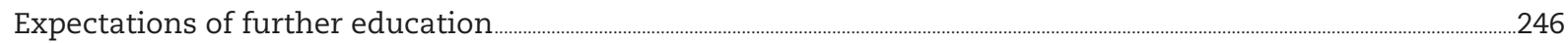

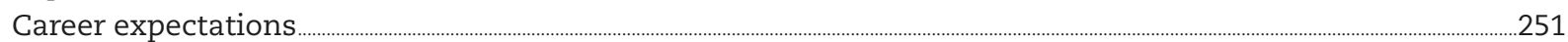

Spotlight on intergenerational educational mobility: Evidence from the European Social Survey ......................................258

Chapter 9

Policies and practices to support the resilience of students with an immigrant background ....................................263

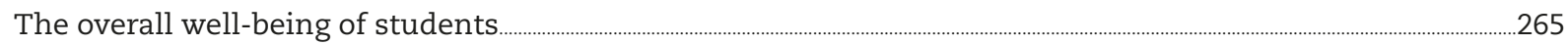

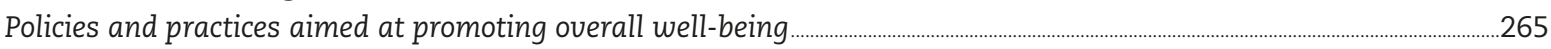

The importance of access to education for all children with an immigrant background ...................................................266

Examples of policies to promote access to quality early education .......................................................................................................................26

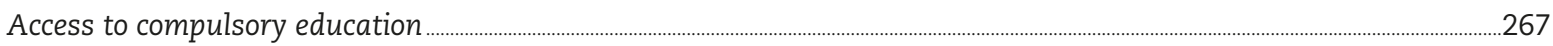

Examples of policies to promote access to vocational education and training, and higher education .....................................267

Evidence on ability grouping, grade repetition and early tracking ..............................................................................................................268

Examples of policies to reduce grade repetition and early tracking ....................................................................................................................269

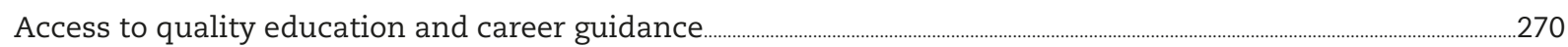

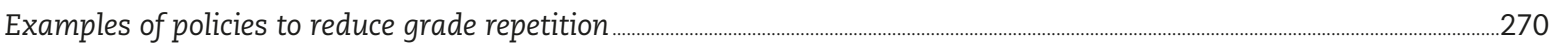

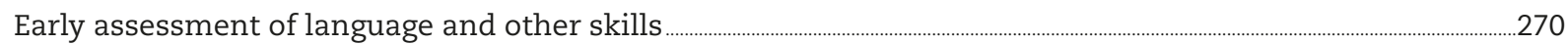

Examples of policies to promote early language assessment of all children ……..................................................................................271

Examples of policies to promote rapid language assessments of newly arrived immigrant children......................................271

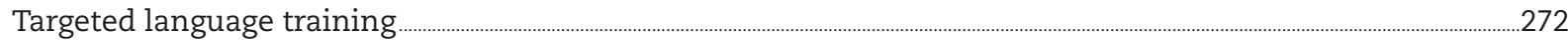

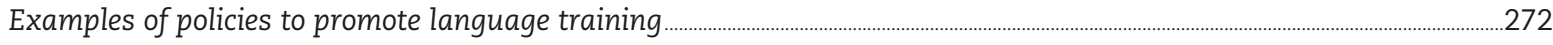

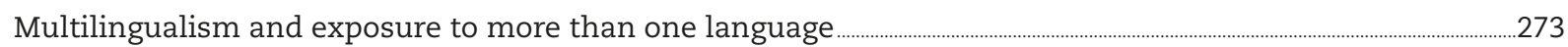

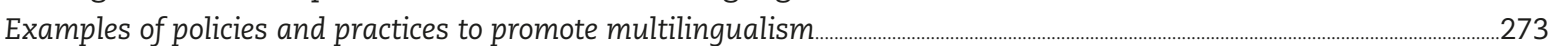

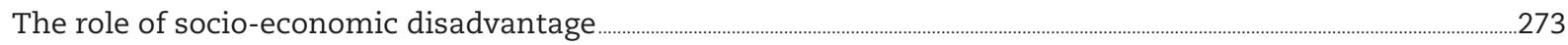

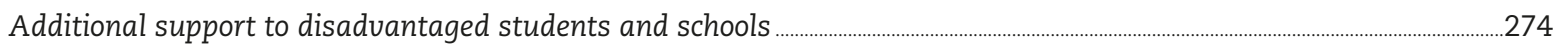

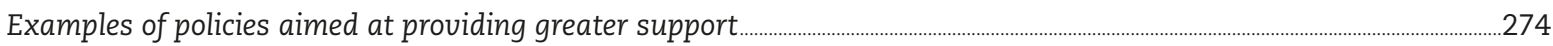

Evidence on the concentration of students with an immigrant background in disadvantaged schools ..................................274

Examples of policies aimed at limiting the concentration of disadvantaged students...........................................................................2.

Links between language and socio-economic background ………................................................................................................................. 276

Achieving a supportive climate at school through positive relationships ………..........................................................................277

Examples of policies that promote a bully-free environment .................................................................................................................................. 277

Evidence on the availability of and participation in extracurricular activities ................................................................................278

Examples of practices to encourage participation in sports and extracurricular activities ........................................................279

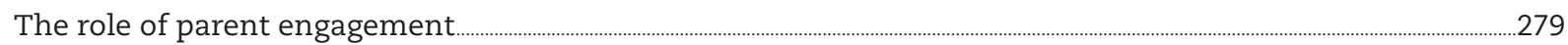

Examples of policies and practices that promote parent engagement ………............................................................................................................. 280

The role of diversity-aware teachers for supporting all learners ...................................................................................................................281

Examples of policies and practices for building a diversity-aware teaching force …..............................................................................281

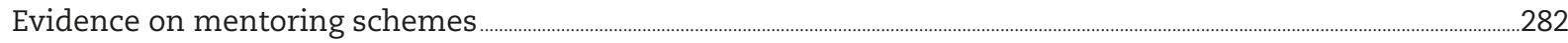

Examples of practices aimed to promote mentoring ....................................................................................................................................................................28

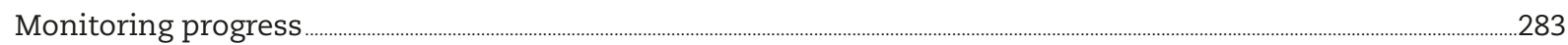

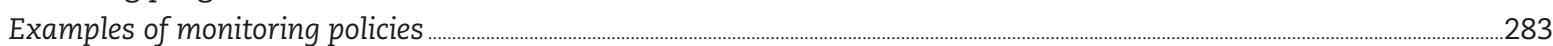


BOXES

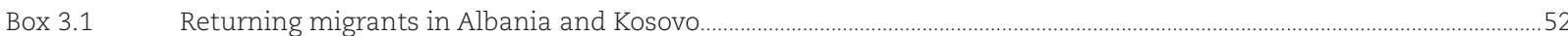

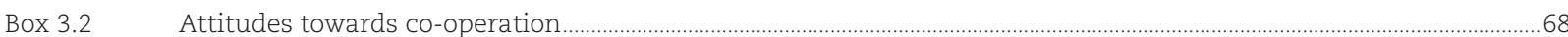

Box 5.1 Estimation of the language distance index: Levensthein distance and the Automated Similarity Judgment Program..

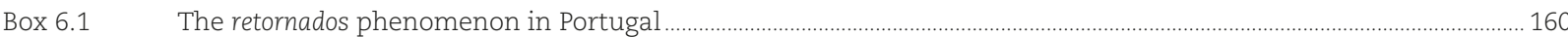

Box 6.2 Socio-economic status and performance gaps between native and immigrant students in the United States .......... 164

Box 6.3 The impact on proficiency of immigrant background and socio-economic status at different levels

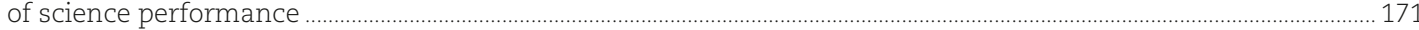

Box 7.1 Teachers' need for professional development in a multicultural setting, evidence from the Teaching

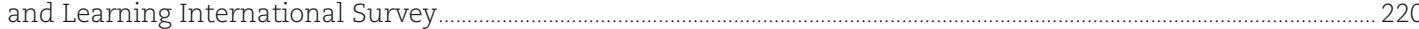

Box 7.2 The role of sports in promoting academic performance and the social well-being of immigrant students............224

\section{FIGURES}

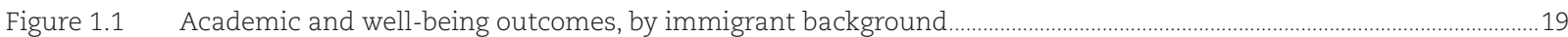

Figure 1.2 Relative risk for immigrant students of not being resilient, by resilience outcome ........................................................2.

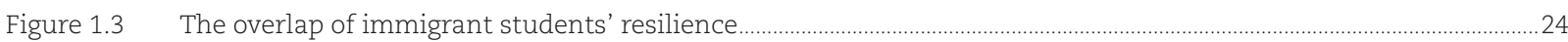

Figure 2.1 A graphical description of the elements characterising resilience …….......................................................................31

Figure 2.2 Profile of students with an immigrant background ..................................................................................................... 33

Figure 2.3 Adjustment as a multidimensional outcome .....................................................................................................................3

Figure 2.4 The multilevel nature of risk and protective factors ........................................................................................................... 35

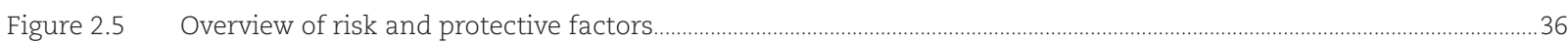

Figure 3.1 A classification of PISA students by immigrant background ........................................................................................................ 48

Figure 3.2 Trends between 2003 and 2015 in the percentage of native-born students with native born parents .........................50

Figure 3.3 Percentage of students with an immigrant background, by group ..................................................................... 51

Figure 3.4 Trends between 2003 and 2015 in the percentage of students with an immigrant background, by group .................55

Figure 3.5 Trends between 2003 and 2015 in the prevalence of late arrivals ....................................................................................5

Figure 3.6 Estimates of the global prevalence of late arrivals ............................................................................................................... 57

Figure 3.7 Percentage of students attaining baseline academic proficiency, by immigrant background .......................................61

Figure 3.8 Difference in attaining baseline academic proficiency, by immigrant group ..............................................................62

Figure 3.9 Difference in attaining baseline academic proficiency, by age at arrival...........................................................................63

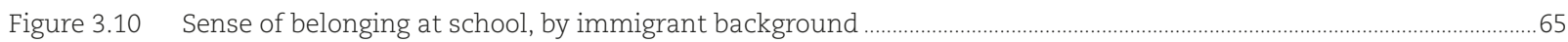

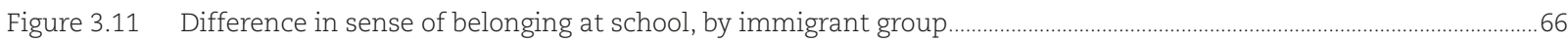

Figure 3.12 Difference in sense of belonging at school, by age at arrival .................................................................................... 67

Figure 3.13 Trends between 2003 and 2015 in sense of belonging at school, by immigrant background ............................................68

Figure 3.14 Valuing teamwork and valuing relationships, by immigrant background..........................................................................69

Figure 3.15 Satisfaction with life, by immigrant background ................................................................................................................... 71

Figure 3.16 Low schoolwork-related anxiety, by immigrant background .......................................................................................................73

Figure 3.17 Difference in motivation to achieve, by immigrant background............................................................................................74

Figure 3.18 Academically sound and socially and emotionally well-adapted students, by immigrant background.....................76

Figure 3.19 Differences in the percentage of academically sound and socially and emotionally well-adapted students,

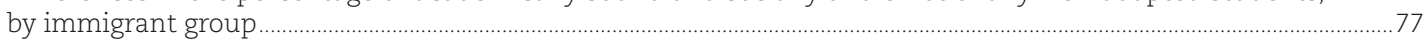

Figure 3.A1.1 Asylum applications submitted by unaccompanied minors in the EU 28, by year and age ...........................................83

Figure 3.A1.2 Asylum applications submitted by unaccompanied minors in the EU 28, by year and country of origin .................. 84

Figure 3.A1.3 Unaccompanied minors apprehended at the United States border, by fiscal year and country of origin...................85

Figure 3.a Feelings of safety in the local area among young people, by immigrant background ....................................................91

Figure 3.b Health conditions affecting daily activities among young people, by immigrant background .......................................94

Figure 3.c Subjective health among young people, by immigrant background ...............................................................................94

Figure 3.d Participation in social activities, by immigrant background ............................................................................................. 96

Figure 3.e Relative frequency of participation in social activities among young individuals, by immigrant background ..............96 
Figure 4.1 Attaining baseline academic proficiency, by country of origin ................................................................................. 101

Figure 4.2 Difference between immigrant and native students' sense of belonging at school, by country of origin................ 103

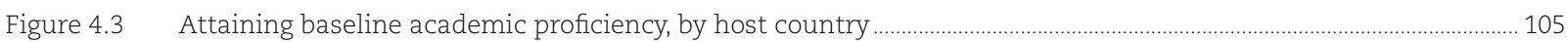

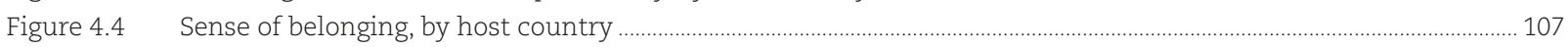

Figure 4.5 Students working for pay, by immigrant background.......................................................................................................... 108

Figure 4.6 Difference between immigrant and native students in attaining baseline academic proficiency, before

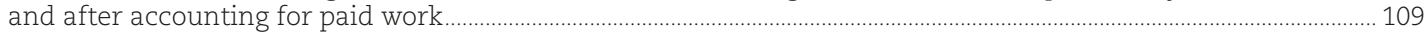

Figure 4.7 Students doing unpaid work, by immigrant background................................................................................ 110

Figure 4.8 Students who had attended pre-primary education, by immigrant background ....................................................... 111

Figure 4.9 Difference between immigrant and native students in attaining baseline academic proficiency,

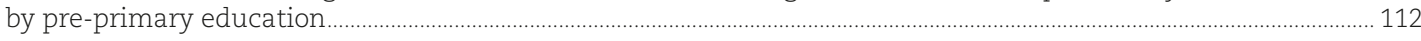

Figure 5.1 The role of the language spoken at home in the resilience process.................................................................... 118

Figure 5.2 Percentage of students with an immigrant background and non-native-speaking students .................................... 124

Figure 5.3a Percentage of non-native speakers, by immigrant background ................................................................................ 125

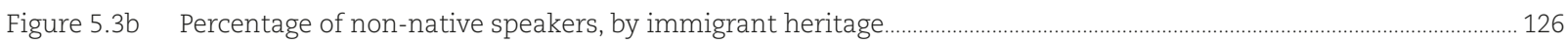

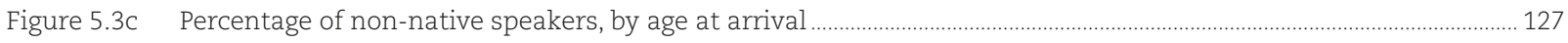

Figure 5.4 Difference in reading scores, by immigrant background and language spoken at home ........................................... 128

Figure 5.5a Students attaining baseline academic proficiency, by immigrant background and language spoken at home .......... 129

Figure 5.5b Students attaining baseline academic proficiency, by immigrant heritage and language spoken at home............. 130

Figure 5.6 Students attaining baseline academic proficiency, selected countries ............................................................. 132

Figure 5.7 Difference between late and early arrivals in attaining baseline academic proficiency ............................................... 133

Figure 5.8a Students reporting a sense of belonging at school, by immigrant background and language spoken at home......... 134

Figure 5.8b Students reporting a sense of belonging at school, by immigrant heritage and language spoken at home ............ 135

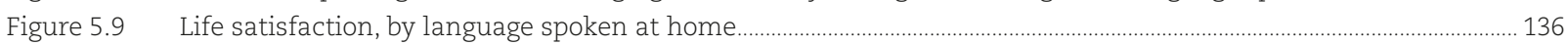

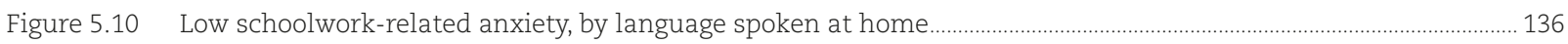

Figure 5.11 Non-native-speaking students with an immigrant background, by language spoken at home ................................... 138

Figure 6.1 How socio-economic status affects the resilience process ........................................................................... 153

Figure 6.2 Average socio-economic status, by immigrant background ………………........................................................................... 155

Figure 6.3 Difference between immigrant and native students in socio-economic status, by immigrant generation.............. 156

Figure 6.4 Difference between immigrant and native students in socio-economic status, by immigrant heritage .................. 157

Figure 6.5 Socio-economic status, by students' and parents' immigrant background ..................................................................... 159

Figure 6.6 Change between 2003 and 2015 in socio-economic difference between immigrant and native students................ 160

Figure 6.7 Difference between immigrant and native students in attaining baseline academic proficiency ............................ 163

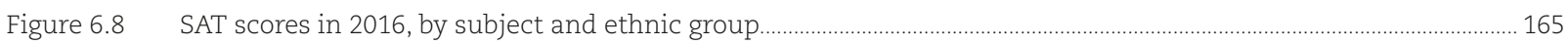

Figure 6.9 Change in the likelihood of attaining baseline academic proficiency related to socio-economic status,

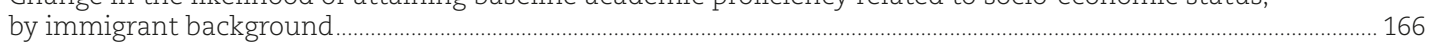

Figure 6.10 Difference between immigrant and native students in attaining baseline academic proficiency,

by socio-economic tercile .............................................................................................................................................................. 167

Figure 6.11a Disadvantaged students attaining baseline academic proficiency, by immigrant background ................................... 169

Figure 6.11b Attaining baseline academic proficiency, by immigrant background and socio-economic status ............................ 170

Figure 6.12 Immigrant-native gaps in science results across the distribution of scores.............................................................. 172

Figure 6.13 Difference between immigrant and native students in reporting a sense of belonging at school ........................... 174

Figure 6.14 Change in the likelihood of reporting a sense of belonging at school related to socio-economic status,

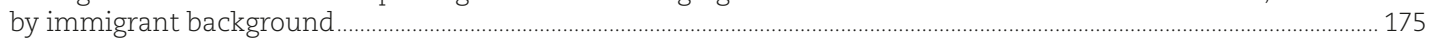

Figure 6.15 Difference between immigrant and native students in feeling satisfied with life ......................................................... 176

Figure 6.16 Difference between immigrant and native students in reporting low schoolwork-related anxiety ……................... 176

Figure 6.17 Years of parents' education, by immigrant background .................................................................................................... 177

Figure 6.18 Index of parents' highest occupational status, by immigrant background .......................................................... 179

Figure 6.19 Index of household possessions, by immigrant background ........................................................................ 180

Figure 6.20 Socio-economic status and academic outcomes .................................................................................................... 182

Figure 7.1 How education policies can promote the resilience of students with an immigrant background.............................. 191

Figure 7.2 Enrolment in urban schools, by immigrant background .................................................................................................. 194

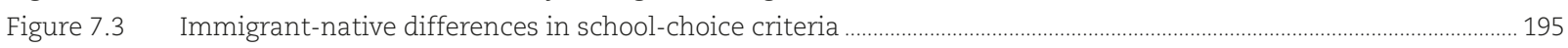

Figure 7.4 Immigrant-native differences in the importance of a school's religious philosophy ................................................... 196 
Figure 7.5 Immigrant-native differences in the importance of financial aid for school ....................................................... 197

Figure 7.6 Immigrant-native differences in the importance of school climate ………............................................................... 197

Figure 7.7 Avoiding high concentrations of immigrant students in particular schools ..................................................... 198

Figure 7.8 Academic proficiency and concentration of immigrant students in school .............................................................. 200

Figure 7.9 Sense of belonging and concentration of immigrant students in school .......................................................... 202

Figure 7.10 Students whose parents are involved in the school community, by immigrant background ....................................203

Figure 7.11 Disciplinary climate in schools attended by the average immigrant and native student ............................................206

Figure 7.12 Truancy rates in schools attended by the average immigrant and native student .....................................................209

Figure 7.13 Victims of frequent bullying, by immigrant background .................................................................................................. 211

Figure 7.14 Students reporting unfair treatment by teachers, by immigrant background...............................................................2214

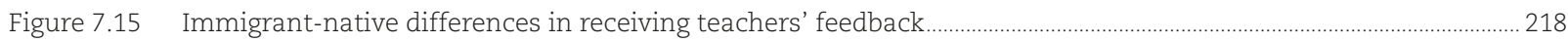

Figure 7.16 Teacher's need for professional development in a multicultural setting ........................................................................ 221

Figure 7.17 The association between sports distance and immigrant boys' science scores in four destination countries........ 225

Figure 7.18 Immigrant-native differences in grade repetition ........................................................................................................ 229

Figure 7.19 Immigrant-native differences in enrolment in vocational training ............................................................................ 232

Figure 8.1 Expectation to complete tertiary education, by immigrant background ...........................................................................2 246

Figure 8.2 Difference in the expectation to complete tertiary education.............................................................................. 247

Figure 8.3 Students with ambitious but realistic educational expectations, by immigrant background ...................................2 248

Figure 8.4 Expectation to complete only lower secondary education, by immigrant background .............................................. 249

Figure 8.5 Difference in parents' expectation that their child will complete tertiary education ...................................................2 250

Figure 8.6 Ambitious career expectations, by immigrant background.............................................................................. 252

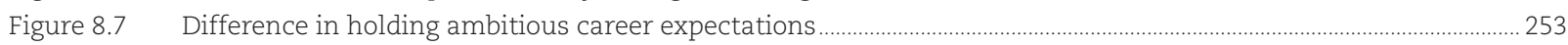

Figure 8.8 Students with ambitious but realistic career expectations, by immigrant background..............................................254

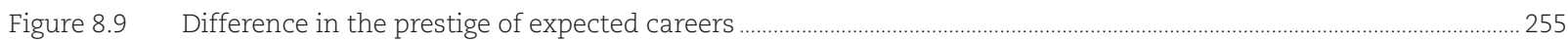

Figure 8.10 Change between 2006 and 2015 in ambitious career expectations, by immigrant background .............................2256

\section{TABLES}

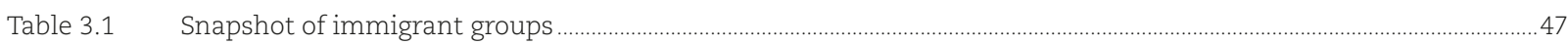

Table 3.5 Snapshot of the academic, social, emotional and motivational resilience of immigrant students ................................59

Table 3.6 Snapshot of academic resilience, by immigrant background .................................................................................................. 60

Table 3.A1.1 Asylum applications submitted by unaccompanied minors in selected European countries, by year

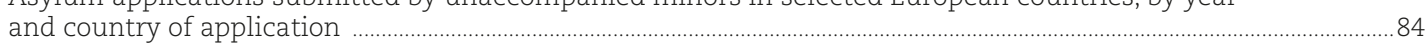

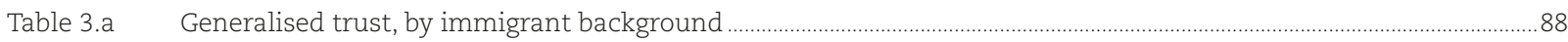

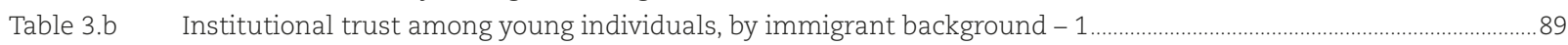

Table 3.c Institutional trust among young individuals, by immigrant background - 2 …...............................................................90

Table 3.d Satisfaction with democracy, the state of economy and the government among young individuals,

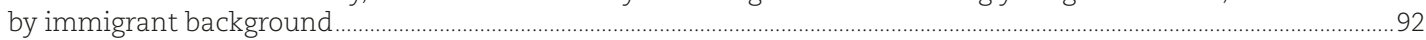

Table 3.e Satisfaction with education and health services among young individuals, by immigrant background ....................93

Table 4.12 Change in the likelihood that students will reach baseline levels of academic proficiency,

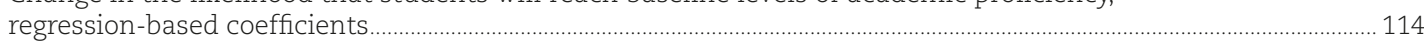

Table 5.1 Snapshot of language barriers to attaining baseline academic proficiency ...................................................................... 119

Table 5.2 Snapshot of language barriers to feeling a sense of belonging at school ........................................................................ 120

Table 5.15 Linguistic distance between the PISA test language and languages spoken at home ............................................ 140

Table 5.A1.1 Attaining baseline academic proficiency and linguistic distance ....................................................................... 143

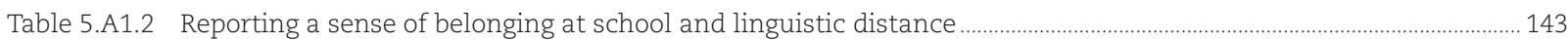

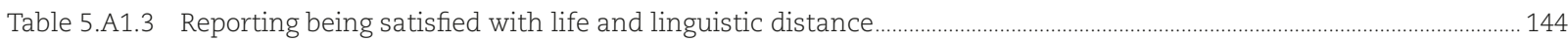

Table 5.A1.4 Reporting low levels of schoolwork-related anxiety and linguistic distance........................................................... 144

Table 5.A1.5 High achievement motivation and linguistic distance ............................................................................................... 144

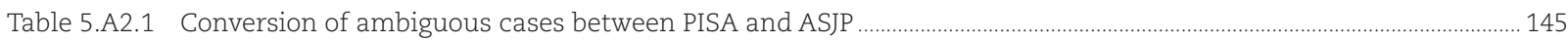

Table 6.1 Snapshot of the socio-economic status of immigrant and native students.......................................................... 151

Table 6.2 Snapshot of the relation between immigrant-native gaps in socio-economic background and gaps in acaemic and well-being outcomes. 
Table 7.1

Table 7.2

Table 7.13

Table 7.15

Table 7.17

Table 7.19

Table 7.21

Table 7.23

Table 7.31

Table 7.32

Table 7.35

Table 7.38

Table 7.A1.1

Table 7.A2.1

Table 7.A2.2

Snapshot of school-level risk factors for immigrant students -1

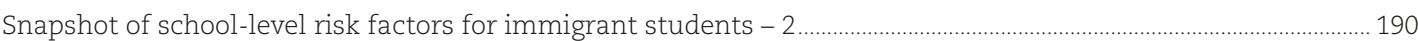

Parents' involvement in the school community, and students' academic and well-being outcomes .......................204

School disciplinary climate, and students' academic and well-being outcomes ............................................................ 207

School-level truancy, and students' academic and well-being outcomes ....................................................................... 210

Frequent bullying, and students' academic and well-being outcomes ......................................................................... 213

Perceived frequent unfair treatment by teachers, and students' academic and well-being outcomes .................... 216

Receiving frequent feedback from the science teacher, and students' well-being ....................................................2 219

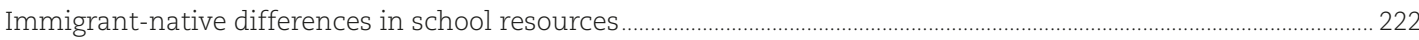

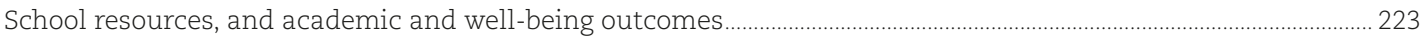

Grade repetition and students' well-being outcomes ................................................................................................ 231

Enrolment in vocational programmes and students' well-being outcomes ..........................................................2 233

The association between sports distance and immigrant students' science scores..................................................2235

Change in school level disciplinary climate associated with school level inputs, regression-based coefficients ....... 236

Change in the likelihood that students will report having frequently experienced being unfairly treated

by their teachers, regression-based coefficients

Table 8.1 Snapshot of the expectations of immigrant students for the future

Table 8.b

Correlation between respondent's level of education and the highest level of education of their parents, by immigrant background

Table 8.c

Educational mobility, by age group and immigrant background

Table 9.1 Interaction between tracking and attendance at pre-primary education.

Table 9.2

Targeting efforts on key risk factors for the academic resilience of immigrant students: The relative importance of language and socio-economic background.

Table 9.3 Targeting efforts on key risk factors for the social resilience of immigrant students: The relative importance

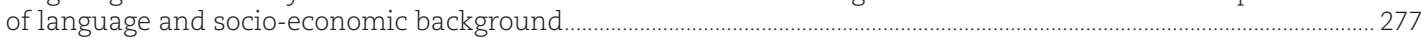

Table 9.4 Interaction between feedback and perceived unfair treatment by teachers

\section{Follow OECD Publications on:}

http://twitter.com/OECD_Pubs

http://www.facebook.com/OECDPublications

in. http://www.linkedin.com/groups/OECD-Publications-4645871

Yoube http://www.youtube.com/oecdilibrary

http://www.oecd.org/oecddirect/

\section{This book has...}

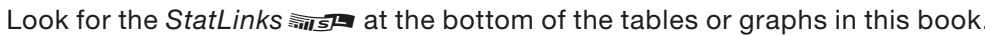
To download the matching Excel® spreadsheet, just type the link into your Internet browser, starting with the $h t t p: / / d x$.doi.org prefix, or click on the link from the e-book edition. 



\section{Executive Summary}

Migration flows are profoundly changing the composition of classrooms. Analyses of PISA data reveal that in 2015, almost one in four 15-year-old students in OECD countries reported that they were either foreign-born or had at least one foreign-born parent. In Switzerland and Luxembourg more than one in two 15-year-old students reported that they were either foreign born or had at least one parent who was. Between 2003 and 2015, the share of students who had either migrated or who had a parent who had migrated across international borders grew by six percentage points, on average across OECD countries.

Migration flows from several decades ago still loom large. Of all groups of students with an immigrant background, defined here as either being foreign-born or having at least one foreign-born parent, the share of second-generation immigrant students (native-born children of foreign-born parents) grew most rapidly (by three percentage points) on average across OECD countries between 2003 and 2015. The share of native-born students with a mixed heritage, i.e. students who were born in the country in which they sat the PISA test and have one native- and one foreign-born parent, grew by two percentage points, on average, across OECD countries. Migration waves after 2000, which are reflected in the share of foreignborn students, account for only a one percentage-point increase, on average across OECD countries. In 2015, recent arrivals - foreign-born students who had settled in the host country at or after the age of 12 - represented about one-third of all first-generation immigrant students, on average.

The ability of societies to maintain social cohesion in the presence of large migration flows depends on their capacity to integrate immigrants. Education can help immigrants acquire skills and contribute to the host-country economy; it can also contribute to migrants' social and emotional well-being and sustain their motivation to participate in the social and civic life of their new communities. But ensuring that students with an immigrant background enjoy academic, social and emotional well-being implies that these students must first overcome the adversities associated with displacement, socio-economic disadvantage, language barriers and the difficulty of forging a new identity - all at the same time.

The capacity of students with an immigrant background to overcome these hardships and be resilient should be judged not only on their ability to attain baseline levels of academic proficiency, but also on their sense of belonging at school, their satisfaction with life, their level of schoolwork-related anxiety and their motivation to achieve. These five indicators represent key dimensions of well-being measured by PISA in 2015.

Students with an immigrant background tend to underperform in school. This is particularly true of first-generation immigrant students (foreign-born students of foreign-born parents). On average across OECD countries, as much as $51 \%$ of first-generation immigrant students failed to reach baseline academic proficiency in reading, mathematics and science, compared to $28 \%$ percent of students without an immigrant background who failed to reach that level. Similar differences are observed in most other wellbeing outcomes as well: $41 \%$ of first-generation immigrant students reported a weak sense of belonging, compared to $33 \%$ of students without an immigrant background who so reported; $31 \%$ of first-generation immigrant students reported low life satisfaction, compared to $28 \%$ of students without an immigrant background; and $67 \%$ of first-generation immigrant students reported high schoolwork-related anxiety, compared to $61 \%$ of students without an immigrant background.

Academic underperformance among students with an immigrant background is particularly pronounced in Austria, Belgium, Denmark, Finland, Germany, Iceland, Japan, Luxembourg, Slovenia, Sweden and Switzerland. In these countries, immigrant students (students, native- or foreign-born, who have two foreign-born parents) are more than twice as likely as students without an immigrant background to fail to achieve baseline academic proficiency. 
But even in some countries where academic underperformance among students with an immigrant background is not as marked, the analysis also shows that students with an immigrant background suffer in other measures of well-being too. In the Slovak Republic and Spain, for example, immigrant students were considerably less likely than native students to report a strong sense of belonging at school. In France, Iceland, Spain and the United Kingdom, immigrant students were considerably less likely to report being satisfied with their life. In Austria, Finland, Luxembourg and Switzerland, they were considerably more likely than native students to report high levels of schoolwork-related anxiety. While in most countries, immigrant students expressed greater motivation to achieve, in Israel and Mexico, immigrant students were significantly less likely to report high achievement motivation than students who had no direct experience of migration.

Socio-economic disadvantage and language barriers are two of the greatest obstacles to the successful integration of students with an immigrant background. For example, differences in socio-economic status explain over one-fifth of the gap between immigrant students and students without an immigrant background in the likelihood of attaining baseline levels of academic proficiency, on average across OECD countries. Similarly, immigrant students in OECD countries who do not speak the language of assessment at home are around eight percentage points less likely to be academically resilient than native-speaking immigrant students.

Education systems, schools and teachers can play a significant role in helping students with an immigrant background integrate into their communities, overcome adversity and build their academic, social, emotional and motivational resilience. Introducing early assessment of language and other skills, providing targeted language training, building a diversity-aware teaching force that can support all learners, offering additional support to disadvantaged students and schools, implementing effective anti-bullying programmes, ensuring the availability of and participation in extracurricular activities, and engaging parents can improve the well-being of students with an immigrant background, in all of its facets. 


\section{Reader's Guide}

\section{Data underlying the figures}

Two symbols are used to denote missing data:

c There are too few observations or no observations to provide reliable estimates (i.e. there are fewer than 30 students or fewer than 5 schools with valid data).

m Data are not available. These data were not submitted by the country or were collected but subsequently removed from the publication for technical reasons.

\section{Country coverage}

Analyses based on data from the Programme for International Student Assessment (PISA) presented in this publication feature results on all countries and economies that are present in the PISA Public Use Databases (various years), including all 35 OECD countries. Analyses based on European Social Survey data feature results on those countries that took part in at least two ESS rounds and for which at least 30 immigrants could be identified in the pooled sample.

The statistical data for Israel are supplied by and under the responsibility of the relevant Israeli authorities. The use of such data by the OECD is without prejudice to the status of the Golan Heights, East Jerusalem and Israeli settlements in the West Bank under the terms of international law.

B-S-J-G (China) refers to the four PISA-participating China provinces: Beijing, Shanghai, Jiangsu and Guangdong.

FYROM refers to the Former Yugoslav Republic of Macedonia.

Only data for the adjudicated region of Ciudad Autónoma de Buenos Aires (CABA) are reported in figures and in the text.

Results for Kazakhstan, Malaysia and Argentina are reported only in tables available on line.

Because life stasfaction was not asked to students participating in PISA in 2015 in the Flemish Community of Belgium, whenever analyses involve self-reported life satisfaction, results for Belgium exclude the sample of students from the Flemish Community.

\section{International averages}

The OECD and EU averages correspond to the arithmetic mean of the respective country estimates. They were calculated for most indicators presented in this report.

In this publication, the OECD and EU averages are generally used when the focus is on comparing characteristics of education systems. In the case of some countries, data may not be available for specific indicators, or specific categories may not apply. Readers should, therefore, keep in mind that the terms "OECD average" and "EU average" refer to the OECD/EU countries included in the respective comparisons. In cases where data are not available or do not apply for all sub-categories of a given population or indicator, the "OECD average" and "EU average" may be consistent within each column of a table but not necessarily across all columns of a table. In analyses involving data from multiple years, the OECD and EU averages are reported on consistent sets of OECD and EU countries. 


\title{
Rounding figures
}

Because of rounding, some figures in tables may not add up exactly to the totals. Totals, differences and averages are always calculated on the basis of exact numbers and are rounded only after calculation. All standard errors in this publication have been rounded to one or two decimal places. Where the value 0.0 or 0.00 is shown, this does not imply that the standard error is zero, but that it is smaller than 0.05 or 0.005 , respectively.

\section{Reporting student data}

The report uses "15-year-olds" as shorthand for the PISA target population. PISA covers students who are aged between 15 years 3 months and 16 years 2 months at the time of assessment and who are enrolled in school and have completed at least 6 years of formal schooling, regardless of the type of institution in which they are enrolled, and whether they are in full-time or part-time education, whether they attend academic or vocational programmes, and whether they attend public or private schools or foreign schools within the country.

\section{Reporting school data}

The principals of the schools in which students were assessed provided information on their schools' characteristics by completing a school questionnaire. Where responses from school principals are presented in this publication, they are weighted so that they are proportionate to the number of 15 -year-olds enrolled in the school.

\section{Focusing on statistically significant differences}

This volume discusses only differences or changes that are significant at the $5 \%$ level $(p<0.05)$. These are denoted in darker colours in figures and in bold font in tables.

\author{
Abbreviations used in this report \\ $\%$ point diff. Percentage-point difference \\ Mean diff. Mean difference \\ S.E. Standard Error \\ ISCO International Standard Classification of Occupations \\ ISCED International Standard Classification of Education \\ ESCS PISA index of economic, social and cultural status
}




\section{Chapter 1}

\section{Overview - The resilience of students with an immigrant background: Factors that shape well-being}

This chapter summarises the main findings of the report. It identifies different groups of students with an immigrant background and their academic, social, emotional and motivational outcomes. It illustrates differences in the outcomes of different groups of students in different education systems as well as factors at the individual, family, school and education system levels that can shape student academic proficiency and broader well-being. It concludes by identifying the policy implications of the report.

\section{Notes regarding Cyprus}

Note by Turkey: The information in this document with reference to "Cyprus" relates to the southern part of the Island. There is no single authority representing both Turkish and Greek Cypriot people on the Island. Turkey recognises the Turkish Republic of Northern Cyprus (TRNC). Until a lasting and equitable solution is found within the context of the United Nations, Turkey shall preserve its position concerning the "Cyprus issue".

Note by all the European Union Member States of the OECD and the European Union: The Republic of Cyprus is recognised by all members of the United Nations with the exception of Turkey. The information in this document relates to the area under the effective control of the Government of the Republic of Cyprus.

\section{Note regarding data from Israel}

The statistical data for Israel are supplied by and under the responsibility of the relevant Israeli authorities. The use of such data by the OECD is without prejudice to the status of the Golan Heights, East Jerusalem and Israeli settlements in the West Bank under the terms of international law. 
A

n estimated 4.8 million migrants arrived at OECD countries in 2015 , an increase of about $10 \%$ over the previous year, with family reunification and free movement across borders each accounting for about a third of these entries. The recent wave of migration has reinforced a long and steady upward trend in the share of immigrants in OECD countries, which has grown by more than $30 \%$ since 2000 and has become increasingly diverse. While migration flows can create difficulties for host communities, they also represent an opportunity for countries that face ageing native-born populations and the associated threat of labour and skills shortages. Effective education and social policies are necessary to integrate migrant children successfully into society and unlock the potential benefits of migration.

The ability of societies to maintain social cohesion in the presence of large migration flows depends on their capacity to integrate foreign-born populations. Education can help migrants acquire skills and contribute to the host-country economy; they can also contribute to migrants' social and emotional wellbeing, and sustain their motivation to participate in the social and civic life of their new communities. But ensuring that students with an immigrant background have good well-being outcomes is difficult, because many foreign-born students, the children of foreign-born parents, or mixed-heritage students need to overcome the adversities related to displacement, socio-economic disadvantage, language barriers and the conflicting pressures involved in forging a new identity - often all at the same time.

Given the importance of academic success, and social and emotional well-being for the long-term economic and social stability of migrants, this report examines between-country differences in the academic, social, emotional and motivation outcomes of students with an immigrant background and uses the framework of resilience to identify how countries can promote their long-term integration through education.

The report identifies different types of students with an immigrant background and maps the academic, social, emotional and motivation outcomes of these students in a wide range of countries. Students with an immigrant background are defined as those students who are either foreign-born or who have at least one foreign-born parent while native students are students who are native-born from two native-born parents. Among students with an immigrant background, the following groups are identified: immigrant students, a group that includes first-generation immigrant students (foreign-born children of two foreignborn parents ${ }^{1}$ ) and second-generation immigrant students (native-born children of two foreign-born parents ${ }^{2}$ ); native students of mixed heritage (native-born students with one native-born and one foreignborn parent) and returning foreign-born students (foreign-born students of two native-born parents ${ }^{3}$ ).

The report identifies factors that promote the well-being of students with an immigrant background, and the policies and practices that can be implemented to promote their resilience overall. The key dimensions of well-being considered in this report are: academic proficiency, sense of belonging to the school community, life satisfaction, schoolwork-related anxiety and achievement motivation.

\section{A profile of students with an immigrant background in OECD and EU countries}

Migration flows are profoundly changing the composition of classrooms. Analyses of PISA data reveal that in 2015, almost one in four 15-year-old students in OECD and EU countries was either foreign-born or had at least one foreign-born parent. This figure is considerably higher than the statistics reported using PISA data on the number of immigrant students in OECD and EU countries (OECD, 2016; European Commission, 2017).

The discrepancy between prevalence figures cited in this report and those that appear in previous publications lies in the definition of students with an immigrant background. Like previous publications, this report considers the circumstances and experiences of native- and foreign-born children of two foreign-born parents (or one foreign-born parent in the case of single-parent households). But unlike those earlier publications it also considers the experiences of foreign-born children of native-born parents and of native-born children who have one native-born and one foreign-born parent. In Switzerland and Luxembourg more than one in two 15-year-old students were either foreign-born or had at least one parent who was. Between 2003 and 2015, the share of students who had either migrated or who had at least one parent who had crossed an international border to settle elsewhere grew by six percentage points on average across OECD and seven percentage points across EU countries. 
Migration flows from several decades ago weigh heavily on this increase. Of all groups of students with an immigrant background, the share of second-generation immigrant students grew most rapidly (by 3 percentage points) on average across OECD countries over the 2003-15 period. The share of native-born students of mixed heritage grew by 2 percentage points, on average, across OECD countries. Migration waves after 2000, which are reflected in the share of foreign-born students, account only for a one percentage-point increase, on average, across OECD countries. In 2015, late arrivals - foreign-born students who had settled in the host country at or after the age of 12 - represented about one-third of all firstgeneration immigrant students, on average.

These averages mask large differences across countries. In Portugal the number of native students of mixed heritage grew most rapidly (by eight percentage points). In Ireland the fastest growing group was that of first-generation immigrant students. This group increased by as much as nine percentage points between 2003 and 2015. In Italy, the share of both first- and second-generation immigrant students grew by three percentage points. Between 2003 and 2015, the share of late arrivals among first-generation immigrant students grew in 14 out of 36 countries and economies with available data. The increase was larger than twenty percentage points Austria, Latvia, Luxembourg, the Slovak Republic, Sweden, Turkey, Tunisia and Uruguay.

\section{Resilience: A multidimensional construct}

This report conceives students' resilience as the capacity of students with an immigrant background to reach adequate levels of adjustment across multiple well-being dimensions.

\section{Figure 1.1 - Academic and well-being outcomes, by immigrant background} OECD average

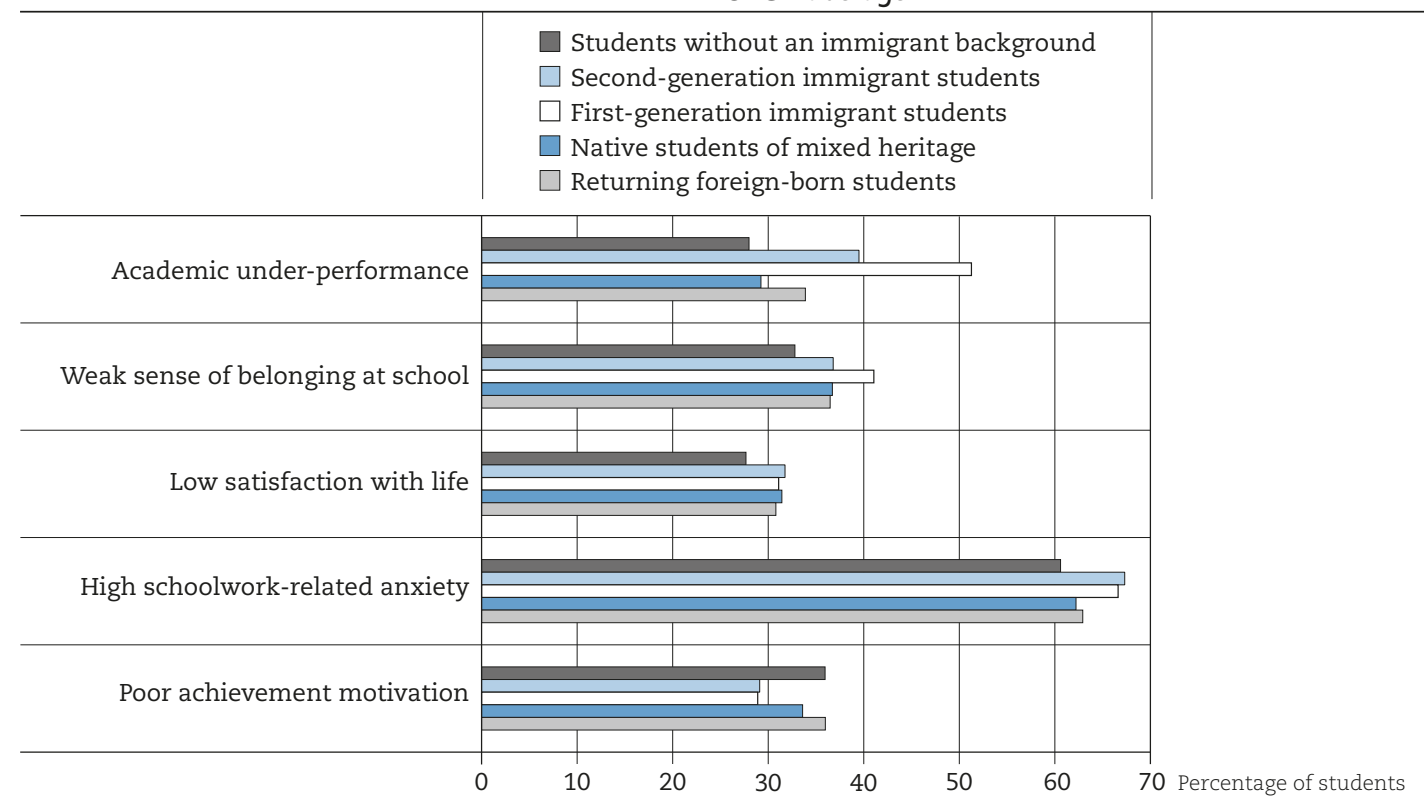

Notes: Differences in all outcomes between students without an immigrant background and all categories of students with an immigrant background are statistically significant, except for the difference in the percentage of students with poor achievement motivation between students without an immigrant background and returning foreign-born students.

Academic under-performance implies that a student failed to attain at least proficiency Level 2 in all three core PISA subjects: science, reading and mathematics.

Weak sense of belonging implies that a student reported that he or she "disagrees" or "strongly disagrees" with the statement "I feel like I belong at school" and "agrees" or "strongly agrees" with the statement "I feel like an outsider at school".

Low satisfaction with life implies that a student reported a life satisfaction of 6 or less on a 0-10 scale.

High school-work related anxiety implies that a student reported that he or she "agrees" or "strongly agrees" with the statements "I often worry that it will be difficult for me taking a test" and "Even if I am well prepared for a test, I feel very anxious".

Poor achievement motivation implies that a student "disagrees" or "strongly disagrees" with the statement "I want to be the best, whatever I do".

Source: OECD, PISA 2015 Database, Table 1.1.

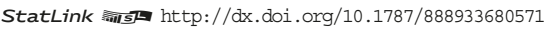


The capacity of students with an immigrant background to overcome the adversities inherent in displacement and be resilient should be judged not only based on their attainment of baseline levels of academic proficiency, but also on their sense of belonging at school, their satisfaction with life, their level of schoolwork-related anxiety and their motivation to achieve. These five indicators represent key dimensions of well-being measured by PISA 2015. Figure 1.1 illustrates the percentage of students with and without an immigrant background across OECD countries who do not reach baseline levels of academic proficiency ${ }^{4}$, who reported a weak sense of belonging at school ${ }^{5}$, who reported low satisfaction with life ${ }^{6}$, high schoolwork-related anxiety ${ }^{7}$ and poor motivation to achieve ${ }^{8}$.

Figure 1.2 shows country-specific profiles in the relative risk of not attaining baseline levels of academic proficiency, a sense of belonging at school, satisfaction with life, schoolwork-related anxiety and achievement motivation for a key category of students with an immigrant background: immigrant students. These are students who have two foreign-born parents, irrespective of their own place of birth. As such, Figure 1.2 paints a comprehensive picture of immigrant students' relative vulnerability compared to native students in their host country but also relative to the vulnerability experienced by other immigrant students in OECD countries.

Figure 1.2 suggests that immigrant students face greater vulnerability than native students when it comes to academic resilience (compared to their vulnerability in other dimensions of resilience). For example, on average across OECD countries, immigrant students had a 1.75 times greater risk of failing to reach baseline levels of academic proficiency than native students did. Immigrant students were also somewhat less likely than native students to report a strong sense of belonging at school (on average across OECD countries, immigrant students had a 1.25 times greater risk of reporting a weak sense of belonging at school compared to native students). They were less likely to report being satisfied with their life (1.24 times less likely, on average) and to report low schoolwork-related anxiety (1.13 times less likely, on average). By contrast, immigrant students were more likely than native students to express high motivation to achieve. On average across OECD countries, immigrant students had an $11 \%$ lower risk of expressing low motivation to achieve compared to native students.

Academic underperformance is common to most students with an immigrant background, but particularly first-generation immigrant students. As much as $51 \%$ of first-generation immigrant students failed to reach baseline levels of academic proficiency in reading, mathematics and science in 2015 , compared to $28 \%$ of students without an immigrant background. There are disparities in most other well-being outcomes as well: $41 \%$ of first-generation immigrant students reported a weak sense of belonging, compared to $33 \%$ of students without an immigrant background; 31\% of first-generation immigrant students reported low satisfaction with life, compared to $28 \%$ of students without an immigrant background; and $67 \%$ of firstgeneration immigrant students reported high schoolwork-related anxiety, compared to $61 \%$ of students without an immigrant background.

Immigrant students were at least twice as likely as native students to fail to achieve baseline levels of academic proficiency in Austria, Belgium, Denmark, Finland, Germany, Iceland, Japan, Luxembourg, Slovenia and Switzerland. By contrast, immigrant students in Australia, Canada and Hungary were as likely as native students to fail to achieve baseline academic proficiency.

In most countries, immigrant students are less vulnerable when it comes to sense of belonging at school than they are when considering academic proficiency. However, in Iceland, the Slovak Republic and Spain, immigrant students were considerably less likely than native students to report a sense of belonging at school. In particular, in the Slovak Republic, immigrant students were almost twice as likely as native students to report a weak sense of belonging at school.

In Australia, Canada, and New Zealand, immigrant students were at a lower risk of reporting a weak sense of belonging at school. The difference was particularly marked in Australia, where immigrant students had $24 \%$ less risk than native students of reporting so.

In France, Iceland, and Spain, immigrant students were considerably less likely than native students to report being satisfied with their life. And in Austria, Finland, Luxembourg and Switzerland, they were considerably more likely than native students to report high levels of schoolwork-related anxiety. In Switzerland, immigrant students were 1.5 times more likely than native students to report high schoolwork-related anxiety. 
Figure $1.2[1 / 2]$ - Relative risk for immigrant students of not being resilient, by resilience outcome Selected countries

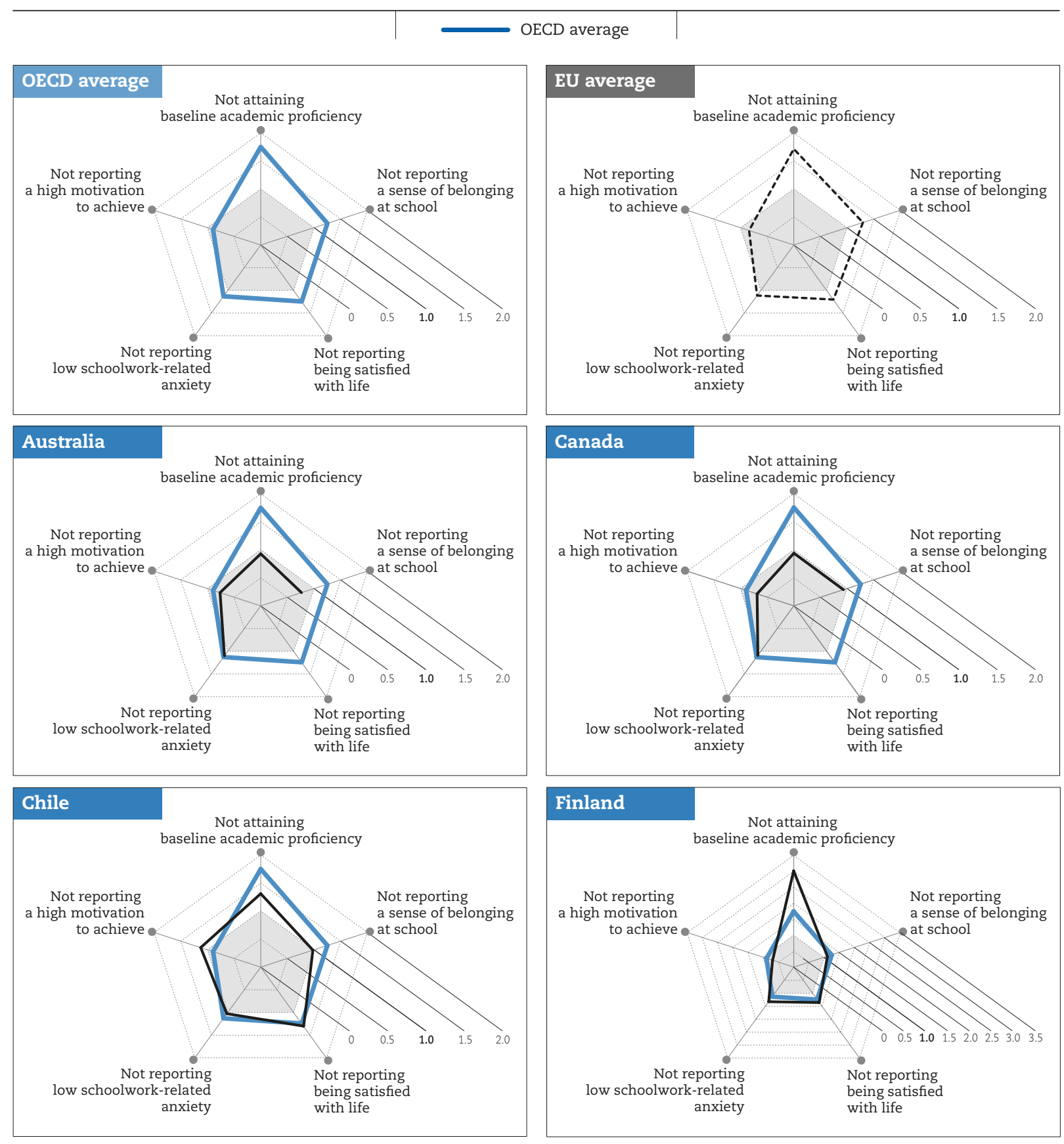

Notes: All measures of relative risk compare immigrant students to native students.

Students who attain baseline academic proficiency are students who reach at least PISA proficiency Level 2 in all three core PISA subjects: science, reading and mathematics.

Students who reported a sense of belonging at school are those who reported that they "agree" or "strongly agree" with the statement "I feel like I belong at school" and "disagree" or "strongly disagree" with the statement "I feel like an outsider at school". Students who reported being satisfied with life are those who reported a life satisfaction of 7 or above on a scale from 0 to 10.

Students who reported low schoolwork-related anxiety are those who reported that they "disagree" or "strongly disagree" with the statements "I often worry that it will be difficult for me taking a test" and "Even if I am well prepared for a test, I feel very anxious". Students who reported high motivation to achieve are those who reported that they "agree" or "strongly agree" with the statement "I want to be the best, whatever I do".

Countries and economies are ranked in alphabetical order.

Source: OECD, PISA 2015 Database, Table 1.2.

StatLink ails http://dx.doi.org/10.1787/888933680590 
Figure $1.2[2 / 2]$ - Relative risk for immigrant students of not being resilient, by resilience outcome Selected countries

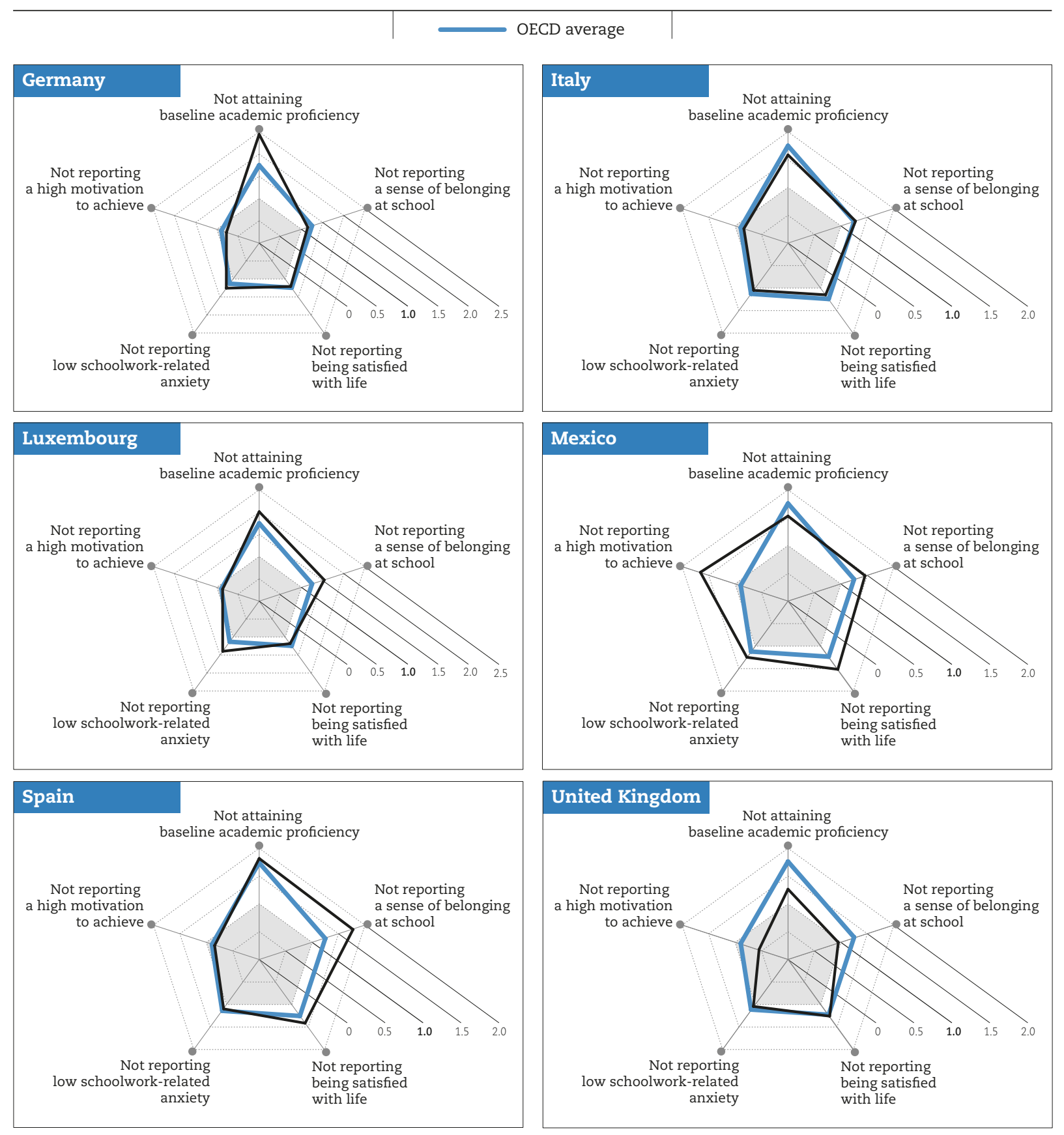

Notes: All measures of relative risk compare immigrant students to native students.

Students who attain baseline academic proficiency are students who reach at least PISA proficiency Level 2 in all three core PISA subjects: science, reading and mathematics.

Students who reported a sense of belonging at school are those who reported that they "agree" or "strongly agree" with the statement "I feel like I belong at school" and "disagree" or "strongly disagree" with the statement "I feel like an outsider at school".

Students who reported being satisfied with life are those who reported a life satisfaction of 7 or above on a scale from 0 to 10.

Students who reported low schoolwork-related anxiety are those who reported that they "disagree" or "strongly disagree" with the statements "I often worry that it will be difficult for me taking a test" and "Even if I am well prepared for a test, I feel very anxious".

Students who reported high motivation to achieve are those who reported that they "agree" or "strongly agree" with the statement "I want to be the best, whatever I do".

Countries and economies are ranked in alphabetical order.

Source: OECD, PISA 2015 Database, Table 1.2.

StatLink ants http://dx.doi.org/10.1787/888933680590 
In most countries, immigrant students expressed greater motivation to achieve than native students. In particular, in Belgium, Canada, Denmark, Finland and the Netherlands, immigrant students had about $30 \%$ less risk of reporting low motivation compared to native students and in the United Kingdom immigrant students had $46 \%$ less risk of so reporting. In Israel and Mexico, immigrant students were more likely than native students to report low motivation to achieve.

Figure 1.2 and Table 1.2 (available on line) suggest that countries differ greatly in the dimensions of wellbeing to which immigrant students are most vulnerable. For example, while immigrant students in Belgium, Finland, Germany and Slovenia appear to be particularly vulnerable to poor academic proficiency but not to other aspects of well-being, students in Mexico, the Slovak Republic and Spain appear to be particularly likely to have only a weak sense of belonging at school and to report low satisfaction with life.

Figure 1.3 shows more precisely the extent to which immigrant students can be considered to be resilient overall; it also shows country variations in the dimensions in which immigrant students are particularly vulnerable. The figure focuses on three key indicators that characterise immigrant students' resilience: academic proficiency, sense of belonging and life satisfaction.

For a selection of countries with available data on all dimensions, Figure 1.3 presents the percentage of immigrant students who reach baseline levels on all three indicators, as well as those who reach baseline levels on different combinations of the indicators (academic and sense of belonging, but not life satisfaction; academic and life satisfaction, but not sense of belonging etc.). Table 1.3 (available on line) reports the data for the rest of the PISA countries.

Results suggest that in some countries, such as the Czech Republic, Estonia, Hong Kong (China), Ireland, Macao (China) and the United Kingdom, many immigrant students who achieve baseline levels of academic proficiency suffer low life satisfaction, a weak sense of belonging or both. By contrast, in Austria, Croatia, Finland, Hungary, the Netherlands and Spain, immigrant students who achieve baseline academic proficiency were also more likely to report high satisfaction with life and a strong sense of belonging or both.

\section{Resilience and country of origin/country of destination}

The country immigrant students migrated from, and the country in which they settle, influence the likelihood that these students will be academically, socially and emotionally resilient. For example, firstgeneration immigrant students from Somalia who settled in Finland are about eight percentage points less likely than immigrant students from Iraq who also settled in Finland to be academically resilient, but they are equally likely be socially resilient. By contrast, first-generation immigrant students are over 45 percentage points less likely to be academically resilient and eight percentage points less likely to be socially resilient than first-generation immigrant students from the Russian Federation who settled in Finland.

Immigrant students with the same heritage but living in different host countries are not equally likely to be academically or socio-emotionally resilient, after accounting for socio-economic status. For example, first-generation South African immigrant students in Australia are almost 50 percentage points more likely to be academically resilient than those in New Zealand. First-generation immigrant students from the Russian Federation who settled in Latvia are over 45 percentage points more likely to be socially resilient than those who settled in the Czech Republic.

Students with an immigrant background are more likely than native students to work for pay or work in the household. The difference in likelihood to work for pay is a particularly strong mediating factor between immigrant background and academic performance in Brazil, Bulgaria, the Slovak Republic and Turkey. On average across OECD countries with available data, immigrant students are 12 percentage points less likely than native students to have participated in pre-primary programmes (13 percentage points less likely across EU countries). The difference is larger than 20 percentage points in the United Kingdom and Ireland. 
Figure $1.3[1 / 2]$ - The overlap of immigrant students' resilience

Percentage of students who are academically, socially and/or emotionally resilient
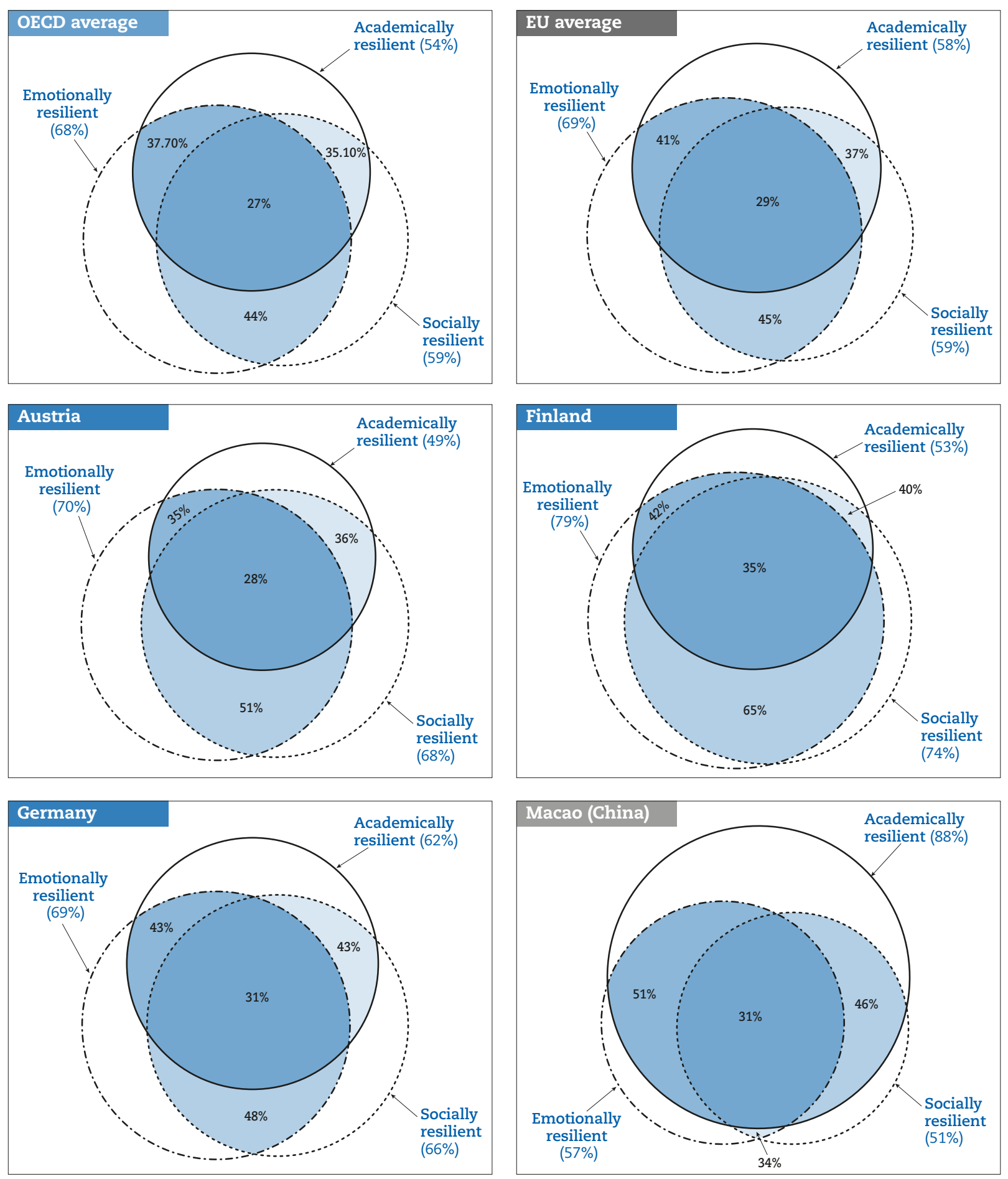

Notes: Academically resilient immigrant students are immigrant students who reach at least PISA proficiency level two in all three PISA core subjects - math, reading and science.

Socially resilient immigrant students are immigrant students who reported that they "agree" or "strongly agree" with the statement "I feel like I belong at school" and "disagree" or "strongly disagree" with the statement "I feel like an outsider at school".

Emotionally resilient immigrant students are immigrant students who reported a life satisfaction of 7 or above on a scale from 0 to 10 .

Source: OECD, PISA 2015 Database, Table 1.3. 
Figure $1.3[2 / 2]$ - The overlap of immigrant students' resilience

Percentage of students who are academically, socially and/or emotionally resilient
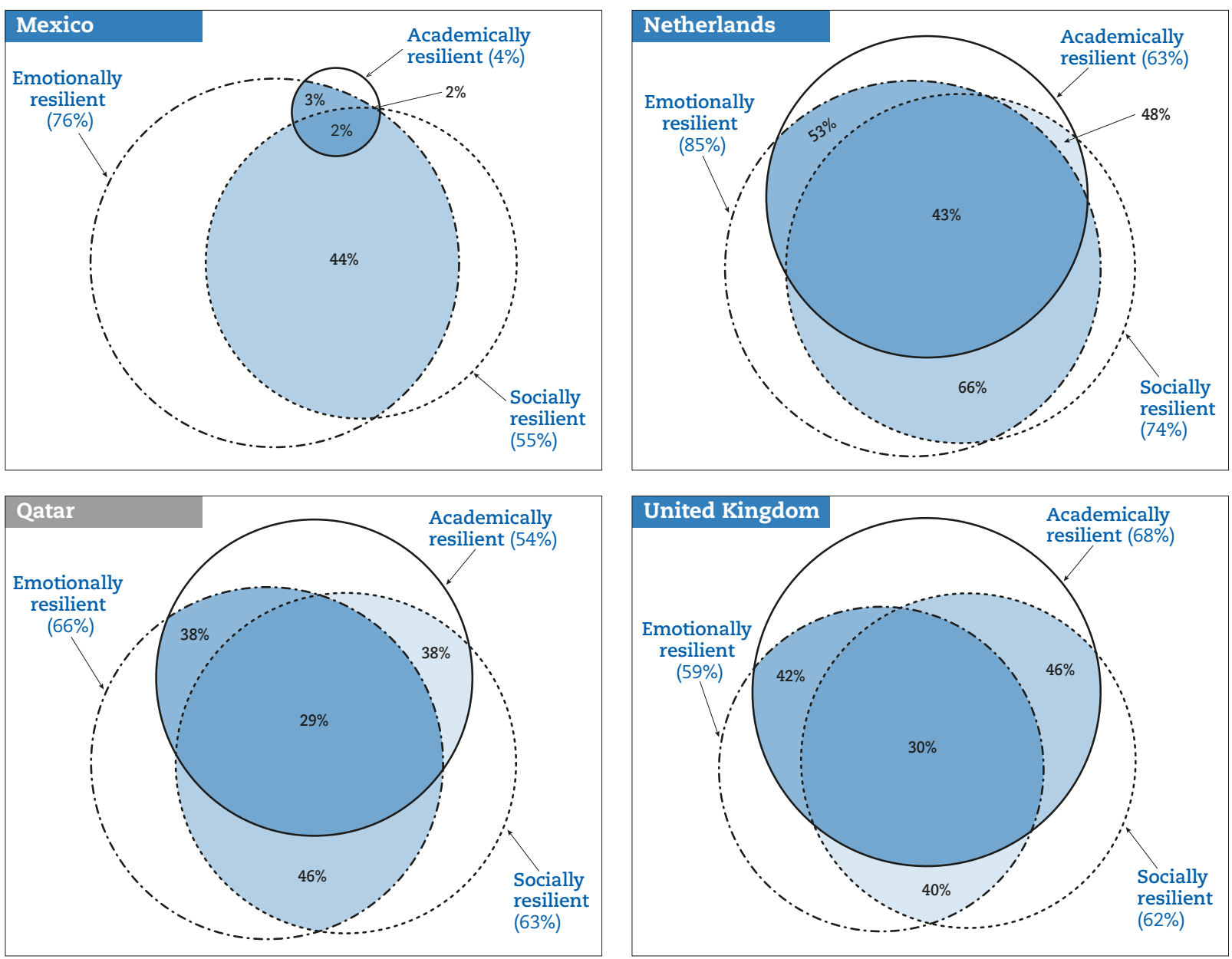

Notes: Academically resilient immigrant students are immigrant students who reach at least PISA proficiency level two in all three PISA core subjects - math, reading and science.

Socially resilient immigrant students are immigrant students who reported that they "agree" or "strongly agree" with the statement "I feel like I belong at school" and "disagree" or "strongly disagree" with the statement "I feel like an outsider at school".

Emotionally resilient immigrant students are immigrant students who reported a life satisfaction of 7 or above on a scale from 0 to 10. Source: OECD, PISA 2015 Database, Table 1.3.

\section{Sources of disadvantage}

Students with an immigrant background face multiple sources of disadvantage that affect their academic performance and their general well-being. A lack of fluency in the language spoken in the host country is one of these sources. Language barriers can also amplify the effects of other sources of disadvantage, such as having migrated after the age of 12, lack of parental support, studying in a disadvantaged school or attending a school with a poor disciplinary climate. For example, on average across OECD countries, immigrant students who do not speak the language of assessment at home are around eight percentage points less likely to be academically resilient than native-speaking immigrant students (nine percentage points less likely across EU countries). Immigrant students who are non-native speakers are five percentage points less likely than those who are native speakers to report a sense of belonging at school, on average across OECD countries (six percentage points less likely across EU countries). The greater the linguistic distance between the language spoken at home and the language of instruction, the less likely a student will attain baseline academic proficiency and report a sense of belonging at school. 
On average and in most PISA countries, second-generation and first-generation immigrant students are socio-economically disadvantaged compared to native students. By contrast, returning foreign-born students and native students of mixed heritage are more advantaged than native students. Differences in socio-economic status explain about one-fifth of the gap between students with an immigrant background and native students in the likelihood of attaining baseline levels of academic proficiency, on average across OECD and EU countries. Ciudad Autónoma de Buenos Aires (Argentina) (hereafter "CABA [Argentina]"), Costa Rica, Croatia, France, Greece, Hong Kong (China), Luxembourg and the Netherlands, socio-economic status explains a considerable fraction of immigrant students' academic disadvantage, while in the United States, immigrant and native students with a similar socio-economic profile have equal chances of attaining baseline academic proficiency.

Socio-economic disadvantage is one of the factors that explain differences between students with an immigrant background and native students in well-being, but the link tends to be weaker than that with academic outcomes. For example, in Greece, differences in socio-economic status explain $45 \%$ of the gap in academic performance between immigrant and native students but only $13 \%$ of the gap in sense of belonging and $22 \%$ of the difference in schoolwork-related anxiety. In CABA (Argentina), France, Hong Kong (China) and the United States, disparities in socio-economic status between immigrant and native students account for almost the entirety of performance differences between the two groups. By contrast, in Bulgaria, Chile, Estonia, Latvia, Macao (China), Portugal and Tunisia, academic differences between immigrant and native students are not explained by disparities in the socio-economic status of these two groups.

In most countries and economies, socio-economic advantage is more strongly associated with better performance and social well-being among native students than among immigrant students. On average across OECD and EU countries, a one-point increase in the PISA index of economic, social and cultural status widens the gap between the percentages of immigrant students and native students who attain baseline academic proficiency by four percentage points; the gap in the percentage who reported a sense of belonging at school widens by two percentage points. While a rising tide lifts all boats, some boats are lifted higher than others.

\section{Differences in the learning environment}

On average across countries that distributed the PISA parent questionnaire, the parents of immigrant students are four percentage points more likely than native parents to choose a school based on the availability of financial aid (financial support given to families to cover education-related expenses) and three percentage points less likely to choose a school based on the school climate. School climate is found to have a strong influence on the performance of immigrant students. On average across OECD and EU countries, in schools with a higher concentration of immigrant students, the academic performance, and social and emotional well-being of students tends to be lower. However, in almost every country, and on average across OECD and EU countries, once the schools' socio-economic profile is accounted for, these differences disappear.

The disciplinary climate at school tends to be worse and truancy more prevalent in the schools attended by the average immigrant students. These differences are related to disparities between immigrant students and native students in academic performance and well-being. Immigrant students are more likely than native students to be victims of bullying and perceived unfair treatment by teachers, which contribute to differences between native and immigrant students in academic performance and wellbeing. On average across OECD countries, immigrant students are four percentage points more likely to have repeated a grade (six percentage points more likely across EU countries) and four percentage points less likely to be enrolled in a vocational programme (five percentage points less likely across EU countries) than native students with similar PISA scores and a similar socio-economic background.

\section{Expectations for the future}

On average across OECD countries, immigrant students are eight percentage points more likely than native students of similar socio-economic status and academic performance to expect to complete tertiary education (seven percentage points across EU countries). However, immigrant students are less likely than native students to hold ambitious but realistic expectations for future education. 
On average across OECD countries, the percentage of students who expect to complete tertiary education and who also attain baseline academic proficiency is four percentage points lower among immigrant students than among native students (five percentage points lower across EU countries). In Mexico, for every immigrant student who holds ambitious and realistic expectations for further education there are 10 native students with similar expectations; in Beijing-Shanghai-Jiangsu-Guangdong (China), Brazil, Bulgaria, Iceland and Tunisia, the ratio is also greater than one to two.

On average across OECD countries, immigrant students are 11 percentage points more likely than native students of similar socio-economic status and academic performance to expect to have a high-status career, such as manager, professional or associate professional (nine percentage points more likely across EU countries). However, they are nine percentage points less likely to expect so and also attain baseline academic proficiency (11 percentage points less likely across EU countries). In Mexico, for every immigrant student who holds ambitious and realistic career expectations, there are approximately nine native students with similar expectations; in Brazil, Bulgaria, CABA (Argentina), the Former Yugoslav Republic of Macedonia and Tunisia, the ratio is also greater than one to two.

\section{What can education policy do to help immigrant students become more resilient?}

By defining resilience using multiple indicators reflecting the overall well-being of students, which includes academic, social, emotional and motivational well-being, the report identifies a clear role for education systems in promoting the full development of children with an immigrant background. The report recognises the different set of vulnerabilities that accompany direct and indirect displacement (being foreign-born or having foreign-born parents) and the fact that they may pertain to the psychological sphere (such as having to negotiate between multiple identities as in the case of native-born students of mixed heritage). While education systems clearly can and should play a role in promoting the wellbeing of students with an immigrant background, their role should be seen in light of a broad and coordinated effort encompassing the education, health, social and welfare systems and potentially involving partnerships between schools, hospitals, universities and community organisations.

In order to adequately address the risks associated with having an immigrant background and supporting the resilience of students with such background, teachers and educators need to know the background and circumstances of their students, develop the tact that is necessary to discuss their background and be aware of the broad set of mechanisms through which different experiences of migration can affect academic performance, social integration, emotional and psychological well-being. Teachers and educators should provide students with an immigrant background with the support they need to be able to achieve their potential, but use care so as to avoid stigmatising such students because of their background if and when targeted initiatives are implemented.

Language barriers and a relatively disadvantaged socio-economic status are key risk factors that greatly increase the vulnerability of students with an immigrant background, in particular of first-generation immigrant students who settle in a new country at or after the age of 12. Teachers are key to help students with an immigrant background adjust in their classrooms and society more generally and teachers in many education systems appear keen to provide additional input to students with an immigrant background. However, many students with an immigrant background report feeling that they are unfairly treated by their teachers, suggesting that teachers may not know how to effectively support their students. Many teachers recognise this, so much so that in many education systems teachers report feeling a need to develop their ability to deal with multicultural classrooms. Just as countries invest in developing language programmes and initiatives aimed at supporting socio-economically disadvantaged students, so they should invest in widening the availability of programmes designed to help teachers teach in diverse classrooms and upgrade the quality of existing training modules. 


\section{Notes}

1. Foreign-born students with one foreign-born parent living in single-parent households are also considered first-generation immigrant students.

2. Native-born students with one foreign-born parent living in single-parent households are also considered second-generation immigrant students.

3. Foreign-born students with one native-born parent living in single-parent households are also considered returning foreign-born students.

4. Students who do not attain baseline academic proficiency are students who failed to attain at least proficiency Level 2 in all three core PISA subjects: science, reading and mathematics.

5. A student who reported a weak sense of belonging at school is a student who reported that he or she "disagrees" or "strongly disagrees" with the statement "I feel like I belong at school" and "agrees" or "strongly agrees" with the statement "I feel like an outsider at school".

6. A student who reported low satisfaction with life is a student who reported a life satisfaction of 6 or less on a 0-10 scale.

7. A student who reported high schoolwork-related anxiety is a student who reported that he or she "agrees" or "strongly agrees" with the statements "I often worry that it will be difficult for me taking a test" and "Even if I am well prepared for a test, I feel very anxious".

8. A student who reported poor motivation to achieve is a student who reported that he or she "disagrees" or "strongly disagrees" with the statement "I want to be the best, whatever I do".

\section{References}

European Commission (2017), Education and Training Monitor 2017, Publications Office of the European Union, Luxembourg, https://ec.europa.eu/education/sites/education/files/monitor2017_en.pdf.

OECD (2016), PISA 2015 Results (Volume I): Excellence and Equity in Education, PISA, OECD Publishing, Paris, http://dx.doi. org/10.1787/9789264266490-en. 


\section{Chapter 2 \\ The resilience of students with an immigrant background}

This chapter introduces the concept of resilience as it applies to students with an immigrant background. Resilience is the ability to overcome adversity and adjust positively to a new life. It defines the terms "adversity", "adjustment" and "vulnerability", as used in the report, and identifies several of the risk and protective factors that are related to how well - or poorly - students with an immigrant background integrate into their host communities. The chapter concludes with a brief look at the two main sources of data for the report: the Programme for International Student Assessment (PISA) and the European Social Survey (ESS). 
A n estimated 4.8 million migrants arrived at OECD countries in 2015 , an increase of about $10 \%$ over the previous year, with family reunification and free movement across borders each accounting for about a third of these entries (OECD, 2016c; OECD, 2015b). The recent wave of migration has reinforced a long and steady upward trend in the share of immigrants in OECD countries, which has grown by more than 30\% since 2000 and has become increasingly diverse (OECD/EU, 2015). Over this period, several OECD countries that had previously been the country of origin of many migrants, including Ireland, Italy and Spain, became destination countries. Before the global economic crisis of 2008, immigration rates in these countries were sometimes as high as those of traditional OECD immigration countries (OECD, 2015b).

Children represent a significant portion of global migration flows, especially within refugee populations. According to a 2016 UNICEF report, 1 in 8 migrants worldwide is a child, as is more than one in two refugees - a proportion that has doubled between 2005 and 2015 (UNICEF, 2016). Accommodating the unprecedented inflows of migrant children into education systems is one of the key challenges facing host countries.

Migration flows are already profoundly changing the composition of classrooms in OECD countries. Between 2003 and 2015, the share of students with foreign-born parents rose by four percentage points, on average across OECD countries, and by more than five percentage points in Austria, Belgium, Canada, Ireland, Italy, Luxembourg, New Zealand, Norway, Spain, Sweden, Switzerland, the United Kingdom and the United States. More than one in two students who participated in the 2015 round of the Programme for International Student Assessment (PISA) in Luxembourg, Macao (China), Qatar and the United Arab Emirates had foreign-born parents, as did close to one in three students in Canada, Hong Kong (China) and Switzerland.

While migration flows can create difficulties for host communities, they also represent an opportunity for countries that face ageing native-born populations and the associated threat of labour and skills shortages (Boeri et al., 2012; Cerna, 2016; EMN, 2011; OECD/EU, 2014). Effective education and social policies are necessary to integrate migrant children successfully into society and unlock the potential benefits of migration. Education systems determine immigrants' ability to eventually participate in the labour markets of host countries, contribute to welfare arrangements, and feel part of their communities. The growing share of children among those fleeing conflict (IOM, 2015) has led to a re-examination of how best to integrate foreign-born children into their new communities. This is particularly important given the high likelihood that a large number of young migrants will settle permanently in their country of destination.

This report studies the overall resilience of students with an immigrant background, including academic, social and emotional dimensions, as they integrate into education systems. It aims to identify both the risk factors that prevent immigrant students from successfully integrating and the protective factors that enable these students to thrive. The report is innovative in several respects:

- First, it provides new insights into who has an immigrant background. The report paints a detailed picture of the diversity of circumstances that arise as the face and nature of international migration changes.

- Second, it uses a range of measures - academic, social and emotional, and those related to motivation when evaluating the ability of different education systems to integrate students with an immigrant background. In recognising that education systems should strive to promote academic achievement and students' well-being, the outcomes of interest in this report are students' ability to achieve at least baseline levels of performance in the core PISA subjects (science, reading and mathematics) and their sense of belonging at school, their satisfaction with life, anxiety at school and their motivation to achieve.

- Finally, the report investigates the cumulative or multiplicative nature of risk and protective factors that affect the outcomes of different groups of students with an immigrant background. Cumulative disadvantage is observed when students with an immigrant background are saddled with more risk factors (or have fewer protective factors) than their native peers. Multiplicative disadvantage is observed when risk factors hinder students with an immigrant background more (and when protective factors help immigrant students less) than they do students without an immigrant background. 


\section{Resilience}

The term "resilience" was originally used in physics and engineering to characterise the ability of materials to resume their original shape or condition after being subjected to a shock (Treloar, 1975), and in medicine to describe the ability of patients to recover after traumatic events, such as surgery or accidents (Boyden and Mann, 2005). It is also widely used in ecology (Holling, 1973; Gunderson, 2000) and other system-level domains. The concept of resilience, in the sense used in this report, dates back to the post-World War II period. World War II affected tens of millions of people across the globe, including children. The war left behind orphaned, injured, sick, traumatised and starving children (Werner, 2000). In fact, the United Nations International Children's Emergency Fund (UNICEF) was founded to address this global emergency (Diers, 2013). Finding ways to help children recover from severe adversity was the main focus of researchers at the time. In this regard, resilience research has its roots in research and theory in child development, clinical sciences and the study of individual differences (Cicchetti, 2013; Evans, Li and Whipple, 2013; Luthar, 2006; Masten, 2013). So how and why is resilience, a term used in such different contexts, relevant in social sciences?

Resilience refers to an individual's ability to overcome adversity and display positive adjustment (Daniel and Wassell, 2002; Howard et al., 1999). Individuals' vulnerability to hardship depends not only on the individual himself or herself, but also on his or her environment and the interplay between the two.

Figure 2.1 illustrates the key elements that characterise resilience and how they relate to each other. Adversity refers to external events and circumstances that cause shock to the individual. Adjustment refers to the positive adaptation of the individual who experiences adversity. Vulnerability refers to the likelihood that adversity will lead to positive adjustment or negative outcomes. Risk and protective factors are the host of individual and environmental characteristics that determine an individual's degree of vulnerability.

Figure 2.1 - A graphical description of the elements characterising resilience

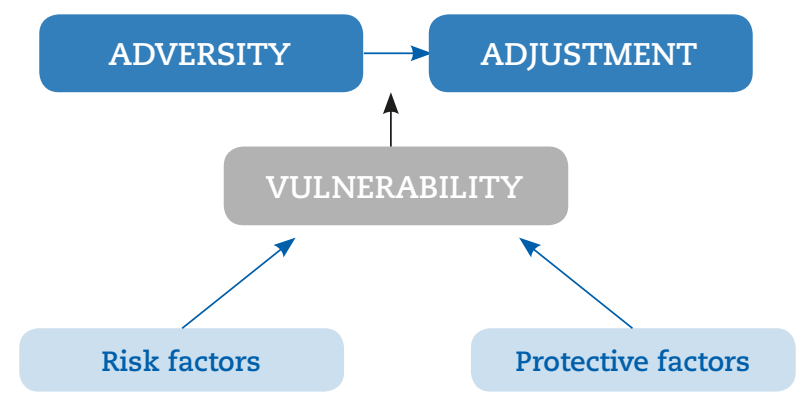

The concept of resilience is increasingly used to identify when, how and why people who have been exposed to negative experiences display less vulnerability (Luthar, 2003; Masten, Powell and Luthar, 2003; Rutter, 2006). Resilience expresses individuals' ability to cope with adverse circumstances. Resilience research provides evidence on how people's responses to adversity differ. Institutional and social features play a key role in reducing individuals' vulnerability to adversity: context importantly shapes not only the likelihood that individuals will be exposed to adverse circumstances, but also individual capacity to overcome adversity. In other words, showing that some individuals overcome adversity, and understanding what factors facilitate or hinder individuals' success in the face of hardship, should not be used as an excuse to abandon efforts aimed at reducing people's exposure to adverse circumstances and to forge contests that reduce individuals' vulnerability to adversity. Indeed, it should be used to identify the policies and practices that support and promote individuals' positive adjustment in the face of adversity.

Past research on student resilience in education settings arose from empirical research in education identifying large socio-economic disparities in academic achievement (Coleman et al., 1966; Peaker, 1971; Jencks, 1972; Crane, 1996; Sutton and Soderstrom, 1999; Martin et al., 2012; Mullis et al., 2012; OECD, 2011; Sandoval-Hernandez and Cortes, 2012; White, 1982; McLoyd, 1998; Buchmann, 2002; Sirin, 2005). 
Although most applied work identifies socio-economic disadvantage as a risk factor for poor academic performance, some disadvantaged students beat the odds against them and achieve good academic outcomes despite their background. Resilience research attempts to determine whether certain factors are related to the ability of some disadvantaged students to achieve academically.

Past cross-national analyses of student resilience based on large-scale international assessments such as PISA typically identify adversity in terms of relative socio-economic deprivation. Disadvantaged students are described as those who fall in the bottom quartile of the national distribution of an index designed to capture economic, social and cultural status (the PISA ESCS index) (OECD, 2012; Agasisti et al., 2018). Adjustment is also considered in relative terms and is regarded as students' ability to perform among the top quarter of students internationally in one of the PISA assessment domains (adjusting for the international association between academic achievement and socio-economic status). Resilient students are typically compared to disadvantaged low achievers, students who are also socio-economically disadvantaged, but who fail to achieve at high levels in the PISA test.

This report uses the following definitions for resilience-related terms:

- Adversity refers to the process of international migration as it applies to the group of students who either have directly experienced the difficulties associated with having to settle in a new country or have parents who did. While people migrate out of the hope to build a better life for themselves and their loved ones, the act of displacement forces individuals to adapt to a new reality. It can break or loosen individuals' connectedness with their community, and forces them to create new social networks and learn new ways of being and behaving in their host community. Many migrants have to learn a new language; others may face economic hardship and find it difficult to access welfare and social services. Many have fled war, political insecurity or persecution. Most have to negotiate complex identities.

- Adjustment refers to children's positive adaptation, both overall and in key areas, namely academic, social, emotional and motivational. Since this study focuses on the role education systems can play in integrating students with an immigrant background, the measures of adjustment considered here reflect the goals and roles of education systems. Thus, in this report, adjustment is manifested in students' acquisition of academic skills and in their social, emotional and motivational well-being. These are key determinants of immigrant children's current well-being. Moreover, they are key indicators of these children's capacity to thrive economically, socially and emotionally as adults.

- Vulnerability refers to the likelihood that students with an immigrant background will be able to acquire key academic skills and report good levels of social, emotional and motivational well-being. Implicit in the concept of vulnerability is a comparison with students who did not experience adversity because they or their families do not have an immigrant background.

- Risk and protective factors refer to all individual, household, school and system-level characteristics that influence vulnerability because they explain the degree to which students with an immigrant background can be expected to have acquired academic skills and to report social and emotional wellbeing. The report explicitly considers two mechanisms through which risk and protective factors can determine the outcomes of students with an immigrant background: the extent to which students with an immigrant background are more or less exposed to risk and protective factors than students without an immigrant background are, and the extent to which risk and protective factors are differently related to outcomes, depending on students' immigrant background.

\section{Adversity}

Adversity is what must be overcome to display positive adjustment. In the context of this report, having migrated internationally, or having parents who did is the source of adversity. The report does not consider the education consequences for children who had migrated within their country of origin, such as children who moved from one region to another, or who moved from a rural to an urban area (UNESCO, Global Education Monitoring Report, 2015).

Migration is a life-changing experience that fundamentally reshapes individuals' lives. Researchers identify key stressors that are associated with moving and settling in a new country, including the loss 
of close relationships and social networks, housing problems, obtaining legal documentation, learning a new language, changing family roles, and adjusting to new school systems and labour markets (Garza, Reyes and Trueba, 2004; Igoa, 1995; Portes and Rumbaut, 2001; Suarez-Orozco and Suarez-Orozco, 2001; Zhou, 1997). Immigrant children, as dependents of their parents, rarely have much to say about the decision to migrate. They follow their families and bear both the positive and negative consequences of migration (Suarez-Orozco and Suarez-Orozco, 2001). In fact, the hope to build a better future for their children is usually what drives families to migrate to a new country in the first place.

This report considers two key factors that determine the type of adversity children with an immigrant background might suffer: whether the child directly experienced migration or whether the child's parents did and, if the child is foreign-born and directly experienced migration, the age at which he or she migrated. The report distinguishes between first-generation immigrant students (foreign-born students with two foreign-born parents), second-generation immigrant students (native-born students with two foreign-born parents), students of mixed heritage (native-born students with one foreign-born and one native-born parent), and returning foreign-born immigrant students (foreign-born students with at least one native-born parent).

For first-generation immigrant students, an additional factor that defines the level of adversity is the age at which the student migrated. Children who had migrated at an early age often share a life history that is more similar to that of second-generation immigrant students than to that of other first-generation students. By contrast, students who had migrated when they were older often face greater institutional barriers - such as having to adapt to a different education system, and to different ways of being and behaving than those in their country of origin. Students who had migrated at an early age may face another kind of adversity because they do not have long-term memories of and attachments to their parents' country of origin; they may find it difficult to reconcile different identities. Figure 2.2 shows the profiles of migration-related adversity considered in this report.

Figure 2.2 - Profile of students with an immigrant background

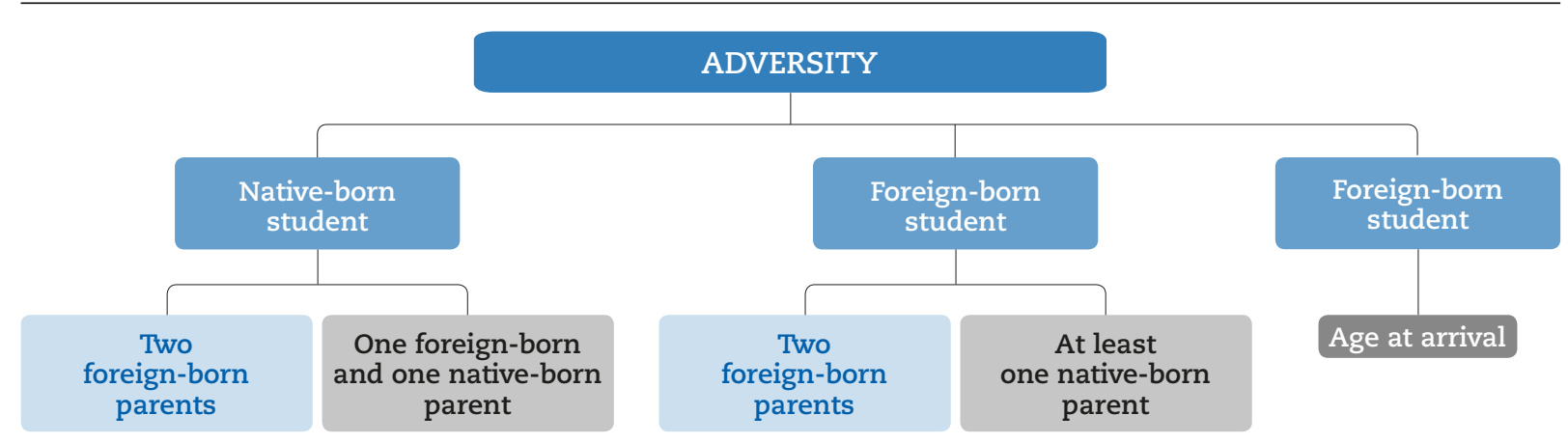

\section{Adjustment}

Key to resilience research is conceptualising and measuring adjustment (Masten, 2011; Rutter, 2012a; Ungar, 2011). Individuals are generally considered to be resilient if they experienced adversity but have "better-than-expected" outcomes. While one line of research has conceptualised "better-than-expected" as achieving a baseline level that is generally not achieved by individuals who have faced hardships (McCormick, Kuo and Masten, 2011), others have considered "better-than-expected" as implying achievement well above the average level of outcomes in various domains.

Identifying the threshold above which an individual facing adversity should be considered as resilient, and the outcomes considered when defining adjustment have important implications for designing the policies and programmes that can mitigate the negative consequences of adversity. Research on student resilience, particularly cross-country research designed to identify the role of education systems (OECD, 2011), considers positive adjustment in terms of subject-specific academic skills. It defines "better-thanexpected" outcomes in terms of students' ability to excel academically despite the hardships they face. 
The seminal report on student resilience, which introduced the concept of resilience in the context of PISA - Against the Odds: Disadvantaged Students Who Succeed in School (OECD, 2011) - defines student resilience as the ability of students in the bottom quarter of the national distribution of socio-economic status to perform in the top quarter of the international distribution of subject-specific performance, discounted for the association, at the international level, between socio-economic status and subjectspecific performance.

In this report, academic resilience refers to students' ability to acquire a strong foundation in the core subjects of reading, mathematics and science - skills needed for a smooth transition from compulsory schooling into further education, training or the labour market. More specifically, positive adjustment requires that a student reaches PISA proficiency Level 2, considered to be the baseline level of proficiency, in those subjects. Longitudinal studies suggest that students who reach the PISA baseline level of proficiency do better in life than those who do not (OECD 2010a; OECD 2012).

The 2009 Canadian Youth in Transition Survey, which followed up on students who were assessed by PISA in 2000, shows that 15-year-olds scoring below Level 2 in reading face a disproportionately higher risk of not participating in post-secondary education and of poor labour-market outcomes at age 19, and even more so at age 21 (OECD, 2010b). A similar longitudinal survey in Switzerland, which followed the PISA 2000 cohort until 2010, shows that students scoring below Level 2 in reading are at high risk of not completing upper secondary education. About $19 \%$ of students who had scored at Level 1, and more than $30 \%$ of students who had scored below Level 1 had not completed any upper secondary programme by the age of 25 , compared to less than $10 \%$ of those students who had scored above the baseline level of proficiency in reading (Scharenberg et al., 2014).

Two follow-up studies in Uruguay, based on the 2003 and 2006 PISA cohorts, similarly indicate that students who had scored below Level 2 in the mathematics tests were significantly less likely to complete upper secondary education (Cardozo, 2009) and more likely to have repeated a grade or dropped out of school, even after accounting for other demographic and social differences among students (Ríos González, 2014). A Danish study that linked PISA to the Survey of Adult Skills (a product of the OECD Programme for the International Assessment of Adult Competencies, or PIAAC) also shows that students who had scored below Level 2 in reading in PISA 2000 were more likely to have received income transfers for more than a year between the ages of 18 and 27 - meaning that they were unemployed or ill for long periods (Rosdahl, 2014). And the Longitudinal Study of Australian Youth (LSAY) shows that, in 2013, the $25 \%$ of students who had the lowest scores in mathematics in 2003 were more likely to be unemployed or not in the labour force than the second $25 \%$ of students (LSAY, 2014).

Figure 2.3 - Adjustment as a multidimensional outcome

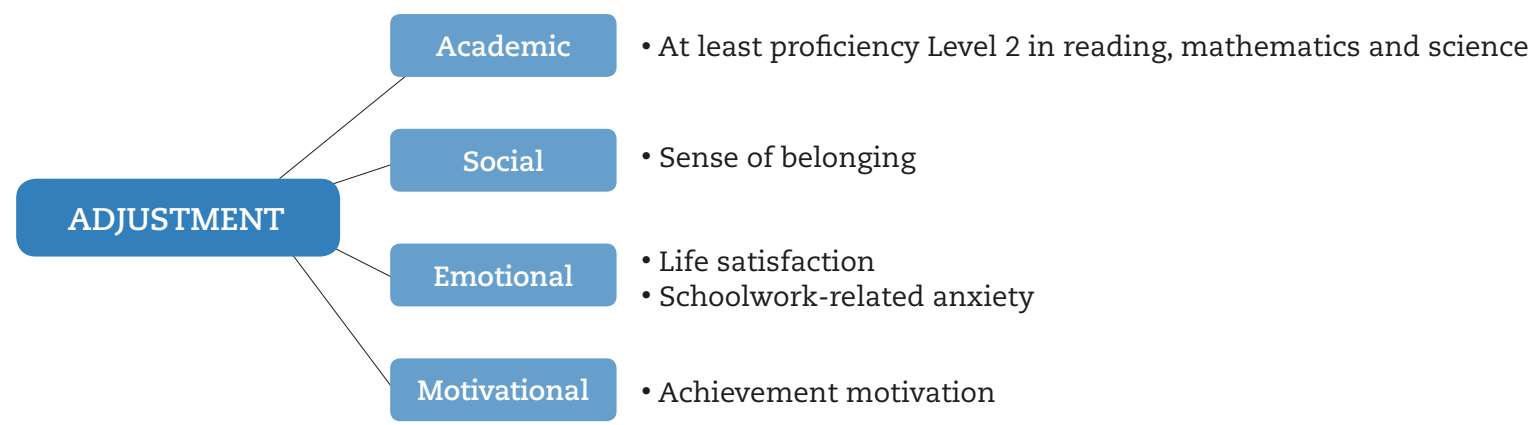

Yet, performance in standardised assessments has been found to explain only so much of students' success later in life (Stankov 1999; Sternberg 1995). In fact, employment and full participation in society require much more than just cognitive abilities (Levin, 2012). Recent theoretical and methodological developments support the need to apply measures of well-being when assessing the efficiency of different policy interventions (see CAE, 2011, also known as the final report of the Stiglitz-Sen-Fitoussi Commission 
on the Measurement of Economic Performance and Social Progress). Academic results represent only one dimension of student well-being (Borgonovi and Pál, 2016). Consequently, education systems should also be evaluated in terms of their capacity to develop all aspects of human potential.

Adaptation therefore encompasses not only students' ability to achieve a baseline level of skills in all core academic subjects, but also their ability to attain baseline levels of self-reported satisfaction with life, social integration and a sense of agency and motivation to achieve - in other words, to be socially, emotionally and motivationally resilient. Figure 2.3 shows the outcomes considered in this report and how overall resilience can be broken down into four dimensions: academic, social, emotional and motivational. Analyses presented in this report identify immigrant students' overall resilience as well as the extent to which they are vulnerable in specific dimensions. By identifying areas of relative strength and weakness in adaptation processes, the report provides detailed information to education policy makers about dimensions of adjustment students struggle with the most.

\section{Vulnerability: Risk and protective factors}

Children with an immigrant background are at risk of suffering poor educational outcomes (Fazel and Stein, 2002; Williams, 1991; Wolff and Fesseha, 1999). However, not all do and some children cope successfully in spite of facing adversity (Rutter, 2000; Masten, 2001; Ungar, 2005a; Ungar, 2005b). A key objective of this report is to replace a "deficit model" of students with an immigrant background, in which these students are perceived as a liability for host countries, with a "resource model", in which these students are regarded as full members of their communities and potential contributors to the economic, social and cultural life of their communities.

The study of resilience is essentially the study of individuals' unique capacity to beat the odds against them and overcome disadvantage and adversity. Individuals vary in their ability to overcome disadvantage because of their willingness and ability to mobilise their own psychological and physical resources, and the resources available in their social and physical environment (Wong, 2008). In other words, in order to understand why student outcomes differ even when students experience similar types of disadvantage, it is important to identify the personality characteristics, institutional and environmental resources that moderate the negative effects of stress (Bernard, 1995; Kirby and Fraser, 1997; Masten, 1994; Werner and Smith, 1992).

Figure 2.4 - The multilevel nature of risk and protective factors

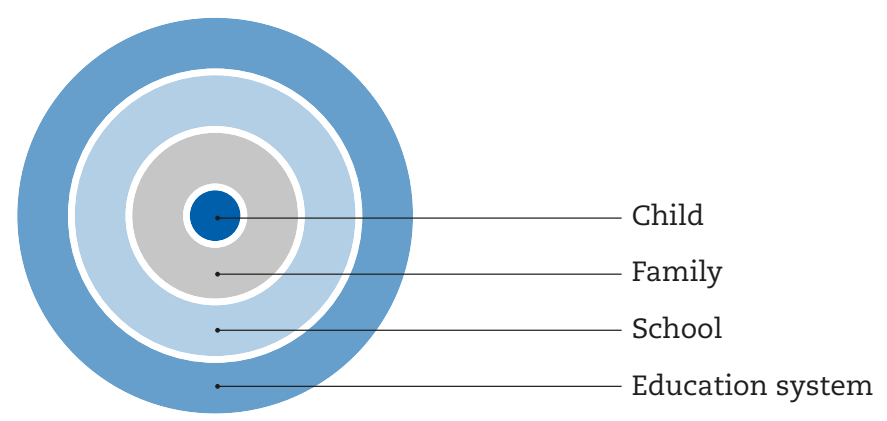

In most cases, researchers identify three sets of risk and protective factors that moderate the effects of adversity and promote academic resilience: attributes of the children themselves; characteristics of their families; and attributes of their wider social environment, which encompasses the school, the neighbourhood and the wider community (Masten and Garmezy, 1985; Werner and Smith, 1982, 1992). Resilience research has shown that some of the risk factors that are generally associated with increased vulnerability to adversity, if experienced at particular times, at specific degrees, and at times during which individuals have sufficient coping mechanisms, can have unexpected "steeling effects" and reduce vulnerability (Rutter, 2012b). Just as vaccinations protect individuals from specific diseases by prompting 
immune systems' production of antibodies, so manageable risk factors can help individuals develop effective coping mechanisms. Figure 2.4 illustrates the multilevel nature of risk and protective factors, ranging from individual to system-level factors; Figure 2.5 identifies risk and protective factors examined in this report vis-à-vis immigrant students' likelihood to achieve good education outcomes.

Lerner (2006) argues that the study of resilience requires a multidimensional approach because resilience involves the interaction between individuals and their social and institutional environments. Individual attributes refer to children's characteristics and experiences, family attributes refer to socioeconomic background and parenting related issues, whereas the extra-familial level includes neighbourhood, school and system level related factors (Rutter, 2000; Masten, 2001; Fraser, 2004; Waaktaar and Christie, 2000; Dyregrov, 2000; Raundalen, 2000; Luthar and Cicchetti, 2000). More recently, researchers have also started focusing on the genetic basis of children's well-being (Cloninger, 2004), but this aspect is not examined in this report.

Figure 2.5 - Overview of risk and protective factors

\begin{tabular}{|l|}
\hline \multicolumn{1}{|c|}{ Individual } \\
\hline - Gender \\
- Country of origin \\
- Paid or unpaid work \\
out of school \\
- Language spoken \\
at home \\
- Pre-primary education \\
\hline
\end{tabular}

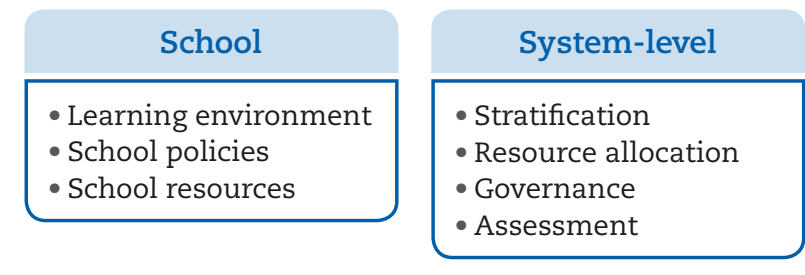

\section{Analytical choices taken in this report to study the resilience of students with an immigrant background}

When attempting to identify factors that shape the likelihood that students with an immigrant background will display academic, social, emotional and motivational resilience, the central question is: what is the relevant comparison group to evaluate the vulnerability of such students? Standard analyses of the academic resilience of socio-economically disadvantaged students typically compare, within countries, the group of disadvantaged students who are high performers (academically resilient students) with the group of disadvantaged students who are not (disadvantaged low achievers). Across countries, comparisons are conducted considering the overall prevalence of disadvantaged students who perform above a certain threshold.

In this report, multiple comparison groups are considered in order to provide a nuanced picture of the vulnerability experienced by students with an immigrant background from both a national and an international perspective. Underlying differences in the background characteristics of students with an immigrant background that are not captured in the PISA study are also accounted for, to the extent possible. Using multiple comparison groups results in a more detailed picture of the success of different education systems in promoting the overall resilience, as well as adjustment in different dimensions of well-being, of different groups of students. For example, by comparing the percentage of students with an immigrant background who are academically resilient in country A to the percentage of students with an immigrant background who are academically resilient in country $\mathrm{B}$, the report illustrates the capacity of education systems to promote absolute levels of academic resilience. But in the absence of a relative approach through which students with an immigrant background in country A are compared to students without an immigrant background in the same country, it is impossible to capture the disadvantage that students with an immigrant background may face in the long term when labour market and social opportunities are determined by relative rather than absolute performance levels. 
To account for broad unobserved differences across different groups of students with an immigrant background, students who have a direct experience of migration (because they are foreign-born) are compared with those who have an indirect experience of migration (because they have foreign-born parents). The outcomes of students from different countries of origin who settled in the same country of destination are compared with those of students from the same country of origin who settled in different countries of destination to evaluate the ability of an education system to cater to the specific needs of different populations, or of different education systems to promote integration of similar immigrant groups. In each case, comparisons also consider students' socio-economic status since that varies markedly across groups and is an important determinant of academic, social, emotional and motivational well-being.

The following six comparison groups are considered when identifying migration-specific adversity, and both relative and absolute vulnerability from national and international perspectives:

- students with an immigrant background in other countries

- students without an immigrant background in the same country

- different groups of students with an immigrant background

- students from the same country of origin who did not migrate

- students from the same country of origin who migrated to different countries

- students from different countries of origin who migrated to the same country of destination.

\section{Data sources}

The report is primarily based on data from the Programme for International Student Assessment (PISA). Data from the European Social Survey (ESS) are used to complement PISA data in dedicated Spotlights in Chapters 3 and 8.

\section{The Programme for International Student Assessment}

PISA is a triennial survey of 15-year-old students and was first implemented in 2000. PISA assesses the extent to which 15-year-old students, near the end of their compulsory education, have acquired key knowledge and skills that are essential for full participation in modern societies. The assessment focuses on the core school subjects of science, reading and mathematics. Students' proficiency in an innovative domain is also assessed (in 2015, this domain is collaborative problem solving). The assessment does not just ascertain whether students can reproduce knowledge; it also examines how well students can extrapolate from what they have learned and can apply that knowledge in unfamiliar settings, both in and outside of school. This approach reflects the fact that modern economies reward individuals not for what they know, but for what they can do with what they know.

The triennial nature of the study means that PISA can be used to monitor trends in students' acquisition of knowledge and skills across countries and in different demographic subgroups within each country. Forty-three countries and economies took part in the first assessment and by 2015 this number had grown to 72 countries and economies. Approximately 540000 students completed the assessment in 2015, representing about 29 million 15-year-olds.

In addition to all OECD countries, the survey has been or is being conducted in:

- East, South and Southeast Asia: Beijing, Shanghai, Jiangsu and Guangdong (China), Hong Kong (China), Indonesia, Macao (China), Malaysia, Singapore, Chinese Taipei, Thailand and Viet Nam.

- Central, Mediterranean and Eastern Europe, and Central Asia: Albania, Bulgaria, Croatia, Georgia, Kazakhstan, Kosovo, Lebanon, Lithuania, the Former Yugoslav Republic of Macedonia, Malta, Moldova, Montenegro, Romania and the Russian Federation.

- The Middle East: Jordan, Qatar and the United Arab Emirates.

- Central and South America: Argentina, Brazil, Colombia, Costa Rica, Dominican Republic, Peru, Trinidad and Tobago, Uruguay.

- Africa: Algeria and Tunisia. 
In each round of PISA, one of the core domains is tested in detail, taking up nearly half of the total testing time. The major domain in 2015 was science, as it was in 2006. Reading was the major domain in 2000 and 2009, and mathematics was the major domain in 2003 and 2012. With this alternating schedule of major domains, a thorough analysis of achievement in each of the three core areas is presented every nine years; an analysis of trends is offered every three years.

The PISA 2015 Assessment and Analytical Framework (OECD, 2016a) presents definitions and more detailed descriptions of the domains assessed in PISA 2015:

- Science literacy is defined as the ability to engage with science-related issues, and with the ideas of science, as a reflective citizen. A scientifically literate person is willing to engage in reasoned discourse about science and technology, which requires the competencies to explain phenomena scientifically, evaluate and design scientific enquiry, and interpret data and evidence scientifically.

- Reading literacy is defined as students' ability to understand, use, reflect on and engage with written texts in order to achieve one's goals, develop one's knowledge and potential, and participate in society.

- Mathematical literacy is defined as students' capacity to formulate, employ and interpret mathematics in a variety of contexts. It includes reasoning mathematically and using mathematical concepts, procedures, facts and tools to describe, explain and predict phenomena. It assists individuals in recognising the role that mathematics plays in the world and to make the well-founded judgements and decisions needed by constructive, engaged and reflective citizens.

The main PISA instruments are a two-hour assessment and a series of background questionnaires. Until 2012 the PISA assessment was delivered through paper-and-pencil booklets. For the first time, PISA 2015 delivered the assessment of all subjects via computer. Paper-based assessments were provided for countries that chose not to test their students by computer, but the paper-based assessment was limited to questions that could measure trends in science, reading and mathematics performance.

To gather contextual information, PISA 2015 asked students and the principal of their school to respond to questionnaires. The student questionnaire took about 35 minutes to complete; the questionnaire for principals took about 45 minutes to complete. The PISA 2015 Assessment and Analytical Framework (OECD, 2016a) presents the questionnaire framework in detail. The questionnaires from all assessments since PISA's inception are available on the PISA website: www.pisa.oecd.org.

Participating students also answered a background questionnaire, which was designed to take 35 minutes to complete. The questionnaire sought information about the students themselves, their homes, and their school and learning experiences. School principals completed a questionnaire that covered the school system and the learning environment. For additional information, some countries/economies decided to distribute a questionnaire to teachers. In some countries/economies, optional questionnaires were distributed to parents, who were asked to provide information on their perceptions of and involvement in their child's school, their support for learning in the home, and their child's career expectations, particularly in science. Data from the parental questionnaire were used in this report. Countries could choose two other optional questionnaires for students: one asked students about their familiarity with and use of information and communication technologies (ICT); and the second sought information about students' education to date, including any interruptions in their schooling, and whether and how they are preparing for a future career. Data from the educational careers questionnaire were used in this report.

The contextual information collected through the student, school and optional questionnaires are complimented by system-level data. Indicators describing the general structure of the education systems, such as expenditure on education, stratification, assessments and examinations, appraisals of teachers and school leaders, instruction time, teachers' salaries, actual teaching time and teacher training are routinely developed and applied by the OECD (e.g. in the annual OECD publication, Education at a Glance). These data are extracted from Education at a Glance 2016 (OECD, 2016b), Education at a Glance 2015 (OECD, 2015a) and Education at a Glance 2014 (OECD, 2014) for the countries that participate in the annual OECD data collection that is administered through the OECD Indicators of Education Systems (INES) Network. For other countries and economies, a special system-level data collection was conducted in collaboration with PISA Governing Board members and National Project Managers. 
Differences between countries in the nature and extent of pre-primary education and care, in the age at entry into formal schooling, in the structure of the education system, and in the prevalence of grade repetition mean that school grade levels are often not good indicators of where students are in their cognitive development. To better compare student performance internationally, PISA targets students of a specific age. PISA students are aged between 15 years 3 months and 16 years 2 months at the time of the assessment, and have completed at least 6 years of formal schooling. They can be enrolled in any type of institution, participate in full-time or part-time education, in academic or vocational programmes, and attend public or private schools or foreign schools within the country. Using this age across countries and over time allows PISA to compare consistently the knowledge and skills of individuals born in the same year who are still in school at age 15, despite the diversity of their education histories in and outside of school.

The population of PISA-participating students is defined by strict technical standards, as are the students who are excluded from participating. The overall exclusion rate within a country was required to be below $5 \%$ to ensure that, under reasonable assumptions, any distortions in national mean scores would remain within plus or minus 5 score points, i.e. typically within the order of magnitude of 2 standard errors of sampling. Exclusion could take place either through the schools that participated or the students who participated within schools.

There are several reasons why a school or a student could be excluded from PISA. Schools might be excluded because they are situated in remote regions and are inaccessible, because they are very small, or because of organisational or operational factors that precluded participation. Students might be excluded because of intellectual disability or limited proficiency in the language of the assessment.

The fact that the PISA target population covers 15-year-olds who are enrolled in school, have reasonable language proficiency has implications for results presented in this report, since many recently arrived immigrants were excluded from the PISA target population (see Chapter 3 for a detailed description).

\section{European Social Survey}

The European Social Survey (ESS) is an academically driven cross-national survey that has been mapping attitudes and behavioural changes in Europe's social, political and moral climate since its establishment in 2001.

The survey conducts face-to-face interviews every two years with newly selected, cross-sectional samples that are representative of all persons above the age of 14 and who are resident within private households in each country. The sample size requested to participating countries is at least 1500 respondents, although for countries with smaller populations the number of respondents can be smaller. The first round was conducted in 2002 in 22 countries. Since then around 350000 face-to-face interviews have been carried out and over 35 countries have participated in at least one ESS round. Participating countries include Albania, Austria, Belgium, Bulgaria, Croatia, Czech Republic, Denmark, Estonia, Finland, France, Germany, Greece, Hungary, Iceland, Ireland, Israel, Italy, Kosovo, Latvia, Lithuania, Luxembourg, Netherlands, Norway, Poland, Portugal, Romania, Russian Federation, Slovakia, Slovenia, Spain, Sweden, Switzerland, Turkey and United Kingdom.

The questionnaire consists of a main core section of questions that have been administered in every ESS round and are thus easily comparable over time. These questions were developed following the recommendations made by academic experts who were consulted by the Core Scientific Team during the early planning stages of the ESS. The core modules contain questions aimed at identifying individuals' attitudes towards the media, health and wellbeing, trust in institutions and governments, education and occupation, social capital and social trust, household circumstances, citizen involvement and democracy, social exclusion, political values and engagement, immigration and crime. In addition to questions on attitudes and dispositions, the ESS contains information on socio-demographic variables such as respondents' ethnic and immigrant background, household income, level of education, employment and occupational status of the respondent, his/ her parents and partner.

In addition to the 'core' modules that are administered in each round, multinational teams of researchers based in ESS countries were selected to contribute to the design of additional 'rotating questionnaires'. 
"Rotating questionnaires" that have been administered so far include questions on citizen involvement, health and care, economic morality, family, work and wellbeing, timing of life, personal and social wellbeing, welfare attitudes, ageism, trust in the police and courts, democracy, immigration, social inequalities in health and attitudes to climate change and energy security. Some of these topics have been included in more than one ESS round.

ESS data are freely accessible for academics, policymakers and civil society and there are more than 100000 registered users of the data. These data are used to develop soundly-based indicators of national progress, based on citizens' perceptions and judgements of key aspects of their societies. They also serve to help researchers and policymakers identify trends in social structure, conditions and attitudes in Europe and to interpret how European societies are changing in social, political and moral terms.

The latest available ESS data are from round 8, which contains data collected in 2016 in 23 European countries. Data from ESS8 for 18 countries were released in October of 2017. 


\section{References}

Agasisti, T. et al. (2018), "Academic resilience: What schools and countries do to help disadvantaged students succeed in PISA”, OECD Education Working Papers, No. 167, OECD Publishing, Paris, http://dx.doi.org/10.1787/e22490ac-en.

Bernard, B. (1995), Fostering Resiliency in Kids: Protective Factors in the Family School and Community, West Ed Regional Educational Laboratory, San Francisco.

Boeri, T. et al. (2012), Brain Gain and Brain Drain: The Global Competition to Attract High- Skilled Migrants, Oxford University Press, Oxford.

Borgonovi, F. and J. Pál (2016), "A framework for the analysis of student well-being in the PISA 2015 study: Being 15 in 2015”, OECD Education Working Papers, No. 140, OECD Publishing, Paris, http://dx.doi.org/10.1787/19939019.

Boyden, J. and G. Mann (2005), “Children's risk, resilience, and coping extreme situations”, in Ungar M. (ed.), Handbook for Working with Children and Youth: Pathways to Resilience Across Cultures and Contexts, SAGE, Thousand Oaks, CA, pp. 3-26.

Buchmann, C. (2002), "Measuring family background in international studies of education: Conceptual issues and methodological challenges”, in Porter, A.C. and A. Gamoran (eds.), Methodological Advances in Cross-National Surveys of Educational Achievement, National Academy Press, Washington, DC, pp.150-197.

Cardozo, S. (2009), "Experiencias laborales y deserción en la cohorte de estudiantes evaluados por pisa 2003 en Uruguay: nuevas evidencias”, REICE- Revista Iberoamericana sobre Calidad, Eficacia y Cambio en Educación, Vol. 7/4, pp. $198-218$.

Cerna, L. (2016), Immigration Policies and the Global Competition for Talent, Palgrave Macmillan, Basingstoke.

Cicchetti, D. (2013), "An overview of developmental psychopathology", in P.D. Zelazo (ed.), The Oxford Handbook of Developmental Psychology, Vol. 2. Self and other, Oxford University Press, New York, NY, pp. 455-480.

Cloninger, C.R. (2004), Feeling Good: The Science of Well-Being, Oxford University Press, Oxford.

Coleman, J.S. et al. (1966), Equality of Educational Opportunity, U.S. Department of Health, Education, \& Welfare, Washington, DC.

Crane, J. (1996), "Effects of home background, SES, and maternal test scores on mathematics achievement", Journal of Educational Research, Vol. 89/5, pp. 305-314.

Daniel, B. and S. Wassell (2002), Adolescence: Assessing and Promoting Resilience in Vulnerable Children 3, Jessica Kingsley, London.

Diers, J. (2013), "Why the world needs to get serious about adolescents: A view from UNICEF", Journal of Research on Adolescence, Vol. 23, pp. 214-222, http://dx.doi.org/10.1111/jora.12042.

EMN (2011), Satisfying labour demand through migration, EMN Synthesis Report, Home Affairs, Brussels.

Evans, G.W., D. Li and S.S. Whipple (2013), "Cumulative risk and child development”, Psychological Bulletin, advance online publication, http://dx.doi.org/10.1037/a0031808.

Fazel, M. and A. Stein (2002), "The mental health of refugee children”, Archives of disease in childhood, Vol. 87/5, pp. 366-370.

Fraser, M. (1997), Risk and Resilience in Childhood: An Ecological Perspective, NASW Press, Washington, DC.

Fraser, M. (2004), "The ecology of childhood: A multisystems perspective”, in Fraser, Mark (ed.), Risk and Resilience in Childhood: An Ecological Perspective, National Association of Social Workers, Washington, DC.

Garza, E., P. Reyes and E. Trueba (2004), Resiliency and Success: Migrant Children in the United States, Paradigm, Boulder, CO.

Gunderson, L.H. (2000), "Ecological resilience - In theory and application”, Annual Review of Ecology and Systematics, Vol. 31 , pp.425-439.

Holling, C.S. (1973), "Resilience and stability of ecological systems", Annual Review of Ecology and Systematics, Vol. 4, pp.1-23.

Howard, S., J. Dryden and B. Johnson (1999), "Childhood resilience: Review and critique of literature", Oxford Review of Education, Vol. 25, pp. 307-23.

Igoa, C. (1995), The Inner World of the Immigrant Child, Lawrence Erlbaum, Mahwah, NJ.

IOM (2015), IOM and UNICEF Data Brief: Migration of Children to Europe, International Organization for Migration, www.iom.int/ sites/default/files/press_release/file/IOM-UNICEF-Data-Brief-Refugee-and-Migrant-Crisis-in-Europe-30.11.15.pdf.

Jencks, C. (1972), "The Coleman report and the conventional wisdom”, in F. Mosteller and D.P. Moynihan (eds.), On Equality of Educational Opportunity, Vintage, New York, NY, pp. 69-115. 
Kirby L. D. and M. W. Fraser (1997), "Risk and resilience in childhood”, in M. W. Fraser (ed.), Risk and Resilience in Childhood: An Ecological Perspective, NASW Press, Washington, DC, pp. 10-33.

Lerner, R.M. (2006), "Developmental science, developmental systems, and contemporary theories of human development”, in Damon W. and R. M. Lerner (series eds.) \& R. M. Lerner (Vol. ed.), Handbook of Child Psychology: Vol 1. Theoretical models of human development, 6th ed., Wiley, Hoboken, NJ, pp. 1-17.

Levin, H. (2012), "More than just test scores", Prospects Vol. 42/3, pp. 269-284.

Longitudinal Study of Australian Youth (LSAY) (2014), Y03 Cohort Report, www.lsay.edu.au/cohort/2003/3.html (accessed on 20 October 2016).

Luthar S.S. (2003), Resilience and Vulnerability: Adaptation in the Context of Childhood Adversities, Cambridge University Press, Cambridge.

Luthar, S.S. (2006), "Resilience in development: A synthesis of research across five decades", in Cicchetti, D. and D.J. Cohen (eds.), Developmental Psychopathology: Vol. 3. Risk, Disorder, and Adaptation, 2nd ed., Wiley, Hoboken, NJ, pp. 739-795.

Luthar, S.S. and D. Cicchetti (2000), "The construct of resilience: Implications for interventions and social policies", Development and Psychopathology, Vol. 12/04, pp. 857-885.

Martin, M.O. et al. (2012), TIMSS 2011 International Results in Science, TIMSS \& PIRLS International Study Center, Boston College, Chestnut Hill, MA.

Masten, A.S. (1994), "Resilience in individual development: Successful adaptation despite risk and adversity", in Wang. M.C. and E.W. Gordon (eds.), Educational Resilience in Inner-City America: Challenges and Prospects, Lawrence Erlbaum, Hillsdale, NJ, pp. 3-25.

Masten, A.S. (2001), "Ordinary magic: Resilience processes in development”, American Psychologist, Vol. 56, pp. 227-238, http://dx.doi.org/10.1037/0003-066X.56.3.227.

Masten, A. (2011), "Resilience in children threatened by extreme adversity: Frameworks for research, practice, and translational synergy", Development and Psychopathology, Vol. 23, pp. 493-506.

Masten, A.S. (2013), "Risk and resilience in development", in Zelazo, P.D. (ed.), Oxford handbook of developmental psychology, Oxford University Press, New York, pp. 579-607.

Masten, A.S., J.L. Powell and S.S. Luthar (2003), “A resilience framework for research, policy, and practice”, in Luthar, S. (ed.) Resilience and Vulnerability: Adaptation in the Context of Childhood Adversities, Cambridge University Press, New York, pp. 1-25, https://doi.org/10.1017/CBO9780511615788.003.

Masten, A. and N. Garmezy (1985), "Risk, vulnerability, and protective factors in developmental psychopathology", in Lahey, B. and A. Kazdin (eds.), Advances in Clinical Child Psychology, Vol. 8, Plenum Press, New York, pp. 1-52.

McCormick, C.M., S.I.-C. Kuo and A.S. Masten (2011), "Developmental tasks across the lifespan”, in Fingerman et al. (eds.), The Handbook of Lifespan Development, Springer, New York, NY.

McLoyd, V.C. (1998), “Socioeconomic disadvantage and child development”, American Psychologist, Vol. 53/2, pp. 185-204, http://dx.doi.org/10.1037/0003-066X.53.2.185.

McNelles, L.R. and J.A. Connolly (1999), "Intimacy between adolescent friends: Age and gender differences in intimate affect and intimate behaviors", Journal of Research on Adolescence, Vol. 9/2, pp. 143-159, http://dx.doi.org/10.1207/ s15327795jra0902_2.

Mullis, I.V.S. et al. (2012), TIMSS 2011 international results in mathematics, TIMSS \& PIRLS International Study Center, Boston College, Chestnut Hill, MA.

OECD (2016c), International Migration Outlook 2016, OECD Publishing, Paris, http://dx.doi.org/10.1787/migr outlook-2016-en.

OECD (2016a), PISA 2015 Assessment and Analytical Framework: Science, Reading, Mathematic and Financial Literacy, OECD Publishing, Paris, http://dx.doi.org/10.1787/9789264255425-en.

OECD (2016b), Education at a Glance 2016: OECD Indicators, OECD Publishing, Paris. http://dx.doi.org/10.187/eag-2016-en.

OECD (2015a), Education at a Glance 2015: OECD Indicators, OECD Publishing, Paris, http://dx.doi.org/10.1787/eag-2015-en//y7.

OECD (2015b), International Migration Outlook 2015, OECD Publishing, Paris, http://dx.doi.org/10.1787/migr_outlook-2015-en.

OECD (2014), Education at a Glance 2014: OECD Indicators, OECD Publishing, Paris, http://dx.doi.org/10.1787/eag-2014-en.

OECD (2012), Learning beyond Fifteen: Ten Years after PISA, OECD Publishing, Paris, http://dx.doi.org/10.1787/9789264172104-en. 
OECD. (2011), Against the Odds: Disadvantaged Students who Succeed in School, retrieved from http://dx.doi.org/10.1787/ 9789264090873-en.

OECD (2010a), Pathways to Success: How Knowledge and Skills at Age 15 Shape Future Lives in Canada, OECD Publishing, Paris, http://dx.doi.org/10.1787/9789264081925-en.

OECD (2010b), Closing the Gap for Immigrant Students: Policies, Practice and Performance, OECD Publishing, Paris, http://dx.doi. org/10.1787/9789264075788-en.

OECD/European Union (2015), Indicators of Immigrant Integration 2015: Settling In, OECD Publishing, Paris, http://dx.doi. org/10.1787/9789264234024-en.

OECD/European Union (2014), Matching Economic Migration with Labour Market Needs, OECD, Paris, http://dx.doi. org/10.1787/9789264216501-en.

Peaker, G. (1971), The Plowden Children Four Years Later, National Foundation for Educational Research in England and Wales, London.

Portes, A. and R.G. Rumbaut (2001), Legacies: The story of the Immigrant Second Generations. University of California Press, Berkeley.

Ríos González A. (2014), “Calendario y determinantes de riesgo educativo: la cohorte Pisa 2006-2011 en Uruguay”, (Timing and determinants of the fall in educational risk: PISA 2006-2011 cohort in Uruguay), Revista de Ciencias Sociales, No. 35, pp. 109-136.

Rosdahl, A. (2014), "Fra 15 til 27 år. PISA 2000-eleverne I 2011/12" (From 15 to 27 years. The PISA 2000- students in 2011/12), SFI-Rapport 14:13, SFI - Det Nationale Forskningscenter for Velfærd, Copenhagen.

Rutter, M. (2000), "Resilience Reconsidered: Conceptual considerations, empirical findings, and policy implications”, in Shonkoff, J.P. and S.J. Meisels (eds.) Handbook of Early Childhood intervention, Cambridge University Press, Cambridge.

Rutter, M. (2006), "Implications of resilience concepts for scientific understanding", Annals of the New York Academy of Sciences, Vol. 1094/1, pp. 1-12.

Rutter, M. (2012a), "Resilience: Causal pathways and social ecology”, in Ungar, M. (ed.), The Social Ecology of Resilience: A Handbook of Theory and Practice, Springer, New York, pp. 33-42.

Rutter, M. (2012b), "Resilience as a dynamic concept”, Development and Psychopathology, Vol.24/2, pp. 335-344, https://dx. doi.org/10.1017/S0954579412000028.

Sandoval-Hernandez, A. and D. Cortes (2012), Factors and Conditions that Promote Academic Resilience: A Cross-Country Perspective, Paper presented at the annual meeting of the 56th Annual Conference of the Comparative and International Education Society, Caribe Hilton, San Juan, Puerto Rico.

Scharenberg et al. (2014), Education Pathways from Compulsory School to Young Adulthood: The First Ten Years, TREE, Basel.

Sirin, S.R. (2005), "Socioeconomic status and academic achievement: A meta-analytic review of research", Review of Educational Research, Vol. 75/3, pp. 417-453, http://dx.doi.org/10.3102/00346543075003417.

Stankov, L. (1999), "Mining on the "no man's land" between intelligence and personality", Ackerman, P.L. and P.C Kyllonen (eds.), Learning and Individual Differences: Process, Trait and Content Determinants, American Psychological Association, Washington, DC, pp. 315-337.

Sternberg, R. (1995), "Diversifying instruction and assessment", The Educational Forum Vol.59/1, pp. 47-52.

Suarez-Orozco, C. and M.M. Suarez-Orozco, (2001), Children of immigration, Harvard University Press, Cambridge, MA.

Sutton, A. and I. Soderstrom (1999) "Predicting elementary and secondary school achievement with school-related and demographic factors", Journal of Educational Research, Vol 92/6, pp. 330-338.

Treloar, L.R.G. (1975), The Physics of Rubber Elasticity, Oxford University Press, Oxford.

Ungar, M. (2011), "Community resilience for youth and families: Facilitative physical and social capital in contexts of adversity”, Children and Youth Social Services Review, Vol. 33, pp. 1742-1748.

Ungar, M. (2005), "Resilience among children in child welfare, corrections, mental health and education settings: Recommendations for service”, Child \& youth Care Forum, Vol. 34/6, pp. 423-444, http://dx.doi.org/10.1007/s10566-005-7755-7.

Ungar, M. (ed.) (2005), Handbook for working with children and youth: Pathways to resilience across cultures and contexts, Sage Publications, Thousand Oaks. 
UNESCO, EFA Global Monitoring Report (2015), Education for All: Achievements and Challenges: 2000-2015,UNESCO, Paris.

UNICEF (2016), Uprooted: The Growing Crisis for Refugee and Migrant Children, UNICEF, New York.

Waaktaar, T. and H.J. Christie (2000), Styrk Sterke Sider. Håndbok i Resiliencebyggende Grupper for Barn og Ungdom Med Psykososiale Belastninger, Kommuneforlaget, Oslo

Werner, E.E. (2000), Through the Eyes of Innocents: Children Witness World War II, Westview Press, Boulder, CO.

Werner, E.E. and R.S. Smith (1982), Vulnerable but Invincible: A Longitudinal Study of Resilient Children and Youth, McGraw-Hill, New York.

Werner, E.E. and R.S. Smith, (1992), Overcoming the Odds: High-risk Children from Birth to Adulthood, Cornell University Pres, New York.

White, K. R. (1982), "The relation between socioeconomic status and academic achievement", Psychological Bulletin, Vol. 91/3, pp. 461-481.

Williams, C. (1991), "Primary prevention and the need for a public health approach", in Westermeyer, J., C.L. Williams and A.N. Nguyen (eds.), Mental Health Service for Refugees, US. Government Printing Office, Washington, DC.

Wolff, P. and G. Fesseha (1999), "The orphans of Eritrea: A five- year follow up study”, Journal of Child Psychiatry, Vol. 40/8, Cambridge University Press, www.sou.gov.se/barniasylproc/dokument/ud_asylum_060918.pdf.

Wong, D.F.K. (2008), "Differential impacts of stressful life events and social support on the mental health of mainland Chinese immigrant and local youth in Hong Kong: A resilience perspective”, British Journal of Social Work, Vol. 38/2, pp. 236-52.

Zhou, M. (1997), "Growing up American: The challenge of immigrant children and children of immigrants", Annual Review of Sociology, Vol. 23, pp. 63-95. 


\section{Chapter 3 \\ Adversity and adjustment: The resilience of students with an immigrant background}

This chapter defines several categories of students depending on their migration-related experiences that are used extensively in the report. It discusses the prevalence of students with an immigrant background in education systems around the world, and the particular challenges education systems face in integrating immigrant students who had arrived in the host country when they were 12 years old or older. The chapter examines differences between students with and without an immigrant background in their ability to attain baseline academic proficiency, and in their degree of well-being, as measured by their sense of belonging at school, their satisfaction with life, how anxious they feel about their schoolwork, and their motivation to achieve.

\section{Notes regarding Cyprus}

Note by Turkey: The information in this document with reference to "Cyprus" relates to the southern part of the Island. There is no single authority representing both Turkish and Greek Cypriot people on the Island. Turkey recognises the Turkish Republic of Northern Cyprus (TRNC). Until a lasting and equitable solution is found within the context of the United Nations, Turkey shall preserve its position concerning the "Cyprus issue".

Note by all the European Union Member States of the OECD and the European Union: The Republic of Cyprus is recognised by all members of the United Nations with the exception of Turkey. The information in this document relates to the area under the effective control of the Government of the Republic of Cyprus.

\section{Note regarding data from Israel}

The statistical data for Israel are supplied by and under the responsibility of the relevant Israeli authorities. The use of such data by the OECD is without prejudice to the status of the Golan Heights, East Jerusalem and Israeli settlements in the West Bank under the terms of international law. 


\section{What the data tell us - Overview of migrant groups}

- In 2015, almost one in four 15-year-old students in OECD and EU countries had an immigrant background, i.e. he or she was foreign-born or had at least one parent who was.

- Between 2003 and 2015, the share of students with an immigrant background grew by six percentage points, on average across OECD (seven percentage points across EU countries).

- Over the past decade, of all groups of students with an immigrant background, the share of second-generation immigrant students, native-born children of foreign-born parents, grew the most, on average across OECD and EU countries.

- On average across OECD and EU countries in 2015, late arrivals - foreign-born students who settled in the host country at or after the age of 12 - represented about one-third of all firstgeneration immigrant students. Between 2003 and 2015, their share grew in 14 out of 36 countries and economies with available data. The increase was larger than twenty percentage points Austria, Latvia, Luxembourg, the Slovak Republic, Sweden, Turkey, Tunisia and Uruguay.

$S$ participating students to report whether they and/or their parents were born in the country in which the student sat the PISA assessment or in a different country. In a number of countries, the student questionnaire was designed to identify the country in which students and/or their parents were born, if this was different from the country in which students sat the assessment. Students could select from a short list, adapted to the specific country context so as to reflect the main migrant communities in the country, as well as a remainder category, "other". The questionnaire also asked foreign-born students to identify the age at which they migrated. ${ }^{1}$

Traditional analyses of PISA data have considered students with an immigrant background as students who have foreign-born parents. These students are further distinguished between the native-born children of two foreign-born parents (second-generation immigrant students) and foreign-born students who have two foreign-born parents (first-generation immigrant students). According to these definitions, students who have families with a mixed background - i.e. students who have one native-born parent and one foreign-born parent - are considered as not having an immigrant background.

The standard PISA categorisation of students with an immigrant background has been useful for analysing subject-specific outcomes, but it obscures differences across family characteristics that may be of particular relevance when attempting to identify the effects of migration on broader education outcomes, including subject-specific performance, motivation, and social and emotional well-being.

PISA data can be used to characterise three types of migration-related adversity:

- having two foreign-born parents

- living in a mixed household

- being foreign-born.

\section{Who are the students with an immigrant background? Having two foreign-born parents}

Whether or not a student has direct experience of migration, having two foreign-born parents means that a student may have greater difficulty in understanding the formal and informal rules and processes that govern the functioning of the education system of the host country, and the social and cultural practices and traditions that regulate the local community. For example, the student may find it difficult to talk with their family about specific authors examined in language-of-instruction courses, historical figures and cultural references. The degree of adversity that stems from having foreign-born parents varies, depending on the parents' level of education (observed in PISA), the parents' level of openness to and curiosity about the host country's institutional framework (unobserved in PISA) and the age at which the student's parents migrated (unobserved in PISA). 
Table 3.1 - Snapshot of immigrant groups

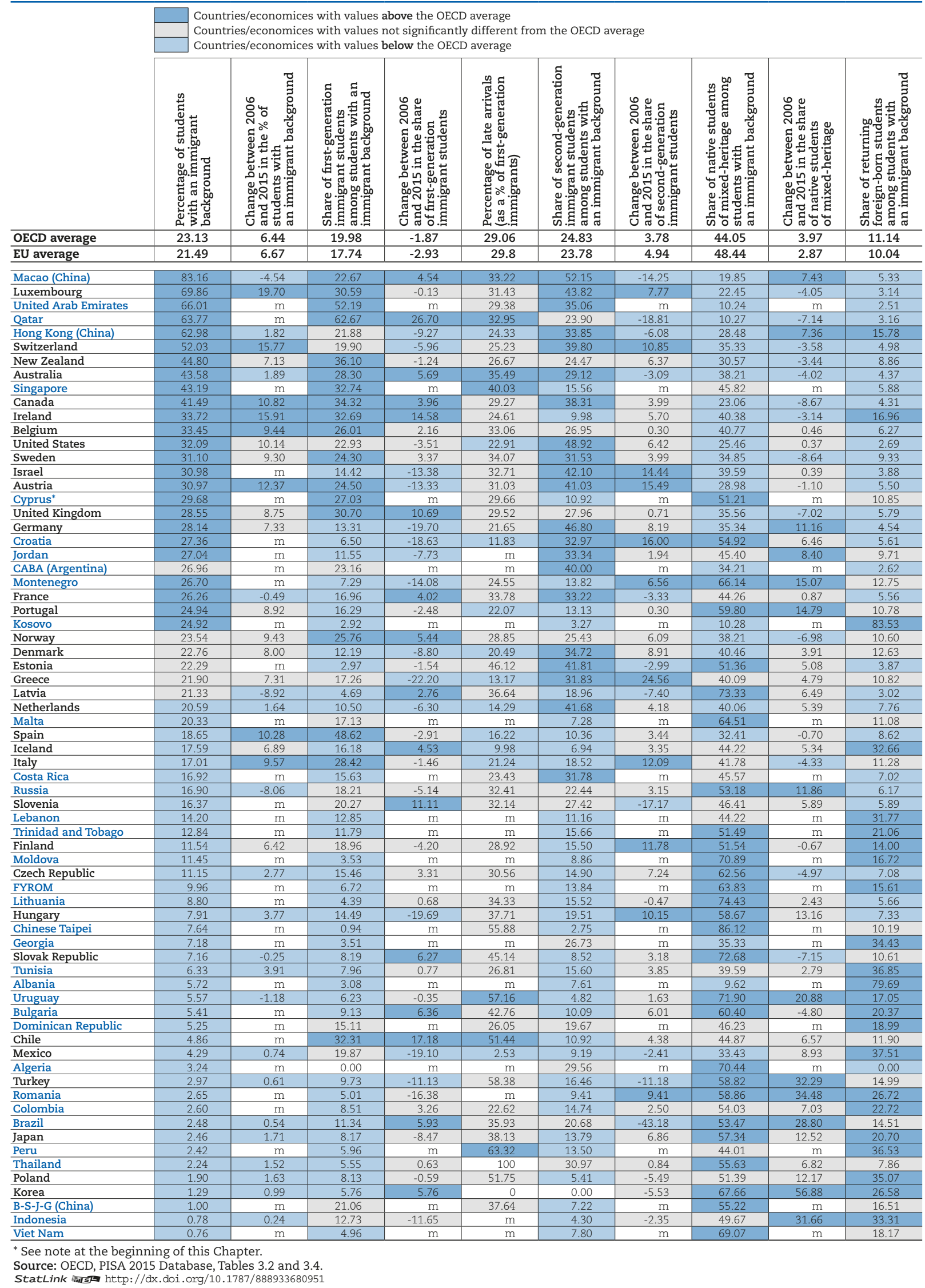


Figure 3.1 - A classification of PISA students by immigrant background

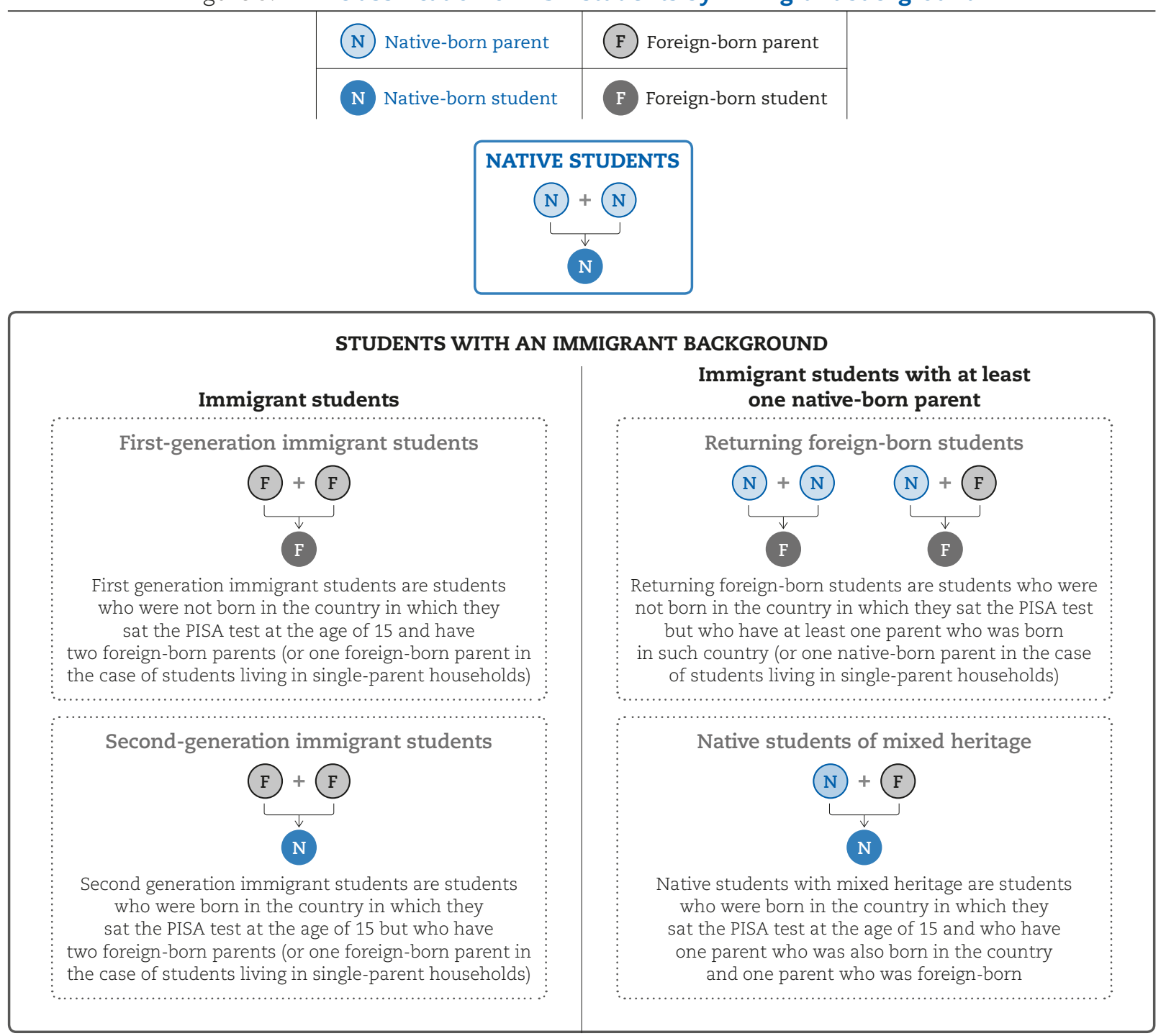

\section{Living in a mixed household}

Living in a mixed household, with one foreign-born and one native-born parent, means that students can rely on the institutional knowledge of the native-born parent and are thus less likely to suffer the same level of adversity as the children of two foreign-born parents. However, students in mixed families might struggle with feelings of belonging and a sense of identity. Students with one foreign-born and one nativeborn parent, in fact, need to develop a personal identity that integrates and transcends the experiences of both parents.

\section{Being foreign-born}

Migration is a life-changing experience, and research identifies specific difficulties associated with moving and settling in a new country. These difficulties, which include the loss of close relationships, experiencing stress related to expectations about the unknown, having to learn a new language and adjusting to a new school system (Garza, Reyes and Trueba, 2004; Igoa, 1995; Portes and Rumbaut, 2001; Suarez-Orozco and Suarez-Orozco, 2001; Zhou, 1997) tend to be greater when children move at a late age.

Some children who fled war, persecution and extreme poverty in their country of origin experienced extremely difficult circumstances prior to migrating. They often missed learning opportunities during the migration phase and upon arrival, while waiting for their legal status and permanent residence to be 
determined. This means that they often lag behind academically compared to native-born children of the same age; as a result, they may struggle at school and find it difficult to build social relationships with children of their age. Refugees and asylum seekers often face additional tensions as a result of being part of broken families, with some family members dead or left behind in the country of origin.

\section{The prevalence of students with an immigrant background}

Figure 3.2 suggests that in 6 out of the 69 countries and economies with available data in PISA 2015, the native-born children of native-born parents represent a minority, while in 26 countries and economies, the native-born children of native-born parents represented more than 9 out of 1015 -year-old students. Native-born children of native-born parents were a minority in Switzerland (48\%), Hong Kong (China) (37\%), Qatar (36\%), the United Arab Emirates (34\%), Luxembourg (30\%) and Macao (China) (17\%). By contrast, on average across OECD countries, around 77\% of students were native-born children of nativeborn parents. Still, this means that, across OECD countries, as many as $23 \%$ of 15 -year-old students had some form of recent experience of migration in the family: either they were born in another country or at least one of their parents was (Table 3.2, available on line).

Figure 3.2 indicates that the percentage of native-born children of native-born parents decreased between 2003 and 2015 in as many as 26 out of the 39 countries and economies with comparable data. On average across OECD countries, the decrease was as large as 6 percentage points (seven across EU countries) and it was over 15 percentage points in Ireland, Luxembourg and Switzerland. The percentage of native-born students of native-born parents increased only in Latvia, Macao (China) the Russian Federation (hereafter "Russia") and Uruguay.

While in most countries the number of students without a recent experience of migration in the family shrank significantly between 2003 and 2015, countries differ markedly in the composition of their student population and in how the make-up of the group with an immigrant background has evolved over time. Figure 3.3 classifies students according to whether they or their parents are foreign-born and identifies four major groups: foreign-born students with two foreign-born parents (first-generation immigrants), foreign-born students with at least one parent who is native-born (returning foreignborn immigrants), native-born students of two foreign-born parents (second-generation immigrants), and native-born students of one foreign-born and one native-born parent (native students of mixed heritage).

On average across OECD countries, in 2015, around 31\% of students with an immigrant background (and around $28 \%$ of students on average across EU countries) were native-born students with two foreign-born parents (or one foreign-born parent in the case of students living in single-parent households), 38\% (44\% across EU countries) were native-born students of mixed heritage (those with one native-born and one foreign-born parent), 23\% (21\% across EU countries) were foreign-born children of foreign-born parents, and $8 \%$ (also across EU countries) were returning foreign-born immigrants - i.e. they were born outside the country of assessment but had at least one parent who was native-born.

Figure 3.3 suggests a large degree of heterogeneity in the composition of the group of students with an immigrant background. Students who are foreign-born and have foreign-born parents were a majority only in Qatar and the United Arab Emirates. In as many as 25 out of the 69 countries and economies with available data, this group represented less than $10 \%$ of students with an immigrant background. In all other countries and economies, either the student or at least one of the students' parents was born in the country in which the student sat the PISA assessment.

In Macao (China), more than one in two students with an immigrant background is native-born with two foreign-born parents. In 27 countries and economies, between one in two and one in four students, among all students whose family has a recent history of migration, shares this profile, as does fewer than one in ten students in 16 other countries and economies. In 29 countries and economies, more than one in two students with an immigrant background are native-born of mixed heritage (with one native-born and one foreign-born parent), while in Albania, Kosovo, Macao (China), Qatar and the UnitedArab Emirates, fewer than one in five students whose family has a recent history of migration shares this profile. 
Figure 3.2 Trends between 2003 and 2015 in the percentage of native-born students with native born parents

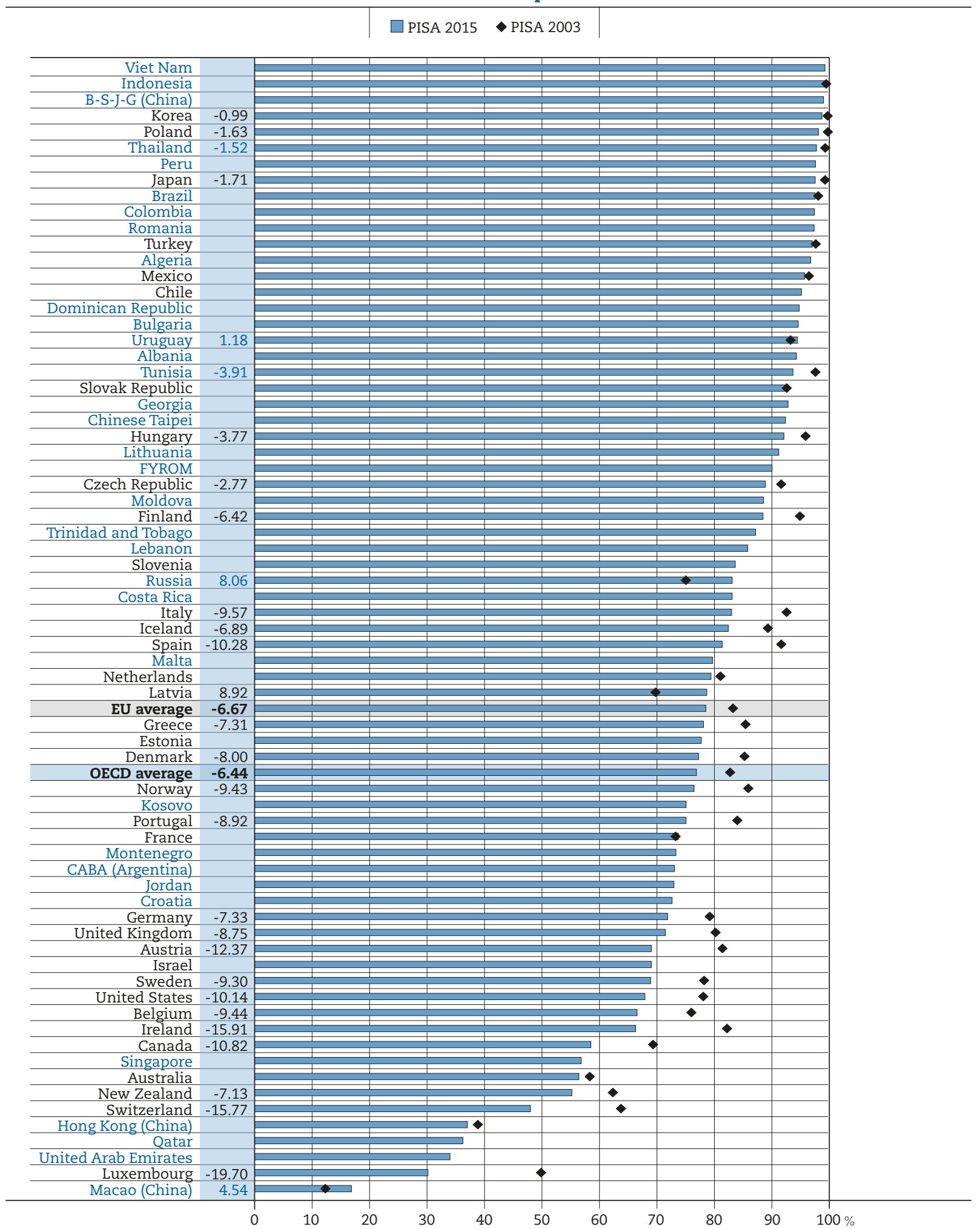

Note: Only countries/economies that participated in PISA 2003 and PISA 2015 are shown.

Statistically significant differences between PISA 2015 and PISA 2003 are shown next to country/economy names.

Countries and economies are ranked in descending order of the percentage of native-born students with native-born parents in 2015.

Source: OECD, PISA 2015 and 2003 Database, Table 3.2.

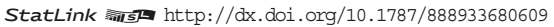


Figure 3.3 - Percentage of students with an immigrant background, by group Percentage of students that are either first-generation immigrants, returning foreign-born immigrants, second-generation immigrants, or native students of mixed heritage, by country

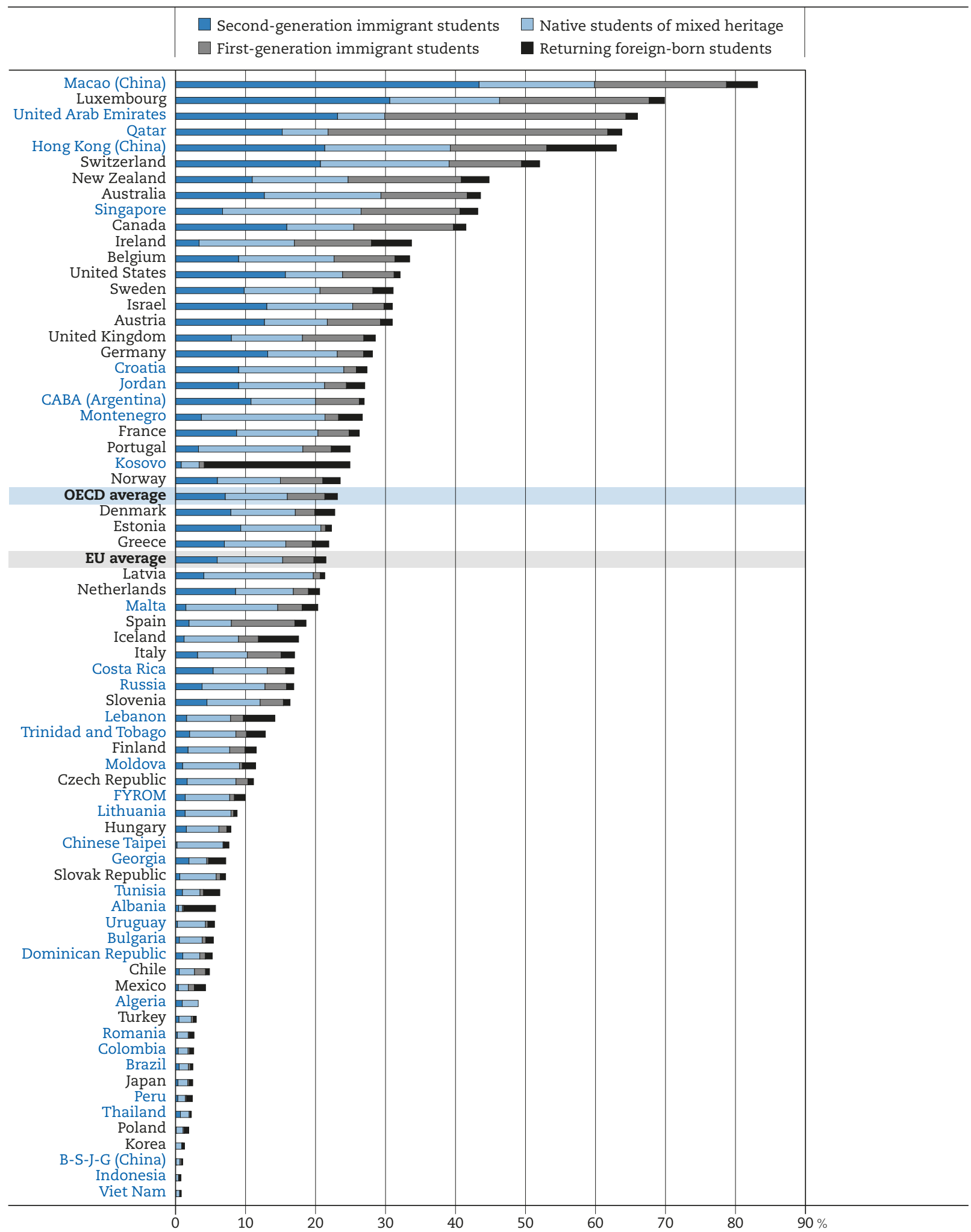

Countries and economies are ranked in descending order of the percentage of students with an immigrant background.

Source: OECD, PISA 2015 and 2003 Database, Table 3.2.

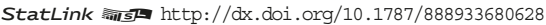


Albania and Kosovo are important outliers as more than eight in ten students with an immigrant background are foreign-born returning migrants: students who were born in a different country with at least one parent who was born in Albania/Kosovo and who left the country at one point, most likely because of armed conflict, and decided to go back after the end of hostilities.

\section{Box 3.1. Returning migrants in Albania and Kosovo}

In Albania and Kosovo, the profile of students with a recent history of family migration looks remarkably different from that in all the other countries and economies that participated in PISA 2015. In the majority of countries and economies, the proportion of returning foreign-born students is small: around one in ten students, on average across OECD countries. But in Albania and Kosovo, four out of five students with an immigrant background are foreign-born returning students. These are students who were born abroad in 2000 (or 1999) and who have at least one parent who was born in Albania/Kosovo. This unique profile reflects the migration trends seen in this part of the Balkans since the last decade of the 20th century. The period of political instability and war that affected the region in the 1990s resulted in hundreds of thousands of people migrating from Albania and Kosovo, mostly to other parts of Europe. While that migration continued into the 21st century, the return of some migrants and inflows of refugees have also contributed to the demographic shifts observed in these countries during this period of time.

In 1989, Albania had a population of 3.2 million. Between that year and 2001, around 600000 to 800000 people emigrated from the country (King and Mai, 2013). The outflows grew significantly from 1991 with the fall of the dictatorship and the organisation of the first general elections. Since then, three major outflows, mostly for economic reasons, occurred in 1991-92, 1997-98 and 1998-99, with Italy and Greece as the main destination countries (IOM, n.d.). In the 2000s, emigration rates remained high (up to 481000 Albanians left the country in that decade) and the situation has not changed much in recent years (INSTAT, 2013; Observatory for Children's Rights, 2017).

However, return migration has become significant too. The International Organization for Migration (IOM) (n.d.) estimates that that between 2001 and 2011, up to 139827 immigrants returned to Albania. Another study suggests that between 2007 and 2012, some 180000 Albanians living in Greece returned to Albania (ACIT, 2012). Similarly, according to the Institute of Statistics of Albania (INSTAT, 2013), up to 133544 Albanian migrants aged 18 years and older, 98414 of whom were men, returned to Albania between 2009 and 2013. Migrants returning to Albania tend to be relatively young, working-age men who move back to the country for employment and family reasons.

Similarly, Kosovo had a population of almost two million in 1991, and more than four in five Kosovars were of Albanian ethnicity (Statistical Office of Kosovo, 2008). The increase in emigration from Kosovo began in 1989 in response to the abolition of the country's autonomous status, the subsequent dismissal of tens of thousands of Albanians from their jobs, and the calling for compulsory military service for Serbs during the Milosevic era. But emigration rates exploded with the outbreak of war in Kosovo in 1998-99, when some 800000 people fled the country (Vathi and Black, 2007). The end of the war did not mean the end of emigration flows, however. Since then, there has been a constant, small-scale migration of Kosovars to EU countries, mainly for economic and family-reunification reasons (Arenliu and Weine, 2016). An exception to this small-scale migration trend was a brief but rather significant episode of increased migration outflows from both Kosovo and Albania that took place in early 2015 (Mollers et al., 2017).

It is hard to estimate the size of Kosovo's diaspora but, according to some studies, it ranges between 380000 and 874000 people (UNDP, 2015: XII-XIII), most of them living in Germany (35.25\%) and Switzerland (22.94\%) (Ask, 2014). The return and repatriation of migrants has been a major characteristic of the post-conflict era in Kosovo. The literature suggests that most Kosovars who left the country because of the war returned between 1999 and 2001. Nonetheless, return migration trends have remained constant and significant since then, and the number of returnees is expected to remain high for years to come (Arenliu and Weine, 2016). 
The governments of Albania and Kosovo are responsible for developing policy responses to help students with an immigrant background thrive in school and in life. However, the profile of most immigrant students in these two countries is different from that of immigrant students in all other countries and economies that participated in PISA 2015. The majority of them are the children of a generation that had to leave the country in large numbers, most under difficult circumstances. Thus, education systems in Albania and Kosovo are likely to face some region-specific challenges linked to the particular migration experiences observed in these two countries over the past three decades.

The challenge seems greater in Kosovo because of the larger proportion of returning migrant students. In 2015, only 1 in 20 15-year-old students in Albania belonged to this group; but in Kosovo, more than 1 in 5 students did. However, this higher rate in Kosovo is specific to the particular cohort of students born around 2000; the rate is expected to decrease over subsequent cohorts. This is because the cohort of students who sat the 2015 PISA test was born right after the end of the war in Kosovo, at a time when one-third of the population was still living outside the country after having fled war. Between 1999 and 2001, most of those who had fled Kosovo returned (Arenliu and Weine, 2016).

In addition, those who fled the war in Kosovo, and their children, are more likely to encounter greater difficulties when they return, given the trauma of war and flight. Unemployment among returnees in Kosovo is high, and decent housing is scarce (UNICEF, 2012). Returnees also suffer traumatic stress, and mental and physical health problems.

Those who stayed longer in host countries, who returned involuntarily, or who lack the support of friends and family in Kosovo are more likely to have problems reintegrating (Arenliu and Weine, 2016). Certain minority groups, such as Roma, have faced greater reintegration problems. For example, $70 \%$ of Roma children, and children born and raised in the destination country are particularly at risk of developing mental health problems and dropping out of school (Knaus, 2007). The majority of returnee children in Kosovo suffer emotional problems, with three in four requiring clinical treatment. The poor environment for child rearing and difficulties encountered in establishing social contacts with peers are key risk factors affecting children's mental health. The incidence of adaptation and mental health problems is greater among those children who returned involuntarily (HIT Foundation, 2014).

To deal with these problems, the Kosovo Reintegration Fund allocated more than EUR 180 million to a series of programmes in 2011. These included developing curricula for language training for students in need; training teachers to provide psychosocial and acclimatisation assistance to repatriated children; and organising language courses for repatriated children. But there were significant delays in spending these resources (UNICEF, 2012). An evaluation of the Kosovo Education Strategic Plan (KESP) 2011-16 shows that some progress was made in enrolments in pre-university education and higher education for the total population, and in teacher re-qualification programmes. Nonetheless, more needs to be done to help returnee children integrate into the education system. This is acknowledged in the KESP 2017-21, which also includes a series of support programmes targeting vulnerable groups, including Roma, Ashkali and Egyptian students, and students with special needs (MEST, 2016).

The impact of returnee migrants on the Albanian education system seems weaker than that observed in Kosovo as the proportion of 15-year-old students who were returning foreign-born students in PISA 2015 was four times smaller in Albania than Kosovo. However, as in Kosovo, most of the students with an immigrant background in Albania in 2015 - around four in five of these students - were returning migrants. The living conditions for many returning migrants in Albania are poor, usually worse than those in their host country (INSTAT, 2013). Returnee children also suffer from psychological problems, including confusion, sadness, stress, anxiety and depression, associated with their migration experience. Many of them also report feeling that they had been doubly discriminated against - "racism there and racism here" - in both the host country where they grew up and in Albania. 
Psychological problems are more severe among those who recently returned and those who were older when they returned (Vathi and Duci, 2016). The Strategy on Reintegration of Returned Albanian Citizens 2010-15 provides support to returning migrants. Assistance for children and young people aims to facilitate enrolment in school, the recognition of skills and qualifications obtained abroad, and access to employment, vocational training and further education (Government of Albania, 2010). Returnee students must receive an individual work plan from their school to help them integrate and fill the gaps in their education resulting from their absence from school. However, there are reports of a lack of guidance, training and institutional capacity to apply these working plans effectively; and in most cases these plans are rejected by returnee students. In addition, organised psycho-social services are inadequate to meet the psycho-social needs of returnee children and to help them integrate in school (Observatory for Children's Rights, 2017).

On average across OECD countries, between 2003 and 2015 the percentage of students without an immigrant background decreased by 6 percentage points from 82\% in 2003 to 77\% in 2015, shrinking by more than 10 percentage points in Austria, Canada, Ireland, Luxembourg, Spain, Switzerland and the United States. Overall, the percentage of students without an immigrant background increased in only four of the countries with comparable data for the same period: in Uruguay, it increased by one percentage point; in Macao (China), by five percentage points; in Russia by, eight percentage points; and in Latvia, by nine percentage points.

Overall changes in the percentage of students with an immigrant background have been accompanied by changes in the composition of this student population. Figure 3.4 displays, for a selected group of countries, the percentage-point increase between 2003 and 2015 in the size of the overall population of students with an immigrant background and of the four groups of students included in that population (full results are available in Table 3.2 on line). On average across OECD and EU countries between 2003 and 2015, the greatest increase was in the percentage of second-generation immigrant students (by three percentage points across OECD and EU countries), followed by the percentage of native students of mixed heritage (by two percentage points; by three percentage points across EU countries) and of first-generation immigrant students (by one percentage point across OECD and EU countries). The increase in the number of returning foreign-born students was close to zero across OECD countries ( 0.16 percentage point) as well as EU countries ( 0.08 percentage point).

In most countries shown, the expansion of the population of students with an immigrant background largely reflects increases in the number of second-generation immigrant students and of native students of mixed heritage. In Austria, Canada and Luxembourg the largest rise was in the size of the first group, increasing up to 15 percentage points in Luxembourg. In Germany, the expansion of the two groups was almost identical (six and five percentage points, respectively), which balanced out the decrease of five percentage points in the number of first-generation immigrant students. When highlighting these findings, it is important to note that PISA 2015 data do not reflect the tens of thousands of refugees and asylum seekers who arrived in Germany just before or after the PISA 2015 survey was administered. By contrast, in Portugal, almost all of the surge in the percentage of students with an immigrant background can be attributed to the increase in the percentage of native students of mixed heritage (eight percentage points).

In the other selected countries, the growth was less concentrated on the two second-generation groups. In Ireland the group that grew the most was first-generation immigrant students (nine percentage points). Italy saw equal percentage-point increases in the number of first-generation immigrant students, secondgeneration immigrant students and native students of mixed heritage.

\section{First-generation immigrant students: Differences related to the age at arrival}

A crucial challenge for education systems is integrating children who settled in the country at or after the age of 12. In this report, these are also called as "late arrivals". By contrast, students who had arrived in the country of destination before the age of 12 , referred to as "early arrivals" in this report, usually started their schooling in the host country or at least attended several years of primary school in that country. While these students were largely socialised in the host country and community (and thus were confronted with fewer language barriers and less disruption in their studies because of changing education systems), they nonetheless have experienced migration personally. 
Figure 3.4 - Trends between 2003 and 2015 in the percentage of students with an immigrant background, by group

Percentage-point increase between 2003 and 215 in the size of the population of students with an immigrant background and of the four groups of students included in that population for a selected group of countries

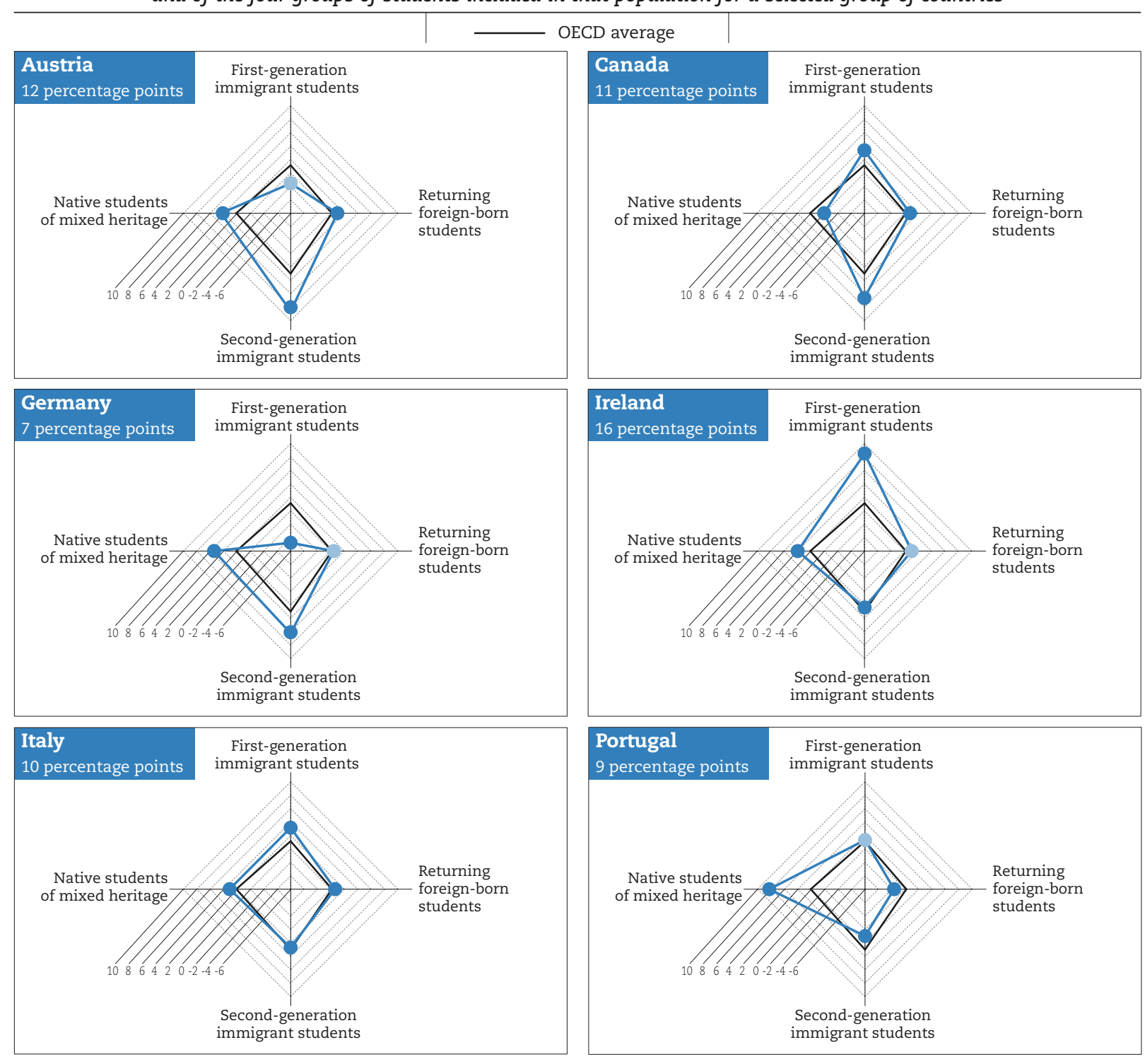

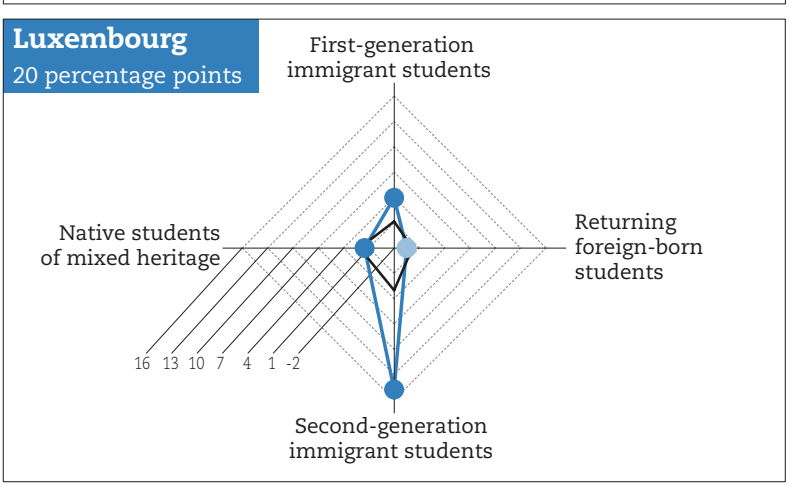

Notes: Statistically significant differences for countries are marked in a darker tone. OECD average values are all statistically significant. The percentage-point change in the percentage of students with an immigrant background between 2003 and 2015 is reported under the country name.

Source: OECD, PISA 2015 Database, Table 3.2.

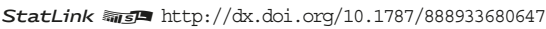


In 2015, on average across OECD countries, $71 \%$ of foreign-born immigrant students of two foreign-born parents were early arrivals and as many as $88 \%$ of returning foreign-born students were (Table 3.4, available on line). Conversely, as many as $29 \%$ of foreign-born immigrant students with two foreign-born parents were late arrivals as were $12 \%$ of returning foreign-born immigrant students. In 2003 , only around $22 \%$ of foreign-born immigrant students with two foreign-born parents were late arrivals as were $9 \%$ of returning foreign-born students.

Foreign-born students who settle in a new country after the age of 12 usually represent a minority of the immigrant student population. On average across OECD countries they represented only around $5 \%$ of the overall student body in 2015. Most of them (around 3.5\%) were foreign-born students of foreign-born parents while about $1.5 \%$ were foreign-born students with at least one native-born parent (Table 3.3, available on line). Late arrivals with at least one parent who is native-born can rely on that parent for language support and guidance in integrating; they also might have established family links and have visited the country prior to settling. However, those who settled after the age of 12 and whose parents are also foreign-born do not have such support within the immediate family.

Figure 3.5 shows that between 2003 and 2015 the percentage of late arrivals with foreign-born parents increased only marginally, on average across OECD countries. But the OECD average masks large differences across countries in the relative proportion of this group of students in the total student population. The proportion of this group increased in as many as 16 of the 39 countries and economies with available data. The increase was larger than one and a half percentage points in Australia, Austria, Canada, Ireland, Luxembourg, Sweden and the United Kingdom. In Luxembourg, the proportion of late arrivals whose parents are also foreign-born grew by five percentage points (from about $2 \%$ of students in 2006 to almost $7 \%$ of students in 2015).

Figure 3.5 - Trends between 2003 and 2015 in the prevalence of late arrivals Percentage of late arrivals whose parents are also foreign-born in 2003 and 2015

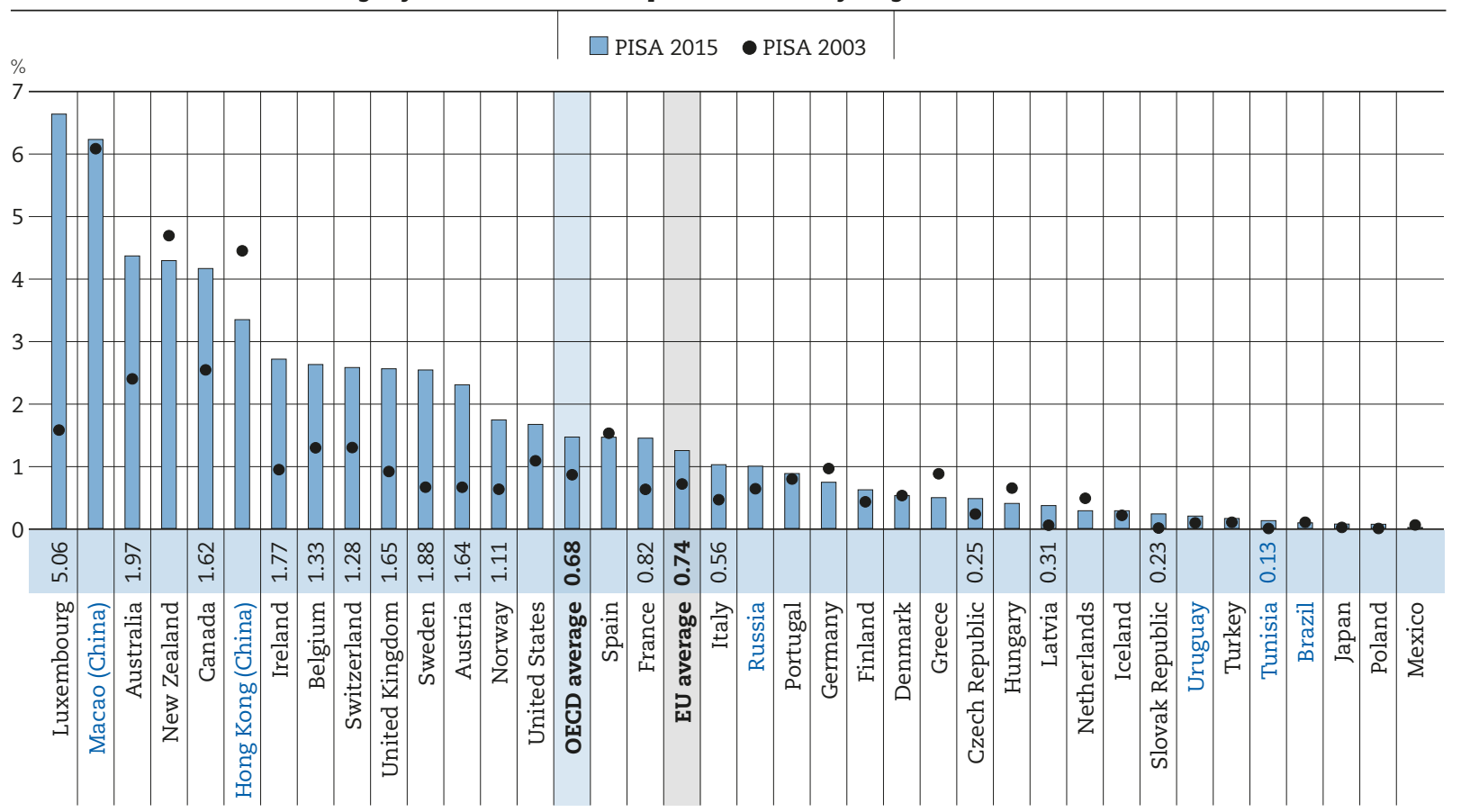

Notes: Results are displayed only for countries/economies that participated in both PISA 2003 and PISA 2015 and have valid data on late arrivals with foreign-born parents in both rounds.

Statistically significant differences between PISA 2015 and PISA 2003 are shown next to country/economy names.

Late arrivals are foreign-born students who arrived in the host country at or after the age of 12.

Countries and economies are ranked in descending order of the percentage of late arrivals whose parents are also foreign-born in 2015.

Source: OECD, PISA 2015 Database, Table 3.3.

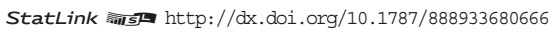


Figure 3.6 presents data on the number of foreign-born students who had arrived after the age of 12 in the country in which they sat the PISA test. Overall across the 56 countries with available data, about 8 600 foreign-born students had arrived at or after the age of 12 to the country where they sat the PISA test. The vast majority of these students - about 3000 - had immigrated to Qatar or the United Arab Emirates.

Figure 3.6 Estimates of the global prevalence of late arrivals

Number of foreign-born students who had arrived at or after the age of 12 in the country in which they sat the PISA test

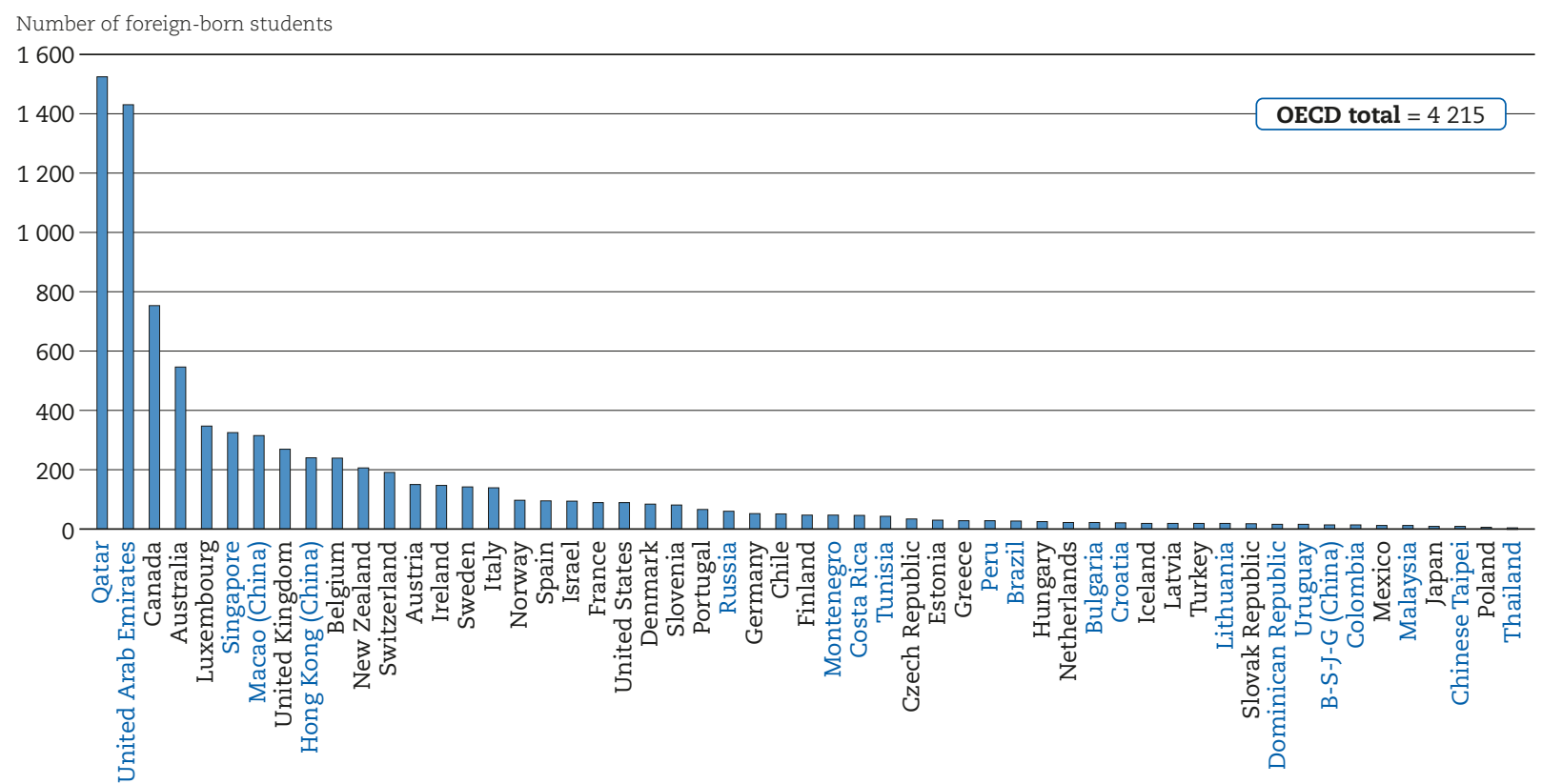

Countries and economies are ranked in descending order of the number of foreign-born students who had arrived at or after the age of 12 in the country in which they sat the PISA test.

Source: OECD, PISA 2015 Database.

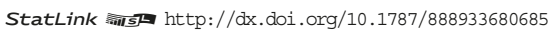

What the data tell us - The outcomes of students with an immigrant background

- Students with an immigrant background are considered to be resilient overall (across academic, social and emotional dimensions) if they attained baseline academic proficiency, they reported a sense of belonging at school and reported being satisfied with life. In 20 out of 32 countries and economies with available data, the percentage of first-generation immigrant students who are academically sound and socio-emotionally adjusted is lower than the percentage of native students who do. On average across OECD countries, the difference is of 17 percentage points (15 percentage points across EU countries) but it is over twenty percentage points in Austria, Finland, Germany, Greece, Iceland, Luxembourg, Mexico, the Netherlands, Spain and Switzerland.

- Immigrant students who are not resilient across these three dimensions are especially vulnerable to suffering from low academic proficiency, although the relative importance of different sources of vulnerability varies across countries.

- On average across OECD and EU countries in 2015, around three in four native students - but only around 6 in 10 students with an immigrant background attained the baseline level of proficiency in the three core PISA subjects - science, reading and mathematics. Finland is the country where differences are most marked: $83 \%$ of native students in Finland attained baseline levels of performance in the three PISA core subjects but only $41 \%$ of first-generation immigrant students did. 
- The performance gap between native students and students with an immigrant background is wider among foreign-born students and, in particular, among late arrivals (students who immigrated at or after the age of 12). Late arrivals are over 35 percentage points less likely than native students to achieve baseline levels of academic proficiency in Austria, France, Germany, Finland, Iceland and Sweden.

- The age at which foreign-born students immigrated is strongly related to the likelihood that they will report feeling a sense of belonging at school. In Germany, immigrant students who had arrived at or after the age of 12 were 45 percentage points less likely to report feeling that they belong at school than those who immigrated before the age of 12. In the United Kingdom, early arrivals exhibit no gap in sense of belonging compared to native students, while late arrivals are significantly disadvantaged.

- On average across OECD and EU countries, students with an immigrant background were four percentage points less likely to report being satisfied with life and to report low schoolwork-related anxiety than native students. Immigrant students, and especially first-generation immigrants, were more likely than native students to express high achievement motivation. The difference between the two groups of students is as large as 36 percentage points in the Netherlands and 23 percentage points in Belgium.

\section{The academic resilience of students with an immigrant background}

In this report academic resilience is defined as students' ability to attain or surpass the baseline level of performance in the three core PISA subjects - science, reading and mathematics. In all three subjects, the baseline level is the level at which students are able to tackle tasks that require, at least, a minimal ability and disposition to think autonomously.

In science, the baseline level of proficiency corresponds to the level at which students can not only use everyday knowledge about familiar scientific phenomena to recognise the correct explanation for them, but can also use such knowledge to identify the question being addressed in a simple experimental design or to identify, in simple cases, whether a conclusion is valid based on the data provided. In mathematics, the baseline level of skills is defined as the level at which students can not only carry out a routine procedure, such as an arithmetic operation, in situations where all the instructions are given to them, but can also interpret and recognise how a (simple) situation (e.g. comparing the total distance across two alternative routes, or converting prices into a different currency) can be represented mathematically. In reading, the baseline level of skills is defined as the level at which students can not only read simple and familiar texts and understand them literally, but can also demonstrate, even in the absence of explicit directions, some ability to connect several pieces of information, draw inferences that go beyond the explicitly stated information, and connect a text to their personal experience and knowledge (OECD, 2016).

On average across OECD countries in $2015,72 \%$ of native students (71\% across EU countries) - but $64 \%$ of students with an immigrant background (62\% across EU countries) attained the baseline level of proficiency in the three core PISA subjects (Table 3.7, available on line). However, large differences can be observed both across and within countries, and across students' specific immigrant background, in the prevalence of students who attained the baseline level of proficiency. For example, over $80 \%$ of native students in Canada, Denmark, Estonia, Finland, Germany, Hong Kong (China), Japan, Singapore and Switzerland attained the baseline level of proficiency in all three core subjects but less than $20 \%$ of native students in Algeria, the Dominican Republic, the Former Yugoslav Republic of Macedonia (hereafter "FYROM"), Kosovo, Qatar and Tunisia did. Among the group of countries where over $80 \%$ of native students attained the baseline levels of proficiency, in Canada, Hong Kong (China) and Singapore, over $80 \%$ of students with a recent history of immigration also attained baseline levels of proficiency while only around $62 \%$ of this group in Germany, $65 \%$ of this group in Switzerland and $66 \%$ of this group in Denmark did. 
Table 3.5 - Snapshot of the academic, social, emotional and motivational resilience of immigrant students

\begin{tabular}{|c|c|c|c|c|c|c|c|c|c|c|}
\hline & \multicolumn{10}{|c|}{$\begin{array}{l}\text { Countries/economices with values above the OECD average } \\
\text { Countries/economices with values not significantly different from the OECD average } \\
\text { Countries/economices with values below the OECD average }\end{array}$} \\
\hline & 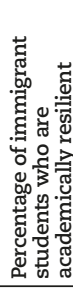 & 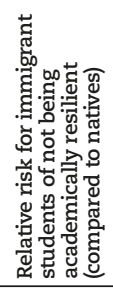 & 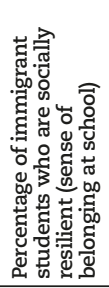 & 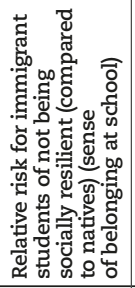 & 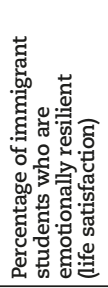 & 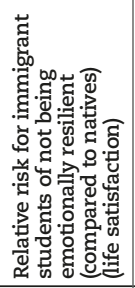 & 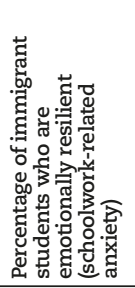 & 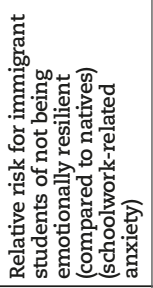 & 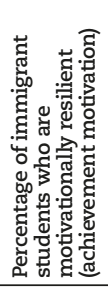 & 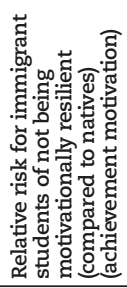 \\
\hline OECD average & 53.86 & 1.75 & 59.99 & 1.25 & 67.20 & 1.24 & 32.12 & 1.13 & 69.63 & 0.89 \\
\hline EU average & 54.57 & 1.74 & 58.13 & 1.30 & 68.97 & 1.21 & 34.17 & 1.13 & 66.11 & 0.84 \\
\hline Singapore & 90.52 & 0.58 & 66.95 & 0.94 & $\mathrm{~m}$ & $\mathrm{~m}$ & 24.14 & 0.9 & 85.12 & 1.4 \\
\hline Macao (China) & 87.7 & 0.56 & 51.35 & 1.01 & 56.85 & 1.06 & 26.92 & 0.96 & 57.73 & 0.91 \\
\hline Hong Kong (China) & 83.69 & 1.41 & 57.68 & 1.07 & 53.31 & 1.17 & 27.58 & 0.98 & 83.48 & 0.89 \\
\hline Canada & 82.36 & 0.94 & 64.25 & 0.93 & $\mathrm{~m}$ & $\mathrm{~m}$ & 26.1 & 1.09 & 85.98 & 0.69 \\
\hline Ireland & 76.33 & 1.18 & 60.13 & 1.26 & 67.59 & 1.24 & 24.25 & 1.07 & 86.38 & 1.06 \\
\hline Estonia & 75.33 & 1.66 & 64.24 & 1.44 & 70.67 & 1.2 & 38.08 & 1.08 & 65.64 & 0.98 \\
\hline Australia & 73.49 & 0.93 & 69.16 & 0.76 & $\mathrm{~m}$ & $\mathrm{~m}$ & 21.69 & 1.1 & 89.01 & 0.76 \\
\hline New Zealand & 71.1 & 1.06 & 67.85 & 0.85 & $\mathrm{~m}$ & $\mathrm{~m}$ & 22.22 & 1.01 & 87.17 & 0.81 \\
\hline Hungary & 68.48 & 0.87 & 67.03 & 0.98 & 77.25 & 0.74 & 45.73 & 0.93 & 61.69 & 1.07 \\
\hline Russia & 66.87 & 1.17 & 63.65 & 1.11 & 76.48 & 0.96 & 37.27 & 1.03 & 74.03 & 0.97 \\
\hline United Kingdom & 66.48 & 1.25 & 61.78 & 0.95 & 59.13 & 1.28 & 18.26 & 1.06 & 93.82 & 0.55 \\
\hline Lithuania & 64.44 & 1.04 & 47.62 & 0.88 & 74.06 & 1.29 & 39.12 & 0.92 & 58.01 & 1.25 \\
\hline Latvia & 63.91 & 1.34 & 63.79 & 1.45 & 69.03 & 1.15 & 43.69 & 1.17 & 69.91 & 0.84 \\
\hline Malta & 62.43 & 0.88 & 47.04 & 1.42 & $\mathrm{~m}$ & $\mathrm{~m}$ & $\mathrm{~m}$ & $\mathrm{~m}$ & $\mathrm{~m}$ & $\mathrm{~m}$ \\
\hline Portugal & 61.82 & 1.32 & 71.13 & 1.3 & 68.16 & 1.18 & 30.46 & 0.94 & 79.15 & 0.9 \\
\hline United Arab Emirates & 59.05 & 0.53 & 63.6 & 0.92 & 65.26 & 1.22 & 28.44 & 1.05 & 91.8 & 1.23 \\
\hline Netherlands & 58.86 & 1.9 & 73.68 & 1.22 & 84.86 & 1.11 & 48.38 & 1.24 & 56.77 & 0.65 \\
\hline Switzerland & 58.04 & 2.52 & 61.38 & 1.3 & 77.03 & 1.37 & 48.24 & 1.52 & 48.41 & 0.77 \\
\hline United States & 57.9 & 1.43 & 62.36 & 1.05 & 67.28 & 1.18 & 24.47 & 1.05 & 93.47 & 1.04 \\
\hline Norway & 57.84 & 1.94 & 69.75 & 1.09 & $\mathrm{~m}$ & $\mathrm{~m}$ & 24.64 & 1.14 & 77.72 & 0.6 \\
\hline Germany & 57.45 & 2.44 & 65.81 & 1.15 & 69.26 & 1.21 & 42.79 & 1.26 & 52.52 & 0.77 \\
\hline Luxembourg & 56.99 & 2.01 & 53.46 & 1.54 & 71.12 & 1.18 & 38.69 & 1.4 & 53.37 & 0.86 \\
\hline Czech Republic & 56.89 & 1.49 & 52.8 & 1.23 & 63.29 & 1.09 & 47.02 & 1.05 & 74.93 & 0.75 \\
\hline Israel & 56.84 & 1.08 & $\mathrm{~m}$ & $\mathrm{~m}$ & $\mathrm{~m}$ & $\mathrm{~m}$ & 45.27 & 1.02 & 88.12 & 1.36 \\
\hline Croatia & 55.04 & 1.25 & 72.77 & 1.11 & 82.15 & 0.93 & 42.57 & 1.02 & 62.79 & 0.9 \\
\hline Slovenia & 53.6 & 2.31 & 61.54 & 1.19 & 62.58 & 1.23 & 26.08 & 1.11 & 55.35 & 0.87 \\
\hline Spain & 53.54 & 1.83 & 73.41 & 1.78 & 65.94 & 1.41 & 19.38 & 1.09 & 66.51 & 0.84 \\
\hline Belgium & 52.29 & 2.38 & 49.89 & 1.31 & 71.98 & 1.3 & 43.25 & 1.17 & 54.48 & 0.69 \\
\hline Qatar & 52.26 & 0.56 & 62.63 & 0.78 & 66.5 & 1.34 & 25.99 & 1.03 & 90.2 & 1 \\
\hline Denmark & 50.86 & 2.6 & 57.67 & 1.34 & $\mathrm{~m}$ & $\mathrm{~m}$ & 21.23 & 1.12 & 63.48 & 0.7 \\
\hline Italy & 50.57 & 1.59 & 54.38 & 1.28 & 60.36 & 1.15 & 20.31 & 1.05 & 61.76 & 0.83 \\
\hline France & 50.12 & 1.96 & 29.74 & 1.09 & 70.72 & 1.42 & 36.27 & 1.19 & 59.41 & 0.73 \\
\hline Finland & 49.73 & 3.01 & 72.75 & 1.11 & 78.09 & 1.36 & 33.41 & 1.33 & 54.93 & 0.69 \\
\hline Japan & 49.21 & 2.97 & 64.06 & 1.47 & 52.72 & 1.22 & 19.14 & 1.2 & 32.88 & 1.1 \\
\hline Sweden & 48.99 & 2.16 & 56.12 & 1.27 & $\mathrm{~m}$ & $\mathrm{~m}$ & 24.92 & 1.18 & 83.67 & 0.55 \\
\hline Austria & 47.32 & 2.22 & 67.44 & 1.14 & 69.76 & 1.36 & 35.19 & 1.27 & 56.97 & 0.76 \\
\hline Uruguay & 43.71 & 0.98 & 58.05 & 1.3 & 74.72 & 1.05 & 21.59 & 0.96 & 76.35 & 0.96 \\
\hline Cyprus* ${ }^{*}$ & 43.41 & 1.05 & 60.01 & 1.64 & 61.85 & 1.21 & 31.23 & 1.06 & 81.35 & 0.72 \\
\hline Montenegro & 43.35 & 0.88 & 36.79 & 1.23 & 69.23 & 1.21 & 29.42 & 0.99 & 69.86 & 0.9 \\
\hline Moldova & 41.55 & 0.93 & 52.9 & 1.31 & $\mathrm{~m}$ & $\mathrm{~m}$ & $\mathrm{~m}$ & $\mathrm{~m}$ & $\mathrm{~m}$ & $\mathrm{~m}$ \\
\hline Greece & 37.7 & 1.55 & 68.03 & 1.37 & 58.14 & 1.2 & 27.89 & 1.09 & 65.3 & 1.04 \\
\hline CABA (Argentina) & 34.27 & 1.96 & 69.42 & 1.69 & $\mathrm{~m}$ & $\mathrm{~m}$ & $\mathrm{~m}$ & $\mathrm{~m}$ & $\mathrm{~m}$ & $\mathrm{~m}$ \\
\hline Thailand & 34.05 & 1.03 & 48.45 & 1.51 & 63.78 & 1.42 & 35.76 & 0.92 & 95.16 & 1.89 \\
\hline Turkey & 33.24 & 1.13 & 36.56 & 1.23 & 42.14 & 1.13 & 28.73 & 1 & 78.7 & 1.48 \\
\hline Slovak Republic & 32.46 & 1.74 & 23.29 & 1.9 & 60.93 & 1.44 & 50.09 & 0.92 & 64.81 & 1.2 \\
\hline Iceland & 31.82 & 2.08 & 56.22 & 1.61 & 71.32 & 1.4 & 36.16 & 1.17 & 81.61 & 0.74 \\
\hline Chile & 31.81 & 1.31 & 69.43 & 0.98 & 61.43 & 1.3 & 34.4 & 1.03 & 81.53 & 1.13 \\
\hline Georgia & 30.67 & 1.01 & 56.01 & 1.18 & $\mathrm{~m}$ & $\mathrm{~m}$ & $\mathrm{~m}$ & $\mathrm{~m}$ & $\mathrm{~m}$ & $\mathrm{~m}$ \\
\hline Jordan & 30.24 & 0.93 & 64.96 & 1.2 & $\mathrm{~m}$ & $\mathrm{~m}$ & $\mathrm{~m}$ & $\mathrm{~m}$ & $\mathrm{~m}$ & $\mathrm{~m}$ \\
\hline Trinidad and Tobago & 28.2 & 1.24 & 52.83 & 1.64 & $\mathrm{~m}$ & $\mathrm{~m}$ & $\mathrm{~m}$ & $\mathrm{~m}$ & $\mathrm{~m}$ & $\mathrm{~m}$ \\
\hline Bulgaria & 23.81 & 1.52 & 35.73 & 1.36 & 69.48 & 1.01 & 26.01 & 1.14 & 69.65 & 0.71 \\
\hline Costa Rica & 20.12 & 1.22 & 63.68 & 1.01 & 81.07 & 1.08 & 10.18 & 1.03 & 83.29 & 1.06 \\
\hline B-S-J-G (China) & 19.98 & 3.23 & 71.5 & 0.65 & 47.14 & 1.3 & 31.97 & 0.96 & 79.5 & 1.85 \\
\hline Lebanon & 19.71 & 1.04 & 50.92 & 1.23 & $\mathrm{~m}$ & $\mathrm{~m}$ & $\mathrm{~m}$ & $\mathrm{~m}$ & $\mathrm{~m}$ & $\mathrm{~m}$ \\
\hline Albania & 19.51 & 1.22 & $c$ & c & $\mathrm{m}$ & $\mathrm{m}$ & $\mathrm{m}$ & $\mathrm{m}$ & $\mathrm{m}$ & $\mathrm{m}$ \\
\hline Colombia & 17.1 & 1.22 & 39.47 & 1.59 & 79.91 & 0.88 & 9.63 & 1.02 & 81.62 & 2.35 \\
\hline Peru & 17.04 & 1.15 & 46.63 & 1.36 & c & C & C & C & $\mathrm{C}$ & c \\
\hline FYROM & 9.68 & 1.11 & 57.76 & 2.58 & $\mathrm{~m}$ & $\mathrm{~m}$ & $\mathrm{~m}$ & $\mathrm{~m}$ & $\mathrm{~m}$ & $\mathrm{~m}$ \\
\hline Brazil & 7.25 & 1.26 & 43.97 & 1.68 & 72.06 & 1.04 & 24.64 & 0.89 & 83.93 & 0.81 \\
\hline Dominican Republic & 6.55 & 1.01 & 25.67 & 1.44 & 83.22 & 1.02 & 10.62 & 1.04 & 90.5 & 0.63 \\
\hline Kosovo & 6.16 & 1.07 & 68.59 & 1.71 & $\mathrm{~m}$ & $\mathrm{~m}$ & $\mathrm{~m}$ & $\mathrm{~m}$ & $\mathrm{~m}$ & $\mathrm{~m}$ \\
\hline Algeria & 3.9 & 1.06 & 59.41 & 1.2 & $\mathrm{~m}$ & $\mathrm{~m}$ & $\mathrm{~m}$ & $\mathrm{~m}$ & $\mathrm{~m}$ & $\mathrm{~m}$ \\
\hline Mexico & 3.88 & 1.52 & 50.59 & 1.46 & 76.28 & 1.53 & 13.52 & 1.26 & 72.35 & 1.66 \\
\hline Tunisia & 3.79 & 1.16 & 24.83 & 1.48 & 59.52 & 1.02 & 18.75 & 1.18 & 85.89 & 1.37 \\
\hline
\end{tabular}

* See note at the beginning of this Chapter.

Notes: Only countries/economies with valid data for at least one outcome are presented.

Academically resilient students are students with an immigrant background who attained at least prof iciency Level 2 in all three core PISA subjects: science, reading and mathematics.

Socially resilient students are students with an immigrant background who reported that they "agree" or "strongly agree" with the statement "I feel like I belong at school" and "disagree" or "strongly disagree" with the statement "I feel like an outsider at school".

Emotionally resilient students (in terms of life satisfaction) are students with an immigrant background who reported a life satisfaction of 7 or higher on a scale from 0 to $10 . "$

Emotionally resilient students (in terms of schoolwork-related anxiety) are students with an immigrant background who reported that they "disagree" or "strongly disagree" with the statements "I of ten worry that it will be difficult for me taking a test" and "Even if I am well prepared for a test, I feel very anxious". Motivationally resilient students are students with an immigrant background who report high motivation to achieve are students who "agree" or "strongly agree" with the statement "I want to be the best, whatever I do".

Source: OECD, PISA 2015 Database, Tables 3.7, 3.9, 3.10, 3.15 and 3.17.

StatLink 部实 http://dx.doi.org/10.1787/888933680970 
Table 3.6 - Snapshot of academic resilience, by immigrant background

\begin{tabular}{|c|c|c|c|c|c|c|c|c|}
\hline & \multicolumn{8}{|c|}{$\begin{array}{l}\text { Countries/economices with values above the OECD average } \\
\text { Countries/economices with values not significantly different from the OECD average } \\
\text { Countries/economices with values below the OECD average }\end{array}$} \\
\hline & 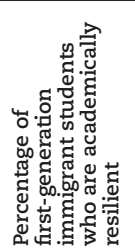 & 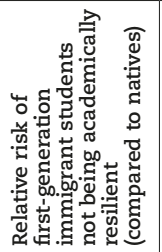 & 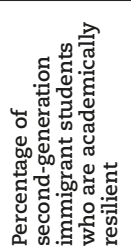 & 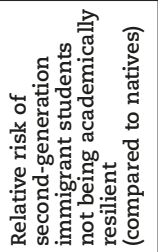 & 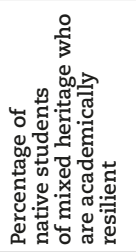 & 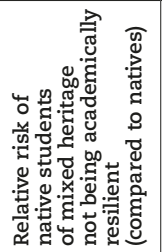 & 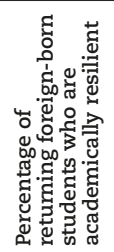 & 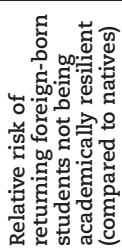 \\
\hline OECD average & 48.73 & 1.96 & 60.50 & 1.54 & 70.76 & 1.09 & 66.11 & 1.28 \\
\hline EU average & 49.82 & 1.99 & 59.83 & 1.60 & 68.59 & 1.12 & 62.08 & 1.36 \\
\hline Singapore & 89.53 & 0.64 & 92.61 & 0.45 & 87.18 & 0.78 & 83.03 & 1.03 \\
\hline Macao (China) & 87.14 & 0.58 & 87.94 & 0.55 & 83.59 & 0.74 & 82.96 & 0.77 \\
\hline Hong Kong (China) & 82.98 & 1.47 & 84.15 & 1.37 & 86.01 & 1.21 & 84.15 & 1.37 \\
\hline Canada & 81.52 & 0.98 & 83.12 & 0.90 & 82.47 & 0.93 & 79.35 & 1.10 \\
\hline Ireland & 76.49 & 1.17 & 75.81 & 1.20 & 81.86 & 0.90 & 83.18 & 0.84 \\
\hline New Zealand & 72.78 & 1.00 & 68.62 & 1.15 & 76.84 & 0.85 & 79.36 & 0.76 \\
\hline Estonia & 72.13 & 1.88 & 75.55 & 1.65 & 79.98 & 1.35 & 71.22 & 1.94 \\
\hline Australia & 69.36 & 1.07 & 77.49 & 0.79 & 75.1 & 0.87 & 76.80 & 0.81 \\
\hline Russia & 69.32 & 1.09 & 64.88 & 1.24 & 74.53 & 0.90 & 60.83 & 1.39 \\
\hline Malta & 66.33 & 0.79 & 53.26 & 1.09 & 60.96 & 0.91 & 52.42 & 1.11 \\
\hline United Arab Emirates & 62.56 & 0.49 & 53.83 & 0.60 & 33.31 & 0.87 & 25.30 & 0.97 \\
\hline United Kingdom & 62.11 & 1.42 & 71.27 & 1.07 & 72.22 & 1.04 & 76.51 & 0.88 \\
\hline Hungary & 58.29 & 1.14 & 76.04 & 0.66 & 72.03 & 0.77 & 73.22 & 0.73 \\
\hline Qatar & 57.53 & 0.50 & 38.44 & 0.72 & 21.46 & 0.92 & 29.18 & 0.83 \\
\hline Portugal & 56.88 & 1.49 & 67.95 & 1.11 & 78.06 & 0.76 & 63.37 & 1.27 \\
\hline Switzerland & 56.30 & 2.62 & 58.91 & 2.46 & 76.42 & 1.41 & 70.26 & 1.78 \\
\hline Luxembourg & 54.80 & 2.11 & 58.51 & 1.94 & 69.69 & 1.42 & 69.43 & 1.43 \\
\hline Lithuania & 53.29 & 1.36 & 67.59 & 0.94 & 62.67 & 1.09 & 44.28 & 1.62 \\
\hline Norway & 52.85 & 2.17 & 62.90 & 1.71 & 78.08 & 1.01 & 66.22 & 1.55 \\
\hline Latvia & 52.26 & 1.77 & 66.80 & 1.23 & 69.97 & 1.12 & 56.07 & 1.63 \\
\hline Croatia & 52.24 & 1.33 & 55.59 & 1.23 & 65.22 & 0.97 & 60.31 & 1.10 \\
\hline Czech Republic & 52.08 & 1.66 & 61.87 & 1.32 & 66.77 & 1.15 & 70.98 & 1.01 \\
\hline Spain & 51.95 & 1.89 & 61.04 & 1.53 & 78.62 & 0.84 & 64.59 & 1.39 \\
\hline United States & 48.78 & 1.74 & 62.18 & 1.28 & 68.63 & 1.06 & 60.88 & 1.33 \\
\hline Netherlands & 48.72 & 2.37 & 61.42 & 1.78 & 73.94 & 1.20 & 67.53 & 1.50 \\
\hline Belgium & 48.58 & 2.57 & 55.87 & 2.20 & 71.38 & 1.43 & 65.20 & 1.74 \\
\hline Denmark & 48.21 & 2.74 & 51.79 & 2.55 & 79.95 & 1.06 & 76.60 & 1.24 \\
\hline Germany & 45.75 & 3.12 & 60.78 & 2.25 & 70.44 & 1.70 & 66.60 & 1.92 \\
\hline Slovenia & 45.60 & 2.71 & 59.51 & 2.01 & 74.41 & 1.27 & 62.25 & 1.88 \\
\hline Italy & 44.98 & 1.76 & 59.14 & 1.31 & 72.18 & 0.89 & 53.07 & 1.50 \\
\hline Montenegro & 43.78 & 0.87 & 43.12 & 0.88 & 47.25 & 0.82 & 27.55 & 1.12 \\
\hline Finland & 41.19 & 3.53 & 60.19 & 2.39 & 80.58 & 1.16 & 70.73 & 1.76 \\
\hline $\begin{array}{l}\text { Cyprus* } \\
\end{array}$ & 40.55 & 1.1 & 50.49 & 0.92 & 51.27 & 0.90 & 47.38 & 0.97 \\
\hline France & 38.68 & 2.41 & 55.96 & 1.73 & 70.54 & 1.16 & 64.05 & 1.41 \\
\hline Austria & 38.67 & 2.58 & 52.48 & 2.00 & 69.16 & 1.30 & 71.22 & 1.21 \\
\hline Sweden & 38.51 & 2.61 & 57.07 & 1.82 & 73.07 & 1.14 & 74.52 & 1.08 \\
\hline Israel & 37.92 & 1.56 & 63.32 & 0.92 & 72.10 & 0.70 & 59.92 & 1.01 \\
\hline Trinidad and Tobago & 37.77 & 1.08 & 20.99 & 1.37 & 42.43 & 1.00 & 50.17 & 0.86 \\
\hline CABA (Argentina) & 31.80 & 2.03 & 35.70 & 1.92 & 56.92 & 1.28 & c & c \\
\hline Greece & 30.74 & 1.72 & 41.48 & 1.46 & 63.75 & 0.90 & 44.41 & 1.38 \\
\hline Iceland & 27.93 & 2.20 & 40.91 & 1.80 & 61.74 & 1.17 & 73.65 & 0.80 \\
\hline Jordan & 27.68 & 0.96 & 31.12 & 0.92 & 36.02 & 0.85 & 32.39 & 0.90 \\
\hline Chile & 27.47 & 1.39 & 44.63 & 1.06 & 54.12 & 0.88 & 43.58 & 1.08 \\
\hline Lebanon & 26.58 & 0.95 & 11.79 & 1.15 & 28.36 & 0.93 & 43.52 & 0.73 \\
\hline Slovak Republic & 26.39 & 1.90 & 38.29 & 1.59 & 55.5 & 1.15 & 56.08 & 1.13 \\
\hline Costa Rica & 20.42 & 1.21 & 19.98 & 1.22 & 31.07 & 1.05 & 31.91 & 1.04 \\
\hline Dominican Republic & 15.09 & 0.92 & 0.00 & 1.08 & 7.17 & 1.01 & 13.25 & 0.94 \\
\hline Brazil & 12.43 & 1.19 & 4.41 & 1.30 & 23.5 & 1.04 & 21.75 & 1.07 \\
\hline Kosovo & 9.89 & 1.03 & 2.82 & 1.11 & 12.31 & 1.00 & 18.45 & 0.93 \\
\hline FYROM & 8.57 & 1.12 & 10.22 & 1.10 & 21.07 & 0.97 & 14.73 & 1.04 \\
\hline Mexico & 2.67 & 1.54 & c & c & 26.09 & 1.17 & 38.12 & 0.98 \\
\hline Algeria & $\mathrm{m}$ & $\mathrm{m}$ & 3.90 & 1.06 & 8.19 & 1.02 & $\mathrm{~m}$ & $\mathrm{~m}$ \\
\hline Japan & c & C & c & c & 76.72 & 1.36 & 74.92 & 1.47 \\
\hline Korea & c & c & $\mathrm{m}$ & $\mathrm{m}$ & 70.85 & 1.33 & c & c \\
\hline Poland & c & c & c & $\mathrm{C}$ & 72.79 & 1.14 & C & C \\
\hline Turkey & c & c & 44.61 & 0.94 & 60.62 & 0.67 & 57.75 & 0.72 \\
\hline Albania & c & c & c & c & 32.28 & 1.02 & 35.89 & 0.97 \\
\hline B-S-J-G (China) & c & c & c & c & 33.05 & 2.70 & c & c \\
\hline Bulgaria & C & C & C & c & 44.81 & 1.10 & 31.99 & 1.36 \\
\hline Colombia & c & c & 11.57 & 1.31 & 21.48 & 1.16 & 27.05 & 1.08 \\
\hline Georgia & c & c & 32.17 & 0.99 & 31.57 & 0.99 & 37.89 & 0.90 \\
\hline Indonesia & c & C & C & $\mathrm{C}$ & C & C & c & C \\
\hline Moldova & c & c & 43.76 & 0.9 & 44.78 & 0.88 & 36.10 & 1.02 \\
\hline Peru & c & c & c & c & 23.95 & 1.06 & 21.70 & 1.09 \\
\hline Romania & c & c & c & c & 38.68 & 1.13 & 38.96 & 1.12 \\
\hline Chinese Taipei & c & c & c & c & 76.67 & 1.14 & 80.45 & 0.96 \\
\hline Thailand & c & c & 32.05 & 1.06 & 38.67 & 0.95 & c & c \\
\hline Tunisia & c & c & 2.43 & 1.18 & 18.54 & 0.98 & 13.56 & 1.04 \\
\hline Uruguay & c & C & c & $\mathrm{C}$ & 36.48 & 1.11 & 53.81 & 0.81 \\
\hline
\end{tabular}

* See note at the beginning of this Chapter.

Notes: Only countries/economies with valid data for at least one outcome are presented.

Academically resilient students are students with an immigrant background who attained at least proficiency Level 2 in all three core PISA subjects: science, reading and mathematics.

Source: OECD, PISA 2015 Database, Table 3.7.

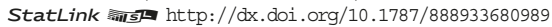


On average the performance gap between native students and students with an immigrant background tends to be wider when the student had a personal experience of migration and the more recent the migration experience. For example, on average across OECD countries, the gap was widest between native students and foreign-born students with foreign-born parents (24 percentage points; 22 percentage points across EU countries), followed by native-born students of foreign-born parents (12 percentage points; 12 percentage points across EU countries). Differences in baseline performance are smaller for students with an immigrant background and at least one native-born parent. On average across OECD countries, compared to native students, returning foreign-born students were six percentage points less likely to attain the baseline levels of proficiency (across EU countries, eight percentage points less likely) and native students of mixed heritage were one percentage point less likely (across EU countries, two percentage points less likely).

The largest gap - 42 percentage points - was observed in Finland: while $83 \%$ of native students attained baseline levels of performance in all three core PISA subjects, only $41 \%$ of first-generation immigrant students did. Figure 3.7 shows that the difference between the percentage of native students and the percentage of first-generation immigrant students who attained baseline levels of proficiency was larger than 30 percentage points in Austria, Belgium, Ciudad Autónoma de Buenos Aires (Argentina) (hereafter "CABA [Argentina]"), Denmark, Finland, France, Germany, Iceland, Mexico, the Slovak Republic, Slovenia and Sweden.

In many countries the gap between the percentage of native students and the percentage of firstgeneration immigrant students who achieved baseline levels of proficiency was considerably larger than that between the percentage of native students and the percentage of second-generation immigrant students who attained those levels of proficiency (Table 3.7, available on line). This gap was particularly large, at more than 15 percentage points, in Germany, France, Finland, Hungary, Israel and Sweden.

Figure 3.7 - Percentage of students attaining baseline academic proficiency, by immigrant background

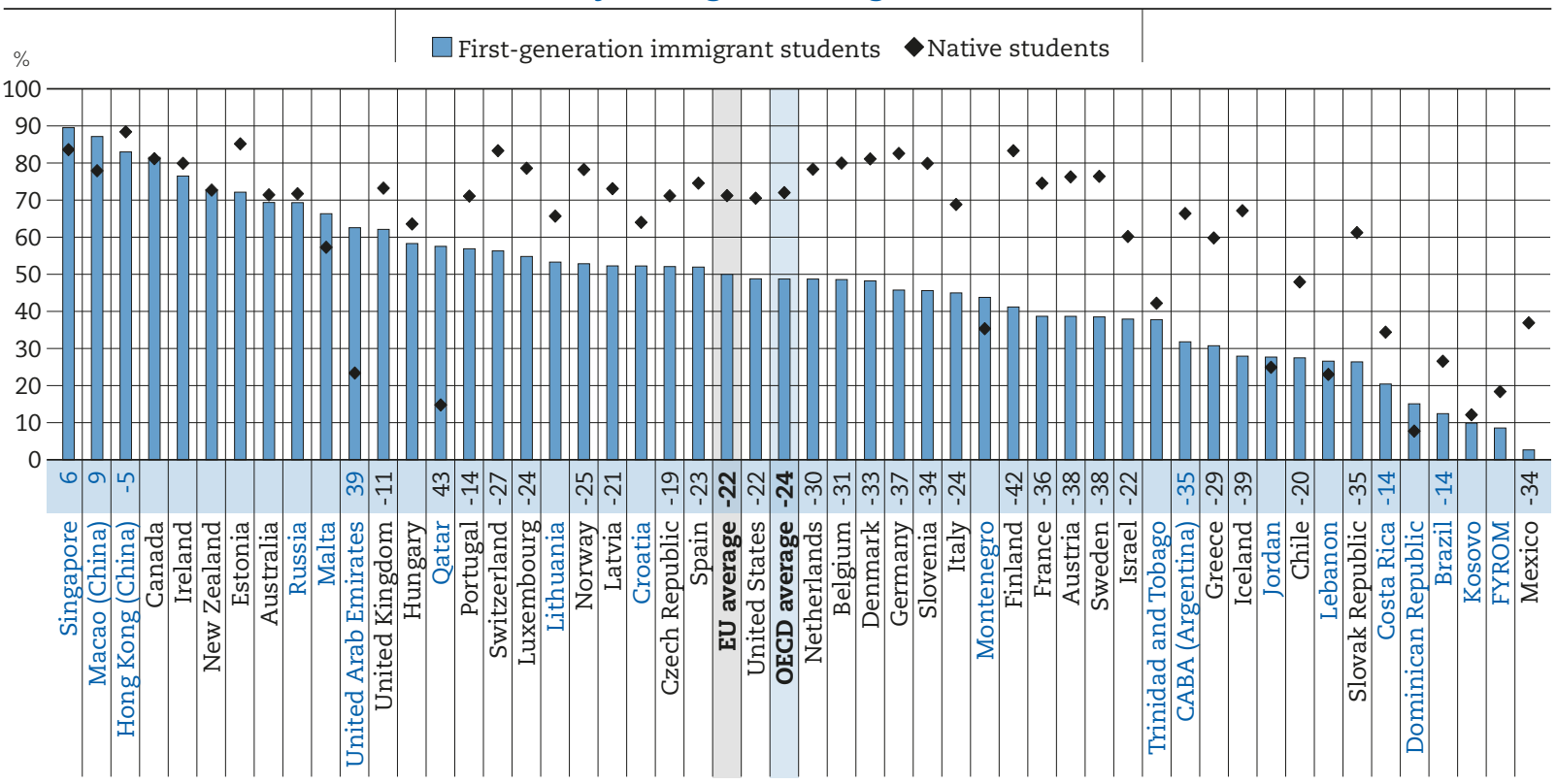

Notes: Only countries with valid values for first-generation immigrant students are shown.

Statistically significant differences between first-generation immigrant and native students are shown next to country/economy names. For the OECD and EU average, this number refers only to the subset of countries/economies with valid information on both groups of students.

Students who attain baseline academic proficiency are students who reach at least PISA proficiency level two in all three PISA core subjects - math, reading and science.

Countries and economies are ranked in descending order of the percentage of first-generation immigrant students attaining baseline academic proficiency.

Source: OECD, PISA 2015 Database, Table 3.7.

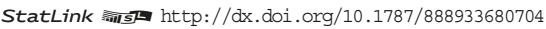


Figure 3.8 - Difference in attaining baseline academic proficiency, by immigrant group Difference between students with an immigrant background and native students in the percentage of students attaining baseline academic proficiency

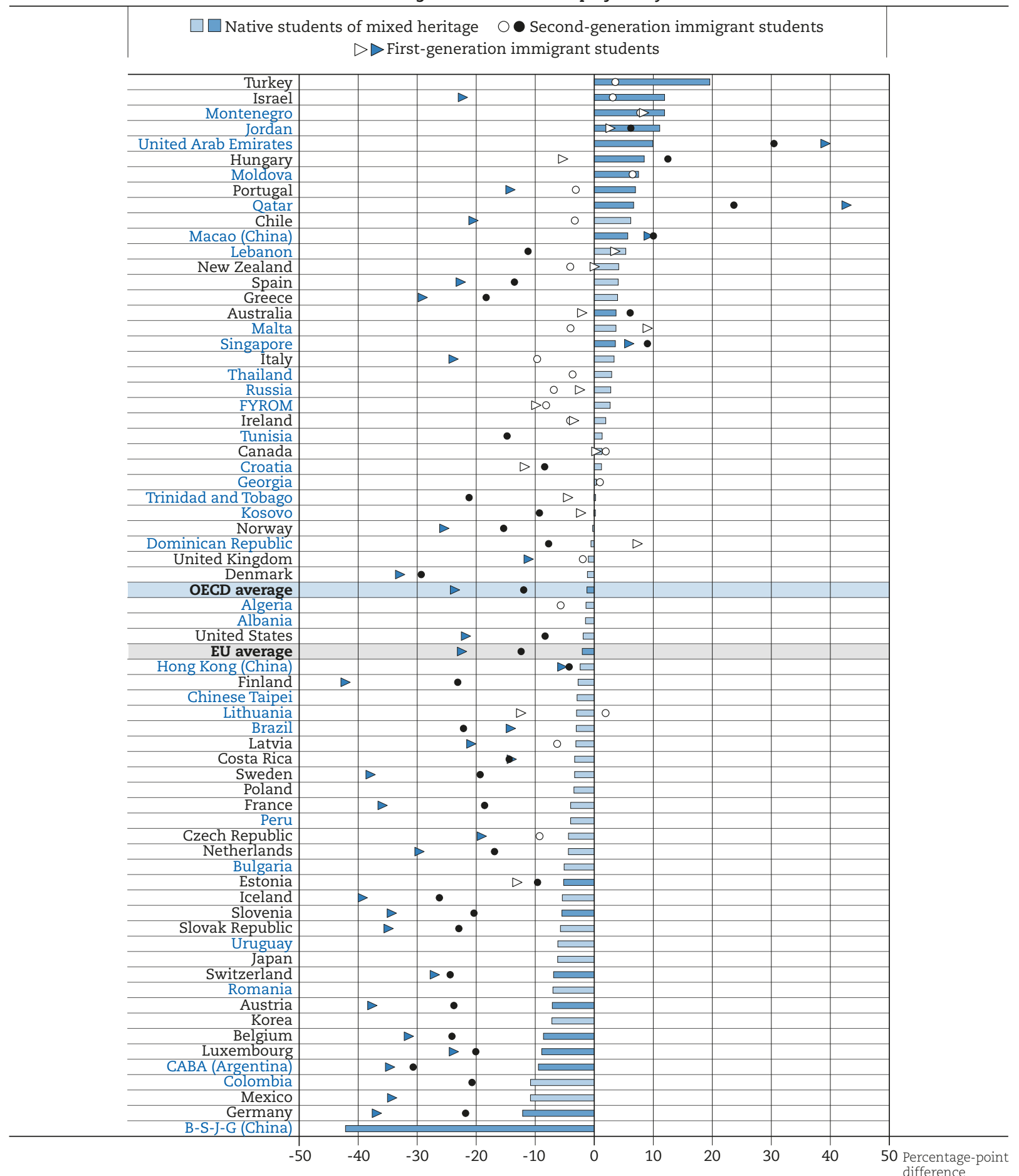

Notes: Statistically significant differences are marked in a darker tone.

Only countries with valid values for native students of mixed heritage are shown.

Students who attain baseline academic proficiency are students who reach at least PISA proficiency level two in all three PISA core subjects - math, reading and science.

Countries and economies are ranked in descending order of the difference in the percentage of native students of mixed heritage and native students attaining baseline academic proficiency.

Source: OECD, PISA 2015 Database, Table 3.7.

StatLink Ails $\mathrm{http}: / / \mathrm{dx} . \mathrm{doi}$. org/10.1787/888933680723 
Figure 3.8 shows that in a large majority of countries, students who were born in the country in which they sat the PISA test and who have one native-born and one foreign-born parent had a similar probability of attaining baseline levels of proficiency as native-born students with two native-born parents. But in Austria, Belgium, CABA (Argentina), Estonia, Germany, Luxembourg, Slovenia and Switzerland, there was a statistically significant gap between these two groups. In Austria, Beijing-Shanghai-Jiangsu-Guangdong (China) (hereafter "B-S-J-G [China]"), Belgium, CABA (Argentina), Estonia, Germany, Luxembourg, Slovenia and Switzerland, native students of mixed heritage were less likely than native students to attain baseline academic proficiency.

First-generation immigrant students - i.e. students who have immigrated and have foreign-born parents show the lowest levels of academic adjustment. Figure 3.9 shows how the gap in the percentage of students who reached the baseline levels of proficiency in reading, mathematics and science between native students and first-generation immigrant students varies according to the age at which the student arrived in the host country. On average across OECD and EU countries, students who had arrived in the country in which they sat the PISA test at or after the age of 12, showed considerably lower levels of academic adjustment than immigrant students who had arrived in the country before the age of 12 .

Although the difference in academic adjustment between the two groups was 15 percentage points, on average across OECD and EU countries, the gap was particularly wide in Belgium, Germany, Israel, Slovenia, Spain, Sweden and the United Kingdom, where it was larger than 20 percentage points. In Luxembourg and Switzerland all foreign-born students, irrespective of the age at which they immigrated to the country, were similarly likely to attain baseline levels of proficiency in the three core PISA subjects and show a similar disadvantage when compared to native students.

Figure 3.9 - Difference in attaining baseline academic proficiency, by age at arrival

Difference between first-generation immigrant and native students in the percentage of students attaining baseline academic proficiency

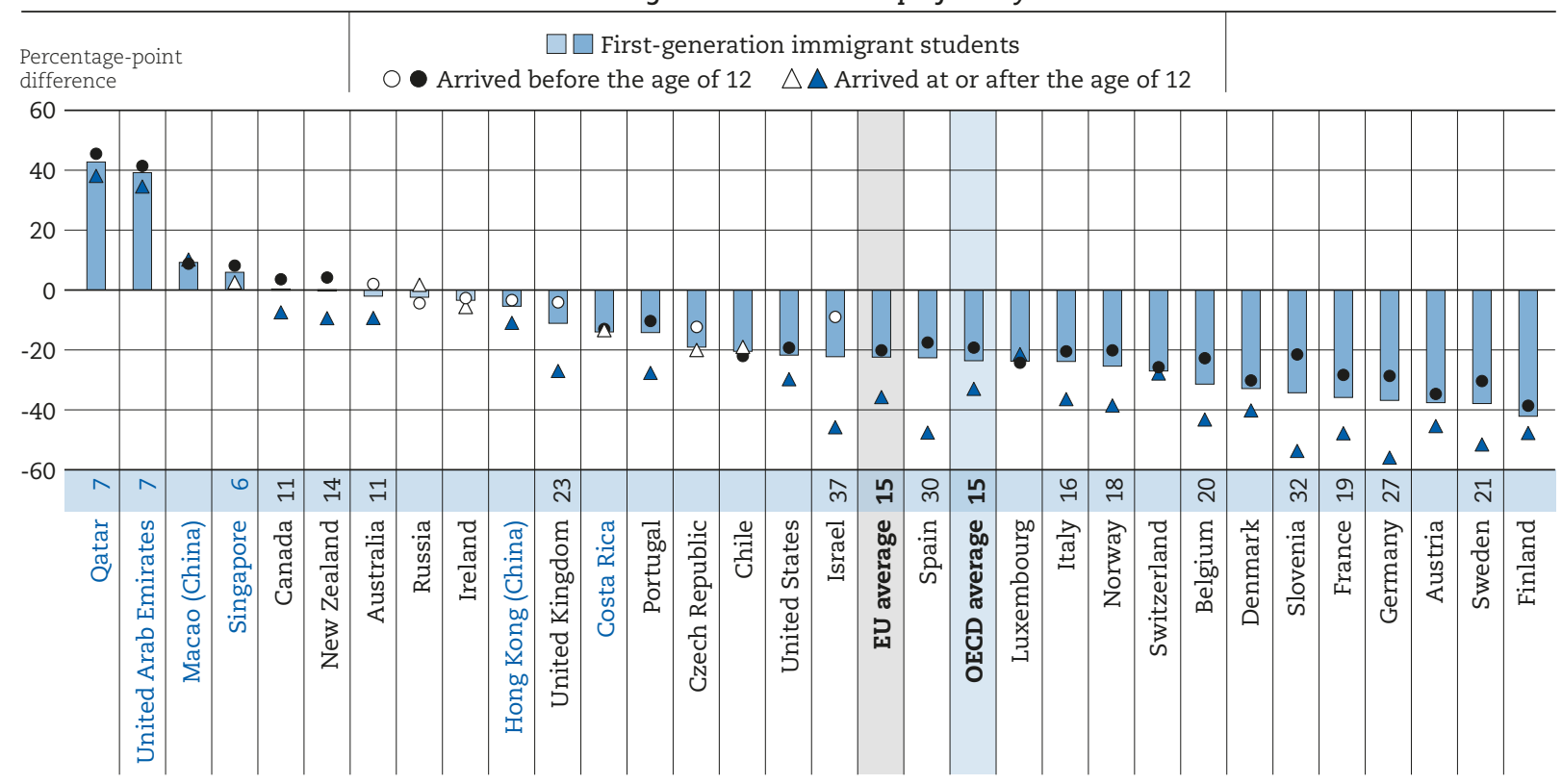

Notes: Statistically significant differences are marked in a darker tone.

Only countries with valid values for both first-generation immigrant students who arrived before the age of 12 and those who arrived at or after the age of 12 are shown.

Statistically significant differences between those that arrived before the age of 12 and those who arrived at or after the age of 12 are shown next to country/economy names. For the OECD and EU average, this number refers only to the subset of countries/economies with valid information on both groups of students.

Students who attain baseline academic proficiency are students who reach at least PISA proficiency level two in all three PISA core subjects - math, reading and science.

Countries and economies are ranked in descending order of the difference in the percentage of first-generation immigrant and native students attaining baseline academic proficiency.

Source: OECD, PISA 2015 Database, Table 3.8.

StatLink 司IT $\mathrm{http}: / / \mathrm{dx}$.doi.org/10.1787/888933680742 
On average across OECD countries the percentage of native students and of first-generation immigrant students who achieved baseline levels of proficiency did not change between 2006 and 2015, but the percentage of second-generation immigrant students who did so increased by about six percentage points, from 54\% in 2006 to 60\% in 2015 (Table 3.9, available on line). PISA shows that in several countries the percentage of native and immigrant students who reached baseline levels of performance in the three core PISA subjects changed significantly between 2006 and 2015 (Table 3.9, available on line). The percentage of native students who attained this level of proficiency increased by more than 10 percentage points in Bulgaria, Colombia, Israel, Romania, Russia and Qatar. Of these countries, Israel is the only country where academic resilience among first-generation immigrant students deteriorated during the period, even though performance improved among their native peers. In Russia, Israel and Qatar, the large improvement of native students' academic performance was accompanied by a similar increase in the percentage of second-generation immigrant students who attained the baseline level of performance in the three subjects. In Qatar the increase among second-generation immigrant students was over 17 percentage points larger than the increase observed among native students. In Spain, first-generation immigrant students improved more than any other group between 2006 and 2015.

In Australia, Canada, Finland, Hungary, Korea, Iceland, the Netherlands, New Zealand, the Slovak Republic and Switzerland, the percentage of native students who achieved baseline levels of proficiency decreased between 2006 and 2015. Among students with an immigrant background there was no decline in the percentage of students with an immigrant background who attained baseline levels of academic proficiency in Canada, Hungary and the Netherlands while a decline was also observed among this group of students in Australia, Finland, Iceland, New Zealand and the Slovak Republic.

\section{The social and emotional resilience of students with an immigrant background Sense of belonging and social integration}

Students' well-being is not just about feeling happy and achieving good grades in school, but also about being engaged with life and with other people (Gale et al., 2013). The social aspect of students' wellbeing captures both the quantity and the quality of students' social networks (Helliwell and Putnam, 2004). People with trustworthy connections - a valuable social support network - can be protected from loneliness, and physical and mental health problems.

A sense of belonging is defined as feeling accepted and liked by the rest of the group, feeling connected to others and feeling like a member of a community (Baumeister and Leary, 1995; Maslow, 1943). Human beings in general, and teenagers in particular, desire strong social ties and quality relationships. Fifteenyear-old students spend most of their time at school. Thus, students who feel that they are part of and are accepted by a school community report that their life has more meaning (Juvonen, 2006). They are more likely to be healthy (Lippman et al., 2011), to perform higher academically and to be more motivated in school (Cohen et al., 2009; Goodenow, 1993; Katja et al., 2002; Sánchez et al., 2005). They are also less likely to engage in risky behaviours, such as substance abuse and truancy (Currie et al., 2012; Resnick et al., 1997; Schulenberg et al., 1994).

In PISA 2015 students were asked to report their feelings about social bonding and isolation, loneliness and belonging to the school community on a 4-point Likert scale ranging from 1 ("strongly agree") to 4 ("strongly disagree"). Students are considered to feel a sense of belonging at school when they agree or strongly agree with the statement "I feel like I belong at school" and disagree or strongly disagree with the statement "I feel like an outsider (or left out of things) at school".2

Table 3.10 (available on line) shows the percentage of students who reported a sense of belonging by immigrant background. On average across OECD countries, $67 \%$ of native students reported a sense of belonging ( $66 \%$ across EU countries), but only $59 \%$ of first-generation immigrant students did ( $57 \%$ across EU countries). Some $63 \%$ of second-generation immigrant students reported a sense of belonging (62\% across EU countries), as did $64 \%$ of returning foreign-born students (60\% across EU countries) and $63 \%$ of native student of mixed heritage (61\% across EU countries).

Figure 3.10 shows that the difference between native and first-generation immigrant students in the percentage of students who reported a sense of belonging was larger than 10 percentage points in Austria, 
Belgium, Brazil, CABA (Argentina), Denmark, the Dominican Republic, Greece, Iceland, Jordan, Latvia, Luxembourg, Malta, Montenegro, Malta, Mexico, Montenegro, Portugal, Spain, Sweden, Switzerland, and Trinidad and Tobago.

Figure 3.10 - Sense of belonging at school, by immigrant background Percentage of students who reported a sense of belonging at school

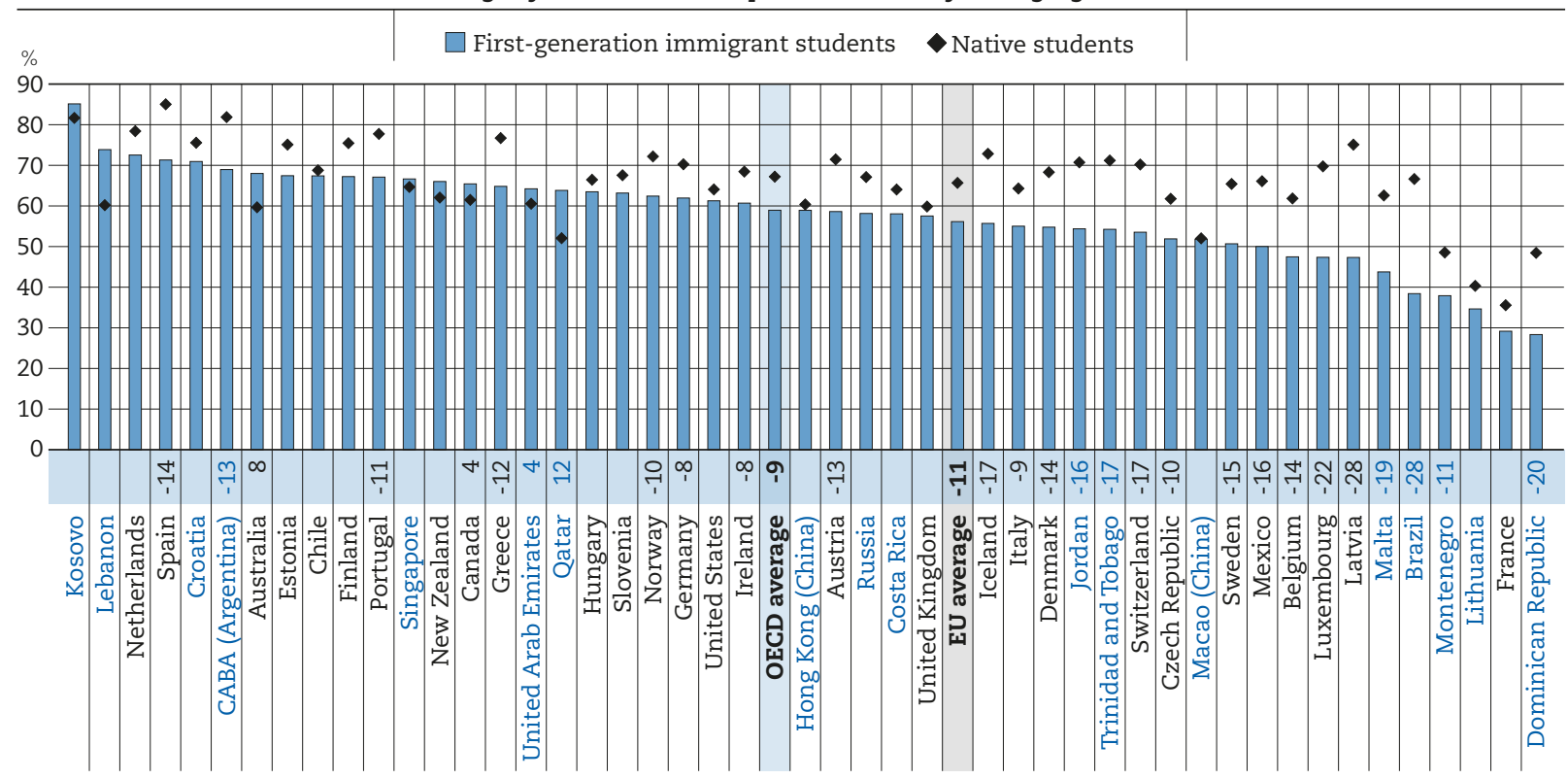

Notes: Only countries with valid values for first-generation immigrant students are shown.

Statistically significant differences between first-generation immigrant and native students are shown next to country/economy names. For the OECD and EU average, this number refers only to the subset of countries/economies with valid information on both groups of students.

Students who report a sense of belonging at school are Students who reported that they "agree" or "strongly agree" with the statement "I feel like I belong at school" and "disagree" or "strongly disagree" with the statement "I feel like an outsider at school".

Countries and economies are ranked in descending order of the percentage of first-generation immigrant students who reported a sense of belonging at school.

Source: OECD, PISA 2015 Database, Table 3.10.

StatLink Ainst http://dx.doi.org/10.1787/888933680761

Figure 3.10 shows that countries differ greatly in the extent to which native students reported a sense of belonging at school. Figure 3.11 illustrates, for countries with available data, the gap between native students and different groups of students with an immigrant background in their sense of belonging at school. In most countries, the gap between the groups was widest when considering first-generation immigrant students, and was smallest when considering native students of mixed heritage. However, in Costa Rica, second-generation immigrant students were as likely as native students to report a sense of belonging at school, while the proportion of native students with mixed heritage who enjoy a sense of belonging at school and are socially integrated was six percentage points smaller than that of native students.

In the majority of countries and economies, native students of mixed heritage reported a similar sense of belonging as native students. However, in Belgium, Brazil, Bulgaria, CABA (Argentina), Costa Rica, the Dominican Republic, Estonia, Latvia, Luxembourg, Mexico, Moldova, Montenegro, Poland, Peru, Sweden, Switzerland and Tunisia, native-born students of mixed heritage were less likely than native-born students with two native-born parents to report a sense of belonging at school.

First-generation immigrant students show the weakest sense of belonging at school. Figure 3.12 shows the variation in the gap in sense of belonging between native students and first-generation immigrant students related to the age at which the student arrived. On average across OECD and EU countries, immigrant students who had arrived in the host country at or after the age of 12 were less likely than students who had arrived before the age of 12 to report a sense of belonging at school. 
Figure 3.11 - Difference in sense of belonging at school, by immigrant group Difference between students with an immigrant background and native students in the percentage of students who reported a sense of belonging at school

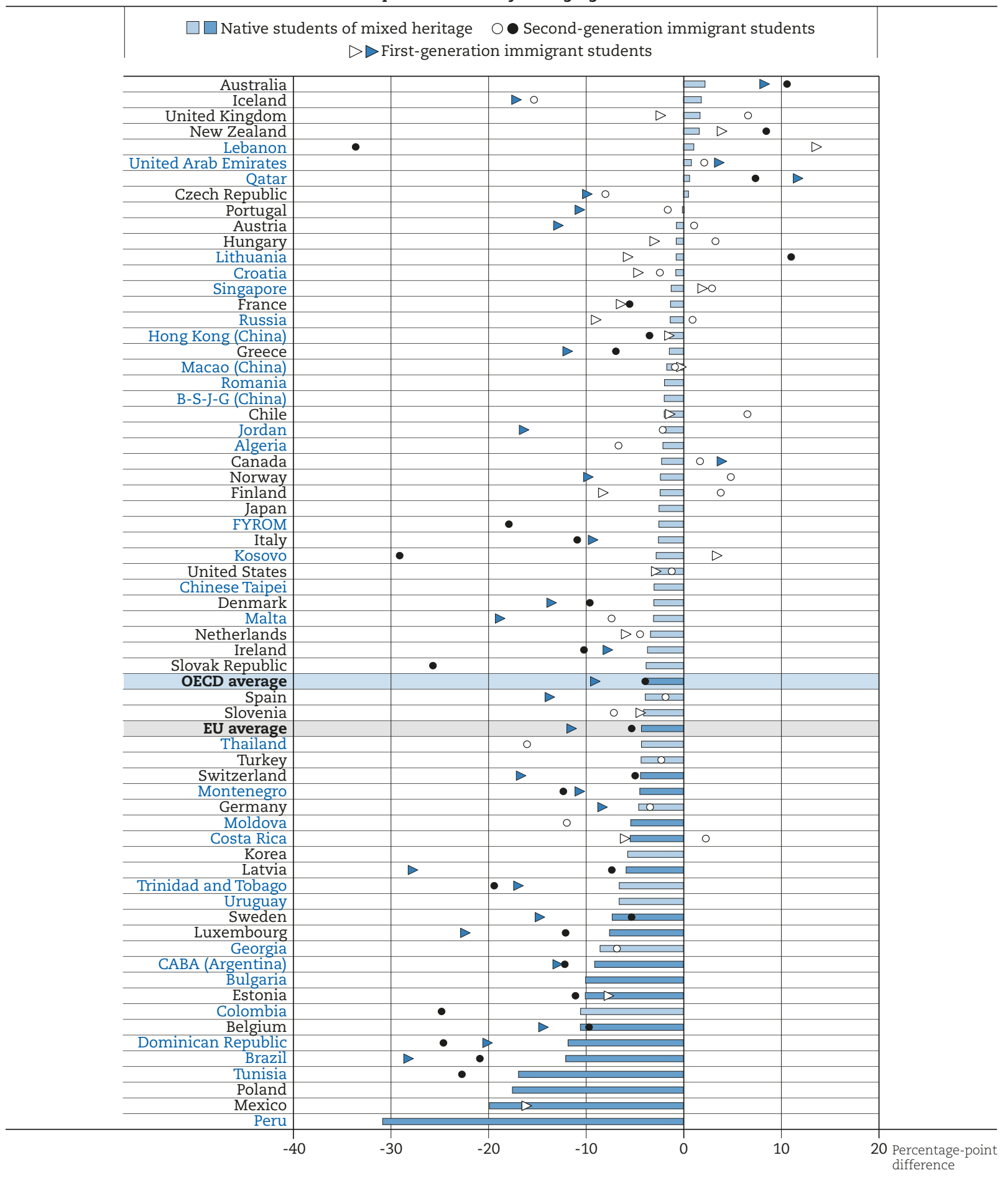

Notes: Statistically significant differences are marked in a darker tone.

Only countries with valid values for native students of mixed heritage are shown.

Students who report a sense of belonging at school are students who reported that they "agree" or "strongly agree" with the statement "I feel like I belong at school" and "disagree" or "strongly disagree" with the statement "I feel like an outsider at school".

Countries and economies are ranked in descending order of the difference in the percentage of native students of mixed heritage and native students who reported a sense of belonging at school.

Source: OECD, PISA 2015 Database, Table 3.10.

StatLink त्ताड़ी http://dx.doi.org/10.1787/888933680780 
Although early arrivals were 12 percentage points more likely to report feeling like they belong at school compared to late arrivals, on average across OECD countries (13 percentage points more likely across EU countries), the difference was particularly wide in Germany (45 percentage points), Sweden (26 percentage points), the United Kingdom (20 percentage points), Austria (18 percentage points), Spain (18 percentage points) and Norway (16 percentage points). Identifying differences in age at arrival is particularly revealing in the case of the United Kingdom where, on average, first-generation immigrant students and native students were equally likely to report a sense of belonging, but late arrivals show the greatest difference compared with native students. This was also the case in Australia, a country where immigrant students who had arrived before the age of 12 were more likely than native students to report a strong sense of belonging and social integration, while those who had arrived at or after the age of 12 reported a similar sense of belonging as native students.

Figure 3.12 - Difference in sense of belonging at school, by age at arrival Difference between first-generation immigrant and native students in the percentage of students who reported a sense of belonging at school

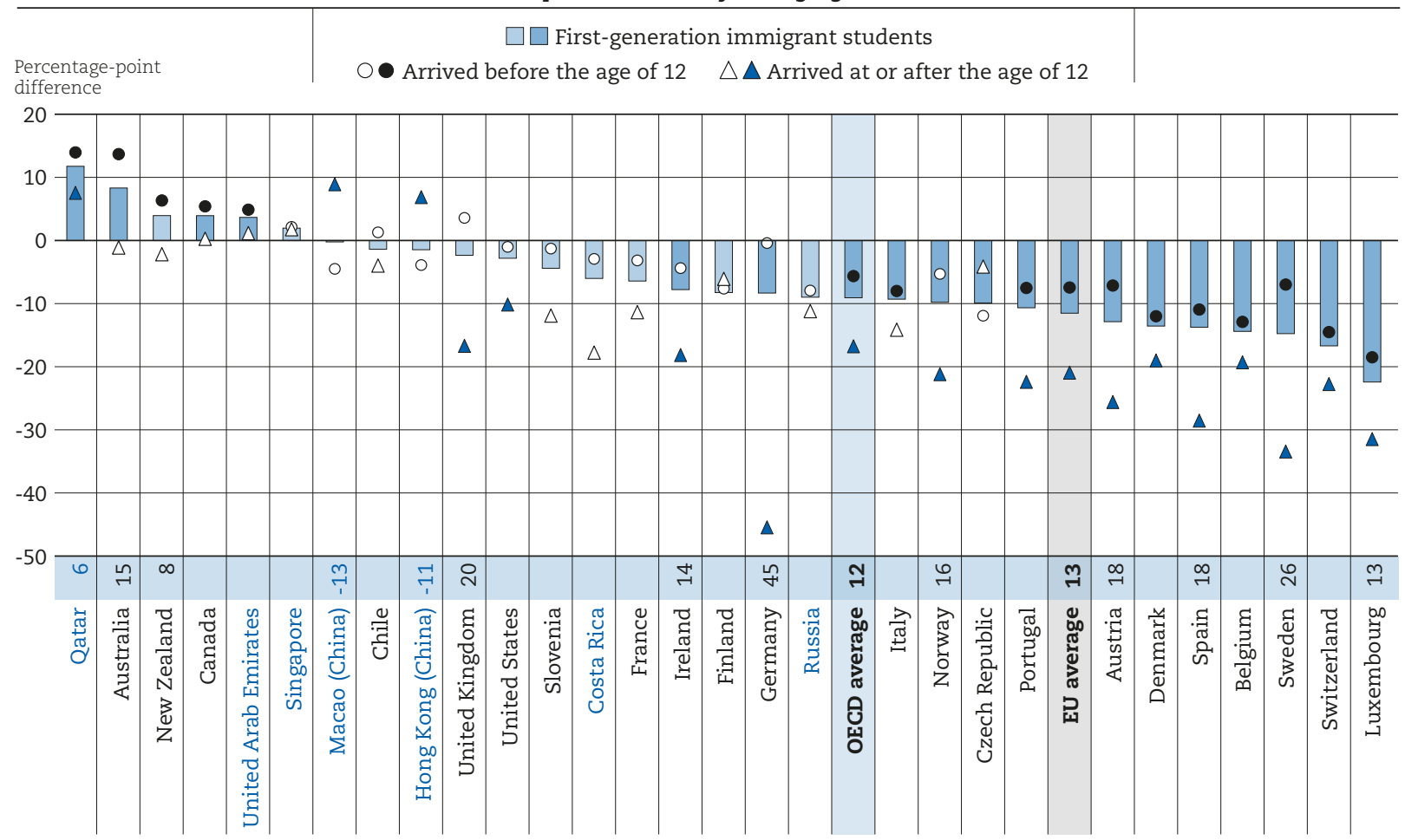

Notes: Statistically significant differences are marked in a darker tone.

Only countries with valid values for both first-generation immigrant students who arrived before the age of 12 and those who arrived at or after the age of 12 are shown.

Statistically significant differences between those that arrived before the age of 12 and those who arrived at or after the age of 12 are shown next to country/economy names. For the OECD and EU average, this number refers only to the subset of countries/economies with valid information on both groups of students.

Students who report a sense of belonging at school are students who reported that they "agree" or "strongly agree" with the statement "I feel like I belong at school" and "disagree" or "strongly disagree" with the statement "I feel like an outsider at school".

Countries and economies are ranked in descending order of the difference in the percentage of first-generation immigrant students and native students who reported a sense of belonging at school.

Source: OECD, PISA 2015 Database, Table 3.11.

StatLink 前5 http://dx.doi.org/10.1787/888933680799

Since questions on sense of belonging were asked in both PISA 2003 and PISA 2015, it is possible to examine the evolution of students' social integration and sense of belonging. Figure 3.13 shows, for countries with available data, how the percentage of native, first-generation immigrant and secondgeneration immigrant students who reported that they feel that they belong at school changed between 2003 and 2015. 
With the exception of Belgium, where the percentage of native students who reported feeling a sense of belonging increased between 2003 and 2015, and Denmark, Hong Kong (China), Macao (China), the Netherlands and Spain, where there were no changes, in all other countries more native students in 2003 than in 2015 reported that they felt well-integrated. The drop in the percentage of native students who so reported was greater than 20 percentage points in Australia, New Zealand, Russia, the Slovak Republic and the United Kingdom. In most countries this decline among native students was matched by a similar decline among both first- and second-generation immigrant students. The drop in the proportion of first-generation immigrant students who reported a sense of belonging was most pronounced in Austria, France, Greece, Hungary, Latvia, Russia, Sweden and the United Kingdom. In Italy and the Slovak Republic, second-generation immigrant students showed the steepest decline during the period. In Australia and New Zealand, the sharp decline in native students' sense of belonging was not shared among first- and second-generation immigrant students.

Figure 3.13 - Trends between 2003 and 2015 in sense of belonging at school, by immigrant background

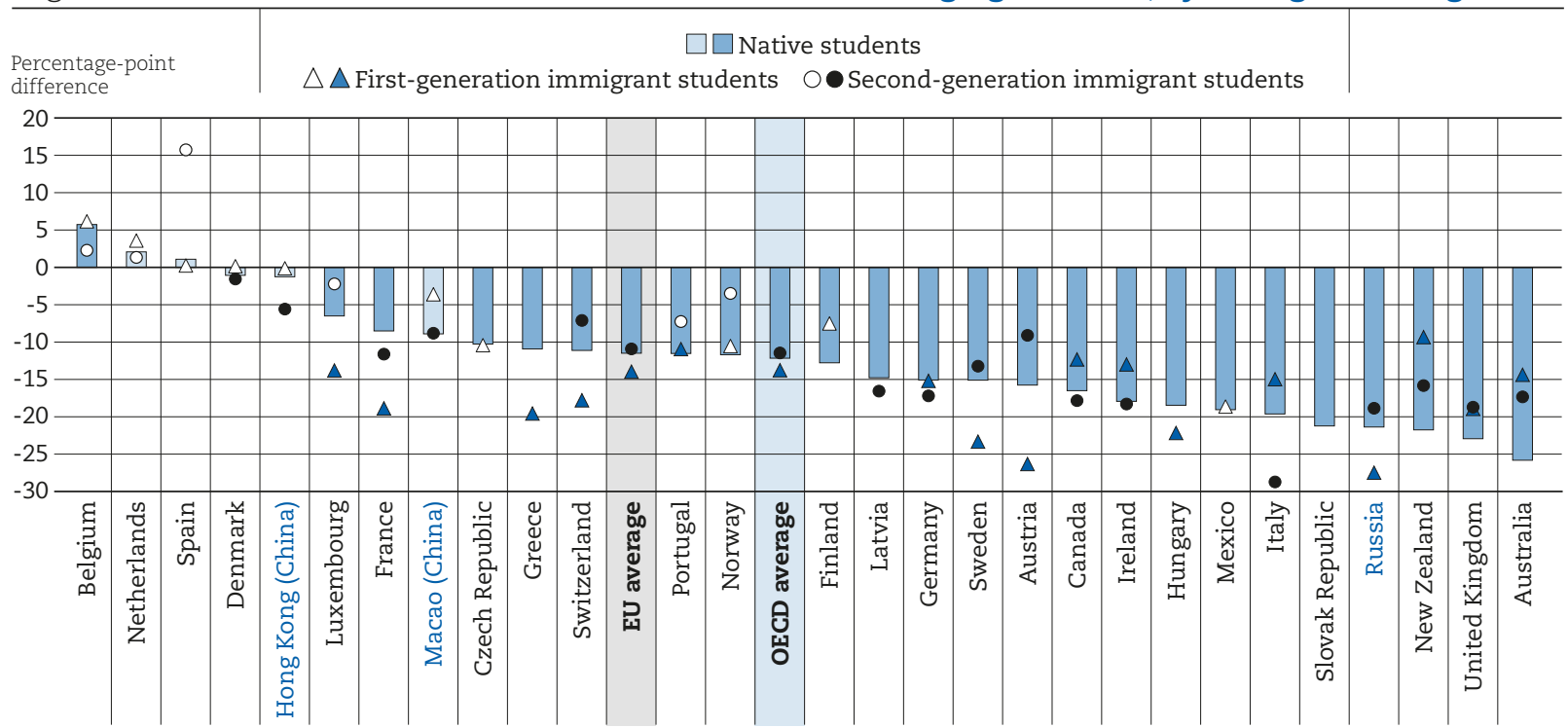

Notes: Results are displayed only for countries/economies that participated in both PISA 2003 and PISA 2015 and have valid data in both rounds for either first- or second-generation immigrant students.

Statistically significant differences between PISA 2015 and 2003 are marked in a darker tone.

Only countries with valid values for first- or second-generation immigrant students are shown.

Students who report a sense of belonging at school are students who reported that they "agree" or "strongly agree" with the statement "I feel like I belong at school" and "disagree" or "strongly disagree" with the statement "I feel like an outsider at school".

Countries and economies are ranked in descending order of the change of the percentage of native students who reported a sense of belonging at school between 2003 and 2015 .

Source: OECD, PISA 2015 and 2012 Database, Table 3.12

StatLink 게대 $\mathrm{http}: / / \mathrm{dx}$.doi.org/10.1787/888933680818

\section{Box 3.2. Attitudes towards co-operation}

Students' capacity to collaborate is receiving growing attention lately as research shows that labour markets increasingly demand collaboration skills (Autor, Levy and Murnane, 2003;Deming, 2017). However, collaboration skills are also important beyond the workplace as the level of well-being of individuals and societies is dependent on their capacity to cooperate with others, solve common problems and live in harmony. For these reasons, education systems in some countries have begun to adapt their curricula and instruction to help their students acquire collaboration skills (Griffin and Care, 2015; Hesse et al., 2015). Socio-economic status is strongly related to students' attitudes and dispositions towards co-operation. The majority of studies show that students of lower socio-economic status are more likely to exhibit behaviour consistent with co-operation and consideration of others (Pitt and Robinson, 2017; Stephens et al., 2012). 
Others indicate that students of higher socio-economic status tend to report higher levels of empathy (Varnum et al., 2015), which might be associated to valuing relationships with others and other positive traits such as honesty, sense of humour and friendliness (Varnum, 2015).

PISA 2015 measured students' attitudes towards co-operation by asking them the extent to which they agree with the following statements: "I am a good listener"; "I enjoy seeing my classmates be successful"; "I take into account what others are interested in"; "I enjoy considering different perspectives"; "I prefer working as part of a team to working alone"; "I find that teams make better decisions than individuals"; "I find that teamwork raises my own efficiency"; and "I enjoy cooperating with peers". Possible answers were "strongly disagree", "disagree", "agree" and "strongly agree". Responses were used to create two indices with a mean of zero and a standard deviation of one across OECD countries. The index of valuing teamwork is based on the first four questions and the index of valuing relationships is based on the last four.

Figure 3.14 shows the index-point difference between immigrant (comprising both first and second generation immigrants) and native students on the two indexes. In 14 countries out of 51 with available data, immigrant students reported that they value teamwork more than native students did, while the opposite was true in only 8 countries and economies. By contrast, in 9 countries and economies, immigrant students reported that they value relationships less than native students did, while the opposite is true in only 8 countries and economies. In Austria, Belgium, Croatia, Iceland, Italy, Sweden, Switzerland and the United States, immigrant students reported that they value teamwork more than native students did; but both groups of students reported similar levels of valuing relationships.

Figure 3.14 - Valuing teamwork and valuing relationships, by immigrant background Difference between immigrant and native students in scores on the PISA indexes of valuing teamwork and valuing relationships

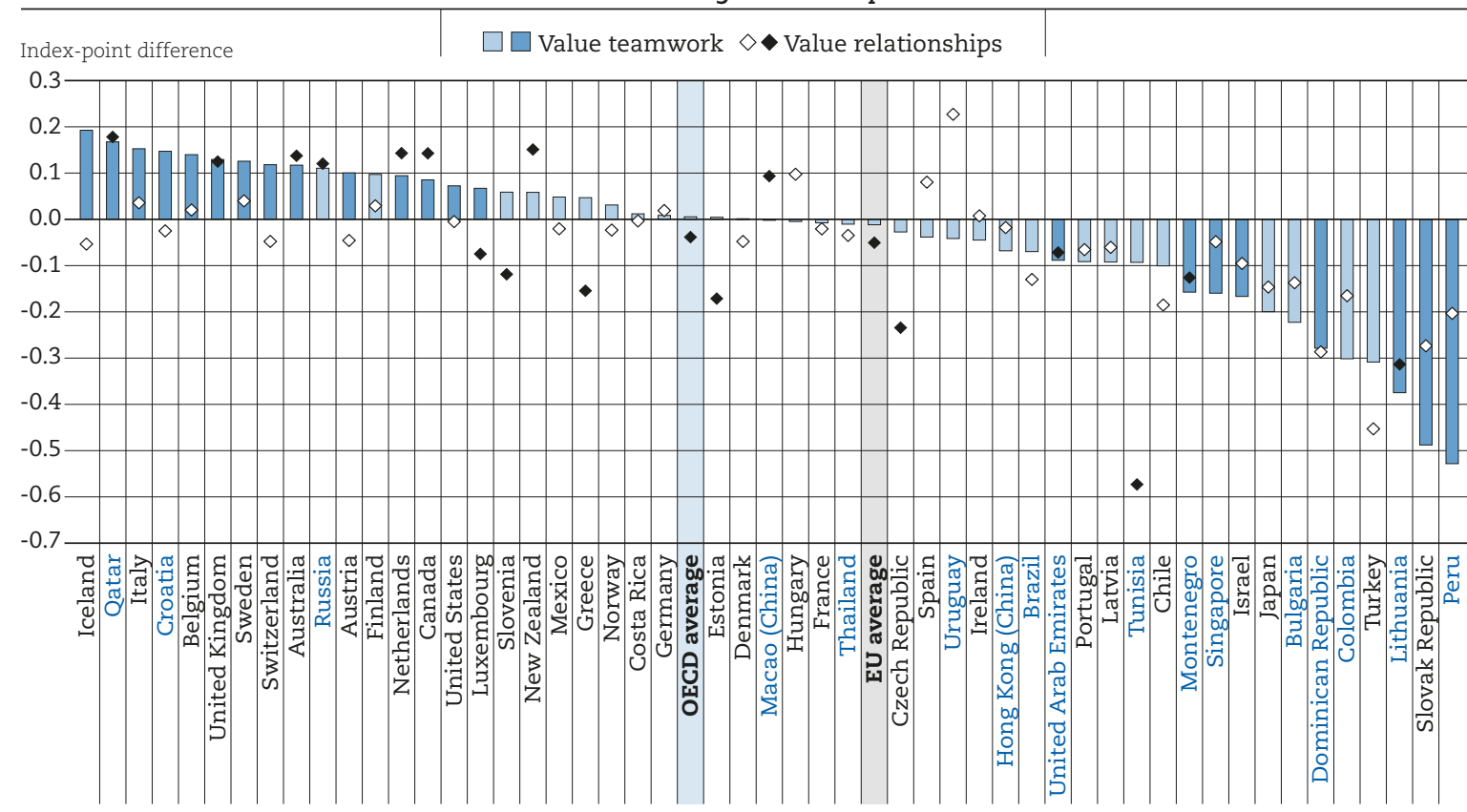

Notes: Only countries with valid values for immigrant students are shown.

The index of valuing teamwork is based on students' level of agreement with the following statements: "I prefer working as part of a team to working alone"; "I find that teams make better decisions than individuals"; "I find that teamwork raises my own efficiency"; and "I enjoy cooperating with peers", with "strongly disagree", "disagree", "agree" and "strongly agree" the possible responses.

The index of valuing relationships is based on students' level of agreement with the following statements: "I am a good listener"; "I enjoy seeing my classmates be successful"; "I take into account what others are interested in"; "I enjoy considering different perspectives", with "strongly disagree", "disagree", "agree" and "strongly agree" the possible responses.

Countries and economies are ranked in descending order of the difference between immigrant and native students in the index of valuing teamrowk. Source: OECD, PISA 2015 Database, Tables 3.13 and 3.14.

StatLink ants http://dx.doi.org/10.1787/888933680837 
In the Czech Republic, Estonia, Greece, Slovenia and Tunisia, immigrant students reported that they value teamwork as much as native students did, but they reported lower levels of valuing relationships than their native peers did. The same was true across OECD and EU countries. A possible explanation for this finding is that, in theory, immigrant students value cooperation at least as much as native students do; but in practice, when they actually co-operate with others, they tend to enjoy the act less than native students do. Due to language and cultural barriers, immigrant students might have difficulty co-operating with their peers, or they might be intentionally excluded by them.

\section{Life satisfaction}

Good educators strive to improve children's life prospects but also care about the quality of their students' current lives. Much of the thinking about the link between education and the quality of students' lives has focused on mental health problems that children might manifest at school. Teenagers are particularly at risk of psychological disorders because adolescence is a period of intense emotional upheaval (Gilman et al., 2008). Satisfaction with life is known to decrease during adolescence (Goldbeck et al., 2007), and low life satisfaction has been linked to school dropout, substance abuse, aggression and misbehaviour among students (Huebner and Alderman, 1993; Valois et al., 2001; Zullig et al., 2001). Approaches that address only mental health and behavioural problems might not do anything to create the conditions in which children and adolescents can flourish. Helping students find greater satisfaction with their lives, rather than just responding when students exhibit behaviours associated with dissatisfaction with life, can sustain the psychological, social and cognitive development of all students (Huebner and Hills, 2013; Suldo, Riley and Shaffer, 2006).

Life satisfaction can be defined as a subjective appraisal of the quality of one's life (Diener et al., 1999). Satisfaction with life is one measure of students' "subjective" well-being (defined as people's self-reported experience and evaluation of life), together with the frequency of positive emotions, such as joy and pride, the frequency of negative emotions, such as anger or sadness, and the sense of having a purpose in life (OECD, 2015).

PISA 2015 asked students to rate their life on a scale from 0 to 10, where 0 means the worst possible life and 10 means the best possible life. Self-reported measures of life satisfaction are more stable indicators of subjective well-being than reports of positive or negative affective states (Gilman et al., 2008). In this report, students who reported a level of satisfaction equal to or greater than 7 are considered to report being satisfied with life, and immigrant students who reported so are considered emotionally resilient.

Data from PISA 2015 show that, on average across OECD countries, students with an immigrant background were less likely than native students to report being satisfied with life. In contrast to results concerning academic adjustment and sense of belonging, the gap in life satisfaction between native students and immigrant students is small, on average, and is similar across the groups of immigrants considered (Table 3.15, available on line). On average across OECD countries, $72 \%$ of native students reported that they are satisfied with their life (74\% across EU countries) while $68 \%$ to $69 \%$ of each of the four groups of students with an immigrant background considered in this report reported the same $167 \%$ to $70 \%$ across EU countries). However, Figure 3.15 shows that countries differ in the percentages of native and first-generation immigrant students who reported being satisfied with life. For example, in Mexico as many as $84 \%$ of native students reported being satisfied with their life, while in Chile $70 \%$ did so. Similarly, while in the Netherlands $76 \%$ of first-generation immigrant students reported being satisfied with life, in the United Kingdom only 59\% did.

Figure 3.15 shows that countries differ greatly in the levels of life satisfaction expressed by native students and by first-generation immigrant students. Table 3.15 (available on line) illustrates, for countries with available data, the differences between native students and different groups of students with an immigrant background in the percentage of students who reported being satisfied with life.

Results suggest that, in most countries, a smaller proportion of first-generation immigrant students than native students reported being satisfied with their life. The gap between the two appears to be larger than the one between second-generation immigrant students and native students which, in turn, is larger 
than the gap between native students and native-born students of mixed heritage. But countries differ markedly in this respect. In as many as 19 of the countries and economies with available data, there is a difference in the percentage of native students and of native students of mixed heritage who report being satisfied with life. In Colombia, this gap is 12 percentage points and is almost as large as the gap between native students and first-generation immigrant students in Chile, France and Spain. In Brazil, native students of mixed heritage were considerably less likely than native students with two native-born parents to report being satisfied with their life.

Figure 3.15 - Satisfaction with life, by immigrant background Percentage of students who reported being satisfied with life

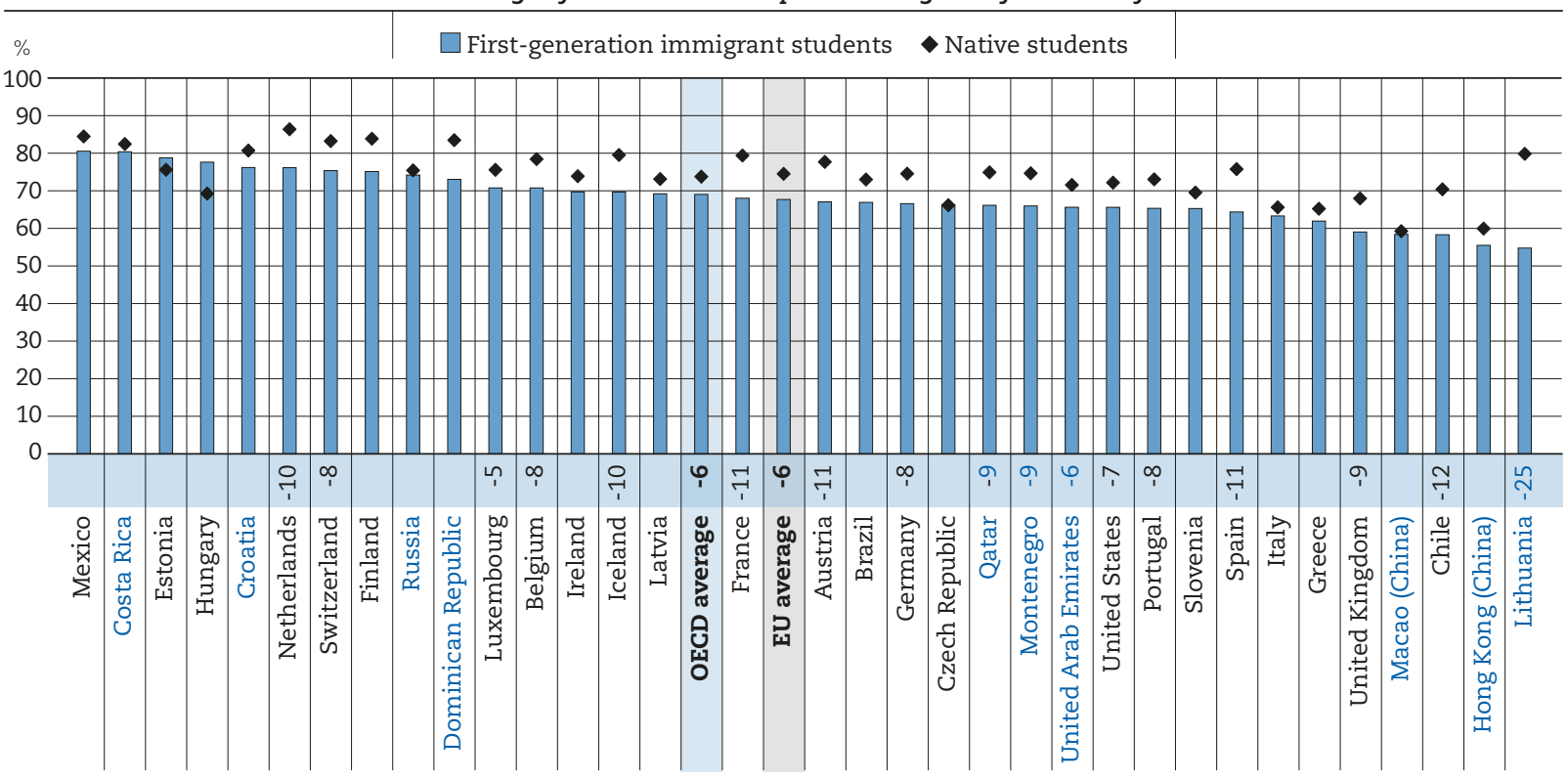

Notes: Only countries with valid values for first-generation immigrant students are shown.

Statistically significant differences between first-generation immigrant and native students are shown next to country/economy names. For the OECD and EU average, this number refers only to the subset of countries/economies with valid information on both groups of students.

Students who report being satisfied with life are students who reported a life satisfaction of 7 or above on a scale from 0 to 10. Countries and economies are ranked in descending order of the percentage of first-generation immigrant students who report being satisfied with life. Source: OECD, PISA 2015 Database, Table 3.15. StatLink ails http://dx.doi.org/10.1787/888933680856

In Ireland, Italy, Greece and Slovenia second-generation immigrant students were considerably less likely than native students to report being satisfied with life, while native students of mixed heritage and firstgeneration immigrant students reported similar levels of life satisfaction as native students. In Germany and Switzerland, the gap in the percentage of students who reported being satisfied with life was wider between native students and both native-born mixed-heritage students and first-generation immigrant than between native students and second-generation immigrant students. In Greece, Ireland, Italy and Slovenia, native-born students of foreign-born parents are the only students who were less likely to report being satisfied with life than native students, on average.

These results suggest that even though the experience of migration has a profound impact on children's emotional well-being, in many countries, native-born children of foreign-born parents or of mixed heritage parents are less satisfied with their lives than are children who had immigrated into the country.

Table 3.16 (available on line) shows the difference between native and first-generation immigrant students in the percentage of students who reported being satisfied with life, depending on the age at which the latter group of students had arrived in the host country. Results indicate that, on average across OECD countries, students who had arrived in the country in which they sat the PISA test at or after the age of 12 reported similar levels of life satisfaction as students who had arrived before the age of 12 . 
In general, differences between these two groups of first-generation immigrant students are small. In some countries, however, the percentage of late arrivals who reported being satisfied with life is more similar to the percentage of native students who so reported than to the percentage of early arrivals who reported being satisfied with life. This might be because of the sense of opportunity and promise that settling in a new community might bring to immigrants, particularly when families immigrate to a new country to improve their economic prospects or to flee war and persecution. In Germany, Ireland, Portugal, the United Kingdom and the United States, the difference in the percentage of students who reported being satisfied with their life is small when comparing native students with immigrant students who arrived after the age of 12 but relatively larger when comparing native students with immigrant students who arrived at or before the age of 12. By contrast, in Belgium, France, Luxembourg, Spain and Switzerland, the most recent arrivals were less likely to report being satisfied with life than native students and other foreign-born students who had arrived in the host before the age of 12 .

\section{Schoolwork-related anxiety}

The anxiety related to school tasks and tests, along with the pressure to get higher marks and the concern about receiving poor grades, is one of the sources of stress most often cited by school-age children and adolescents. Students who suffer from anxiety are more likely to perform poorly, be frequently absent from school, and drop out of school altogether (Cortina, 2008; Ramirez and Beilock, 2011). Excessive levels of anxiety can also negatively affect students' social and emotional development and sense of self-worth, prompt students to use chemical substances to reduce stress, and lead to exhaustion (Salend, 2012; Zeidner, 1998).

In considering students' anxiety, PISA 2015 chose to focus on the students' cognitive and emotional reactions to schoolwork. In this report, students are considered to be well-adjusted if they reported low levels of schoolwork-related anxiety by indicating that they disagree or strongly disagree with the statements "I feel very anxious even if I am well prepared for a test" and "I get very tense when I study for a test". The PISA questions thus cover both study- and test-related anxiety.

On average across OECD countries, around 39\% of native students reported low levels of schoolworkrelated anxiety (41\% across EU countries), but only 33\% of first-generation immigrant students reported low levels of schoolwork anxiety (35\% across EU countries), a difference of about 6 percentage points. Figure 3.16 shows that in as many as 18 of the 43 countries and economies with available data, native students were more likely to report low levels of anxiety than first-generation immigrant students; and in Austria, Finland, France, Germany, Luxembourg, Mexico, the Netherlands and Switzerland, the difference between native and first-generation immigrant students in the percentage of students who reported low schoolwork-related anxiety was larger than 10 percentage points.

Differences in schoolwork-related anxiety across different groups of students with an immigrant background are pronounced (Table 3.17, available on line). For example, the data indicate that, contrary to other aspects of resilience, particularly the social and emotional resilience reflected in students' sense of belonging and satisfaction with life, native-born students of mixed heritage tend to have low levels of schoolwork-related anxiety: only in Austria, Belgium, Latvia, Germany, Luxembourg, Qatar and Switzerland was this group of students less likely to report low levels of anxiety compared to native students.

Table 3.17 also suggests that, in many countries, first- and second-generation immigrant students appear to suffer comparable levels of vulnerability towards anxiety, compared with native students. For example, the difference between native students and both first- and second-generation immigrant students in the percentage of students who reported low schoolwork-related anxiety was large and similar in magnitude in Austria, Finland, Sweden and Switzerland.

Table 3.18 (available on line) reports the difference between native and first-generation immigrant students in the percentage of students who reported low schoolwork-related anxiety, depending on the age at which the latter group of student had arrived in the host country. Results indicate that, in most countries, students who had arrived in the country at or after the age of 12 reported similar levels of schoolwork-related anxiety as students who had arrived in the country before the age of 12 . 
Figure 3.16 - Low schoolwork-related anxiety, by immigrant background Percentage of students who reported low schoolwork-related anxiety

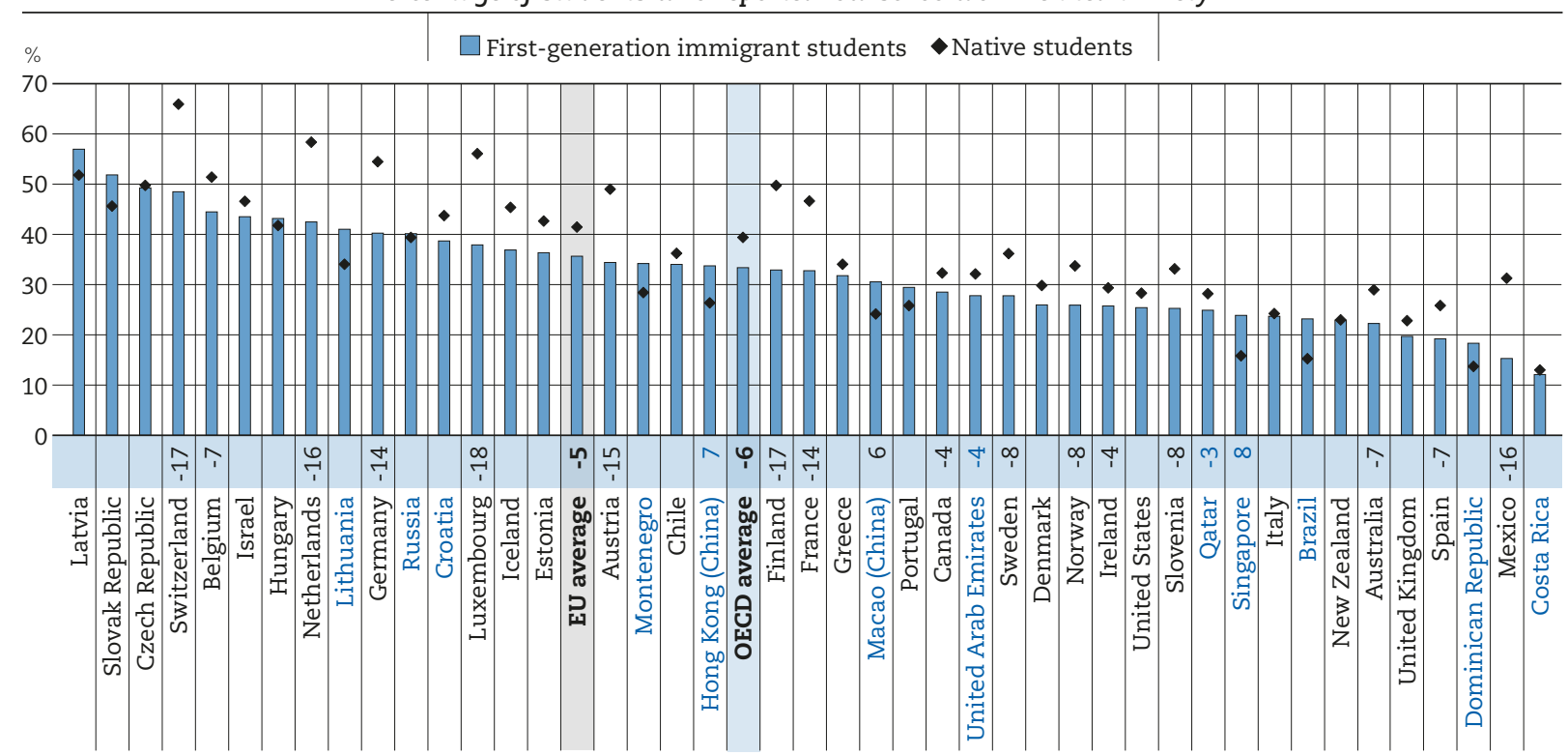

Notes: Only countries with valid values for first-generation immigrant students are shown.

Statistically significant differences between first-generation immigrant and native students are shown next to country/economy names. For the OECD and EU average, this number refers only to the subset of countries/economies with valid information on both groups of students.

Students who report low schoolwork-related anxiety are students who reported that they "disagree" or "strongly disagree" with the statements "I often worry that it will be difficult for me taking a test" and "Even if I am well prepared for a test, I feel very anxious".

Countries and economies are ranked in descending order of the percentage of first-generation immigrant students who report low schoolwork-related anxiety. Source: OECD, PISA 2015 Database, Table 3.17.

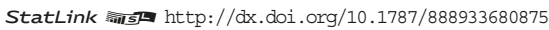

In France, late arrivals were at least 13 percentage points less likely to report low anxiety compared to early arrivals and 22 percentage points less likely compared to native students. In Israel, early arrivals were as likely as native students to report low schoolwork-related anxiety, while late arrivals were 17 percentage points less likely than native students.

\section{Achievement motivation}

One of the most important ingredients of achievement, both in school and in life, is the motivation to achieve (OECD, 2013). In many cases, people with less talent, but greater motivation to reach their goals, are more likely to succeed than those who have talent but are not capable of setting goals for themselves and to stay focused on achieving them (Duckworth et al., 2011; Eccles and Wigfield, 2002). The motivation to achieve goals not only leads individuals to pursue work they perceive to be valuable, it also prompts them to compete with others (Covington, 2000). This drive may come from an internal or external source. Achievement motivation is intrinsic when it is sparked by an interest or enjoyment in the task itself. It is organic to the person, not a product of external pressure. Achievement motivation can be extrinsic when it comes from outside the person. Common sources of extrinsic motivation among students are rewards like good marks, or praise from parents and teachers.

Motivating students is one of the major challenges teachers face every day. As they move into adolescence, children become more able to exercise complex thought, have greater capacities for self-regulation, and hold a stronger desire for meaningful work (Damon, Menon and Bronk, 2003). Despite these blossoming abilities and attitudes, steep declines in motivation to do schoolwork are often observed among adolescents (Lepper, Corpus, and Iyengar, 2005). At a period in life when school should be seen as more relevant, students rate school as less useful and important for their well-being (Wigfield and Cambria, 2010). Because people tend to form beliefs about what they can achieve in life at a young age, the development of positive motivation to achieve at school is a prerequisite for success in life. 
For the first time, PISA 2015 asked students to report whether they "strongly agree", "agree", "disagree" or "strongly disagree" with the following statement: "I want to be the best, whatever I do". In this report, students are considered to be motivated to achieve if they "agree" or "strongly agree" with the statement.

On average, first-generation immigrant students were more likely than native students to report that they want to be the best in whatever they do. Figure 3.17 shows that, on average across OECD countries, $71 \%$ of first-generation immigrant students but only $64 \%$ of native students reported that they want to be the best in whatever they do (across EU countries, 67\% of first-generation immigrant students and $59 \%$ of native students so reported). In as many as 16 countries and economies, first-generation immigrant students were more likely than native students to report that they want to be the best in whatever they do. The gap in achievement motivation in favour of foreign-born students of foreign-born parents was particularly wide in the Netherlands (a difference of 36 percentage points), Belgium (23 percentage points), Austria (22 percentage points), and Sweden, France and Germany (a difference of 16 percentage points).

Figure 3.17 - Difference in motivation to achieve, by immigrant background Percentage of students who reported high motivation to achieve

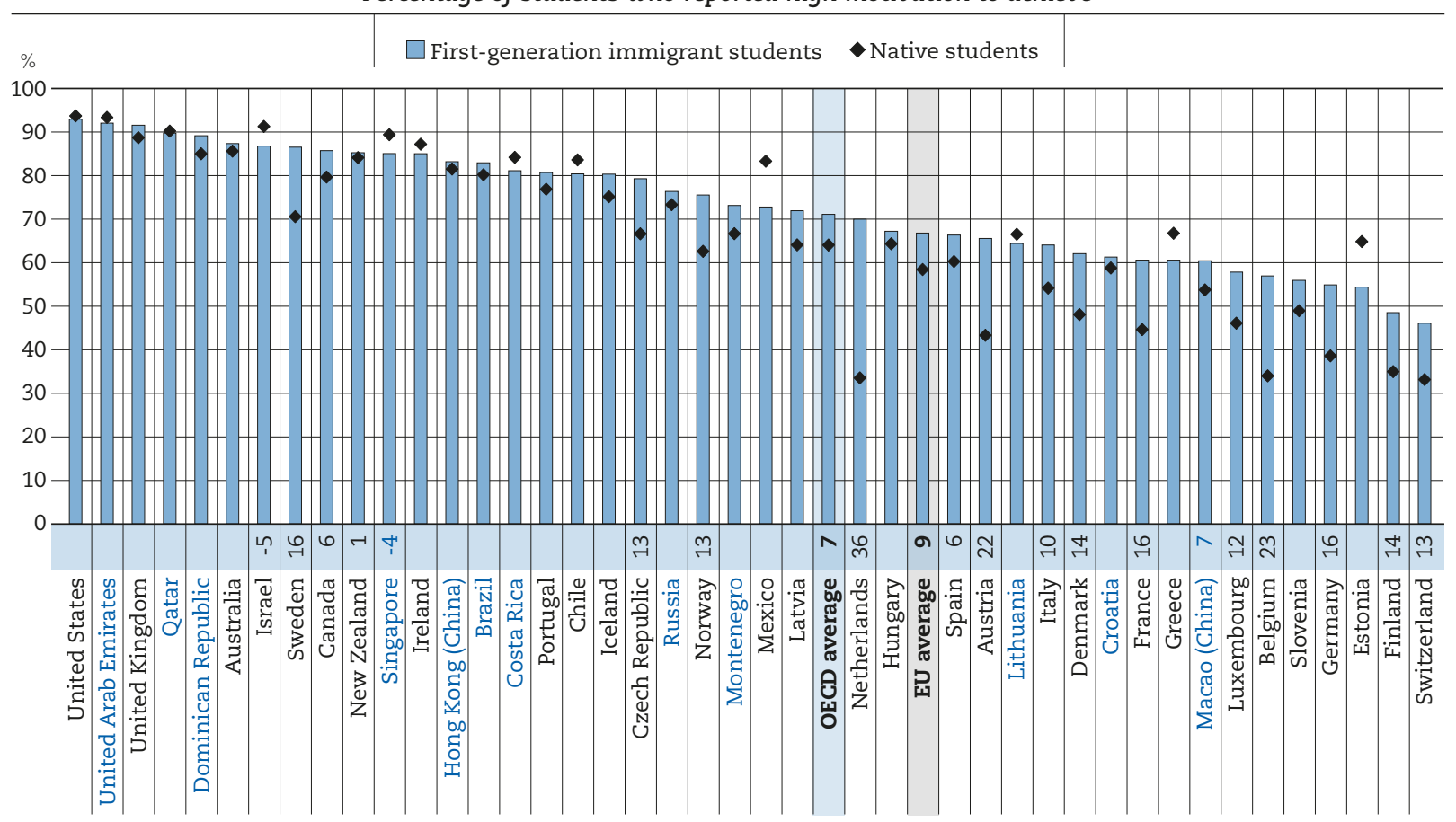

Notes: Only countries with valid values for first-generation immigrant students are shown.

Statistically significant differences between first-generation immigrant and native students are shown next to country/economy names. For the OECD and EU average, this number refers only to the subset of countries/economies with valid information on both groups of students.

Students who report high motivation to achieve are students who "agree" or "strongly agree" with the statement "I want to be the best, whatever I do".

Countries and economies are ranked in descending order of the percentage of first-generation immigrant students who report high motivation to achieve. Source: OECD, PISA 2015 Database, Table 3.19.

StatLink त्ताडा http://dx.doi.org/10.1787/888933680894

Figure 3.17 shows that countries differ greatly in students' self-reported levels of achievement motivation. Over $90 \%$ of native students in the United States agreed or strongly agreed that they want to be the best in whatever they do while only 33\% of native students in Switzerland so reported. Table 3.19 (available on line) shows, for countries with available data, the gap between native students and different groups of students with an immigrant background in the percentage of students who reported being motivated to achieve. 
Colombia, Montenegro and the United States are the only countries where native students of mixed heritage families were less likely than native students to express high levels of achievement motivation. Interestingly, in these countries, this group was the only group of students with an immigrant background who reported different levels of achievement motivation than students without an immigrant background. In Israel, Lithuania, Singapore and the United Arab Emirates, second-generation immigrant students were less likely to report being motivated to achieve than native students, and in Israel and Singapore, first-generation immigrant students were less likely than native students to report so. In all other countries where differences between groups are observed, achievement motivation appears to be greater among students with an immigrant background, with first-generation immigrant students more likely to report being motivated to achieve than all other groups. However, in Finland, the gap between second-generation immigrant students and native students in the percentage of students motivated to achieve was considerably wider than the gap observed between first-generation immigrant students and native students.

Table 3.20 (available on line) shows the variation in achievement motivation between native students and first-generation immigrant students, depending on the age at which the student arrived in the host country. Results indicate that, in most countries, students who had arrived in the country in which they sat the PISA test at or after the age of 12 reported similar achievement motivation as students who had arrived before the age of 12. In Belgium and Sweden a larger proportion of both groups of immigrant students reported high achievement motivation than native-born students and a larger proportion of late arrivals than early arrivals reported high achievement motivation. The difference between the two groups of first-generation immigrant students was 9 percentage points in both countries. In Germany, late arrivals were 34 percentage points more likely than early arrivals to report high achievement motivation. By contrast, in New Zealand and the United Kingdom, the proportion of immigrant students who had arrived before the age of 12 and reported high achievement motivation was larger than the proportions of students who reported so among both native-born students and immigrant students who had arrived at or after the age of 12 . The difference in the gaps in motivation between first-generation immigrant students who had arrived after and those who had arrived before the age of 12 stood at 9 percentage points for both the United Kingdom and New Zealand.

\section{Overall resilience}

Previous sections have shown that, on average, students with an immigrant background are less likely to attain baseline academic proficiency and levels of social and emotional well-being, in other words many students with an immigrant background do not overcome their disadvantage. However, the size of the disadvantage that immigrants face varies across dimensions of resilience and countries. Firstgeneration immigrant students in Finland were 41 percentage points less likely to attain baseline academic proficiency compared to native students, the benchmark used to identify academic resilience (the largest gap among countries with available data); however, there was no statistically significant difference in the percentage of students who report a sense of belonging at school and being satisfied with life between the two groups (the benchmarks used to identify social and emotional resilience respectively). In the United Kingdom, first-generation immigrant students were only 11 percentage points less likely than native students to attain baseline academic proficiency (the lowest negative statistically significant gap); however, they were nine percentage points less likely to report being satisfied with life (above the OECD average of six percentage points). In each country, different groups of students with an immigrant background display different positive adjustments to adversity and different degrees of academic, social and emotional resilience.

To investigate immigration-related disadvantages in a broad measure of resilience, which encompasses academic, social and emotional dimensions, a single indicator of academic and socio-emotional wellbeing was built. Students are defined as being academically sound and socially and emotionally welladapted if they attained baseline academic proficiency, they reported a sense of belonging at school and reported being satisfied with life. Students with an immigrant background who fit in this category are defined as resilient overall. Figure 3.18 shows that in 20 out of 32 countries and economies with available data, the percentage of first-generation immigrant students who fit in this category was lower than the percentage of native students who did. On average across OECD countries, the difference was 
of 17 percentage points (15 percentage points across EU countries) but it was over twenty percentage points in Austria, Finland, Germany, Greece, Iceland, Luxembourg, Mexico, the Netherlands, Spain and Switzerland. The figure also shows that the percentage of more successful students among natives varies greatly between countries: it was as high as 59\% in the Netherlands, but only $9 \%$ in Qatar.

Figure 3.18 - Academically sound and socially and emotionally well-adapted students, by immigrant background

Percentage of students who attain baseline academic proficiency, report a sense of belonging at school and being satisfied with life

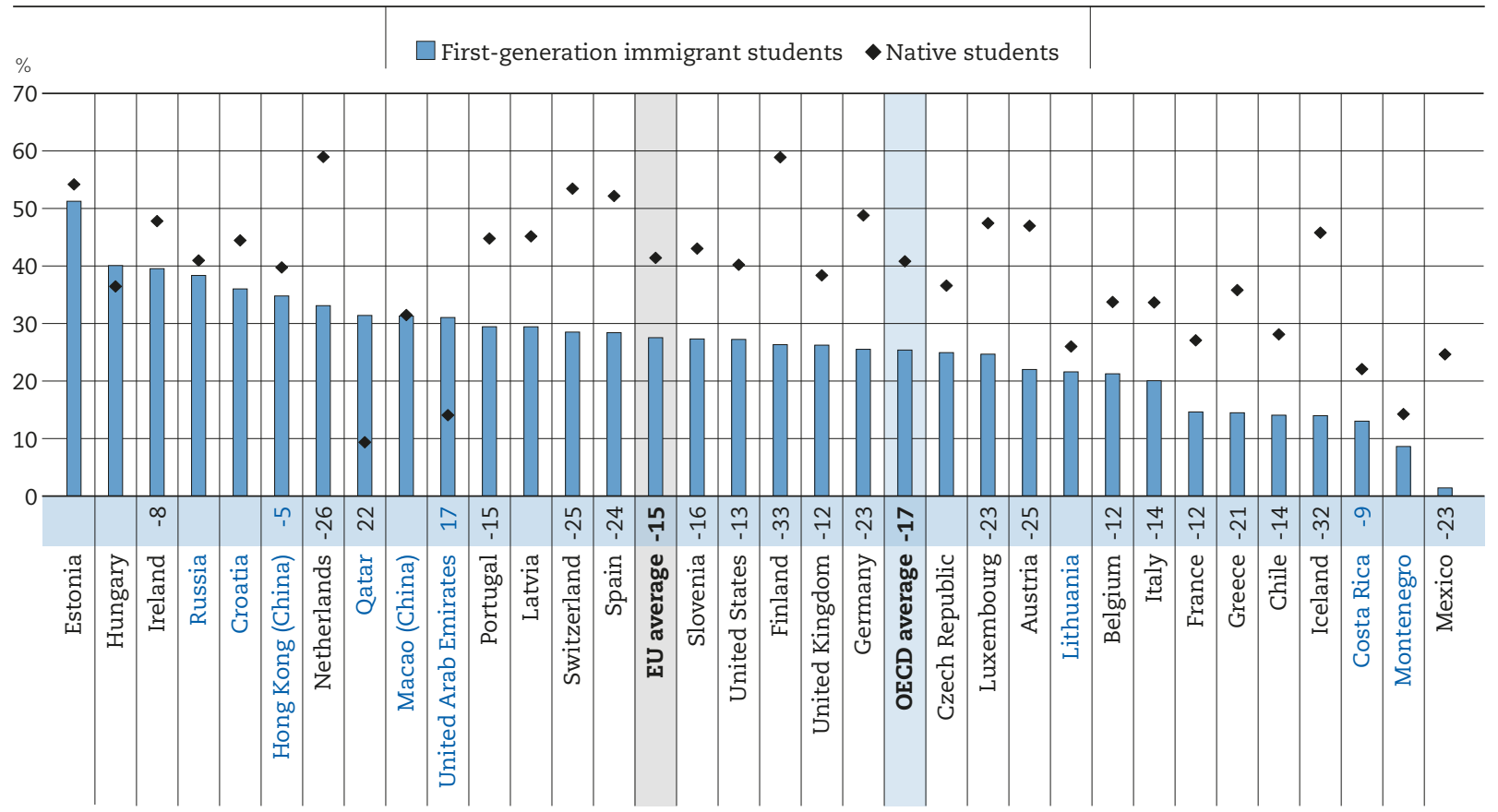

Notes: Only countries with valid values for first-generation immigrant students are shown.

Statistically significant differences between first-generation immigrant and native students are shown next to country/economy names. For the OECD and EU average, this number refers only to the subset of countries/economies with valid information on both groups of students.

Students who attain baseline academic proficiency are students who reach at least PISA proficiency level two in all three PISA core subjects - math, reading and science.

Students who report a sense of belonging at school are Students who reported that they "agree" or "strongly agree" with the statement "I feel like I belong at school" and "disagree" or "strongly disagree" with the statement "I feel like an outsider at school".

Students who report being satisfied with life are students who reported a life satisfaction of 7 or above on a scale from 0 to 10 .

Countries and economies are ranked in descending order of the percentage of first-generation immigrant students who attained baseline academic proficiency, reported a sense of belonging at school and being satisfied with life.

Source: OECD, PISA 2015 Database, Table 3.21.

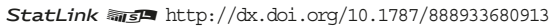

Table 3.21 (available on line) shows that, on average across OECD countries, first-generation immigrant students were six percentage points less likely to be resilient than second-generation immigrant students (five across EU countries). Figure 3.19 shows that in approximately one third of countries and economies with available data, native students of mixed heritage were less likely than native students to attain baseline academic proficiency, report a sense of belonging at school and being satisfied with life. The difference in likelihood was above ten percentage points in Estonia, Switzerland, Luxembourg, Germany, Poland, Switzerland and B-S-J-G (China). However, these students display greater adaptation than first-and second-generation immigrant students. On average across OECD countries, immigrant students with at least one native-born parent (a group that includes return foreign-born students and students of mixed heritage) were 10 percentage points more likely to be resilient than immigrant students with two foreign-born parents (a group that includes first- and second-generation immigrant students) (eight percentage points across EU countries). 
PISA 2015 shows that the likelihood of first-generation immigrant students being resilient overall is strongly related to the age at which they arrived in the host country. Table 3.22 (available on line) shows that, on average across OECD and EU countries, late arrivals were 10 percentage points less likely to be resilient than early arrivals. Late arrivals were 24 percentage points less likely than native students to attain baseline academic proficiency, report a sense of belonging at school and being satisfied with life. In Belgium, Spain and the United Kingdom, the percentage of resilient students among late arrivals was over 14 percentage points lower than the percentage among early arrivals.

Figure 3.19 - Differences in the percentage of academically sound and socially and emotionally well-adapted students, by immigrant group

Difference between students with an immigrant background and native students in the percentage of students who attain baseline academic proficiency, report a sense of belonging at school and being satisfied with life

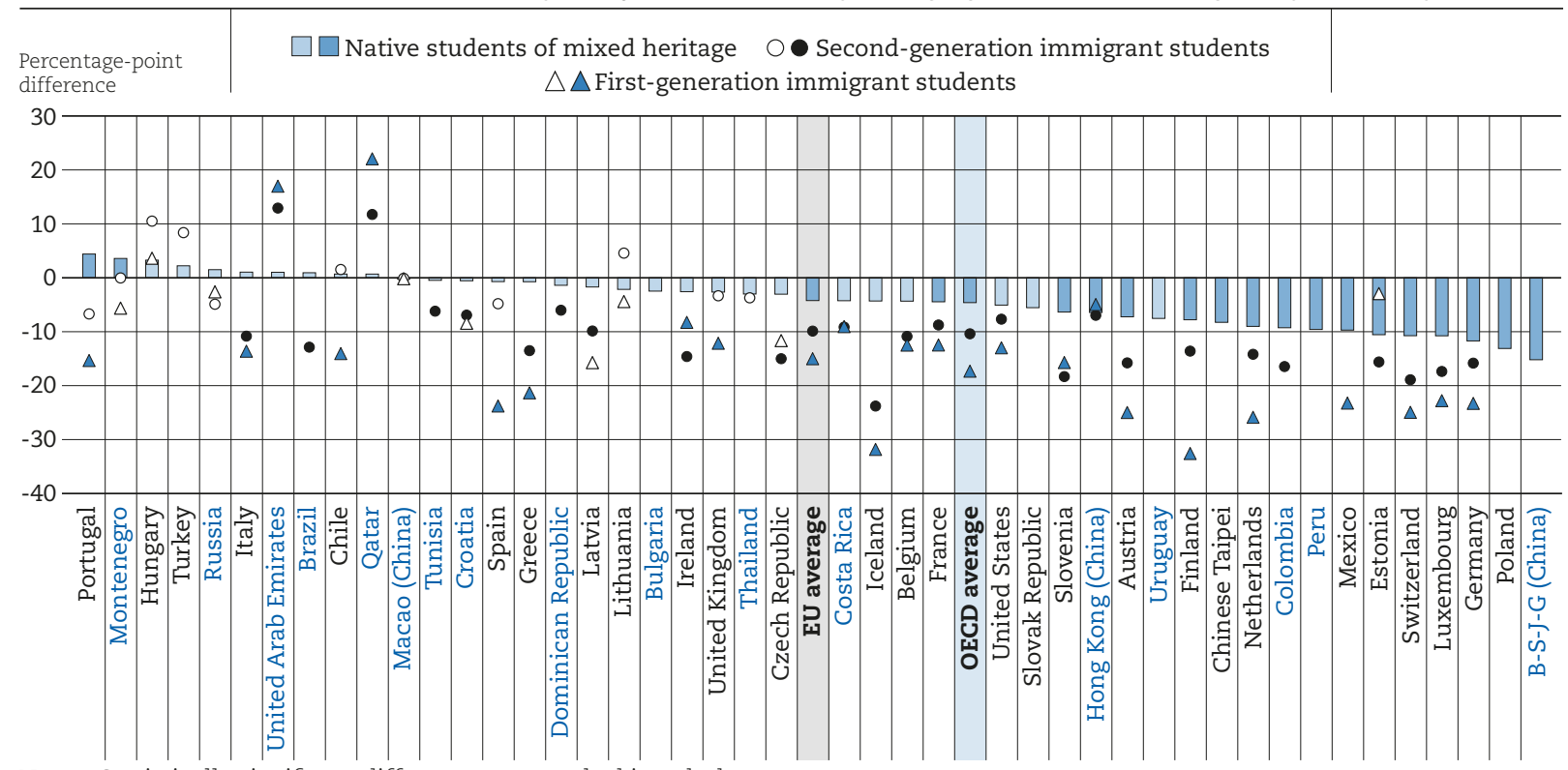

Notes: Statistically significant differences are marked in a darker tone.

Only countries with valid values for native students of mixed heritage are shown.

Students who attain baseline academic proficiency are students who reach at least PISA proficiency level two in all three PISA core subjects - math, reading and science.

Students who report a sense of belonging at school are Students who reported that they "agree" or "strongly agree" with the statement "I feel like I belong at school" and "disagree" or "strongly disagree" with the statement "I feel like an outsider at school".

Students who report being satisfied with life are students who reported a life satisfaction of 7 or above on a scale from 0 to 10 .

Students who report high motivation to achieve are students who "agree" or "strongly agree" with the statement "I want to be the best, whatever I do".

Countries and economies are ranked in descending order of the difference in the percentage of native students of mixed heritage and native students who attained baseline academic proficiency, reported a sense of belonging at school and being satisfied with life.

Source: OECD, PISA 2015 Database, Table 3.21.

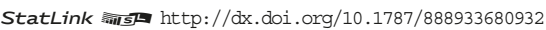




\section{Notes}

1. The questionnaire was modified in 2003 , so information on country of origin and age at arrival is only available in the 2003, 2006, 2009, 2012 and 2015 rounds of PISA.

2. The comparability of questions on students' sense of belonging may be affected by translation issues among students who completed background questionnaires in French.

\section{References}

ACIT (2012), Study on the Economic Impact of the Greek Crisis in Albania, Albanian Centre for Competitiveness and International trade, Tirana, www.usaid.gov/sites/default/files/documents/1863/USAID\%20Study\%20on\%20Greek\%20Crisis.pdf.

Arenliu A. and Weine S.M. (2016), “Reintegrating Returned Migrants to Kosovo”, Psychological Research, Vol. 19, pp. 61-73. www.researchgate.net/publication/286418490_Reintegrating_Returned_Migrants_to_Kosovo.

Statistical Office of Kosovo (2014), Kosovan Migration, Kosovo Agency of Statistics publications, http://ask.rks-gov.net/ media/1380/kosovan-migration-2014.pdf.

Associated Press (2016), Migrant Children Kept from Enrolling in School, Associated Press news, https://apnews.com/ b7f933ef6e054c2ca8e32bd9b477e9ab/ap-exclusive-migrant-children-kept-enrolling-school.

Autor, D.H., F. Levy and R.J. Murnane (2003), “The skill content of recent technological change: An empirical exploration”, The Quarterly Journal of Economics, Vol. 118/4, pp. 1279-1333, https://doi.org/10.1162/003355303322552801.

Baumeister, R.F. and M. R. Leary (1995), “The need to belong: Desire for interpersonal attachments as a fundamental human motivation”, Psychological Bulletin, Vol.117/3, pp. 497-529, http://dx.doi.org/10.1037/0033-2909.117.3.497.

Cardozo, S. (2009), "Experiencias laborales y deserción en la cohorte de estudiantes evaluados por pisa 2003 en Uruguay: nuevas evidencias”, REICE- Revista Iberoamericana sobre Calidad, Eficacia y Cambio en Educación, Vol. 7/4, pp. 198-218.

Cohen, J. et al. (2009), "School climate: Research, policy, practice, and teacher education”, Teachers College Record, Vol. 111/1, pp. 180-213.

Cortina, K.S. (2008), "Leistungsängstlichkeit [Performance anxiety]”, in Schneider, W. and M. Hasselhorn (eds.), Handbuch Der Pädagogischen Psychologie, Hogrefe, Göttingen, pp. 50-61.

Covington, M.V. (2000), "Goal theory, motivation, and school achievement: An integrative review", Annual Review of Psychology, Vol. 51/1, pp. 171-200, http://dx.doi.org/10.1146/annurev.psych.51.1.171.

Currie, C. et al. (eds.) (2012), Social Determinants of Health and Well-Being among Young People - Health Behaviour in School-Aged Children (HBSC) Study: International Report from the 2009/2010 Survey, World Health Organization Regional Office for Europe, Copenhagen.

Damon, W., J. Menon and K.C. Bronk (2003), “The development of purpose during adolescence”, Journal of Applied Developmental Science, Vol. 7/3, pp. 119-128, http://dx.doi.org/10.1207/S1532480XADS070322.

Deming, D.J. (2017), "The growing importance of social skills in the labour market”, The Quarterly Journal of Economics, Vol. 132/4, pp. 1593-1640, https://doi.org/10.1093/qje/qjx022.

Diener, E. et al. (1999), "Subjective well-being: Three decades of progress”, Psychological Bulletin, Vol. 125/2, pp. 276-302.

Duckworth, A.L. et al. (2011), "Self-regulation strategies improve self-discipline in adolescents: Benefits of mental contrasting and implementation intentions", Educational Psychology, Vol. 31/1, pp. 17-26, http://dx.doi.org/10.1080/014434 10.2010 .506003$.

Eccles, J.S. and A. Wigfield (2002), "Motivational beliefs, values, and goals", Annual Review of Psychology, Vol.53, pp. 109-132, http://dx.doi.org/10.1146/annurev.psych.53.100901.135153.

European Commission (2017a), Communication from the Commission to the European Parliament and the Council. Protection of Children in Migration, European Commission, Brussels, https:/lec.europa.eu/home-affairs/sites/homeaffairs/files/whatwe-do/policies/european-agenda-migration/20170412_communication_on_the_protection_of_children_in_migration_ en.pdf.

European Commission (2017b), Communication from the Commission to the European Parliament, the Council, the European Economic and Social Committee and the Committee of the Regions on the Delivery of the European Agenda on Migration, European Commission, Brussels, https://ec.europa.eu/home-affairs/sites/homeaffairs/files/what-we-do/policies/european-agenda -migration/20170927_communication_on_the_delivery_of_the_eam_en.pdf. 
European Commission (2017c), Annex to the Commission Recommendation Establishing a Common "Return Handbook" to be used by Member States' Competent Authorities when Carrying out Return Related Tasks, European Commission, Brussels, https://ec.europa.eu/home-affairs/sites/homeaffairs/files/what-we-do/policies/european-agenda-migration/20170927_ recommendation_on_establishing_a_common_return_handbook_annex_en.pdf.

European Commission (2015), Policies, Practices and Data on Unaccompanied Minors in the EU Member States and Norway, Synthesis Report for the EMN Focussed Study 2014, European Commission, Brussels, http://ec.europa.eu/anti-trafficking/ sites/antitrafficking/files/emn_study_2014_uams.pdf.

European Union Agency for Fundamental Rights (2017), Monthly Data Collection: August 2017, European Union Agency for Fundamental Rights monthly reports, http://fra.europa.eu/en/theme/asylum-migration-borders/overviews/august-2017. (accessed 15 January 2018)

European Union Agency for Fundamental Rights (2016a), Thematic Focus: Children, European Union Agency for Fundamental Rights website publication, http://fra.europa.eu/en/theme/asylum-migration-borders/overviews/focuschildren (accessed 15 January 2018).

European Union Agency for Fundamental Rights (2016b), Key Migration Issues: One Year on from InitialRreporting, European Union Agency for Fundamental Rights publications, http://fra.europa.eu/en/theme/asylum-migration-borders/overviews/ focus-one-year.

EUROSTAT (2017), 63300 Unaccompanied Minors Among Asylum Seekers Registered in the EU in 2016, EUROSTAT news release, http://ec.europa.eu/eurostat/documents/2995521/8016696/3-11052017-AP-EN.pdf/30ca2206-0db9-4076-a681-e069a4bc5290.

Fundacion porCausa (2017a), MENA desaparecidos, published in www.vozpopuli.com, www.vozpopuli.com/altavoz/ cronicas/mena-caos-burocratico-mafias-ponen-riesgo-menores-desaparecidos-europa_0_1037597552.html.

Fundacion porCausa (2017b), Menores refugiados explotados sexualmente en Grecia: "No tenía otra opción”, published in www. eldiario.es, www.eldiario.es/desalambre/Prostitucion-menores-migrantes-atrapados-Atenas_0_686631743.html.

Gale, C.R, I.J. Deary and M. Stafford (2013), "A life course approach to psychological and social wellbeing”, in Kuh, D. et al. (eds.), A Life Course Approach to Healthy Ageing, Oxford University Press, Oxford, pp. 46-62.

Garza, E., P. Reyes and E.T. Trueba (2004), Resiliency and Success. Migrant Children in the U.S., Routledge, Taylor and Francis, New York.

Gilman, R. et al. (2008), "Cross-national adolescent multidimensional life satisfaction reports: Analyses of mean scores and response style differences", Journal of Youth and Adolescence, Vol. 37/2, pp. 142-154, http://dx.doi.org/10.1007/s10964007-9172-8.

Goldbeck, L. et al. (2007), "Life satisfaction decreases during adolescence", Quality of Life Research: An International Journal of Quality of Life Aspects of Treatment, Care and Rehabilitation, Vol. 16/6, pp. 969-979, http://dx.doi.org/10.1007/s11136-0079205-5.

Goodenow, C. (1993), "Classroom belonging among early adolescent students relationships to motivation and achievement”, The Journal of Early Adolescence, Vol. 13/1, pp. 21-43, http://dx.doi.org/10.1177/0272431693013001002.

Government of Albania (2010), Strategy on Reintegration of Returned Albanian Citizens 2010-2015, Government of Albania, www.esiweb.org/pdf/schengen_whitelist_project_Strategy\%20on\%20Reintegration\%20of\%20Returned\%20Albanian\%20 Citizens\%202010-2015.pdf.

Griffin, P. and E. Care (2015), "ATC21S Method”, in Griffin, P. and E. Care (eds.), Assessment and Teaching of 21st Century Skills: Methods and Approach, Springer, Dordrecht, pp. 3-33.

House of Lords (2016), "Children in Crisis: Unaccompanied Migrant Children in the EU, European Union Committee 2nd Report of Session 2016-17”, Authority of the House of Lords, https://ec.europa.eu/info/sites/info/files/children_in_crisis_ unaccompanied migrant children_in the eu_houseoflords en.pdf.

Helliwell, J.F. and Putnam, R.D. (2004), "The social context of well-being", Philosophical Transactions of the Royal Society B: Biological Studies, Vol. 359, pp. 1435-1446.

Hesse, F. et al. (2015), "A framework for teachable collaborative problem solving skills", in Griffin, P. and E. Care (eds.), Assessment and Teaching of 21st Century Skills: Methods and Approach, Springer, Dordrecht, pp. 37-56.

HIT Foundation (2014), Monitoring Returned Minors, HIT Foundation, Nidos, the University of Groningen and Micado Migration, https://engi.eu/wp-content/plugins/download-attachments/includes/download.php?id=87.

Huddleston T. and A. Wolffhardt (2016), Back to School: Responding to the Needs of Newcomer Refugee Youth, Migration Policy Group, www.sirius-migrationeducation.org/wp-content/uploads/2017/03/MPG-Back-to-School-Responding-to-the-needs -of-newcomer-refugee-youth.pdf. 
Huebner, E.S. and G.L. Alderman (1993), "Convergent and discriminant validation of a children's life satisfaction scale: Its relationship to self- and teacher-reported psychological problems and school functioning", Social Indicators Research, Vol. 30/1, pp. 71-82, http://dx.doi.org/10.1007/BF01080333.

Huebner, E.S. and K.J. Hills (2013), "Assessment of subjective well-being in children and adolescents", in D.H. Saklofske, Reynolds, C.R. and V. Schwean (eds.), The Oxford Handbook of Child Psychological Assessment, Oxford University Press, New York, NY.

Human Rights Watch (2016a), Mexico: Asylum Elusive for Migrant Children, Human Rights Watch news, www.hrw.org/ news/2016/03/31/mexico-asylum-elusive-migrant-children.

Human Rights Watch (2016b), Libya: End "Horrific" Abuse of Detained Migrants, Human Rights Watch news, www.hrw.org/ news/2016/12/14/libya-end-horrific-abuse-detained-migrants.

Human Rights Watch (2016c), Closed Doors Mexico's Failure to Protect Central American Refugee and Migrant Children, Human Rights Watch, www.hrw.org/report/2016/03/31/closed-doors/mexicos-failure-protect-central-american-refugee-and-migrantchildren.

Igoa, C. (1995). The Inner World of the Immigrant Child, Lawrence Erlbaum, Mahwah, NJ.

INSTAT (2013), Return Migration and Reintegration in Albania. INSTAT \& IOM, www.albania.iom.int/publications/reports/ Return\%20Migration\%20and\%20Reintegration\%20in\%20Albania\%202013.pdf.

IOM (n.d.), "Migration and Albania”, webpage, www.albania.iom.int/index.php/en/albania (accessed 7 September 2017).

Juvonen, J. (2006), "Sense of belonging, social bonds, and school functioning", in Alexander, P.A. and P.H. Winne (eds.), Handbook of Educational Psychology, Lawrence Erlbaum Associates Publishers, Mahwah, NJ, pp. 655-674.

Katja, R. et al. (2002), "Relationships among adolescent subjective well-being, health behavior, and school satisfaction", Journal of School Health, Vol. 72/6, pp. 243-249, http://dx.doi.org/10.1111/j.1746-1561.2002.tb07337.x.

King, R. and Mai, N. (2013), Out Of Albania: From Crisis Migration to Social Inclusion in Italy, Berghahn Books, www.jstor.org/ stable/j.ctt9ad5b1.

Lepper, M.R., J.H. Corpus and S.S. Iyengar (2005), "Intrinsic and extrinsic motivational orientations in the classroom: Age differences and academic correlates”, Journal of Educational Psychology, Vol. 97/2, pp. 184-196, http://citeseerx.ist.psu.edu/ viewdoc/download?doi=10.1.1.508.3582\&rep=rep1\&type=pdf.

Lippman, L.H., K.A. Moore and H. McIntosh (2011), "Positive indicators of child well-being: A conceptual framework, measures, and methodological issues", Applied Research in Quality of Life, Vol. 6/4, pp. 425-449, http://dx.doi.org/10.1007/ s11482-011-9138-6.

Longitudinal Study of Australian Youth (LSAY) (2014), Y03 Cohort Report, www.lsay.edu.au/cohort/2003/3.html (accessed 20 October 2016).

Maslow, A.H. (1943), “A theory of human motivation”, Psychological Review, Vol. 50/4, pp. 370-396.

MEST (2016), Kosovo Education Strategy Plan 2017-2021, Ministry of Education, Science and Technology of Kosovo publications, www.kryeministri-ks.net/repository/docs/KOSOVO_EDUCATION_STRATEGIC_PLAN.pdf.

Missing Children Europe (2016), SUMMIT REPORT: Best Practices and Key Challenges on Interagency Cooperation to Safeguard Unaccompanied Children from Going Missing, Missing Children Europe, http://missingchildreneurope.eu/Portals/0/Docs/ Best $\% 20$ practices $\% 20$ and $\% 20$ key $\% 20$ challenges $\% 20$ for $\% 20$ interagency $\% 20$ cooperation $\% 20$ to $\% 20$ safeguard $\% 20$ unaccompanied\%20migrant\%20children\%20from\%20going\%20missing.pdf.

Möllers, J. et al. (2017), "Exit or Voice? The Recent Drivers of Kosovar Out-migration”, Int Migr, 55: 173-186, http:// onlinelibrary.wiley.com/doi/10.1111/imig.12336/full.

Observatory for Children's Rights (2017), Challenges of Returned Migrants Regarding the Integration in the Country Focus on Families (with Children), Observatory/ ADA, http://observator.org.al/wp-content/uploads/2017/06/Assessment_of returned_migrants_challenges_to_integration_in_the_country-Fier_region.pdf.

OECD (2016), PISA 2015 Results (Volume I): Excellence and Equity in Education, PISA, OECD Publishing, Paris, http://dx.doi. org/10.1787/9789264266490-en.

OECD (2015), How's Life? 2015: Measuring Well-being, OECD Publishing, Paris, http://dx.doi.org/10.1787/how_life-2015-en.

OECD (2013), PISA 2012 Results: Ready to Learn: Students' Engagement, Drive and Self-Beliefs (Volume III), PISA, OECD Publishing, Paris, http://dx.doi.org/10.1787/9789264201170-en. 
OECD (2010), Closing the Gap for Immigrant Students: Policies, Practice and Performance, OECD Publishing, Paris, http://dx.doi. org/10.1787/9789264075788-en.

Pew Research Centre (2014), Children 12 and Under are Fastest Growing Group of Unaccompanied Minors at U.S. Border, Pew Research Centre news, www.pewresearch.org/fact-tank/2014/07/22/children-12-and-under-are-fastest-growing-groupof-unaccompanied-minors-at-u-s-border/.

Pitt, P.K. and A.R. Robinson (2017), "Social class and prosocial behavior: Current evidence, caveats, and questions", Current Opinion in Psychology, Vol. 18, pp. 6-10, https://doi.org/10.1016/j.copsyc.2017.06.003.

Portes, A. and Rumbaut, R. G. (2001), Legacies: The Story of the Immigrant Second Generations, University of California Press, Berkeley.

Ramirez, G. and S.L. Beilock (2011), "Writing about testing worries boosts exam performance in the classroom", Science, Vol. 331/6014, pp. 211-213, http://dx.doi.org/10.1126/science.1199427.

Resnick, M.D. et al. (1997), "Protecting adolescents from harm: Findings from the national longitudinal study on adolescent health", JAMA, Vol. 278/10, pp. 823-832, https://pdfs.semanticscholar.org/6994/963fcb809762927eeb8c422f4 be82f9efaaa.pdf.

Ríos González, A. (2014), "Calendario y determinantes de riesgo educativo: la cohorte Pisa 2006-2011 en Uruguay", (Timing and determinants of the fall in educational risk: Pisa 2006-2011 cohort in Uruguay), Revista de Ciencias Sociales, n. 35, pp. 109-136.

Rosdahl, A. (2014), "Fra 15 til 27 år. PISA 2000-eleverne I 2011/12" (From 15 to 27 years. The PISA 2000- students in 2011/12), SFI-Rapport 14:13, SFI - Det Nationale Forskningscenter for Velfærd, Copenhagen.

Salend, S.J. (2012), “Teaching students not to sweat the test", Phi Delta Kappan, Vol. 93/6, pp. 20-25, http://dx.doi. org/10.1177/003172171209300605.

Sánchez, B., Y. Colón and P. Esparza (2005), "The role of sense of school belonging and gender in the academic adjustment of Latino adolescents", Journal of Youth and Adolescence, Vol. 34/6, pp. 619-628, Springer, New York, NY, http://dx.doi. org/10.1007/s10964-005-8950-4.

Scharenberg et al. (2014), Education Pathways from Compulsory School to Young Adulthood: The First Ten Years, TREE, Basel.

Schulenberg, J. et al. (1994), "High school educational success and subsequent substance use: A panel analysis following adolescents into young adulthood", Journal of Health and Social Behavior, Vol. 35/1, pp. 45-62, http://dx.doi. org/10.2307/2137334.

Statistical Office of Kosovo (2008), Demographic Changes of the Kosovo Population 1948-2006, Statistical Office of Kosovo, http://ask.rks-gov.net/media/1835/demographic-changes-of-the-kosovo-population-1948-2006.pdf.

Stephens, N.M. et al. (2012), “Unseen disadvantage: How American universities' focus on independence undermines the academic performance of first-generation college students", Journal of Personality and Social Psychology, Vol. 102/6, pp. 1178-1197, http://dx.doi.org/10.1037/a0027143.

Suarez-Orozco, C. and M. Suarez-Orozco (2001), Children of Immigration, Harvard University Press, Cambridge, MA.

Suldo, S.M., K.N. Riley and E.J. Shaffer (2006), "Academic correlates of children and adolescents life satisfaction”, School Psychology International, Vol. 27/5, pp. 567-582, http://dx.doi.org/10.1177/0143034306073411.

Terre des hommes (2010), Disappearing, Departing, Running Away - A Surfeit of Children in Europe, Stämpfli Publications SA, Berne, www.statewatch.org/news/2010/jan/eu-disappearing-departing-running-away-a_surfeit-of-children-in-europe.pdf.

The Atlantic (2016), Across the Border and Into School, www.theatlantic.com/education/archive/2016/08/across-the-borderand-into-school/496652/.

The Bureau of Investigative Journalism (2016), The Thousands of Former Child Refugees Deported to Afghanistan and Iraq, The Bureau of Investigative Journalism online publication, www.thebureauinvestigates.com/stories/2016-02-09/revealed-thethousands-of-former-child-refugees-deported-to-afghanistan-and-iraq (accessed 10 September 2017)

UNDP (2015), Kosovo Human Development Report 2014, Migration as a Force for Development, http://hdr.undp.org/sites/ default/files/khdr2014english.pdf.

UNHRC / Council of Europe (2014), Unaccompanied and Separated Asylum-Seeking and Refugee Children Turning Eighteen: What to Celebrate?, UNCHRC and Council of Europe, https://rm.coe.int/unhcr-coereporttransitionadulthood/native/1680724c42.

UNHR/UNICEF/IOM (2017), Refugee and Migrant Children in Europe Accompanied, Unaccompanied and Separated, UNHR, https:// data2.unhcr.org/en/documents/download/60348. 
UNICEF (2017a), A Deadly Journey for Children: The Central Mediterranean Migration Route, UNICEF, https://weshare.unicef.org/ CS.aspx?VP3=SearchResult \&VBID=\&PN=4\&IID=2AMZIFEZ2KY.

UNICEF (2017b), A child is a child: Protecting children on the move from violence, abuse and exploitation, UNICEF, www.unicef.org/ publications/files/UNICEF_A_child_is_a_child_May_2017_EN.pdf.

UNICEF (2017C), Education Uprooted: For Every migrant, Refugee and Displaced Child, Education, UNICEF, www.unicef.org/ publications/index_100817.html.

UNICEF (2012), Silent Harm, UNICEF Kosovo, www.unicef.org/kosovoprogramme/SILENT_HARM_Eng_Web.pdf.

US Department of Education (2014), Educational Services for Immigrant Children and Those Recently Arrived to the United States, Laws and Guidance Civil Rights, US Department of Education online material, www2.ed.gov/policy/rights/guid/ unaccompanied-children.html.

US Government Accountability Office (2015), Unaccompanied Alien Children: Actions Needed to Ensure Children Receive Required Care in DHS Custody, GAO-15-521: Published: Jul 14, 2015, www.gao.gov/products/GAO-15-521.

Valois, R. F. et al. (2001), "Relationship between life satisfaction and violent behaviors among adolescents", American Journal of Health Behavior, Vol. 25/4, pp. 353-366.

Varnum, M.E.W. (2015), "Higher in status, (even) better-than-average”, Frontiers in Psychology, Vol. 6, https://doi.org/10.3389/ fpsyg.2015.00496.

Vathi, Z. and Black, R. (2007), "Migration and poverty reduction in Kosovo", Development Research Centre on Migration, Globalisation and Poverty Working Paper, no. C12, https://pdfs.semanticscholar.org/3eb1/23d94df5f49864b316cf254c5cfc52f 9cea0.pdf.

Vathi, Z. and V. Duci (2016), "Making other dreams: The impact of migration on the psychosocial wellbeing of Albanianorigin children and young people upon their families' return to Albania”, Childhood, Vol. 23(1) 53-68, http://journals.sagepub. com/doi/pdf/10.1177/0907568214566078.

Wigfield, A. and J. Cambria (2010), "Students' achievement values, goal orientations, and interest: Definitions, development, and relations to achievement outcomes”, Developmental Review, Vol. 30/1, pp. 1-35, http://dx.doi.org/10.1016/j. dr.2009.12.001.

Zeidner, M. (1998), Test Anxiety - The State of the Art, Kluwer Academic/Plenum Publishers, New York, NY.

Zhou, M. (1997), "Growing up American: The challenge of immigrant children and children of immigrants", Annual Review of Sociology, Vol. 23, pp. 63-95.

Zullig, K.J. et al. (2001), "Relationship between perceived life satisfaction and adolescents' substance abuse”, The Journal of Adolescent Health: Official Publication of the Society for Adolescent Medicine, Vol. 29/4, pp. 279-288, http://dx.doi.org/10.1016/ s1054-139X(01)00269-5. 


\section{Annex 3.A1}

\section{Unaccompanied children}

Unaccompanied minors and unaccompanied children are defined by the UN Convention on the Rights of the Child (UNCRC) as those "who have been separated from both parents and other relatives and are not being cared for by an adult who, by law or custom, is responsible for doing so". The UNCRC also states that the best interests of the child must be a primary consideration in all actions affecting children. Providing access to education and offering further support can help these children integrate successfully into the education system in the host country. However, a significant proportion of unaccompanied minors in many OECD countries face serious difficulties not only in obtaining access to education but also in receiving basic services and therefore may be particularly vulnerable to suffering from poor academic outcomes and low levels of social, emotional and motivational well-being.

The number of unaccompanied minors grew in the past few five years: in 2015-16, UNICEF recorded at least 300000 unaccompanied minors in around 80 countries, almost five times more than the 66000 registered in 2010-11 (UNICEF, 2017b). One of the regions where the numbers have increased most dramatically is Europe (see Figure 3.A1.1). According to Eurostat, unaccompanied minors submitted 63290 applications for asylum in EU-28 countries in 2016. Around 90\% of these children were boys; nine in ten of them were 14 years old or older. As Figure 3.A1.2 shows, more than half of these minors came from Afghanistan and Syria, but there is also a significant representation from Iraq, Eritrea, Somalia, Gambia and Pakistan. Germany received almost 1 in 6 of all applications for asylum submitted by unaccompanied minors in 2016, surpassing Sweden as the country receiving most applications (see Figure 3.A1.3). As of December of 2017, data on unaccompanied minors applying for asylum in 2017 had not been released. Nevertheless, not all unaccompanied minors apply for asylum, so the number of these minors arriving in Europe is estimated to be higher. International organizations indicate that data on unaccompanied children and minors not applying for asylum is almost non-existent, which makes rather difficult to estimate the real number of unaccompanied minors arriving to a country (UNHR/UNICEF/IOM, 2017). In a study carried out by the European Commission in 2013, only 13 EU countries had data on unaccompanied minors who were not applying for asylum. These figures revealed that, in the same year, the number of unaccompanied minors applying for asylum, and the number of those not applying for asylum were practically the same: around 13000.

Another region where unaccompanied minors are growing in numbers is along the Mexican route to the United States and Canada. Data from the US Border Patrol (USBP) indicates that the number of unaccompanied minors apprehended at the southwest border of the United States has increased over the past decade (see Figure 3.A1.3).

Figure 3.A1.1 - Asylum applications submitted by unaccompanied minors in the EU 28, by year and age

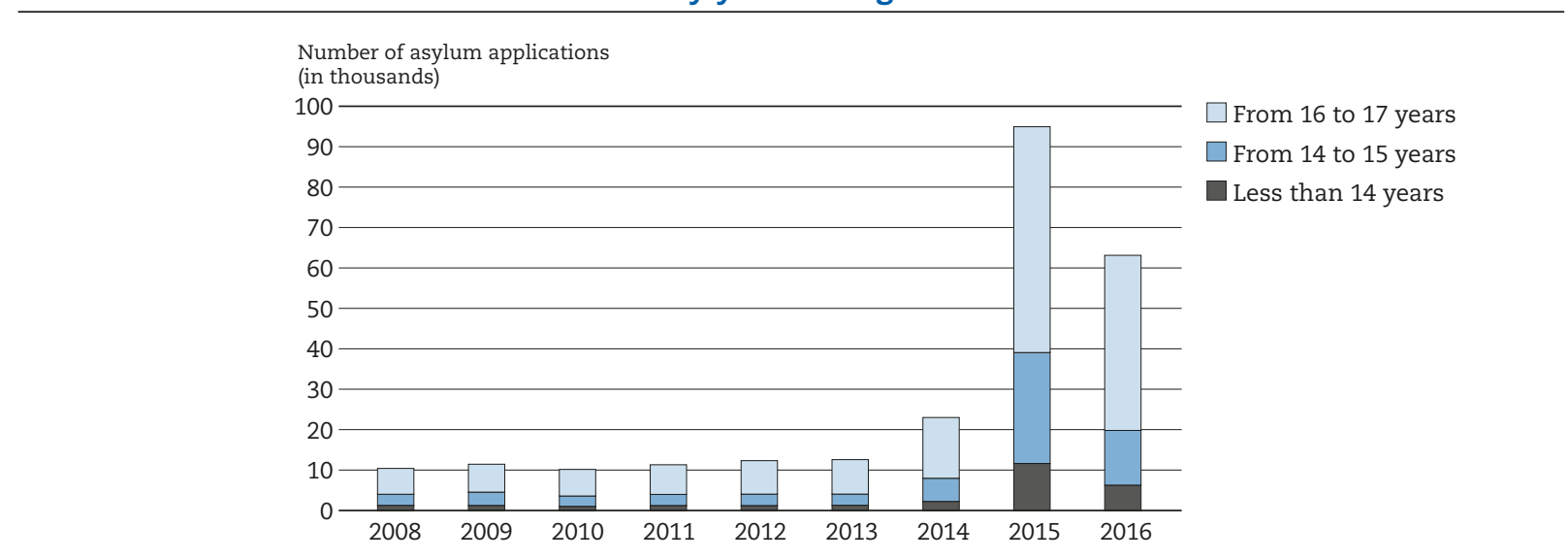

Source: Data adapted from: Eurostat, Asylum applicants considered to be unaccompanied minors by citizenship, age and sex. Annual data. http://appsso.eurostat.ec.europa.eu/nui/show.do?dataset=migr_asyunaa\&lang=en (accessed on 15 September, 2017).

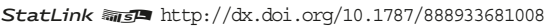


Figure 3.A1.2 - Asylum applications submitted by unaccompanied minors in the EU 28, by year and country of origin

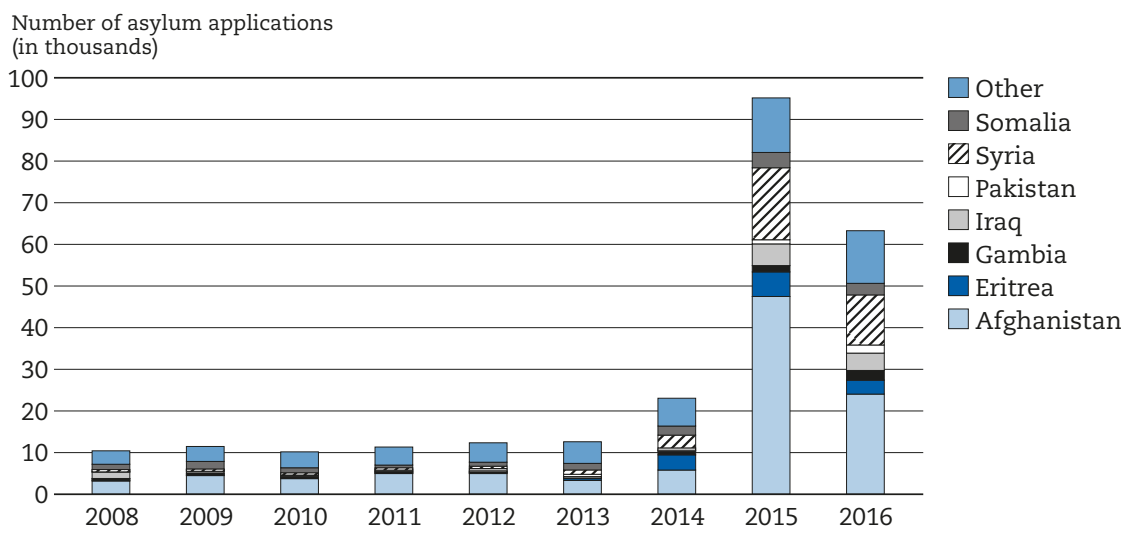

Source: Data adapted from: Eurostat, Asylum applicants considered to be unaccompanied minors by citizenship, age and sex. Annual data. http://appsso.eurostat.ec.europa.eu/nui/show.do?dataset=migr_asyunaa\&lang=en (accessed on 15 September, 2017).

StatLink 青IS http://dx.doi.org/10.1787/888933681027

Table 3A1.1 - Asylum applications submitted by unaccompanied minors in selected European countries, by year and country of application

\begin{tabular}{|c|c|c|c|c|c|}
\hline & 2012 & 2013 & 2014 & 2015 & 2016 \\
\hline Belgium & 975 & 420 & 475 & 2545 & 1020 \\
\hline Bulgaria & 60 & 185 & 940 & 1815 & 2750 \\
\hline Czech Republic & 5 & 0 & 5 & 15 & 0 \\
\hline Denmark & 355 & 350 & 820 & 2130 & 1185 \\
\hline Germany & 2095 & 2485 & 4400 & 22255 & 35935 \\
\hline Estonia & 0 & 5 & 0 & 0 & 0 \\
\hline Ireland & 25 & 20 & 30 & 35 & 35 \\
\hline Greece & 75 & 325 & 440 & 420 & 2350 \\
\hline Spain & 15 & 10 & 15 & 25 & 30 \\
\hline France & 490 & 365 & 270 & 320 & 475 \\
\hline Croatia & 70 & 55 & 10 & 5 & 170 \\
\hline Cyprus* & 25 & 55 & 50 & 105 & 215 \\
\hline Italy & 970 & 805 & 2505 & 4070 & 6020 \\
\hline Latvia & 0 & 5 & 0 & 10 & 5 \\
\hline Lithuania & 5 & 0 & 5 & 5 & 0 \\
\hline Luxembourg & 15 & 45 & 30 & 105 & 50 \\
\hline Hungary & 185 & 380 & 605 & 8805 & 1220 \\
\hline Malta & 105 & 335 & 55 & 35 & 15 \\
\hline Netherlands & 380 & 310 & 960 & 3860 & 1705 \\
\hline Austria & 1375 & 935 & 1975 & 8275 & 3900 \\
\hline Poland & 245 & 255 & 185 & 150 & 140 \\
\hline Portugal & 10 & 55 & 15 & 50 & 25 \\
\hline Romania & 135 & 15 & 95 & 55 & 45 \\
\hline Slovenia & 50 & 30 & 65 & 40 & 245 \\
\hline Slovak Republic & 5 & 5 & 10 & 5 & 0 \\
\hline Finland & 165 & 160 & 195 & 2535 & 370 \\
\hline Sweden & 3580 & 3850 & 7050 & 34300 & 2195 \\
\hline United Kingdom & 1125 & 1265 & 1945 & 3255 & 3175 \\
\hline Iceland & 5 & 0 & 0 & 5 & 20 \\
\hline Liechtenstein & 0 & 0 & 0 & 5 & 5 \\
\hline Norway & 705 & 670 & 940 & 4790 & 270 \\
\hline Switzerland & 495 & 355 & 780 & 2670 & 1985 \\
\hline TOTAL & 13720 & 13695 & 24820 & 102590 & 65340 \\
\hline
\end{tabular}

* See note at the beginning of this Chapter.

Source: Adapted from: Eurostat, Asylum applicants considered to be unaccompanied minors by citizenship, age and sex Annual data, http://appsso.eurostat.ec.europa.eu/nui/show.do?dataset=migr_asyunaa\&lang=en (accessed on 15 September, 2017).

StatLink ails http://dx.doi.org/10.1787/888933681065 
Figure 3.A1.3 - Unaccompanied minors apprehended at the United States border, by fiscal year and country of origin

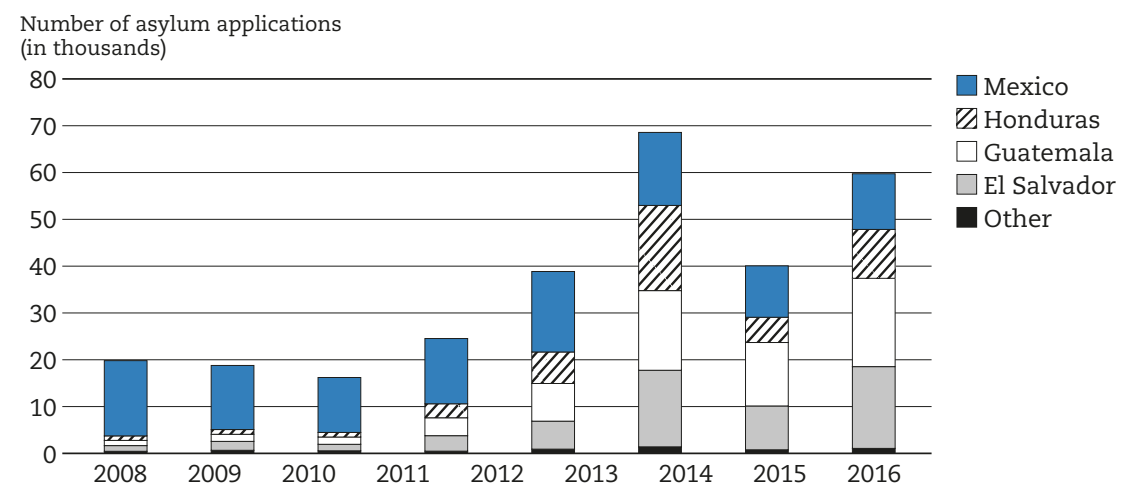

Note: Data presented by fiscal year, starting on October 1st.

Source: Adapted from: U.S. Customs and Border Protection, Southwest Border Migration Statistics, www.cbp.gov/newsroom/stats/swborder-migration (accessed on 15 September, 2017).

StatLink (ailst http://dx.doi.org/10.1787/888933681046

\section{Countries' obligations towards unaccompanied minors}

Countries are responsible for unaccompanied minors who arrive on their territory and, in accordance with the UNRC's mandate, the "best interests" of children must govern every aspect of their treatment (UNHCR, 1989). This involves quickly identifying children at risk, ensuring family unity, preventing arbitrary detention, and providing legal representation, appropriate reception conditions and basic social protection as soon as possible, particularly through access to healthcare and education. But there are significant differences in the way OECD countries handle this responsibility.

In the EU context, there is a great heterogeneity in procedures, practices and resources. In principle, after authorities immediately identify unaccompanied minors, child protection authorities should ensure that these children are accommodated in special facilities that provide an adequate standard of living and access to education and healthcare. In addition, a guardian should be assigned as soon as possible to ensure that these children's rights are adequately safeguarded (European Union Agency for Fundamental Rights, 2016a).

\section{Access to education}

The main challenge for host-country education systems is to enrol unaccompanied minors in school as soon as possible. Many of these children have spent a long time without attending school and further delays in enrolment are an unnecessary extension of their exclusion from education. Although EU member states must ensure access to education to asylum-seeking children within the first three months of their arrival, delays are common. These delays usually occur for two reasons. First, because of the long period of time that many unaccompanied minors have to stay in reception centres where education is, at best, only provided informally by NGOs and volunteers (European Union Agency for Fundamental Rights, 2016a). Second, because once having abandoned the reception centres and moved to a care facility, the number of places available and the procedures in place may delay enrolment in school for several months.

In addition, in some countries there are certain age-related restrictions that might make it particularly difficult - or even impossible - for unaccompanied minors to eventually enrol in school. The European Council on Refugees and Exiles (ECRE) warns that in some countries unaccompanied minors remain outside the education system. ECRE also reports that in many EU member states many children have to wait for up to several months before accessing compulsory education or second-language courses. Unaccompanied minors who are older than the limit set for enrolment in compulsory schooling when they arrive in their destination country may find it particularly difficult to access education or language courses. The failure to ensure prompt school enrolment to these minors may have serious consequences on the development of these children. 
Prompt enrolment in school is essential, but unaccompanied minors also require further support to ensure their successful integration into schools. The majority of unaccompanied minors arriving in a country have not attended school for a long time. They tend to be unfamiliar with the education system and many of them have - at best - only limited knowledge of the language of instruction. On top of that, the majority of unaccompanied minors have experienced traumatic events during their journey. Overall, these children face greater obstacles to success in school. For instance, in Spain, NGOs report that 80\% of unaccompanied minors drop out of school (Huddleston and Wolffhardt, 2016). For all of these reasons, further assistance in the form of language courses, additional support in class, educational counselling and psychological help are essential for the educational and broader well-being of unaccompanied minors.

Additional sources of stress and anxiety among unaccompanied minors are protracted asylum proceedings and the provision of temporary leave to remain rather than permanent solutions. Uncertainty about future rights to remain in the country might discourage unaccompanied minors from pursuing education goals or social activities, de facto limiting these children's ability to plan for their future and preventing them from being able to develop to their full potential.

\section{References}

European Union Agency for Fundamental Rights (2016), Thematic focus: Children, European Union Agency for Fundamental Rights website publication, http://fra.europa.eu/en/theme/asylum-migration-borders/overviews/focus-children.

Huddleston T. and Wolffhardt A. (2016), Back to School: Responding to the needs of newcomer refugee youth, Migration Policy Group, Brussels, www.sirius-migrationeducation.org/wp-content/uploads/2017/03/MPG-Back-to-School-Responding-tothe-needs-of-newcomer-refugee-youth.pdf.

UNHR (1989), Convention on the Rights of the Child, United Nations, New York, www.ohchr.org/EN/Professionalinterest/ Pages/CRC.aspx, (accessed 15 January 2018).

UNHR, UNICEF and IOM (2017), Refugee and Migrant Children in Europe Accompanied, Unaccompanied and Separated, UNHCR, Paris, https://data2.unhcr.org/en/documents/download/60348.

UNICEF (2017b), A child is a child: Protecting children on the move from violence, abuse and exploitation, UNICEF, New York, www.unicef.org/publications/files/UNICEF_A_child_is_a_child_May_2017_EN.pdf. 


\section{Spotlight on social outcomes among native and immigrant young adults in Europe: Evidence from the European Social Survey}

The focus of this report is on the academic and other well-being outcomes of 15-year old students in a wide range of countries and economies that participated in PISA 2015. The PISA data analysed in this report provide extensive information on students' proficiency in mathematics, reading and science; their sense of belonging to the school community; their satisfaction with life; and their level of schoolwork-related anxiety and achievement motivation. However, the long-term integration prospects of immigrant students depend not only on their academic proficiency and their social and emotional well-being, but also on their physical well-being as well as their attitudes and dispositions.

Since PISA does not contain information on the broader circumstances of young people with an immigrant background, such as their attitudes, dispositions and social outcomes, data from the European Social Survey (ESS) are used in this Spotlight to explore such differences. Two important differences distinguish the types of analyses that were conducted using PISA data and those illustrated in this Spotlight. First, PISA examines 15-year-old students while analyses presented in this Spotlight refer to individuals who were between the age of 15 and 20 at the time in which the ESS interview took place, irrespective of whether they were students or not. The focus on a broader age range was due to the fact that ESS has a small age-specific sample. Second, while in PISA the socio-economic condition of respondents is characterised using a composite indicator of socio-economic status, the PISA index of Economic, Social and Cultural Status (ESCS), in ESS parental educational attainment is used as the key control.

Although the ESS survey contains information on a wide range of outcomes that characterise the well-being of individuals and their long-term integration prospects, analyses presented in this Spotlight refer to a set of indicators that were considered in all of the first eight rounds of ESS available up to date. Pooling data from the eight ESS rounds is necessary because of sample-size limitations. Only countries with a representative sample of at least 30 individuals categorised as young immigrants are included in the analysis. Immigrant individuals are defined as those who are either foreign-born or are native-born but have two foreign-born parents. The 19 countries considered are: Austria, Belgium, Denmark, Estonia, Finland, France, Germany, Greece, Ireland, Israel, Luxembourg, the Netherlands, Norway, Portugal, Slovenia, Spain, Sweden, Switzerland and the United Kingdom.

The most recent ESS study is round eight, which contains information collected in 2016. However, at the time this analysis was conducted (December 2017), data from round eight was not yet available for Portugal and Spain. In both cases, the analysis is based on data from rounds one through seven. This Spotlight reports findings from around 19000 15-20 year-olds in Europe, some 12\% of whom were immigrants.

The outcomes analysed in this Spotlight are: trust (generalised trust; institutional trust; feelings of safety in the local area); satisfaction (with democracy, the state of the economy, the national government and education and health services); and other well-being variables (self-reported health; social life).

\section{Trust}

\section{Generalised trust}

Generalised trust is a feeling of goodwill towards anonymous others. It allows for smooth interactions in complex societies, where people engage frequently with others whom they do not know and from whom they differ in many ways. Generalised trust involves an "indiscriminate belief in the general benevolence of one's fellow citizen" (Sturgis et al., 2010) and the "expectation that other members of the community will behave in a cooperative and honest way" (Fukuyama, 1995). Monitoring disparities in generalised trust between young native and immigrant people and how these differ across countries can help to identify if immigrants feel welcome and safe in their communities and if they believe in the goodwill and openness of natives towards them.

The ESS includes three questions on generalised trust with a 0 to 10 response format. The questions are: “(...) generally speaking, would you say that most people can be trusted, or that you can't be too careful in dealing with people?" (Responses from 0 "You can't be too careful" to 10 "Most people can be trusted"); 
"(...) do you think that most people would try to take advantage of you if they got the chance, or would they try to be fair?" (Responses from 0 "Most people try to take advantage of me" to 10 "Most people try to be fair"); and "Would you say that most of the time people try to be helpful or that they are mostly looking out for themselves?" (Responses from 0 "People mostly look out for themselves" to 10 "People mostly try to be helpful").

Table 3.a indicates that young immigrant people report lower levels of generalised trust than natives and that such difference reflect, to a large extent, differences in the two groups in parental educational attainment. On average across all countries analysed, the mean value on the 0 to 10 point scale of young natives' responses to the question on whether most people can be trusted is 5.39. The corresponding figure among young immigrants is 4.98 , a difference of 0.41 . Differences between young natives and immigrants are particularly pronounced (larger than 0.70) in Austria, Denmark, the Netherlands, Sweden and Switzerland. Differences between young natives and immigrants in the extent to which they report that most people can be trusted are reduced by around a quarter on average across all the countries examined (from a difference of 0.41 points to a difference of 0.33 points) when natives and immigrants with similarly educated parents are compared.

\section{Table 3.a - Generalised trust, by immigrant background}

\begin{tabular}{|c|c|c|c|c|c|c|c|c|c|}
\hline & \multicolumn{3}{|c|}{$\begin{array}{l}\text { Most people can be trusted (10) } \\
\text { or you can't be too careful (0) }\end{array}$} & \multicolumn{3}{|c|}{$\begin{array}{l}\text { Most people try to take advantage } \\
\text { of you (0), or try to be fair (10) }\end{array}$} & \multicolumn{3}{|c|}{$\begin{array}{c}\text { Most of the time people are helpful (10) } \\
\text { or mostly looking out } \\
\text { for themselves (0) }\end{array}$} \\
\hline & \multirow[b]{2}{*}{$\begin{array}{l}\text { Mean } \\
\text { among } \\
\text { young } \\
\text { natives }\end{array}$} & \multicolumn{2}{|c|}{$\begin{array}{l}\text { Mean differences } \\
\text { between immigrant } \\
\text { and native } \\
\text { young people }\end{array}$} & \multirow[b]{2}{*}{$\begin{array}{l}\text { Mean } \\
\text { among } \\
\text { young } \\
\text { natives }\end{array}$} & \multicolumn{2}{|c|}{$\begin{array}{l}\text { Mean differences } \\
\text { between immigrant } \\
\text { and native } \\
\text { young people }\end{array}$} & \multirow[b]{2}{*}{$\begin{array}{l}\text { Mean } \\
\text { among } \\
\text { young } \\
\text { natives }\end{array}$} & \multicolumn{2}{|c|}{$\begin{array}{l}\text { Mean differences } \\
\text { between immigrant } \\
\text { and native } \\
\text { young people }\end{array}$} \\
\hline & & $\begin{array}{c}\text { Before } \\
\text { accounting } \\
\text { for parental } \\
\text { education }\end{array}$ & $\begin{array}{c}\text { After } \\
\text { accounting } \\
\text { for parental } \\
\text { education }\end{array}$ & & $\begin{array}{c}\text { Before } \\
\text { accounting } \\
\text { for parental } \\
\text { education }\end{array}$ & $\begin{array}{c}\text { After } \\
\text { accounting } \\
\text { for parental } \\
\text { education }\end{array}$ & & $\begin{array}{c}\text { Before } \\
\text { accounting } \\
\text { for parental } \\
\text { education }\end{array}$ & $\begin{array}{l}\text { After accounting } \\
\text { for parental } \\
\text { education }\end{array}$ \\
\hline Austria & 5.59 & -0.71 & -0.71 & 6.10 & -0.93 & -0.95 & 5.51 & -0.58 & -0.65 \\
\hline Belgium & 5.28 & -0.61 & -0.46 & 5.88 & -0.11 & -0.10 & 4.97 & -0.62 & -0.64 \\
\hline Denmark & 6.45 & -0.97 & -0.70 & 6.91 & -0.24 & -0.07 & 5.79 & -0.05 & -0.07 \\
\hline Estonia & 5.44 & -0.44 & -0.51 & 5.82 & -0.71 & -0.79 & 5.18 & -1.21 & -1.14 \\
\hline Finland & 6.52 & -0.65 & -0.34 & 6.78 & 0.19 & 0.19 & 5.65 & 0.39 & 0.45 \\
\hline France & 4.70 & -0.52 & -0.28 & 6.02 & -0.46 & -0.31 & 4.71 & -0.16 & -0.05 \\
\hline Germany & 5.04 & -0.44 & -0.25 & 6.07 & -0.33 & -0.26 & 5.12 & 0.19 & 0.23 \\
\hline Greece & 4.47 & 0.34 & 0.36 & 4.36 & 0.26 & 0.27 & 3.72 & -0.21 & -0.20 \\
\hline Ireland & 5.57 & -0.33 & -0.34 & 5.96 & -0.27 & -0.23 & 5.69 & -0.24 & -0.27 \\
\hline Israel & 5.15 & -0.05 & 0.00 & 5.32 & 0.60 & 0.80 & 5.27 & -0.44 & -0.54 \\
\hline Luxembourg & 5.04 & -0.20 & 0.06 & 5.89 & -0.08 & 0.06 & 5.23 & 0.44 & 0.67 \\
\hline Netherlands & 5.97 & -0.83 & -0.85 & 6.47 & -0.19 & -0.15 & 5.50 & 0.10 & 0.27 \\
\hline Norway & 6.21 & -0.56 & -0.49 & 6.70 & -0.65 & -0.48 & 5.94 & -0.02 & -0.15 \\
\hline Portugal & 4.34 & 0.09 & -0.14 & 5.49 & -0.04 & 0.05 & 4.66 & -0.29 & -0.44 \\
\hline Slovenia & 4.77 & -0.81 & -0.76 & 5.34 & -0.54 & -0.49 & 5.01 & -0.25 & -0.26 \\
\hline Spain & 5.20 & 0.26 & 0.21 & 5.57 & 0.18 & 0.30 & 4.39 & 0.96 & 0.99 \\
\hline Sweden & 5.90 & -0.81 & -0.64 & 6.59 & -0.79 & -0.69 & 5.77 & -0.31 & -0.29 \\
\hline Switzerland & 5.62 & -0.77 & -0.67 & 6.40 & -0.58 & -0.43 & 5.73 & -0.18 & -0.22 \\
\hline United Kingdom & 5.21 & 0.18 & 0.20 & 5.58 & -0.24 & -0.15 & 5.36 & 0.26 & 0.31 \\
\hline Average & 5.39 & -0.41 & -0.33 & 5.96 & -0.26 & -0.18 & 5.22 & -0.12 & -0.11 \\
\hline
\end{tabular}

Notes: Individuals defined as immigrants are those who are either foreign-born or are native-born but have two foreign-born parents.

Statistically significant differences between immigrant and native young people are highlighted in bold and blue. A ligher tone is applied to negative differences (i.e. when immigrants' mean value is smaller than natives' mean value) and a darker tone is applied to positive differences (i.e. when immigrants' mean value is greater than natives' mean value).

Only countries that participated in at least two rounds and with a sample of at least 30 immigrant individuals are included in the analysis. Countries are ranked in alphabetical order.

Source: European Social Survey rounds 1-8 (pooled data).

StatLink न्मा51 http://dx.doi.org/10.1787/888933681084

Similarly, on average across all countries analysed, the mean value on the 0 to 10 point scale of young natives' responses to the question on whether most people will try to be fair can be trusted is 5.96 while among young immigrant individuals the average index value is 5.70 (a 0.26 point difference). The differences between the two groups is particularly pronounced (larger than 0.70) in Austria, Estonia and Sweden. 
Differences young natives and immigrants in the extent to which they report that most people try to be fair were also greatly reduced when differences between the two groups in parental educational background was controlled for. Israel is a significant outlier because it is the only country where young immigrants reported higher mean index values when comparing individuals with similarly educated parents.

Differences between young natives and immigrants on the extent to which people try to be helpful are mostly not statistically significant. Only in Austria, Belgium and Estonia young natives report higher mean index values, a difference that cannot be explained by differences among the two groups in parental educational attainment. In Spain young immigrants report higher mean index levels than young natives both before and after accounting for parental education.

\section{Institutional trust}

Another dimension that characterises the way in which young people feel towards society is the extent to which they report feeling that institutions are responsive to their needs (Hetherington 1998; North, 1990). The ESS survey contains questions on people's trust in the following seven institutions: the [country]'s parliament; the legal system; the police; politicians; political parties; the European Parliament; the United Nations". Respondents could use a score ranging from 0 (no trust) to 10 (complete trust). Higher values therefore represent greater levels of trust.

Table 3.b and Table 3.c show very few differences between young immigrant and native people in their reported levels of trust towards institutions. When such differences exist, they are indicative of a greater level of institutional trust among young immigrant individuals. For example, in countries such as Germany, Greece, Ireland, Norway, Switzerland and the United Kingdom young immigrant individuals report higher levels of trust towards the European parliament than young native individuals, after accounting for differences in parental educational attainment. Similarly, in Spain and Germany young immigrants report greater trust in the legal system than young native people.

Table 3.b - Institutional trust among young individuals, by immigrant background - 1

\begin{tabular}{|c|c|c|c|c|c|c|c|c|c|}
\hline & \multicolumn{3}{|c|}{ Trust in country's parliament $(0-10)$} & \multicolumn{3}{|c|}{ Trust in the legal system $(0-10)$} & \multicolumn{3}{|c|}{ Trust in the police $(0-10)$} \\
\hline & \multirow[b]{2}{*}{$\begin{array}{l}\text { Mean } \\
\text { among } \\
\text { young } \\
\text { natives }\end{array}$} & \multicolumn{2}{|c|}{$\begin{array}{l}\text { Mean differences } \\
\text { between immigrant } \\
\text { and native } \\
\text { young people }\end{array}$} & \multirow[b]{2}{*}{$\begin{array}{l}\text { Mean } \\
\text { among } \\
\text { young } \\
\text { natives }\end{array}$} & \multicolumn{2}{|c|}{$\begin{array}{l}\text { Mean differences } \\
\text { between immigrant } \\
\text { and native } \\
\text { young people }\end{array}$} & \multirow[b]{2}{*}{$\begin{array}{l}\text { Mean } \\
\text { among } \\
\text { young } \\
\text { natives }\end{array}$} & \multicolumn{2}{|c|}{$\begin{array}{l}\text { Mean differences } \\
\text { between immigrant } \\
\text { and native } \\
\text { young people }\end{array}$} \\
\hline & & $\begin{array}{l}\text { Before } \\
\text { accounting } \\
\text { for parental } \\
\text { education }\end{array}$ & $\begin{array}{c}\text { After } \\
\text { accounting } \\
\text { for parental } \\
\text { education }\end{array}$ & & $\begin{array}{l}\text { Before } \\
\text { accounting } \\
\text { for parental } \\
\text { education }\end{array}$ & $\begin{array}{l}\text { After } \\
\text { accounting } \\
\text { for parental } \\
\text { education }\end{array}$ & & $\begin{array}{l}\text { Before } \\
\text { accounting } \\
\text { for parental } \\
\text { education }\end{array}$ & $\begin{array}{l}\text { After } \\
\text { accounting } \\
\text { for parental } \\
\text { education }\end{array}$ \\
\hline Austria & 5.11 & 0.15 & 0.19 & 5.89 & -0.16 & -0.11 & 5.94 & 0.48 & 0.45 \\
\hline Belgium & 5.41 & 0.33 & 0.57 & 5.93 & 0.41 & 0.60 & 6.39 & -0.05 & 0.21 \\
\hline Denmark & 6.49 & -0.88 & -0.58 & 7.38 & -0.57 & -0.27 & 7.69 & -0.15 & -0.02 \\
\hline Estonia & 5.00 & -0.35 & -0.39 & 5.82 & -0.10 & -0.19 & 6.32 & -0.52 & -0.68 \\
\hline Finland & 6.40 & -0.62 & -0.13 & 7.12 & -0.79 & -0.29 & 7.94 & -0.35 & 0.24 \\
\hline France & 4.55 & -0.33 & 0.03 & 5.48 & -0.19 & 0.04 & 5.83 & -0.64 & -0.39 \\
\hline Germany & 5.17 & 0.43 & 0.61 & 6.20 & 0.45 & 0.59 & 6.80 & 0.08 & 0.08 \\
\hline Greece & 3.82 & 0.25 & 0.27 & 5.15 & 0.64 & 0.65 & 4.99 & 0.94 & 0.93 \\
\hline Ireland & 4.51 & 0.05 & 0.10 & 5.89 & 0.16 & 0.24 & 6.29 & 0.04 & 0.05 \\
\hline Israel & 4.63 & -0.28 & -0.22 & 5.95 & -0.45 & -0.41 & 5.52 & 0.01 & 0.03 \\
\hline Luxembourg & 5.64 & 0.39 & 0.59 & 6.26 & 0.21 & 0.27 & 6.33 & 0.71 & 1.05 \\
\hline Netherlands & 5.60 & 0.16 & 0.29 & 6.27 & 0.18 & 0.39 & 6.29 & -0.25 & 0.10 \\
\hline Norway & 6.26 & -0.08 & 0.35 & 6.87 & -0.18 & 0.14 & 7.31 & 0.12 & 0.35 \\
\hline Portugal & 3.94 & -0.44 & -0.17 & 4.45 & -0.45 & -0.20 & 5.43 & -0.44 & -0.29 \\
\hline Slovenia & 4.18 & -0.35 & -0.13 & 4.85 & -0.28 & -0.09 & 5.75 & 0.44 & 0.48 \\
\hline Spain & 4.76 & 0.38 & 0.42 & 4.68 & 1.23 & 1.27 & 5.61 & 1.04 & 1.10 \\
\hline Sweden & 6.15 & -0.30 & -0.35 & 6.46 & -0.38 & -0.41 & 6.82 & -0.31 & -0.26 \\
\hline Switzerland & 6.35 & -0.02 & 0.07 & 6.79 & -0.07 & -0.02 & 6.83 & 0.15 & 0.17 \\
\hline United Kingdom & 4.83 & 0.53 & 0.36 & 5.63 & 0.37 & 0.29 & 6.38 & 0.22 & 0.12 \\
\hline Average & 5.20 & -0.05 & 0.10 & 5.95 & 0.00 & 0.13 & 6.34 & 0.08 & 0.20 \\
\hline
\end{tabular}

Notes: Individuals defined as immigrants are those who are either foreign-born or are native-born but have two foreign-born parents.

Statistically significant differences between immigrant and native young people are highlighted in bold and blue. A ligher tone is applied to negative differences (i.e. when immigrants' mean value is smaller than natives' mean value) and a darker tone is applied to positive differences (i.e. when immigrants' mean value is greater than natives' mean value).

Only countries that participated in at least two rounds and with a sample of at least 30 immigrant individuals are included in the analysis. Countries are ranked in alphabetical order.

Source: European Social Survey rounds 1-8 (pooled data).

StatLink 凋s http://dx.doi.org/10.1787/888933681103 
Table 3.c - Institutional trust among young individuals, by immigrant background - 2

\begin{tabular}{|c|c|c|c|c|c|c|c|c|c|c|c|c|}
\hline & \multicolumn{3}{|c|}{$\begin{array}{l}\text { Trust in politicians } \\
(0-10)\end{array}$} & \multicolumn{3}{|c|}{$\begin{array}{l}\text { Trust in political parties } \\
(0-10)\end{array}$} & \multicolumn{3}{|c|}{$\begin{array}{l}\text { Trust in the European } \\
\text { Parliament }(0-10)\end{array}$} & \multicolumn{3}{|c|}{$\begin{array}{c}\text { Trust in the United Nations } \\
(0-10)\end{array}$} \\
\hline & \multirow[b]{2}{*}{\begin{tabular}{|c|} 
Mean \\
among \\
young \\
natives \\
\end{tabular}} & \multicolumn{2}{|c|}{$\begin{array}{c}\text { Mean differences } \\
\text { between immigrant } \\
\text { and native } \\
\text { young people } \\
\end{array}$} & \multirow[b]{2}{*}{\begin{tabular}{|c|} 
Mean \\
among \\
young \\
natives
\end{tabular}} & \multicolumn{2}{|c|}{$\begin{array}{c}\text { Mean differences } \\
\text { between immigrant } \\
\text { and native } \\
\text { young people } \\
\end{array}$} & \multirow[b]{2}{*}{$\begin{array}{l}\text { Mean } \\
\text { among } \\
\text { young } \\
\text { natives }\end{array}$} & \multicolumn{2}{|c|}{$\begin{array}{l}\text { Mean differences } \\
\text { between immigrant } \\
\text { and native } \\
\text { young people }\end{array}$} & \multirow[b]{2}{*}{$\begin{array}{l}\text { Mean } \\
\text { among } \\
\text { young } \\
\text { natives }\end{array}$} & \multicolumn{2}{|c|}{$\begin{array}{l}\text { Mean differences } \\
\text { between immigrant } \\
\text { and native } \\
\text { young people } \\
\end{array}$} \\
\hline & & \begin{tabular}{|c|} 
Before \\
accounting \\
for parental \\
education
\end{tabular} & $\begin{array}{c}\text { After } \\
\text { accounting } \\
\text { for parental } \\
\text { education }\end{array}$ & & \begin{tabular}{|c|} 
Before \\
accounting \\
for parental \\
education
\end{tabular} & \begin{tabular}{|c|} 
After \\
accounting \\
for parental \\
education
\end{tabular} & & \begin{tabular}{|c|} 
Before \\
accounting \\
for parental \\
education
\end{tabular} & \begin{tabular}{|c|} 
After \\
accounting \\
for parental \\
education
\end{tabular} & & \begin{tabular}{|c|} 
Before \\
accounting \\
for parental \\
education
\end{tabular} & \begin{tabular}{|c|} 
After \\
accounting \\
for parental \\
education
\end{tabular} \\
\hline Austria & 3.35 & -0.25 & -0.24 & 3.61 & -0.25 & -0.40 & 4.91 & -0.37 & 0.20 & 5.18 & 0.09 & 0.20 \\
\hline Belgium & 4.79 & 0.15 & 0.25 & 4.95 & 0.15 & 0.16 & 6.17 & 0.16 & 0.29 & 6.36 & 0.15 & 0.29 \\
\hline Denmark & 5.63 & -0.67 & -0.39 & 6.03 & -0.67 & -0.11 & 6.67 & -0.37 & -0.67 & 7.34 & -0.72 & -0.67 \\
\hline Estonia & 3.99 & -0.32 & -0.40 & 4.06 & -0.32 & -0.37 & 5.82 & -0.28 & 0.20 & 6.14 & 0.18 & 0.20 \\
\hline Finland & 5.55 & -0.33 & -0.08 & 5.83 & -0.33 & -0.07 & 6.29 & -0.33 & 0.43 & 6.98 & 0.00 & 0.43 \\
\hline France & 3.64 & -0.01 & 0.28 & 3.88 & -0.01 & 0.58 & 5.22 & 0.13 & 0.07 & 5.98 & -0.36 & 0.07 \\
\hline Germany & 4.17 & 0.23 & 0.28 & 4.49 & 0.23 & 0.15 & 5.44 & 0.08 & 0.57 & 5.54 & 0.48 & 0.57 \\
\hline Greece & 2.67 & 0.51 & 0.52 & 2.39 & 0.51 & 0.85 & 4.57 & 0.84 & 1.00 & 4.19 & 1.01 & 1.00 \\
\hline Ireland & 3.83 & -0.03 & 0.06 & 3.81 & -0.03 & -0.06 & 5.51 & 0.01 & 1.80 & 6.08 & 1.65 & 1.80 \\
\hline Israel & 4.00 & 0.21 & 0.25 & 4.17 & 0.21 & 0.29 & 5.48 & 0.18 & -0.33 & 5.14 & 0.10 & -0.33 \\
\hline Luxembourg & 4.93 & -0.35 & -0.03 & 5.01 & -0.35 & 0.25 & 6.13 & 0.23 & 1.55 & 6.18 & 1.13 & 1.55 \\
\hline Netherlands & 5.53 & 0.08 & 0.28 & 5.72 & 0.08 & 0.06 & 6.01 & -0.14 & 0.31 & 6.25 & -0.02 & 0.31 \\
\hline Norway & 5.08 & 0.21 & 0.20 & 5.30 & 0.21 & 0.38 & 5.78 & 0.40 & 0.65 & 7.48 & 0.54 & 0.65 \\
\hline Portugal & 2.73 & -0.41 & -0.05 & 2.60 & -0.41 & -0.15 & 5.12 & -0.37 & -0.49 & 5.81 & -0.63 & -0.49 \\
\hline Slovenia & 3.14 & -0.16 & 0.01 & 3.62 & -0.16 & -0.34 & 4.94 & -0.59 & 0.17 & 5.19 & -0.09 & 0.17 \\
\hline Spain & 3.11 & 0.70 & 0.73 & 3.23 & 0.70 & 0.64 & 5.29 & 0.61 & 0.39 & 5.68 & 0.33 & 0.39 \\
\hline Sweden & 5.14 & -0.47 & -0.66 & 5.29 & -0.47 & -0.69 & 6.10 & -0.55 & -1.10 & 7.24 & -0.66 & -1.10 \\
\hline Switzerland & 5.42 & -0.21 & -0.15 & 5.64 & -0.21 & -0.39 & 5.73 & -0.42 & 0.37 & 6.32 & 0.23 & 0.37 \\
\hline United Kingdom & 4.19 & 0.54 & 0.34 & 4.31 & 0.54 & 0.17 & 4.84 & 0.36 & 0.77 & 5.76 & 0.77 & 0.77 \\
\hline Average & 4.26 & -0.03 & 0.06 & 4.42 & -0.03 & 0.05 & 5.58 & -0.02 & 0.33 & 6.05 & 0.22 & 0.33 \\
\hline
\end{tabular}

Notes: Individuals defined as immigrants are those who are either foreign-born or are native-born but have two foreign-born parents. Statistically significant differences between immigrant and native young people are highlighted in bold and blue. A ligher tone is applied to negative differences (i.e. when immigrants' mean value is smaller than natives' mean value) and a darker tone is applied to positive differences (i.e. when immigrants' mean value is greater than natives' mean value).

Only countries that participated in at least two rounds and with a sample of at least 30 immigrant individuals are included in the analysis Countries are ranked in alphabetical order.

Source: European Social Survey rounds 1-8 (pooled data).

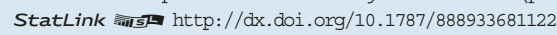

\section{Feelings of safety in local area}

Feelings of safety are associated with institutional trust, particularly trust in the police, (Cheurprakobkit, 2006) and sense of belonging to the community (Ross and Jang, 2000). Other important determinants are the size of the community, with individuals living in urban centres reporting lower levels of safety (Zani et al., 2001). As a result, for immigrants, feeling safe in local area is important for developing a sense of belonging and trust in the community given that they often have few existing strong community ties based on shared experiences growing up in the local area. However, the fact that they are more likely to live in urban centres, and to live in more socio-economically disadvantaged neighbourhoods where crime rates are higher, may lower their levels of perceived safety (Pendakur et al., 2016; Chiswick, Lee and Miller, 2002).

The ESS includes the following question regarding feelings of safety in the local area: "How safe do you - or would you - feel walking alone in this area after dark?". Responses could be reported on a four-point Likert scale ranging from "very safe" to "very unsafe".

Figure 3.a shows that young immigrants are less likely than young natives to live in areas where they feel very safe walking alone after dark. On average across the 19 countries included in the analysis, around 31\% of young natives and $27 \%$ of young immigrants report feeling very safe walking alone in their local area after dark. The largest gap between the two groups of young people is observed in Austria (16 percentage points), Switzerland (14 percentage points) and Germany (7 percentage points). By contrast, France is the only country where the proportion of young immigrants who report feeling very safe walking alone in the local area after dark (45\%) is greater than that of natives (32\%). However, differences between young natives and immigrants in the extent to which they report feeling very safe when walking alone in their local area after dark can be partly explained by differences in parental educational attainment. On average across all 
countries analysed, the native-immigrant gap decreases from 3.60 point difference to 3.28 point difference when parental educational attainment is considered. The magnitude of this reduction is 2 percentage points in Austria, 0.6 percentage point in France and 0.3 in Switzerland. After controlling for parental educational attainment, differences become non-statistically significant in Germany.

Figure 3.a - Feelings of safety in the local area among young people, by immigrant background Percentage of young people that report feeling "very safe" walking alone in their local area after dark

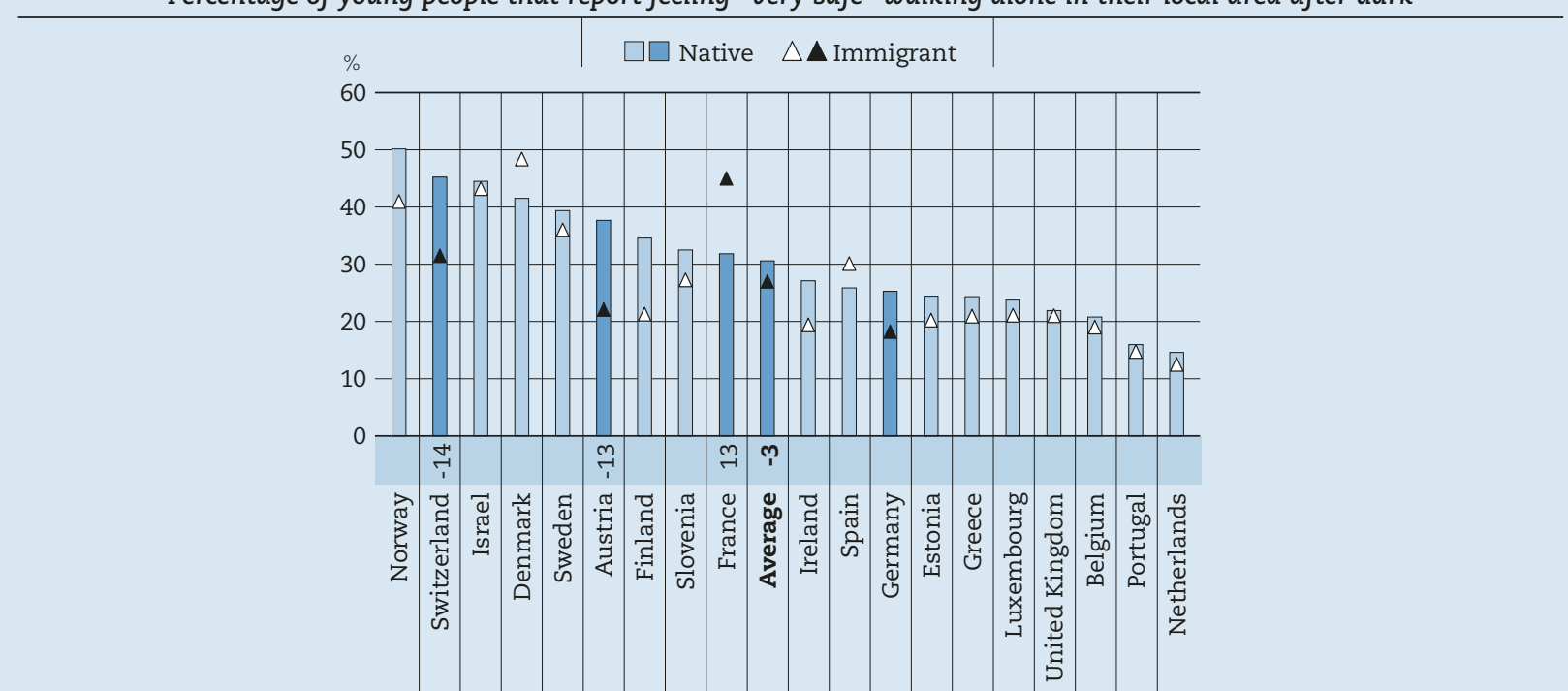

Notes: Individuals defined as immigrants are those who are either foreign-born or are native-born but have two foreign-born parents. A ligher tone of blue and a white triangle apply to countries where differences between young immigrant and native individuals before accounting for parental education are not statistically significant. A darker tone of blue and a black triangle apply to countries where differences between young immigrant and native individuals before accounting for parental education are statistically significant.

Statistically significant differences between young immigrant and native individuals after accounting for parental education are shown next to country/economy names.

Only countries that participated in at least two rounds and with a sample of at least 30 immigrant individuals are included in the analysis Countries are ranked in descending order of the percentage of young native individuals that report feeling "very safe" walking alone in local area after dark. Source: European Social Survey rounds 1-8 (pooled data).

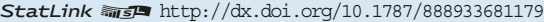

\section{Satisfaction with institutions}

Disparities in satisfaction with institutions between young native and immigrant individuals and how these differ across countries can help complete the picture of young immigrants' feelings and experiences in the hosting society. To the extent and when national administrative and judicial institutions work well, citizens are also more likely to believe that parliaments and governments are attentive to their interests (Rohrschneider, 2005).

Satisfaction with certain institutions is particularly important for young immigrants because it is associated to other outcomes of great relevance for their successful integration. For instance, research shows that how citizens view the performance of the public sector may affect democratic values such as trust in administrative agencies and trust in governance, as well as participatory behaviour (e.g. Van de Walle and Bouckaert, 2003; Vigoda-Gadot, 2003). Immigrants' satisfaction with institutions may be shaped not only by the quality of institutions in the country of destination but also by the quality of institutions in their country of origin. Some studies suggest that emigrating from a country characterised by severe political repression may result in more negative attitudes towards government in the host country (Bueker, 2005; Ramakrishnan, 2005). However, other studies indicate that immigrants from such countries might value democratic freedoms more and have more positive attitudes towards institutions in the host country (DeSipio, 1996; de la Garza, Falcon, and Chris Garcia, 1996). Research also suggests that positive attitudes towards government are more common among first-generation migrants than among native-origin and second-generation immigrants, with these two last groups presenting much more similar levels of trust and satisfaction (Maxwell, 2010). 
The ESS contains a series of questions asking about the level of satisfaction with five institutions. In particular, there are three questions on satisfaction with democracy, the state of the economy and the national government. They are: "On the whole, how satisfied are you with the present state of the economy in [country]? (...) Now thinking about the [country] government, how satisfied are you with the way it is doing its job? (...)And on the whole, how satisfied are you with the way democracy works in [country]?" For these three questions, respondents are asked to rate their level of satisfaction from 0 ("Extremely dissatisfied") to 10 (“Extremely satisfied"). There are also two questions regarding the state of education and health services in the country. They are: "(...) please say what you think overall about the state of education in [country] nowadays" and "(...) please say what you think overall about the state of health services in [country] nowadays". Possible responses to both range from 0 ("Extremely bad") to 10 ("Extremely good").

Tables 3.d and 3.e indicate that, on average across all participating countries, young immigrants report higher levels of satisfaction for all institutions considered. The widest gaps between immigrants and natives are observed in relation to the state of public services, namely education and health services. The narrowest gap is related to the state of the economy in the country. For all institutions analysed, the difference is larger after accounting for parents' education, except in the case of satisfaction with the state of health services, where the difference is slightly smaller. The widening of the gap when considering parents' level of education is particularly significant in relation to satisfaction with the way democracy works.

Countries differ both in the magnitude of the difference between young native and immigrants and in the degree to which parents' education explains these differences. For instance, in Germany, young immigrants report significantly greater satisfaction education and health services than young natives while in Austria there are no differences between the two groups. Similarly, when considering satisfaction with the state of education, in the Netherlands, the difference between the two groups nearly doubles in size after accounting for parents' education, but it becomes not statistically significant among young people in the United Kingdom.

Table 3.d - Satisfaction with democracy, the state of economy and the government among young individuals, by immigrant background

\begin{tabular}{|c|c|c|c|c|c|c|c|c|c|}
\hline & \multicolumn{3}{|c|}{$\begin{array}{l}\text { How satisfied with the democracy } \\
\text { works in the country }(0-10)\end{array}$} & \multicolumn{3}{|c|}{$\begin{array}{l}\text { How satisfied with the state } \\
\text { of the economy in the country }(0-10)\end{array}$} & \multicolumn{3}{|c|}{$\begin{array}{l}\text { How satisfied with the national } \\
\text { government }(0-10)\end{array}$} \\
\hline & \multirow[b]{2}{*}{$\begin{array}{l}\text { Mean } \\
\text { among } \\
\text { young } \\
\text { natives }\end{array}$} & \multicolumn{2}{|c|}{$\begin{array}{l}\text { Mean differences } \\
\text { between immigrant } \\
\text { and native } \\
\text { young people }\end{array}$} & \multirow[b]{2}{*}{$\begin{array}{l}\text { Mean } \\
\text { among } \\
\text { young } \\
\text { natives }\end{array}$} & \multicolumn{2}{|c|}{$\begin{array}{l}\text { Mean differences } \\
\text { between immigrant } \\
\text { and native } \\
\text { young people }\end{array}$} & \multirow[b]{2}{*}{$\begin{array}{l}\text { Mean } \\
\text { among } \\
\text { young } \\
\text { natives }\end{array}$} & \multicolumn{2}{|c|}{$\begin{array}{l}\text { Mean differences } \\
\text { between immigrant } \\
\text { and native } \\
\text { young people }\end{array}$} \\
\hline & & $\begin{array}{l}\text { Before } \\
\text { accounting } \\
\text { for parental } \\
\text { education }\end{array}$ & $\begin{array}{l}\text { After } \\
\text { accounting } \\
\text { for parental } \\
\text { education }\end{array}$ & & $\begin{array}{l}\text { Before } \\
\text { accounting } \\
\text { for parental } \\
\text { education }\end{array}$ & $\begin{array}{l}\text { After } \\
\text { accounting } \\
\text { for parental } \\
\text { education }\end{array}$ & & $\begin{array}{l}\text { Before } \\
\text { accounting } \\
\text { for parental } \\
\text { education }\end{array}$ & $\begin{array}{l}\text { After } \\
\text { accounting } \\
\text { for parental } \\
\text { education }\end{array}$ \\
\hline Austria & 6.12 & -0.06 & -0.12 & 5.61 & 0.19 & 0.22 & 4.36 & 0.16 & 0.06 \\
\hline Belgium & 6.10 & 0.32 & 0.44 & 5.40 & 0.32 & 0.44 & 5.00 & 0.75 & 0.74 \\
\hline Denmark & 7.49 & -0.24 & 0.13 & 6.51 & -0.31 & -0.19 & 5.56 & 0.07 & 0.06 \\
\hline Estonia & 5.64 & -0.77 & -0.76 & 5.12 & -0.69 & -0.55 & 4.88 & -0.45 & -0.44 \\
\hline Finland & 7.11 & 0.12 & 0.31 & 6.70 & 0.12 & 0.01 & 6.35 & 0.54 & 0.61 \\
\hline France & 5.36 & 0.19 & 0.52 & 4.01 & 0.39 & 0.43 & 4.16 & 0.09 & 0.17 \\
\hline Germany & 5.91 & 0.69 & 0.86 & 4.98 & 0.42 & 0.42 & 4.73 & 0.53 & 0.56 \\
\hline Greece & 4.61 & 0.95 & 0.95 & 3.02 & -0.28 & -0.27 & 3.35 & -0.03 & -0.03 \\
\hline Ireland & 5.71 & -0.12 & 0.04 & 4.51 & 0.28 & 0.36 & 4.25 & 0.22 & 0.39 \\
\hline Israel & 5.54 & 0.38 & 0.45 & 4.19 & 0.95 & 0.99 & 4.15 & 1.03 & 1.15 \\
\hline Luxembourg & 6.72 & 0.36 & 0.61 & 6.42 & 0.73 & 0.72 & 6.03 & 0.83 & 1.00 \\
\hline Netherlands & 6.46 & 0.33 & 0.51 & 5.61 & -0.44 & -0.46 & 5.34 & 0.22 & 0.32 \\
\hline Norway & 6.98 & 0.67 & 0.99 & 7.06 & 0.36 & 0.50 & 5.60 & 0.81 & 1.05 \\
\hline Portugal & 4.53 & 0.34 & 0.77 & 3.46 & -0.04 & 0.19 & 3.58 & -0.22 & 0.11 \\
\hline Slovenia & 4.99 & 0.47 & 0.66 & 5.23 & 0.30 & 0.35 & 4.44 & 0.14 & 0.27 \\
\hline Spain & 5.32 & 0.33 & 0.23 & 4.26 & 0.86 & 0.83 & 3.85 & 0.84 & 0.83 \\
\hline Sweden & 6.99 & 0.08 & 0.05 & 6.25 & -0.31 & -0.59 & 5.66 & -0.10 & -0.44 \\
\hline Switzerland & 7.36 & 0.05 & 0.13 & 6.59 & 0.39 & 0.42 & 6.50 & 0.50 & 0.49 \\
\hline United Kingdom & 5.35 & 0.87 & 0.70 & 4.98 & 0.64 & 0.55 & 4.69 & 0.54 & 0.44 \\
\hline Average & 6.01 & 0.26 & 0.39 & 5.26 & 0.20 & 0.23 & 4.87 & 0.34 & 0.39 \\
\hline
\end{tabular}

Notes: Individuals defined as immigrants are those who are either foreign-born or are native-born but have two foreign-born parents. Statistically significant differences between immigrant and native young people are highlighted in bold and blue. A ligher tone is applied to negative differences (i.e. when immigrants' mean value is smaller than natives' mean value) and a darker tone is applied to positive differences (i.e. when immigrants' mean value is greater than natives' mean value).

Only countries that participated in at least two rounds and with a sample of at least 30 immigrant individuals are included in the analysis Countries are ranked in alphabetical order.

Source: European Social Survey rounds 1-8 (pooled data).

StatLink ails http://dx.doi.org/10.1787/888933681141 
Table 3.e - Satisfaction with education and health services among young individuals, by immigrant background

\begin{tabular}{|c|c|c|c|c|c|c|}
\hline & \multicolumn{3}{|c|}{$\begin{array}{l}\text { How satisfied with the state of education } \\
\text { in the country nowadays }(0-10)\end{array}$} & \multicolumn{3}{|c|}{$\begin{array}{l}\text { How satisfied with the state of health services } \\
\text { in the country nowadays }(0-10)\end{array}$} \\
\hline & \multirow[b]{2}{*}{$\begin{array}{l}\text { Mean among } \\
\text { young natives }\end{array}$} & \multicolumn{2}{|c|}{$\begin{array}{c}\text { Mean differences } \\
\text { between immigrant } \\
\text { and native young people }\end{array}$} & \multirow[b]{2}{*}{$\begin{array}{c}\text { Mean among } \\
\text { young natives }\end{array}$} & \multicolumn{2}{|c|}{$\begin{array}{c}\text { Mean differences } \\
\text { between immigrant } \\
\text { and native young people }\end{array}$} \\
\hline & & $\begin{array}{c}\text { Before accounting for } \\
\text { parental education }\end{array}$ & $\begin{array}{l}\text { After accounting for } \\
\text { parental education }\end{array}$ & & $\begin{array}{l}\text { Before accounting for } \\
\text { parental education }\end{array}$ & $\begin{array}{l}\text { After accounting for } \\
\text { parental education }\end{array}$ \\
\hline Austria & 5.52 & 0.28 & 0.13 & 6.92 & 0.17 & 0.10 \\
\hline Belgium & 6.92 & 0.19 & 0.12 & 7.42 & 0.44 & 0.41 \\
\hline Denmark & 7.61 & 0.47 & 0.55 & 7.28 & 0.24 & 0.38 \\
\hline Estonia & 6.68 & -0.87 & -0.90 & 6.42 & 0.50 & -0.52 \\
\hline Finland & 8.03 & -0.01 & 0.59 & 7.32 & 0.53 & 0.75 \\
\hline France & 5.48 & 0.27 & 0.12 & 6.67 & 0.79 & 0.83 \\
\hline Germany & 5.21 & 0.67 & 0.50 & 6.11 & 0.96 & 0.97 \\
\hline Greece & 3.84 & 0.99 & 0.98 & 3.97 & 0.61 & 0.61 \\
\hline Ireland & 6.18 & 0.40 & 0.38 & 4.56 & 1.01 & 1.23 \\
\hline Israel & 5.45 & -0.20 & -0.21 & 7.21 & 0.75 & 0.94 \\
\hline Luxembourg & 5.00 & 1.30 & 1.26 & 7.07 & 0.83 & 0.88 \\
\hline Netherlands & 6.22 & 0.48 & 0.83 & 6.39 & 0.74 & 0.83 \\
\hline Norway & 6.81 & 0.76 & 0.72 & 6.61 & 0.97 & 0.95 \\
\hline Portugal & 4.40 & 0.62 & 0.76 & 4.45 & 0.59 & 0.60 \\
\hline Slovenia & 5.97 & 0.49 & 0.36 & 6.03 & 0.75 & 0.68 \\
\hline Spain & 5.21 & 1.16 & 1.29 & 6.03 & 0.98 & 1.06 \\
\hline Sweden & 6.44 & 0.53 & 0.54 & 6.38 & 0.35 & 0.04 \\
\hline Switzerland & 6.96 & 0.44 & 0.42 & 7.57 & 0.49 & 0.48 \\
\hline United Kingdom & 6.22 & 0.43 & 0.38 & 6.18 & 0.29 & 0.28 \\
\hline Average & 6.01 & 0.44 & 0.46 & 6.35 & 0.63 & 0.61 \\
\hline
\end{tabular}

Notes: Individuals defined as immigrants are those who are either foreign-born or are native-born but have two foreign-born parents.

Statistically significant differences between immigrant and native young people are highlighted in bold and blue. A ligher tone is applied to negative differences (i.e. when immigrants' mean value is smaller than natives' mean value) and a darker tone is applied to positive differences (i.e. when immigrants' mean value is greater than natives' mean value).

Only countries that participated in at least two rounds and with a sample of at least 30 immigrant individuals are included in the analysis. Countries are ranked in alphabetical order.

Source: European Social Survey rounds 1-8 (pooled data).

StatLink न्ञाजा $\mathrm{http}: / / \mathrm{dx}$. doi.org/10.1787/888933681160

By contrast, Estonia and the Netherlands are the only countries where young immigrants report less satisfaction with at least one institution. In the Netherlands, young immigrants are significantly less satisfied with the state of the economy than are young natives. Young immigrants in Estonia report significantly less satisfaction with democracy, with the state of the economy and with the state of education than did young natives, and did not report greater satisfaction than natives with any of the issues considered.

\section{Other well-being outcomes \\ Self-reported health}

Well-being data from the ESS can complement PISA analysis on the well-being of 15 year-olds students in several dimensions. Self-reported health is one of them. People that are socio-economically disadvantaged and low-educated are much more likely to suffer from poor health (Grossman, 2000; Grossman, 2006; Schütte et al., 2013; van der Kooi et al., 2013). However, poor health tends to be a problem of older people and, therefore, differences between native and immigrant young people in levels of self-reported health are expected to be small at young ages.

Health status was monitored in ESS through two questions. The first asks respondents about the state of their health in general using the following response categories "very good"; "good"; "fair"; "bad"; "very bad". The second question was designed to identify the presence of long-standing illnesses and whether such conditions limit respondents' daily activities. More specifically, respondents were asked: "Are you hampered in your daily activities in any way by any longstanding illness, or disability, infirmity or mental health problem?" Respondents who could choose between one of the following respondents categories: "No", "Yes a lot" and "Yes to some extent". 
Figure 3.b - Health conditions affecting daily activities among young people, by immigrant background

Percentage of young people that report being hampered in daily activities by illness, disability, infirmity or mental problems "a lot" or "to some extent"

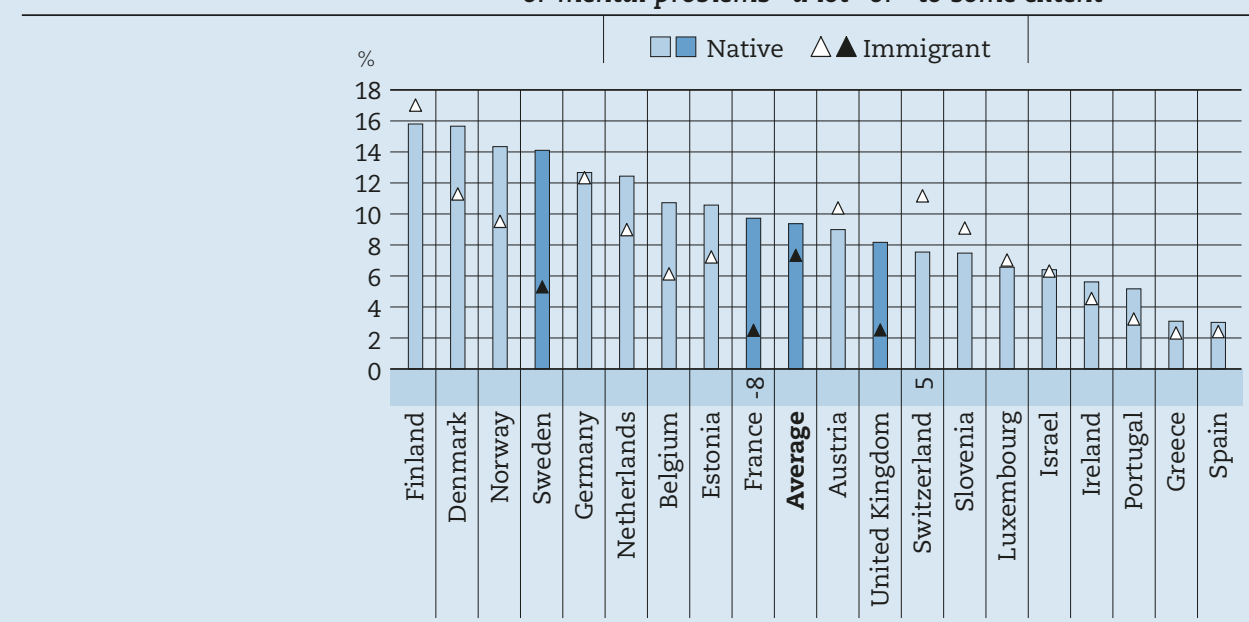

Notes: Individuals defined as immigrants are those who are either foreign-born or are native-born but have two foreign-born parents. A ligher tone of blue and a white triangle apply to countries where differences between young immigrant and native individuals before accounting for parental education are not statistically significant. A darker tone of blue and a black triangle apply to countries where differences between young immigrant and native individuals before accounting for parental education are statistically significant.

Statistically significant differences between young immigrant and native individuals after accounting for parental education are shown next to country/economy names.

Only countries that participated in at least two rounds and with a sample of at least 30 immigrant individuals are included in the analysis. Countries are ranked in descending order of the percentage of native young people that report being hampered in daily activities by illness, disability, infirmity or mental problem "a lot" or "to some extent".

Source: European Social Survey rounds 1-8 (pooled data).

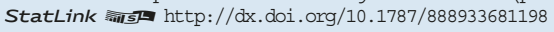

Figure 3.c - Subjective health among young people, by immigrant background Percentage of young people that report "very good" general health

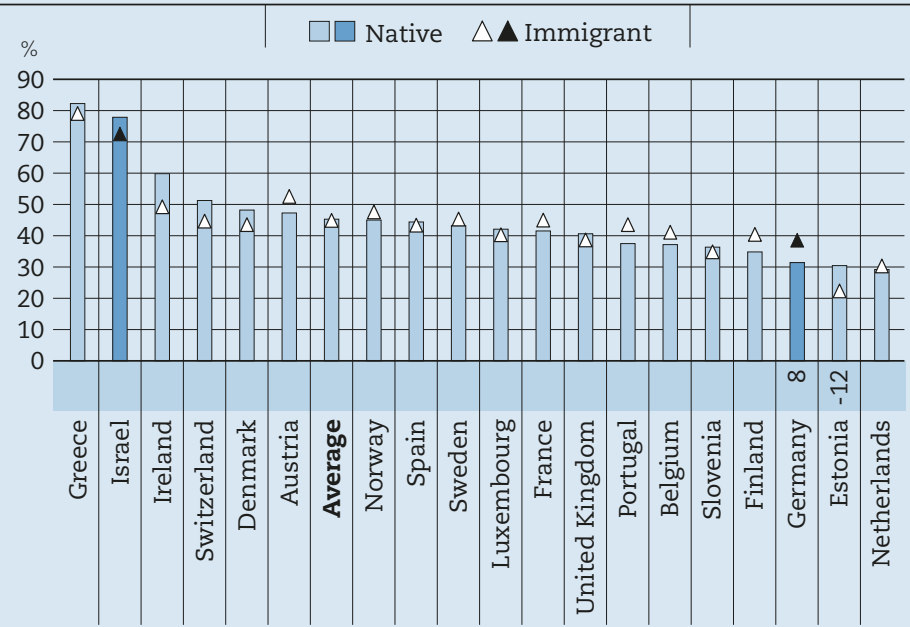

Notes: Individuals defined as immigrants are those who are either foreign-born or are native-born but have two foreign-born parents. A ligher tone of blue and a white triangle apply to countries where differences between young immigrant and native individuals before accounting for parental education are not statistically significant. A darker tone of blue and a black triangle apply to countries where differences between young immigrant and native individuals before accounting for parental education are statistically significant.

Statistically significant differences between young immigrant and native individuals after accounting for parental education are shown next to country/economy names.

Only countries that participated in at least two rounds and with a sample of at least 30 immigrant individuals are included in the analysis. Countries are ranked in descending order of the the percentage of native young people that report "very good" general health.

Source: European Social Survey rounds 1-8 (pooled data).

StatLink inists http://dx.doi.org/10.1787/888933681217 
Figures 3.b and 3.c show that there are generally no differences in self-reported health between young natives and immigrants. On average across the 19 countries analysed, 9\% of young natives and 7\% of young immigrants report that they are hampered in their daily activities by illness, disability, infirmity or mental health problems. Differences are statistically significant in Sweden (9\% point difference), France (7\% point difference) and the United Kingdom (6\% point difference). However, when differences in parental educational attainment are considered, differences between young natives and young immigrants in the extent to which they reported that they are hampered in their daily activities by illness, disability, infirmity or mental health problems decrease. Differences become non-statistically significant on average and in Sweden and the United Kingdom. By contrast, differences become statistically significant after accounting for parental educational attainment in Switzerland. Similarly, on average across all these countries, there are no statistically significant differences between young natives and young immigrants in the percentage of respondents who reported that their health is very good. Only in Israel is the percentage of young natives who report very good health significantly higher (78\%) than that of young immigrants (73\%). By contrast, in Germany the proportion of young immigrants who report very good health (39\%) is significantly larger than that of young natives (31\%). When parental educational attainment is considered, differences become non-statistically significant in Israel, but increase in Germany (from 7.15 point difference to 8.06 point difference) and become statistically significant in Estonia, where a greater proportion of young natives than immigrants report very good health (12.49 point difference).

\section{Participation in social networks}

Having an active social life is important for young people's well-being. Research shows that engagement in positive social activities in early adulthood is associated with better psychological outcomes later in life (Carmichel, Reis and Duberstein, 2015). The development of social networks among immigrants both within and across ethnic groups may have multiple buffering effects from negative social, political and economic circumstances in the host country (Lew, 2004; Portes and Rumbaut, 2006). Extended co-ethnic networks allow immigrants to share information and resources, identify economic and educational opportunities, share expertise and interchange services (Coleman, 1988; Vélez-Ibáñez and Greenberg, 1992). In adolescence, better social relations are related to better school outcomes among immigrants (Fang, Sun and Yuen, 2014).

The ESS asked participants to respond to a series of questions about their social life and two of these questions are good at characterising participation in social networks among young people: "how often do you meet socially with friends, relatives or work colleagues?" and "compared to other people of your age, how often would you say you take part in social activities?. Respondents could select one of the following responses for the first question "never"; "less than once a month"; "once a month"; "once a week"; "several times a week" and "every day". Respondents could select one of the following responses for the second question: "much less than most"; "less than most"; "about the same"; "more than most"; "much more than most".

Figures 3.d and 3.e show that young immigrants tend to be involved in social activities less often than natives, and report that they participate in these sorts of activities less often than most people their age. On average across the 19 countries considered, $20 \%$ of young natives and $23 \%$ of young immigrants report that they meet socially with their friends, relatives or work colleagues once a week or less. Differences between young natives and immigrants are significant in Spain (17\% point difference), Norway (13\% point difference), the United Kingdom (10\% point difference), Denmark (10\% point difference) and Sweden (10\% point difference). However, differences in parental educational attainment can partly explain these differences. Gaps between young natives and young immigrants in the extent to which they report that they meet socially with their friends, relatives or work colleagues once a week or less become non-statistically significant on average across the 19 countries when parental educational attainment is considered. The difference becomes statistically significant in Slovenia (11 point difference) and it increases by 1 percentage point in Spain and Denmark, by 2 percentage points in Sweden and by 4 percentage points in the United Kingdom. By contrast, the immigrant-native gap decreases by about 1 percentage point in Norway after accounting for parental educational attainment. Similarly, on average across the 19 participating countries, around 31\% of young immigrants but only $23 \%$ of young natives report taking part in social activities less often or much less often than most people their age. Differences are statistically significant in 11 out of the 19 countries analysed, and are particularly large in Greece (19 percentage points), Luxembourg (16 percentage points) and Spain (14 percentage points). When considering differences in parental educational attainment, these differences become non-statistically significant on average across all countries analysed and in Germany, 
Ireland, the Netherlands and Switzerland. In addition, differences decrease by 1 percentage point in Israel and by 4 point difference in Luxembourg. By contrast, differences increase by half a percentage point in Spain and by 1 percentage point in Estonia and Sweden.

Figure 3.d - Participation in social activities, by immigrant background Percentage of young people that report participating in social meetings with friends, relatives or work colleagues once a week or less

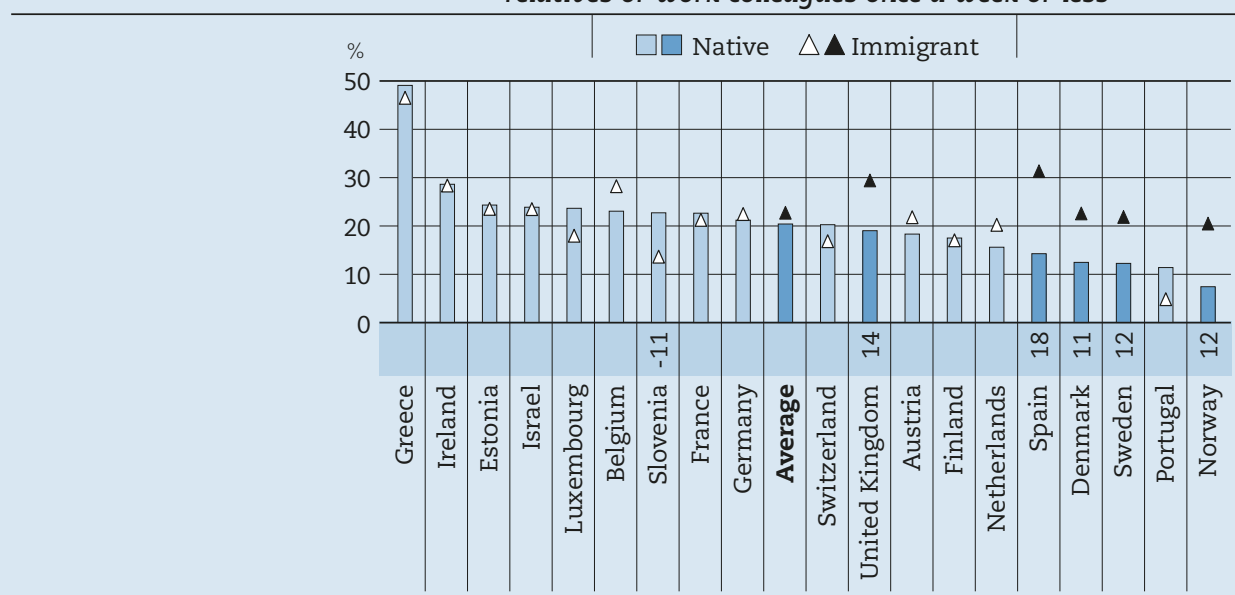

Notes: Individuals defined as immigrants are those who are either foreign-born or are native-born but have two foreign-born parents. A ligher tone of blue and a white triangle apply to countries where differences between young immigrant and native individuals before accounting for parental education are not statistically significant. A darker tone of blue and a black triangle apply to countries where differences between young immigrant and native individuals before accounting for parental education are statistically significant.

Statistically significant differences between young immigrant and native individuals after accounting for parental education are shown next to country/economy names.

Only countries that participated in at least two rounds and with a sample of at least 30 immigrant individuals are included in the analysis. Countries are ranked in descending order of the percentage of young natives that report participating in social meetings with friends, relatives or work colleagues once a week or less.

Source: European Social Survey rounds 1-8 (pooled data).

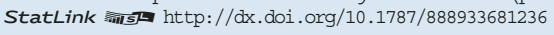

Figure 3.e - Relative frequency of participation in social activities among young individuals, by immigrant background

Percentage of young people that report taking part in social activities less often than other people of their age

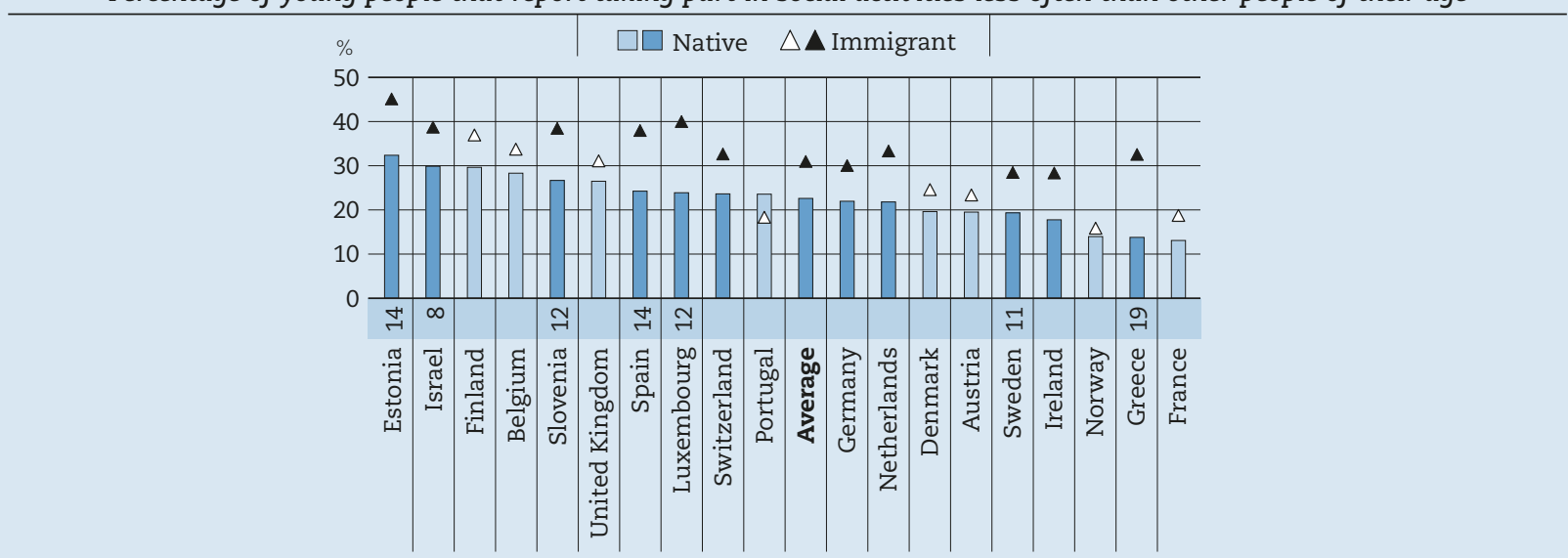

Notes: Individuals defined as immigrants are those who are either foreign-born or are native-born but have two foreign-born parents. A ligher tone of blue and a white triangle apply to countries where differences between young immigrant and native individuals before accounting for parental education are not statistically significant. A darker tone of blue and a black triangle apply to countries where differences between young immigrant and native individuals before accounting for parental education are statistically significant. Statistically significant differences between young immigrant and native individuals after accounting for parental education are shown next to country/economy names.

Only countries that participated in at least two rounds and with a sample of at least 30 immigrant individuals are included in the analysis. Countries are ranked in descending order of the percentage of young natives that report taking part in social activities less often than other people of their age. Source: European Social Survey rounds 1-8 (pooled data).

StatLink Ailst http://dx.doi.org/10.1787/888933681255 


\section{References}

Bueker, C. (2005), "Political incorporation among immigrants from ten areas of origin: The persistence of source country effects", International Migration Review, Vol. 39/1, pp. 103-140.

Carmichael, C.L, H.T. Reis and P.R. Duberstein (2015), “In your 20s it's quantity, in your 30s it's quality: the prognostic value of social activity across 30 years of adulthood”, Psychology and Ageing, Vol. 30/1, pp. 95-105.

Cheurprakobkit, S. (2006), "The impact of race, police experience, and feeling of safety on attitude toward the police", Journal of Police and Criminal Psychology, Vol. 21/2, pp. 55-67.

Chiswick, B.R., Y.L. Lee and P.W. Miller (2002), "The determinants of the geographic concentration among immigrants: Application to Australia”, IZA Discussion Paper, No. 462, https://ssrn.com/abstract=306962.

Coleman, J.S. (1988), "Social capital in the creation of human capital”, American Journal of Sociology, Vol. 94S, pp. S95-S120.

De La Garza, R., A. Falcon and F. Chris Garcia (1996), "Will the real Americans please stand up: Anglo and MexicanAmerican support of core American political values”, American Journal of Political Science, Vol. 40/2, pp. $335-351$.

De Sipio, L. (1996), "Making citizens or good citizens? Naturalization as a predictor of organizational and electoral behavior among Latino immigrants”, Hispanic Journal of Behavioral Sciences, Vol. 18/2, pp. 194-213.

Fang, L., R.C.F. Sun and M.J. Yuen (2014), “Acculturation, economic stress, social relationships and school satisfaction among migrant children in urban China”, Happiness Studies, Vol. 17/2, pp. 507-531.

Fukuyama, F. (1995), Trust: Social Virtues and the Creation of Prosperity, Free Press, New York.

Grossman M. (2000), "The human capital model”, in Culyer AJ, Newhouse JP (eds.), Handbook of Health Economics, Vol. 1. Elsevier Science, Amsterdam, pp. 347-408.

Grossman, M. (2006), "Education and nonmarket outcomes”, Handbook of the Economics of Education, Elsevier, Amsterdam.

Hetherington, M. J. (1998), “The political relevance of political trust”, American Political Science Review, Vol. 92, pp. $791-808$.

Lew, J. (2004), "The "other" story of model minorities: Korean American high school dropouts in an urban context”, Anthropology \& Education Quarterly, Vol. 35/3, pp. 303-323.

Maxwell, R. (2010), "Evaluating migrant integration: Political attitudes across generations in Europe", International Migration Review, Vol. 44/1, pp. 25-52.

North, D. C. (1990), Institutions, Institutional Change and Economic Performance, Cambridge University Press, New York.

Portes, A., P. Fernández-Kelly and W. Haller (2005), "Segmented assimilation on the ground: The new second generation in early adulthood”, Ethnic and Racial Studies, Vol. 28/6, pp. 1000-1040.

Portes, A. and R.G. Rumbaut (2006), Immigrant America: A Portrait, University of California Press, Berkeley.

Pendakur, K., R. Pendakur and P. Bevelander (2016), "Are residential and workplace concentration correlated for immigrants? Evidence for Sweden”, Journal of International Migration and Integration, Vol. 17, pp. 687-706, https://doi. org/10.1007/s12134-015-0430-4.

Ramakrishnan, K. (2005), Democracy in Immigrant America: Changing Demographics and Political Participation, Stanford University Press, Stanford, CA.

Rohrschneider, R. (2005), "Institutional quality and perceptions of representation in advanced industrial democracies", Comparative Political Studies, Vol. 3/7, pp. 850-874.

Ross and Jang (2000), "Neighborhood disorder, fear, and mistrust: the buffering role of social ties with neighbors", American Journal of Community Psychology, Vol. 28/4, pp. 401-420.

Schütte S. et al. (2013), "Social differences in self-reported health among men and women in 31 countries in Europe", Scandinavian Journal of Public Health, Vol. 41/1, pp. 51-57.

Sturgis, O., S. Read and N. Allum (2010), “Does intelligence foster generalized trust? An empirical test using the UK birth cohort studies", Intelligence, Vol. 38/1, pp. 45-54.

van der Kooi A.L et al. (2013), "The modifying influence of country development on the effect of individual educational attainment on self-rated health", American Journal of Public Health, Vol. 103/11, pp. e49-e54.

Van de Walle S. and G. Bouckaert (2003), "Public service performance and trust in governance: The problem of causality", International Journal of Public Administration, Vol. 26, pp. 891-914. 
Vélez-Ibáñez, C.G. and J.B. Greenberg (1992), "Formation and transformation of funds of knowledge among U.S.-Mexican households", Anthropology \& Education Quarterly, Vol. 23/4, pp. 313-335.

Vigoda-Gadot, E. (2003), Managing Collaboration in Public Administration: Governance, Businesses, and Citizens in the Service of Modern Society, Praeger, Westport, CT.

Zani, B., E. Cicognani and C. Albanesi (2001), "Adolescents' sense of community and feeling of unsafety in the urban environment”, Journal of Community and Applied Social Psychology, Vol. 11, pp. 475-489. 


\section{Chapter 4 \\ Individual characteristics and the resilience of students with an immigrant background}

This chapter examines some of the individual characteristics of students with an immigrant background that are related to their academic, social, emotional and motivational resilience. The magnitude of linguistic and cultural differences between an immigrant student's country of origin and the country in which his or her family settled is associated with these students' likelihood of integrating well into the host community. Other characteristics considered in the chapter are whether or not these students work for pay, whether they have participated in pre-primary education, and their gender.

\section{Notes regarding Cyprus}

Note by Turkey: The information in this document with reference to "Cyprus" relates to the southern part of the Island. There is no single authority representing both Turkish and Greek Cypriot people on the Island. Turkey recognises the Turkish Republic of Northern Cyprus (TRNC). Until a lasting and equitable solution is found within the context of the United Nations, Turkey shall preserve its position concerning the "Cyprus issue".

Note by all the European Union Member States of the OECD and the European Union: The Republic of Cyprus is recognised by all members of the United Nations with the exception of Turkey. The information in this document relates to the area under the effective control of the Government of the Republic of Cyprus.

\section{Note regarding data from Israel}

The statistical data for Israel are supplied by and under the responsibility of the relevant Israeli authorities. The use of such data by the OECD is without prejudice to the status of the Golan Heights, East Jerusalem and Israeli settlements in the West Bank under the terms of international law. 


\section{What the data tell us}

- The country students migrated from, and the country in which they settled, influence the likelihood that these students will be academically, socially and emotionally resilient. For example in Finland, first-generation immigrant students from Somalia are about eight percentage points less likely than those from Iraq to be academically resilient, but they are equally likely be socially resilient. By contrast, they are about 46 percentage points less likely to be academically resilient and eight percentage points less likely to be socially resilient than first-generation immigrant students from the Russian Federation.

- Immigrant students with the same heritage but living in different host countries are not equally likely to be academically or socio-emotionally resilient, after accounting for socio-economic status. For example, South African first-generation immigrant students who settled in Australia were almost 50 percentage points more likely to be academically resilient than first-generation immigrant students from South Africa who settled in New Zealand.

- Immigrant students are more likely than native students to work for pay or work in the household. The difference in likelihood to work for pay is a particularly strong mediating factor between immigrant background and academic performance in Brazil, Bulgaria, the Slovak Republic and Turkey.

- On average across OECD countries with available data, immigrant students are 12 percentage points less likely than native students to have participated in pre-primary programmes (13 percentage points less likely across EU countries). The difference is larger than 20 percentage points in the United Kingdom and Ireland.

\section{Country of birth effects}

The academic performance of students with an immigrant background in a given host country is significantly related to their country of origin. While socio-economic and linguistic differences across countries partly explain this relationship, other factors, such as cultural similarities and the quality of host- and origin-country education systems are likely to play a role. Figure 4.1 illustrates these points by pooling data from PISA 2006, 2009, 2012 and 2015. The figure shows, for a selected group of countries with available information, how immigrant students in the same host country and with similar socioeconomic status perform depending on their country of origin. Specifically, it compares the percentage of students who attain baseline levels of proficiency in the core PISA subjects ${ }^{1}$ among native students and first- and second-generation immigrant students from different countries. In this chapter, native-born students of foreign-born parents are considered second-generation immigrant students from a given country, when both their parents were born in that country, or one parent for students living in singleparent households. Native-born students of foreign-born parents born in two different countries are not considered in the analyses by country of origin.

In Luxembourg, for example, first-generation immigrant students from Cape Verde are 29 percentage points less likely to attain baseline levels of academic proficiency than native students, while firstgeneration immigrant students from Portugal are only 16 percentage points less likely. Conversely, French first-generation immigrant students are five percentage points more likely to attain baseline academic proficiency than Luxembourger native students. While differences across countries of origin are narrower for second-generation immigrant students than for first-generation immigrant students, the variation is still remarkably large. For example, the gap between students without an immigrant background in Luxembourg and second-generation immigrant students from Italy whose parents settled in Luxembourg is about 13 percentage points larger than the same gap observed among second-generation immigrant students in Luxembourg whose parents were born in Cape Verde. In Finland, academic performance varies even more depending on immigrant students' country of origin. First-generation immigrant students from Somalia are 56 percentage points less likely than native students to attain baseline academic proficiency, while students from the Russian Federation (hereafter "Russia") are only ten percentage points less likely. 
Figure 4.1 - Attaining baseline academic proficiency, by country of origin Difference between immigrant and native students in the percentage of students attaining baseline academic proficiency

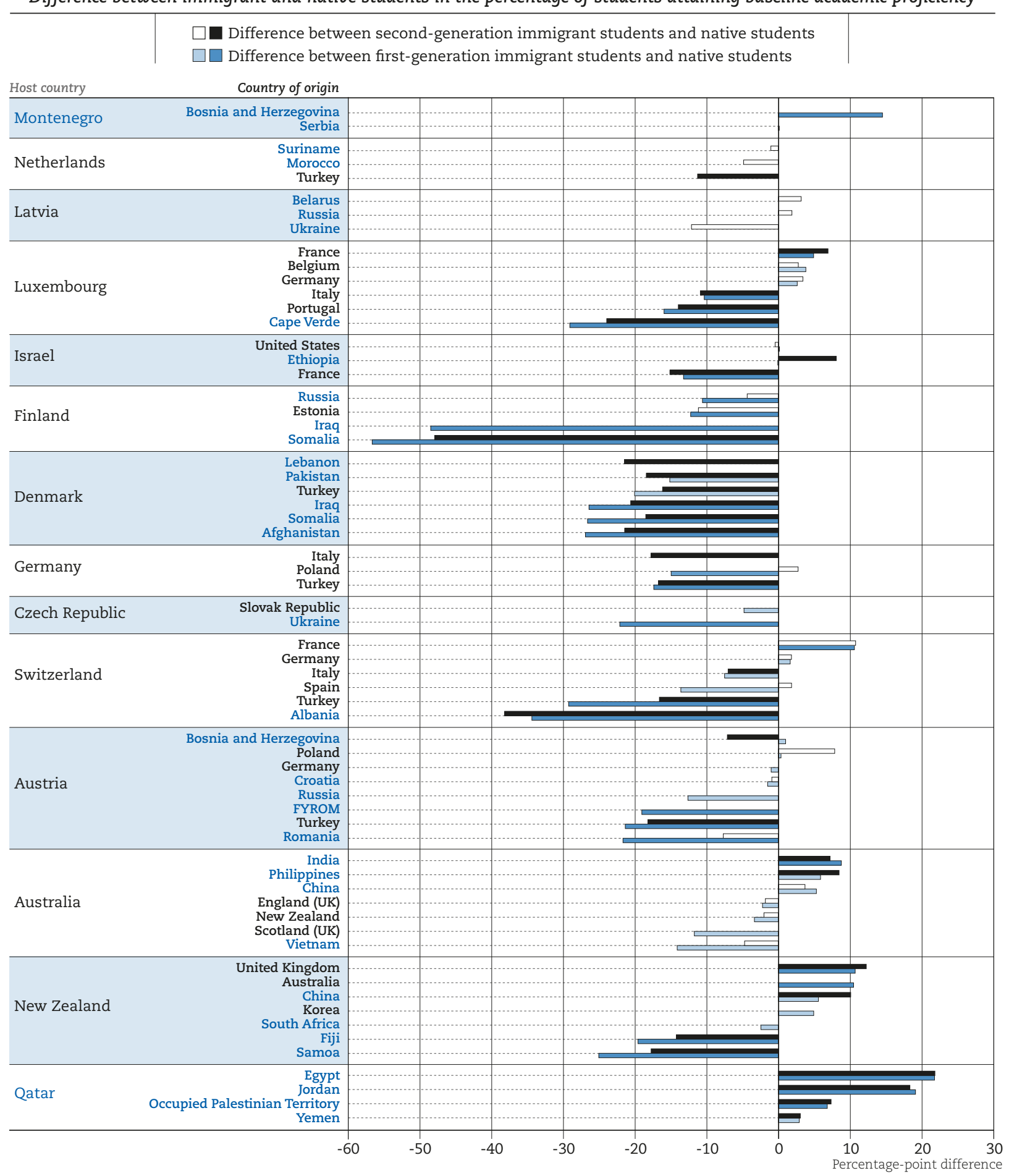

Notes: Estimates are obtained by pooling data from the PISA 2006, 2009, 2012 and 2015 Databases.

Statistically significant differences are marked in a darker tone.

Only countries with at least 30 immigrants attending at least 5 different schools from a minimum of 2 foreign countries were included in the analysis.

All estimates control for the socio-economic status of students.

Students who attain baseline academic proficiency are those who attain at least proficiency Level 2 in all three core PISA subjects: science, reading and mathematics.

Source: OECD, PISA 2006, 2009, 2012 and 2015 Databases.

StatLink 司IT $\mathrm{http}: / / \mathrm{dx}$.doi.org/10.1787/888933681274 
In New Zealand, first-generation immigrant students from Australia and the United Kingdom are over 10 percentage points more likely than native students to attain baseline academic proficiency, while first-generation immigrant students from Samoa are 25 percentage points less likely than native students.

Clearly, socio-economic disparities between immigrant students from different countries account for a significant part of the academic gaps, yet they are not the sole explanation. First, all estimates presented account for students' socio-economic status. Second, in some countries, immigrant students from economically diverse countries have similar academic performance. For example, in Denmark, second-generation immigrant students from Afghanistan, Iraq, Lebanon, Pakistan, Somalia and Turkey are all between 16 and 22 percentage points less likely than native students to attain baseline academic proficiency. First-generation immigrant students in Denmark from Afghanistan, Iraq and Somalia are between 26 and 27 percentage points less likely than native students to attain baseline academic proficiency. In Germany, second-generation immigrant students from Italy are 18 percentage points less likely than native students to attain baseline academic proficiency, while those from Turkey are 17 percentage points less likely than native students.

Linguistic differences are also likely to explain some of the academic gaps, such as the marked difference between French and Turkish immigrant students in Switzerland. However, they do not explain all differences. Iraqi and Somali first-generation immigrant students in Finland are, respectively, 48 and 57 percentage points less likely than native students to attain baseline academic proficiency, and Arabic is a national language in both countries of origin. In the Czech Republic, first-generation immigrant students from the Slovak Republic are as likely as native students to attain baseline academic proficiency, while first-generation immigrant students from Ukraine are 22 percentage points less likely than native students to do so. In all three countries, the national language is of Slavic origin.

The culture and education acquired before migrating are strongly related to the performance of firstgeneration immigrant students. In Luxembourg, Italian and Portuguese first-generation immigrant students are likely to experience similar socio-economic and linguistic difficulties; however, the former groups of students is 10 percentage points less likely than native students to attain baseline academic proficiency, while the latter are 16 percentage points less likely. Similarly, in Montenegro, first-generation immigrant students from Serbia are as likely as native students to attain baseline academic proficiency, while those from Bosnia Herzegovina are 15 percentage points more likely to do so. Differences can be explained by varying cultural affinity between host countries and countries of origin, as well as by differences in education before the students migrated.

The barriers to academic achievement faced by immigrant students tend to be lower for secondgeneration immigrants. However, the extent to which they are varies greatly across countries of origin and destination countries. In Switzerland, compared to native students, Turkish first-generation immigrant students are 29 percentage points less likely to attain baseline academic proficiency, while second-generation immigrants are only 17 percentage points less likely. In Denmark, first-generation immigrant students from both Somalia and Afghanistan are 27 percentage points less likely to attain baseline academic proficiency than native students are. While second-generation immigrant students from Afghanistan are 21 percentage points less likely to attain baseline academic proficiency than native Danish students, Somalian second-generation immigrant students are 18 percentage points less likely. In some cases there is only a marginal difference between first- and second-generation immigrant students in their academic performance, implying that barriers to achievement do not change across generations. For example, in Luxembourg, first- and second-generation immigrant students from Italy are 10 and 11 percentage points, respectively, less likely than native students to attain baseline academic proficiency.

PISA shows that the social well-being of immigrant students in a given host country also varies markedly according to students' country of origin. Figure 4.2 compares, for a selected group of countries with available information, the percentage of students who reported a sense of belonging at school ${ }^{2}$ among native students and immigrant students from different countries. All estimates account for the socioeconomic status of students and are obtained from pooled PISA 2003, 2009, 2012 and 2015 data. 
Figure 4.2 - Difference between immigrant and native students' sense of belonging at school, by country of origin

Difference between immigrant and native students in the percentage of students reporting a sense of belonging at school

$\square$ Difference between second-generation immigrant students and native students

$\square \square$ Difference between first-generation immigrant students and native students

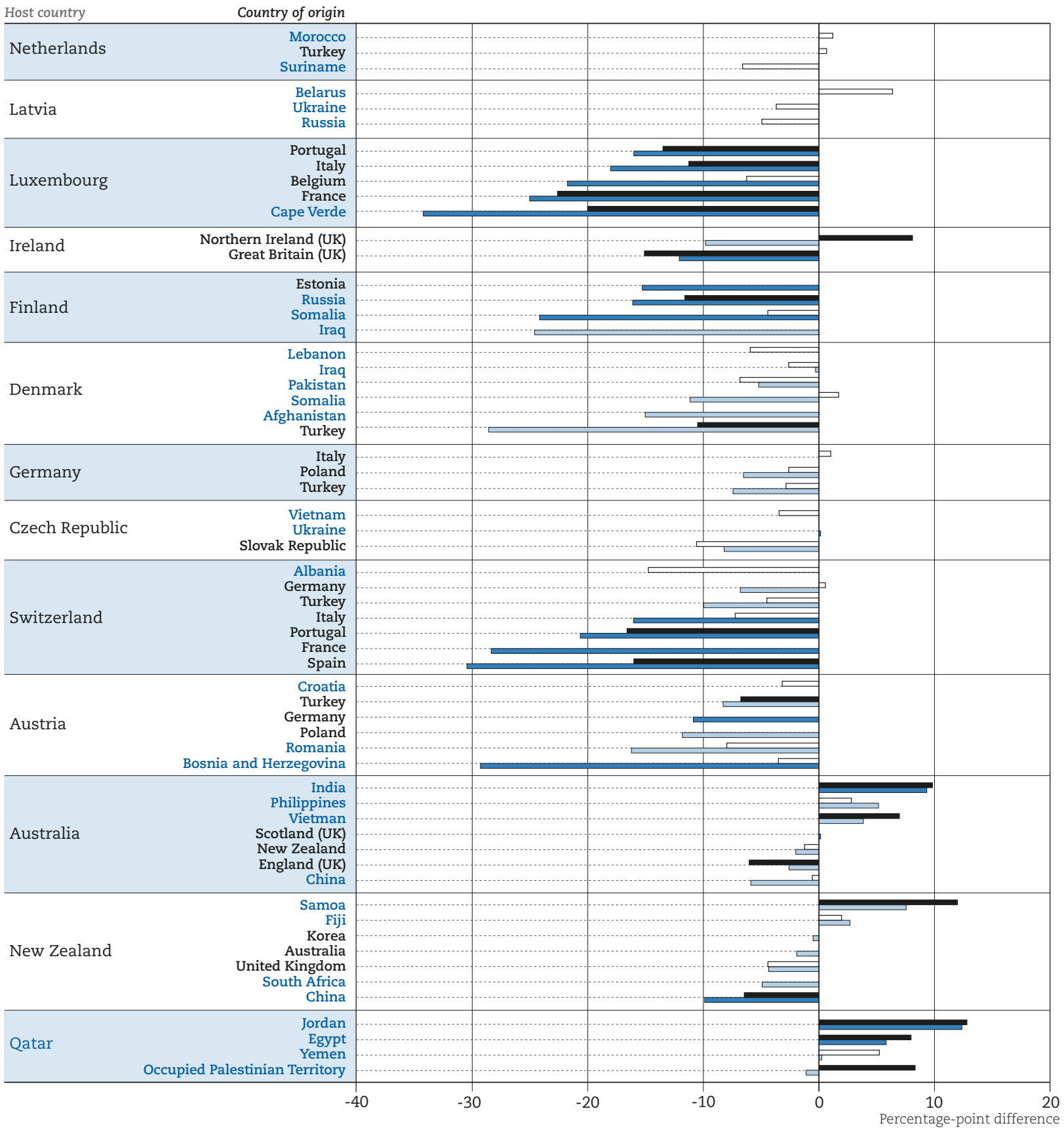

Notes: Estimates are obtained by pooling data from the PISA 2003, 2012 and 2015 Databases.

Statistically significant differences are marked in a darker tone.

Only countries with at least 30 immigrants attending at least 5 different schools from a minimum of 2 foreign countries were included in the analysis.

All estimates control for the socio-economic status of students.

Students who report a sense of belonging at school are those who reported that they "agree" or "strongly agree" with the statement "I feel like I belong at school" and "disagree" or "strongly disagree" with the statement "I feel like an outsider at school".

Source: OECD, PISA 2003, 2012 and 2015 Database.

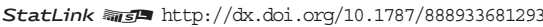


Important determinants of the social well-being of immigrant students are cultural differences between the heritage and host country's culture. In Finland, first-generation immigrant students coming from Russia and Estonia are 16 and 15 percentage points, respectively, less likely than native students to report a sense of belonging at school. By contrast, first-generation immigrant students from Somalia are 24 percentage points less likely to report so than native Finnish students. Clearly, the adversity that Somalian immigrants have to overcome to become socially integrated is greater than that faced by Russians or Estonians in this case, because the culture in Finland is more distant from Somalians' heritage.

The geographical proximity and the historical ties between two countries influence the flow of immigrants between the countries. Past migrant flows are reflected in the size of immigrant communities in host countries, which has an impact on the ease with which immigrant students can integrate and become socially resilient. Although Spain and Italy are culturally close, first-generation immigrants from the two countries experience different degrees of adversity in Switzerland, where Italians are the largest foreign group and Italian is one of the official languages. While immigrant students from Spain are 30 percentage points less likely than native Swiss students to report a sense of belonging at school, those from Italy are only 16 percentage points less likely to report so. Similarly, in Luxembourg, where the Portuguese and Italian communities are among the largest, immigrants from the two countries are significantly more likely to feel like they belong at school compared to French immigrants, even though French is among the official languages in Luxembourg. First-generation immigrant students from Portugal are 16 percentage points less likely than native students to report a sense of belonging at school, while first-generation immigrant students from France are 25 percentage points less likely to report so.

A comparison of Figures 4.1 and 4.2 shows that the interaction of host- and origin-country characteristics influences the academic and social resilience of students in different ways. In Switzerland, French firstgeneration immigrant students are significantly more likely than Turkish first-generation immigrant students to be academically resilient, while the opposite is true when it comes to social resilience. While the French students could be academically favoured by linguistic and cultural proximity to Luxembourgers, different factors influence the likelihood of feeling a sense of belonging at school. For example, Turkish immigrant students might integrate more easily because they have a more close-knit community in Luxembourg.

\section{Country of destination effects}

The discussion above identifies some of the risk and protective factors associated with immigrants with different countries of origin moving to a specific country, such as their socio-economic status, the quality of education in the country of origin, and linguistic and cultural differences between origin and host countries. While these factors clearly matter, the performance of immigrant students is also strongly related to the characteristics of education systems in host countries. To illustrate this point, Figure 4.3 compares the academic performance of immigrant students from the same country of origin in different host countries. For countries of origin that took part in PISA, the result for the students who did not migrate and have native-born parents (the native students) is also displayed. Estimates account for differences in socio-economic status and are obtained by pooling data from PISA 2006, 2009, 2012 and 2015.

Results presented in Figure 4.3 show that immigrant students from the same country of origin (meaning that they were either born in that country or had both parents who were) have very different likelihoods of being academically resilient depending on the country where they settle. On average after accounting for socio-economic status, first-generation immigrant students from Albania who settled in Greece are 11 percentage points more likely to attain baseline academic proficiency than those who settled in Montenegro, and about 8 percentage points more likely than those who sat the PISA test in Albania. Second-generation immigrant students from Arab-speaking countries who settled in Denmark are about 13 percentage points more likely to be academically resilient compared to those who settled in Finland. The difference is even larger when it comes to second-generation immigrants coming from Iraq (15 percentage points). South African first-generation immigrant students in Australia are almost 50 percentage points more likely to be academically resilient than those in New Zealand. Host communities have different capacities to nurture the talents of students with different intellectual and cultural backgrounds. 
Figure 4.3 - Attaining baseline academic proficiency, by host country Percentage of immigrant students from the same country of origin attaining baseline academic proficiency after accounting for socio-economic status, by host country

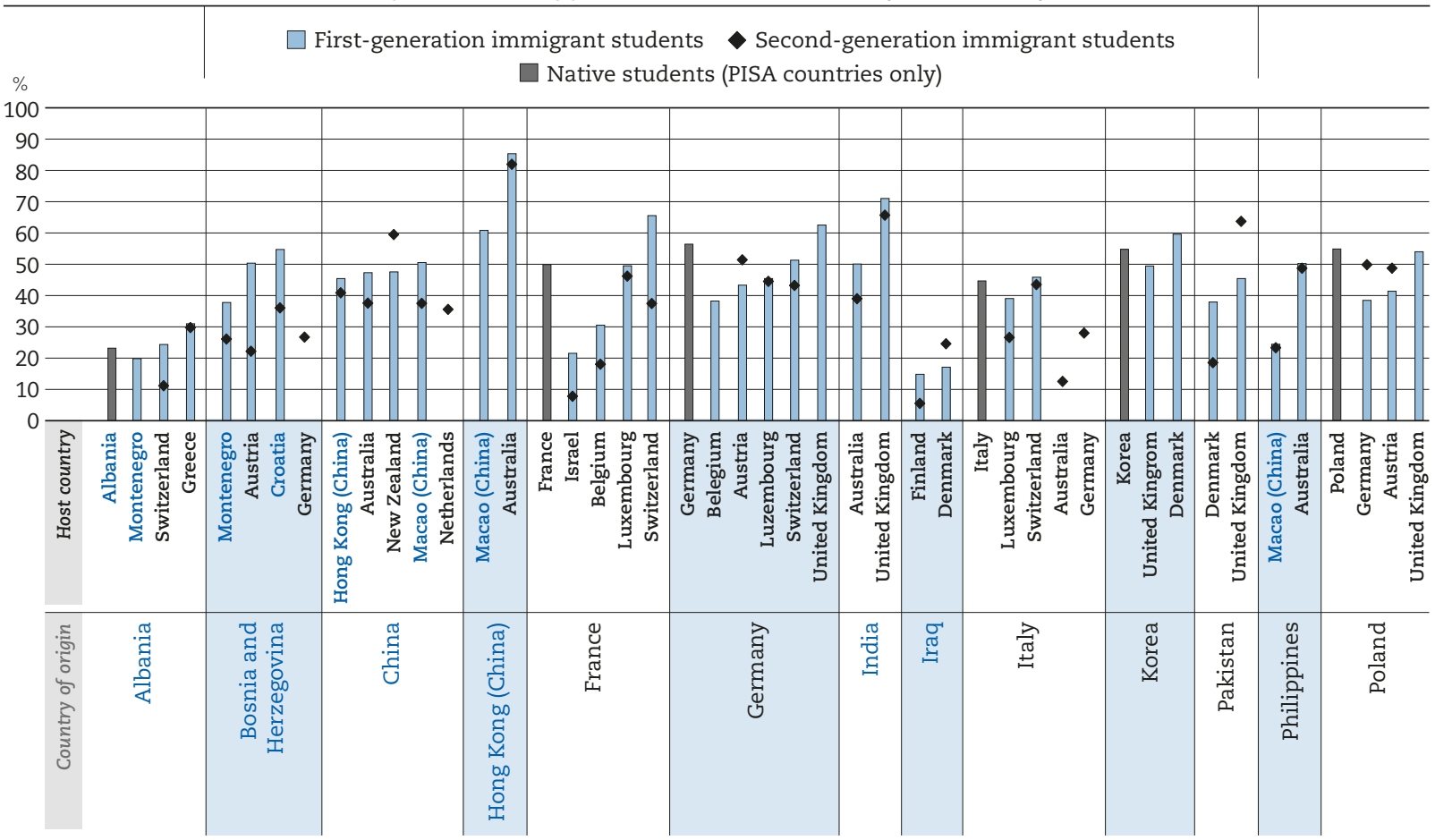

$\%$

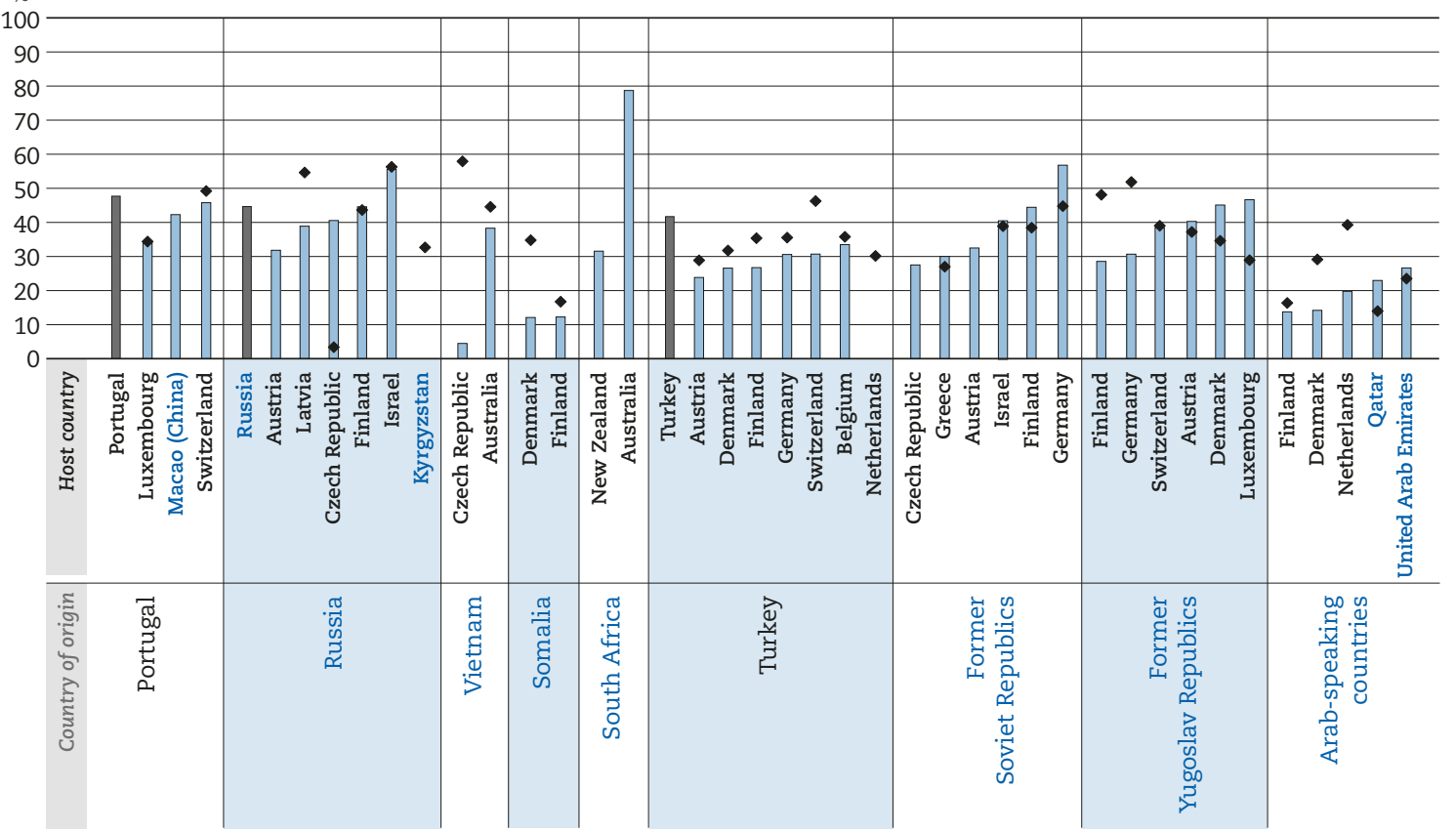

Notes: Estimates are obtained by pooling data from the PISA 2006, 2009, 2012 and 2015 Databases.

The average performance by immigrant group and host country accounts for differences in socio-economic status. It corresponds to the predicted performance of the group if all immigrant students who migrated from that country of origin and all the non-immigrant students across all the host countries shared the same socio-economic status of the average student.

Students who attain baseline academic proficiency are those who attain at least proficiency Level 2 in all three core PISA subjects: science, reading and mathematics.

The coverage of destination countries is limited by the fact that only some countries collect detailed information on immigrants' country of birth. Only destination countries with data on the academic performance of at least 20 immigrant students of the same origin are shown.

Source: OECD, PISA 2006, 2009, 2012 and 2015 Database.

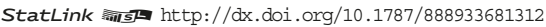


PISA shows that, in some host countries, education systems manage to promote the academic achievement of immigrants irrespective of their country of origin. For first-generation immigrant students from Germany, India, Pakistan and Poland, the United Kingdom is the destination country where they have the highest likelihood of being academically resilient (among those countries/economies for which there is available data from PISA). Similarly, Australia and Switzerland are among the countries where immigrant students from all countries of origin with available data perform best. The ability of such countries to nurture students from diverse backgrounds stems from several factors, including the selectivity of their immigration policies, the overall quality of their education systems, the language of instruction, and the extent to which their societies have, historically, been open to diversity.

In other destination countries, education systems are more effective with immigrant students from certain countries with which they have more in common culturally, historically or linguistically. For example, first- and second-generation immigrant students from Russia have the highest likelihood of being academically resilient in Israel, among the destination countries with available data. By contrast, first- and second-generation immigrant students from France have the lowest likelihood of being academically resilient in Israel compared to other destination countries.

An interesting comparison is that between students who migrated and those who did not migrate from the same country of origin. The comparison emphasises the adversity related to migration and the difficulties in overcoming it. Figure 4.3 indicates that native students in Albania tend to perform on a par academically compared to Albanian students of similar socio-economic status and who migrated to Switzerland. By contrast, first-generation immigrant students from Albania who moved to Greece have higher chances of attaining baseline academic proficiency than native Albanian students. Compared to Albanian first-generation immigrants in Switzerland, they show greater adjustment to the initial adversity associated with migrating.

After accounting for socio-economic status, for Russian students, only second-generation immigrants who settled in Latvia and first- and second-generation immigrants who settled in Israel are more likely to attain baseline academic proficiency than those who stayed in their country of origin. Polish students who sat the PISA assessment in their home country had similar chances of attaining baseline academic proficiency as second-generation immigrant Polish students living in Germany and Austria, and as firstgeneration immigrants in the United Kingdom. However, these results should be interpreted with caution because they represent the predicted outcome if all immigrant students from the same country of origin and the native students in the host countries had the socio-economic status as the average student. This implies that the predicted value for native students often corresponds to the academic performance of the most socio-economically advantaged students who remained in the country of origin, since destination countries tend to be better-off, economically, than countries of origin.

Figure 4.4 is similar to Figure 4.3 but it represents the percentage of immigrant students from the same country of origin in different host countries who reported a sense of belonging at school. Estimates account for differences in socio-economic status and are obtained by pooling data from PISA 2003, 2012 and 2015. Results show that the social well-being of immigrant students varies remarkably according to the country in which they (or their parents) settle. First-generation immigrant students from Russia who settled in Latvia are over 45 percentage points more likely than those who settled in the Czech Republic to report a sense of belonging at school. Second-generation immigrant students from Arab-speaking countries who settled in Australia are about 37 percentage points more likely than those who settled in Qatar to report a sense of belonging at school, despite the linguistic differences between the two countries.

Results presented in Figure 4.4 show that $89 \%$ of second-generation immigrant students from Iraq who live in Finland report a sense of belonging at school, while only $63 \%$ of those who live in Denmark report the same. Similarly, $82 \%$ of Somalian second-generation immigrant students who live in Finland reported a sense of belonging at school, while only 63\% of those living in Denmark reported so. While $83 \%$ of second-generation immigrant students from Arab-speaking countries living in Finland report a sense of belonging at school, only $63 \%$ of those living in Denmark report so. These results suggest that the psychological well-being of immigrant students is affected not only by cultural or linguistic differences between the country of origin and the host country, but also by how schools and communities help these students deal with daily problems of living, learning and communicating. 
Figure 4.4 - Sense of belonging, by host country Percentage of immigrant students from the same country of origin reporting a sense of belonging after accounting for socioeconomic status, by host country

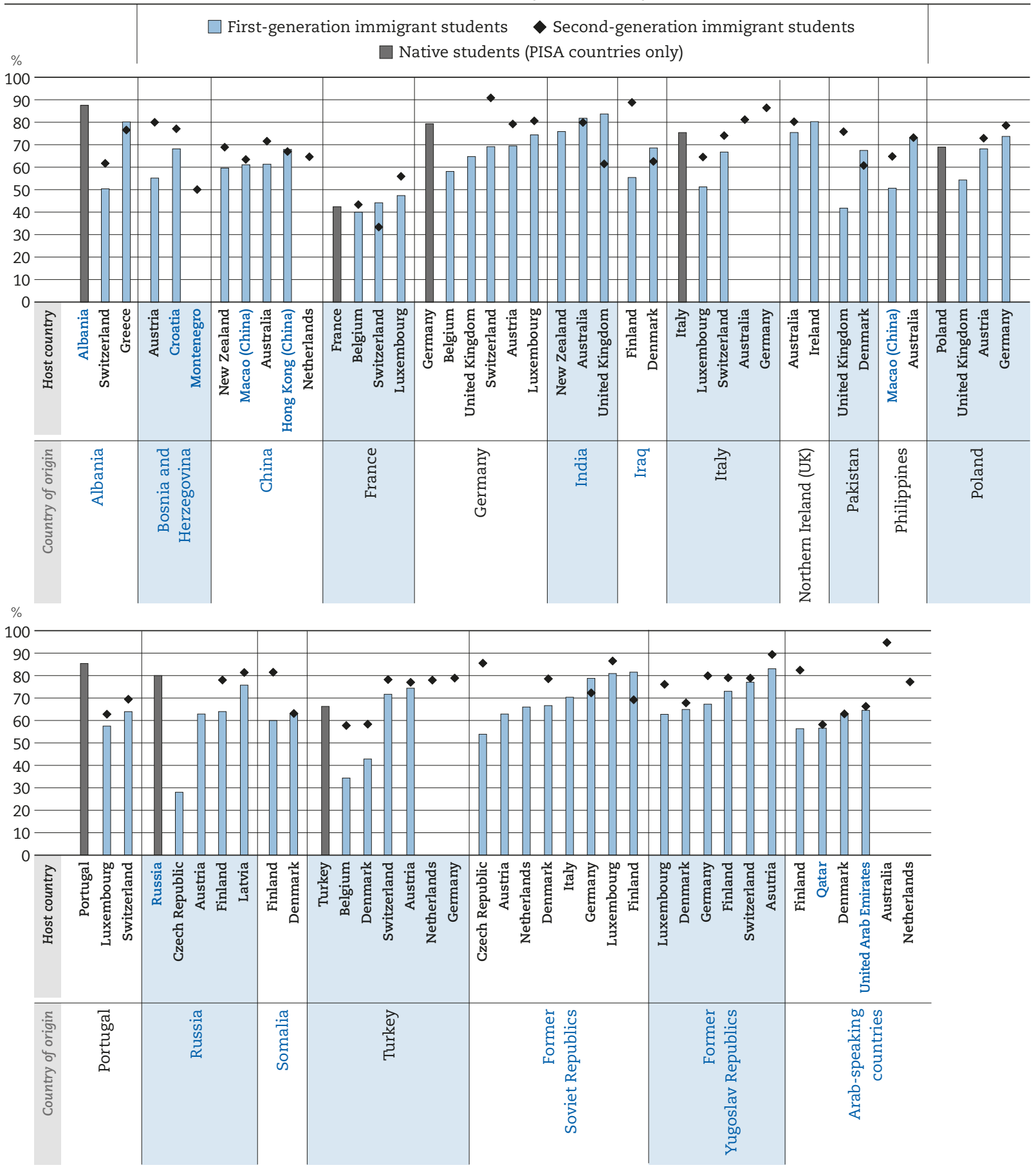

Notes: Estimates are obtained by pooling data from the PISA 2003, 2012 and 2015 Databases.

The average sense of belonging by immigrant group and host country accounts for differences in socio-economic status. It corresponds to the predicted sense of belonging of the group if all immigrant students who migrated from that country of origin and all the non-immigrant students across all the host countries shared the same socio-economic status of the average student.

Students who report a sense of belonging at school are those who reported that they "agree" or "strongly agree" with the statement "I feel like I belong at school" and "disagree" or "strongly disagree" with the statement "I feel like an outsider at school".

The coverage of destination countries is limited by the fact that only some countries collect detailed information on immigrants' country of birth. Only destination countries with data on the sense of belonging of at least 20 immigrant students of the same origin are shown.

Source: OECD, PISA 2003, 2012 and 2015 Database.

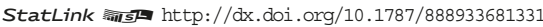


The figure also shows that, for most of the countries of origin that participated in PISA, native-born students who remained in the country, are more likely to report a sense of belonging at school than those who have parents who migrated but especially compared to those who themselves migrated. This reflects the social and emotional disadvantage that result from displacement. However, the results also show that some immigrant students manage to adjust to such adversity and, in some cases, are more likely to report a sense of belonging at school than their peers who had not migrated.

\section{Working for pay and doing unpaid work}

Working in a paid or unpaid job are two important factors shaping students' academic and well-being outcomes and can be a mediating factor between immigrant background and resilience. The probability of working in the household or working for pay can be affected by family characteristics and socio-economic status (Gager, Cooney and Call, 1999). The demand for adolescents to work tends to be greater in single parent and multi-generational households and when the number of siblings is greater (Gager, Cooney and Call, 1999). PISA 2015 shows that more boys than girls work for pay and fewer boys than girls do unpaid household work. Furthermore, across OECD countries disadvantage students are about 6 percentage points more likely to work for pay than advantage students. Students who work for pay tend to score lower in science are more likely to report feeling like an outsider at school, having low expectations for further education, arriving late for school, and skipping school (OECD, 2017).

PISA 2015 measured whether students did paid work by asking students if they worked for pay before or after school during the most recent day they attended school. Similarly, students' involvement in unpaid work was measured by asking students if they worked in the household or took care of other family members before or after school during the most recent day they attended school.

Figure 4.5 - Students working for pay, by immigrant background

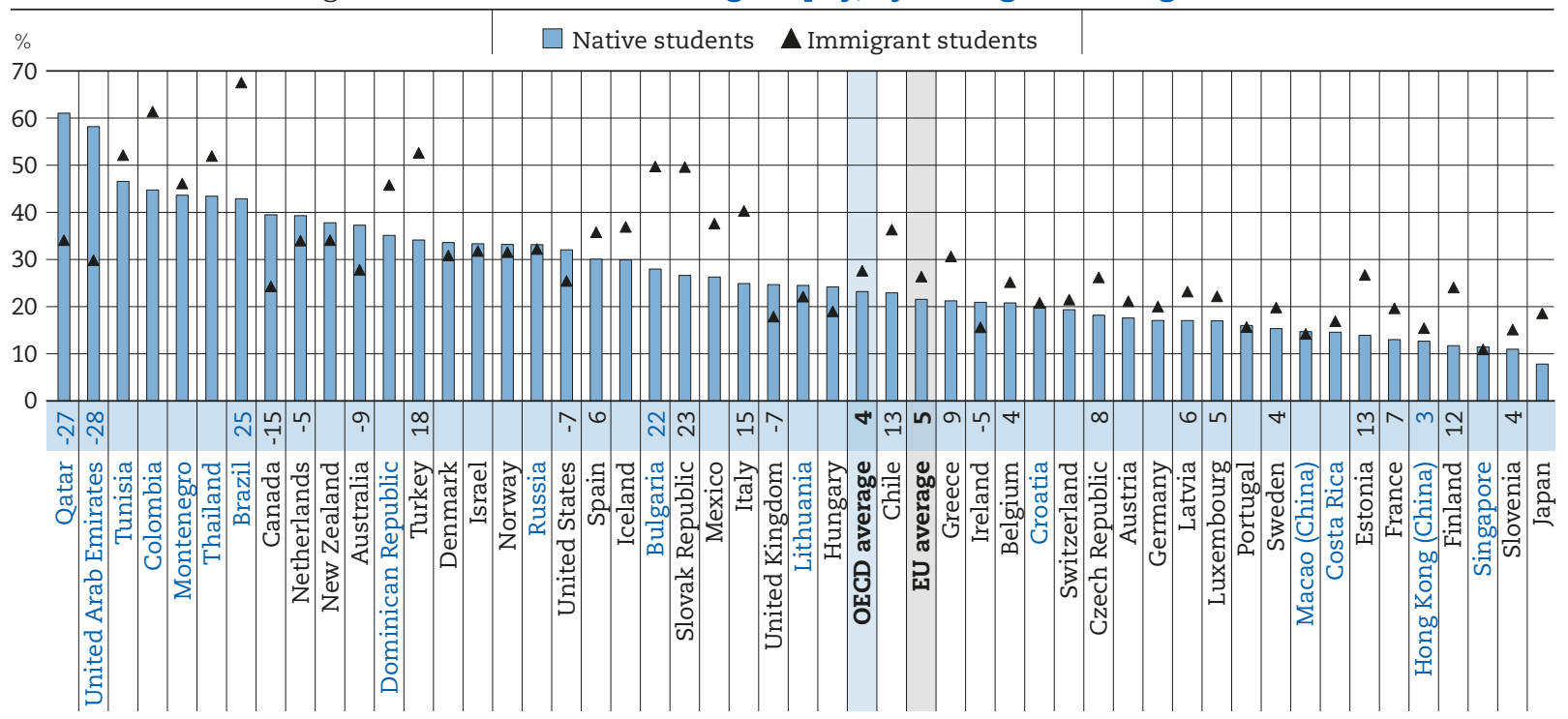

Notes: Only countries with valid values for immigrant students are shown.

Students who work for pay are those who reported that they had worked for pay before or after school during the most recent school day. Statistically significant differences in the percentage of students who work for pay between immigrant and native students are shown next to the country/economy name.

Countries and economies are ranked in descending order of the percentage of native students who work for pay.

Source: OECD, PISA 2015 Database, Table 4.1

StatLink ailst http://dx.doi.org/10.1787/888933681350

Figure 4.5 shows that, in most countries and economies, the proportion of students who worked for pay in 2015 was greater among immigrant students than among native students (results on other categories of students with an immigrant background are available in Table 4.1 available on line). On average across OECD countries, the proportion of immigrant students who reported that they had worked for pay before or after school during the most recent day was four percentage points larger than that of native students 
(5 percentage points greater across EU countries). In 18 countries and economies, a greater percentage of immigrant students than native students worked for pay. This difference was greater than 15 percentage points in Brazil, Bulgaria, Italy, the Slovak Republic and Turkey. By contrast, in eight countries and economies, native students were more likely to work for pay than immigrant students. The difference was particularly large in Canada, Qatar and the United Arab Emirates, where the percentage of students who worked for pay was at least 15 percentage points larger among native students than among immigrant students.

PISA reveals that the difference between native and immigrant students in the likelihood of working for pay is an important mediating factor between immigrant background and academic resilience. Figure 4.6 shows the difference in the percentage of students attaining baseline academic proficiency among native and immigrant students, before and after accounting for whether they worked for pay during the most recent school day. In 16 countries and economies, the performance gap between native and immigrant students shrank after participation in paid work was accounted for. On average across OECD and EU countries, the difference between native and immigrant students in the percentage of students who attained baseline academic proficiency in 2015 decreased by one percentage point after accounting for the difference in the percentage of students who work for pay. The narrowing of the performance gap was larger than five percentage points in Brazil, Bulgaria, the Slovak Republic and Turkey.

Figure 4.6 - Difference between immigrant and native students in attaining baseline academic proficiency, before and after accounting for paid work

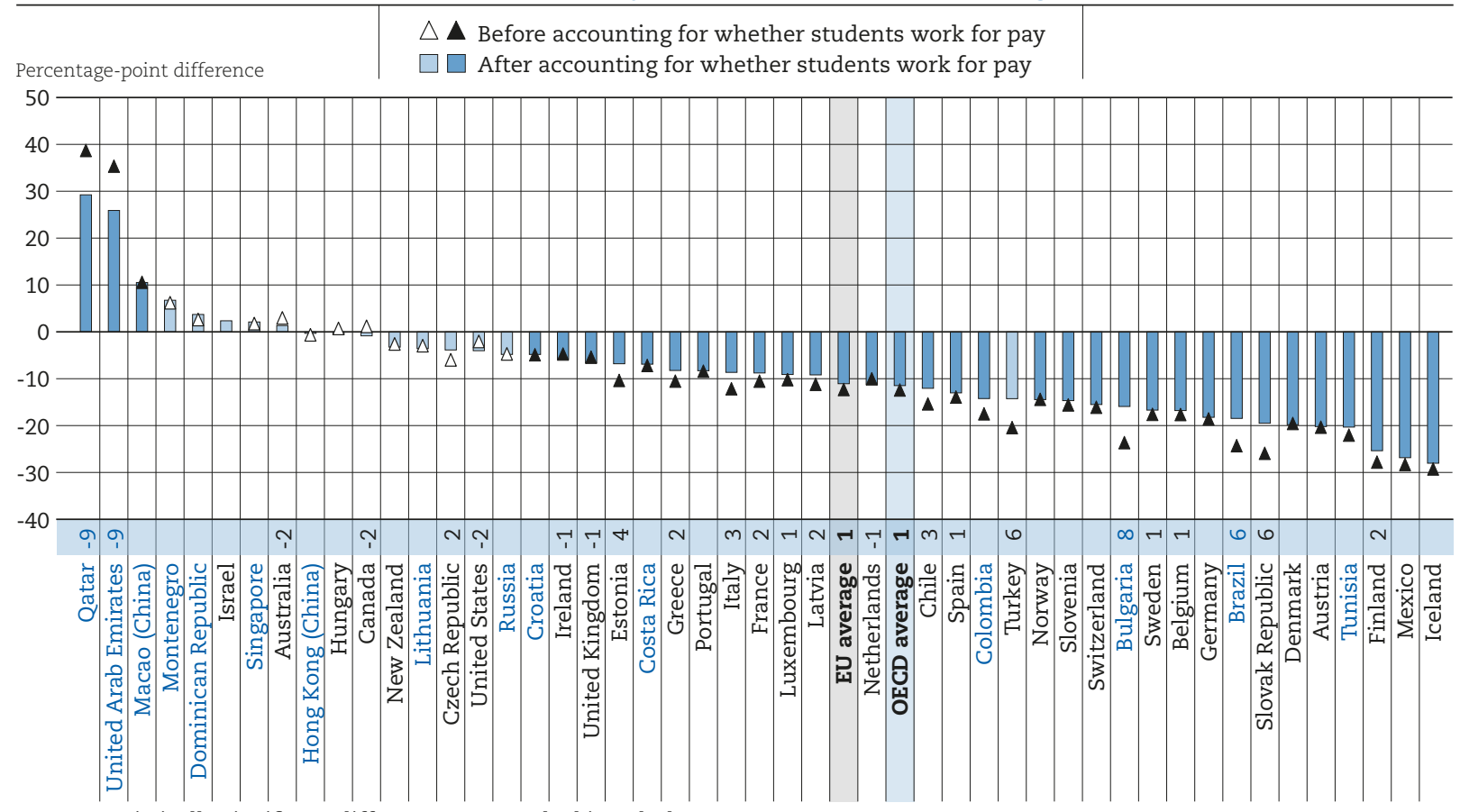

Notes: Statistically significant differences are marked in a darker tone.

Only countries/economies with valid data on the immigrant-native gap in attaining baseline academic proficiency are shown.

Students who work for pay are those who reported that they had worked for pay before or after school during the most recent school day. Statistically significant differences in the immigrant-native gaps calculated before and after accounting for whether students work for pay are shown next to the country/economy name.

Countries and economies are ranked in descending order of the percentage-point difference between immigrant and native students in the percentage of students attaining baseline academic proficiency, after accounting for whether students work for pay.

Source: OECD, PISA 2015 Database, Table 4.3.

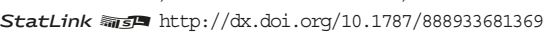

Figure 4.7 shows that, in most countries, immigrant students are more likely than native students to work in the household or take care of family members. On average across OECD and EU countries, the percentage of students who in 2015 reported that they did unpaid work at home during the most recent school day was two percentage points larger among immigrant students than among native students 
(results for other categories of students with an immigrant background are available in Table 4.2 available on line). Overall, differences between native and immigrant students in participation in unpaid work activities are smaller than those related to paid work. The difference was larger than 10 percentage points only in Costa Rica, Greece and the Netherlands. In Latvia, Lithuania and the United Arab Emirates, native students were more likely than immigrant students to report that they do unpaid work in the household. Interestingly, in a set of countries where immigrant students were less likely than native students to work for pay, the opposite was true when considering work in the household. This was the case in Australia, Canada, the Netherlands, the United Kingdom, the United States and Qatar.

Figure 4.7 - Students doing unpaid work, by immigrant background

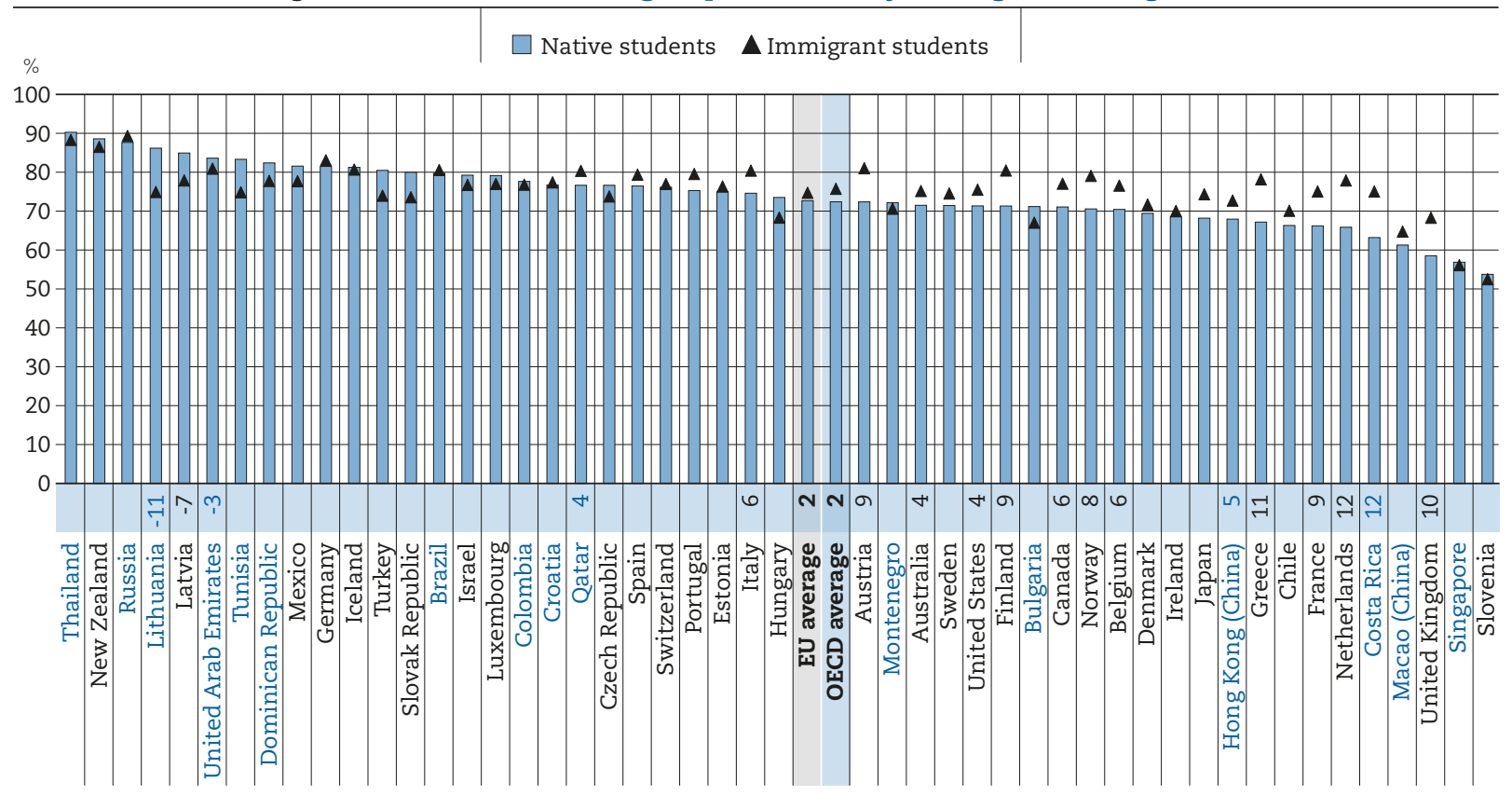

Notes: Only countries with valid values for immigrant students are shown.

Students who do unpaid work are those who reported that they had worked in the household or taken care of other family members before or after school during the most recent school day.

Statistically significant differences in the percentage of students doing unpaid work between immigrant and native students are shown next to the country/economy name.

Countries and economies are ranked in descending order of the percentage of native students doing unpaid work.

Source: OECD, PISA 2015 Database, Table 4.2.

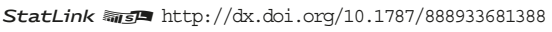

Table 4.3 (available on line) shows that accounting for the likelihood of doing unpaid work in the household reduces the academic gap between immigrant and native students only slightly. On average across OECD and EU countries, the percentage-point difference in the likelihood of attaining baseline academic proficiency between native and immigrant students decreased by 0.1 percentage point. The change was greater than 0.5 percentage point in Austria, Greece and the United Kingdom, where immigrant students were at least nine percentage points more likely than native students to work in the household.

\section{Participation in pre-primary education}

Attendance at pre-primary education is strongly associated with the academic proficiency and wellbeing of students and can be a mediating factor between immigrant background and academic resilience. Research shows that when students do not attend school, inequalities in education tend to increase (Downey, Von Hippel and Broh, 2004). By the time children first enter formal schooling many of these inequalities are already evident and tend to persist as students progress through education (Berlinski, Galiani and Gertler, 2009; Entwisle, Alexander and Olson, 1997; Mistry et al., 2010). Earlier entry into preprimary school helps students to be better prepared for entry into formal schooling (Chetty et al., 2011). 
However, to reduce inequalities in education it is essential that access to pre-primary education is universal and learning opportunities across pre-primary schools are of high quality and relatively homogeneous (PISA 2015). PISA 2015 shows that, across OECD countries, attendance at pre-primary school is associated with better performance at the age of 15, even after accounting for students' socioeconomic status. Furthermore, among students who had attended pre-primary education, disadvantaged students are more likely to have attended pre-primary education for shorter periods of time.

In 2015 PISA administered a questionnaire among the parents of students participating in the study asking, among other things, if their children had taken part in pre-primary education. ${ }^{3}$ Figure 4.8 shows that the rate at which immigrant students participate in pre-primary programmes varies significantly across countries. In Spain in 2015, 94\% of immigrant students had parents who reported that their children had attended a pre-primary programme as youngsters, while in Germany only $46 \%$ of them did. In 11 countries and economies out of the 16 included in the analysis, the rate of participation in pre-primary programmes was considerably lower among immigrant students than among native students (results for other categories of students with an immigrant background are available in Table 4.4 available on line). On average across OECD countries, $88 \%$ of the parent of native students reported that their children had participated in a pre-primary programme, while only $76 \%$ of immigrant students had parents who so reported (a difference of 12 percentage points; 13 percentage points on average across EU countries). The difference was greater than 15 percentage points in Belgium, Ireland, Italy, Malta and the United Kingdom.

Figure 4.8 - Students who had attended pre-primary education, by immigrant background Percentage-point difference between immigrant and native students in the proportion of students who had attended pre-primary education

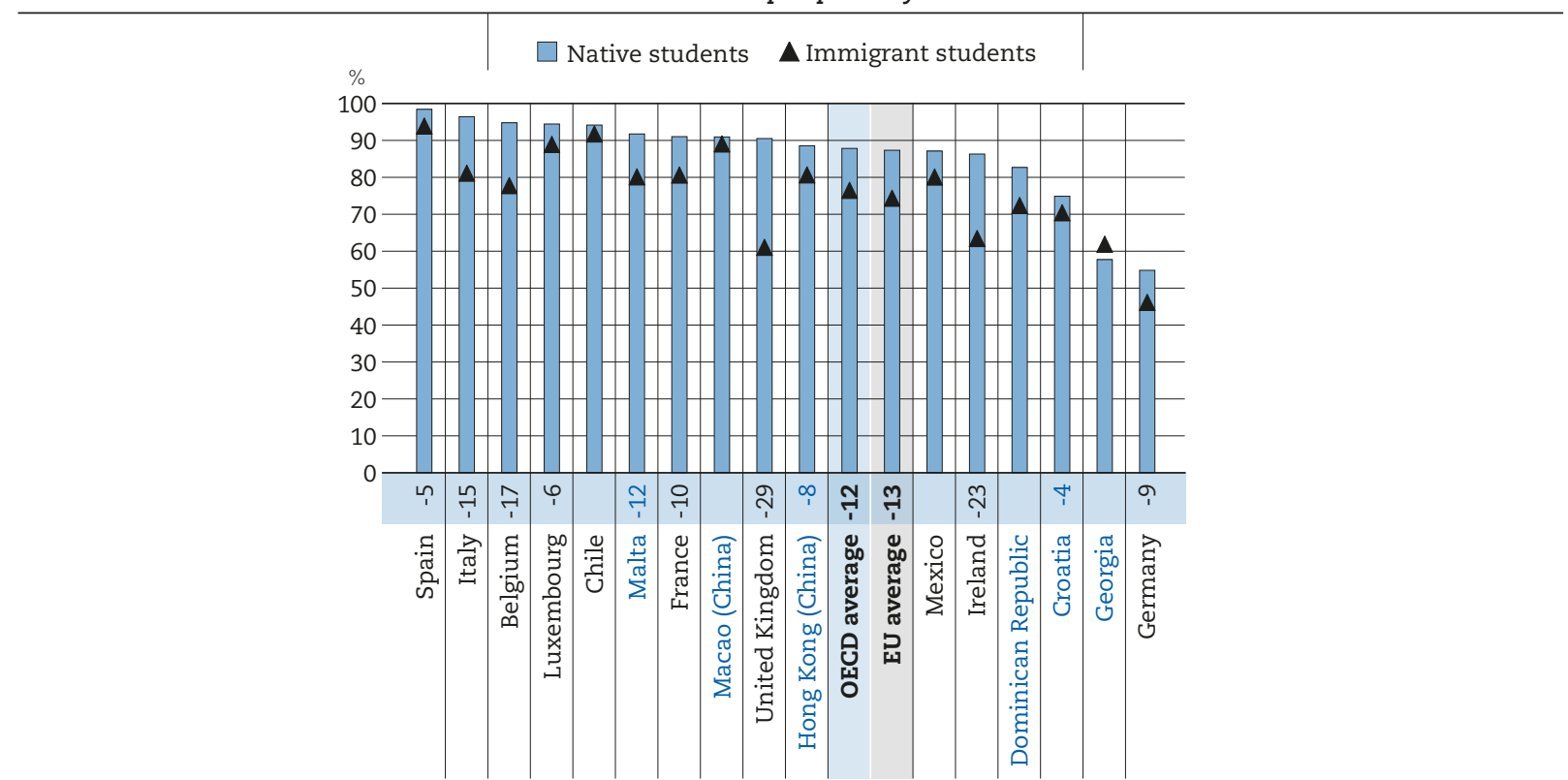

Notes: Only countries that distributed the parental questionnaire are shown.

Statistically significant differences in the percentage of students who attended pre-primary education between immigrant and native students are shown next to the country/economy name.

Countries and economies are ranked in descending order of the percentage of native students who had attended pre-primary education.

Source: OECD, PISA 2015 Database, Table 4.4.

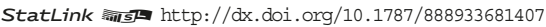

The difference in participation rates is attributable to different factors in each country. In some countries, it may be due to limited access to such programmes in immigrant students' countries of origin. Table 4.4 (available on line) shows that, in most countries and economies, second-generation immigrant students were more likely to have participated in a pre-primary programme than first-generation immigrant students. The difference between the two groups of immigrant students was nine percentage points across OECD countries (ten percentage points across EU countries). Second-generation immigrant students were 
thus only eight percentage points less likely to have attended pre-primary education than native students (seven percentage points across EU countries). In Croatia and Luxembourg, second-generation immigrant students were as likely as native students to have participated in a pre-primary programme, and were over 13 percentage points more likely than first-generation immigrant students to have done so.

In some countries, participation in pre-primary education was low among both first- and second-generation immigrant students. This could be due to parents' resistance to pre-primary education, possibly because these parents had little experience of these types of programmes in their country of origin. However, as shown in Table 4.4 (available on line), returning foreign-born students were also less likely than native students to have participated in a pre-primary programme. On average across OECD countries, they were six percentage points less likely to have done so (eight percentage points across EU countries); in France, Italy, Luxembourg and Malta, they were over 10 percentage points less likely.

In other countries, these differences could reflect a broader socio-economic divide. PISA finds that socio-economically disadvantaged students are considerably less likely than their more advantaged peers to have attended pre-primary education. Table 4.4 (available on line) reports the percentage-point difference in the percentage of native students and students with different immigrant backgrounds who had attended pre-primary programmes, before and after accounting for their socio-economic status. On average across OECD countries, controlling for socio-economic status reduces the gap between native and immigrant students in the percentage of students who had enrolled in pre-primary programmes from 12 to 11 percentage points (results for other categories of students with an immigrant background are available in Table 4.4 available on line). In all countries, accounting for socio-economic status reduces the gap between native and immigrant students by, at most, three percentage points. Differences in socioeconomic status between the two groups explain only a small part of the difference in participation rates.

Figure 4.9 - Difference between immigrant and native students in attaining baseline academic proficiency, by pre-primary education

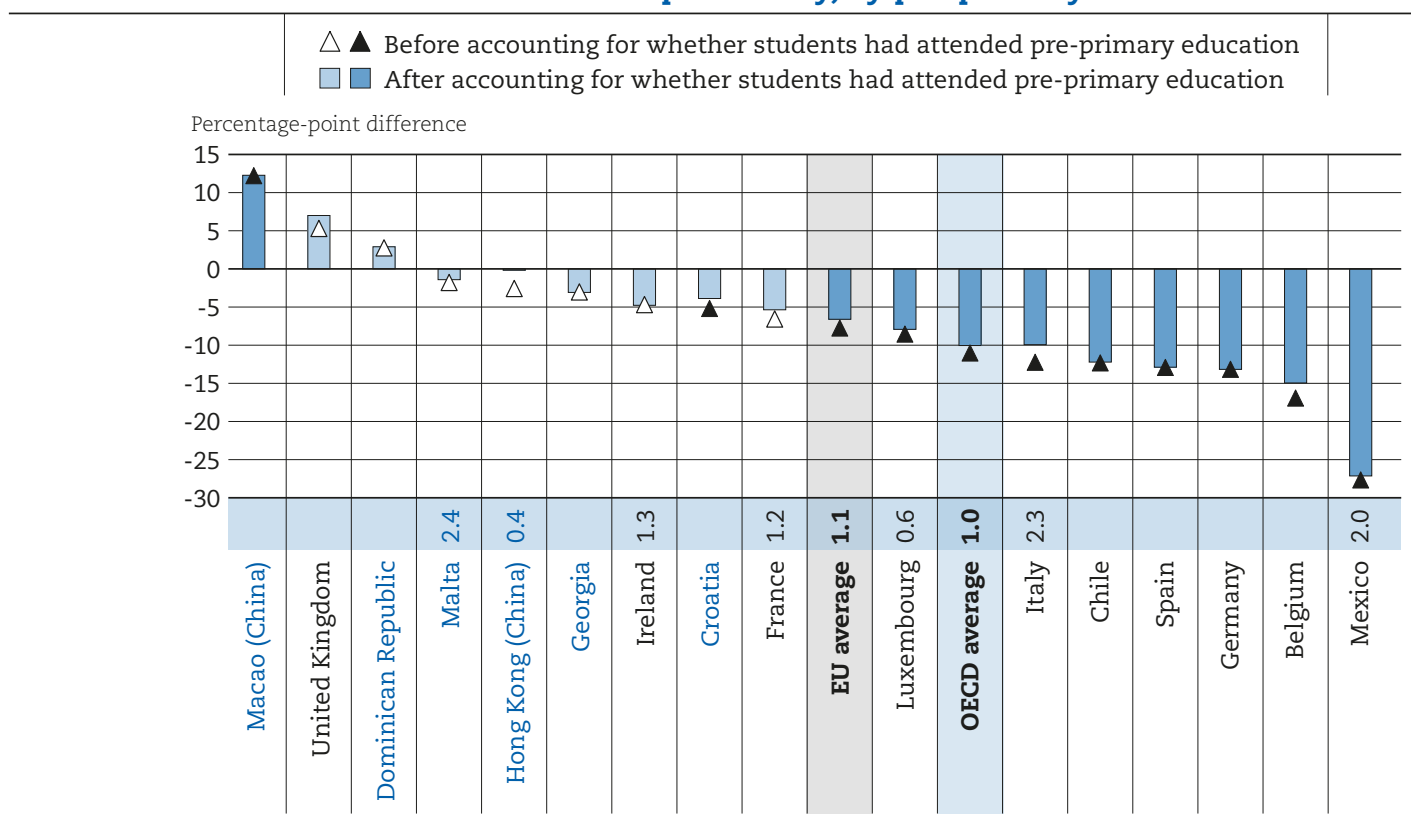

Notes: Statistically significant differences are marked in a darker tone.

Only countries that distributed the parental questionnaire are shown.

Results account for students' socio-economic status as measured by their score on the PISA index of economic, social and cultural status (ESCS).

Statistically significant differences in the immigrant-native gaps calculated before and after accounting for whether students had attended pre-primary education are shown next to the country/economy name.

Countries and economies are ranked in descending order of the percentage-point difference between immigrant and native students in the percentage of students attaining baseline academic proficiency, after accounting for whether students attended pre-primary education.

Source: OECD, PISA 2015 Database, Table 4.5.

StatLink inist http://dx.doi.org/10.1787/888933681426 
Figure 4.9 reveals that the gap in participation in pre-primary education between native and immigrant students explains part of the gap in academic performance between the two groups. On average across OECD and EU countries, the difference between native and immigrant students in the percentage of students who attained baseline academic proficiency decreases by one percentage point after accounting for participation in pre-primary education. In Belgium and Italy, the change associated with accounting for participation in pre-primary education socio-economic status was two percentage points.

\section{Gender differences}

In many OECD countries over the past few decades, the traditional gender gap in education outcomes, in which boys outperform girls, has been inverted. Evidence suggests that girls have overtaken boys in many academic areas (Breen et al. 2010; Buchmann, DiPrete, and McDaniel 2008). It is particularly striking that girls are consistently more likely than boys to achieve the baseline levels of proficiency in the three core PISA subjects (science, reading and mathematics), the indicator of academic adjustment examined in this report (OECD, 2015). At the same time, in many OECD societies, immigration is predominantly from countries where boys still outperform girls (Fleischmann and Kristen; 2014). Girls' advantage in education appears to be greater among children from socio-economically disadvantaged families (Entwisle, Alexander, and Olson 2007); since immigrant children are over-represented among disadvantaged students, it is possible that the gender gap in favour of girls might be more pronounced among immigrant students than native students.

A key question, therefore, is whether the gender gap among students with an immigrant background mirrors the gender gap that is prevalent among native students. Similarity between gender gaps observed within immigrant communities and gender gaps observed within native populations has been considered an important indicator of assimilation and integration, since gender norms often differ markedly between immigrant communities and native populations (Alba and Nee 1997; Fleischmann and Kristen; 2014).

There is little evidence concerning patterns of gender gaps within immigrant communities, but the evidence available points towards a general pattern of girls' advantage resembling that prevalent within native populations (Dronkers and Kornder 2014; Fleischmann and Kristen; 2014). Nonetheless, there is some heterogeneity related to the specific profile of immigrant communities and broad patterns of gender disparities in countries of destination (Fleischmann and Kristen; 2014).

Results presented in Table 4.7 (available on line) suggest similarities in the relative outcomes of boys and girls with an immigrant background and of native boys and girls. Gender gaps in academic achievement among students with an immigrant background are similar to those observed among native students. Among native students in 30 out of 72 countries, girls were more likely than boys (by around two percentage points across OECD and EU countries) to reach baseline levels of academic proficiency. In all countries except for Macao, Malta, and the United Arab Emirates, the gender gap in favour of girls was similar among all groups of immigrant students, while in Mexico and New Zealand, girls' advantage was even more pronounced among first-generation immigrants.

Gender gaps in social and emotional outcomes are also similar across immigrant backgrounds. In 42 countries and economies, among native students, girls were more likely than boys to report a sense of belonging at school. In Germany, the same was true among second-generation immigrant students, while the opposite was true among native students. In Iceland, native boys and girls expressed a similarly strong sense of belonging while, among first-generation immigrant students, girls were significantly more likely than boys to report a sense of belonging at school. Table 4.9 (available on line) shows that these gender gaps are inverted when it comes to life satisfaction. In 40 out of 46 countries and economies with available data, native boys were more likely than native girls (by around 10 percentage points across OECD and 11 percentage points across EU countries) to report being satisfied with life. In Chile, the gap was reversed among first-generation immigrant students, while in Portugal this gap was even larger among second-generation immigrant students.

In all countries with available data except for the Dominican Republic, Macao (China) and the United Arab Emirates, native girls were less likely than native boys to report low levels of schoolwork-related anxiety. The gap was greater than 10 percentage points in most countries; on average across OECD 
and EU countries it was as large as 17 percentage points. In Canada, Chile, Costa Rica, Finland and Ireland, the gap was narrower among first-generation immigrant students; in Australia, Canada, Italy, Luxembourg and the United Kingdom, it was smaller among second-generation immigrant students. Girls also tended to report lower levels of motivation than boys in most countries and economies. On average across OECD countries, among native students, girls were six percentage points less likely to report high levels of achievement motivation (seven percentage points less likely across EU countries). However, among first-generation immigrant students, the gap was four percentage points (six percentage points across EU countries). In Chile, New Zealand and the United Kingdom, among first-generation immigrant students, girls were more likely than boys to report high levels of achievement motivation. In Austria and Belgium the gender gap in achievement motivation was still in favour of boys, but was narrower among first-generation immigrant students than among native students.

In order to identify differences in gender gaps related to the region of origin, analyses were conducted on the pooled sample of immigrant students and of students with an immigrant background who participated in PISA 2015 introducing the students' region of origin (with the European and North American region as the reference group) as a variable, controlling for students' and schools' socio-economic profile and country of destination. Analyses do not reveal any differences in the gender gaps related to region of origin (Table 4.12). Subsample analyses were conducted on foreign-born and native-born students (models 2 and 3 in each table) to identify possible assimilation processes or differences associated with recent arrival from a particular region of the world (Table 4.12). No gender gaps emerge.

\section{Table 4.12 Change in the likelihood that students will reach baseline levels of academic proficiency, regression-based coefficients}

\begin{tabular}{|c|c|c|c|c|c|c|}
\hline & \multicolumn{6}{|c|}{ Effect on the likelihood of attaining baseline academic proficiency } \\
\hline & $\begin{array}{l}\text { Students with } \\
\text { an immigrant } \\
\text { background }\end{array}$ & $\begin{array}{c}\text { Native-born } \\
\text { students with } \\
\text { an immigrant } \\
\text { background }\end{array}$ & $\begin{array}{c}\text { Foreign-born } \\
\text { students with } \\
\text { an immigrant } \\
\text { background }\end{array}$ & $\begin{array}{l}\text { Immigrant } \\
\text { students }\end{array}$ & $\begin{array}{c}\text { First- } \\
\text { generation } \\
\text { immigrant } \\
\text { students }\end{array}$ & $\begin{array}{l}\text { Second- } \\
\text { generation } \\
\text { immigrant } \\
\text { students }\end{array}$ \\
\hline Female students & $\begin{array}{r}1.52 \\
(1.60)\end{array}$ & $\begin{array}{r}1.34 \\
(1.86)\end{array}$ & $\begin{array}{r}0.82 \\
(1.79)\end{array}$ & $\begin{array}{r}1.16 \\
(1.62)\end{array}$ & $\begin{array}{r}0.81 \\
(2.28)\end{array}$ & $\begin{array}{r}0.81 \\
(2.28)\end{array}$ \\
\hline Socio-economic status (ESCS) & $\begin{array}{l}5.73^{* * * *} \\
(0.61)\end{array}$ & $\begin{array}{l}6.24^{* * * *} \\
(0.73)\end{array}$ & $\begin{array}{l}3.41^{* * * *} \\
(1.00)\end{array}$ & $\begin{array}{c}2.44^{* * *} \\
(0.78)\end{array}$ & $\begin{array}{l}3.91^{* * *} \\
(1.06)\end{array}$ & $\begin{array}{c}1.84^{*} \\
(0.99)\end{array}$ \\
\hline $\begin{array}{l}\text { School Socio-economic profile } \\
\text { (school average ESCS) }\end{array}$ & $\begin{array}{l}22.49^{* * *} \\
(1.47)\end{array}$ & $\begin{array}{l}22.1^{\text {**** }} \\
(1.64)\end{array}$ & $\begin{array}{l}22.43^{* * *} \\
(2.60)\end{array}$ & $\begin{array}{l}27.9^{* * *} \\
(1.97)\end{array}$ & $\begin{array}{l}28.09^{* * *} \\
(2.10)\end{array}$ & $\begin{array}{l}26.96^{* * *} \\
(2.80)\end{array}$ \\
\hline Oceania & $\begin{array}{l}-5.14^{* *} \\
(2.36)\end{array}$ & $\begin{array}{r}-4.39 \\
(2.79)\end{array}$ & $\begin{array}{l}-14.67^{* *} \\
(6.20)\end{array}$ & $\begin{array}{l}-11.63^{* * *} \\
(4.46)\end{array}$ & $\begin{array}{l}-15.37^{* *} \\
(6.72)\end{array}$ & $\begin{array}{l}-6.45 \\
(6.03)\end{array}$ \\
\hline South America & $\begin{array}{r}1.99 \\
(3.17)\end{array}$ & $\begin{array}{r}3.42 \\
(3.57)\end{array}$ & $\begin{array}{r}1.99 \\
(6.65)\end{array}$ & $\begin{array}{r}1.22 \\
(5.73)\end{array}$ & $\begin{array}{r}5.98 \\
(7.82)\end{array}$ & $\begin{array}{l}-2.26 \\
(6.72)\end{array}$ \\
\hline Africa & $\begin{array}{l}-3.06 \\
(2.73)\end{array}$ & $\begin{array}{l}-1.94 \\
(2.95)\end{array}$ & $\begin{array}{l}-9.62^{*} \\
(5.58)\end{array}$ & $\begin{array}{l}-0.66 \\
(3.95)\end{array}$ & $\begin{array}{l}-6.25 \\
(6.07)\end{array}$ & $\begin{array}{l}-2.15 \\
(4.56)\end{array}$ \\
\hline East Asia and South East Asia & $\begin{array}{c}3.86^{*} \\
(2.23)\end{array}$ & $\begin{array}{l}8.2^{* * * *} \\
(2.97)\end{array}$ & $\begin{array}{l}-7.48 \\
(5.03)\end{array}$ & $\begin{array}{r}3.28 \\
(3.20)\end{array}$ & $\begin{array}{c}-11.03^{* *} \\
(4.32)\end{array}$ & $\begin{array}{l}10.98^{\text {*** }} \\
(4.13)\end{array}$ \\
\hline Western Asia & $\begin{array}{l}-7.53^{* * *} \\
(2.75)\end{array}$ & $\begin{array}{l}-8.24^{* * *} \\
(3.06)\end{array}$ & $\begin{array}{l}-10.48^{*} \\
(5.68)\end{array}$ & $\begin{array}{l}-10.6^{* * *} \\
(3.88)\end{array}$ & $\begin{array}{r}-10.01 \\
(6.24)\end{array}$ & $\begin{array}{l}-14.85^{* * *} \\
(4.26)\end{array}$ \\
\hline Central America and Caribbean & $\begin{array}{r}-8.72 \\
(7.60)\end{array}$ & $\begin{array}{r}6.28 \\
(8.59)\end{array}$ & $\begin{array}{l}-3.25 \\
(9.86)\end{array}$ & $\begin{array}{r}4.68 \\
(8.46)\end{array}$ & $\begin{array}{r}1.45 \\
(12.30)\end{array}$ & $\begin{array}{r}5.73 \\
(10.16)\end{array}$ \\
\hline Female*Africa & $\begin{array}{l}-2.43 \\
(3.43)\end{array}$ & $\begin{array}{l}-2.11 \\
(4.06)\end{array}$ & $\begin{array}{r}2.44 \\
(6.61)\end{array}$ & $\begin{array}{l}-1.17 \\
(4.73)\end{array}$ & $\begin{array}{r}2.01 \\
(6.88)\end{array}$ & $\begin{array}{r}-0.72 \\
(5.74)\end{array}$ \\
\hline $\begin{array}{l}\text { Female*Central America } \\
\text { and Caribbean }\end{array}$ & $\begin{array}{l}-3.14 \\
(6.60)\end{array}$ & $\begin{array}{l}-2.95 \\
(7.18)\end{array}$ & $\begin{array}{r}3.65 \\
(6.98)\end{array}$ & $\begin{array}{l}-2.76 \\
(3.97)\end{array}$ & $\begin{array}{r}3.37 \\
(7.82)\end{array}$ & $\begin{array}{l}-4.57 \\
(5.01)\end{array}$ \\
\hline $\begin{array}{l}\text { Female*East Asia and South East } \\
\text { Asia }\end{array}$ & $\begin{array}{r}1.91 \\
(2.78)\end{array}$ & $\begin{array}{r}2.13 \\
(2.82)\end{array}$ & $\begin{array}{r}2.3 \\
(6.49)\end{array}$ & $\begin{array}{r}1.12 \\
(2.44)\end{array}$ & $\begin{array}{r}2.48 \\
(4.35)\end{array}$ & $\begin{array}{r}0.09 \\
(3.14)\end{array}$ \\
\hline Female*Oceania & $\begin{array}{r}3.8 \\
(3.03)\end{array}$ & $\begin{array}{r}1.58 \\
(2.91)\end{array}$ & $\begin{array}{l}14.29 \\
(9.49)\end{array}$ & $\begin{array}{r}4.49 \\
(5.34)\end{array}$ & $\begin{array}{r}7.29 \\
(7.19)\end{array}$ & $\begin{array}{r}0.05 \\
(7.65)\end{array}$ \\
\hline Female*South America & $\begin{array}{l}-4.28 \\
(2.82)\end{array}$ & $\begin{array}{l}-4.67 \\
(3.08)\end{array}$ & $\begin{array}{r}1.96 \\
(9.73)\end{array}$ & $\begin{array}{r}-3.2 \\
(6.94)\end{array}$ & $\begin{array}{r}-7.4 \\
(11.02)\end{array}$ & $\begin{array}{r}-0.1 \\
(9.23)\end{array}$ \\
\hline Female*Western Asia & $\begin{array}{l}-0.58 \\
(3.31)\end{array}$ & $\begin{array}{r}-1.08 \\
(3.59)\end{array}$ & $\begin{array}{r}6.54 \\
(6.36)\end{array}$ & $\begin{array}{r}6.53 \\
(4.04)\end{array}$ & $\begin{array}{r}9.06 \\
(6.93)\end{array}$ & $\begin{array}{r}5.51 \\
(4.62)\end{array}$ \\
\hline Adjuted R squared & 0.230 & 0.230 & 0.250 & 0.243 & 0.249 & 0.251 \\
\hline Number of Observations & 69148 & 53105 & 16043 & 28482 & 11569 & 16913 \\
\hline
\end{tabular}

Notes: Standard error in parentheses.

${ }^{*} \mathrm{p}<0.10,{ }^{* *} \mathrm{p}<0.05,{ }^{* * *} \mathrm{p}<0.01$

North American and European students are the base case to which students from other regions are compared.

ESCS refers to the PISA index of economic, social and cultural status.

Source: OECD, PISA 2015 Database.

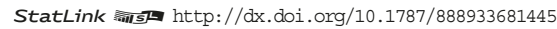




\section{Notes}

1. Students who attain at least proficiency Level 2 in all three PISA core subjects - science, reading and mathematics.

2. Students who reported that they "agree" or "strongly agree" with the statement "I feel like I belong at school", and "disagree" or "strongly disagree" with the statement "I feel like an outsider at school".

3. Information on participation in pre-primary education is also asked to the students themselves. However, since students may not adequately remember about their participation in such activities and recollection may vary across groups of students, the analyses presented in this chapter are based on data derived from the parental questionnaire.

\section{References}

Alba, R. and V. Nee. (1997), "Rethinking assimilation theory for a new era of Immigration" International Migration Review, Vol. 31/4, pp. 826-74.

Berlinski, S., S. Galiani and P. Gertler (2009), "The effect of pre-primary education on primary school performance", Journal of Public Economics, Vol. 93/1, pp. 219-234, www.ifs.org.uk/publications/3583.

Breen, R. et al. (2010), "Long-term trends in educational inequality in Europe: Class inequalities and gender differences." European Sociological Review, Vol. 26/1, pp. 31-48.

Buchmann, C., T.A. DiPrete and A. McDaniel (2008), "Gender inequalities in education” Annual Review of Sociology, Vol. 34, pp. 319-37.

Chetty, R. et al. (2011), "How does your kindergarten classroom affect your earnings? Evidence from Project STAR", The Quarterly Journal of Economics, Vol. 126/4, pp. 1593-1660, http://dx.doi.org/10.3386/w16381.

Downey, D., P. Von Hippel and B. Broh (2004), "Are schools the great equalizer? Cognitive inequality over the summer months and the school year", American Sociological Review, Vol. 69/5, pp. 613-635, www.jstor.org/stable/3593031.

Dronkers, J. and N. Kornder (2014), "Do migrant girls always perform better? Differences between the reading and math Scores of 15-year-old daughters and sons of migrants in PISA 2009", Educational Research and Evaluation, Vol. 20/1, pp. 44-66.

Entwisle, D.R., K.L. Alexander and L.S. Olson (2007), "Early schooling: The handicap of being poor and male", Sociology of Education, Vol. 80/2, pp. 114-38.

Entwisle, D., K. Alexander and L. Olson (1997), Children, Schools and Inequality, Westview Press, Boulder, CO.

Fleischmann, F. and C. Kristen (2014) "Gender Inequalities in the Education of the Second Generation in Western Countries”, Sociology of Education, Vol. 87/3, pp. 143-170.

Gager, C.T., T.M. Cooney and K.T. Call (1999), "The effects of family characteristics and time use on teenagers' household labor", Journal of Marriage and Family, Vol. 61/2, pp. 982-994, http://dx.doi.org/10.2307/354018.

Mistry, R.S. et al. (2010), "Family and social risk, and parental investments during the early childhood years as predictors of low-income children's school readiness outcomes", Early Childhood Research Quarterly, Vol. 25/4, pp. 432-449, http:// dx.doi.org/10.1016/j.ecresq.2010.01.002.

OECD (2015), The ABC of Gender Equality in Education: Aptitude, Behaviour, Confidence, OECD Publishing, Paris, http://dx.doi.org/10.1787/9789264229945-en.

OECD (2017), PISA 2015 Results (Volume III): Students' Well-Being, OECD Publishing, Paris, http://dx.doi.org/10.1787/ 9789264273856-en. 



\title{
Chapter 5 \\ Language barriers and the resilience of students with an immigrant background
}

\begin{abstract}
Immigrant students face multiple sources of disadvantage that affect their academic performance and their general well-being. Fluency in the language spoken in the host country is one of these source factors. Language barriers can also amplify the effects of other sources of disadvantage, such as having migrated after the age of 12, lack of parental support, studying in a disadvantaged school or attending a school with a poor disciplinary climate. This chapter examines language as a risk factor when considering the academic, social, emotional and motivational resilience of immigrant students.
\end{abstract}

\section{Notes regarding Cyprus}

Note by Turkey: The information in this document with reference to "Cyprus" relates to the southern part of the Island. There is no single authority representing both Turkish and Greek Cypriot people on the Island. Turkey recognises the Turkish Republic of Northern Cyprus (TRNC). Until a lasting and equitable solution is found within the context of the United Nations, Turkey shall preserve its position concerning the "Cyprus issue".

Note by all the European Union Member States of the OECD and the European Union: The Republic of Cyprus is recognised by all members of the United Nations with the exception of Turkey. The information in this document relates to the area under the effective control of the Government of the Republic of Cyprus.

\section{Note regarding data from Israel}

The statistical data for Israel are supplied by and under the responsibility of the relevant Israeli authorities. The use of such data by the OECD is without prejudice to the status of the Golan Heights, East Jerusalem and Israeli settlements in the West Bank under the terms of international law. 


\section{What the data tell us}

- The language spoken at home strongly affects the likelihood that immigrant students will be academically resilient. On average across OECD countries, immigrant students who do not speak the language of assessment at home are around eight percentage points less likely to be academically resilient than native-speaking immigrant students (nine percentage points less likely across EU countries).

- On average across OECD countries, native-speaking immigrant students with at least one foreignborn parent are two percentage points less likely than native students to attain baseline levels of proficiency in the core PISA subjects, while non-native-speaking immigrant students are about 17 percentage points less likely to do so (EU figures 3 and 18 percentage points).

- Immigrant students who are non-native speakers are five percentage points less likely than those who are native speakers to report a sense of belonging at school, on average across OECD countries (six percentage points less likely across EU countries).

- The greater the linguistic distance between the language spoken at home and the language of instruction, the less likely a student will attain baseline academic proficiency and report a sense of belonging at school.

$\mathbf{R}$ esearch indicates that fluency in the host-country language is one of the most important determinants of social and economic integration of immigrant students (OECD, 2006). Since humans communicate first and foremost by speaking, writing and reading, learning the language spoken in the host country has an immediate impact on immigrants' lives and on their integration. Investing in acquiring the host-country language has a positive impact on almost all facets of life but especially so on the integration of immigrant children in education settings (Van Tubergen, Maas and Flap, 2004; Van Tubergen and Kalmijn, 2005).

In the economic domain, language fluency is positively associated with higher productivity and wages because it facilitates the transfer and adaptation of skills in the job market (Chiswick and Miller, 1995; Hayfron, 2001; Dustmann and Fabbri, 2003; Dustmann and Soest, 2001). Likewise, immigrants with good language skills are more likely to be better at searching for work and landing jobs that match their skills and qualifications (Leslie and Lindley, 2001; Frijters, Shields and Price, 2005). It is also easier for immigrants who are fluent in the host-country language to acquire additional education, training and experience in the labour market.

Figure 5.1 - The role of the language spoken at home in the resilience process

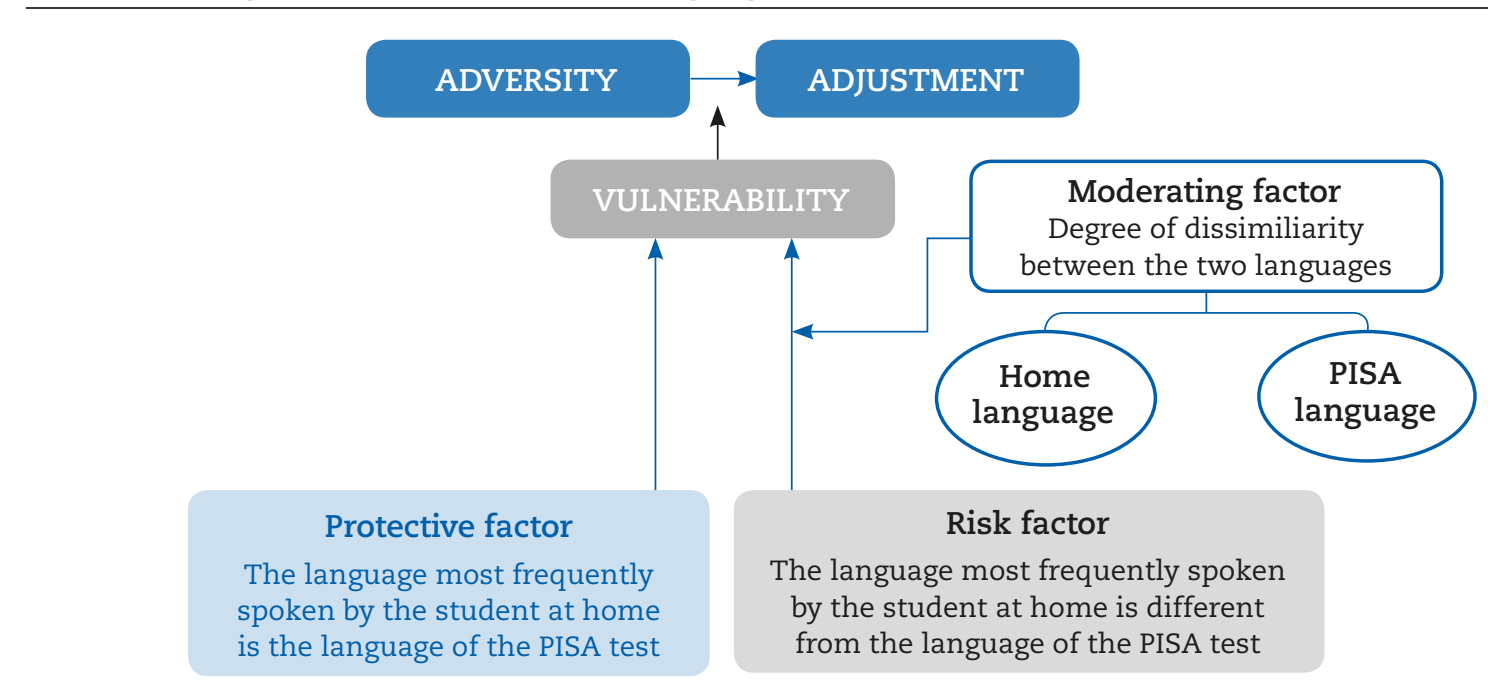


Table 5.1 - Snapshot of language barriers to attaining baseline academic proficiency

\begin{tabular}{|c|c|c|c|c|c|c|}
\hline & \multicolumn{6}{|c|}{$\begin{array}{l}\text { Countries/economices with values above the OECD average } \\
\text { Countries/economices with values not significantly different from the OECD average } \\
\text { Countries/economices with values below the OECD average }\end{array}$} \\
\hline & $\begin{array}{c}\text { Share of immigrant } \\
\text { students who } \\
\text { are non-native } \\
\text { speakers }\end{array}$ & $\begin{array}{c}\text { Relative risk } \\
\text { of native-speaking } \\
\text { immigrant } \\
\text { students not being } \\
\text { academically } \\
\text { resilient (compared } \\
\text { to native-speaking } \\
\text { native students) } \\
\end{array}$ & $\begin{array}{c}\text { Relative risk } \\
\text { of non-native } \\
\text { speaking immigrant } \\
\text { students not being } \\
\text { academically } \\
\text { resilient (compared } \\
\text { to non-native- } \\
\text { speaking native } \\
\text { students) } \\
\end{array}$ & $\begin{array}{l}\text { Share of } \\
\text { immigrant } \\
\text { students with } \\
\text { at least one } \\
\text { native-born } \\
\text { parent who } \\
\text { are non-native } \\
\text { speakers } \\
\end{array}$ & $\begin{array}{c}\text { Relative risk } \\
\text { of native-speaking } \\
\text { immigrant students } \\
\text { with at least } \\
\text { one native-born } \\
\text { parent not being } \\
\text { academically resilient } \\
\text { (compared to native- } \\
\text { speaking native } \\
\text { students) } \\
\end{array}$ & $\begin{array}{c}\text { Relative risk of } \\
\text { non-native-speaking } \\
\text { immigrant students } \\
\text { with at least one } \\
\text { native-born parent not } \\
\text { being academically } \\
\text { resilient (compared to } \\
\text { non-native-speaking } \\
\text { native students) }\end{array}$ \\
\hline OECD average & 49.18 & 1.52 & 1.12 & 12.74 & 1.05 & 0.99 \\
\hline EU average & 48.50 & 1.59 & 1.20 & 17.79 & 1.11 & 1.02 \\
\hline Lebanon & 97.87 & c & 1.05 & 97.38 & c & 0.83 \\
\hline Iceland & 83.25 & c & $\mathrm{c}$ & 9.58 & 1.04 & C \\
\hline Finland & 76.95 & 2.56 & 1.93 & 12.11 & 1.15 & 1.51 \\
\hline Luxembourg & 76.54 & $c$ & 2.38 & 83.82 & c & 1.51 \\
\hline Austria & 74.25 & 1.62 & 1.34 & 22.86 & 1.05 & 1.17 \\
\hline Slovenia & 73.58 & 1.84 & 0.89 & 12.02 & 1.19 & 0.92 \\
\hline Singapore & 70.02 & 0.73 & 0.4 & 52.65 & 0.88 & 0.67 \\
\hline Sweden & 68.09 & 1.9 & 1.66 & 13.52 & 1.05 & 1.2 \\
\hline United States & 66.93 & 1.2 & 0.8 & 13.44 & 1.03 & 0.84 \\
\hline Czech Republic & 65.82 & 1.71 & 0.68 & 10.94 & 1.13 & 0.69 \\
\hline Switzerland & 65.1 & 1.83 & 1.53 & 17.7 & 1.33 & 1.2 \\
\hline Japan & 62.04 & c & c & 6.3 & 1.31 & c \\
\hline Malta & 61.72 & 1.75 & 0.93 & 72.19 & 1.56 & 0.97 \\
\hline Italy & 59.13 & 1.48 & 1.21 & 15.86 & 1 & 1.06 \\
\hline Norway & 58.74 & 1.79 & 0.97 & 8.08 & 1.09 & 0.81 \\
\hline Germany & 54.33 & 1.99 & 0.98 & 15.89 & 1.51 & 1.03 \\
\hline Cyprus** & 53.18 & 0.92 & 1.58 & 25.29 & 0.92 & 1.1 \\
\hline Belgium & 52.97 & 2.03 & 1.54 & 23.78 & 1.33 & 1.16 \\
\hline Spain & 52.27 & 1.72 & 1.96 & 23.66 & 0.91 & 1.13 \\
\hline Bulgaria & 52.11 & c & 0.82 & 16.9 & 1.15 & 0.92 \\
\hline Slovak Republic & 51.68 & 1.8 & 0.87 & 10.02 & 1.18 & 0.89 \\
\hline Denmark & 50.54 & 2.37 & 1.36 & 7.71 & 1.02 & 1.07 \\
\hline Canada & 49.52 & 0.89 & 0.72 & 8.97 & 0.96 & 0.83 \\
\hline Ireland & 49.46 & 1.02 & c & 0.91 & 0.89 & $c$ \\
\hline United Arab Emirates & 48.63 & 0.58 & 0.52 & 23.25 & 0.9 & 0.86 \\
\hline Qatar & 47.84 & 0.61 & 0.56 & 30.06 & 0.9 & 0.95 \\
\hline Netherlands & 47.73 & 1.67 & 0.82 & 10.69 & 1.19 & 0.71 \\
\hline United Kingdom & 44.04 & 1.2 & 0.93 & 5.77 & 0.98 & 1.21 \\
\hline Israel & 42.44 & 1.06 & 0.72 & 8.97 & 0.7 & 0.69 \\
\hline France & 41.41 & 1.86 & 0.94 & 9.97 & 1.1 & 0.98 \\
\hline New Zealand & 41.07 & 0.94 & 0.55 & 3.45 & 0.82 & c \\
\hline Australia & 38.38 & 0.84 & 0.46 & 4.49 & 0.84 & 0.71 \\
\hline Greece & 35.58 & 1.46 & 0.85 & 6.33 & 1.01 & 0.54 \\
\hline Tunisia & 33.59 & 1.15 & c & 20.36 & 0.99 & 1.08 \\
\hline Turkey & 30.74 & 1.09 & c & 5.15 & 0.68 & c \\
\hline Uruguay & 28.6 & c & c & 12.67 & 1.02 & 0.98 \\
\hline Dominican Republic & 27.96 & 1 & C & 10.21 & 0.98 & c \\
\hline Albania & 27.91 & c & c & 7.63 & 1.03 & c \\
\hline Lithuania & 26.72 & 0.97 & 0.72 & 16.14 & 1.12 & 0.74 \\
\hline FYROM & 26.38 & 1.17 & C & 14 & 0.98 & 0.87 \\
\hline Thailand & 25.99 & 1.1 & c & 9.22 & 0.99 & c \\
\hline Latvia & 25.59 & 1.15 & 1.3 & 16.34 & 1.09 & 1.05 \\
\hline Portugal & 25.4 & 1.29 & c & 3.09 & 0.82 & c \\
\hline B-S-J-G (China) & 21.96 & c & c & 2.48 & 2.93 & c \\
\hline Mexico & 20.93 & 1.54 & c & 8.87 & 1.06 & c \\
\hline Hungary & 20.1 & 0.84 & 0.71 & 6.91 & 0.75 & c \\
\hline Trinidad and Tobago & 18.78 & 1.24 & c & 3.04 & 0.95 & c \\
\hline Brazil & 15.02 & 1.3 & c & 8.36 & 1.03 & 1.26 \\
\hline Russia & 14.96 & 1.07 & 1.42 & 1.1 & 0.96 & c \\
\hline Peru & 14.8 & c & c & 15.42 & 1.04 & c \\
\hline Macao (China) & 14.13 & 0.53 & 0.84 & 20.44 & 0.77 & 0.8 \\
\hline Moldova & 14.13 & 0.9 & C & 14.38 & 0.87 & 1.07 \\
\hline Estonia & 13.82 & 1.58 & 1.09 & 17.91 & 1.36 & 0.76 \\
\hline Georgia & 13.79 & 0.96 & c & 13.22 & 0.93 & 0.91 \\
\hline Montenegro & 13.38 & 0.87 & 0.76 & 3.29 & 0.86 & 0.9 \\
\hline Algeria & 13.2 & 1.04 & c & 21.38 & 0.98 & c \\
\hline CABA (Argentina) & 12.43 & 1.92 & c & 5.02 & 1.28 & c \\
\hline Colombia & 8.39 & 1.27 & c & 4.25 & 1.13 & c \\
\hline Croatia & 7.92 & 1.23 & 1.05 & 4.54 & 0.96 & 1.04 \\
\hline Hong Kong (China) & 7.58 & 1.14 & c & 3.11 & 1.19 & c \\
\hline Jordan & 6.42 & 0.91 & 1.09 & 7.57 & 0.85 & 0.97 \\
\hline Costa Rica & 4.69 & 1.24 & c & 5.32 & 1.05 & c \\
\hline Chile & 4.46 & 1.32 & c & 6.45 & 0.88 & c \\
\hline Kosovo & 3.29 & 1.06 & c & 2.17 & 0.93 & c \\
\hline Korea & c & c & c & 1.66 & 1 & c \\
\hline Poland & c & c & C & 12.84 & 1.13 & c \\
\hline Indonesia & c & c & c & 45.73 & $c$ & c \\
\hline Romania & c & c & c & 20.16 & 1.17 & c \\
\hline Chinese Taipei & c & c & c & 2.23 & 1.14 & c \\
\hline Viet Nam & c & c & c & 5.3 & 0.92 & c \\
\hline
\end{tabular}

* See note at the beginning of this Chapter.

Notes: Native-speaking students are students who speak most frequently at home the language of the PISA assessment.

Non-native-speaking students are students who reported that the language they most frequently speak at home is different from the language of the PISA assessment.

Academically resilient students are students with an immigrant background who attained at least proficiency Level 2 in all three core PISA subjects: science, reading and mathematics.

Source: OECD, PISA 2015 Database, Table 5.4

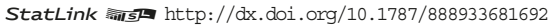


Table 5.2 - Snapshot of language barriers to feeling a sense of belonging at school

\begin{tabular}{|c|c|c|c|c|}
\hline & \multicolumn{4}{|c|}{$\begin{array}{l}\text { Countries/economices with values above the OECD average } \\
\text { Countries/economices with values not significantly different from the OECD average } \\
\text { Countries/economices with values below the OECD average }\end{array}$} \\
\hline & $\begin{array}{l}\text { Relative risk of native- } \\
\text { speaking immigrant students } \\
\text { not being socially resilient } \\
\text { (compared to native-speaking } \\
\text { native students) (sense of } \\
\text { belonging at school) }\end{array}$ & $\begin{array}{l}\text { Relative risk of non-native- } \\
\text { speaking immigrant students } \\
\text { not being socially resilient } \\
\text { (compared to non-native- } \\
\text { speaking native students) } \\
\text { (sense of belonging at school) }\end{array}$ & $\begin{array}{l}\text { Relative risk of native- } \\
\text { speaking immigrant students } \\
\text { with at least one native-born } \\
\text { parent not being socially } \\
\text { resilient (compared to native- } \\
\text { speaking native students) } \\
\text { (sense of belonging at school) }\end{array}$ & $\begin{array}{l}\text { Relative risk of non-native- } \\
\text { speaking immigrant students } \\
\text { with at least one native-born } \\
\text { parent not being socially } \\
\text { resilient (compared to } \\
\text { non-native-speaking native } \\
\text { students) (sense of belonging } \\
\text { at school) }\end{array}$ \\
\hline OECD average & 1.11 & 1.03 & 1.08 & 1.04 \\
\hline EU average & 1.15 & 1.08 & 1.10 & 1.06 \\
\hline Australia & 0.74 & 0.65 & 0.93 & 0.95 \\
\hline Norway & 0.74 & 0.63 & 1.06 & 0.94 \\
\hline Lithuania & 0.77 & 0.96 & 1.03 & 0.88 \\
\hline Luxembourg & 0.79 & 1.56 & 0.86 & 1.21 \\
\hline New Zealand & 0.8 & 0.6 & 0.96 & c \\
\hline United Kingdom & 0.8 & 1.23 & 0.97 & 0.88 \\
\hline Finland & 0.84 & 0.81 & 1.11 & 0.99 \\
\hline Qatar & 0.85 & 0.65 & 1.01 & 0.94 \\
\hline Canada & 0.89 & 0.76 & 1.06 & 0.96 \\
\hline Hungary & 0.91 & 1.04 & 0.97 & c \\
\hline Singapore & 0.97 & 0.84 & 1.11 & 0.94 \\
\hline Georgia & 0.98 & c & 1.28 & 1.3 \\
\hline Chile & 0.99 & c & 1 & c \\
\hline Austria & 0.99 & 1.16 & 0.97 & 1.26 \\
\hline Costa Rica & 1.03 & $c$ & 1.14 & $c$ \\
\hline United Arab Emirates & 1.03 & 0.65 & 1.08 & 0.88 \\
\hline Macao (China) & 1.05 & 1.04 & 1.13 & 0.87 \\
\hline Hong Kong (China) & 1.05 & 1.34 & 1.02 & 1 \\
\hline Russia & 1.1 & 1.2 & 1.07 & c \\
\hline France & 1.11 & 0.89 & 1.02 & 1.02 \\
\hline United States & 1.11 & 1.16 & 1.1 & 1.11 \\
\hline Netherlands & 1.11 & 1.2 & 1.12 & 1.31 \\
\hline Croatia & 1.12 & 0.78 & 1.02 & 0.87 \\
\hline Germany & 1.13 & 1 & 1.14 & 1.08 \\
\hline Italy & 1.13 & 1.14 & 1.11 & 0.93 \\
\hline Moldova & 1.16 & c & 1.15 & 0.87 \\
\hline Slovenia & 1.17 & 0.68 & 1.09 & 0.88 \\
\hline Sweden & 1.18 & 0.86 & 1.2 & 0.88 \\
\hline Jordan & 1.18 & 1.18 & 1.08 & 1.01 \\
\hline Turkey & 1.19 & $c$ & 1.07 & c \\
\hline Greece & 1.2 & 0.96 & 1.06 & 0.97 \\
\hline Czech Republic & 1.2 & 1 & 0.95 & 1 \\
\hline Montenegro & 1.21 & 1.23 & 1.11 & 1.55 \\
\hline Ireland & 1.24 & $\mathrm{~m}$ & 1.04 & $\mathrm{~m}$ \\
\hline Portugal & 1.25 & 0.58 & 1 & 0.56 \\
\hline Malta & 1.27 & 1.41 & 1.16 & 1.04 \\
\hline Belgium & 1.27 & 1.22 & 1.25 & 1.31 \\
\hline Denmark & 1.29 & 0.85 & 1.07 & 0.97 \\
\hline Switzerland & 1.34 & 0.96 & 1.17 & 0.86 \\
\hline Thailand & 1.34 & c & 1.2 & c \\
\hline Latvia & 1.38 & 1.46 & 1.16 & 1.46 \\
\hline Estonia & 1.38 & 1.16 & 1.46 & 0.89 \\
\hline Dominican Republic & 1.41 & c & 1.09 & c \\
\hline Spain & 1.45 & 1.49 & 1.21 & 1.37 \\
\hline Tunisia & 1.47 & c & 1.3 & 1.23 \\
\hline Trinidad and Tobago & 1.53 & c & 1.21 & c \\
\hline Cyprus* & 1.55 & 1.09 & 1.32 & 1.11 \\
\hline Colombia & 1.6 & c & 1.36 & c \\
\hline Mexico & 1.61 & c & 1.27 & c \\
\hline Brazil & 1.65 & c & 1.36 & c \\
\hline CABA (Argentina) & 1.65 & 0.84 & 1.43 & c \\
\hline Kosovo & 1.83 & c & 0.99 & c \\
\hline FYROM & 2.94 & c & 1.21 & 0.69 \\
\hline Iceland & c & 1.19 & 0.84 & 0.79 \\
\hline Japan & c & c & 1.05 & c \\
\hline Korea & c & c & 0.99 & c \\
\hline Poland & c & c & 1.25 & c \\
\hline Slovak Republic & c & 1.65 & 1.04 & 1.44 \\
\hline Albania & C & C & 1.36 & c \\
\hline Algeria & c & c & 1.04 & C \\
\hline B-S-J-G (China) & c & c & 1.26 & c \\
\hline Bulgaria & c & c & 1.13 & 1.31 \\
\hline Indonesia & C & c & c & c \\
\hline Lebanon & c & 1.16 & c & 0.95 \\
\hline Peru & C & C & 1.58 & C \\
\hline Romania & c & C & 1.06 & C \\
\hline Chinese Taipei & C & c & 1.14 & C \\
\hline Uruguay & c & c & 1.15 & 1.33 \\
\hline Viet Nam & c & c & 1.47 & C \\
\hline
\end{tabular}

* See note at the beginning of this Chapter.

Notes: Only countries/economies with valid data for at least one outcome are presented.

Native-speaking students are students who speak most frequently at home the language of the PISA assessment.

Non-native-speaking students are students who reported that the language they most frequently speak at home is different from the language of the PISA

Socially resilient students are students with an immigrant background who reported that they "agree" or "strongly agree" with the statement "I feel like I belong at school" and "disagree" or "strongly disagree" with the statement "I feel like an outsider at school".

Source: OECD, PISA 2015 Database.

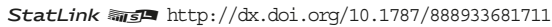


The positive effects of language proficiency go beyond the labour market, and encompass health, marriage, social integration and political participation (Isphording, 2015; Clarke and Isphording, 2017). Immigrants who are fluent in the host-community language can interact more frequently and intensively with local populations and have greater access to information (Espenshade and Calhoun, 1993; Gordon, 1964). Increased intercultural contact makes it easier for immigrants to learn the values, norms and traditions in the host country and eases the way towards integration (Chiswick and Miller, 1996).

Since the 1990s, language training has been a key policy priority in many countries to ensure that immigrants are able to contribute to the economic and social life of their communities and are, in turn, also to benefit from them (Joppke, 2007). Civic integration policies introduced in the Netherlands were among the first in Europe to emphasise knowledge of host country language and culture. Shortly after, language policies were implemented by other countries, including Austria, Denmark, Finland, France and Germany. Eventually, the focus on language acquisition also became one of the principles of the EU statement on integration policy. The fourth principle states: "Basic knowledge of the host society's language, history, and institutions is indispensable to integration" (Council of the European Union 2004, 20). The obligatory character of civic integration policies and their strong focus on language acquisition exemplify the importance given to language for integration.

Just as fluency in the language spoken in the host community is important for adults because it ensures their economic and social integration, language fluency among school-aged children ensures that they are able to make the most of the learning opportunities offered by schools (Boykin, Tyler and Miller, 2005; Dustmann, Machin and Schonberg, 2010; Geay, McNally and Telhaj, 2013). While the effect of language use at home on the academic outcomes of immigrants has been explored in depth both in the empirical and theoretical literature (OECD, 2015b; OECD, 2010; OECD, 2006), less is known about the role language fluency plays in shaping the socio-emotional and motivational resilience of immigrant students.

Language fluency enables children with an immigrant background to participate actively in the social life of their school, and develop a sense of belonging at their school community and beyond (Coll and Magnuson, 1997; Zhou and Xiong, 2005; Dawson and Williams, 2008). Language facilitates the socialisation of children with an immigrant background in their new environment and supports their acculturation in the destination country.

Children with an immigrant background with language difficulties are found to be more likely to be bullied, discriminated against and are more likely to suffer emotional problems, such as depression and low self-esteem (Gil, Vega and Dimas, 1994; Padilla and Perez, 2003; Romero and Roberts, 2003; Smart and Smart, 1995). The sooner children become fluent in the host-country language, the more they can benefit from new opportunities. Thus, in many countries, schools emphasise language acquisition for children with an immigrant background.

Language barriers can also make it difficult for immigrant parents to help their children integrate into their new community. For instance, parents who are not fluent in the host-country language might be particularly at risk of being out of the labour force or experience economic hardship. This may hinder them from providing the material resources or the intangible assistance, such as supporting them in school and course selection and encouraging good study strategies, that could help in their children's education (Bermudez, 1994; Moles, 1993).

Unfortunately large-scale international assessments have limited information on the mother tongue of immigrant students or the variety of languages students speak within the family, the choices such students and their families make about the use of their mother tongue or the language of instruction within the home and the reasons behind such choices, the level of proficiency in different languages students and their families possess and the context in which they use specific languages. Although language is crucial to promote immigrant students' integration, the classification of language groups developed in this chapter is based on limited set of information contained in the PISA dataset: the language of the PISA test and the language that the student reports speaking most frequently at home. 
The language of assessment generally reflects the language that is spoken in the country that conducted the PISA test and in which students are taught. However, in some countries and contexts multiple language communities coexist and students are taught in more than one language.

The PISA background questionnaire asked students to report which language they speak most frequently at home. In this report ton-native speakers are students who reported that the language they speak most frequently at home is different from the language of the PISA test, while native speakers are students who reported that the language they speak most frequently at home is the same as that of the PISA test. This classification may hide important differences: some students may be bilingual and be native speakers in multiple languages, other students may speak at home the language of instruction even if they are nonnative speakers, because they and their parents may feel this could help them gain proficiency at a faster pace. In this chapter, native students are defined as those without an immigrant background who speak most frequently at home the language of the PISA test. ${ }^{1,2}$

\section{Individual characteristics and use of the host-country language at home}

How recently a child (or his or her family) immigrated, their socio-economic status and their country of origin have all been shown to be correlated with the use of host-country language at home. The effects of these individual characteristics are understood better when situated within the theoretical framework developed by Chiswick and Miller (1995). Their framework classifies the determinants of language acquisition into three groups: factors that affect immigrants' exposure to the language of the host country, factors that shape immigrants' ability to become fluent in a new language, and factors that influence the efficiency with which immigrants become fluent.

Immigrant students' exposure to the host-country language is determined by the amount of time they have spent in the host country, the number of interactions that occur per unit of time, on average, and the efficacy of those interactions. Second-generation immigrant children are born and raised in the host country. Their schooling has taken place only within the host country and they have been exposed to the destination-country language for longer than first-generation immigrant students, especially if they had also attended pre-primary school. It is thus easier for second-generation immigrant students than for first-generation immigrant students to be fluent in the destination-country language. Moreover, immigrants who have lived in the host country for longer will have been more exposed to the hostcountry language and are more likely to be fluent in it (Isphording and Otten, 2013).

Immigrants' age at arrival in the host country matters too. Immigrant students who had arrived as young children might be able to acquire the host-country language with much greater ease (Newport, 2002). In fact, supporters of the Critical Period Hypothesis argue that the age of 12 marks an important threshold, after which the efficiency with which people acquire foreign-language skills decreases markedly. Thus, first-generation immigrants (compared to second-generation immigrants), immigrants who have been in the country for a shorter period, and immigrants who had arrived after the age of 12 might be at a double disadvantage when it comes to overcoming language barriers.

Research has consistently shown that parents' educational background is one of the most significant determinants of immigrant children's academic and well-being outcomes (Capps, 2005; Bilgili et al., 2015). Immigrant children of highly educated parents are also more likely than their peers with low-educated parents to become proficient more quickly in a new language. Highly educated people who are also proficient in their native language might be better able to understand what is required to master a new language, and how to seek and access support to do so.

The official language of the country of origin is also an important determinant of language use at home. Countries of origin and destination might share an historical link, such as through colonialism, whereby immigrants from former colonies might already speak the language of the host country in addition to a second language or local dialect. Language, itself, might be the bond that links a country of origin to a destination country. For example, there are strong migration flows among Spanish-speaking countries. In both of these cases, an immigrant child does not have to learn a new language when he or she arrives in the host country. 
For many children with an immigrant background, however, learning the host-country's language is an enormous challenge; but difficulties might be reduced if the language in the country of origin has similar roots as the host-country language. No research to date has explored the relationship between language similarity, or proximity, and migrant students' academic, socio-emotional and motivational resilience. When the difference between two languages is larger, it might be more difficult to learn the host-country language, which could have implications for the resilience of students with an immigrant background.

\section{Immigrant background and languages spoken at home: An overview}

PISA reveals that in 2015, on average across OECD countries, $12 \%$ of students did not speak the language of assessment as their main language at home (15\% on average across EU countries). However, there were considerable differences across countries. For example, in Luxembourg, $84 \%$ of students did not speak the language of assessment at home, while in Japan, only $1 \%$ of students did not speak the language of assessment at home.

PISA data also reveal that, while there is an association between having an immigrant background and not speaking the language of assessment at home, one doesn't necessarily imply the other. For example, although the percentage of immigrant students and the percentage of students who do not speak the language of assessment at home were practically the same in 2015 at the OECD average level (12\% and $15 \%$, respectively, at the EU average level), the two groups do not overlap perfectly. In fact, on average across OECD countries, $49 \%$ of immigrant students and $6 \%$ of native students did not speak the language of assessment at home (49\% and 10\%, respectively, across EU countries). Among students who did not speak the language of assessment at home, $68 \%$ were students with an immigrant background and $32 \%$ were native students (61\% and 39\%, respectively, across EU countries).

Figure 5.2 shows the percentages of immigrant students, native-born students of mixed heritage, and students who do not speak the language of assessment at home in the countries and economies that participated in PISA 2015. In the majority of them, there were more immigrant students and native students of mixed heritage than students who speak at home a language that is different from the language of instruction. In a number of countries, including Australia, Canada, New Zealand and the United Kingdom, the share of immigrant students was larger than the share of students who speak a different language at home. These are countries where most immigrants come from territories where the host language is spoken - predominantly former colonies of the British Empire. By contrast, in Indonesia, Lebanon, Luxembourg, Malta and Singapore, the share of students who do not speak the language of assessment was larger than the share of immigrant students. These countries are home to established language minorities.

PISA data reveal that in 2015 speaking a language at home that is different from the language of the assessment was more frequent among immigrant students. Figure 5.3a shows the percentage of native students and of first- and second-generation immigrant students participating in PISA 2015 who reported not speaking the language of assessment at home. Significant differences between immigrant students (first- and second-generation combined) and native students are reported next to the name of each country or economy. In all countries and economies shown except Luxembourg, Macao (China) and Malta, the percentage of students who reported not speaking the language of assessment at home was greater among immigrant students than among native students.

The figure also shows that in most countries it was more common for first-generation immigrant students than for second-generation immigrant students to speak a language at home that is different from the language of assessment. On average across OECD countries, $6 \%$ of native students $(10 \%$ across EU countries), $60 \%$ of first-generation immigrant students ( $60 \%$ across EU countries), and $41 \%$ of second-generation immigrant students ( $40 \%$ across EU countries) reported not speaking the language of assessment at home. In Austria, Finland, Iceland and Slovenia, more than $70 \%$ of immigrant students, but only $5 \%$ or less of native students, reported speaking a language at home that is different from the language of assessment. Luxembourg, Macao (China) and Malta are the only countries and economies where it was more common for native students to speak a language at home that is different from the language of instruction. 
Figure 5.2 - Percentage of students with an immigrant background and non-native-speaking students

$\square$ Immigrant students $\square$ Immigrant students with at least one native-born parent

$\checkmark$ Non-native-speaking students

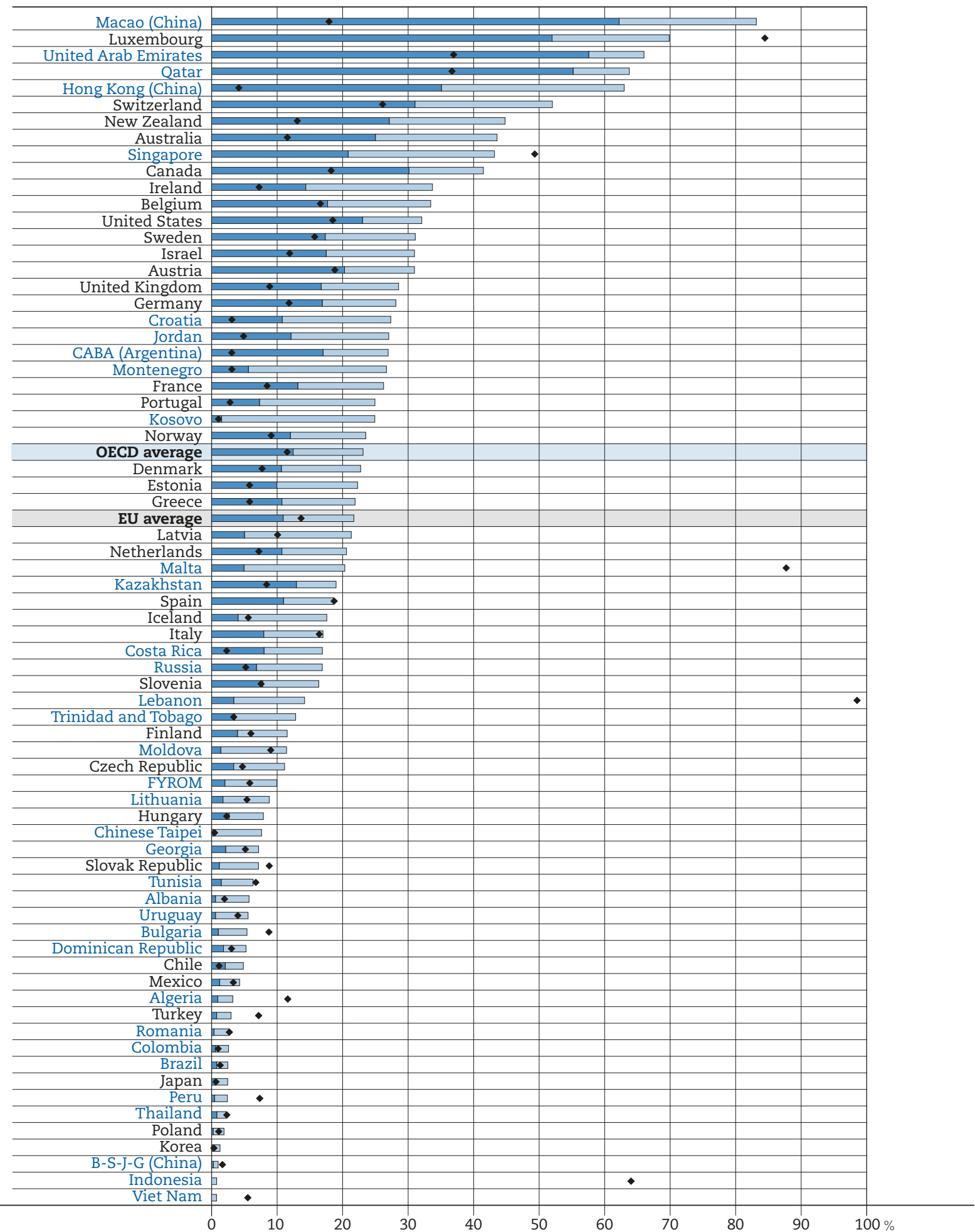

Notes: Non-native-speaking students are students who reported that the language they most frequently speak at home is different from the language of the PISA assessment.

Countries and economies are ranked in descending order of the percentage of students with an immigrant background.

Source: OECD, PISA 2015 Database, Table 5.3.

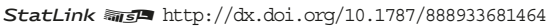


Figure $5.3 a$ - Percentage of non-native speakers, by immigrant background

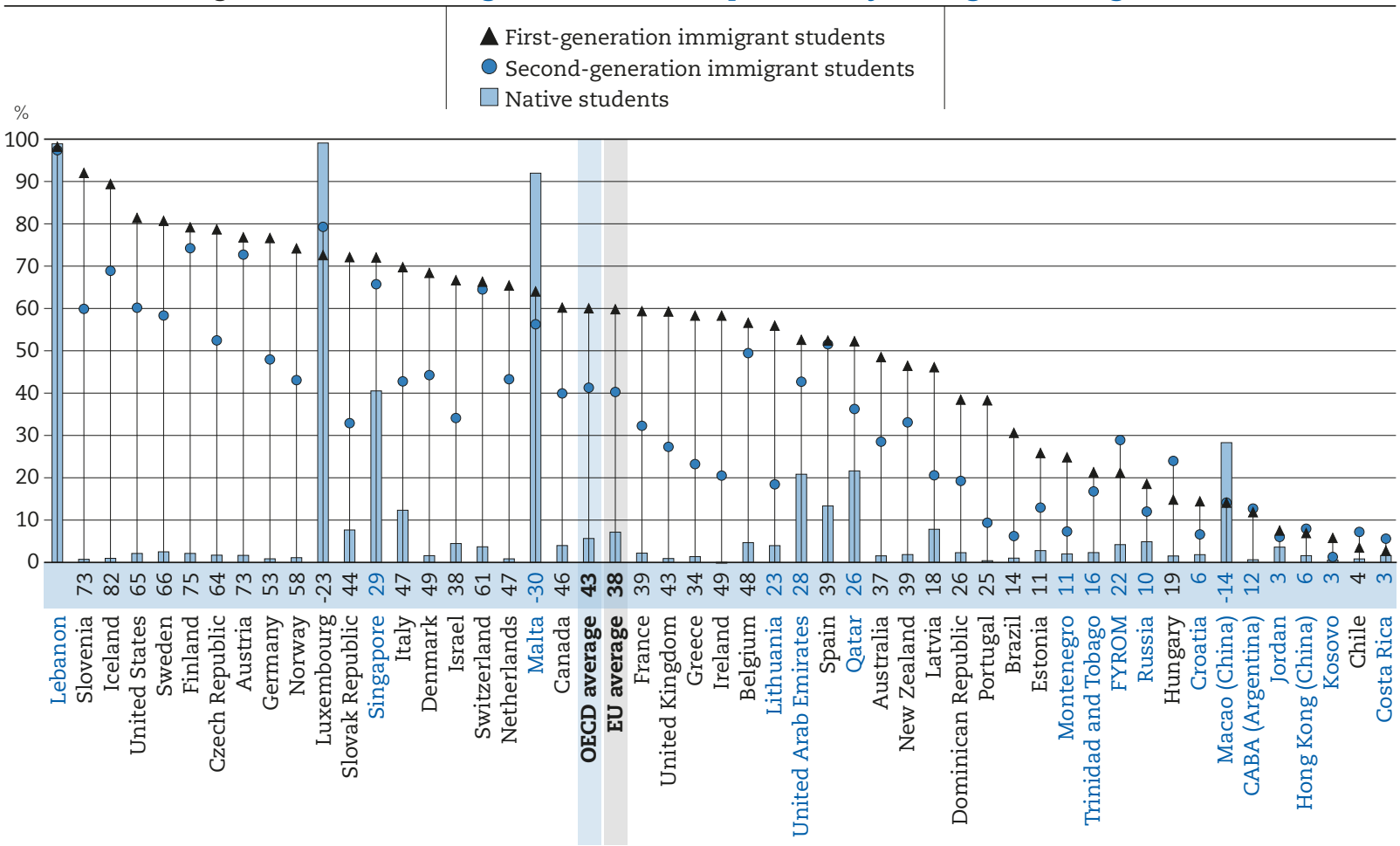

Notes: Non-native-speakers are students who reported that the language they most frequently speak at home is different from the language of the PISA assessment.

Only countries with valid values for first- and second-generation immigrant students are shown.

Statistically significant differences in the percentage of non-native-speaking students among immigrant and native students are reported next to country/economy names.

Countries and economies are ranked in descending order of the percentage of first-generation immigrant students who do not speak the language of assessment at home.

Source: OECD, PISA 2015 Database, Table 5.4

StatLink anist http://dx.doi.org/10.1787/888933681483

Figure 5.3b shows the percentage of returning foreign-born students (that is, foreign-born students who have at least one native-born parent), native students of mixed heritage (native students with one nativeborn and one foreign-born parent) and immigrant students (a category which comprises both native and foreign-born students who have foreign born parents) who do not speak the language of assessment at home. In all countries and economies except Brazil, Chile, Colombia, Costa Rica, Estonia, Georgia, Jordan, Kosovo, Lebanon, Luxembourg, Malta, Moldova and Peru, immigrant students with two foreign-born parents were more likely to speak a language at home that is different from the language of assessment compared to returning foreign-born students and native students of mixed-heritage (students with an immigrant background who have at least one native-born parent). In Finland, Iceland and Slovenia, more than $70 \%$ of immigrant students with two foreign-born parents reported not speaking the language of assessment at home while less than $15 \%$ of other students with an immigrant background who have at least one nativeborn parent so reported. Luxembourg, Macao (China) and Malta were the only countries and economies where students with an immigrant background who have at least one native-born parent were more likely to be non-native speakers than the children of foreign-born parents.

PISA data indicate that among all groups of students with an immigrant background, first-generation students were the least likely to speak the language of instruction at home in 2015, particularly if they arrived in the country in which they sat the PISA test at or after the age of 12 (Figure 5.3c). On average across OECD the share of non-native speakers among late arrivals was 13 percentage points larger than that of non-native speakers among immigrant students who had arrived before the age of 12 (early arrivals) (14\% across EU countries). In the Czech Republic, Finland, Slovenia and Sweden, over $90 \%$ of late arrivals reported that they did not speak the language of assessment at home. 
Figure $5.3 \mathrm{~b}$ - Percentage of non-native speakers, by immigrant heritage

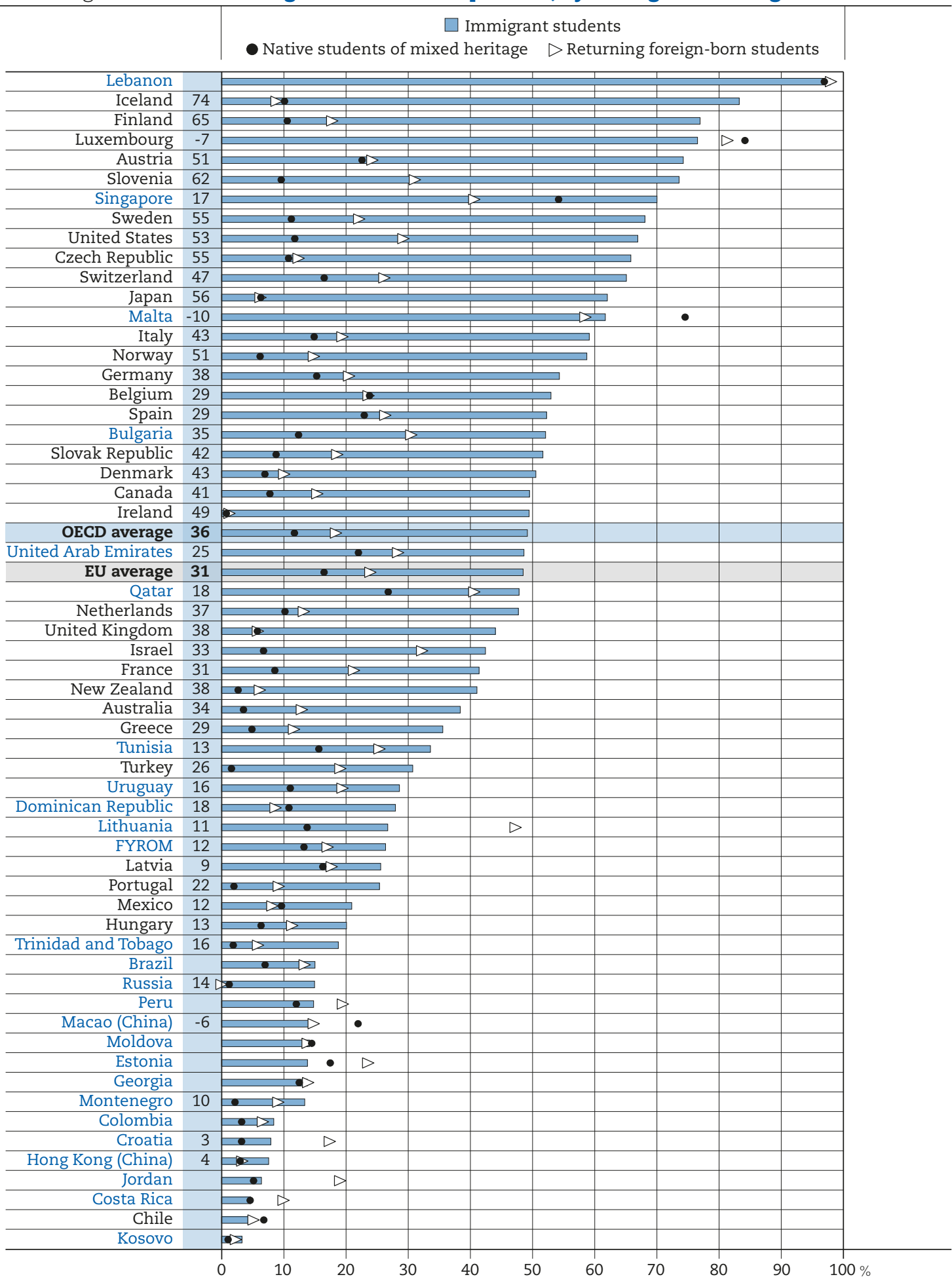

Notes: Non-native-speakers are students who reported that the language they most frequently speak at home is different from the language of the PISA assessment.

Only countries with valid values for returning foreign-born students and native students of mixed heritage are shown.

Statistically significant differences in the percentage of non-native-speakers among immigrant students and immigrant students with at least one native-born parent are reported nex to country/economy names.

Countries and economies are ranked in descending order of the percentage of immigrants students who do not speak the language of assessment at home. Source: OECD, PISA 2015 Database, Table 5.4.

StatLink 司Ist http://dx.doi.org/10.1787/888933681502 
Figure $5.3 \mathrm{c}-$ Percentage of non-native speakers, by age at arrival

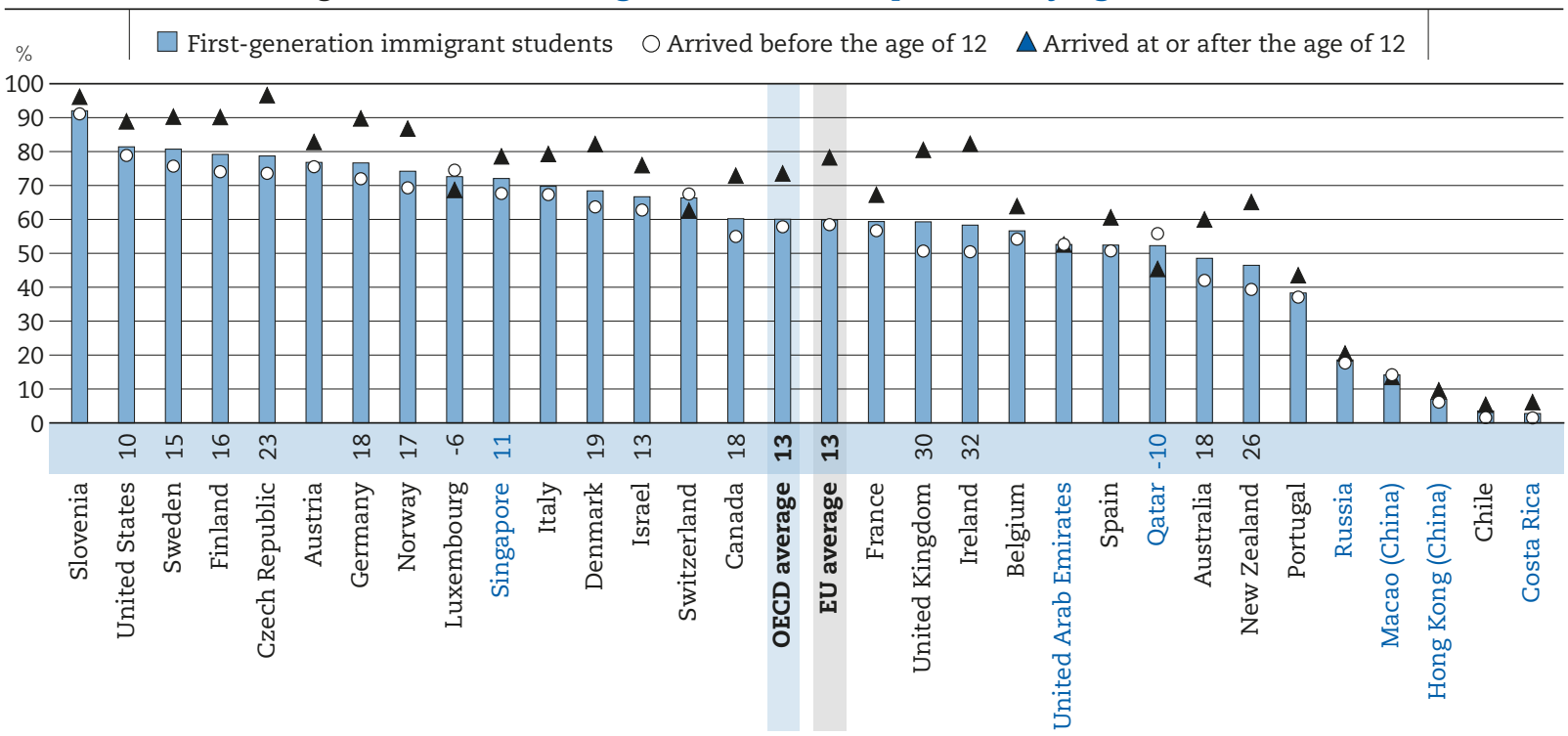

Notes: Non-native-speakers are students who reported that the language they most frequently speak at home is different from the language of the PISA assessment.

Only countries with valid values for first-generation immigrants who arrived before the age of 12 and those who arrived at or after the age of 12 are shown.

Statistically significant differences in the percentage of non-native-speakers among students who arived at or after the age of 12 and among those who arrived before the age of 12 are reported next to country/economy names.

Countries and economies are ranked in descending order of the percentage of first-generation immigrant students who do not speak the language of assessment at home.

Source: OECD, PISA 2015 Database, Table 5.6.

StatLink ailst http://dx.doi.org/10.1787/888933681521

\section{Language barriers and the academic performance of students with an immigrant background}

PISA reveals that speaking a language at home that is different from the language of assessment can explain much of the difference in academic performance between native students and students with an immigrant background. First and foremost, it affects students' proficiency in reading, which in turn also influences their competence in other domains. One way to examine the association between the language spoken at home and students' performance is to analyse students' performance in reading relative to their performance in mathematics. By controlling for mathematics performance, students' languagespecific abilities are isolated from their general information-processing skills.

Figure 5.4 compares the reading scores of native students who speak the language of assessment at home and of immigrant students who do, and do not, speak the language of assessment at home, after accounting for their mathematics scores (results for other groups of students with an immigrant background can be found in Table 5.7). Significant differences between immigrant students who do and those who do not speak the language of assessment at home are reported next to country names. In almost all countries and economies, in 2015 there was no significant difference in reading scores between immigrant and native students who reported speaking the language of assessment at home after accounting for their mathematics performance and their socio-economic status. In Macao (China), Jordan, Portugal, Qatar and the United Arab Emirates, immigrant students who reported speaking the language of assessment at home scored higher than native students who reported the same, after accounting for the two variables.

By contrast, in most countries, immigrant students who reported that they did not speak the language of assessment at home had lower scores in reading than both native students and immigrant students who reported speaking the language of assessment at home, after accounting for their mathematics scores and socio-economic status. On average across OECD countries, the gap in reading scores between nativespeaking and non-native-speaking immigrant students was 16 points (16 points across EU countries); 
but differences can be much starker. For instance, in the Slovak Republic, the score-point difference in reading performance between immigrant students who reported that they did not speak the language of assessment at home and native students who reported that they did was 56 points. In Ciudad Autónoma de Buenos Aires (Argentina) (hereafter "CABA [Argentina]"), Estonia, Finland and the Russian Federation (hereafter "Russia"), non-native-speaking immigrant students also scored much lower in reading than both native students and immigrant students who reported speaking the language of assessment at home.

Figure 5.4 - Difference in reading scores, by immigrant background and language spoken at home After accounting for performance in mathematics and socio-economic status

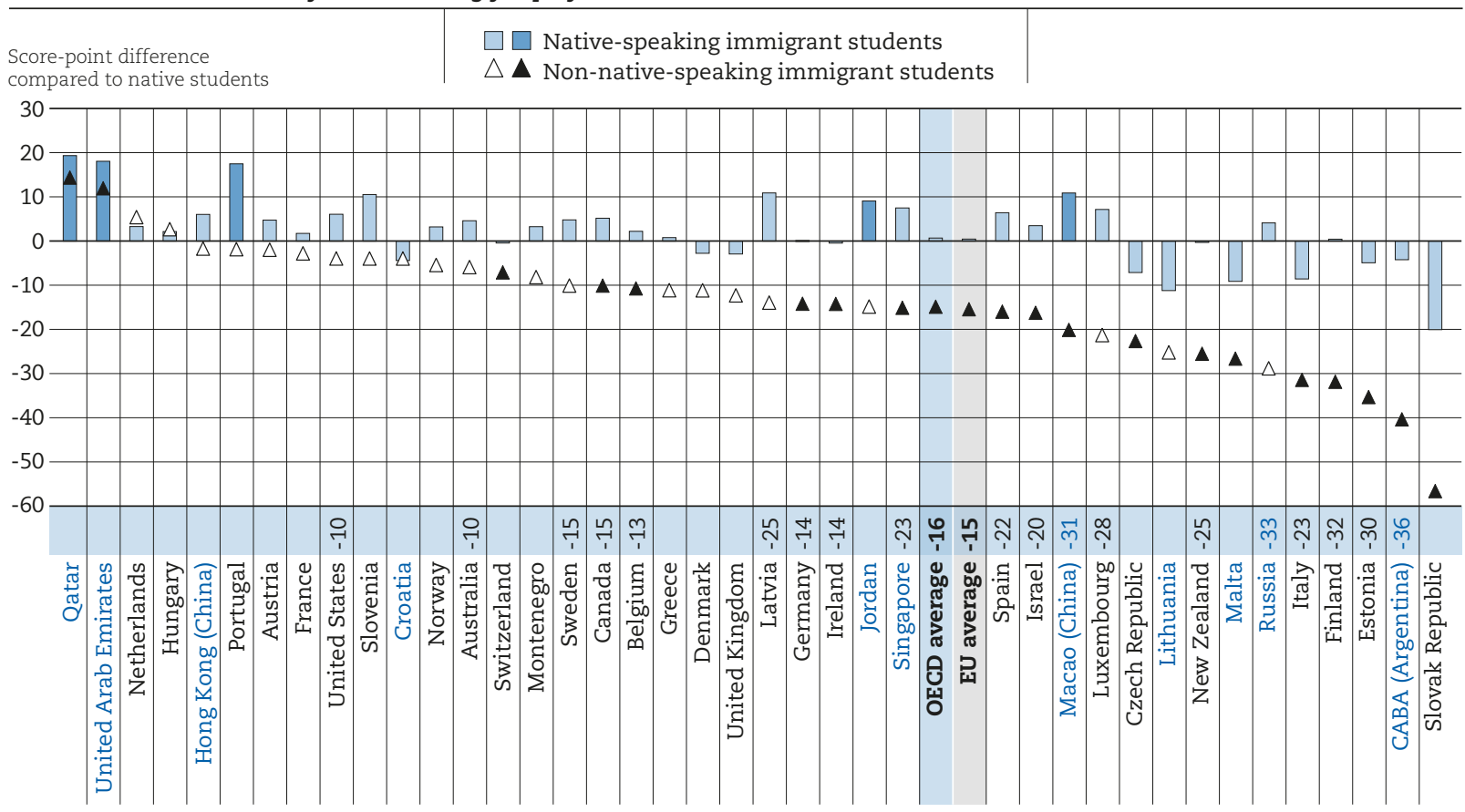

Notes: Statistically significant differences are marked in a darker tone.

Native students are students without an immigrant background who speak most frequently at home the language of the PISA assessment. Native-speaking students are students who speak most frequently at home the language of the PISA assessment.

Non-native-speaking students are those who reported that the language they most frequently speak at home is different from the language of the PISA assessment.

Only countries with valid values for both native- and non-native-speaking immigrant students are shown.

Statistically significant differences between non-native- and native-speaking immigrant students are shown next to country/economy names. For the OECD and EU averages, this number refers only to the subset of countries/economies with valid information on both groups of students.

Countries and economies are ranked in descending order of the gap in reading scores between non-native-speaking immigrant students and native students, adjusted for socio-economic status and performance in mathematics.

Source: OECD, PISA 2015 Database, Table 5.7.

StatLink 形) http://dx.doi.org/10.1787/888933681540

Language fluency is associated with students' proficiency in all academic domains, even those with less language content. Table 5.8 (available on line) shows score-point differences between native students and different groups of students with an immigrant background in mathematics performance, after accounting for socio-economic status. PISA results show, for example, that in the majority of countries and economies considered, immigrant students who reported that they did not speak the language of assessment at home scored lower in mathematics than native-speaking immigrant students. While the OECD average gap between the two groups was 9 score points, in Croatia, Germany, Hong Kong (China), Jordan, Latvia, Luxembourg, Macao (China), Russia and Switzerland, the gap was more than 25 points wide. In Croatia, Hong Kong (China), Ireland and Russia, immigrant students who reported speaking the language of assessment at home were not at a disadvantage compared to native students. However, immigrant students who reported that they did not speak the language of assessment at home scored much lower than native students. 
In the majority of countries, non-native-speaking students of mixed-heritage and returning foreign-born students perform as well as native students in reading (Table 5.7, available on line). But, as shown in Table 5.8 (available on line), mathematics scores tell a different story. In the majority of countries and economies, non-native-speaking students of mixed heritage and returning foreign-born students (who together constitute the group of students identified as immigrant students who have at least one nativeborn parent) scored lower in mathematics than native-speaking immigrant students. On average across OECD countries, the performance gap in mathematics was 28 score points ( 26 points across EU countries) about three times larger than the performance gap between native students and immigrant students who have two foreign-born parents. This gap was greater than 25 score points in 20 out of 21 countries where the language penalty is statistically significant. These results indicate that the impact of difficulties with the host-country language on returning foreign-born students and native students of mixed-heritage on mathematics scores seems to be greater than for immigrant students with two foreign-born parents.

\section{Attaining baseline levels of proficiency in the core PISA subjects}

PISA shows that whether or not immigrant students speak the language of the assessment at home is strongly associated with their overall academic performance. Indeed, the language spoken at home is significantly associated with students' likelihood of reaching the baseline levels of proficiency in the three core PISA subjects: reading, mathematics and science. Figure 5.5a compares the percentage of immigrant students who are academically resilient among immigrants who do and those who do not speak the language of assessment at home with the percentage of native students who attain that level of proficiency.

Figure $5.5 \mathrm{a}$ - Students attaining baseline academic proficiency, by immigrant background and language spoken at home After accounting for socio-economic status

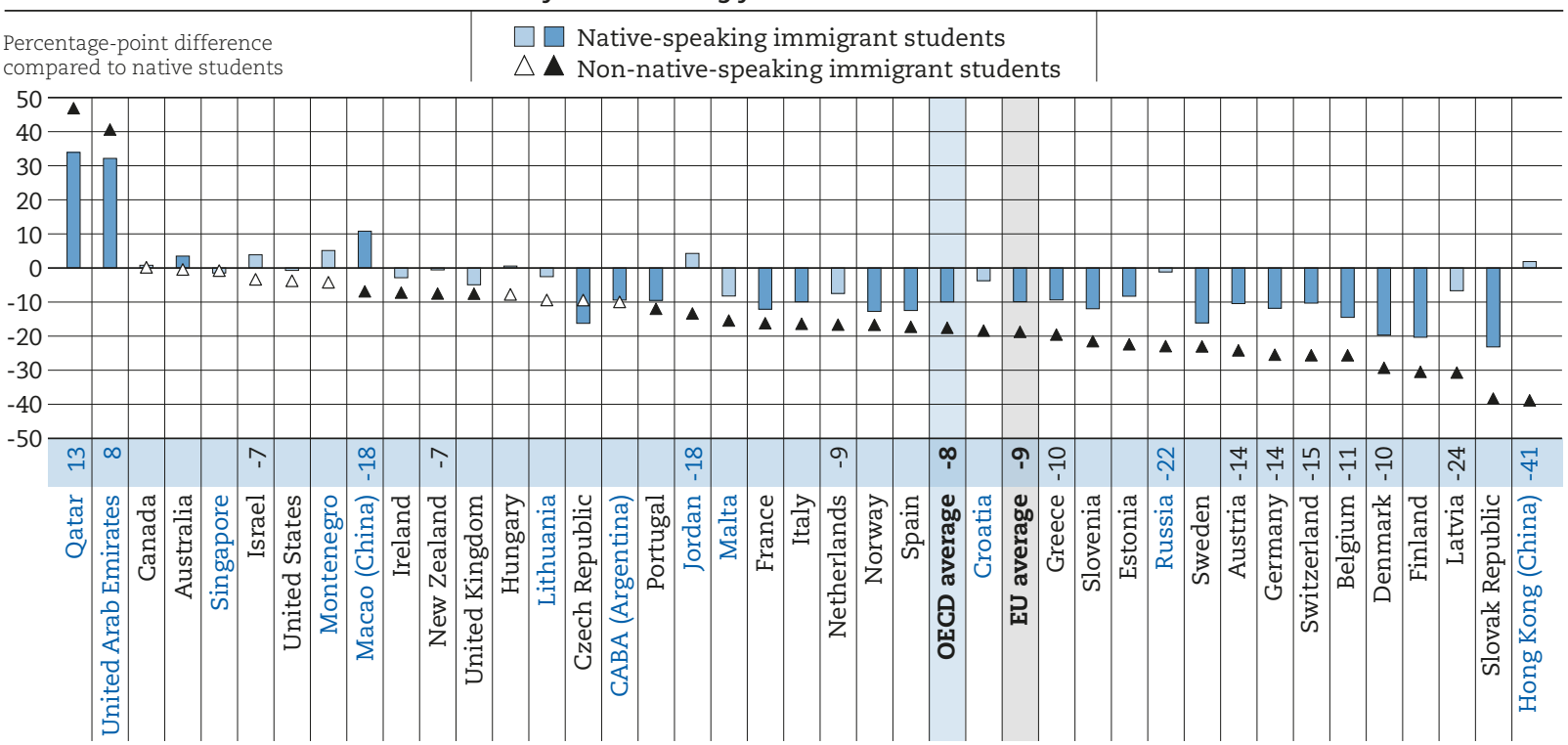

Notes: Statistically significant differences are marked in a darker tone.

Students who attain baseline academic proficiency are those who attain at least proficiency Level 2 in all three core PISA subjects: science, reading and mathematics.

Native students are students without an immigrant background who speak most frequently at home the language of the PISA assessment. Native-speaking students are students who speak most frequently at home the language of the PISA assessment.

Non-native-speaking students are those who reported that the language they most frequently speak at home is different from the language of the PISA assessment.

Only countries with valid values for both native- and non-native-speaking immigrant students are shown.

Statistically significant differences between non-native- and native-speaking immigrant students with at least one native-born parent are shown next to country/economy names. For the OECD and EU averages, this number refers only to the subset of countries/economies with valid information on both groups of students.

Countries and economies are ranked in descending order of the gap between non-native-speaking immigrant students and native students in the percentage of students attaining baseline academic proficiency, adjusted for socio-economic status.

Source: OECD, PISA 2015 Database, Table 5.9.

StatLink anist http://dx.doi.org/10.1787/888933681559 
In most countries and economies, the percentage of non-native-speaking immigrant students who perform at proficiency Level 2 or higher in reading, mathematics and science is lower than the percentage of native students who do. On average in 2015 across OECD countries, 18 percentage points separated the two groups (19 percentage points across EU countries); but in Finland, Hong Kong (China), Latvia and the Slovak Republic, the difference was 30 percentage points or more. In 14 countries and economies, immigrant students who were non-native speakers were less likely to attain baseline levels of proficiency compared to native-speaking immigrant students. The differences between the two groups in the percentage of students who attained the baseline level of proficiency in the three core PISA subjects ranged from 7 percentage points to 41 percentage points. In Croatia, Hong Kong (China), Ireland, Jordan, Latvia, Malta, the Netherlands, New Zealand and Russia and the United Kingdom native students and immigrant students who are native-language speakers stood an equal chance of reaching baseline levels of proficiency in all three subjects, while immigrant students who are non-native speakers were significantly less likely to achieve the same result. In these countries, fluency in the language of assessment is key to whether immigrant students attain the baseline level of proficiency in reading, mathematics and science, after accounting for socio-economic status.

\section{Figure $5.5 \mathrm{~b}$ - Students attaining baseline academic proficiency, by immigrant heritage and language spoken at home \\ After accounting for socio-economic status}

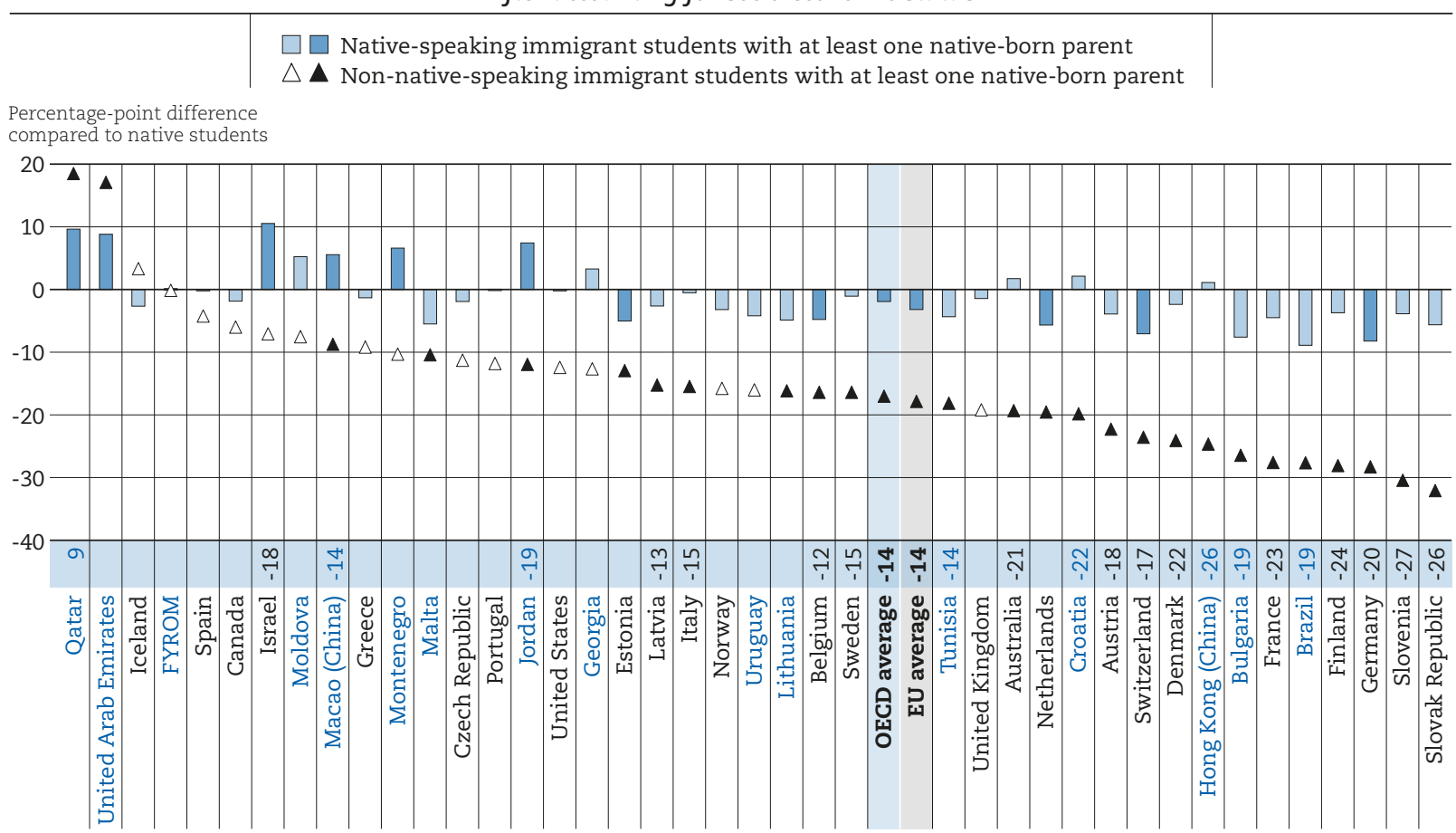

Notes: Statistically significant differences are marked in a darker tone.

Students who attain baseline academic proficiency are those who attain at least proficiency Level 2 in all three core PISA subjects: science, reading and mathematics.

Native students are students without an immigrant background who speak most frequently at home the language of the PISA assessment. Native-speaking students are students who speak most frequently at home the language of the PISA assessment.

Non-native-speaking students are those who reported that the language they most frequently speak at home is different from the language of the PISA assessment.

Only countries with valid values for both native- and non-native-speaking immigrant students with at least one native-born parent are shown.

Statistically significant differences between non-native- and native-speaking immigrant students with at least one native-born parent are shown next to country/economy names. For the OECD and EU averages, this number refers only to the subset of countries/economies with valid information on both groups of students.

Countries and economies are ranked in descending order of the gap between non-native-speaking immigrant students with at least one native-born parent and native students in the percentage of students attaining baseline academic proficiency, adjusted for socio-economic status.

Source: OECD, PISA 2015 Database, Table 5.9

StatLink 部 http://dx.doi.org/10.1787/888933681578 
Figure $5.5 \mathrm{~b}$ shows that the impact of language fluency is similar, if not stronger, among immigrant students who have at least one native-born parent. On average across OECD countries, the difference in the percentage of immigrant students in this group reaching baseline levels of proficiency between students who do and those who do not speak the language of assessment at home is 14 percentage points (14 across EU countries) a larger difference than among immigrant students with two foreign-born parents. In 14 countries and economies, native-speaking immigrant students with at least one foreign-born parent are as likely as native students to attain the baseline level of proficiency in PISA subjects; but non-native-speaking students within this group are not. In Bulgaria, Finland, France, the Slovak Republic and Slovenia, the difference compared to native students is more than 25 percentage points for non-native speakers, and it is not statistically significant for native speakers. These results suggest that fluency in the language of assessment is linked to academic resilience among immigrant students with at least one foreign-born parent.

Linguistic barriers to academic achievement vary significantly across the four previously defined categories of students with an immigrant background (first-generation immigrant students, secondgeneration immigrant students, returning foreign-born students, and native students of mixed heritage) (Table 5.10, available on line). On average across OECD countries and in most countries and economies, the students most affected by being non-native speakers as opposed to native speakers are returning foreignborn students, followed by first-generation immigrant students, native students with a mixed heritage and finally second-generation immigrant students. However, as shown in Figure 5.6, there are significant differences across countries. In France, for example, non-native-speaking returning foreign-born students are $33 \%$ less likely than native students to reach baseline levels of proficiency in reading, mathematics and science (a 26 percentage-point difference compared to native-speaking returning foreign-born students), while other groups of students with an immigrant background show less or non-significant language-related impact on their performance.

In Denmark, proficiency in the host-country language plays a much larger role among second-generation immigrant students and native students of mixed heritage. Among the former category of students, the language-related difference in the likelihood of students attaining baseline levels of academic achievement is 11 percentage points in favour of those who speak the language of assessment. Among the latter group, the difference is 23 percentage points. There is no statistically significant difference between native- and non-native speakers in the likelihood of first-generation immigrant students and returning foreign-born students attaining baseline levels of academic proficiency.

In Austria, the effect of speaking a language at home that is different from the one of assessment is large for first-generation immigrant students and native students of mixed heritage, while it is not significant for other groups of students with an immigrant background. In Switzerland, the languagerelated disadvantage is similar for all groups of students with an immigrant background except for returning foreign-born students, but that is probably due to small sample-size effects.

In Australia, native-speaking first-generation immigrant students and native students of mixed heritage have the same probability of attaining baseline proficiency in the three core PISA subjects as native students. However, non-native-speaking students among these groups of students with an immigrant background show significant disadvantages compared to native students and native-speaking students. Caution is advised when analysing results in Figure 5.6, because the sample of the groups considered might be small and varies across the different groups.

Language barriers also explain part of the relatively low performance among first-generation immigrant students related to their age at arrival in the host country. Table 5.6 (available on line) shows that in the majority of countries and economies, late arrivals are more likely than early arrivals to speak at home a language that is different from the language of assessment. Figure 5.7 shows that in several countries and economies, fluency in the host-country language accounts for a significant portion of the performance gaps between early arrivals (students who had arrived before the age of 12) and late arrivals (students who had arrived at or after the age of 12). On average across OECD countries, the difference between the two groups of students in the percentage of students who attain baseline proficiency in all three core PISA subjects is reduced by 5 percentage points (from 16 percentage points to 11 percentage points) after the language spoken at home is taken into account. Across EU countries, the difference shrinks by almost 5 percentage points (from around 17 to 12 percentage points). 
Figure 5.6 - Students attaining baseline academic proficiency, selected countries Percentage-point difference compared to native students, after accounting for socio-economic status

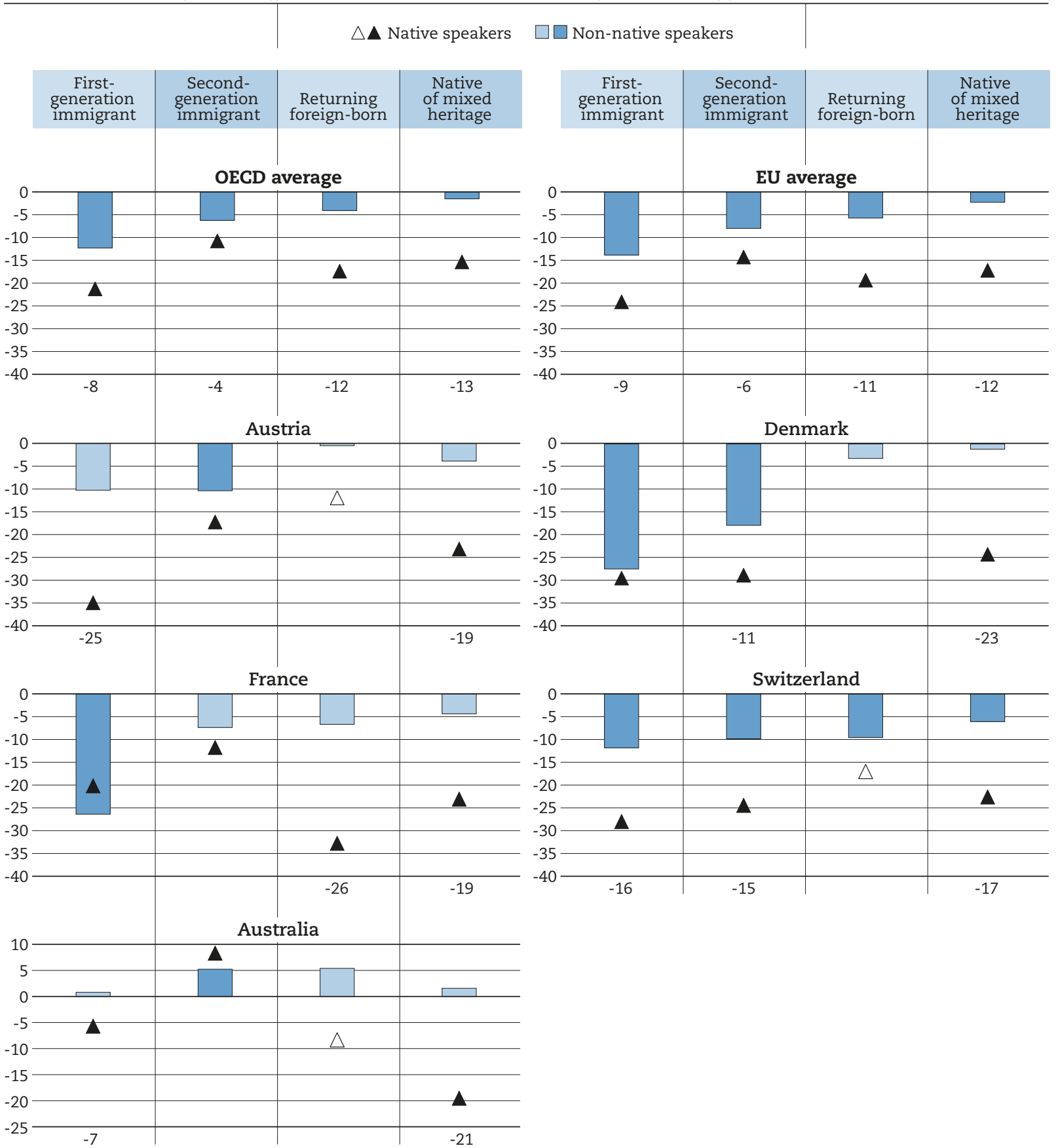

Notes: Statistically significant differences are marked in a darker tone.

Students who attain baseline academic proficiency are those who attain at least proficiency Level 2 in all three core PISA subjects: science, reading and mathematics.

Native students are students without an immigrant background who speak most frequently at home the language of the PISA assessment. Native-speaking students are students who speak most frequently at home the language of the PISA assessment.

Non-native-speaking students are those who reported that the language they most frequently speak at home is different from the language of the PISA assessment.

Statistically significant differences between non-native- and native-speaking students with an immigrant background are shown at the bottom of the panels. For the OECD and EU averages, this number refers only to the subset of countries/economies with valid information on both groups of students.

Source: OECD, PISA 2015 Database, Table 5.10.

StatLink तiाs http://dx.doi.org/10.1787/888933681597 
In Austria, Germany and Slovenia, these differences are reduced by more than 10 percentage points. In Slovenia, linguistic differences explain a large part of the late arrival penalty: after the effect of speaking a different language is accounted for, the gap between late and early arrivals is reduced by 19 percentage points (from 22 percentage points to a not statistically significant 3 percentage points).

Figure 5.7 - Difference between late and early arrivals in attaining baseline academic proficiency After accounting for socio-economic status

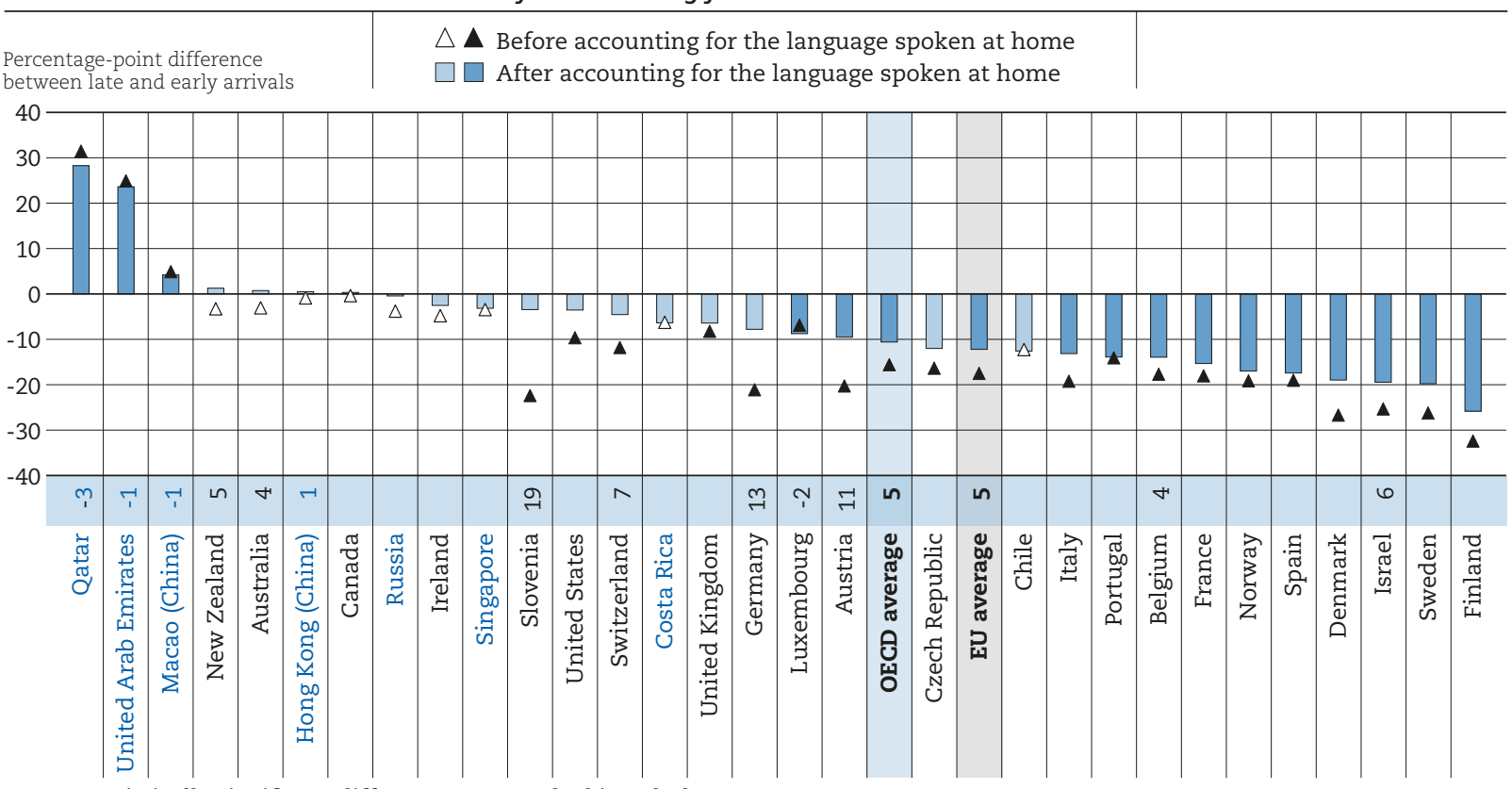

Notes: Statistically significant differences are marked in a darker tone.

Early arrivals are first-generation immigrant students who arrived at the country where they sat the PISA test before the age of 12 . Late arrivals are first-generation immigrant students who arrived at the country where they sat the PISA test at or after the age of 12.

Statistically significant differences in the late arrival gap before and after accounting for socio-economic status are shown next to the country/economy names.

Countries and economies are ranked in descending order of the percentage-point difference between late arrivals and early arrivals in the percentage of students attaining baseline academic proficiency, after accounting for the language spoken at home and socio-economic status.

Source: OECD, PISA 2015 Database, Table 5.11.

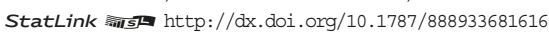

\section{Language barriers and the well-being of students with an immigrant background}

Speaking a language at home that is different from the host-country language has a significant impact on the sense of belonging reported by students with an immigrant background. Figure 5.8a shows differences in the percentage of immigrant students who attain a baseline sense of belonging - i.e. who feel that they belong at school ${ }^{3}$ - across the groups defined in previous sections (non-native-speaking immigrant students, native-speaking immigrant students and native students) (results for all groups of students with an immigrant background can be found in Table 5.13 available on line). Figure 5.8a shows that in 2015, in a large number of countries and economies, non-native-speaking immigrant students were less likely than native and native-speaking immigrant students to feel like they belong at school. They were also less likely to be socially resilient. On average across OECD countries, the share of students who reported a sense of belonging was five percentage points smaller among non-native-speaking immigrant students than among native-speaking immigrant students, and nine percentage points smaller than among native students (six and twelve percentage points, respectively, across EU countries). In several countries and economies, native-speaking immigrant students had equal or higher chances of reporting a sense of belonging at school compared to native students, and had significantly greater chances compared to nonnative-speaking immigrant students. This is the case in Greece, Italy, Macao (China) and Sweden, while in Norway and the United Kingdom, native-speaking immigrant students were more likely to report that they feel like they belong at school, even compared to native students. 
Figure $5.8 \mathrm{a}$ - Students reporting a sense of belonging at school, by immigrant background and language spoken at home

After accounting for socio-economic status

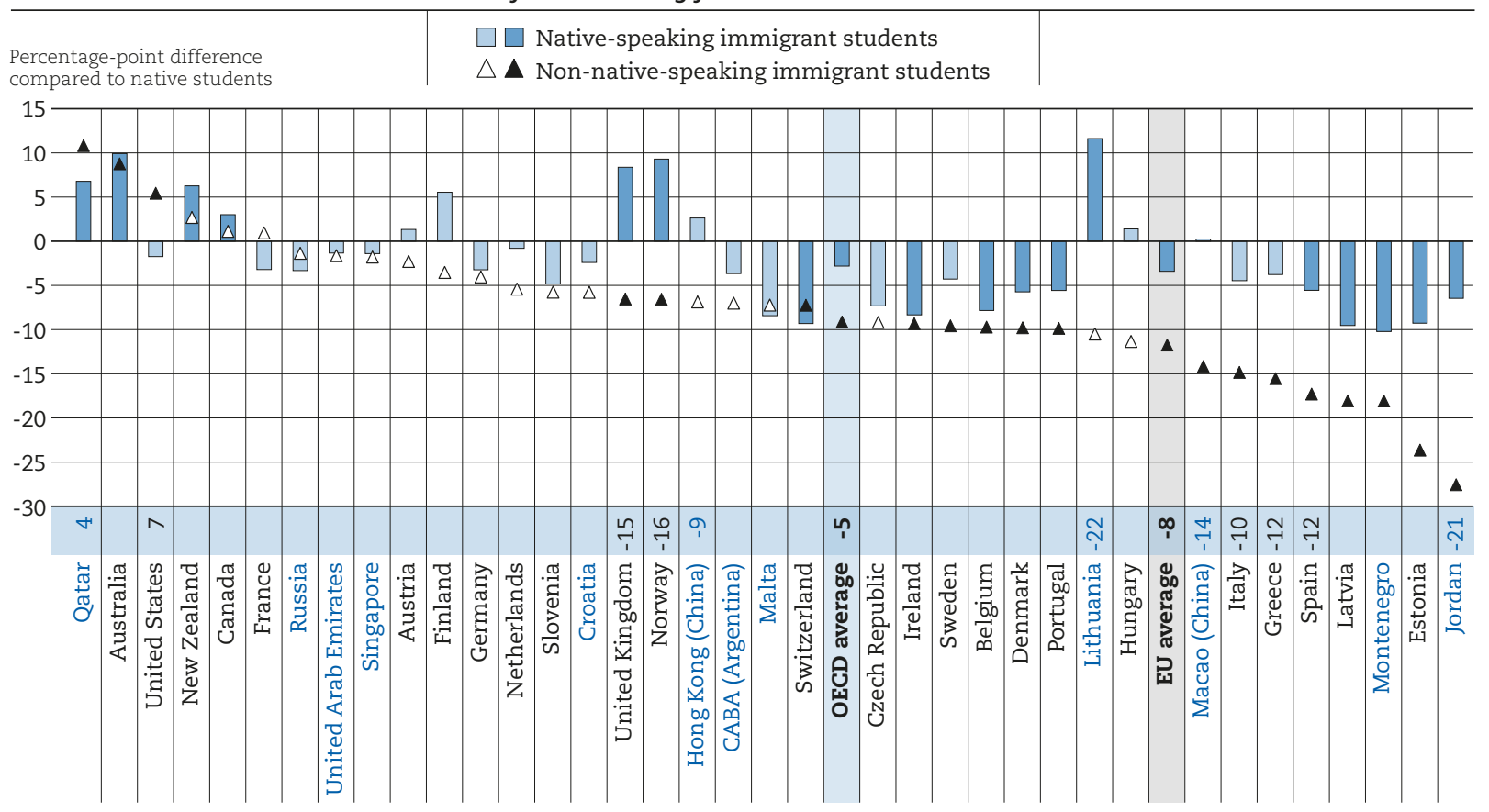

Notes: Statistically significant differences are marked in a darker tone.

Students who reported a sense of belonging at school are those who reported that they "agree" or "strongly agree" with the statement "I feel like I belong at school" and "disagree" or "strongly disagree" with the statement "I feel like an outsider at school".

Native students are students without an immigrant background who speak most frequently at home the language of the PISA assessment. Native-speaking students are students who speak most frequently at home the language of the PISA assessment.

Non-native-speaking students are those who reported that the language they most frequently speak at home is different from the language of the PISA assessment.

Only countries with valid values for both native- and non-native-speaking immigrant students are shown.

Statistically significant differences between non-native- and native-speaking immigrant students with at least one native-born parent are shown next to country/economy names. For the OECD and EU averages, this number refers only to the subset of countries/economies with valid information on both groups of students.

Countries and economies are ranked in descending order of the gap between non-native-speaking immigrant students and native students in the percentage of students who reported a sense of belonging at school, adjusted for socio-economic status.

Source: OECD, PISA 2015 Database, Table 5.12.

StatLink तils $\mathrm{http}: / / \mathrm{dx}$.doi.org/10.1787/888933681635

Figure $5.8 \mathrm{~b}$ reports the same differences in sense of belonging but for immigrant students with at least one native-born parent (a category which includes returning foreign-born students and native students of mixed heritage). On average across OECD, the share of students who reported that they feel like they belong at school among non-native-speaking students was eight percentage points smaller than the share among native-speaking students (eight percentage points across EU countries), and 12 percentage points smaller than the share among native students (13\% across EU countries). In Bulgaria, Latvia, Norway, Slovenia, Spain, the United Arab Emirates and Uruguay, native-speaking immigrant students with at least one native-born parent were as likely to report a sense of belonging at school as native students, but much more likely than non-native-speaking immigrant students with at least one native-born parent. In Montenegro, Norway and the Slovak Republic, the difference between native-speaking and non-nativespeaking immigrant students with at least one native-born parent in the shares of students who reported that they feel like they belong at school was larger than 25 percentage points. Overall, language seems to play a more decisive role in determining students' sense of belonging among immigrant students with at least one native-born parent than among immigrant students with two foreign-born parents.

Table 5.13 (available on line) examines language-related differences in the sense of belonging at school for each of the four categories of students with an immigrant background. Several effects are not statistically significant because of issues related to sample size. Nonetheless, some interesting results emerge. 


\section{Figure $5.8 \mathrm{~b}$ - Students reporting a sense of belonging at school, by immigrant heritage and language spoken at home \\ After accounting for socio-economic status}

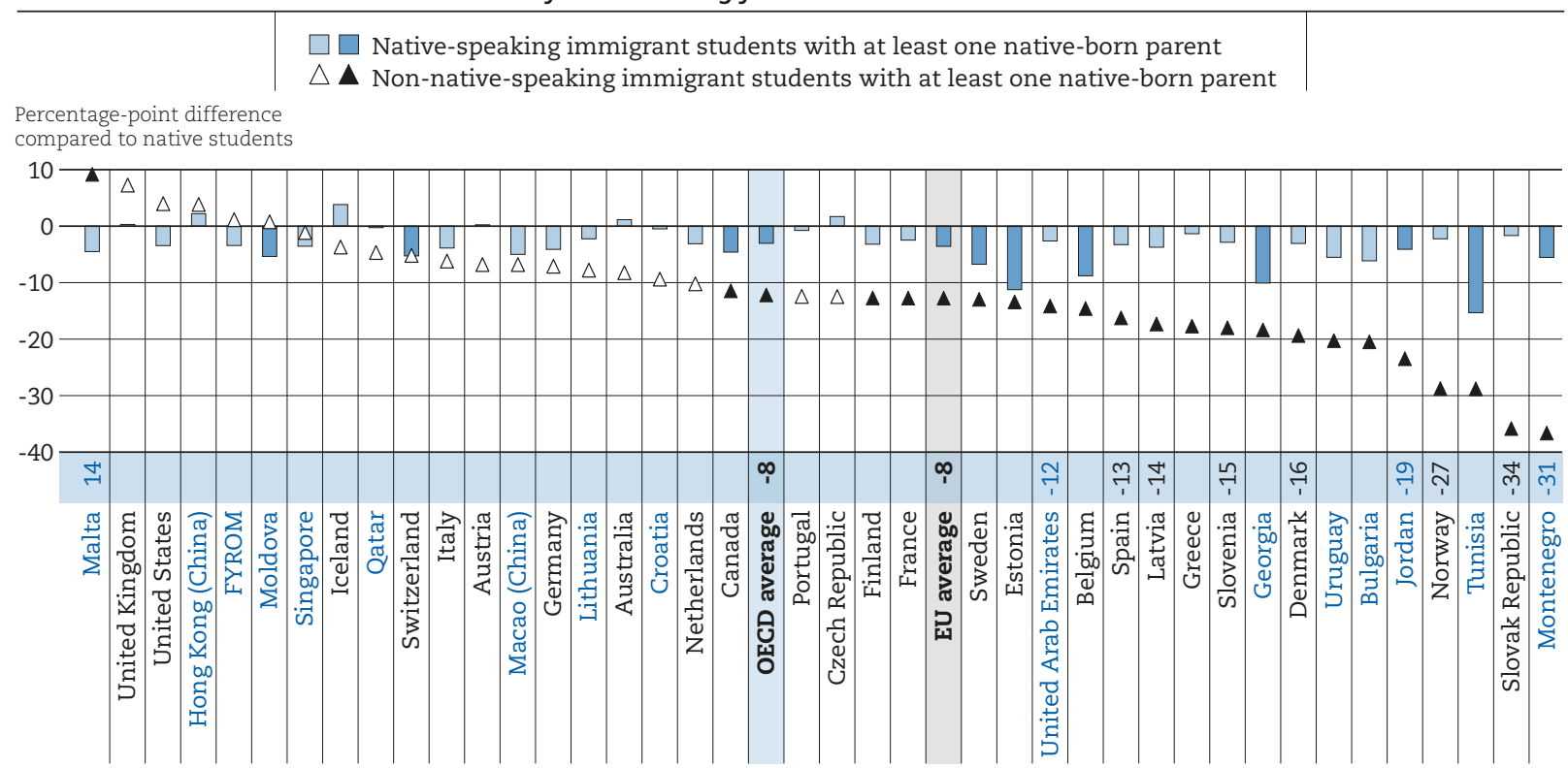

Notes: Statistically significant differences are marked in a darker tone.

Students who reported a sense of belonging at school are those who reported that they "agree" or "strongly agree" with the statement "I feel like I belong at school" and "disagree" or "strongly disagree" with the statement "I feel like an outsider at school".

Native students are students without an immigrant background who speak most frequently at home the language of the PISA assessment. Native-speaking students are students who speak most frequently at home the language of the PISA assessment.

Non-native-speaking students are those who reported that the language that they most frequently speak at home is different from the language of the PISA assessment.

Only countries with valid values for both native- and non-native-speaking immigrant students with at least one native-born parent are shown.

Statistically significant differences between non-native- and native-speaking immigrant students with at least one native-born parent are shown next to country/economy names. For the OECD and EU averages, this number refers only to the subset of countries/economies with valid information on both groups of students.

Countries and economies are ranked in descending order of the gap between non-native-speaking immigrant students with at least one native-born parent and native students in the percentage of students who reported a sense of belonging at school, adjusted for socio-economic status.

Source: OECD, PISA 2015 Database, Table 5.12.

StatLink Ails $\mathrm{http}: / / \mathrm{dx}$.doi.org/10.1787/888933681654

Linguistic differences were particularly important in Greece, Macao (China), Norway, Sweden and the United Kingdom, where native-speaking first-generation immigrant students were as likely to report a sense of belonging as native students, but non-native speakers within this group were significantly less likely to report so. In all five countries, the difference in the percentages of native- and non-native speaking first-generation immigrant students who reported that they feel like they belong at school was more than 10 percentage points. Curiously, in Norway and the United Kingdom, native-speaking secondgeneration immigrant students were more likely than native students to feel like they belong at school, but the same was not true among their non-native-speaking peers. By contrast, in the United Kingdom, non-native-speaking native students of mixed heritage were more likely to report a sense of belonging compared to native students and native-speaking students with the same immigrant background.

Speaking a language at home that is different from the language of instruction is also associated with the emotional well-being of students, as measured by their satisfaction with life and self-reported levels of anxiety. Figure 5.9 shows the percentage of students who reported being satisfied with life ${ }^{4}$ among students who do and those who do not speak the language of assessment at home. In the great majority of countries, students who speak the language of assessment at home were more likely to report being satisfied with life than students who speak a different language (detailed results for each group of students with an immigrant background can be found Table 5.14 available on line). On average across OECD countries, the share of students who reported being satisfied with life was 5 percentage points 
larger among students who speak the language of instruction at home than the share among students who do not speak the language of instruction at home. In B-S-J-G (China), Colombia, Costa Rica, Dominican Republic, Iceland, Mexico, Montenegro, Peru and Portugal, the difference between the two groups was greater than 10 percentage points.

Figure 5.9 - Life satisfaction, by language spoken at home

Percentage of students who reported being satisfied with life

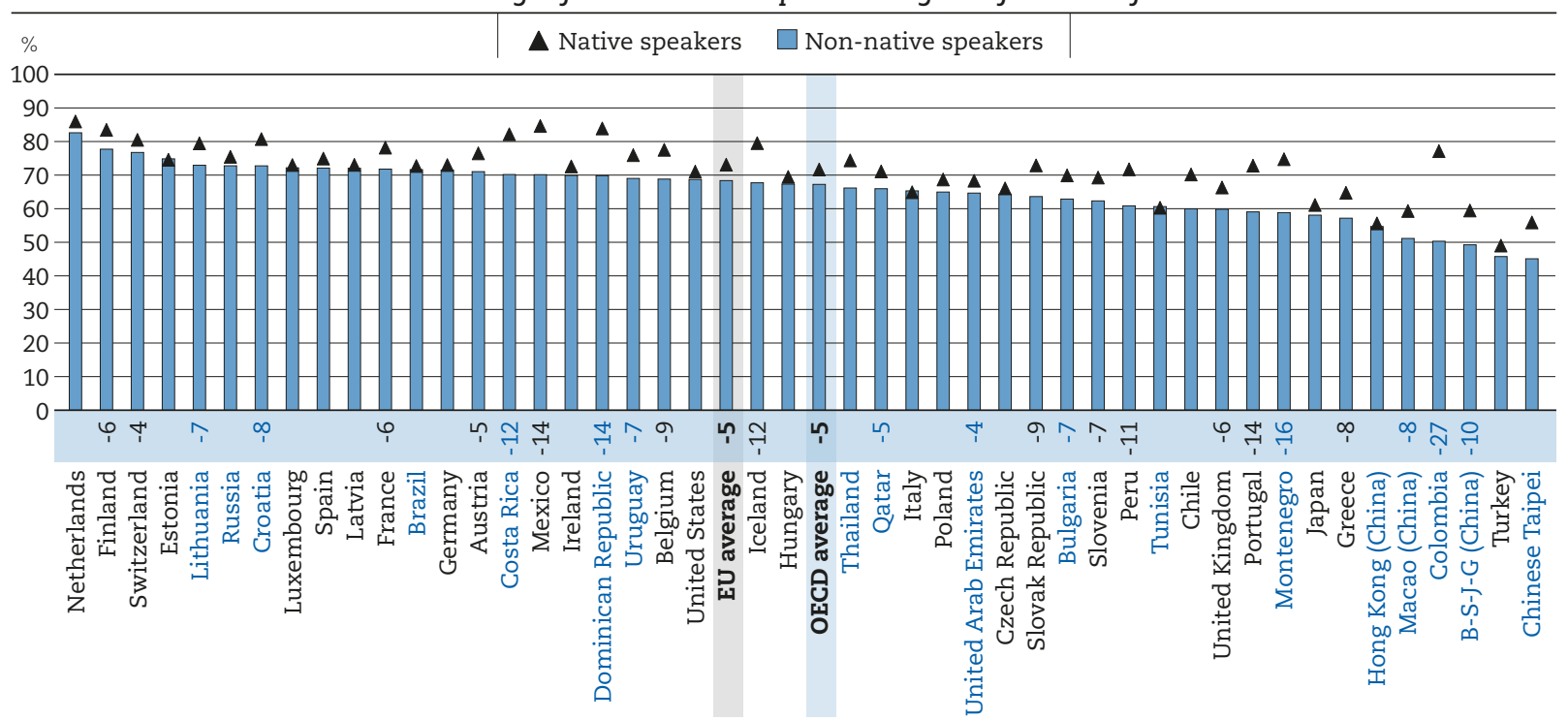

Notes: Statistically significant differences between non-native and native-speakers are shown next to the country/economy names. Only countries/economies with valid data on native and non-native speakers are shown.

Students who reported being satisfied with life are those who reported a life satisfaction of 7 or above on a scale from 0 to 10 .

Countries and economies are ranked in descending order of the percentage of non-native-speaking students who reported that they are satisfied with life. Source: OECD, PISA 2015 Database, Table 5.14.

StatLink ants http://dx.doi.org/10.1787/888933681673

Figure 5.10 - Low schoolwork-related anxiety, by language spoken at home Percentage of students who reported low levels of schoolwork-related anxiety

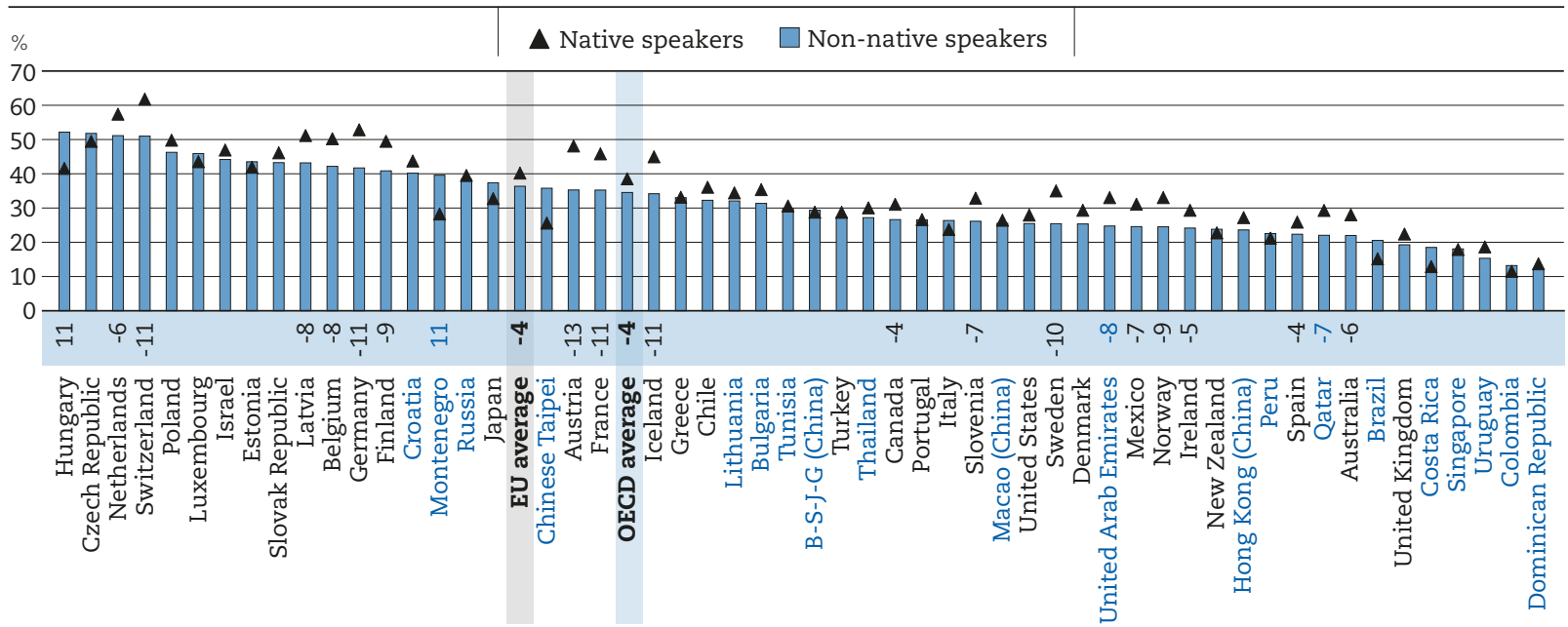

Notes: Statistically significant differences between non-native and native-speakers are shown next to the country/economy names Only countries/economies with valid data on native and non-native speakers are shown.

Students who reported low schoolwork-related anxiety are those who reported that they "disagree" or "strongly disagree" with the statements "I often worry that it will be difficult for me taking a test" and "Even if I am well prepared for a test, I feel very anxious".

Countries and economies are ranked in descending order of the percentage of non-native-speaking students who reported low levels of schoolwork-related anxiety.

Source: OECD, PISA 2015 Database, Table 5.14.

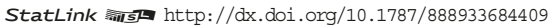


Figure 5.10 shows the percentage of students who reported low schoolwork-related anxiety ${ }^{5}$ among students who speak the language of instruction at home and those who do not (detailed results for each group of students with an immigrant background can be found Table 5.14 available on line). In several countries, speaking a different language at home was associated with a greater chance of being anxious. On average across OECD and EU countries, the difference between the percentage of students who reported speaking and those who reported not speaking the language of assessment at home and who reported low schoolwork-related anxiety was four percentage points. In Austria, France, Germany, Iceland, Sweden and Switzerland, the difference between the two groups was larger than 10 percentage points.

\section{Language groups and linguistic distance}

The figures and analyses presented so far report information on the linguistic background of students based on whether a student reported speaking the language of the assessment at home or not in 2015. But this information says nothing about the composition of the non-native language group, which can be diverse. Figure 5.11 shows some of the different linguistic groups that are included in the population of students with an immigrant background in a selected group of PISA countries. Specifically, it focuses on students in this group who reported speaking a language at home that is different from the one in which they were assessed. The countries shown vary considerably in the languages spoken at home by students with an immigrant background.

In Austria and Denmark, there were more than ten well-defined language groups. In both countries, $20 \%$ of students with an immigrant background were included in one language group; the rest were distributed across other groups. In Luxembourg, there were fewer language groups; but one of them Portuguese - was spoken by $39 \%$ of students with an immigrant background who reported speaking a language at home that is different from the language in which they sat the PISA assessment. In another set of countries, most students with an immigrant background belonged to a single language group. This is the case in Estonia and the United States, where Russian and Spanish, respectively, were the most commonly spoken languages among students with an immigrant background who reported that they do not speak the language of assessment at home.

Given the wide spectrum of languages that students with an immigrant background speak in PISAparticipating countries, it is insufficient, for research and policy purposes, to distinguish solely between students who predominantly speak, at home, the same language as that of the assessment and those who speak a different language. Languages can be more or less similar to one another; therefore, identifying the specific language that an immigrant speaks can shed light on the magnitude of the language penalty he or she faces. For example, the language barrier that immigrants from Spanish-speaking countries face when settling in Italy is not the same as the one that Italian-speaking immigrants face when they settle in Finland.

This section quantifies the association between students' outcomes and the degree of linguistic proximity between the language that students primarily speak at home and the language in which they sat the PISA test. It builds on the observation made in previous sections of this chapter that students with an immigrant background who report speaking the language of assessment at home are more likely to be academically, socially and emotionally resilient than those who do not. The following analysis aims to establish if the relative difficulty in learning a distal language explains differences in outcomes among students with an immigrant background, especially among immigrant students who arrived after the age of 12, a critical age for acquiring language proficiency.

To investigate such relationships, this section uses a lexicostatistical measure of linguistic proximity. The Automated Similarity Judgment Program (ASJP) was developed by the German Max Planck Institute for Evolutionary Anthropology. It is based on a comparison of the pronunciation of words that have the same meaning in pairs of languages, using a composite Levensthein distance indicator. Box 3.1 explains how this measure is computed, as detailed in Bakker et al. (2009). In order to determine whether the variability in the outcomes of students with an immigrant background is associated with how similar/ dissimilar their mother tongue is to the language of their host country, the linguistic proximity indicator was computed for all pairs of languages that appear in the PISA student sample (see Table 5.15 for a sample of language pairs). The Language Distance Index (LDI) is then used as a control in models that estimate differences in academic and general well-being outcomes. 
Figure 5.11 - Non-native-speaking students with an immigrant background, by language spoken at home Selected OECD countries

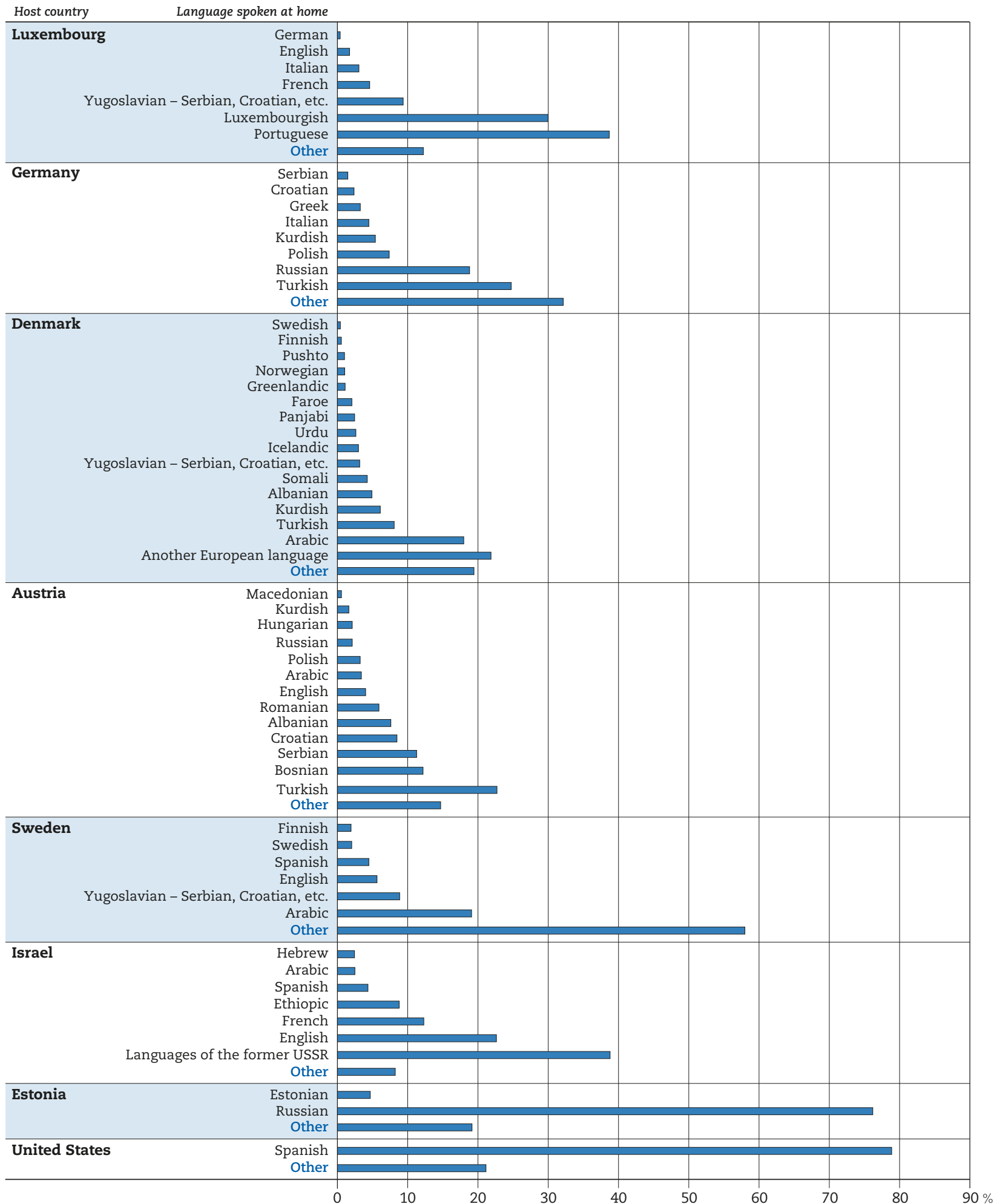

Note: Non-native-speaking students are students who reported that the language they most frequently speak at home is different from the language of the PISA assessment.

Source: OECD, PISA 2015 Database.

StatLink न्माडा $\mathrm{http}: / / \mathrm{dx}$. doi.org/10.1787/888933684428 
Languages can differ in a number of aspects: vocabulary, grammar, pronunciation, scripture and phonetic inventories. The overall distance between any two languages reflects the degree of dissimilarity across all key aspects and the ease/difficulty with which individuals speaking one language can acquire proficiency and mastery in the other language. A key limitation of the ASJP is that the resulting indicator only captures differences in pronunciation between languages. This is particularly relevant because the ASJP measures the distance between languages only in their spoken form, while the PISA measures are based on a written text. However, the main advantage of the ASJP measure is that it is easily computable for any pair of languages and thus readily available for analyses. For this reason, it is the most widely used measure of linguistic distance in empirical work (Bakker et al., 2009; Isphording and Otten, 2014).

\section{Box 5.1. Estimation of the language distance index: Levensthein distance and the Automated Similarity Judgment Program}

The Levensthein distance is a metric developed to identify the difference between two sequences. When comparing words, the Levenshtein distance characterises the minimum number of single-character edits (insertions, deletions or substitutions) that one is required to perform in order to change one word into the other (Levenshtein, 1966). This section is based on previous work exploiting the Levenshtein distance to compute the level of dissimilarity across combinations of languages (Bakker et al., 2009).

The Max Planck's ASJP developed a composite indicator based on the automatic comparison of the pronunciation of 40 words that have the same meaning from 4664 languages. The indicator is built using the following procedure. First, each pair of words $i$ with the same meaning is judged according to the similarity in pronunciation, by counting the number of insertions, deletions or substitutions of consonants and vowels that are necessary to transfer the phonetic transcription of one word (in language $\mathrm{x}$ ) to the other correspondent word in language $\mathrm{y}$, obtaining a measure of the distance between language $\mathrm{x}$ and $\mathrm{y}$ for the pair of words $i, D_{i}(x, y)$. For example, the English word person expressed phonetically as pers $3 n$ - needs two insertions, deletions or substitutions to be transformed into the same word in Spanish, persona.

To aid interpretations, the table below displays some examples of the Levenshtein distance between words of different languages with the same meaning. This first value estimated, for each pair of words, is then normalised by the potential maximum distance between both words, obtaining $D_{i}^{n}(x, y)$. The average the normalised distances estimated for the 40 words in the list is then computed obtaining the normalised language distance between languages $x$ and $y, L D_{(x, y)}=\Sigma_{i} D_{i}(x, y) \frac{1}{M}$. This estimate is normalised again by dividing it by the global distance $T_{(x, y)}=\Sigma_{i}{ }_{j} D\left(x_{i}, y_{i}\right) \frac{1}{M(M-1)}$, which is the average distance between any word in the list in language $\alpha$ with any word in the list for language $\beta$.

Finally, to obtain a definitive measure of language distance, the previous vale of normalised language distance $\mathrm{LD}_{(x, y)}$ is divided by the global distance $\mathrm{T}_{(x, y)}$ to obtain the normalised and divided Levensthein distance $\operatorname{LDND}_{(x, y)}=\frac{\operatorname{LD}(x, y)}{T_{(x, y)}}$.

For example, the Levensthein distance between Spanish and English for the word "you" equals 1 because in Spanish the word you is pronounced as "tu" while in English it is pronounced as "yu" (requiring one substitution). The Levensthein distance between Spanish and English for the word "night" equals 3 because in Spanish the word night is pronounced as "noCe" while in English it is pronounced as "nEit" (requiring three substitutions).

Source: Brown et al. (2008)

Table 5.15 shows large variations in linguistic proximity for non-native speakers, ranging from 19.60 the distance between Serbian and Croatian - to 104.06, the estimated dissimilarity between English and Vietnamese. Within countries, there are significant differences in the language distance that various groups of immigrants face. For example, among immigrants who live in Spain, the language distance faced by students who speak Catalan at home and who sat the PISA test in Valencian is considerably different from the one faced by students who speak Basque at home and who sat the test in Valencian. The language-distance index for the first pair of languages is 26.34 , while it is 103.15 for the second pair. 
Table 5.15 - Linguistic distance between the PISA test language and languages spoken at home

\begin{tabular}{|c|c|c|c|c|c|c|c|}
\hline & \multicolumn{3}{|c|}{ Maximum LDI } & \multicolumn{3}{|c|}{ Minimum LDI } & \multirow[b]{2}{*}{ Difference } \\
\hline & Test language & $\begin{array}{l}\text { Language } \\
\text { spoken at home }\end{array}$ & Value & Test language & $\begin{array}{l}\text { Language } \\
\text { spoken at home }\end{array}$ & Value & \\
\hline Spain & Valencian & Basque & 103.15 & Valencian & Catalan & 26.34 & 76.81 \\
\hline Croatia & Croatian & Hungarian & 94.37 & Croatian & Serbian & 19.60 & 74.77 \\
\hline Czech Republic & Czech & Chinese & 102.01 & Czech & Slovak & 32.82 & 69.19 \\
\hline FYROM & Turkish & Serbian & 97.97 & Macedonian & Serbian & 36.59 & 61.38 \\
\hline Finland & Swedish & Thai & 100.99 & Finnish & Estonian & 41.93 & 59.06 \\
\hline Luxembourg & French & German & 97.01 & German & Luxembourgish & 41.94 & 55.07 \\
\hline Denmark & Danish & Somali & 102.27 & Danish & Norwegian & 47.85 & 54.42 \\
\hline Belgium & Dutch & Turkish & 102.33 & Dutch & German dialect (BEL) & 48.83 & 53.50 \\
\hline Switzerland & German & Turkish & 100.05 & Italian & Spanish & 58.31 & 41.74 \\
\hline Latvia & Latvian & Ukrainian & 92.27 & Russian & Belarusian & 59.2 & 33.07 \\
\hline Sweden & English & Arabic & 98.03 & Swedish & English & 66.26 & 31.77 \\
\hline Australia & English & Vietnamese & 104.06 & English & German & 72.61 & 31.45 \\
\hline Lithuania & Russian & Lithuanian & 91.33 & Polish & Russian & 61.06 & 30.27 \\
\hline Moldova & Russian & Romanian & 96.68 & Russian & Bulgarian & 66.64 & 30.04 \\
\hline Austria & German & Turkish & 100.05 & German & English & 72.61 & 27.44 \\
\hline Uruguay & Spanish & English & 92.25 & Spanish & Portuguese & 67.96 & 24.29 \\
\hline Israel & Arabic & Spanish & 98.49 & Hebrew & Arabic & 77.63 & 20.86 \\
\hline Costa Rica & Spanish & Mandarin & 98.66 & Spanish & French & 84.03 & 14.63 \\
\hline Germany & German & Turkish & 100.05 & German & Italian & 86.61 & 13.44 \\
\hline Dominican Republic & Spanish & Creole & 97.06 & Spanish & French & 84.03 & 13.03 \\
\hline Peru & Spanish & Aymara & 102.43 & Spanish & English & 92.25 & 10.18 \\
\hline Colombia & Spanish & English & 92.25 & Spanish & French & 84.03 & 8.22 \\
\hline Georgia & Russian & Azerbaijani & 101.15 & Azerbaijani & Georgian & 93.83 & 7.32 \\
\hline United Kingdom & English & Scottish Gaelic & 96.72 & Welsh & Irish & 89.56 & 7.16 \\
\hline Italy & Slovenian & German & 92.96 & Italian & German & 86.61 & 6.35 \\
\hline Macao (China) & Chinese & Portuguese & 101.76 & English & Portuguese & 95.45 & 6.31 \\
\hline Lebanon & English & Arabic & 98.03 & English & French & 92.06 & 5.97 \\
\hline Slovenia & Slovenian & Hungarian & 93.93 & Slovenian & Italian & 88.61 & 5.32 \\
\hline Korea & Korean & Japanese & 99.61 & Korean & Chinese & 95.91 & 3.70 \\
\hline New Zealand & English & Chinese & 101.27 & English & Samoan & 97.76 & 3.51 \\
\hline Singapore & English & Chinese & 101.27 & English & Malay & 98.51 & 2.76 \\
\hline Hong Kong (China) & Chinese & English & 101.27 & English & Cantonese & 98.52 & 2.75 \\
\hline Slovak Republic & Hungarian & Romany & 98.03 & Slovak & Romany & 95.81 & 2.22 \\
\hline Qatar & English & Arabic & 98.03 & English & Hindi & 97.04 & 0.99 \\
\hline Norway & Nynorsk & Swedish & 48.53 & Bokmål & Danish & 47.85 & 0.68 \\
\hline United Arab Emirates & English & Arabic & 98.03 & English & Arabic & 98.03 & 0.00 \\
\hline
\end{tabular}

Source: OECD, PISA 2015 Database and Wichmann, Søren, Eric W. Holman, and Cecil H. Brown (eds.), 2016. The ASJP Database (version 17).

StatLink ants http://dx.doi.org/10.1787/888933681730

\section{Linguistic distance and students' outcomes}

To investigate the effect of language distance on outcomes of interest a series of models were developed and replicated for each measure of resilience: academic, social, emotional and motivational. Results are presented in Tables 5.A1.1 through 5.A1.5 in Annex 5.A1. All analyses were conducted on the pooled PISA 2015 sample, weighting each country for population size and weighting individual students to derive estimates representative at the population level. All regressions included destination-country fixed effects.

Results reported in Table 5.A1.1 indicate that the greater the dissimilarity between the language a student speaks at home and the one in which the student sat the PISA test, the lower his or her likelihood of attaining baseline academic proficiency. Results presented in Model 1 of Table 5.A1.1 indicate that, on average, the percentage of students who reach baseline levels of academic proficiency is 4.3 percentage points lower among students with an immigrant background who speak the language of assessment at home compared to native students. However, the gap is greater among students with an immigrant background who do not speak the language of assessment at home and it increases with the linguistic 
distance between the home and assessment languages. A 10-point increase in the linguistic-distance indicator corresponds to a 1.6 percentage-point reduction in the likelihood of reaching baseline levels of academic performance.

Composition effects explain some of the differences between students with and without an immigrant background as well as the gap associated with language distance. When comparing students of the same gender and with similar socio-economic status, the disadvantage related to linguistic distance shrinks (Model 2a). However, once differences in the Human Development Index (HDI) and GDP between countries of origin and host countries are considered, the coefficient associated with having an immigrant background returns to previous levels and the negative effect of linguistic distance grows (Model 2b). In model $2 \mathrm{~b}$, a 10-point increase in linguistic distance reduces the probability of reaching baseline academic levels by 1.1 percentage points.

Models 3 and 4 reveal large variations in the extent to which greater linguistic distance reduces the likelihood that 15-year-old students will attain baseline academic proficiency. They show the interaction between the linguistic distance indicator and the socio-economic status and gender of students. Specifically, the negative effect of linguistic distance on the likelihood of reaching baseline levels of performance in the three core PISA subjects tends to be larger among socio-economically advantaged students and among boys. Since 15-year-old boys tend to struggle more than girls with text comprehension (OECD, 2015a), irrespective of their language proficiency, this result appears to suggest that while girls might be able to overcome language barriers, boys might not, which could prevent them from developing academic resilience. Language dissimilarity might represent a greater barrier to advantaged students than to disadvantaged students because disadvantaged students face so many constraints to developing academic resilience that their likelihood of being academically resilient is already low, even before considering whatever language barriers they might face. The more advantaged the student, the more salient the language difficulties in influencing the likelihood that the student will attain baseline levels of proficiency.

Models 5 and 6 focus on immigrant students and identify whether arriving in the host country earlier reduces the negative consequences associated with having a mother tongue that is very different from the language of instruction. Results confirm the critical-period hypothesis: children who had arrived in their host country before the age of 12 have a greater chance of being academically resilient. Indeed, among students who had arrived at or before the age of 12, the share of academically resilient students is 14 percentage points larger than the share of academically resilient students who had arrived after the age of 12. When including age at arrival in the regression (Model 5), the effect of linguistic distance is still statistically significant and large: a one-point increase in the index of linguistic distance reduces the chance of reaching baseline levels of academic achievement by 1.3 percentage points. When also considering the interaction of age at arrival and the linguistic distance indicator (Model 6), the effect of the linguistic-distance variable and its interaction with age at arrival are not statistically significant at conventional levels (5\%). Nevertheless, the coefficients are negative, as expected.

Table 5.A1.2 identifies the relationship between linguistic distance and the likelihood of reporting a sense of belonging. When considering only immigrant background, gender, socio-economic status and score on the linguistic distance indicator for students (Models $2 \mathrm{a}$ and $2 \mathrm{~b}$ ), the indicator of linguistic distance is either not statistically significant or it has only small effects. However, when also considering HDI and GDP differentials and the interaction of the linguistic-distance indicator with gender and socio-economic status (Models 2b, 3 and 4), the effect of linguistic distance on sense of belonging at school is statistically significant and similar to that on academic resilience. In Model 3, students with an immigrant background who speak the language of assessment at home have a 3.4 percentage points lower chance of reporting a strong sense of belonging than their native peers. However, immigrant students who do not speak the language of assessment at home have even lower likelihoods, which decrease by 1 percentage points with each 10-point increase in linguistic distance.

Unlike Table 5.A1.1, Table 5.A1.2 shows no significant interaction between socio-economic status and linguistic distance. By contrast, the interaction between linguistic distance and gender is statistically significant and strong in Model 4. A 10-point increase on the index of linguistic distance leads to a 1.3 percentage-point reduction in the chance of boys reporting a sense of belonging at school, but only a 0.7 percentage-point reduction in the likelihood of girls reporting so. 
Table 5.A1.2 also confirms the critical-period hypothesis, since the main effect of the early-arrival variable is statistically significant in Model 5. However, when also including its interaction with linguistic distance (Model 6), the main effect of the early-arrival variable is not statistically significant, while the main effect of linguistic distance and the interaction of the two variables is significant. For foreign-born students who had arrived at or after the age of 12, a 10-point increase in the linguistic distance between the language they speak at home and the one in which they sat the PISA test reduces their chances of reporting a sense of belonging by 2.4 percentage points. By contrast, among immigrant students who had arrived before the age of 12, a 10-point increase in linguistic distance translates into a 1.7 percentage-point reduction in the likelihood of reporting a sense of belonging at school.

Tables 5.A1.3 and 5.A1.4 present the output from the six models using life satisfaction and anxiety as outcome variables. In Table 5.A1.3, the index of linguistic distance is statistically significant in only three models and at low significance levels. When including GDP and HDI differentials as well as the gender and socio-economic status of students, together with their interaction with linguistic distance in the regression (Models 2b, 3 and 4), a 10-point increase in linguistic distance reduces students' chances of reporting satisfaction with life by 0.4 percentage point. In Table 5.A1.4, linguistic distance is not statistically significant in any of the model specifications except for the fifth, in which it interacts with students' age at arrival and it assumes a positive value. Results show that linguistic distance has an impact on cognitive outcomes and social well-being, but a negligible one on emotional and motivational well-being.

Table 5.A1.5 presents the results from the regressions that were run with motivational resilience as the outcome variable. The coefficient for linguistic distance is not statistically significant, or small and significant at low levels in all models except for the fourth, in which the interaction of the variable with gender is included. In this model, the linguistic distance variable and the interaction with gender are statistically significant. According to Model 4, a 10-point increase in linguistic distance reduces the likelihood of attaining high levels of achievement motivation by 0.3 percentage point among boys, but it increases the chance by 0.02 percentage point among girls. Results indicate that there are significant gender-based differences in the effect of speaking a different language on achievement motivation. 


\section{Annex 5.A1}

This section explains the models that were used to investigate the effects of linguistic distance on students' academic and well-being outcomes and presents results. For each outcome, a set of eight separate models was developed. First, the outcome of interest was considered to be a function of whether the student has an immigrant background, as well as the linguistic distance between the language spoken at home by the student and the one in which he or she sat the assessment (Model 1). Model 2a is identical to the first but also accounts for potential socio-economic and gender differences. Model 2b is identical to 2a but it controls for differences in GDP and the Human Development Index (HDI) between the host and origin countries of immigrant students in 2010, as do all the following models. (For a detailed explanation of how these measures were obtained, please see Annex 2.) Models 3 and 4 also include interaction terms of linguistic distance with socio-economic background and gender, respectively. Model 5 introduces a binary variable that identifies students who arrived in the host country before the age of 12 and those who arrived later. Model 6 also includes an interaction of that variable with the linguistic-distance indicator. Since the binary variable for early arrival assumes non-missing values only for foreign-born students, the immigrant variable is not included in the last two models. In all tables, the coefficient for linguistic distance reports the effects of a 10-point increase in the linguistic-distance indicator.

Table 5.A1.1 - Attaining baseline academic proficiency and linguistic distance

\begin{tabular}{|c|c|c|c|c|c|c|c|}
\hline Variable & Model 1 & Model 2a & Model 2b & Model 3 & Model 4 & Model 5 & Model 6 \\
\hline Students with an immigrant background & $\begin{array}{c}-4.24^{* * *} \\
-(0.71)\end{array}$ & $\begin{array}{c}-2.63^{* * *} \\
-(0.71)\end{array}$ & $\begin{array}{c}-4.3^{* * *} \\
-(1.18)\end{array}$ & $\begin{array}{l}-4.29^{* * *} \\
-(1.18)\end{array}$ & $\begin{array}{c}-4.3^{* * *} \\
-(1.18)\end{array}$ & & \\
\hline Linguistic Distance & $\begin{array}{l}-1.62^{* * *} \\
(0.20)\end{array}$ & $\begin{array}{l}-0.74^{* * *} \\
(0.19)\end{array}$ & $\begin{array}{l}-1.08^{* * *} \\
(0.20)\end{array}$ & $\begin{array}{l}-1.15^{* * *} \\
(0.21)\end{array}$ & $\begin{array}{l}-1.28^{* * *} \\
(0.22)\end{array}$ & $\begin{array}{l}-1.23^{* * *} \\
(0.47)\end{array}$ & $\begin{array}{l}-0.74 \\
(0.70)\end{array}$ \\
\hline Socio-economic background (ESCS) & & $\begin{array}{l}12.68^{* * *} \\
(0.20)\end{array}$ & $\begin{array}{l}12.85^{* * *} \\
(0.19)\end{array}$ & $\begin{array}{l}12.89^{* * *} \\
(0.20)\end{array}$ & $\begin{array}{l}12.85^{* * *} \\
(0.19)\end{array}$ & $\begin{array}{l}10.07^{* * *} \\
(1.38)\end{array}$ & $\begin{array}{l}10.23^{* * *} \\
(1.39)\end{array}$ \\
\hline Female Students & & $\begin{array}{c}1.44^{* * *} \\
(0.34)\end{array}$ & $\begin{array}{c}1.64^{* * * *} \\
(0.38)\end{array}$ & $\begin{array}{l}1.64^{* * *} \\
(0.38)\end{array}$ & $\begin{array}{l}1.55^{* * *} \\
(0.38)\end{array}$ & $\begin{array}{c}5.15^{* *} \\
(2.18)\end{array}$ & $\begin{array}{l}5.29^{* *} \\
(2.20)\end{array}$ \\
\hline ESCS*Linguistic distance & & & & $\begin{array}{l}-0.16^{* *} \\
(0.08)\end{array}$ & & & \\
\hline Female students*Linguistic distance & & & & & $\begin{array}{c}0.4^{* *} \\
(0.16)\end{array}$ & & \\
\hline Arrivaed before the age of 12 & & & & & & $\begin{array}{l}14.31^{\text {*** }} \\
(3.52)\end{array}$ & $\begin{array}{l}14.87^{* * *} \\
(3.81)\end{array}$ \\
\hline Arrived before the age of $12^{*}$ Linguistic distance & & & & & & & $\begin{array}{l}-0.71 \\
-0.78\end{array}$ \\
\hline Constant & $\begin{array}{l}58.5^{* * *} \\
(0.40)\end{array}$ & $\begin{array}{l}63.38^{* * *} \\
(0.38)\end{array}$ & $\begin{array}{l}62.97^{* * *} \\
(0.38)\end{array}$ & $\begin{array}{l}62.99^{* * *} \\
(0.38)\end{array}$ & $\begin{array}{l}63.01^{* * *} \\
(3.93)\end{array}$ & $\begin{array}{l}44.5^{* * *} \\
(3.94)\end{array}$ & $\begin{aligned} & 43.91^{* * *} \\
- & (3.94)\end{aligned}$ \\
\hline Observations & 445912 & 443802 & 389873 & 389873 & 389873 & 12589 & 12589 \\
\hline Adjusted R-squared & 0.186 & 0.251 & 0.264 & 0.264 & 0.264 & 0.294 & 0.295 \\
\hline Country FE & Yes & Yes & Yes & Yes & Yes & Yes & Yes \\
\hline GDP and HDI differential & No & No & Yes & Yes & Yes & Yes & Yes \\
\hline
\end{tabular}

Notes: Standard error in parentheses.

${ }^{*} \mathrm{p}<0.10,{ }^{* *} \mathrm{p}<0.05,{ }^{* * *} \mathrm{p}<0.01$

Source: OECD, PISA 2015 Database and Wichmann, Søren, Eric W. Holman, and Cecil H. Brown (eds.), 2016. The ASJP Database (version 17).

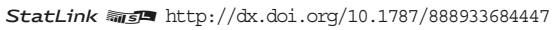

Table 5.A1.2 - Reporting a sense of belonging at school and linguistic distance

\begin{tabular}{|c|c|c|c|c|c|c|c|}
\hline Variable & Model 1 & Model 2a & Model 2b & Model 3 & Model 4 & Model 5 & Model 6 \\
\hline Students with an immigrant background & $\begin{array}{l}-2.26^{* * *} \\
(0.70)\end{array}$ & $\begin{array}{l}-1.93^{* * *} \\
(0.70)\end{array}$ & $\begin{array}{l}-3.41^{* * *} \\
(0.83)\end{array}$ & $\begin{array}{l}-3.41^{* * *} \\
(0.83)\end{array}$ & $\begin{array}{l}-3.41^{* * *} \\
(0.83)\end{array}$ & & \\
\hline Linguistic Distance & $\begin{array}{l}-0.34^{* *} \\
(0.15)\end{array}$ & $\begin{array}{r}-0.13 \\
(0.15)\end{array}$ & $\begin{array}{l}-0.99^{* * *} \\
(0.17)\end{array}$ & $\begin{array}{l}-1.04^{* * *} \\
(0.17)\end{array}$ & $\begin{array}{l}-1.25^{* * *} \\
(0.23)\end{array}$ & $\begin{array}{l}-1.11^{* *} \\
(0.44)\end{array}$ & $\begin{array}{l}-2.38^{* * *} \\
(0.65)\end{array}$ \\
\hline Socio-economic background (ESCS) & & $\begin{array}{l}3.03^{* * *} \\
(0.16)\end{array}$ & $\begin{array}{l}3.12^{* * *} \\
(0.17)\end{array}$ & $\begin{array}{l}3.15^{* * *} \\
(0.17)\end{array}$ & $\begin{array}{l}3.13^{* * *} \\
(0.17)\end{array}$ & $\begin{array}{c}2.76^{* *} \\
(1.11)\end{array}$ & $\begin{array}{l}2.84^{* * *} \\
(1.10)\end{array}$ \\
\hline Female Students & & $\begin{array}{l}2.77^{* * *} \\
(0.34)\end{array}$ & $\begin{array}{l}3.03^{* * *} \\
(0.31)\end{array}$ & $\begin{array}{l}3.03^{* * *} \\
(0.31)\end{array}$ & $\begin{array}{l}2.92^{* * * *} \\
(0.31)\end{array}$ & $\begin{array}{r}3.47 \\
(2.32)\end{array}$ & $\begin{array}{r}3.56 \\
-(2.32)\end{array}$ \\
\hline ESCS*Linguistic distance & & & & $\begin{array}{l}-0.12 \\
(0.08)\end{array}$ & & & \\
\hline Female students*Linguistic distance & & & & & $\begin{array}{l}0.52^{* *} \\
(0.21)\end{array}$ & & \\
\hline Arrivaed before the age of 12 & & & & & & $\begin{array}{l}7.34^{* * *} \\
(2.82)\end{array}$ & $\begin{array}{r}5.06 \\
(3.19)\end{array}$ \\
\hline Arrived before the age of $12^{*}$ Linguistic distance & & & & & & & $\begin{array}{l}1.68^{* *} \\
-0.71\end{array}$ \\
\hline Constant & $\begin{array}{l}66.87^{* * *} \\
(0.26)\end{array}$ & $\begin{array}{l}66.79^{* * *} \\
(0.34)\end{array}$ & $\begin{array}{l}67.3^{* * *} \\
(0.32)\end{array}$ & $\begin{array}{l}67.31^{* * *} \\
(0.32)\end{array}$ & $\begin{array}{l}67.35^{* * *} \\
(0.32)\end{array}$ & $\begin{array}{l}53.28^{* * *} \\
(2.84)\end{array}$ & $\begin{array}{l}55.19^{* * *} \\
(3.15)\end{array}$ \\
\hline Observations & 426121 & 424499 & 373237 & 373237 & 373237 & 12013 & 12013 \\
\hline Adjusted R-squared & 0.05 & 0.055 & 0.056 & 0.057 & 0.057 & 0.037 & 0.039 \\
\hline Country FE & Yes & Yes & Yes & Yes & Yes & Yes & Yes \\
\hline GDP and HDI differential & No & No & Yes & Yes & Yes & Yes & Yes \\
\hline
\end{tabular}


Table 5.A1.3 - Reporting being satisfied with life and linguistic distance

\begin{tabular}{|c|c|c|c|c|c|c|c|}
\hline Variable & Model 1 & Model 2a & Model 2b & Model 3 & Model 4 & Model 5 & Model 6 \\
\hline Students with an immigrant background & $\begin{array}{l}-4.58^{* * *} \\
(0.67)\end{array}$ & $\begin{array}{l}-4.03^{* * *} \\
(0.70)\end{array}$ & $\begin{array}{l}-5.95^{* * *} \\
(1.30)\end{array}$ & $\begin{array}{l}-5.95^{* * *} \\
(1.30)\end{array}$ & $\begin{array}{l}-5.95^{* * *} \\
(1.29)\end{array}$ & & \\
\hline Linguistic Distance & $\begin{array}{l}-0.13 \\
(0.12)\end{array}$ & $\begin{array}{r}0.09 \\
(0.12)\end{array}$ & $\begin{array}{l}-0.4^{* *} \\
(0.18)\end{array}$ & $\begin{array}{l}-0.38^{* *} \\
(0.17)\end{array}$ & $\begin{array}{l}-0.41^{*} \\
(0.23)\end{array}$ & $\begin{array}{r}-0.8 \\
(0.55)\end{array}$ & $\begin{array}{r}-0.81 \\
(0.65)\end{array}$ \\
\hline Socio-economic background (ESCS) & & $\begin{array}{c}3.04^{* * * *} \\
(0.19)\end{array}$ & $(0.20)^{3^{* * *}}$ & $\begin{array}{l}2.99^{* * *} \\
(0.21)\end{array}$ & $(0.20)^{3^{* * *}}$ & $\begin{array}{c}3.7^{* * *} \\
(1.07)\end{array}$ & $\begin{array}{c}3.7^{* * *} \\
-(1.07)\end{array}$ \\
\hline Female Student & & $\begin{array}{l}-7.27^{* * *} \\
(0.33)\end{array}$ & $\begin{array}{l}-6.85^{* * *} \\
(0.32)\end{array}$ & $\begin{array}{l}-6.85^{* * *} \\
(0.32)\end{array}$ & $\begin{array}{l}-6.85^{* * *} \\
(0.31)\end{array}$ & $\begin{array}{l}-5.82^{* * *} \\
(2.23)\end{array}$ & $\begin{array}{l}-5.82^{2 * *} \\
-(2.23)\end{array}$ \\
\hline ESCS*Linguistic distance & & & & $\begin{array}{r}0.06 \\
(0.08)\end{array}$ & & & \\
\hline Female students*Linguistic distance & & & & & $\begin{array}{r}0.01 \\
(0.23)\end{array}$ & & \\
\hline Arrivaed before the age of 12 & & & & & & $\begin{array}{r}1.71 \\
(2.82)\end{array}$ & $\begin{array}{r}1.69 \\
(3.19)\end{array}$ \\
\hline Arrived before the age of $12^{*}$ Linguistic distance & & & & & & & $\begin{array}{r}0.01 \\
-0.85\end{array}$ \\
\hline Constant & $\begin{array}{l}70.85^{* * *} \\
(0.23)\end{array}$ & $\begin{array}{l}75.57^{* * *} \\
(0.29)\end{array}$ & $\begin{array}{l}75.37^{* * *} \\
(0.26)\end{array}$ & $\begin{array}{l}75.36^{* * *} \\
(0.26)\end{array}$ & $\begin{array}{l}75.37^{* * *} \\
(0.25)\end{array}$ & $\begin{array}{l}69.45^{* * *} \\
(3.27)\end{array}$ & $\begin{array}{l}69.47^{* * *} \\
-(3.58)\end{array}$ \\
\hline Observations & 303018 & 301804 & 267673 & 267673 & 267673 & 9827 & 9827 \\
\hline Adjusted R-squared & 0.037 & 0.047 & 0.050 & 0.050 & 0.050 & 0.037 & 0.037 \\
\hline Country FE & Yes & Yes & Yes & Yes & Yes & Yes & Yes \\
\hline GDP and HDI differential & No & No & Yes & Yes & Yes & Yes & Yes \\
\hline
\end{tabular}

Notes: Standard error in parentheses.

${ }^{*} \mathrm{p}<0.10,{ }^{* *} \mathrm{p}<0.05,{ }^{* * *} \mathrm{p}<0.01$

Source: OECD, PISA 2015 Database and Wichmann, Søren, Eric W. Holman, and Cecil H. Brown (eds.), 2016. The ASJP Database (version 17).

StatLink ails http://dx.doi.org/10.1787/888933684485

\section{Table 5.A1.4 - Reporting low levels of schoolwork-related anxiety and linguistic distance}

\begin{tabular}{|c|c|c|c|c|c|c|c|}
\hline Variable & Model 1 & Model 2a & Model 2b & Model 3 & Model 4 & Model 5 & Model 6 \\
\hline Students with an immigrant background & $\begin{array}{l}-2.51^{* * *} \\
(0.54)\end{array}$ & $\begin{array}{l}-2.03^{* * *} \\
(0.54)\end{array}$ & $\begin{array}{l}-2.24^{* * *} \\
(0.85)\end{array}$ & $\begin{array}{l}-2.23^{* * *} \\
(0.85)\end{array}$ & $\begin{array}{l}-2.24^{* * *} \\
(0.85)\end{array}$ & & \\
\hline Linguistic Distance & $\begin{array}{l}-0.11 \\
(0.11)\end{array}$ & $\begin{array}{r}0.06 \\
(0.11)\end{array}$ & $\begin{array}{r}0.07 \\
(0.11)\end{array}$ & $\begin{array}{r}0.05 \\
(0.12)\end{array}$ & $\begin{array}{r}-0.07 \\
(0.13)\end{array}$ & $\begin{array}{l}1.01^{* *} \\
(0.43)\end{array}$ & $\begin{array}{r}0.63 \\
(0.65)\end{array}$ \\
\hline Socio-economic background (ESCS) & & $\begin{array}{l}2.43^{* * *} \\
(0.16)\end{array}$ & $\begin{array}{l}2.31^{* * * *} \\
(0.19)\end{array}$ & $\begin{array}{l}2.32^{* * *} \\
(0.19)\end{array}$ & $\begin{array}{l}2.31^{* * *} \\
(0.19)\end{array}$ & $\begin{array}{c}2.85^{* *} \\
(1.32)\end{array}$ & $\begin{array}{c}2.88^{* *} \\
(1.32)\end{array}$ \\
\hline Female Student & & $\begin{array}{c}-13.15^{* * *} \\
(0.32)\end{array}$ & $\begin{array}{l}-13^{* * *} \\
(0.35)\end{array}$ & $\begin{array}{l}-13^{* * *} \\
(0.35)\end{array}$ & $\begin{array}{c}-13.07^{* * *} \\
(0.35)\end{array}$ & $\begin{array}{l}-14.46^{* * *} \\
(2.05)\end{array}$ & $\begin{array}{l}-14.43^{* * *} \\
-(2.05)\end{array}$ \\
\hline ESCS*Linguistic distance & & & & $\begin{array}{l}-0.04 \\
(0.07)\end{array}$ & & & \\
\hline Female students*Linguistic distance & & & & & $\begin{array}{r}0.28 \\
(0.21)\end{array}$ & & \\
\hline Arrivaed before the age of 12 & & & & & & $\begin{array}{l}5.9^{* *} \\
(2.82)\end{array}$ & $\begin{array}{c}5.18^{*} \\
(3.19)\end{array}$ \\
\hline Arrived before the age of $12^{*}$ Linguistic distance & & & & & & & $\begin{array}{r}0.51 \\
-0.71\end{array}$ \\
\hline Constant & $\begin{array}{l}30.08^{* * *} \\
(0.21)\end{array}$ & $\begin{array}{l}37.45^{* * *} \\
(0.28)\end{array}$ & $\begin{array}{l}37.24^{* * *} \\
(0.28)\end{array}$ & $\begin{array}{l}37.24^{* * *} \\
(0.28)\end{array}$ & $\begin{array}{l}37.27^{* * *} \\
(0.28)\end{array}$ & $\begin{array}{l}30.98^{* * *} \\
(3.03)\end{array}$ & $\begin{array}{l}31.59^{* * *} \\
(3.16)\end{array}$ \\
\hline Observations & 369321 & 367764 & 320721 & 320721 & 320721 & 12287 & 12287 \\
\hline Adjusted R-squared & 0.055 & 0.079 & 0.081 & 0.081 & 0.081 & 0.078 & 0.078 \\
\hline Country FE & Yes & Yes & Yes & Yes & Yes & Yes & Yes \\
\hline GDP and HDI differential & No & No & Yes & Yes & Yes & Yes & Yes \\
\hline
\end{tabular}

Notes: Standard error in parentheses.

${ }^{*} \mathrm{p}<0.10,{ }^{* *} \mathrm{p}<0.05,{ }^{* * *} \mathrm{p}<0.01$

Source: OECD, PISA 2015 Database and Wichmann, Søren, Eric W. Holman, and Cecil H. Brown (eds.), 2016. The ASJP Database (version 17).

StatLink ails http://dx.doi.org/10.1787/888933684504

Table 5.A1.5 - High achievement motivation and linguistic distance

\begin{tabular}{|c|c|c|c|c|c|c|c|}
\hline Variable & Model 1 & Model 2a & Model 2b & Model 3 & Model 4 & Model 5 & Model 6 \\
\hline Students with an immigrant background & $\begin{array}{c}2.01^{* * *} \\
(0.45)\end{array}$ & $\begin{array}{c}2.25^{* * *} \\
(0.45)\end{array}$ & $\begin{array}{c}-0.05 \\
(1.01)\end{array}$ & $\begin{array}{c}-0.04 \\
(1.01)\end{array}$ & $\begin{array}{r}-0.05 \\
(1.01)\end{array}$ & & \\
\hline Linguistic Distance & $\begin{array}{c}-0.12^{*} \\
(0.06)\end{array}$ & $\begin{array}{l}-0.01 \\
(0.06)\end{array}$ & $\begin{array}{l}-0.16^{*} \\
(0.09)\end{array}$ & $\begin{array}{c}-0.2^{* *} \\
(0.09)\end{array}$ & $\begin{array}{l}-0.34^{* * *} \\
(0.13)\end{array}$ & $\begin{array}{r}0.25 \\
(0.28)\end{array}$ & $\begin{array}{r}0.04 \\
(0.65)\end{array}$ \\
\hline Socio-economic background (ESCS) & & $\begin{array}{l}1.73^{* * *} \\
(0.11)\end{array}$ & $\begin{array}{l}1.87^{* * *} \\
(0.12)\end{array}$ & $\begin{array}{c}1.9^{* * *} \\
(0.12)\end{array}$ & $\begin{array}{l}1.88^{* * * *} \\
(0.12)\end{array}$ & $\begin{array}{r}0.91 \\
(0.66)\end{array}$ & $\begin{array}{r}0.92 \\
-(0.66)\end{array}$ \\
\hline Female Students & & $\begin{array}{l}-3.23^{* * *} \\
(0.24)\end{array}$ & $\begin{array}{l}-3.51^{* * *} \\
(0.26)\end{array}$ & $\begin{array}{l}-3.51^{* * *} \\
(0.26)\end{array}$ & $\begin{array}{l}-3.59^{\text {**** }} \\
(0.27)\end{array}$ & $\begin{array}{r}-1.73 \\
(1.65)\end{array}$ & $\begin{array}{l}-1.71 \\
(1.65)\end{array}$ \\
\hline ESCS*Linguistic distance & & & & $\begin{array}{c}-0.1^{* *} \\
(0.05)\end{array}$ & & & \\
\hline Female students*Linguistic distance & & & & & $\begin{array}{c}0.36^{* *} \\
(0.14)\end{array}$ & & \\
\hline Arrivaed before the age of 12 & & & & & & $\begin{array}{r}3.86 \\
(2.82)\end{array}$ & $\begin{array}{r}3.47 \\
(3.19)\end{array}$ \\
\hline Arrived before the age of $12^{*}$ Linguistic distance & & & & & & & $\begin{array}{l}0.28 \\
-0.6\end{array}$ \\
\hline Constant & $\begin{array}{l}75.94^{* * *} \\
(0.18)\end{array}$ & $\begin{array}{l}78.14^{* * *} \\
(0.22)\end{array}$ & $\begin{array}{c}78^{* * *} \\
(0.22)\end{array}$ & $\begin{array}{l}78.01^{* * *} \\
(0.22)\end{array}$ & $\begin{array}{l}78.04^{* * *} \\
(0.22)\end{array}$ & $\begin{array}{l}76.43^{* * *} \\
(2.56)\end{array}$ & $\begin{array}{l}-0.06 \\
76.75^{* * *} \\
(2.80)\end{array}$ \\
\hline Observations & 368769 & 367221 & 320206 & 320206 & 320206 & 12285 & 12285 \\
\hline Adjusted R-squared & 0.187 & 0.189 & 0.192 & 0.192 & 0.192 & 0.12 & 0.12 \\
\hline Country FE & Yes & Yes & Yes & Yes & Yes & Yes & Yes \\
\hline GDP and HDI differential & No & No & Yes & Yes & Yes & Yes & Yes \\
\hline
\end{tabular}

Notes: Standard error in parentheses.

${ }^{*} \mathrm{p}<0.10,{ }^{* *} \mathrm{p}<0.05,{ }^{* * *} \mathrm{p}<0.01$

Source: OECD, PISA 2015 Database and Wichmann, Søren, Eric W. Holman, and Cecil H. Brown (eds.), 2016. The ASJP Database (version 17)

StatLink Ailst http://dx.doi.org/10.1787/888933684523 


\section{Annex 5.A2}

This section outlines some of the methodologic issues encountered and the solutions adopted for the final part of the chapter on linguistic distance.

\section{Classification of languages}

Although most languages are classified identically within PISA and the Max Planck's ASJP, several do not correspond perfectly. In order to obtain measures of linguistic distance for the greatest possible number of language pairs, certain minor assumptions had to be made, some of which have also been adopted by other researchers using the ASJP and PISA data (see Isphording et al., 2015). Table 5.A2.1 lists the arbitrary conversions that were made.

Table 5.A2.1 - Conversion of ambiguous cases between PISA and ASJP

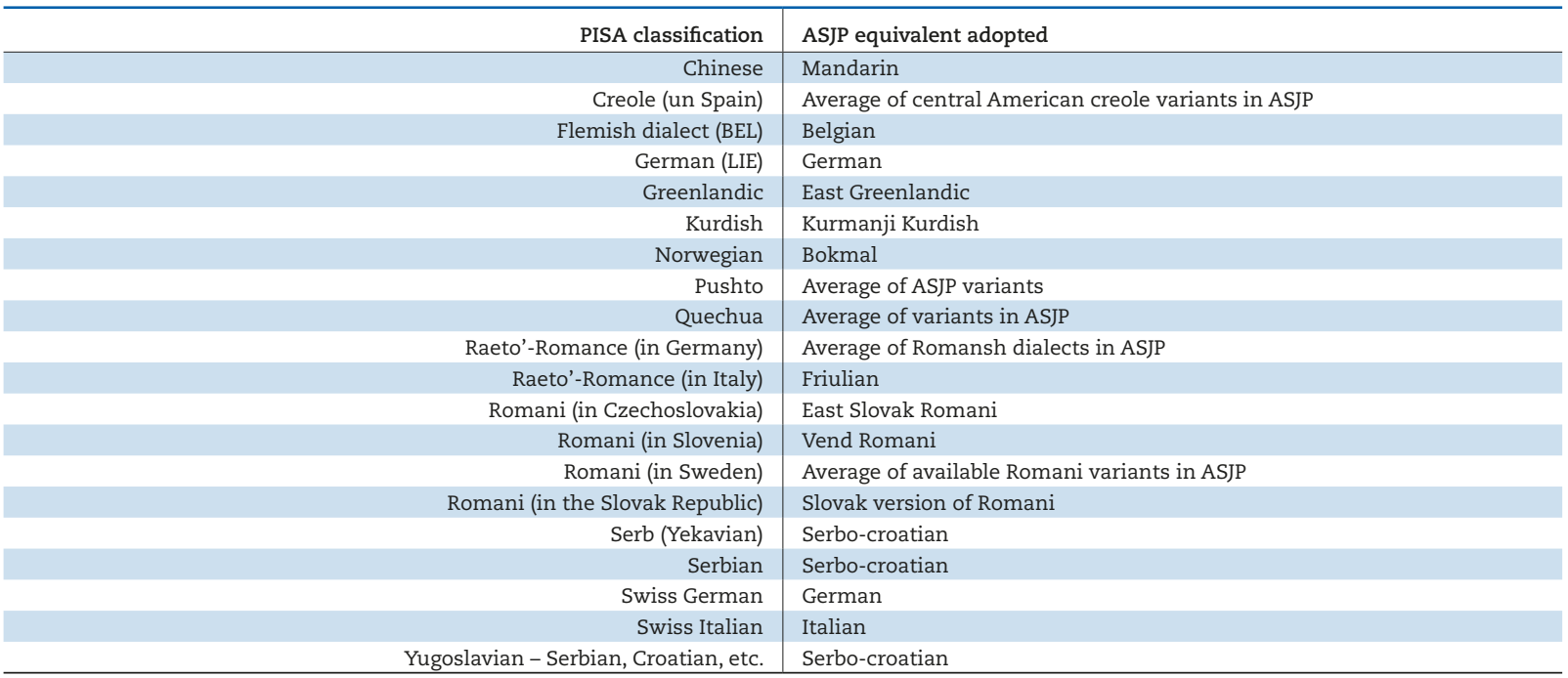

Source: OECD, PISA 2015 Database and Wichmann, Søren, Eric W. Holman, and Cecil H. Brown (eds.), 2016. The ASJP Database (version 17).

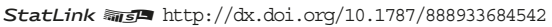

For several students, the linguistic distance indicator could not be calculated because some languages are classified into broad categories in PISA, such as "another language". Overall, the measure of linguistic distance produced is missing for about 11\% of the PISA 2015 sample.

\section{Difference between the GDP and HDI of countries of origin and destination}

Data on per capita GDP for PISA-participating countries and on parents' countries of origin were obtained from the World Bank online database. Specifically, data from 2010 at 2011 PPP-adjusted constant prices were used because they covered the largest portion of the sample of PISA destination and origin countries. Data for the Human Development Index were obtained from the United Nations Human Development Programme online database. For the sake of consistency, figures from 2010 were also used for the HDI.

Using HDI and per capita GDP data for PISA countries and parents' countries of origin, differentials between origin and destination countries in HDI and per capita GDP were constructed for each parent in the sample (differentials were zero for native-born parents). Then, each student was assigned the largest differential (either the mother's or the father's differential), such that native students had a value of zero for both the HDI and the GDP differentials. 


\section{Notes}

1. This classification of a native student applies only to this chapter; in other chapters, native students are also native-born students of native-born parents who do not speak the language of assessment.

2. In some countries and contexts, multiple language communities coexist and students are taught in more than one language. In countries where this is the case, the PISA assessment is available in the relevant multiple languages.

3. Students who reported that they "agree" or "strongly agree" with the statement "I feel like I belong at school" and "disagree" or "strongly disagree" with the statement "I feel like an outsider at school".

4. Students who reported a life satisfaction of 7 or above on a scale from 0 to 10.

5. Students who reported that they "disagree" or "strongly disagree" with the statements "I often worry that it will be difficult for me taking a test" and "Even if I am well prepared for a test, I feel very anxious".

\section{References}

Bermudez, A. (1994), Doing our Homework: How Schools can engage Hispanic Communities, Appalachian Educational Laboratory, Inc, Charleston, WV.

Bakker, D. et al. (2009), "Adding typology to lexicostatistics: a combined approach to language classification", Linguistic Typology, Vol. 12, pp. 167-179.

Bilgili, Ö., T. Huddleston and A.L. Joki (2015), The Dynamics between Integration Policies and Outcomes: a Synthesis of the Literature, MIPEX Project, Brussels.

Boykin, A.W., K.M. Tyler and O. Miller (2005), "In search of cultural themes and their expressions in the dynamics of classroom life", Urban Education, Vol. 40/5, pp. 521-549.

Brown, C.H. et al. (2008), "Automated classification of the world's languages: A description of the method and preliminary results”, STUF-Language Typology and Universals Sprachtypologie und Universalienforschung, Vol. 61/4, pp. 285-308.

Capps, R. (2005), The Health and Well-Being of Young Children of Immigrants, Urban Institute, Washington, D.C.

Chiswick, B.R. and P.W. Miller (1996), "Ethnic networks and language proficiency among immigrants", Journal of Population Economics, Vol. 9/1, pp. 19-35.

Chiswick, B.R. and P.W. Miller (1995), “The endogeneity between language and earnings: International analyses." Journal of Labor Economics, Vol. 13/2, pp. 246-288.

Clarke, A. and I. Isphording (2017), "Language barriers and immigrants health", Health Economics, Vol. 26/6, pp.765-778.

Coll, C.G. and K. Magnuson (1997), “The psychological experience of immigration: A developmental perspective”, in Booth, A., A.C. Crouter and N.S. Landale (eds.), Immigration and the Family: Research and Policy on U.S. immigrants, Lawrence Erlbaum Associates, Hillsdale, NJ, pp. 91-131.

Council of the European Union (2004), Immigrant Integration Policy in the European Union, Brussels, 19 November, 14615/04 (Presse 321).

Dawson, B.A. and S.A. Williams (2008), "The impact of language status as an acculturative stressor on internalizing and externalizing behaviors among Latino/a children: A longitudinal analysis from school entry through third grade”, Journal of Youth and Adolescence, Vol. 37/4, pp. 399-411.

Dustmann, C. and A. van Soest (2001), "Language fluency and earnings: Estimation with misclassified language indicators", The Review of Economics and Statistics, Vol. 83/1, pp. 663-674.

Dustmann, C. and F. Fabbri (2003), "Language proficiency and labour market performance of immigrants in the UK", The Economic Journal, Vol.113/489, pp. 695-717.

Dustmann, C., S. Machin and U. Schönberg (2010), "Ethnicity and educational achievement in compulsory schooling", The Economic Journal, Vol. 120/546, pp. F272-F297.

Espenshade, T.J. and C.A. Calhoun (1993), "An analysis of public opinion toward undocumented immigration”, Population Research and Policy Review, Vol. 12/3, pp. 189-224.

Frijters, P., Shields, M.A. and S.W. Price (2005), "Job search methods and their success: A comparison of immigrants and natives in the UK", The Economic Journal, Vol. 115/507.

Geay, C., S. McNally and S. Telhaj (2013), "Non-native speakers of English in the classroom: What are the effects on pupil performance?”, The Economic Journal, Vol. 123/570, pp. F281-F307. 
Gil, A.G., W.A. Vega and J.M. Dimas (1994), "Acculturative stress and personal adjustment among Hispanic adolescent boys”, Journal of Community Psychology, Vol. 22/1, pp. 43-54.

Gordon, M.M. (1964), Assimilation in American Life: The Role of Race, Religion, and National Origins, Oxford University Press on Demand, Oxford.

Hayfron, J.E. (2001), "Language training, language proficiency and earnings of immigrants in Norway." Applied Economics, Vol. 33/15, pp. 1971-1979.

Isphording, I.E. (2015), "What drives the language proficiency of immigrants?”, IZA World of Labor 2015: 177.

Isphording, I.E. and S. Otten (2013), "The costs of Babylon - linguistic distance in applied economics", Review of International Economics, Vol. 21/2, pp. 354-369.

Isphording, I.E. and S. Otten (2014), "Linguistic barriers in the destination language acquisition of immigrants", Journal of Economic Behavior and Organization, Vol. 105, pp. 30-50.

Isphording, I., E. M. Piopiunik and N. Rodríguez-Planas (2016), "Speaking in numbers: The effect of reading performance on math performance among immigrants”, Economics Letters, Vol. 139, pp. 52-56.

Joppke, C. (2007), "Beyond national models: Civic integration policies for immigrants in Western Europe", West European Politics, Vol. 30/1, pp. 1-22.

Leslie, D. and J. Lindley (2001), “The impact of language ability on employment and earnings of Britain's ethnic communities", Economica, Vol. 68/272, pp. 587-606.

Levenshtein, V.I. (1966), "Binary codes capable of correcting deletions, insertions, and reversals", Soviet Physics Doklady, Vol. 10/8, pp. 707-710.

Moles, O. (1993), "Collaboration between schools and disadvantaged parents: Obstacles and openings", in Chavkin, N.F. (ed.), Families and Schools in a Pluralistic Society, SUNY Press, Albany, NY.Newport, E.L. (2002), "Critical periods in language development”, in Nadel, L. (ed.), Encyclopedia of Cognitive Science, Macmillan Publishers Ltd./Nature Publishing Group, London, pp. 737-740.

OECD (2015a), The ABC of Gender Equality in Education: Aptitude, Behaviour, Confidence, PISA, OECD Publishing, Paris, http:// dx.doi.org/10.1787/9789264229945-en.

OECD (2015b), Immigrant Students at School: Easing the Journey towards Integration, OECD Publishing, Paris, http://dx.doi. org/10.1787/9789264249509-en.

OECD (2010), Closing the Gap for Immigrant Students: Policies, Practice and Performance, OECD Reviews of Migrant Education, OECD Publishing, Paris, http://dx.doi.org/10.1787/9789264075788-en.

OECD (2006), Where Immigrant Students Succeed: A comparative Review of Performance and Engagement in PISA 2003, OECD Publishing, Paris, http://dx.doi.org/10.1787/9789264249509-en.

Padilla, A.M. and W. Perez (2003), "Acculturation, social identity, and social cognition: A new perspective”, Hispanic Journal of Behavioral Sciences, Vol. 25/1, pp. 35-55.

Romero, A.J. and R.E. Roberts (2003), "Stress within a bicultural context for adolescents of Mexican descent", Cultural Diversity and Ethnic Minority Psychology, Vol. 9/2, p. 171.

Smart, J. F. and D.W. Smart (1995), "Acculturative stress of Hispanics: Loss and challenge", Journal of Counseling and Development, JCD, Vol. 73/4, p. 390.

Van Tubergen, F. and M. Kalmijn (2005), "Destination-Language Proficiency in Cross-National Perspective: A Study of Immigrant Groups in Nine Western Countries”, American Journal of Sociology, Vol. 110/5, pp. 1412-1457.

Van Tubergen, F., I. Maas and H. Flap (2004), "The economic incorporation of immigrants in 18 Western societies: Origin, destination, and community effects”, American Sociological Review, Vol. 69/5, pp. 704-727.

Wichmann, S., Er.W. Holman and C.H. Brown (eds.) (2016), The ASJP Database (version 17) available on line, $\underline{\text { http://asjp. }}$ clld.org/ (accessed on 18 February 2018).

Zhou, M. and Y.S. Xiong (2005), "The multifaceted American experiences of the children of Asian immigrants: Lessons for segmented assimilation", Ethnic and Racial Studies, Vol. 28/6, pp. 1119-1152. 



\section{Chapter 6 \\ Resilience and the socio-economic status of students with an immigrant background}

This chapter applies a resilience framework to determine whether students' socio-economic status is a risk or a protective factor for students with an immigrant background. It examines whether socio-economic status can explain why some students with an immigrant background perform worse at school, and report less social and emotional well-being, than others.

\section{Notes regarding Cyprus}

Note by Turkey: The information in this document with reference to "Cyprus" relates to the southern part of the Island. There is no single authority representing both Turkish and Greek Cypriot people on the Island. Turkey recognises the Turkish Republic of Northern Cyprus (TRNC). Until a lasting and equitable solution is found within the context of the United Nations, Turkey shall preserve its position concerning the "Cyprus issue".

Note by all the European Union Member States of the OECD and the European Union: The Republic of Cyprus is recognised by all members of the United Nations with the exception of Turkey. The information in this document relates to the area under the effective control of the Government of the Republic of Cyprus.

\section{Note regarding data from Israel}

The statistical data for Israel are supplied by and under the responsibility of the relevant Israeli authorities. The use of such data by the OECD is without prejudice to the status of the Golan Heights, East Jerusalem and Israeli settlements in the West Bank under the terms of international law. 


\section{What the data tell us}

- On average and in most PISA countries, second-generation and, especially, first-generation immigrant students are socio-economically disadvantaged compared to native students. By contrast, returning foreign-born students and native students of mixed heritage are more advantaged than native students.

- Differences in socio-economic status explain about one-fifth of the gap between students with an immigrant background and native students in the likelihood of attaining baseline levels of academic proficiency, on average across OECD and EU countries. In Ciudad Autónoma de Buenos Aires (Argentina), Costa Rica, Croatia, France, Greece, Hong Kong (China), Luxembourg and the Netherlands, socio-economic status explains a considerable fraction of immigrant students' academic disadvantage, while in the United States, immigrant and native students with a similar socio-economic profile have equal chances of attaining baseline academic proficiency.

- Socio-economic disadvantage is one of the factors that explain differences between students with and without an immigrant background in well-being, but the link tends to be weaker than that with academic outcomes. In Greece, differences in socio-economic status explain $45 \%$ of the academic gap between immigrant and native students but only $12 \%$ of the gap in sense of belonging and $22 \%$ of the one in test anxiety.

- In CABA (Argentina), Croatia, Hong Kong (China) and the United States socio-economic gaps between immigrant and native students account for almost the entirety of academic gaps between the two groups. By contrast, in Chile, Estonia, Finland, Iceland, Latvia, Macao (China), Portugal, Qatar and the United Arab Emirates, academic gaps between immigrant and native students are not explained by differences in the socio-economic status of these two groups.

- In most countries and economies, the positive effect of an improvement in socio-economic status on academic performance and social well-being is greater for native students than for immigrant students. On average across OECD and EU countries, a 1-point increase in the PISA index of economic, social and cultural status increases the gap in the percentage of immigrant and native students who attained baseline academic proficiency by four percentage points and the gap in the percentage who reported a sense of belonging at school by two percentage points.

The impact of socio-economic status on academic performance has been widely documented, and research has identified several mechanisms linking the two (Bianchi et al., 2004; Feinstein, Duchworth and Sabates, 2008; Jæger and Breen, 2016). First and foremost, parents' education and occupational status directly affect the amount of resources that a family can allocate to a child's upbringing. Low income hinders parents' ability to nurture and provide for their children during childhood and adolescence, which is associated with slower cognitive development (Case, Lubotsky and Paxson, 2002; Currie et al., 2012). Higher socio-economic status typically translates into greater educational resources for students, such as books and computers, at home and at school. Cultural resources, such as the time spent parenting, and social resources, including access to social networks, are often transferred from parent to child.

Socio-economic status is one of the strongest determinants of students' academic performance and general well-being (OECD, 2016a; 2017) and has been widely examined in the case of students with an immigrant background (Marks, 2006; Martin, 1998; Portes and MacLeod, 1996). It affects student outcomes through a variety of channels, at the individual, school and system levels. A family's socio-economic status can determine parents' ability to provide for their child's needs and to be involved in their education. It can also influence the socio-economic composition of the school that students attend, which has an impact on the school's resources and environment. For example, wealthy parents can afford private schooling when local public schools are not considered to be of high quality. Parents with high educational attainment are also better able to choose the school that best meets the needs of their children, and in which their children will meet stimulating peers. 
Table 6.1 - Snapshot of the socio-economic status of immigrant and native students

\begin{tabular}{|c|c|c|c|c|c|}
\hline & \multicolumn{5}{|c|}{$\begin{array}{l}\text { Countries/economices with values above the OECD average } \\
\text { Countries/economices with values not significantly different from the OECD average } \\
\text { Countries/economices with values below the OECD average }\end{array}$} \\
\hline & $\begin{array}{l}\text { Difference in the PISA } \\
\text { index of economic, } \\
\text { social and cultural } \\
\text { status (ESCS) } \\
\text { between immigrant } \\
\text { and native students }\end{array}$ & $\begin{array}{l}\text { Difference in the PISA } \\
\text { index of economic, } \\
\text { social and cultural } \\
\text { status (ESCS) between } \\
\text { immigrant students } \\
\text { with at least one } \\
\text { native-born parent } \\
\text { and native students }\end{array}$ & $\begin{array}{c}\text { Difference in parents' } \\
\text { highest educational } \\
\text { attainment } \\
\text { (years of shooling) } \\
\text { between immigrant } \\
\text { and native students }\end{array}$ & $\begin{array}{c}\text { Difference } \\
\text { in the parents' } \\
\text { highest occupational } \\
\text { status (ISEI) } \\
\text { between immigrant } \\
\text { and native students }\end{array}$ & $\begin{array}{l}\text { Difference in the index } \\
\text { of household resoures } \\
\text { (HOMEPOS) } \\
\text { between immigrant } \\
\text { and native students }\end{array}$ \\
\hline OED average & -0.3 & 0.13 & -0.42 & -6.67 & -0.29 \\
\hline EU average & -0.26 & 0.08 & -0.34 & -6.09 & -0.28 \\
\hline CABA (Argentina) & -1.37 & -0.4 & -3.46 & -25.5 & -0.91 \\
\hline United States & -0.82 & -0.08 & -2.55 & -14.61 & -0.42 \\
\hline Hong Kong (China) & -0.8 & -0.57 & -2.08 & -16.3 & -0.49 \\
\hline Luxembourg & -0.79 & -0.2 & -2.27 & -13.29 & -0.54 \\
\hline Mexico & -0.74 & 0.38 & -1.82 & -10.77 & -0.68 \\
\hline Greece & -0.67 & 0.08 & -1.12 & -16.22 & -0.55 \\
\hline Thailand & -0.66 & -0.02 & -2.34 & -8.35 & -0.51 \\
\hline Slovenia & -0.64 & 0.01 & -1.23 & -14.62 & -0.48 \\
\hline Netherlands & -0.6 & 0.1 & -1.54 & -11.29 & -0.43 \\
\hline Costa Rica & -0.6 & 0.02 & -1.48 & -8.64 & -0.55 \\
\hline Austria & -0.59 & 0.06 & -1.12 & -10.56 & -0.6 \\
\hline Denmark & -0.59 & 0.16 & -1.52 & -10.93 & -0.37 \\
\hline Switzerland & -0.57 & 0.13 & -1.41 & -12.78 & -0.3 \\
\hline France & -0.55 & 0.08 & -1.23 & -12.55 & -0.36 \\
\hline Germany & -0.55 & -0.12 & -1.05 & -11.39 & -0.47 \\
\hline Spain & -0.53 & 0.23 & -0.65 & -10.33 & -0.63 \\
\hline Belgium & -0.53 & -0.17 & -1.29 & -10.28 & -0.38 \\
\hline Iceland & -0.52 & 0.12 & -0.97 & -14.85 & -0.4 \\
\hline Sweden & -0.49 & 0 & -0.83 & -8.3 & -0.53 \\
\hline Norway & -0.48 & 0.09 & -0.61 & -11.24 & -0.45 \\
\hline Italy & -0.47 & 0.08 & 0.01 & -14.02 & -0.53 \\
\hline Finland & -0.44 & 0.13 & -0.77 & -8.97 & -0.4 \\
\hline Macao (China) & -0.42 & -0.15 & -1.24 & -7.39 & -0.25 \\
\hline Dominican Republic & -0.35 & 0.32 & -0.52 & -6.82 & -0.44 \\
\hline Croatia & -0.28 & -0.04 & -0.52 & -7.57 & -0.17 \\
\hline Chile & -0.28 & 0.45 & -0.16 & -3.66 & -0.45 \\
\hline Israel & -0.26 & 0.11 & -0.6 & -2.25 & -0.3 \\
\hline Japan & -0.2 & 0.06 & -0.13 & $c$ & -0.01 \\
\hline United Kingdom & -0.13 & 0.13 & 0.05 & -1.25 & -0.26 \\
\hline Czech Republic & -0.11 & -0.04 & 0.34 & -4.17 & -0.3 \\
\hline Cyprus* & -0.11 & 0.14 & 0.43 & -2.11 & -0.37 \\
\hline Bulgaria & -0.08 & 0.06 & -0.28 & -6.86 & 0.11 \\
\hline Russia & -0.06 & 0.09 & -0.16 & -1.55 & 0 \\
\hline Qatar & -0.04 & -0.2 & 0.62 & 4.06 & -0.56 \\
\hline B-S-J-G (China) & -0.03 & -0.19 & 0.66 & c & -0.47 \\
\hline Estonia & -0.03 & -0.01 & 0.22 & -2.23 & -0.03 \\
\hline Trinidad and Tobago & -0.02 & 0.21 & 0.74 & 0.75 & -0.33 \\
\hline Australia & -0.02 & 0.15 & 0.07 & -0.34 & -0.06 \\
\hline Brazil & -0.01 & 0.53 & 0.56 & -0.96 & -0.08 \\
\hline Slovak Republic & -0.01 & 0.02 & 0.58 & -2.76 & -0.25 \\
\hline United Arab Emirates & 0 & -0.17 & 0.99 & 3.12 & -0.54 \\
\hline Canada & 0.03 & 0.23 & 0.3 & 0.68 & -0.06 \\
\hline FYROM & 0.04 & 0.11 & 0.58 & -2.08 & 0 \\
\hline Albania & 0.05 & 0.5 & 0.99 & c & -0.23 \\
\hline Lebanon & 0.07 & 0.45 & 1.63 & -1.81 & -0.14 \\
\hline Portugal & 0.08 & 0.43 & 1.08 & -1.57 & -0.16 \\
\hline Georgia & 0.1 & 0.09 & 0.34 & -0.19 & 0.06 \\
\hline New Zealand & 0.1 & 0.25 & 0.66 & 1.52 & -0.05 \\
\hline Ireland & 0.11 & 0.19 & 0.6 & 2.08 & -0.04 \\
\hline Lithuania & 0.12 & 0.09 & 0.29 & 2.13 & 0.05 \\
\hline Kosovo & 0.15 & 0.18 & 0.01 & 4.19 & 0.17 \\
\hline Peru & 0.16 & 0.76 & 0.46 & 1.67 & 0.03 \\
\hline Jordan & 0.18 & 0.36 & 0.48 & 2.23 & 0.17 \\
\hline Algeria & 0.2 & 0.6 & 0.01 & -2.21 & 0.44 \\
\hline Latvia & 0.25 & 0.02 & 0.5 & 4.29 & 0.19 \\
\hline Hungary & 0.29 & 0.25 & 1.16 & 5.04 & 0.11 \\
\hline Moldova & 0.29 & 0.18 & 0.58 & 4.56 & 0.33 \\
\hline Montenegro & 0.31 & 0.21 & 0.89 & 5.25 & 0.19 \\
\hline Tunisia & 0.34 & 0.61 & 0.94 & 2.39 & 0.25 \\
\hline Colombia & 0.37 & 0.32 & 1.08 & 7.18 & 0.2 \\
\hline Uruguay & 0.4 & 0.15 & 2.17 & 5.86 & -0.11 \\
\hline Singapore & 0.46 & -0.09 & 1.33 & 7.23 & 0.31 \\
\hline Malta & 0.52 & 0.14 & 2.18 & 9.29 & 0.03 \\
\hline Turkey & 0.89 & 1.04 & 3.6 & 8.02 & 0.52 \\
\hline Korea & c & -0.16 & c & c & c \\
\hline Poland & c & 0.31 & c & C & c \\
\hline Indonesia & C & -0.03 & C & C & C \\
\hline Romania & C & 0.13 & c & c & c \\
\hline Chinese Taipei & C & -0.48 & c & c & c \\
\hline Viet Nam & c & 0.24 & c & c & c \\
\hline
\end{tabular}

* See note at the beginning of this Chapter.

Source: OECD, PISA 2015 Database, Tables 6.3, 6.19, 6.20 and 6.1.

StatLink 部实 http://dx.doi.org/10.1787/888933682129 
Table 6.2 - Snapshot of the relation between immigrant-native gaps in socio-economic background and gaps in academic and well-being outcomes

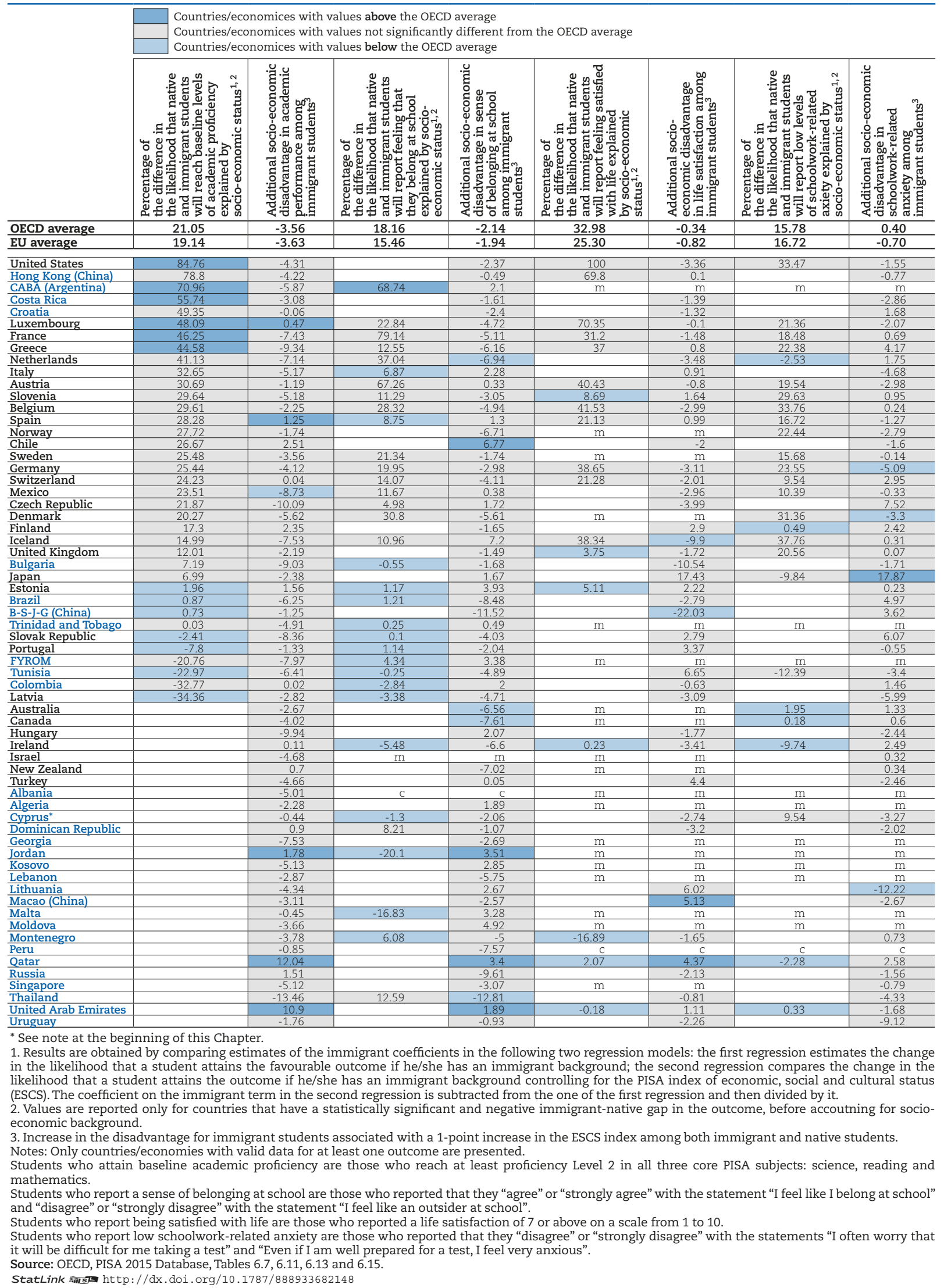


At the system level, socio-economic status is related to spending on education, which affects children's ability to perform and enjoy a sense of well-being. Figure 6.1 shows how socio-economic status can affect the vulnerability of students with an immigrant background, and mediate the effect between immigrant background and academic performance, sense of belonging, life satisfaction and achievement motivation.

Figure 6.1 - How socio-economic status affects the resilience process

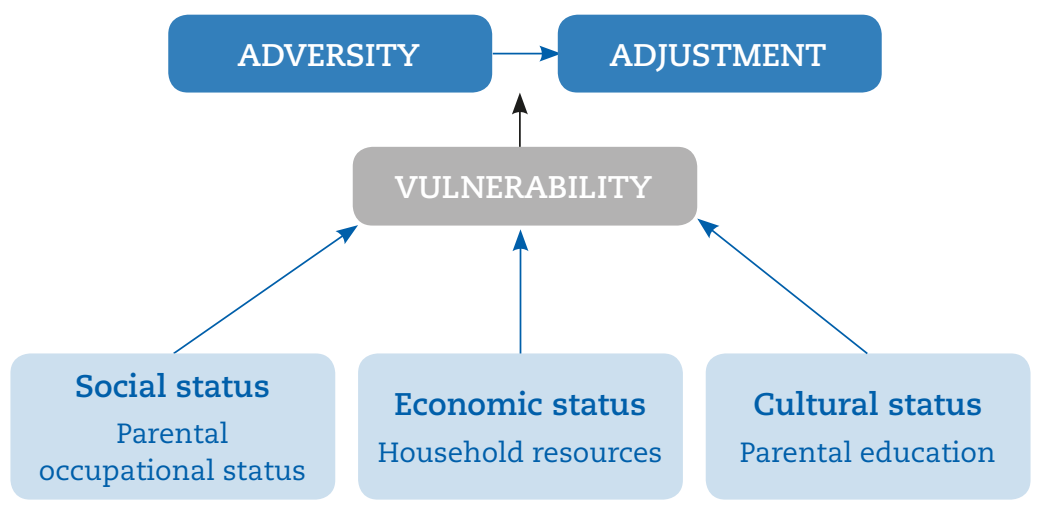

Family background is often related to the type of school children attend, which, in turn, can perpetuate inequities in opportunities to learn. Students from different backgrounds may have varying degrees of exposure to specific content in the classroom because of the instructional time school systems and teachers allocate to them. The time spent on specific content and the way that time is organised are two of the main determinants of student achievement (OECD, 2016b). Research using PISA data suggests that up to one-third of the relationship between socio-economic status and student performance is accounted for by measures of opportunity to learn (Schmidt et al., 2015).

The design of education systems can mediate the relationship between parents' resources and learning outcomes. Sorting and selecting (known as stratification) policies used by schools and education systems, such as early tracking or grade repetition, can lead to differences in academic achievement across socioeconomic backgrounds. While the selection of students for certain grades or programmes should be based primarily on performance, research shows that students' background characteristics also influence those decisions (Agasisti and Cordero, 2017; van de Werfhorst and Mijs, 2010). Other characteristics of education systems, such as the level of resources available to public or private schools, or to urban and rural schools, can strengthen or weaken the relationship between socio-economic status and academic performance (Greenwald, Hedges and Laine, 1996; OECD, 2016b; Rivkin, Hanushek and Kain, 2005).

Socio-economic status can also affect students' satisfaction with life, their sense of belonging at school, and their aspirations for the future. Family wealth can affect adolescents' well-being by limiting their consumption and leisure opportunities, so that disadvantaged students might not have access to things they need to participate fully in society and relate to their peers (Becchetti and Pisani, 2014). Wealth and social status are also linked to the type of school children attend and the environment they are exposed to, which determine their well-being at school (Pajares and Urdan, 2006).

In most PISA countries, the proportion of socio-economically advantaged students who reported being "very satisfied" with life is larger than that of disadvantaged students who so reported (OECD, 2017). However, in a few countries, disadvantaged students tend to be more satisfied with their life. Researchers have identified some possible explanations for the phenomenon. One suggests that when financial resources are scarce, social "safety nets" develop within the community, so that the sense of social integration and life satisfaction among community members grows stronger (Saegert et al., 2001). Another argues that the factors that students take into account when assessing their satisfaction with life may depend on the students' own socio-economic status (Diener et al., 2003; Neff, 2007; Tucker et al., 2006). 
Relative, as opposed to absolute, wealth has a significant impact on students' life satisfaction because adolescents form opinions about themselves partly based on comparisons with their peers (Hudson, 2013; Sweeting and Hunt, 2014). Research shows that measures of socio-economic status are related to students' subjective social status at school (Goodman et al., 2001). Disadvantaged students who attend advantaged schools could suffer from a sense of isolation and might feel discriminated against. Phenomena of this kind have been documented in the United States (Carter, 2007; Davis, 2014) and in Chile (Montt, 2012), among other countries.

While having schools with a socio-economically diverse student body can put the life satisfaction and well-being of disadvantaged students at risk, it can have positive effects on their motivational well-being. Aspirations are shaped by family wealth, social status and neighbourhood characteristics (Stewart et al., 2007). Evidence shows that disadvantaged students could absorb the same attitudes as their advantaged peers and develop high aspirations and expectations for themselves (OECD, 2017).

\section{The socio-economic status of students with an immigrant background}

Many empirical studies examining differences in academic performance and well-being related to socio-economic status rely on indicators that incorporate into one composite variable measures of parents' income, education and occupation. These components, while correlated, measure different aspects of socio-economic status (Bollen, Glanville and Stecklov, 2001; Hauser and Huang, 1997) and reflect a conception of socio-economic status as a combination of property, power and prestige (Bradley and Corwyn, 2002). The PISA background questionnaires include items that capture various aspects of students' socio-economic status. Students are asked about their parents' level of education and occupational status, and about the availability of a set of household items including consumer durables, and educational and cultural resources.

Student responses are used to develop the PISA index of economic, social and cultural status (ECSC), a composite indicator of students' socio-economic status. The index is designed to have a value of zero for the average OECD student and a standard deviation of one across equally weighted OECD countries. For a more detailed explanation of how the ESCS index was constructed, refer to the PISA 2015 Technical Report.

Although both thorough and simple (one number summarises a complex phenomenon such as socioeconomic status), the ESCS index also has some important drawbacks. The most notable is that it does not allow for examining whether the roots of socio-economic disparities in different countries and between different groups of students stem from different mechanisms and processes.

For example, when examining the role socio-economic status plays in explaining performance gaps between students with and without an immigrant background and across different groups of students with an immigrant background in different countries, using the aggregate ESCS indicator does not allow for identifying whether differences are due to disparities in the cultural, economic or social-capital component of the index, and whether the relative importance of cultural, economic and social aspects differs across countries. In country A, for example, disparities in performance between students with an immigrant background and native students that are related to socio-economic status might stem from the fact that students with an immigrant background have low-educated parents, and that, if parents are offered a choice of schools for their child, parents' education becomes crucial for their child's success in education. By contrast, in country B, such differences might stem from the fact that students with an immigrant background are poorer than native students, are more likely to attend schools with fewer educational resources, and do not to have the assets at home that are crucial for learning.

This chapter compares the socio-economic status of native students and of students with an immigrant background, and explores the link between differences in socio-economic status and differences in wellbeing outcomes. The first part of the chapter presents results obtained using the ESCS index, while the second part reports findings based on the three components of the index: the index of parents' highest occupational status, the index of parents' years in education, and the index of family possessions.

The socio-economic status of students, as measured by their values on the ESCS index, differs greatly across students with a different immigrant background and between countries. Figure 6.2 suggests that first-generation immigrant students (foreign-born students with foreign-born parents) tend to be 
disadvantaged compared to native students. In 2015, on average across OECD countries, the ESCS of firstgeneration immigrant students was -0.27 , about one-fourth of a standard deviation below the average OECD student (- 0.23 across OECD countries). In as many as 24 out of 50 countries with available data, the ESCS index points of first-generation immigrant students was lower than those of their native peers, while the opposite was true only in 10 countries. The gap was above 0.5 (one half of a standard deviation) in 17 countries and economies, including Austria, Belgium, France, Iceland, Italy, the Netherlands, Norway, Spain and Sweden, while it was above 0.8 in Ciudad Autónoma de Buenos Aires (Argentina) (hereafter "CABA [Argentina]"), Greece, Hong Kong (China), Mexico and the United States. The largest gap was observed in CABA (Argentina), where the ESCS of foreign-born students with foreign-born parents was 1.38 points lower than that of native students, a difference similar to that between the average German and Mexican student.

In 15 countries and economies, first-generation immigrant students were above the OECD average on the ESCS index. However, they were advantaged compare to native students in only eight of those countries. In Canada, Malta, Qatar and the United Arab Emirates, the ESCS of first-generation immigrant students was more than one half of a standard deviation above the OECD average. While in Canada, Qatar and the United Arab Emirates the native-immigrant gap stood between 0.04 and 0.15 point, it was much higher in Malta: 0.65 point.

Figure 6.2 also shows that native and first-generation immigrant students vary significantly in their values on the ESCS index across countries. In Austria, Italy and Spain, the gap was approximately the same (-0.55), but the values for natives and first-generation immigrants differed widely. In Austria, they were 0.20 for natives and -0.33 for first-generation immigrants. In Italy, natives had a value of -0.04 and first-generation immigrants a value of -0.59 on the index, while in Spain, natives were at -0.46 and firstgeneration immigrants were at -1.00 on the index.

\section{Figure 6.2 - Average socio-economic status, by immigrant background Difference in the PISA index of economic, social and cultural status (ESCS) between first-generation immigrant and native students}

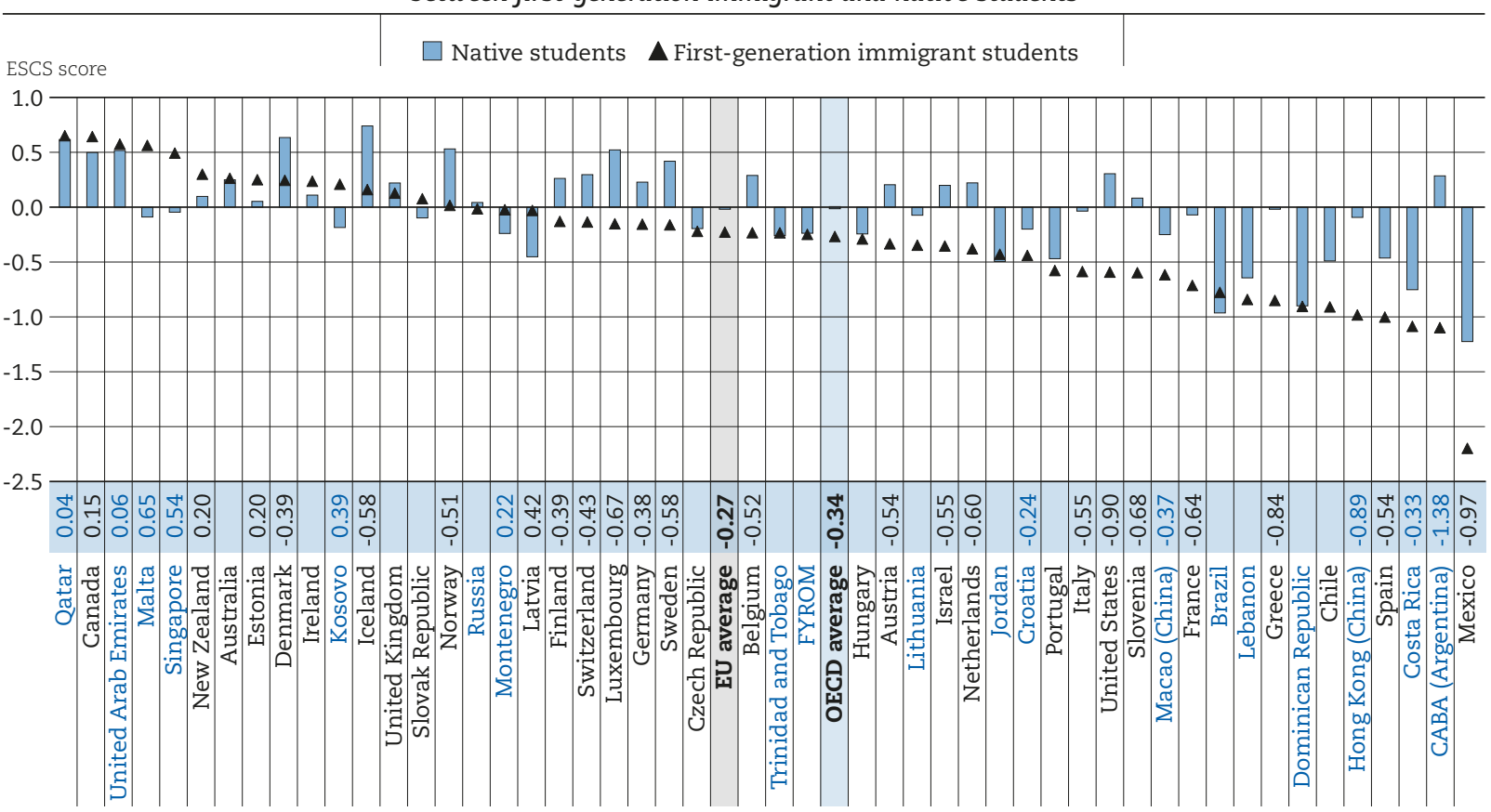

Notes: Only countries with valid estimates of the ESCS score of first-generation immigrant students are shown.

Statistically significant differences in the ESCS score between native and first-generation immigrant students are shown next to country/economy names. For the OECD and EU averages, this number refers only to the subset of countries/economies with valid information for both groups of students.

Countries and economies are ranked in descending order of the socio-economic status of first-generation immigrant students.

Source: OECD, PISA 2015 Database, Table 6.3.

StatLink 证st $\mathrm{http}: / / \mathrm{dx}$.doi.org/10.1787/888933681749 
Native Spanish students had a value on the ESCS index that was 0.46 standard deviation below the OECD average and 0.13 point below the value for first-generation immigrant students in Austria. In CABA (Argentina), Costa Rica, Mexico and Spain, first-generation immigrant students had a value on the socioeconomic index that was at least one standard deviation below the OECD average. This corresponds approximately to the difference in ESCS between the average Danish and Jordanian student. In these countries, native students had a higher value on the ESCS index than first-generation immigrant students, but the gaps differed greatly. In CABA (Argentina), the ESCS of natives was 1.38 points higher, in Mexico it was 0.97 point higher, in Costa Rica it was 0.33 point higher and in Spain it was 0.54 point higher.

Countries differ widely in their average socio-economic status as do the values for native and immigrant students. Therefore, in order to identify in greater detail differences in socio-economic status between the two groups, Figures 6.3 and 6.4 show, for countries with available data, the gaps in the ESCS index between native students and different groups of immigrant students (i.e. first- and second-generation immigrant students).

Figure 6.3 - Difference between immigrant and native students in socio-economic status, by immigrant generation

Difference in the PISA Index of economic, social and cultural status (ESCS)

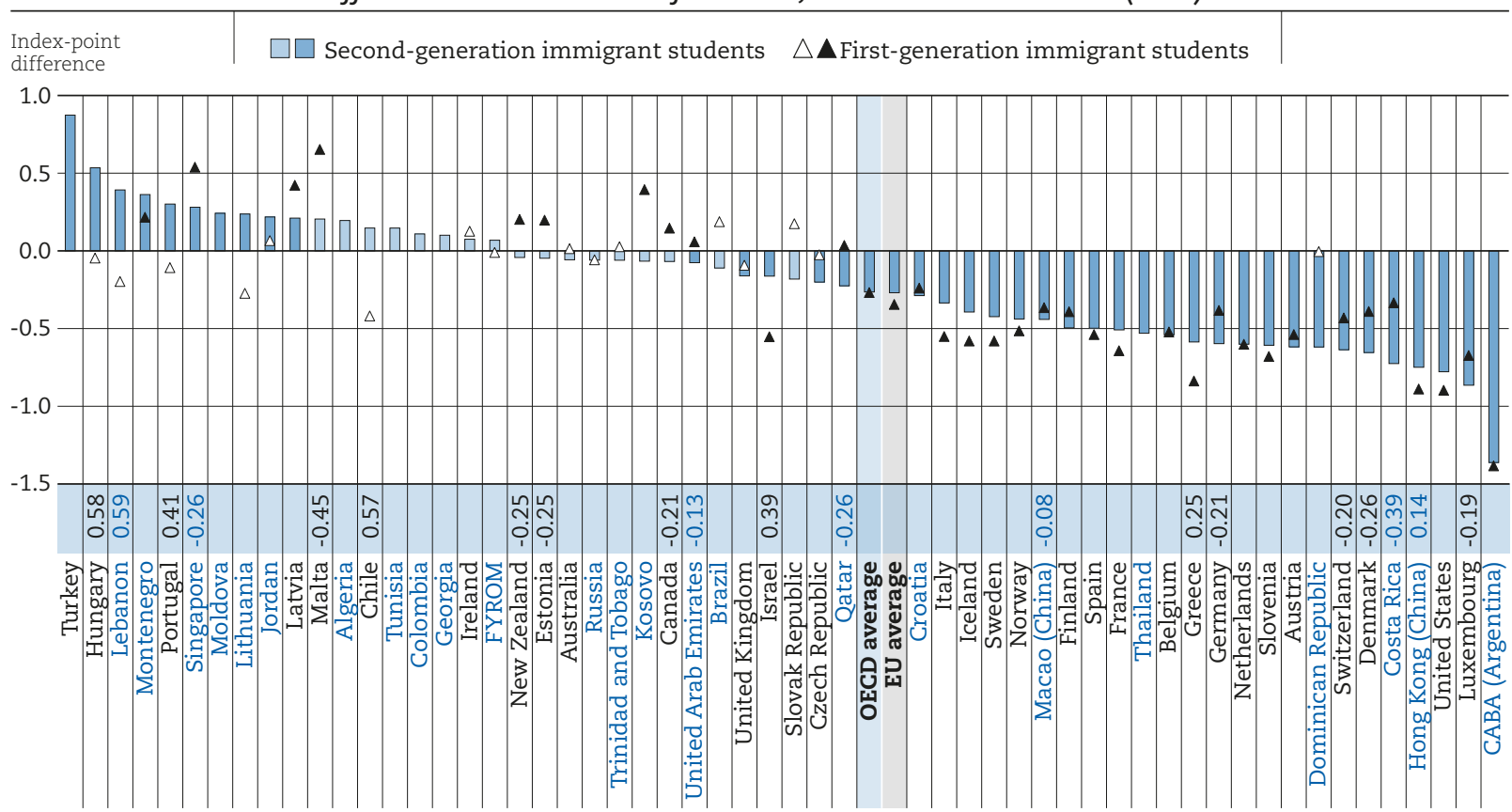

Notes: Statistically significant differences are marked in a darker tone.

Results are displayed only for countries/economies with valid estimates of the ESCS score of second-generation immigrant students.

Statistically significant differences in the ESCS score between second- and first-generation immigrant students are shown next to country/economy names. For the OECD and EU averages, this number refers only to the subset of countries/economies with valid information on both groups of students.

Countries and economies are ranked in descending order of the difference in the ESCS index between second-generation immigrant and native students. Source: OECD, PISA 2015 Database, Table 6.3.

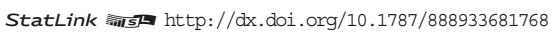

Data from PISA 2015 show that socio-economic differences between students with an immigrant background and native students vary considerably across immigrant backgrounds. Immigrant students (both first- and second-generation immigrant students) tend to be more disadvantaged than native students. By contrast, in the majority of countries, returning foreign-born students and native students of mixed heritage are more advantaged than native students. On average across OECD countries with available data in PISA 2015, the gap between native students and first-generation immigrant students was -0.34 point ( -0.27 point across EU countries), while the gap between native students and second-generation immigrant students was -0.27 point (-0.26 point across EU countries) (Table 6.3, available on line). 
Figure 6.4 - Difference between immigrant and native students in socio-economic status, by immigrant heritage

Difference in the PISA Index of economic, social and cultural status (ESCS)

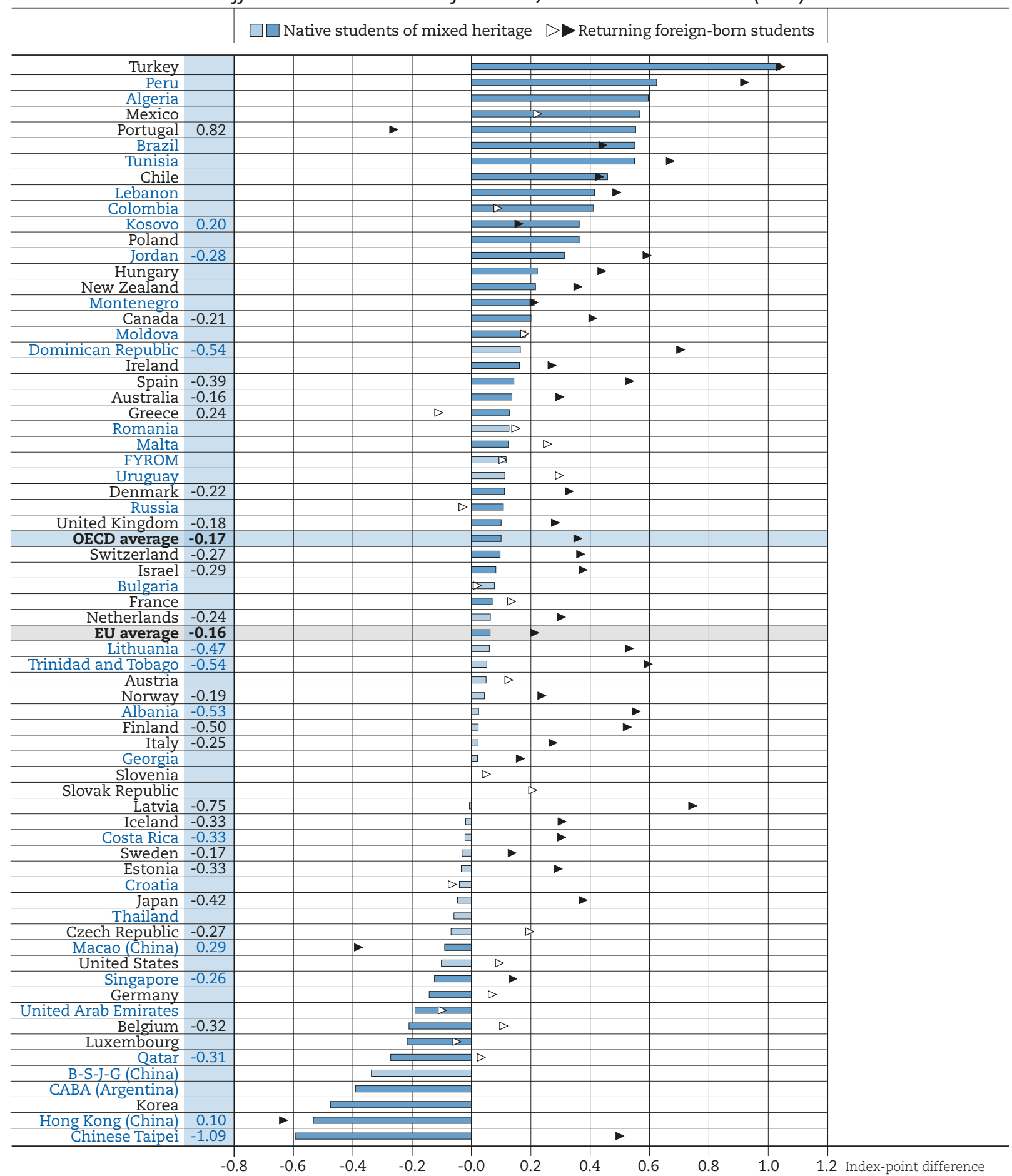

Notes: Statistically significant differences are marked in a darker tone.

Results are displayed only for countries/economies with valid estimates of the ESCS scores of native students of mixed heritage.

Statistically significant differences in the ESCS score between native students of mixed heritage and returning foreign-born students are shown next to country/economy names. For the OECD and EU averages, this number refers only to the subset of countries/economies with valid information on both groups of students.

Countries and economies are ranked in descending order of the difference in the ESCS index between native students of mixed heritage and native students.

Source: OECD, PISA 2015 Database, Table 6.3.

StatLink 部 
On average across OECD countries, native students of mixed heritage and returning foreign-born students had values on the index that were 0.10 and 0.28 point higher, respectively, than that of native students (0.06 and 0.21 point, respectively, across EU countries) (Table 6.3 available on line).

On average across OECD countries, first-generation immigrant students are the most socio-economically disadvantaged compared to native students (Table 6.3). However, second-generation immigrant students are also more disadvantaged than native students. In PISA 2015 their value on the ESCS index was below that of native students in as many as 29 countries and economies (more than the 26 where firstgeneration immigrant students were disadvantaged compared to natives). In 16 countries and economies, the gap amounted to more than one half of a standard deviation; in CABA (Argentina), Luxembourg and the United States, it was greater than 0.75 point.

There was no statistical difference in values on the ESCS index between first- and second-generation immigrant students, on average across OECD and EU countries (Table 6.3). However, some differences can be observed across countries. In Hungary, Lebanon and Portugal, there was no statistical difference between the ESCS value of first-generation immigrant and native students, while the value of secondgeneration immigrant students was at least one-fourth of a standard deviation higher than that of native students. By contrast, in Canada, Estonia, Kosovo, Malta and New Zealand, first-generation immigrant students were socio-economically advantaged compared to natives, while second-generation immigrant students had a similar socio-economic status as natives. Overall, in 12 countries and economies, firstgeneration immigrant students were more advantaged than second-generation immigrant students, while the opposite was true in 7 countries and economies.

Figure 6.4 shows that, on average across OECD countries, returning foreign-born students are the most socio-economically advantaged group among those considered, including native students. In 36 countries and economies out of the 63 with available data in 2015, their value on the ESCS index was higher than that of native students. The opposite was true only in Hong Kong (China), Macao (China) and Portugal. In Albania, the Dominican Republic, Finland, Jordan, Latvia, Lithuania, Peru, Spain, Trinidad and Tobago, Tunisia and Turkey, the gap was greater than half of a standard deviation. Native students of mixed heritage were also more advantaged than native students in 29 countries, and the gap was greater than 0.5 point on the index in 7 countries. However, in Belgium, CABA (Argentina), Germany, Hong Kong (China), Korea, Luxembourg, Macao (China), Qatar, Singapore, Chinese Taipei and the United Arab Emirates, the average value on the ESCS index among native students of mixed heritage was lower than that of native students.

These results suggest that having at least one native-born parent crucially influences the socio-economic status of students with migration in their background. Figure 6.5 shows differences in socio-economic status between foreign-born students with two foreign-born parents and foreign-born students with at least one native parent (first-generation immigrant students and returning foreign-born students). It also shows differences between native-born students with two foreign-born parents and native-born students with at least one native-born parent. On average across OECD countries, returning foreignborn students were 0.59 point higher than first-generation immigrant students on the ESCS index (0.49 point across EU countries). In Algeria, CABA (Argentina), Chile, Finland, France, Iceland, Israel, Italy, Korea, Mexico, the Netherlands, Norway, Spain, Switzerland, Thailand and the United States, the gap was more than 0.75 point. On average across OECD countries, native students of mixed heritage were 0.37 point higher than second-generation immigrant students on the index $(0.31$ point across EU countries).

PISA shows that disparities in socio-economic status between native and immigrant students have evolved differently across countries. Figure 6.6 shows socio-economic differences between native and immigrant students in 2003 and 2015, and any statistically significant change that occurred during that period. On average across OECD countries, the gap between the two groups of students remained unchanged between 2003 and 2015. In Hungary, New Zealand and Turkey, the gap between the two groups was not statistically significant in 2003, but in 2015 immigrant students were more advantaged than native students. In Belgium, France and Germany, the gap shrank by at least 0.2 point and by as much as 0.52 point in Germany. By contrast, in Greece, Hong Kong (China), Ireland, Italy, Spain and the United States, the gap widened by at least 0.23 point between 2003 and 2015. 
Figure 6.5 - Socio-economic status, by students' and parents' immigrant background Difference in the PISA index of economic, social and cultural status (ESCS) between students with an immigrant background having at least one native-born parent and those with two foreign-born parents

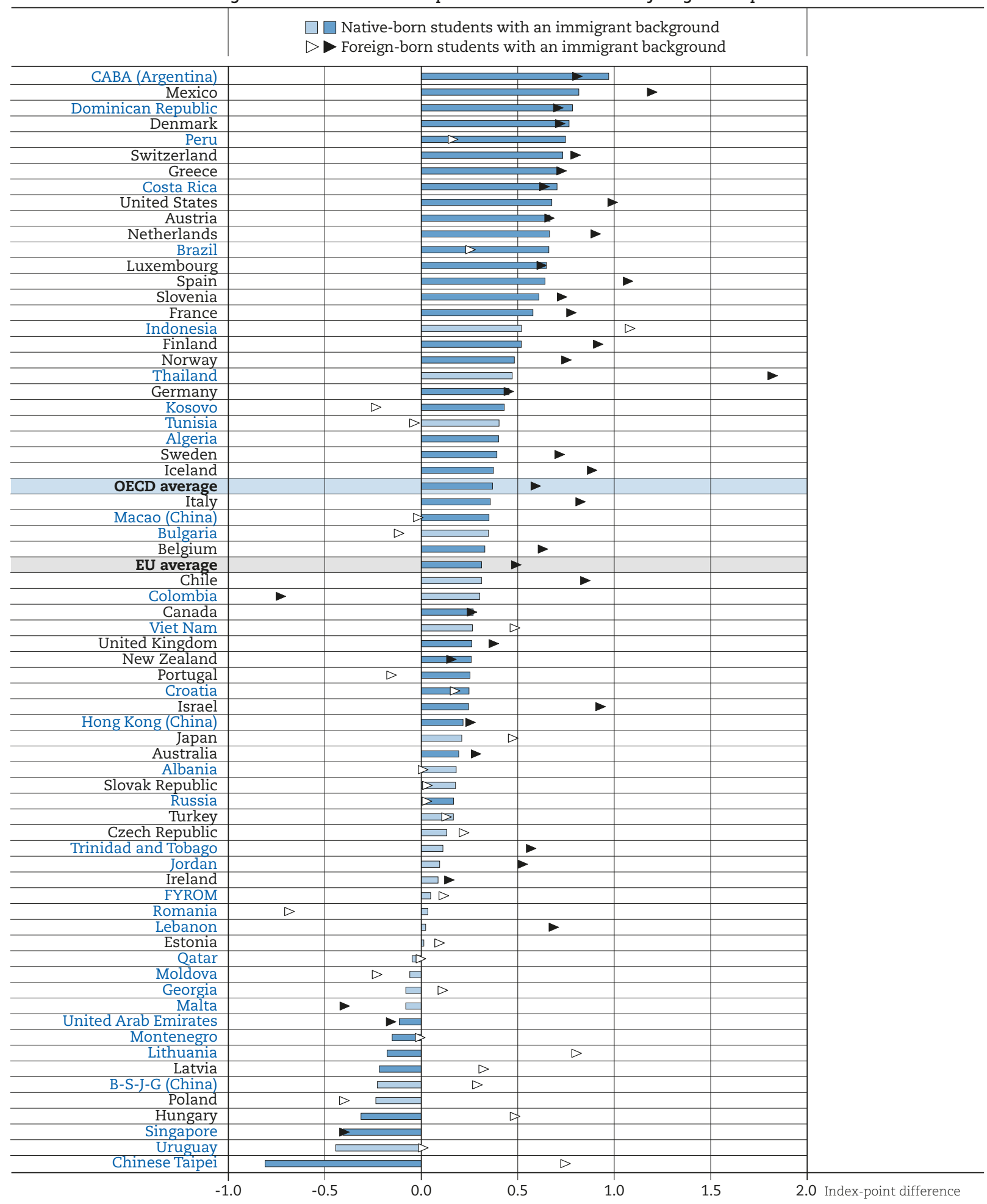

Notes: Only countries/economies with valid data on all groups of students with an immigrant background being compared are shown. Statistically significant differences are marked in a darker tone.

Countries and economies are ranked in descending order of the difference in the PISA index of economic, social and cultural status between native-born students with an immigrant background who have at least one native-born parent and those who have two foreign-born parents.

Source: OECD, PISA 2015 Database, Table 5.6.

StatLink 司实 http://dx.doi.org/10.1787/888933681806 
Figure 6.6 - Change between 2003 and 2015 in socio-economic difference between immigrant and native students

Difference in the PISA index of economic socil and cultural status (ESCS)

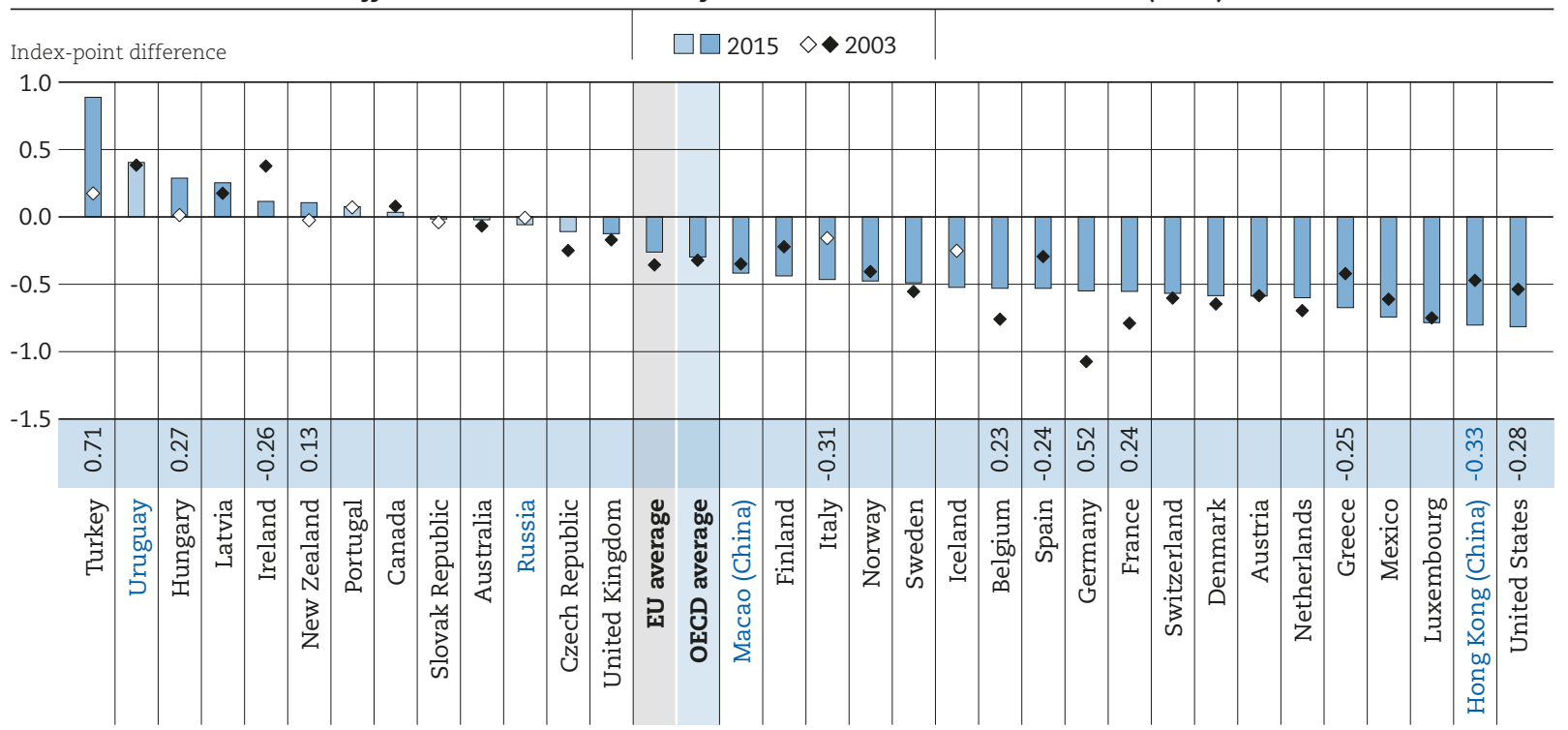

Notes: Results are displayed only for countries/economies that participated in PISA 2003 and PISA 2015 and have valid data for immigrantnative gaps in the ESCS index for both 2003 and 2015.

Statistically significant immigrant-native gaps are marked in a darker tone.

Statistically significant changes in ESCS gaps between immigrant and native students between 2015 and 2003 are shown next to country/ economy names.

Countries and economies are ranked in descending order of the gap in ESCS between immigrant and native students in 2015.

Source: OECD, PISA 2015 and 2003 Databases, Table 6.3.

StatLink Ails $\mathrm{http}: / / \mathrm{dx}$.doi.org/10.1787/888933681825

\section{Box 6.1. The retornados phenomenon in Portugal}

Portugal is an interesting case when it comes to the socio-economic status of students with an immigrant background. Three findings, in particular, run counter to the general pattern observed in the countries and economies that participated in PISA 2015. First, both second-generation immigrants (i.e. those born in Portugal with two foreign-born parents) and native-born students of mixed heritage (i.e. those born in Portugal with one foreign-born parent and one parent who was born in Portugal) are more advantaged, on average, than native students. Second, differences in socio-economic status between native students and first-generation immigrant students (i.e. foreign-born students whose parents are also foreign-born) are not statistically significant. Third, returning foreign-born students (i.e. foreign-born students with at least one parent who was born in Portugal) are more disadvantaged than native students. These surprising results are illustrated in Figures 6.2, 6.3 and 6.4.

The phenomenon of retornados can help explain why both second-generation immigrant students and native students of mixed heritage are more advantaged than native students. The term retornados refers to the white Portuguese community living in the African colonies who were repatriated to Portugal in the months following those countries' independence in 1975. The exact number of retornados is unknown, but estimates range from 500000 to 1 million, with $40 \%$ of them having been born in the colonies. A small number of the retornados did not return to Portugal immediately but moved mainly to Brazil and South Africa. However, most of these people ultimately returned to Portugal.

Portuguese students who participated in PISA 2015 are those whose parents were born around this period of decolonisation. Almost one in five of these students is either second-generation immigrant (3.3\%) or native-born of mixed heritage (15\%). Given the huge demographic impact of retornados in a country with a population of around nine million at the time they repatriated, most of these students are likely to have at least one parent of this generation. 
Most retornados suffered traumatic experiences and significant material losses when leaving the colonies, and social integration was difficult for many of them. However, their socio-economic integration in Portugal was a success. The Instituto de Apoio ao Retorno de Nacionais was a supervisory body created to facilitate economic support to retornados to compensate for their losses in the colonies and help them integrate and thrive in Portugal. Some measures of positive discrimination were implemented, including access to special credit conditions. In addition to this economic support, retornados had certain skills that were essential overseas that helped them achieve entrepreneurial success in Portugal too. These include self-initiative, self-reliance, leadership abilities, and social skills.

Retornados also had better qualifications than the Portuguese already in Portugal, which helped them gain access to the labour market. According to data from the 1981 census, one in three adults over the age of 30 in Portugal was illiterate, and only $2.3 \%$ of adults were university graduates. By contrast, $11 \%$ of retornados were university graduates. In addition, many of them had previously served in or had ties with the overseas administration. Consequently, up to 45000 retornados were employed in the Portuguese public administration. This includes staff members of African universities who helped accelerate the creation of new universities in Portugal (Almeida, 2014; David, 2015; Pires, 2003; Rocha-Trinidade, 1995).

Overall, compared to the population already in Portugal, retornados were better qualified and achieved higher socio-economic status. This advantage is likely to have been passed on to their children, which would help explain some of the results observed in PISA 2015. For instance, Table 6.19 (available on line) shows that parents' of both second-generation immigrant students and nativeborn students of mixed heritage have higher educational attainment than the parents of native students. Similarly, Table 6.10 (available on line) reveals that the parents of the former two groups of students also have higher occupational status than the parents of native students. These differences in parents' education and occupational status explain why both second-generation immigrant students and native-born students of mixed heritage are more socio-economically advantaged than native students in Portugal.

The second singularity - that socio-economic differences between native and first-generation immigrant students are not statistically significant - can be explained by the increasing numbers of high-skilled workers who have been arriving in Portugal since the 1990s, particularly from East European countries, such as Ukraine, Moldova and Romania (Baganha and Fonseca, 2004). Indeed, Figure 6.17 shows that the level of parents' education is higher among first-generation immigrant students than among native students. Furthermore, Figure 6.18 shows that, despite parents' higher educational attainment, the occupational status among parents of first-generation immigrant students is lower than that among parents of native students. These results are in keeping with the findings of many studies that report on problems of over-qualification that affect most of these highly skilled immigrants in Portugal (eg. Alto Comissariado pasa as Migrações, 2016; Oliveira and Fonseca, 2013).

In addition, even though the number of university graduates in Portugal has grown over the past few decades (Barganha and Fonseca, 2004), it is not clear that this upskilling process has had a significant impact among the parents of native students, as defined by PISA. PISA's definition of native students does not include Portuguese-born students who have at least one parent from the retornados generation who was born in the colonies. As explained above, in 1981, there were five times as many university graduates among retornados as among the Portuguese population. Indeed, Table 6.19 (available on line) suggest that this socio-economic advantage was passed on to the succeeding generation.

The third finding that goes against the general pattern observed in PISA 2015 is that foreign-born students who have at least one Portuguese parent are of lower socio-economic status than native students. Only $2.7 \%$ of 15 -year-old students in Portugal are returning foreign-born students. Tables 6.19 and 6.20 (available on line) suggest that the parents of returning foreign-born students have lower educational attainment, but higher occupational status, than the parents of native students.

To a certain extent, these results might be explained by the migration trends affecting Portugal over the past decades, especially the extensively reported inability of Portugal to woo back highly qualified emigrants. Traditionally, migration in Portugal has mainly involved low-skilled workers seeking better professional opportunities and living conditions elsewhere. In 1980, as many as nine in ten Portuguese 
emigrants aged 25 or older living in the top OECD destination countries were low skilled; only $3 \%$ were high skilled. In 2010, two out of three of these emigrants were low skilled, while $14 \%$ were high skilled. Most of the unqualified emigrants moved to France and, to a lesser extent, Germany. In the 2000s, there was a significant increase in migration to Spain, a country with a great demand for low-skilled workers in its then-booming construction sector. But that demand dried up in the wake of the economic crisis. The main destination for high-skilled workers over the past few decades has been Canada, France, Spain and the United States (Justino, 2016). Overall, these figures suggest that most of the five million Portuguese living outside of the country are low skilled. Furthermore, there is little evidence that the high-skilled workers who emigrated from Portugal in the past few decades are returning (Cerdeira et al., 2016). Thus, it is more likely that emigrants returning to Portugal will be the low-skilled workers who can no longer find work in the countries to which they - or they parents - first migrated.

The anomalies described above stem from the multiple migration flows that have affected Portugal in the past half-century, particularly the demographic and socio-economic impact of the retornados generation in Portugal. The migration of Portuguese citizens from the colonies to Portugal is interpreted as international migration in PISA, as the definition of natives excludes any student who was born in Portugal with at least one foreign-born parent from the retornados generation. Retornados were more socio-economically advantaged and better-integrated in the country. Their presence has had a significant and positive impact on the Portuguese education system that is still evident.

\section{Socio-economic status and the academic, social and emotional resilience of students with an immigrant background}

\section{Academic outcomes}

PISA reveals that socio-economic status is an important mediating factor in the relationship between immigrant background and academic resilience. Figure 6.7 shows differences between native and immigrant students in the percentage of students who attained baseline levels of proficiency in the core PISA subjects, ${ }^{1}$ before and after accounting for socio-economic status in PISA 2015. In 25 countries and economies, the gap between the two groups was considerably smaller after socio-economic differences are considered. This means that gaps in academic proficiency between the two groups of students were at least partly due to immigrant students being more socio-economically disadvantaged than native students.

Being disadvantaged is a risk factor for failing to attain baseline levels of academic performance in the three core PISA subjects. On average across OECD countries, the share of native students who attain such levels was 18 percentage points larger than the share of immigrant students who did so, before accounting for socio-economic status. The difference narrows to 14 percentage points when comparing native and immigrant students of similar socio-econonic status. On average across EU countries, the gap was 17 percentage points and 13 percentage points after accounting for socio-economic status. In CABA (Argentina), France, Luxembourg and the United States, the difference between the two groups before and after accounting for socio-economic status was larger than 10 percentage points. In the United States, socio-economic status was particularly influential since the gap between the two groups becomes statistically non-significant after accounting for ESCS.

Socio-economic status also partly explains the achievement gaps observed between native students and immigrant students with at least one native-born parent (Table 6.7, available on line). As discussed earlier, returning foreign-born students tend to have a higher socio-economic status than native students, yet they lag behind in academic performance. In 2015 in 35 countries and economies, the difference between native students and immigrant students with at least one native-born parent in the probability of attaining baseline levels of performance in the core PISA subjects widened after accounting for socio-economic status (Table 6.7). In Canada, Denmark, Estonia, France, Latvia, Lithuania, Montenegro, the Netherlands, Peru, Spain and Tunisia, the gap became negative and statistically significant after accounting for socioeconomic status. Results indicate that the socio-economic advantage observed among returning foreignborn students mitigates the adverse effects of an immigrant background on academic performance, and thus reduces the difference in performance compared with native students. In several countries, accounting for the impact of socio-economic status isolates the penalty for having an immigrant background among returning foreign-born students and gives a better sense of the magnitude of that penalty. 
Figure 6.7 - Difference between immigrant and native students in attaining baseline academic proficiency

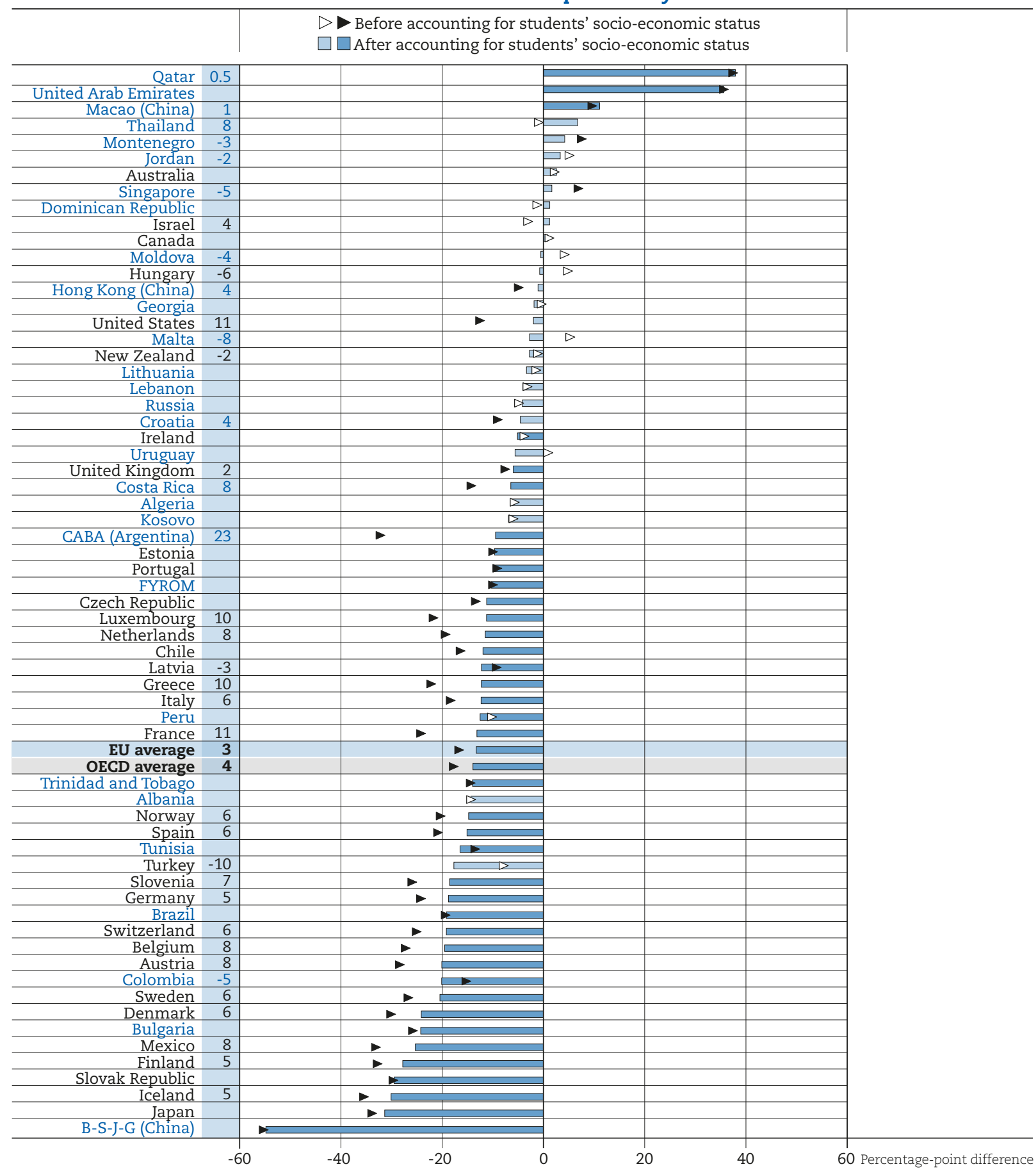

Notes: Only countries/economies with valid data on the immigrant-native gap in attaining baseline academic proficiency are shown. Statistically significant differences are marked in a darker tone.

Only students with non-missing values on PISA index of economic, social and cultural status (ESCS) index are considered.

Statistically significant differences in the immigrant-native gap after and before accounting for socio-economic status are shown next to country/economy names.

Students who attain baseline academic proficiency are students who reach at least PISA proficiency level two in all three PISA core subjects - math, reading and science.

Countries and economies are ranked in descending order of the percentage-point difference between immigrant and native students in the percentage of students attaining baseline academic proficiency after accounting for socio-economic status.

Source: OECD, PISA 2015 Database, Table 6.5.

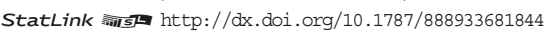


Box 6.2. Socio-economic status and performance gaps between native and immigrant students in the United States

\section{Socio-economic status and performance gaps in the United States}

The percentage of students reaching baseline levels of performance in PISA's core domains - science, reading and mathematics - is considerably lower among immigrant students (comprising firstand second-generation) than among students without an immigrant background (comprising native-born students of native-born parents) in most countries and economies that participated in PISA 2015. Nevertheless, in the majority of these countries and economies, this gap shrinks when the socio-economic status of the student is taken into account (see Figure 6.7). This "adjustment" leads to particularly significant reductions in performance differences in Ciudad Autónoma de Buenos Aires (Argentina) (hereafter "CABA [Argentina]"), France, Greece, Luxembourg and the United States. While in many countries other groups of students with an immigrant background - returning foreign-born students and students of mixed heritage - also suffer from a lower likelihood of reaching baseline levels of academic proficiency, differences in socio-economic status do not explain performance differences between these two groups of students, on the one hand, and students without an immigrant background, on the other (Table 6.7 available on line). However, the United States is the only country among those cited above where, after accounting for socio-economic status, performance differences between immigrant students and students without an immigrant background become statistically not significant.

There are two possible explanations for this. The first refers to the magnitude of the difference in socio-economic status between immigrant students and students without an immigrant background. In the United States, this difference is one of the largest observed in PISA 2015 (Table 6.3 available on line). As a result, when socio-economic status is accounted for, the disparity is larger too. Figure 6.2 shows that, compared to the OECD average, the socio-economic gap between native and first-generation immigrant students is almost three times greater in the United States, exceeded only by that in Turkey and CABA (Argentina).

While it is not possible, using PISA data, to explain why socio-economic status plays such a large role in determining the difference in the likelihood that immigrant students and students without an immigrant background will attain baseline levels of academic proficiency, it is possible to identify some of the specificities of the United States context that might contribute to this result. First, the expansion of access to post-secondary education occurred earlier in the United States than in most other countries; and the parents of immigrant students in the United States tend to come from countries where this expansion happened more recently (Schofer and Meyer, 2005). The effect of this circumstance could also be stronger than in Australia, Canada and New Zealand, for example, because immigration policies in the United States do not necessarily favour betterqualified immigrants (OECD, 2012). These factors might contribute to the findings highlighted in Figure 6.17, which shows that, in the United States, the difference in parents' educational attainment between immigrant students and students without an immigrant background is five times greater than the OECD average, exceeded only by that observed in CABA (Argentina). Given the importance educational attainment plays in shaping adults' labour market outcomes, differences between the two groups in parents' occupational status are also large. Figure 6.18 shows that this gap is almost twice as wide as the OECD average and is among the largest observed among the countries and economies that participated in PISA 2015.

A second possible reason why the performance gap between immigrant students and students without an immigrant background is relatively small in the United States (even before socio-economic status differences are considered) is that some groups of students without an immigrant background, such as Black Americans and Native Americans tend to perform lower than average while some immigrant students, such as Asian Americans, tend to perform higher than average (CEPA, n.d.; College Board, 2016; Hsin and Xie2014; Lee and Zhou, 2017; Liu and Xie, 2016; Noguera, 2003; Zong and Batalova, 2016). 
Unfortunately, since PISA data do not contain information on students' ethnicity it is not possible to test differences between these groups of students and immigrant students using PISA data; but research conducted in the United States based on national data suggests that these factors might play a role in explaining the results observed in PISA that are unique to the United States.

Some of the differences in academic performance between distinct ethnic groups in the United States, which cannot be measured by PISA, are illustrated in Figure 6.8. The figure shows differences in SAT scores (i.e. a standardised test widely used for college admissions in the United States) among secondary school students. It is important to note that while both tests are anonymous, the SAT test differs considerably from the PISA test both in the type of questions asked and relevance for students. Since SAT scores have an important bearing on college admissions, the stakes are considerably higher than they are in PISA, which has no consequences for the individual student.

Figure 6.8 - SAT scores in 2016, by subject and ethnic group

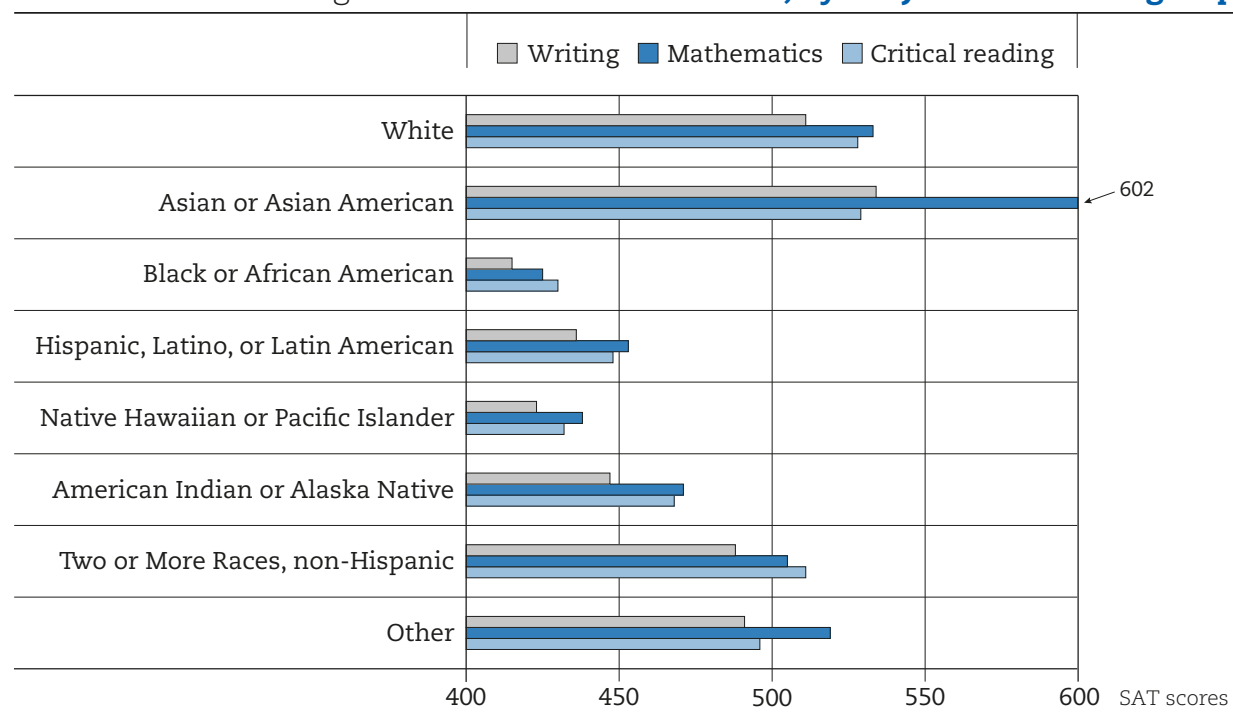

Source: College Board, 2016 College-Bound Seniors

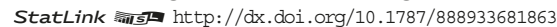

On average, PISA consistently finds a strong relationship between socio-economic status and academic performance (PISA, 2016a). But because of the combined effect of other risk and protective factors, or unobserved factors related to having an immigrant background, the impact of socio-economic status on academic achievement might not be equally strong among native students and students with an immigrant background. Figure 6.9 plots the marginal effect of socio-economic status on the probability of attaining baseline levels of performance in the core PISA subjects among native and immigrant students (results for all groups of students with an immigrant background can be found in Table 6.7 available on line). On average in 2015 across OECD countries, an increase in the ESCS index of one standard deviation was associated with a higher likelihood of achieving baseline proficiency in all core PISA subjects, which corresponded to 14 percentage points among native students but by only 10 percentage points among immigrant students. In Brazil, Denmark, France, Greece, Hungary, Mexico, the Netherlands, Singapore, the Slovak Republic and Tunisia, the marginal effect of socio-economic status on academic performance was smaller among immigrant students by more than 5 percentage points. In these countries, immigrant students appear to be at a double disadvantage: they tend to be of relatively low socio-economic status in the host country, but even when they are somewhat more advantaged, the impact of that higher socio-economic status on their performance is weaker than it is among native students. 
Figure 6.9 - Change in the likelihood of attaining baseline academic proficiency related to socio-economic status, by immigrant background

Percentage-point change associated with a one-unit change in the PISA index of economic, social and cultural status (ESCS)

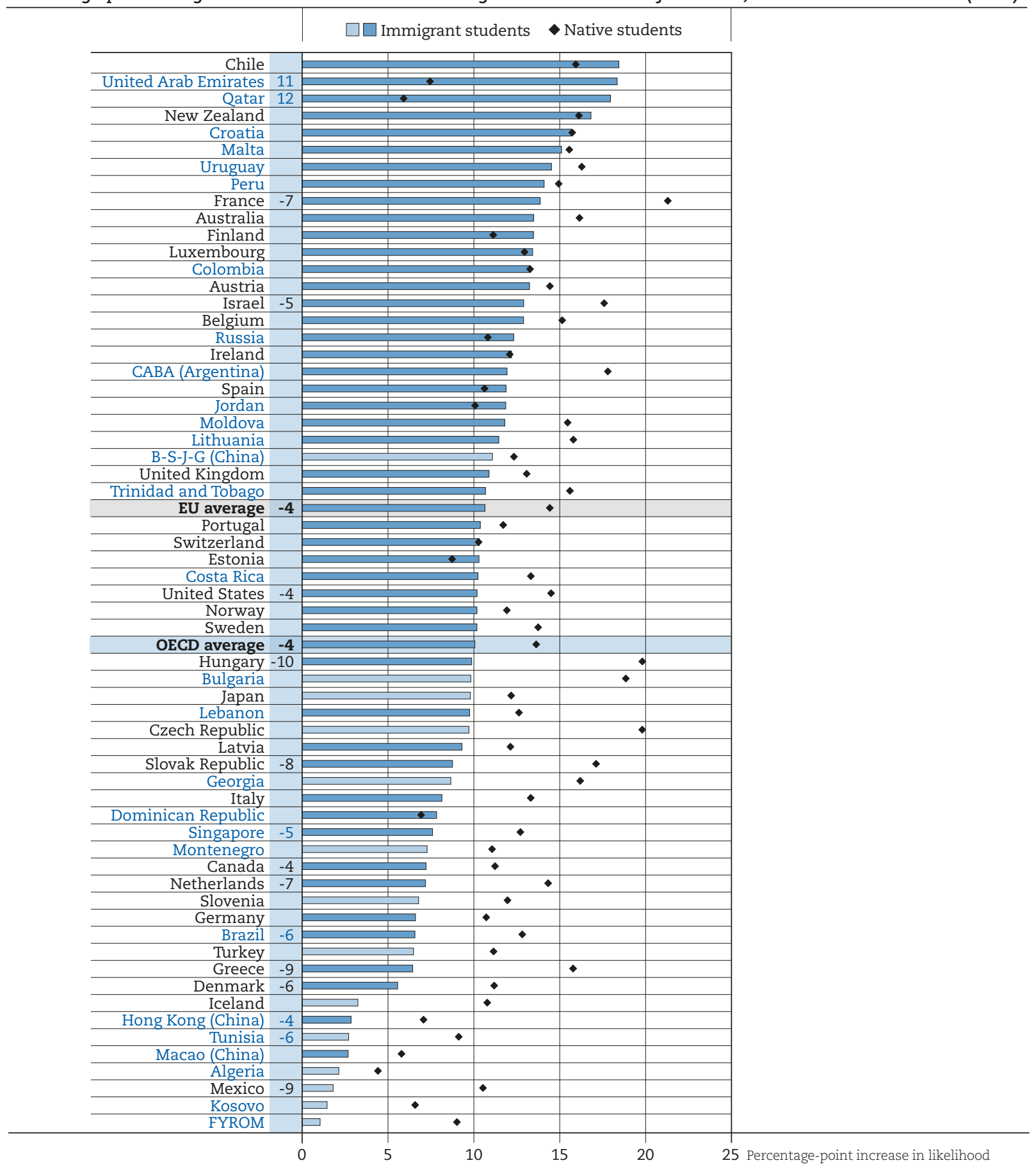

Notes: Statistically significant differences are marked in a darker tone

Only countries with valid data on the marginal effect of socio-economic status on the likelihood of attaining baseline academic proficiency for immigrant students are shown.

Statistically significant differences between immigrant and native students in the marginal effect of socio-economic status on the likelihood of attaining baseline academic proficiency are shown next to country/economy names. For the OECD and EU averages, this number refers only to the subset of countries/economies with valid information on both groups of students.

Countries and economies are ranked in descending order of the marginal effect of ESCS on the probability of attaining baseline proficiency among immigrant students.

Source: OECD, PISA 2015 Database, Table 6.5.

StatLink Ailst $\mathrm{http}: / / \mathrm{dx} . \mathrm{doi}$. org $/ 10.1787 / 888933681882$ 
Figure 6.10 Difference between immigrant and native students in attaining baseline academic proficiency, by socio-economic tercile
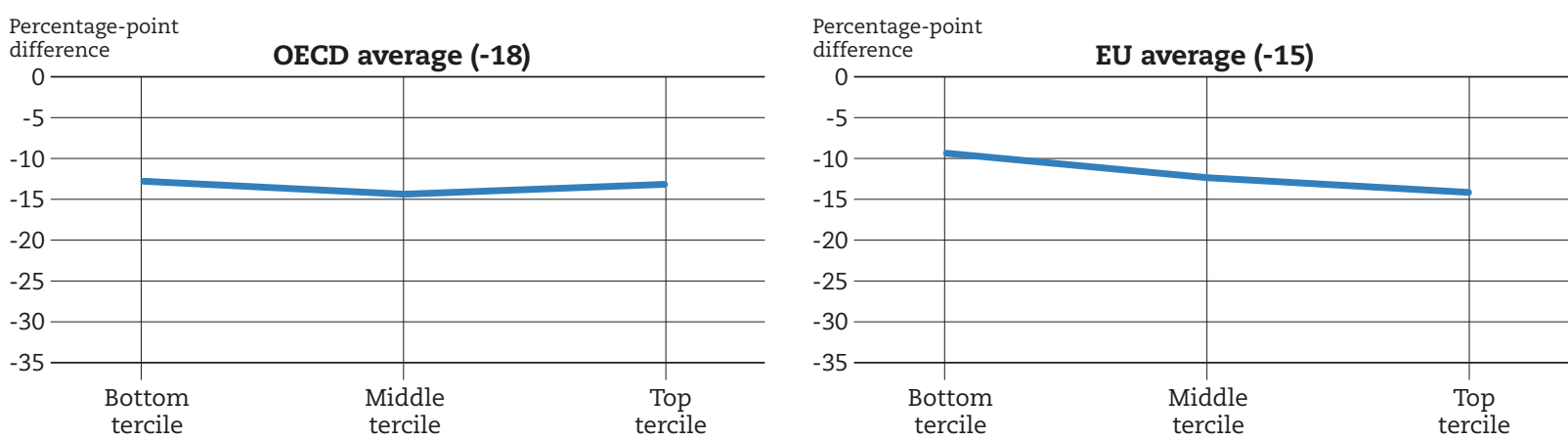

Percentage-point
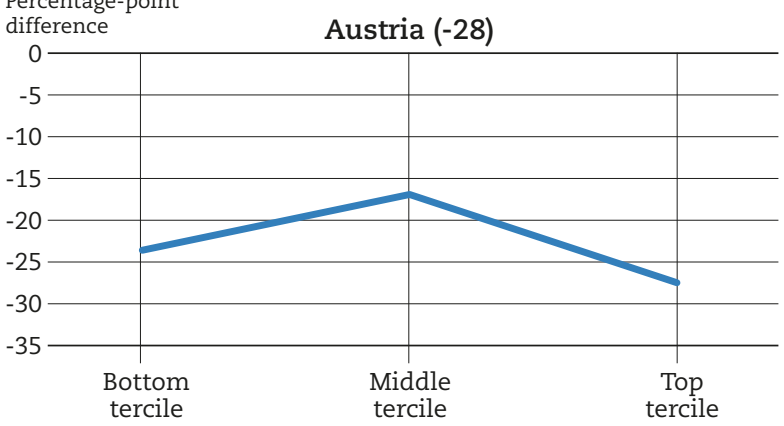

Percentage-point

difference Denmark (-30)

differentage-poin

difference

Greece (-22)
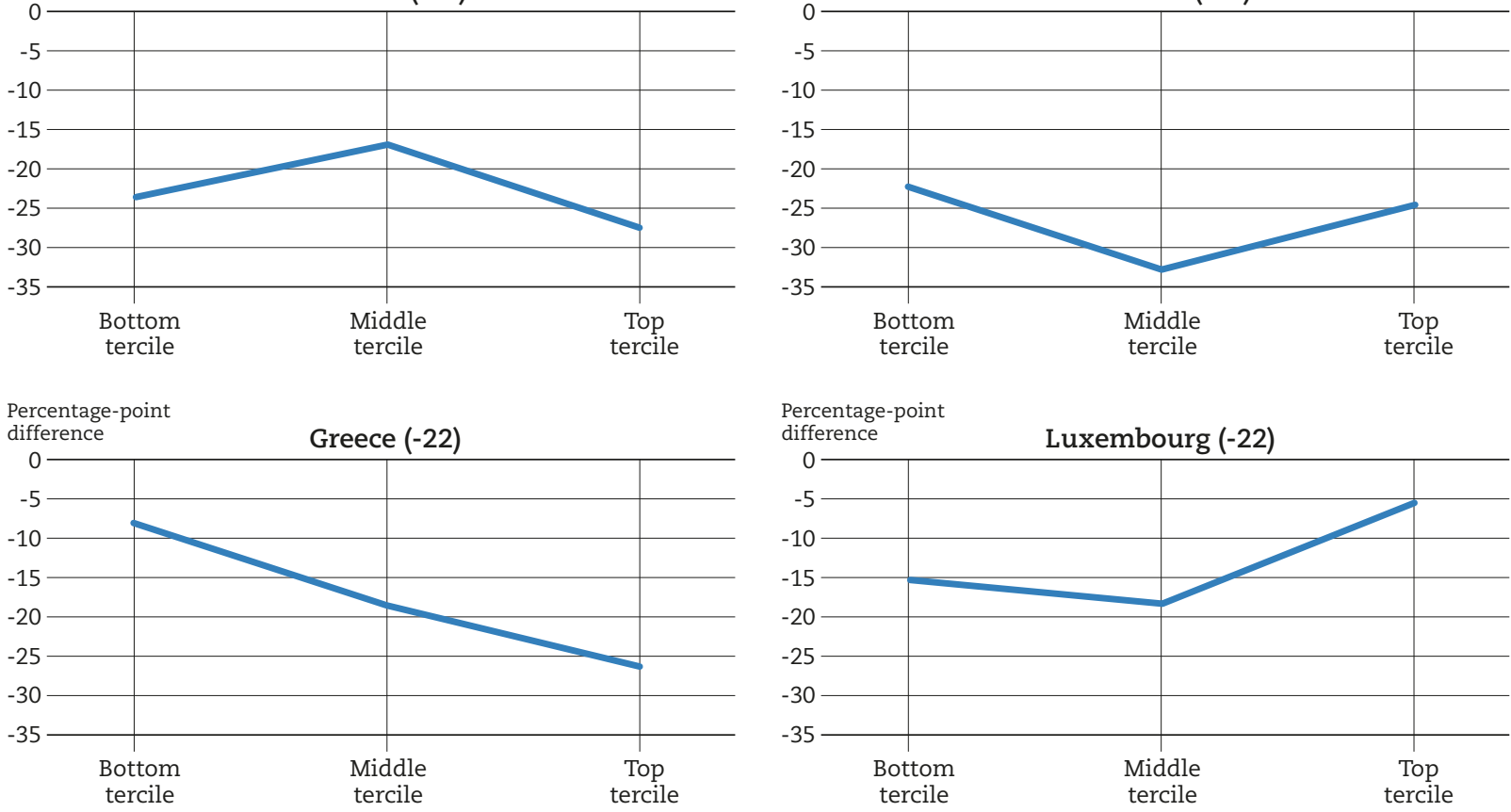

Percentage-point

difference

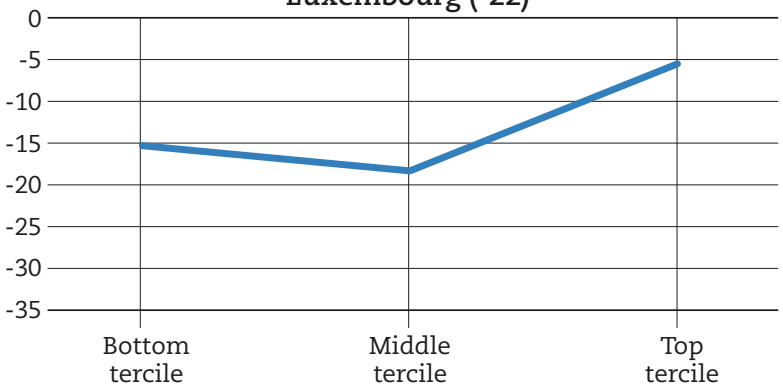

Percentage-point

difference

Switzerland (-25)

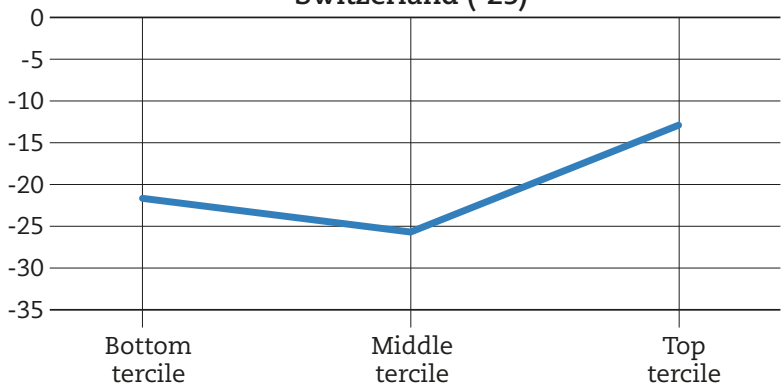

Notes: The average difference in the percentage of immigrant and native students attaining baseline academic proficiency is shown next to country/economy names.

Students who attain baseline academic proficiency are students who reach at least PISA proficiency level two in all three PISA core subjects - math, reading and science.

Only students with non-missing values on the PISA index of economic, social and cultural status ESCS are considered.

All immigrant-native gaps reported are statistically significant.

Source: OECD, PISA 2015 Database, Table 6.8.

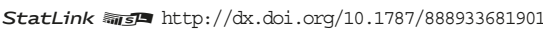


The analyses presented thus far have focused on the average effects of socio-economic status in the relationship between immigrant background and academic achievement. However, as shown in Figure 6.9, in a number of countries and economies, immigrant background and socio-economic status interact significantly, implying that differences in performance between native and immigrant students could differ even across groups of students with a similar socio-economic status. Table 6.8 (available on line) shows differences in the percentage of students who attain baseline levels of proficiency between these two groups of students by tercile of socio-economic status within each PISA-participating country and economy. Students were divided into terciles in order to guarantee sufficiently large sample sizes to carry out the desired analyses. While some clear trends are observed in the data, because of sample-size issues, differences across terciles are generally not statistically significant. Figure 6.10 shows the results for selected countries where some of the differences across terciles are large enough to be statistically significant despite large standard errors. The numbers shown next to country names are average differences between native and immigrant students.

In most countries and economies, the difference between the percentage of native students and immigrant students attaining baseline levels of performance in the core PISA subjects was widest among students in the middle portion of the socio-economic distribution. On average across OECD countries, the gap was 3 percentage points larger in the middle tercile compared to the bottom tercile, and not statistically significant from the gap in the top tercile. In Denmark, Luxembourg and Switzerland, the difference was also largest in the middle group; however, differences across terciles were significantly more pronounced than on average across OECD countries. In Luxembourg and Switzerland, the penalty related to an immigrant background was significantly smaller at the top of the socio-economic distribution and most pronounced in the middle tercile. In both countries, there was a 13 percentage-point difference between the gap at the top and the middle of the distribution. By contrast, in Denmark, the gap was smallest at the bottom of the distribution (although there was no statistically significant difference compared to the gap at the top of the distribution) and was largest in the middle tercile.

The likely explanation for these common patterns is that socio-economic status is a strong predictor of academic achievement, thus extreme values on the ESCS index limit or enhance students' chances of reaching baseline academic proficiency. Socio-economically disadvantaged students might already face so many constraints that being an immigrant alters only slightly their chances of being academically resilient, while advantaged students might already benefit from certain privileges that being an immigrant has little impact on their academic performance. As a result, performance gaps between native and immigrant students are largest at the middle of the socio-economic distribution, where students' performance is most varied and not as affected by their socio-economic status.

In another set of countries and economies, including Austria, Brazil (not represented) and Greece, the difference between the percentage of native students and immigrant students attaining baseline levels of performance in the core PISA subjects was largest in the top tercile of the socio-economic distribution. In Greece, the difference grew as the socio-economic status of the group considered rose, so that the gap between native and immigrant students within the top tercile was 18 percentage points larger than the gap at the bottom of the distribution. Conversely, in Austria, the difference was smallest among students in the middle tercile of the socio-economic distribution, followed by the gap among students in the bottom tercile and then the gap in the top tercile. There was a statistically significant difference of 11 percentage points in the gaps between native and immigrant students when comparing the top and middle terciles.

Another way to gain insights into how an immigrant background can affect student performance is to compare the outcomes of native and immigrant students of different socio-economic status. Comparing socio-economically disadvantaged native students to more privileged immigrant students can shed light on the relative importance of the adversity that stems from being an immigrant or being socioeconomically disadvantaged. Figure 6.11 compares the percentage of students attaining baseline proficiency among native students in the lowest tercile of the national socio-economic distribution, and among immigrant students in the lowest and top terciles of the distribution. 
Figure $6.11 \mathrm{a}$ - Disadvantaged students attaining baseline academic proficiency, by immigrant background

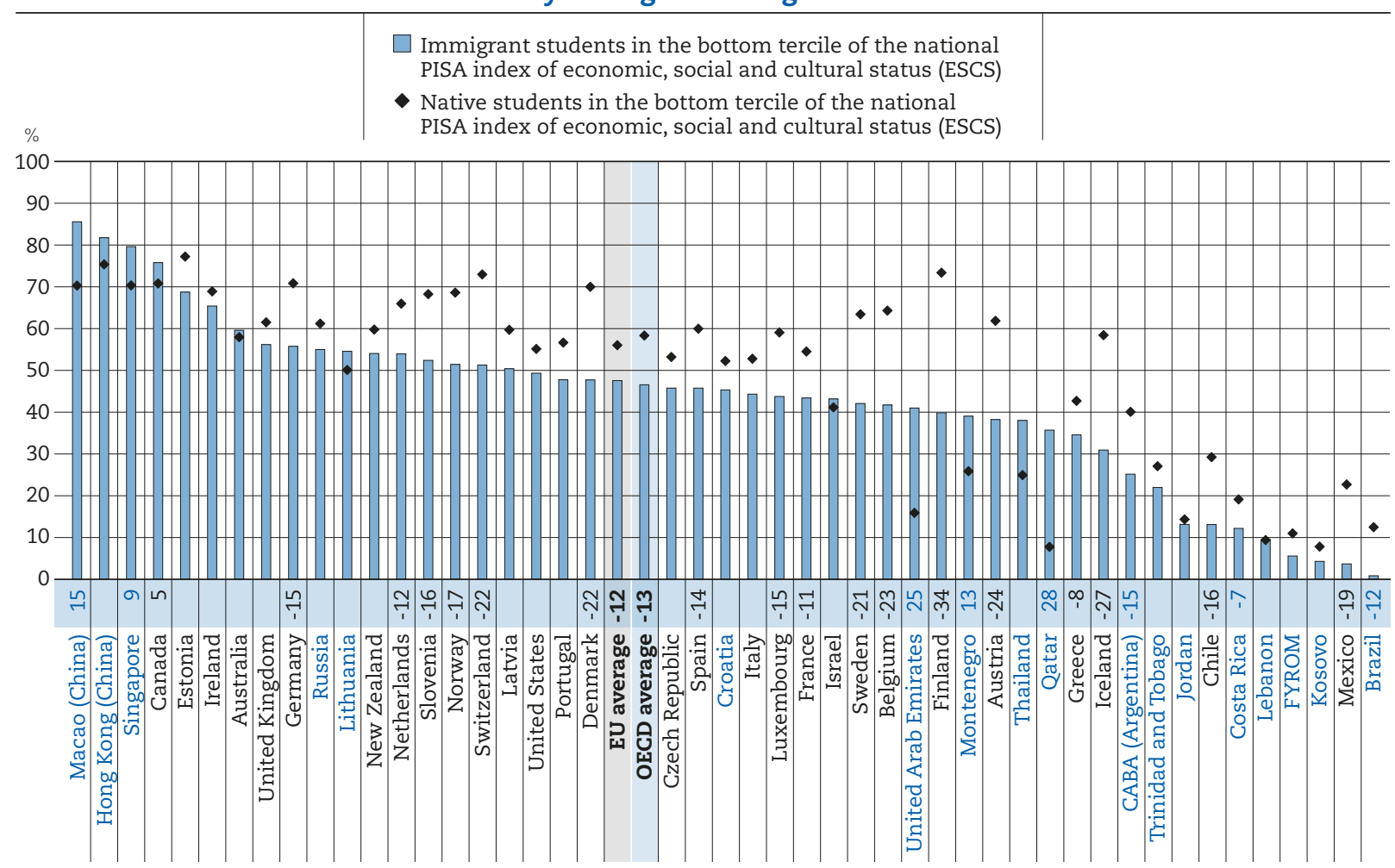

Notes: Only countries with valid estimates for immigrant students in the bottom tercile of the national ESCS distribution are shown. Only students with non-missing values on PISA index of economic, social and cultural status (ESCS) index are considered.

Statistically significant differences between disadvantaged immigrant and native students in the percentage of students attaining baseline academic proficiency are shown next to country/economy names. For the OECD and EU averages, this number refers only to the subset of countries/economies with valid information on both groups of students.

Students who attain baseline academic proficiency are students who reach at least PISA proficiency level two in all three PISA core subjects - math, reading and science.

Countries and economies are ranked in descending order of the percentage of immigrant students in the bottom tercile of the national ESCS distribution attaining baseline proficiency.

Source: OECD, PISA 2015 Database, Table 6.9.

StatLink 前I http://dx.doi.org/10.1787/888933681920

Figure 6.11a shows that, even though differences in academic resilience between native and immigrant students are larger in the middle and top terciles of the socio-economic distribution, in several countries, they are remarkably large in the bottom tercile too. On average across OECD countries, among students in the bottom tercile of national socio-economic status, the share of native students who attain baseline academic proficiency was about 13 percentage points larger than the share of immigrant students who did. But in Austria, Belgium, Denmark, Finland, Iceland, Sweden and Switzerland, the difference between the two groups was larger than 20 percentage points.

Figure $6.11 \mathrm{~b}$ compares native students in the bottom tercile of socio-economic status with immigrant students in the middle and the upper terciles. The data show that economic advantage might not be enough to compensate for the penalty of having an immigrant background. In 27 of 57 countries and economies with available data, there was no statistically significant difference in the percentage of students reaching baseline academic performance across the two groups considered. In Denmark, Germany, Iceland, Mexico and Slovenia, advantaged immigrant students were less likely than disadvantaged native students to attain baseline proficiency. In all of these countries, the difference between the two groups, in favour of the latter, was larger than 8 percentage points. This evidence suggests that, in several PISA-participating countries and economies, having an immigrant background represents a greater obstacle to academic achievement than socio-economic disadvantage. 
Figure $6.11 \mathrm{~b}$ - Attaining baseline academic proficiency, by immigrant background and socio-economic status

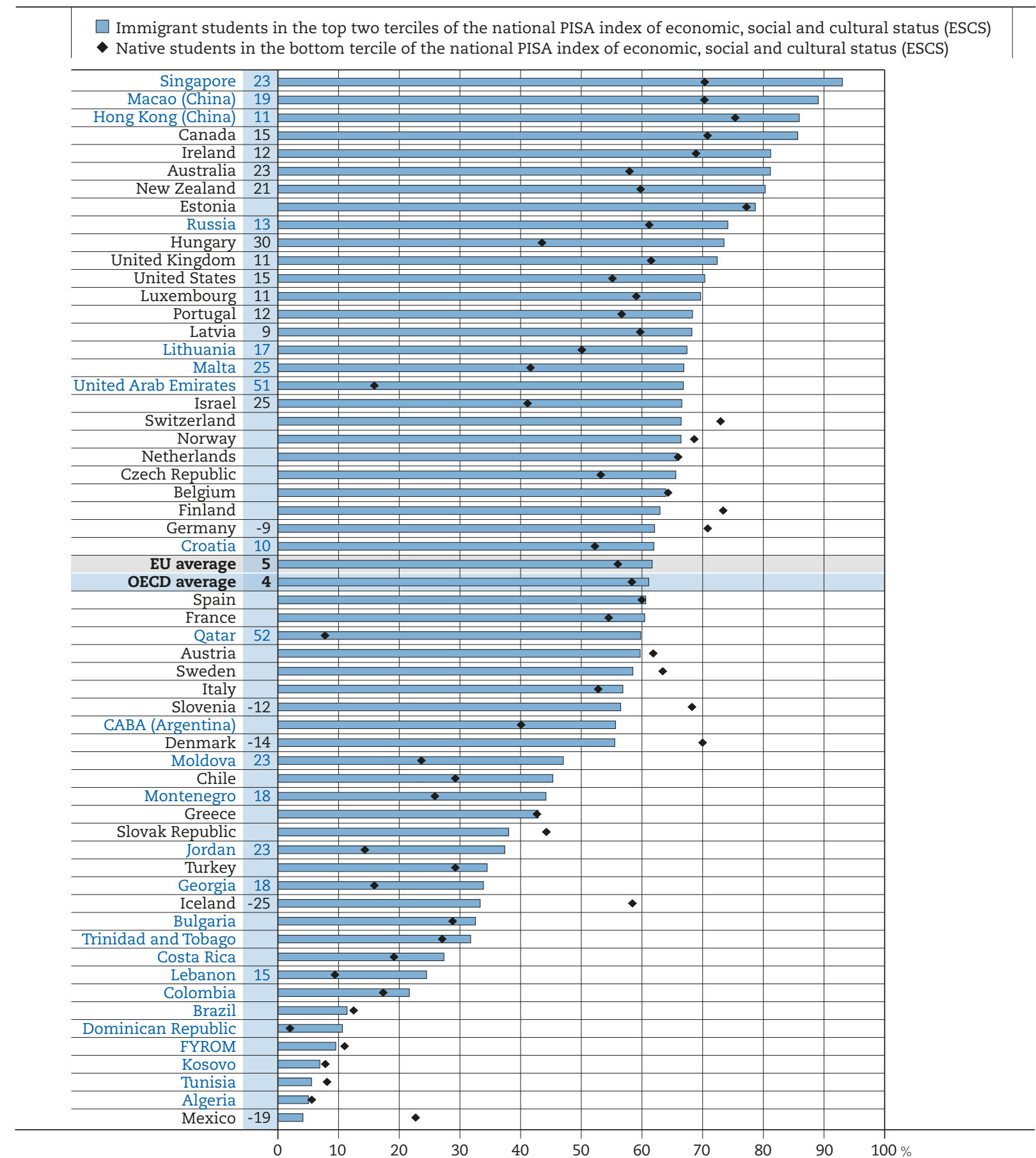

Notes: Only countries with valid estimates for immigrant students in the top two terciles of the national ESCS distribution are shown. Only students with non-missing values on PISA index of economic, social and cultural status (ESCS) index are considered.

Statistically significant differences between immigrant students in the top two terciles of the national ESCS distribution and native students in the bottom tercile of the national ESCS distribution in the percentage of students attaining baseline academic proficiency are shown next to country/economy names. For the OECD and EU averages, this number refers only to the subset of countries/economies with valid information on both groups of students.

Students who attain baseline academic proficiency are students who reach at least PISA proficiency level two in all three PISA core subjects - math, reading and science.

Countries and economies are ranked in descending order of the percentage of immigrant students in the top two terciles of national ESCS distributions attaining baseline proficiency.

Source: OECD, PISA 2015 Database, Table 6.9.

StatLink inist http://dx.doi.org/10.1787/888933681939 
Box 6.3. The impact on proficiency of immigrant background and socio-economic status at different levels of science performance

PISA shows that there are significant differences between native and students with an immigrant background in the percentage of students who attain the baseline level of proficiency in all core PISA domains, and that socio-economic status is one of the variables that explain such differences. The academic outcome variable developed for this report focuses on a specific part of the distribution of academic results within each country/economy, and the methods used in the analysis report average effects. However, the penalty associated with an immigrant background, and the extent to which socio-economic status contributes to it, is likely to vary significantly at different levels of the performance distribution in each country/economy. Quantile regressions, rather than standard linear regressions, are used below to investigate such differences. Specifically, differences in sciences scores between native and immigrant students are computed for three different percentiles (10th, 50th and 90th) of the distribution of science scores within each country/economy, before and after accounting for socio-economic status.

Since the outcome variable used throughout most of this report is binary, it cannot be used for this analysis; therefore, one of the PISA domains had to be selected. Science was chosen because it was the main domain in the PISA 2015 round and because, compared to reading and mathematics, it represents a middle ground in terms of the language skills required to complete the test (with reading requiring the highest and math the lowest). Science scores are also highly correlated with results in the other core domains and with the academic outcome variable used in this report.

Figure 6.12 shows that differences in science performance between native and immigrant students vary significantly across the distribution of scores, and countries show markedly different patterns of variation. In most countries and economies, these differences are largest at the median of the distribution, so that plotting the differences results in a U-shaped curve, as shown for Austria, Belgium, Denmark and Norway. In Belgium and Denmark, the second largest difference was observed among the lowest-achieving students (i.e. those at the 10th percentile of the science performance distribution). In Denmark especially, the gap among students in the lowest decile was similar to that among students at the median (73 and 77 score points, respectively) and significantly smaller than the gap at the top decile (50 points).

By contrast, in Austria the performance difference between native and immigrant students was larger among the highest-achieving students (i.e. those at the 90th percentile of the performance distribution) than among the lowest-achieving students. Although the plot line for Norway is also U-shaped, it is almost flat because the differences between native and immigrant students did not vary greatly across the performance distribution. In another set of countries, the plot line is downward-sloping, as shown in the graphs for Estonia and Mexico. In these cases, the performance differences between native and immigrant students increase as students' proficiency increases, such that the penalty of having an immigrant background was greatest among the highest-achieving students.

In most countries, accounting for socio-economic status shrinks the performance gap between native and immigrant students and reduces the difference between the gaps at the various levels of performance. This is seen, graphically, as an upward shift and flattening of the plotted curves. Furthermore, in most countries and economies the effect of socio-economic status is greater among the median and highest-achieving students, compared to the lowest-achieving students. This is particularly evident in Denmark and Mexico, where the change in the performance gap among students in the bottom tenth percentile was marginal.

Despite some similarities, the impact of socio-economic status on these performance gaps differs significantly across countries. In Austria, Mexico and Norway, accounting for socio-economic status does not completely alter the shape of the plotted curve but just flattens it, reducing differences across the performance deciles. By contrast, in Belgium and Denmark, the curves change from a U-shape to an upward slope, meaning that the performance gap becomes largest among the lowest-achieving students.

In Estonia, accounting for socio-economic status has a remarkably small impact on the performance gap between native and immigrant students. The gap widens among the lowest-achieving students, narrows among the highest-achieving students and remains unaltered at the median. As a result, the curve changes from a downward slope to a U-shape. 
Figure 6.12 - Immigrant-native gaps in science results across the distribution of scores Gaps at the 10th, 50th and 90th percentiles of the national distribution of science scores, selected countries
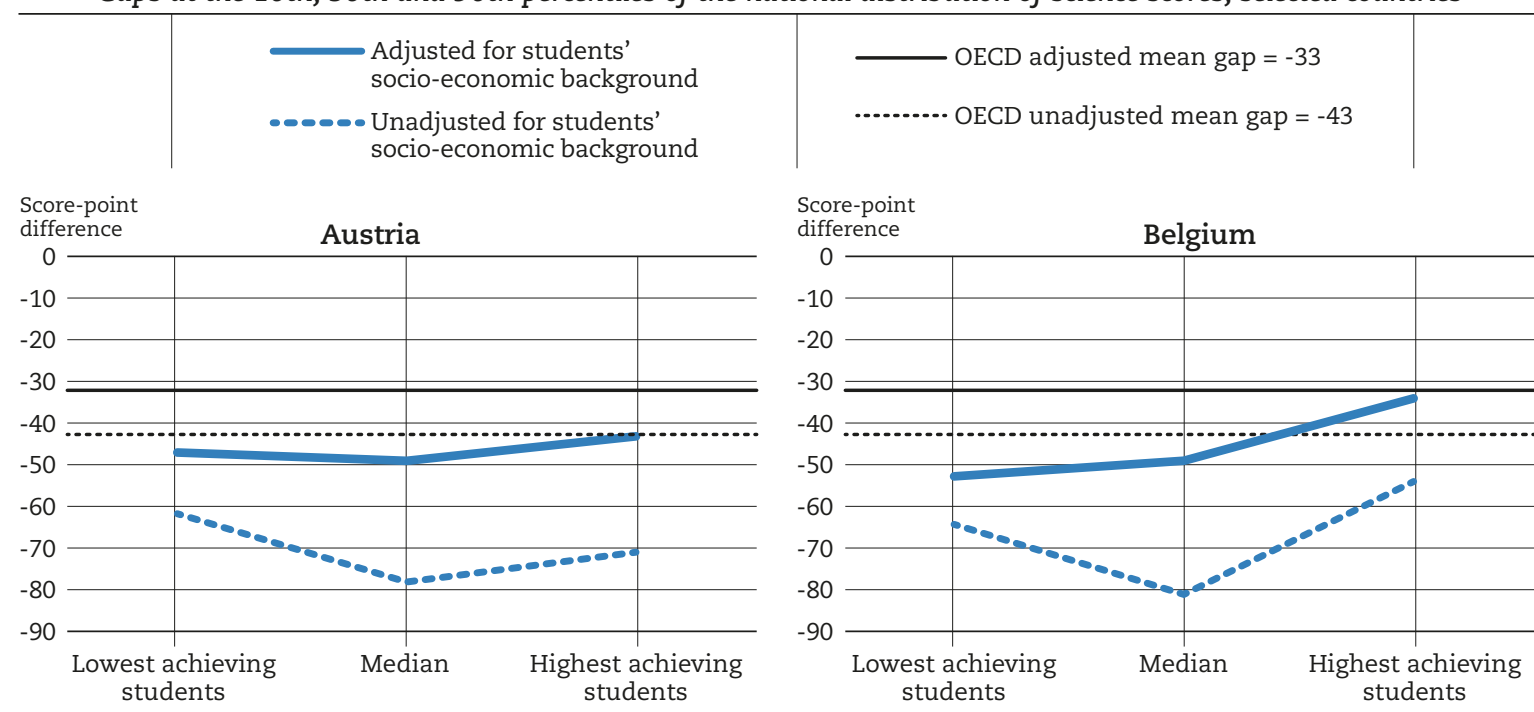

Score-point
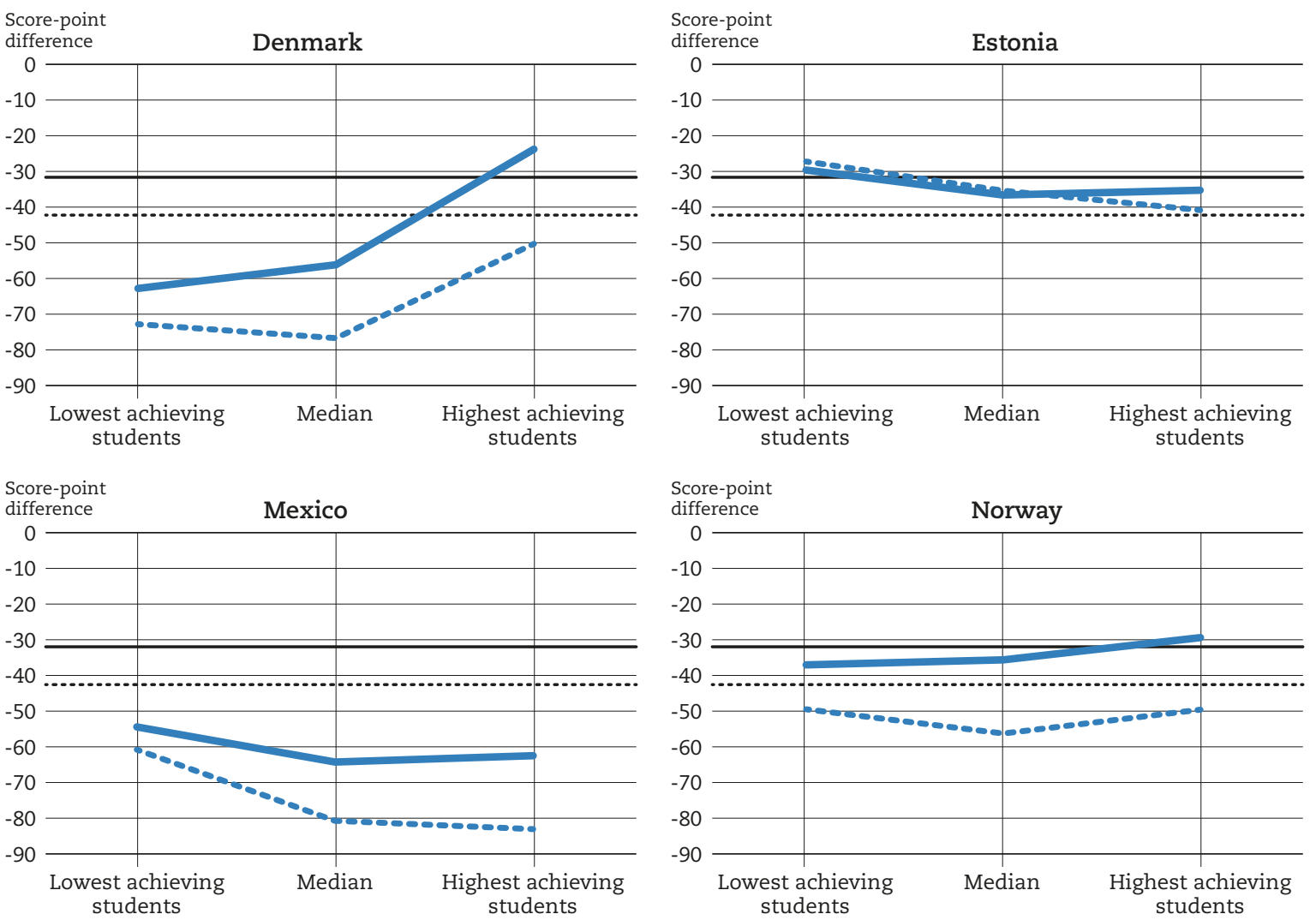

Notes: All data reported is statistically significant.

Lowest-achieving students are those within the lowest decile of the national distribution of science scores; highest-achieving students are those within the highest decile of the national distribution of science scores.

Unadjusted gaps are gross gaps between immigrant and native students, while adjusted gaps account for the socio-economic status of the two groups of students. Only students with non-missing values on the PISA index of economic, social and cultural status (ESCS) are considered.

Results were obtained through quantile regressions.

Source: OECD, PISA 2015 Database, Table 6.10.

StatLink 解政 $\mathrm{http}: / / \mathrm{dx}$. doi.org/10.1787/888933681958 


\section{Social and emotional well-being}

Tables 6.11 to 6.18 (available on line) show that socio-economic status is a statistically significant predictor of social, emotional and emotivational well-being in the majority of countries and economies with available data. Nevertheless, the correlation is markedly weaker than that between socio-economic status and academic performance. On average in 2015 across OECD countries, a one standard-deviation increase in socio-economic status led to a 14 percentage-point increase in the likelihood of attaining baseline academic proficiency; but a similar rise in socio-economic status was linked with only a 3-5 percentagepoint increase in the likelihood of students feeling like they belong at school, feeling satisfied with life or reporting low levels of anxiety. However, since differences in well-being outcomes between native and immigrant students tend to be narrower than gaps in academic achievement, lower socio-economic status still explained a significant part of immigrants' disadvantage in well-being.

Figure 6.13 confirms that socio-economic disadvantage is one of the factors that explain the gap between native and immigrant students in the percentage of students who report a sense of belonging at school. ${ }^{2}$ In 20 countries and economies, this gap shrank after accounting for socio-economic status. Across OECD countries, the gap shrank by around 1 percentage point (from approximately $7 \%$ to $6 \%$ ); in Belgium, CABA (Argentina), Denmark, France, Hong Kong (China), Luxembourg and the United States, the gap shrank by more than three percentage points. In CABA (Argentina) and France, the reduction was such that the gap between native and immigrant students was not statistically significant, while in Belgium, Denmark and Luxembourg, the decrease of about 3 percentage points represented only a small part of the gaps observed before accounting for socio-economic status, all of which were considerably larger than 10 percentage points.

Figure 6.14 reveals that in 14 countries and economies, the impact of socio-economic status on the probability of students feeling that they belong at school was stronger among native students than among immigrant students (first- and second-generation). Across OECD countries, a one standard-deviation increase in socio-economic status led to a five percentage-point higher probability of reporting a sense of belonging and integration among native students, but only a 2.7 percentage-point higher probability of so reporting among immigrant students. In Brazil, Denmark, France, Greece, Ireland, the Netherlands, New Zealand, Norway and Switzerland, higher socio-economic status increased the likelihood of reporting a sense of belonging at school among native students but had no statistically significant effect among immigrant students. In France, this is likely because small samples inflated standard errors; in the other countries, the estimates were close to zero or even negative.

PISA 2015 finds a strong correlation between family wealth and life satisfaction across most countries (OECD, 2017). Figure 6.15 shows that socio-economic disparities partly explain the difference in the percentages of native and immigrant students who reported being satisfied with their life. ${ }^{3}$ In 18 countries and economies, this difference shrank after accounting for socio-economic status. On average across OECD countries, the gap narrowed from 5.9 to to 4.7 percentage points. In Austria, Iceland, Hong Kong (China), Luxembourg and the United States, the difference between the percentage of native and immigrant students who reported being satisfied with their life was reduced by more than three percentage points after accounting for socio-economic status. In the United States, socio-economic status played a particularly significant role, since the adjusted gap was close to zero and not statistically significant.

PISA shows that, in most countries and economies, the effect of socio-economic status on schoolworkrelated anxiety tends to be weaker than its impact on other measures of well-being (Table 6.15, available on line). Results also indicate that the difference in the percentages of native and immigrant students who reported low levels of anxiety ${ }^{4}$ was large compared to those of other well-being outcomes (Table 6.15). Figure 6.16 shows that in Austria, Finland, France, Germany, Japan, Luxembourg, Mexico, Sweden, Switzerland and Tunisia, the difference in the percentages of native and immigrant students who reported low schoolwork-related anxiety was larger than 10 percentage points. After accounting for socio-economic status, this difference was reduced by only 1.8 to 3.6 percentage points. Evidence shows that socio-economic status explains only a small part of immigrants' relatively higher schoolworkrelated anxiety. 


\section{Figure 6.13 - Difference between immigrant and native students in reporting a sense of belonging at school}

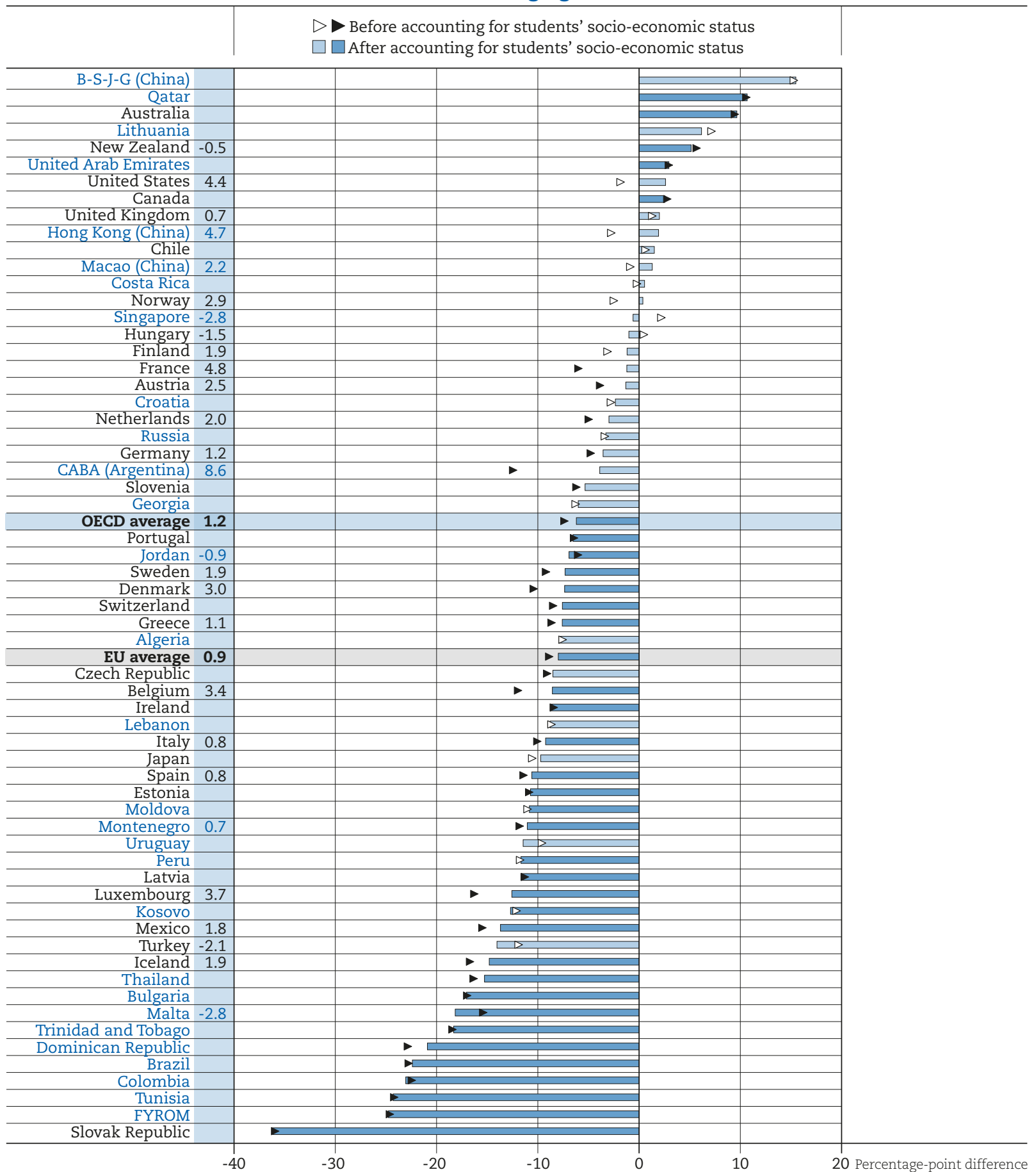

Notes: Statistically significant differences are marked in a darker tone.

Only countries/economies with valid data on the immigrant-native gap in reporting a sense of belonging at school are shown.

Students who reported a sense of belonging at school are those who reported that they "agree" or "strongly agree" with the statement "I feel like I belong at school" and "disagree" or "strongly disagree" with the statement "I feel like an outsider at school".

Only students with non-missing values on PISA index of economic, social and cultural status (ESCS) index are considered.

Statistically significant differences in the immigrant-native gap after and before accounting for socio-economic status are shown next to country/economy names.

Countries and economies are ranked in descending order of the percentage-point difference between immigrant and native students in the percentage of students reporting a sense of belonging at school after accounting for socio-economic status.

Source: OECD, PISA 2015 Database, Table 6.11.

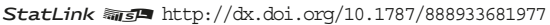


Figure 6.14 - Change in the likelihood of reporting a sense of belonging at school related to socio-economic status, by immigrant background

Percentage-point change associated with a one-unit change in the PISA index of economic, social and cultural status (ESCS)

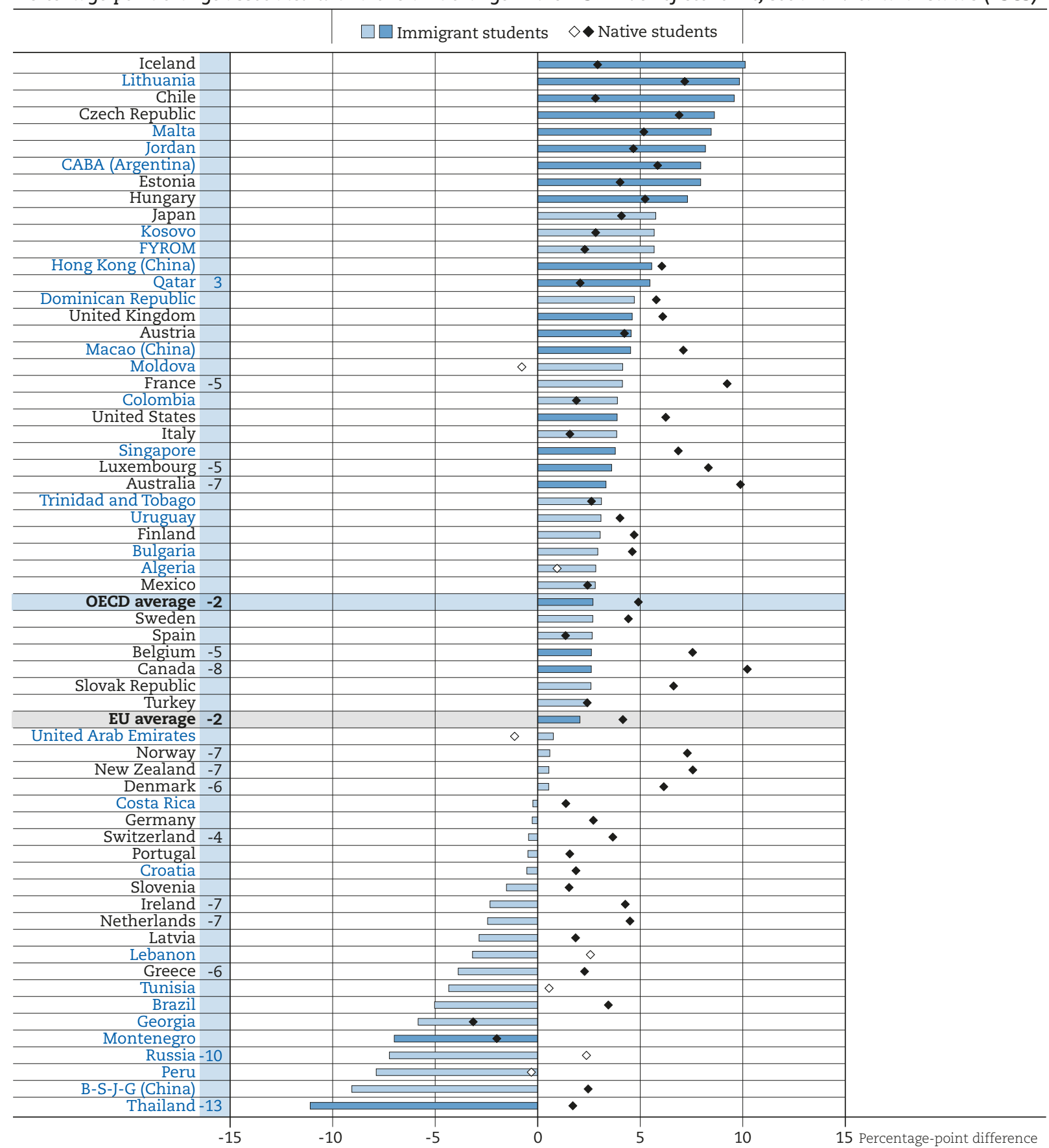

Notes: Statistically significant differences are marked in a darker tone.

Only countries with valid data on the marginal effect of socio-economic status on the likelihood of reporting a sense of belonging for immigrant students are shown.

Statistically significant differences between immigrant and native students in the marginal effect of socio-economic status on the likelihood of feeling a sense of belonging at school are shown next to country/economy names. For the OECD and EU averages, this number refers only to the subset of countries/economies with valid information on both groups of students.

Students who reported a sense of belonging at school are those who reported that they "agree" or "strongly agree" with the statement "I feel like I belong at school" and "disagree" or "strongly disagree" with the statement "I feel like an outsider at school".

Countries and economies are ranked in descending order of the marginal effect of ESCS on the probability of reporting a sense of belonging at school for immigrant students.

Source: OECD, PISA 2015 Database, Table 6.11.

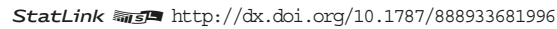


Figure 6.15 - Difference between immigrant and native students in feeling satisfied with life

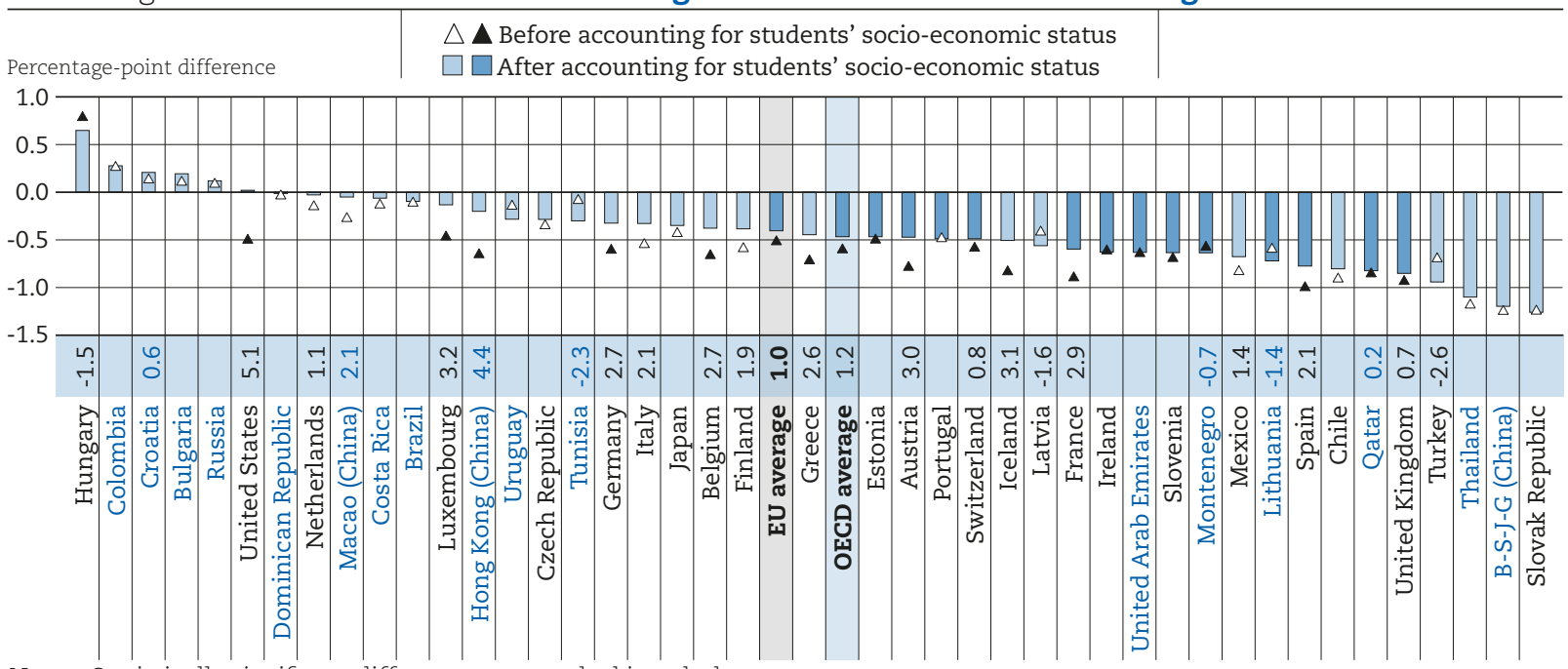

Notes: Statistically significant differences are marked in a darker tone.

Only countries/economies with valid data on the immigrant-native gap in reporting being satisfied with life are shown.

Students who report being satisfied with life are students who reported a life satisfaction of 7 or above on a scale from 0 to 10.

Only students with non-missing values on PISA index of economic, social and cultural status (ESCS) are considered.

Statistically significant differences in the immigrant-native gap after and before accounting for socio-economic status are shown next to country/economy names.

Countries and economies are ranked in descending order of the percentage-point difference between immigrant and native students in the percentage of students who reported being satisfied with life, after accounting for socio-economic status.

Source: OECD, PISA 2015 Database, Table 6.13.

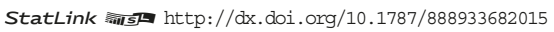

Figure 6.16 Difference between immigrant and native students in reporting low schoolwork-related anxiety

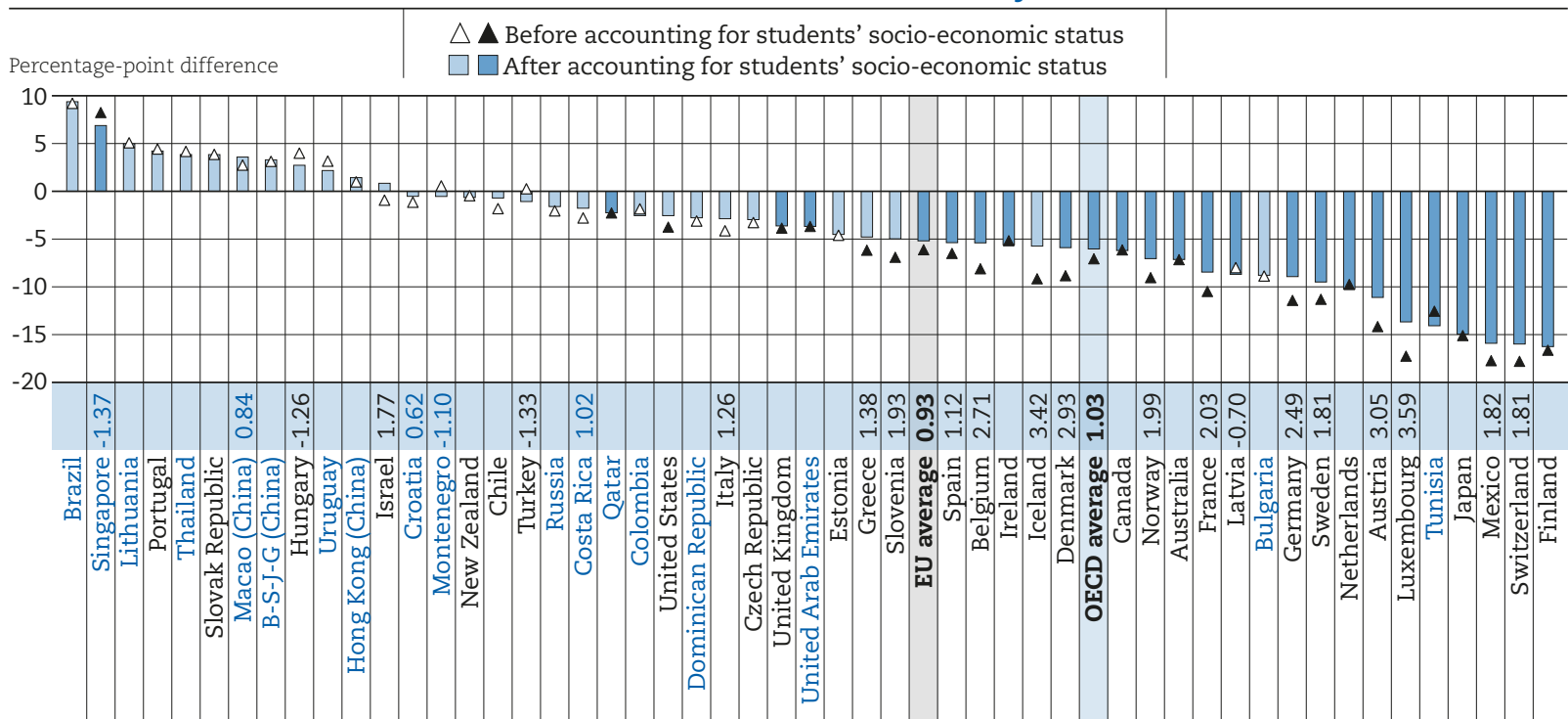

Notes: Statistically significant differences are marked in a darker tone.

Only countries/economies with valid data on the immigrant-native gap in reporting low schoolwork-related anxiety are shown.

Students who report low schoolwork-related anxiety are students who reported that they "disagree" or "strongly disagree" with the statements "I often worry that it will be difficult for me taking a test" and "Even if I am well prepared for a test, I feel very anxious".

Only students with non-missing values on PISA index of economic, social and cultural status (ESCS) are considered.

Statistically significant differences in the immigrant-native gap after and before accounting for socio-economic status are shown next to country/economy names.

Countries and economies are ranked in descending order of the percentage-point difference between immigrant and native students in the percentage of students reporting low schoolwork-related anxiety, after accounting for socio-economic status.

Source: OECD, PISA 2015 Database, Table 6.15.

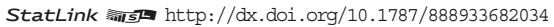




\section{Components of the PISA index of economic, social and cultural status}

The PISA index of economic, social and cultural status (ESCS) summarises different pieces of information into a single measure. It is designed to have the highest possible correlation with its three components and to capture the greatest amount of information. However, parents' education, parents' occupational status and household possessions might not be completely aligned in all instances. For example, highskilled immigrants might have to go through a period of adjustment before they attain an occupational status that matches their education level. Also, an immigrant who has recently entered the host country is likely to own fewer household possessions than a native who has lived in the host country throughout his or her life. This section examines differences between native and immigrant students in the three separate components of the ESCS index.

\section{Parents' education}

PISA 2015 asked students to define the highest level of schooling completed by each of their parents. Responses are coded according to ISCED 1997 classifications. Maternal and paternal levels of education are used to develop an index of highest parental education, which is then converted into an estimated number of years of schooling. A more detailed explanation of how the index is constructed is available in the PISA 2015 Technical Report.

Table 6.19 (available on line) reports the average years of parents' education for native students and students with an immigrant background. On average across OECD countries, the parents of native students completed 13.90 years of schooling, while the parents of first-generation immigrant students completed 13.58 years, an average difference of 0.52 year in those countries with large enough populations for calculating reliable estimates for both groups of students. The parents of second-generation immigrant students completed 13.61 years of schooling ( 0.43 year less than parents of native students, on average across OECD countries with available data), while the parents of returning foreign-born students and of students with a mixed heritage completed 14.74 years and 14.33 years of schooling, respectively ( 0.78 year and 0.43 year more than the parents of native students, respectively, for countries with available data).

Figure 6.17 - Years of parents' education, by immigrant background

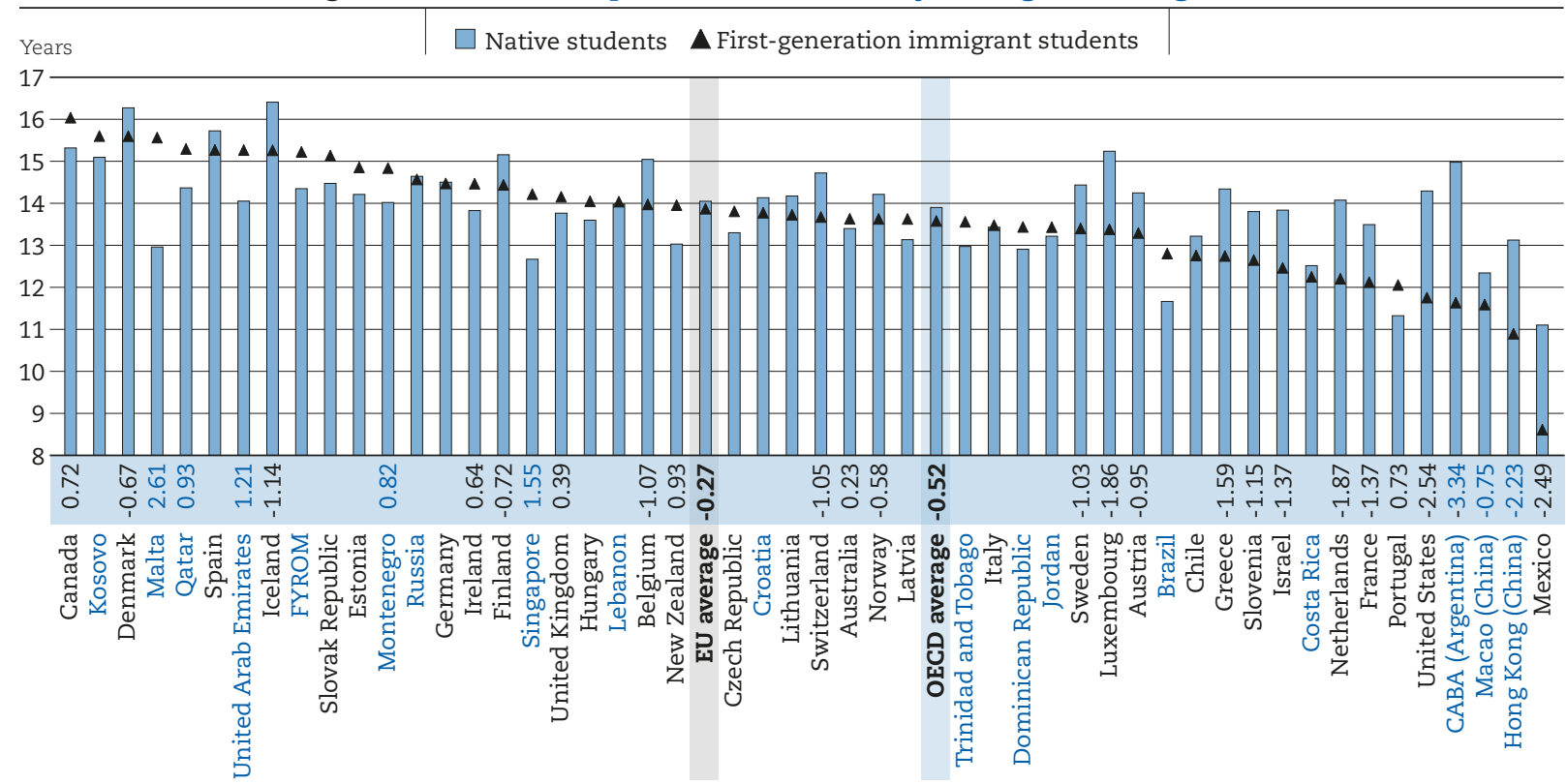

Notes: Only countries and economies with valid data for first-generation immigrant students are shown.

Statistically significant differences between first-generation immigrant and native students in years of parents' education are shown next to country/economy names. For the OECD and EU averages, this number refers only to the subset of countries/economies with valid information for both groups of students.

Countries and economies are ranked in descending order of the years of parents' education among first-generation immigrant students.

Source: OECD, PISA 2015 Database, Table 6.19.

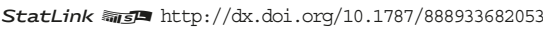


Figure 6.17 shows that in 19 of 50 countries and economies with available data, the parents of native students completed more years of education than the parents of first-generation immigrant students. In 14 countries and economies, they completed at least one year more of schooling, and in CABA (Argentina), Greece, Hong Kong (China), Luxembourg, Mexico, the Netherlands and the United States, they completed more than 1.5 years of schooling more than the parents of first-generation immigrant students. By contrast, in 11 countries, the parents of first-generation immigrant students completed more years of schooling than the parents of native students did.

Countries and economies differ greatly in how many years of education were completed by the parents of native students, ranging from an average of 11 years in Mexico to 15 years in Canada. In order to facilitate the comparison of the various migrant student groups across countries, Figures 6.17 and 6.18 show the differences in years of parents' education between native students and several categories of immigrant students.

In 22 countries and economies, the parents of second-generation immigrant students were less educated than the parents of native students (Table 6.19, available on line). In CABA (Argentina), Costa Rica, Luxembourg and the United States, the differences was more than two years of schooling. By contrast, in 14 countries and economies, the parents of second-generation immigrant students completed more years of schooling than the parents of native students did. In Lebanon, the difference was 3.35 years and in Turkey the difference was 3.04 years, both in favour of the parents of second-generation immigrant students.

On average across OECD countries, there is no statistical difference between first- and second-generation immigrant students in the average number of years of education completed by their parents (Table 6.19). However, there are some differences across countries. In 14 countries and economies, the parents of second-generation immigrant students completed fewer years of education than the parents of firstgeneration immigrant students, while the opposite was true in only 3 countries and economies. In Costa Rica, Denmark, Germany, Malta and Qatar, the difference between the two groups of parents was more than one year of education.

Table 6.19 shows that in 43 of 60 countries and economies with available data, the parents of returning foreign-born students were more educated than the parents of native students. The opposite was true only in Hong Kong (China) and Macao (China). In Brazil, the Dominican Republic, Italy, Lebanon, Peru, Spain, Tunisia and Turkey, this difference amounted to more than 1.5 years of schooling. In 36 of 67 countries and economies with available data, the parents of native students of mixed heritage also completed more years of schooling than the parents of native students did. But the difference -0.43 year, on average across OECD countries - was smaller than that observed between returning foreign-born students and native students.

\section{Parents' occupational status}

In PISA, data on the occupation of students' parents are obtained from responses to open-ended questions. Responses are coded into four-digit International Standard Classification of Occupations (ISCO) codes and then mapped to the international socio-economic index of occupational status (ISEI). The information on each parent's occupational status is then used to produce an index of highest parental occupational status. A higher score on the index indicates a higher occupational status. A more detailed explanation of the construction of the index is available in the PISA 2015 Technical Report.

Figure 6.18 shows the average occupational status for parents of native students and first-generation immigrant students. On average across OECD countries, the parents of native students had a value of 52.5 on the index, while the parents of first-generation immigrant students had a value of 46.6 (a 6.9-point difference among countries with data for both groups of students, which corresponds approximately to the difference in occupational status between a senior official or legislator and a teaching professional). In 25 of 47 countries and economies with available data, the parents of native students had a higher occupational status than the parents of first-generation immigrant students. In CABA (Argentina), Greece, Hong Kong (China), Iceland, Italy, Slovenia and the United States, the difference was larger than 15 points, which corresponded to the average difference in occupational status between the parents of Romanian and Dutch students. In 10 countries and economies, the parents of first-generation immigrant students had higher occupational status than the parents of native students. 
Figure 6.18 - Index of parents' highest occupational status, by immigrant background

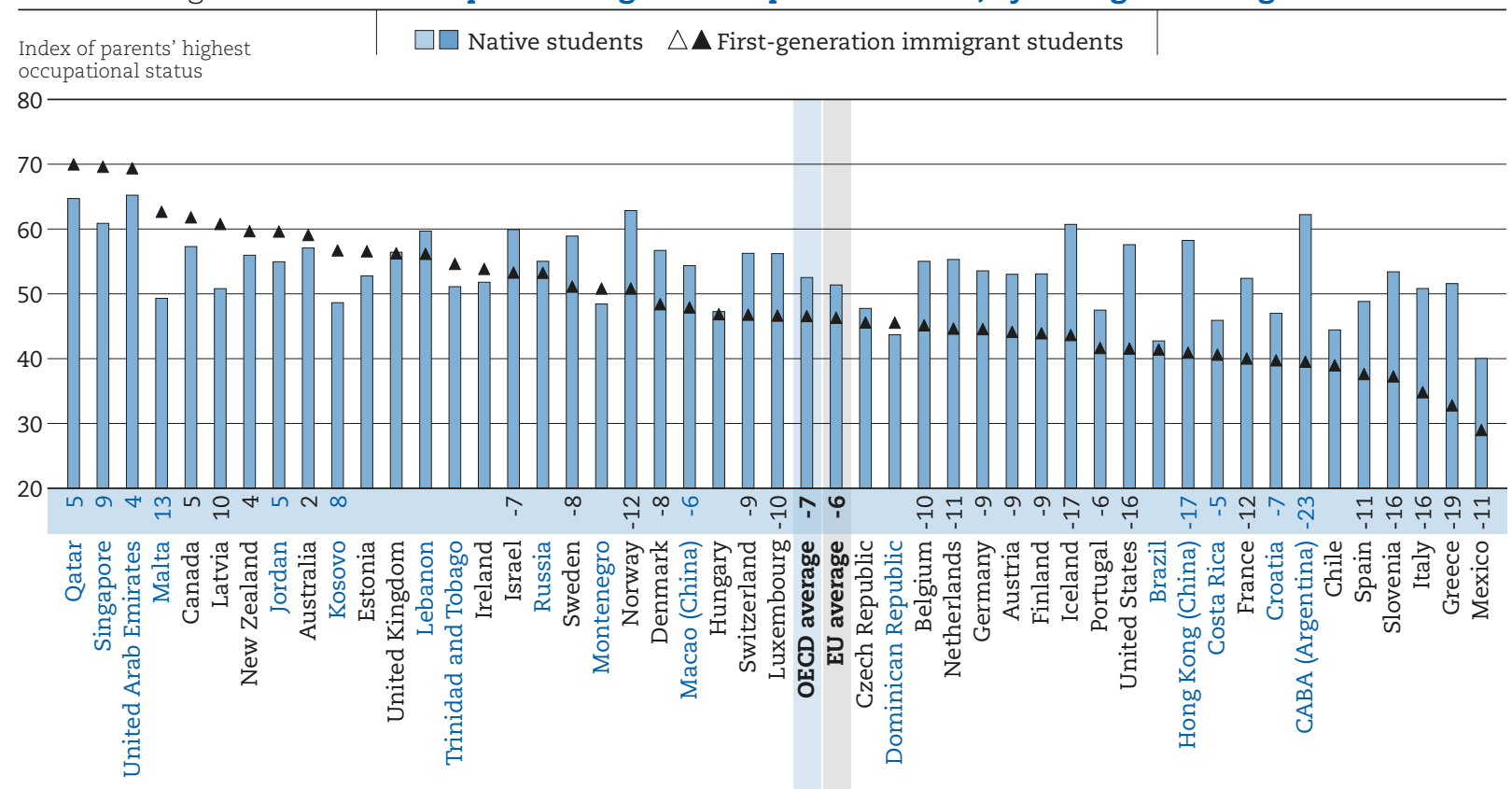

Notes: Only countries and economies with valid data for first-generation immigrant students are shown.

Statistically significant differences in the index of parents' highest occupational status between first-generation immigrant and native students are shown next to country/economy names. For the OECD and EU averages, this number refers only to the subset of countries/ economies with valid information for both groups of students.

Countries and economies are ranked in descending order of the index of parents' highest occupational status among first-generation immigrant students. Source: OECD, PISA 2015 Database, Table 6.20.

StatLink ants http://dx.doi.org/10.1787/888933682072

On average across OECD countries, the parents of second-generation immigrant students were 6.8 points below the parents of native students on the index of parents' highest occupational status (Table 6.20, available on line). In 28 of 54 countries and economies with available data, the highest occupational status of the parents of second-generation immigrants was lower than that of the parents of native students; in 17 countries, the difference was larger than 10 points. At the OECD average level, there was no statistical difference between first- and second-generation immigrant students in their parents' occupational status.

Table 6.20 also shows that in most countries and economies the parents of returning foreign-born students and native students with a mixed heritage tend to have higher occupational status than the parents of native students. On average across OECD countries with available data, the former group was 4.9 points and the latter group 1.6 points higher on the index than the parents of native students. In 28 countries and economies, the parents of returning foreign-born students had higher occupational status than the parents of native students. In Canada, Finland, Lithuania and Peru, the difference was larger than 10 points. Only in Hong Kong (China), Macao (China) and Portugal did the parents of native students have higher occupational status than the parents of returning foreign-born students. In 27 countries and economies, native parents had lower occupational status than the parents of native students of mixed heritage, while the opposite was true in 11 countries.

\section{Household possessions}

PISA 2015 asked students about the availability of 16 household items at home, including three countryspecific items that were seen as appropriate measures of family wealth in the country concerned. In addition, students reported the number of other possessions and books they had at home. Responses were coded into an index of household possessions whose scale was transformed so that zero represented an average OECD student and one was the standard deviation across equally weighted OECD countries. A more detailed explanation of the construction of the index is available in the PISA 2015 Technical Report. 
Figure 6.19 - Index of household possessions, by immigrant background

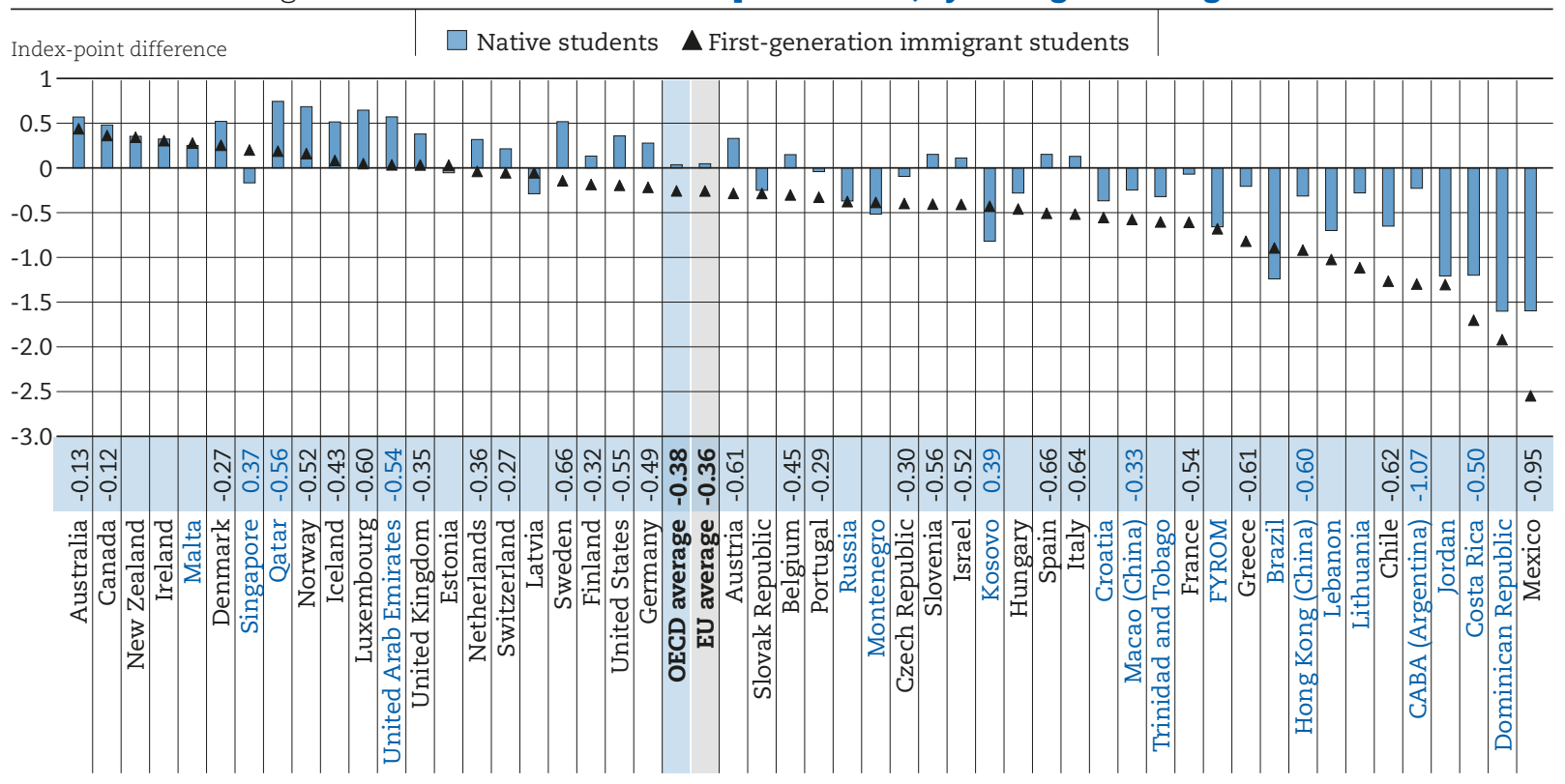

Notes: Only countries and economies with valid data for first-generation immigrant students are shown.

Statistically significant differences in the index of household possessions between first-generation immigrant and native students are shown next to country/economy names. For the OECD and EU averages, this number refers only to the subset of countries with valid data for both groups being compared.

Countries and economies are ranked in descending order of the index of household possessions among first-generation immigrant students.

Source: OECD, PISA 2015 Database, Table 6.21.

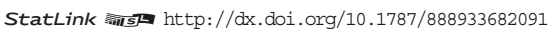

Figure 6.19 shows that in 31 of 50 countries and economies with available data, native students had more household possessions than first-generation immigrant students. On average across OECD countries, first-generation immigrant students were at -0.26 on the index, while native students were at 0.04 , a 0.38-point difference, on average across OECD countries with reliable estimates for both categories of students (approximately equal to the difference between the average PISA households in Switzerland and Greece). In 18 countries and economies, the difference was greater than 0.5 point (half a standard deviation), which corresponds approximately to the difference in number of household possessions between the average student in Luxembourg and the average student in Poland.

The figure reveals that countries differ widely in the household possessions reported by native and firstgeneration immigrant students. For example, in Costa Rica and Norway, the difference in the household possession index between the two groups of students was around half a standard deviation. But in Norway, native students were at 0.68 on the index and first-generation immigrant students were at 0.16 , while in Costa Rica, natives were at -1.20 on the index while first-generation immigrant students were at -1.70 .

On average across OECD countries, the household possession index of second-generation immigrant students was 0.23 point lower than that of native students in 2015 (Table 6.21, available on line). In Austria, CABA (Argentina), Costa Rica, the Dominican Republic, Greece, Luxembourg, Qatar, Thailand and the United Arab Emirates, it was more than 0.5 point lower. However, in 15 countries and economies, household wealth among second-generation immigrant students was higher than that among first-generation immigrant students. In Chile, France, Hungary, Italy, Jordan and Portugal, second-generation immigrant students were more than one-fourth of a standard deviation, on average, above first-generation immigrant students on the index.

Unlike foreign-born students of foreign-born parents, in most countries and economies, the families of foreign-born students with at least one native parent - i.e. returning foreign-born students - are wealthier than the families of native students (Table 6.21). On average across OECD countries, they were 
0.11 point higher than native students on the household possessions index. Native students of mixed heritage also show greater family wealth than native students, but the difference tends to be smaller than that between native students and returning foreign-born students. In Albania, Costa Rica, Denmark, the Dominican Republic, Finland, Georgia, Iceland, Israel, Latvia, Lithuania, Norway, Switzerland, and Trinidad and Tobago, the families of returning foreign-born students had more household possessions than the families of native students, while there was no statistically significant difference in household possessions between native students with mixed heritage and native students.

\section{Socio-economic status and the disadvantage of students with an immigrant background}

The previous section has shown that "socio-economic disadvantage" can stem from various sources, and not necessarily all of them simultaneously. Compared to native students, immigrant students (firstand second-generation immigrant students) tend to have lower economic and social status, but similar cultural status. In the vast majority of countries and economies with available data, the parents of immigrant students have fewer household possessions; in about half of the participating countries/ economies, they have lower occupational status; and in slightly less than half of the countries/economies, they had completed fewer years of education. In the United Kingdom, the parents of immigrant and native students completed the same number of years of education and hold the same occupational status; however, immigrant students have fewer household possessions (a difference in the index of one-third of a standard deviation). In Italy and Spain, years of parents' education are identical across immigrant backgrounds, but the economic and social status of immigrant and native students differ widely. In both countries, the difference in the index of household possessions between native and immigrant students is around two-thirds of a standard deviation, which corresponds to the difference between the average student in Norway and Portugal. When it comes to occupational status, differences are also well above OECD average: 14 points in Italy and 10 points in Spain.

Analyses of PISA data show that socio-economic status, as measured by the PISA index of economic, social and cultural status (ESCS), is a significant mediating factor in the relationship between immigrant background and academic performance. This section extends the previous analyses by looking at the combined effect of each component of the ESCS index and measuring the portion of the gaps between native and immigrant students that it explains.

The Blinder-Oaxaca counterfactual decomposition is used to investigate these effects. It was originally developed to study different labour market outcomes across groups, such as gender or race; but it can be used to investigate any group differences in outcomes. Starting with a set of relevant characteristics that differ across groups, the methodology can be applied to divide the group differences in outcomes into a portion explained by group characteristics (the endowment effect) and residual component. ${ }^{4}$

To investigate differences between native and immigrant students in academic outcomes, the decomposition is applied to the differences between those two groups in the percentage of students reaching baseline proficiency in all core PISA subjects (science, reading and mathematics). The explanatory variables used in the model - i.e. the "endowments" - are the three components of ESCS: parents' education, parents' occupational status and household possessions. Results are presented in Figure 6.20 below. Statistically significant differences in the outcome variable are shown next to country names; the bars represent the portion of the differences explained by each effect.

Results show that, while socio-economic status accounts for a remarkably large share of the differences in academic achievement between the two groups of students, the largest portion of the disparities remains unexplained in most countries and economies. On average across OECD countries, the endowment effect explains about one-third of the observed differences and the rest is unexplained. However, there are significant variations across countries and economies. In CABA (Argentina), Croatia, Hong Kong (China) and the United States, the only significant effect is the endowment effect - meaning that the difference between native and immigrant students is almost entirely explained by socio-economic differences across immigrant backgrounds. In Hong Kong (China) and the United States, the unexplained effect is small, while in CABA (Argentina) and Croatia it is larger but not statistically significant because of sample size issues. 
Figure 6.20 - Socio-economic status and academic outcomes Blinder-Oaxaca decomposition of the proportion of the immigrant-native gap in the percentage of students reaching baseline academic proficiency explained by "endowments"

(i.e. parents' education, parents' occupational status and household possessions), the unexplained proportion and the interaction between the two

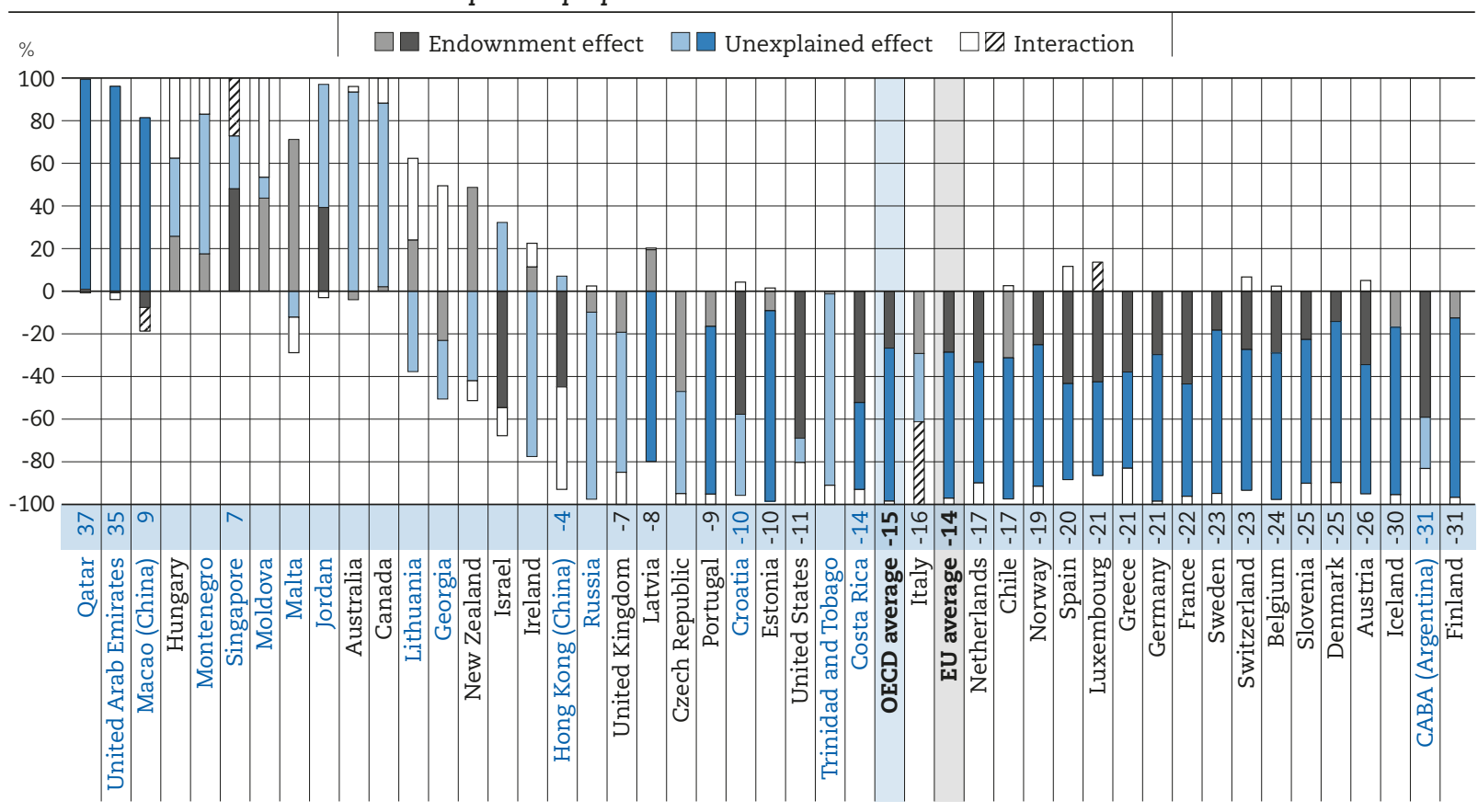

Notes: Statistically significant differences are marked in a darker tone or in a striped pattern.

Only countries/economies with valid data on the immigrant-native gap in attaining baseline academic proficiency are shown.

Statistically significant immigrant-native gaps in the percentage of students attaining baseline academic proficiency are reported next to country/economy names.

Countries and economies are ranked in descending order of the immigrant-native gap in the percentage of students attaining baseline proficiency.

Source: OECD, PISA 2015 Database, Table 6.22.

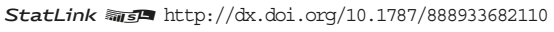

In Chile, Estonia, Finland, Iceland, Latvia, Portugal, Qatar and the United Arab Emirates, the only significant effect is the unexplained effect. In these countries and economies, the gaps are not determined by socioeconomic differences across immigrant backgrounds, so their source lies in other unobserved factors that are not considered in this model. In Austria, Belgium, Costa Rica, Denmark, France, Germany, Greece, Luxembourg, the Netherlands, Norway, Slovenia, Spain, Sweden and Switzerland, both the endowment and the unexplained effects are significant; however, the residual component is greater than the explained effect in all countries except Costa Rica.

These results clearly indicate that socio-economic status is an important determinant of the disadvantage that students with an immigrant background experience, but also that socio-economic status explains only part of the difference between native and immigrant students in the likelihood that students will reach the baseline level of proficiency in each of the three core PISA subjects - the school subjects in which proficiency is internationally recognised as essential if individuals are to lead productive and fulfilling lives. Furthermore, Figure 6.20 shows that the importance of socio-economic status as a determinant of differences in outcomes between native and immigrant students varies across countries. These results indicate that socio-economic status alone cannot explain either within-country or between-country variations in the gap in academic outcomes between native and immigrant students; other factors play an important role. The next chapters explain the "unexplained". 


\section{Notes}

1. Students who attain at least proficiency Level 2 in all three PISA core subjects - science, reading and mathematics.

2. Students who reported that they "agree" or "strongly agree" with the statement "I feel like I belong at school", and "disagree" or "strongly disagree" with the statement "I feel like an outsider at school".

3. Students who reported a life satisfaction of 7 or above on a scale from 0 to 10.

4. Students who reported that they "disagree" or "strongly disagree" with the statements "I often worry that it will be difficult for me taking a test" and "Even if I am well prepared for a test, I feel very anxious".

5. The Blinder-Oaxaca decomposition also produces a third term that represents the interaction between the endowment and the residual effects. Results on the interaction term are presented in the graph for the sake of clarity but they are not commented on because their interpretation is cumbersome and goes beyond the scope of this publication. For a more detailed explanation of how the Blinder-Oaxaca method works, please refer to http://www.stata-journal.com/article.html?article=st0151.

\section{References}

Agasisti, T. and J.M. Cordero (2017), “The determinants of repetition rates in Europe: Early skills or subsequent parents' help?", Journal of Policy Modeling, Vol. 39/1, pp. 129-146, http://dx.doi.org/10.1016/j.jpolmod.2016.07.002.

Almeida, S.J. (2014), "Retornados. Uma história de sucesso por contar" (The Returned. A success story worth telling), Público, www.publico.pt/temas/jornal/retornados-uma-historia-de-sucesso-por-contar-28145408.

Alto Comissariado pasa as Migracoes (2016), Indicadores de Integração de Imigrantes: Relatório Estatístico Anual 2016, Alto Comissariado para as Migrações (ACM, IP), Lisbon.

Baganha, M.I. and M.L. Fonseca (2004), New waves: migration from Eastern to Southern Europe, Luso-American Foundation, Lisbon, www.flad.pt/wp-content/uploads/2014/05/livro29.pdf.

Becchetti, L. and F. Pisani (2014), "Family economic well-being, and (class) relative wealth: An empirical analysis of life satisfaction of secondary school students in three Italian cities", Journal of Happiness Studies, Vol. 15/3, pp. 503-525, http://dx.doi.org/10.1007/s10902-013-9433-z.

Bianchi, S. et al. (2004), "Inequality in parental investment in child-rearing: Expenditures, time and health", in K. Neckerman (ed.), Social Inequality, Russell Sage Foundation, New York, pp. 189-219.

Bollen, K.A., J.L. Glanville and G. Stecklov (2001), "Socio-economic status and class in studies of fertility and health in developing countries", Annual Review of Sociology, Vol. 27/1, pp. 153-185.

Bradley, R.H. and R.F. Corwyn (2002), "Socioeconomic Status and Child Development", Annual review of Psychology, Vol. 53/1, pp. 371-399.

Carter, P.L. (2007), Keepin' It Real: School Success Beyond Black and White, Oxford University Press, New York.

Case, A., D. Lubotsky and C. Paxson (2002), "Economic status and health in childhood: The origins of the gradient", The American Economic Review, Vol. 92/5, pp. 1308-1334, http://doi.org/10.1257/000282802762024520.

CEPA (n.d.), Racial and Ethnic Achievement Gaps, Center for Education Policy Analysis, University of Stanford, http://cepa. stanford.edu/educational-opportunity-monitoring-project/achievement-gaps/race/.

Cerdeira, L. et al. (2016), "Brain drain and the disenchantment of being a higher education student in Portugal", Journal of Higher Education Policy and Management, Vol. 1, pp. 68-77, http://dx.doi.org/10.1080/1360080X.2015.1126892.

College Board (2016), 2016 College-Bound Seniors. Total Group Profile Report, The College Board, New York, https://reports. collegeboard.org/pdf/total-group-2016.pdf.

Currie, C. et al. (eds.) (2012), Social Determinants of Health and Well-Being among Young People - Health Behaviour in School-Aged Children (HBSC) Study: International Report from the 2009/2010 Survey, World Health Organization Regional Office for Europe, Copenhagen.

David, I. (2015), “The retornados: trauma and displacement in post-revolution Portugal”, Ethnicity Studies, Issue 2, pp. 114-130, www.ces.1t/wp-content/uploads/2016/01/7-Etn_St_David_The-retornados.pdf.

Davis, T.M. (2014), "School choice and segregation: 'Tracking' racial equity in magnet schools", Education and Urban Society, Vol. 46/4, pp. 399-433, http://doi.org/10.1177/0013124512448672.

Diener, E., S. Oishi and R.E. Lucas (2003), "Personality, culture, and subjective well-being", Annual Review of Psychology, Vol. 54, pp. 403-425, http://doi.org/10.1146/annurev.psych.54.101601.145056. 
Feinstein, L., K. Duckworth and R. Sabates (2008), Education and the Family: Passing Success across the Generations, Routledge, London.

Goodman, E. et al. (2001), "Adolescents' perceptions of social status: Development and evaluation of a new indicator", Pediatrics, Vol. 108/2, pp. e31-e38.

Greenwald, R., L.V. Hedges and R.D. Laine (1996), "The effect of school resources on student achievement”, Review of Educational Research, Vol. 66/3, pp. 361-396, http://dx.doi.org/10.3102/00346543066003361.

Hauser, R. M. and M. Huang (1997), "Verbal ability and socioeconomic success: a trend analysis", Social Science Research, Vol. 26/3, pp. 331-376, https://doi.org/10.1006/ssre.1997.0604.

Hsin, A. and Yu Xie (2014), "Explaining Asian Americans' academic advantage over whites", Proceedings of the National Academy of Sciences, Vol. 111/23, pp. 8416-8421, https://doi.org/10.1073/pnas.1406402111.

Hudson, E. (2013), "Does relative material wealth matter for child and adolescent life satisfaction?", The Journal of SocioEconomics,Vol. 46, pp. 38-47, https://doi.org/10.1016/j.socec.2013.06.007.

Jæger, M.M. and R. Breen (2016), "A dynamic model of cultural reproduction”, American Journal of Sociology, Vol. 121/4, pp. 1079-1115, http://doi.org/10.1086/684012.

Justino, D. (2016), Emigration from Portugal: Old wine in new bottles?, Migration Policy Institute, Washington, DC, https:// www.migrationpolicy.org/research/emigration-portugal-old-wine-new-bottles.

Lee, J. and M. Zhou (2017), "Why class matters less for Asian-American academic achievement", Journal of Ethnic and Migration Studies, Vol. 43/14, pp. 2316-2330, https://doi.org/10.1080/1369183X.2017.1315851.

Liu, A. and Yu Xie (2016), "Why do Asian Americans academically outperform whites? The cultural explanation revisited", Social Science Research, Vol. 58, pp. 210-226, https://doi.org/10.1016/j.ssresearch.2016.03.004.

Marks, G. (2006), "Accounting for immigrant non-immigrant differences in reading and mathematics in twenty countries", Ethnic and Racial Studies, Vol. 28/5, pp. 925-946, https://doi.org/10.1080/01419870500158943.

Martin, J. (1998), The Migrant Presence, George Allen and Unwin, Sydney.

Montt, G. (2012), Socioeconomic School Composition Effects on Student Outcomes, Doctoral dissertation, University of Notre Dame, Notre Dame, IN, https://curate.nd.edu/show/sn009w05g5g.

Neff, D.F. (2007), "Subjective well-being, poverty and ethnicity in South Africa: Insights from an exploratory analysis", Social Indicators Research, Vol. 80/2, pp. 313-341, http://dx.doi.org/10.1007/s11205-005-5920-x.

Noguera, P.A. (2003), "The trouble with black boys: The role and influence of environmental and cultural factors on the academic performance of African American males”, Urban Education, Vol 38/4, pp. 431-459, http://dx.doi.org/10.1177/004 2085903038004005

OECD (forthcoming), PISA 2015 Technical Report, OECD Publishing, Paris.

OECD (2017), PISA 2015 Results: Students' Well-being, OECD Publishing, Paris, http://dx.doi.org/10.1787/9789264273856-en.

OECD (2016a), Skills Matter: Further Results from the Survey of Adult Skills, OECD Publishing, Paris, http://dx.doi.org/10.1787/ 9789264258051-en.

OECD (2016b), Equations and Inequalities: Making Mathematics Accessible to All, OECD Publishing, Paris, http://dx.doi. org/10.1787/9789264258495-en.

OECD (2012), PISA 2012 Results: Excellence through Equity: Giving Every Student the Chance to Succeed, OECD Publications, Paris, http://dx.doi.org/10.1787/9789264201132-en.

Oliveira, C.R. and V. Fonseca (2013), "Highly skilled immigrants in Portugal: analysing policy developments and its impacts with a typology”, Revista Migrações, n. 11, pp. 79-117, www.om.acm.gov.pt/documents/58428/183863/Migracoes11pp79 117. pdf/9bd500f6-0ef7-4ac1-a5b7-7a93770c500a.

Pajares, F. and T.C. Urdan (eds.) (2006), Self-Efficacy Beliefs of Adolescents, Information Age Publishing, Greenwich.

Pires, R.P. (2003), Migrações e integração (Migration and Integration), Celta Editora, Oeiras.

Portes, A. and D. MacLeod (1996), "Educational progress of children of immigrants: the roles of class, ethnicity and school context", Sociology of Education, Vol. 69/4, pp. 255-275

Rivkin, S.G., E.A. Hanushek and J.F. Kain (2005), “Teachers, schools, and academic achievement”, Econometrica, Vol. 73/2, pp. 417-458, http://dx.doi.org/10.1111/j.1468-0262.2005.00584.X. 
Rocha-Trindade, M. B. (1995), “The repatriation of Portuguese from Africa”, in R. Cohen (ed.), The Cambridge Survey of World Migration, University of Cambridge, Cambridge, pp. 337-341.

Saegert, S., J.P. Thompson and M.R. Warren (eds.) (2001), Social Capital and Poor Communities, Russell Sage Foundation, New York.

Schmidt, W.H. et al. (2015), "The role of schooling in perpetuating educational inequality: an international perspective", Educational Researcher, Vol. 44/7, pp. 371-386, http://dx.doi.org/10.3102/0013189X15603982.

Schofer, E. and Meyer, J.W. (2005) "The worldwide expansion of higher education in the twentieth century", American Sociological Review, Vol 70/6, pp. 898-920, http://dx.doi.org/10.1177/000312240507000602.

Stewart, E.B., E.A. Stewart and R.L. Simons (2007), "The effect of neighborhood context on the college aspirations of African American adolescents", American Educational Research Journal, Vol. 44/4, pp. 896-919, http://dx.doi.org/10.3102/ $\underline{0002831207308637 .}$.

Sweeting, H. and K. Hunt (2014), "Adolescent socio-economic and school-based social status, health and well-being", Social Science and Medicine, Vol. 121, pp. 39-47, http://dx.doi.org/10.1016/j.socscimed.2014.09.037.

Tucker, K.L. et al. (2006), "Testing for measurement invariance in the satisfaction with life scale: A comparison of Russians and North Americans”, Social Indicators Research, Vol. 78/2, pp. 341-360, http://dx.doi.org/10.1007/s11205-005-1037-5.

van de Werfhorst, H.G. and J.J. Mijs (2010), "Achievement inequality and the institutional structure of educational systems: A comparative perspective”, Annual Review of Sociology, Vol. 36, pp. 407-428, http://dx.doi.org/10.1146/annurev. soc.012809.102538.

Watkins, M., C. Ho and R. Butler (2017), "Asian migration and education cultures in the Anglo-sphere”, Journal of Ethnic and Migration Studies, Vol. 43/14, pp. 2283-2299, https://doi.org/10.1080/1369183X.2017.1315849.

Zong, J. and J. Batalova (2016), "Asian Immigrants in the United States”, Migration Policy Institute, Washington, DC, www. migrationpolicy.org/article/asian-immigrants-united-states. 



\section{Chapter 7 \\ How schools and education policy support or undermine student resilience}

This chapter examines the association between school policies and practices and the likelihood that students with an immigrant background attain baseline academic proficiency, and report positive social and emotional outcomes. It discusses how the learning environment, including the disciplinary climate in class, student truancy and bullying, the quantity and quality of school resources, and school policies, including assessment policies and grade repetition, are related to immigrant students' academic, social and emotional, and motivational resilience.

\section{Notes regarding Cyprus}

Note by Turkey: The information in this document with reference to "Cyprus" relates to the southern part of the Island. There is no single authority representing both Turkish and Greek Cypriot people on the Island. Turkey recognises the Turkish Republic of Northern Cyprus (TRNC). Until a lasting and equitable solution is found within the context of the United Nations, Turkey shall preserve its position concerning the "Cyprus issue".

Note by all the European Union Member States of the OECD and the European Union: The Republic of Cyprus is recognised by all members of the United Nations with the exception of Turkey. The information in this document relates to the area under the effective control of the Government of the Republic of Cyprus.

\section{Note regarding data from Israel}

The statistical data for Israel are supplied by and under the responsibility of the relevant Israeli authorities. The use of such data by the OECD is without prejudice to the status of the Golan Heights, East Jerusalem and Israeli settlements in the West Bank under the terms of international law. 


\section{What the data tell us}

- On average across countries that distributed the PISA parent questionnaire, the parents of immigrant students are four percentage points more likely than native parents to choose a school based on the availability of financial aid and three percentage points less likely to choose a school based on the school climate. However, school climate is found to have a strong influence on the performance of immigrant students.

- On average across OECD and EU countries, in schools with a higher concentration of immigrant students the academic performance and social and emotional well-being of students tends to be lower. However, in almost every country and on average across OECD and EU countries, once the schools' socio-economic profile is accounted for, these differences disappear.

- The disciplinary climate at school tends to be worse and truancy more prevalent in the schools attended by the average immigrant student, and these differences are related to differences between immigrant and native students in academic performance and well-being.

- Immigrant students are more likely than native students to be victims of bullying and perceived unfair treatment by teachers, which contribute to differences between native and immigrant students in academic performance and well-being.

- On average across OECD countries, immigrant students are four percentage points more likely to have repeated a grade (six percentage points more likely across EU countries) and four percentage points less likely to be enrolled in a vocational programme (four percentage points less likely across EU countries) than native students with similar PISA scores.

Previous chapters identified some key individual and family-level characteristics that are associated with students' vulnerability to migration-related adversity. However important personal characteristics are in shaping the likelihood that students with an immigrant background will attain high levels of academic achievement, and social and emotional well-being, environmental factors also play a role. Education policies can ensure that the school environments to which immigrant students are exposed are conducive to positive academic, social, emotional and motivational outcomes (Bernard, 1995; Kirby and Fraser, 1997; Masten, 1994; Werner and Smith, 1992).

As Chapter 2 of this report argues, examining why some students with an immigrant background are academically, socially, or emotionally resilient while others are vulnerable to the often adverse circumstances of migration requires the investigation of the multilevel and multi-layered interplay between risk and protective factors at the individual, family, school and system levels. While resilience, in its various dimensions, is an individual attribute, because it is malleable and dependent on context, its promotion can be a goal of education policy and can be fostered by policy makers, school principals and teachers by shaping the schooling environment that immigrant students experience. This chapter aims to highlight the unique role schools and educators can play in promoting students' academic and socioemotional resilience, and how education policy can ensure that students with an immigrant background attend schools that meet their needs.

Since school is the place where students spend most of their time and where most learning takes place, what happens in schools has a potentially disproportionate effect on children's academic outcomes and general well-being. The quality of the school experience is the product of several factors, including the composition of the student body, how many and which resources are available for students, and the policies and practices that teachers, school principals and education systems as a whole put in place. This chapter examines the association between what happens in school and the likelihood that students with an immigrant background are academically, socially and emotionally resilient, and how education policies can promote a school environment that enables immigrant students to thrive. 
Table 7.1 - Snapshot of school-level risk factors for immigrant students - 1

\begin{tabular}{|c|c|c|c|c|c|}
\hline & \multicolumn{5}{|c|}{$\begin{array}{l}\text { Countries/economices with values above the OECD average } \\
\text { Countries/economices with values not significantly different from the OECD average } \\
\text { Countries/economices with values below the OECD average }\end{array}$} \\
\hline & $\begin{array}{l}\text { Relative risk } \\
\text { for immigrant students } \\
\text { of being frequently } \\
\text { bullied }\end{array}$ & $\begin{array}{l}\text { Relative risk } \\
\text { for immigrant students } \\
\text { of reporting to have } \\
\text { been frequently unfairly } \\
\text { treated by their teachers }\end{array}$ & $\begin{array}{l}\text { Increased likelihood } \\
\text { of immigrant students } \\
\text { having received } \\
\text { freguent feedback from } \\
\text { their science teacher } \\
\text { compared to native } \\
\text { students, accounting } \\
\text { for science performance }\end{array}$ & $\begin{array}{l}\text { Increased likelihood } \\
\text { of immigrant students } \\
\text { having repeated a grade } \\
\text { compared to native } \\
\text { students, accounting } \\
\text { for academic } \\
\text { performance and } \\
\text { socio-economic status }\end{array}$ & $\begin{array}{l}\text { Increased likelihood } \\
\text { of immigrant students } \\
\text { attending vocational } \\
\text { programmes compared } \\
\text { to native students, } \\
\text { accounting for academic } \\
\text { performance and socio- } \\
\text { economic status }\end{array}$ \\
\hline OECD average & 1.19 & 1.14 & 4.64 & 4.37 & -3.58 \\
\hline EU average & 1.23 & 1.13 & 4.25 & 5.68 & -4.46 \\
\hline Colombia & 2.31 & 1.07 & -9.61 & 12.16 & -1.06 \\
\hline Slovak Republic & 2.06 & 1.18 & 8.56 & 19.44 & -0.49 \\
\hline Brazil & 1.97 & 1.44 & -6.54 & 10.08 & -1.46 \\
\hline Uruguay & 1.79 & 1.14 & $c$ & 1.61 & -1.64 \\
\hline Tunisia & 1.75 & 1.26 & 4.82 & -1.09 & 0 \\
\hline B-S-J-G (China) & 1.71 & 0.89 & -4.6 & 14.67 & -8.54 \\
\hline Mexico & 1.66 & 1.57 & 2.78 & 12.52 & 0.72 \\
\hline Iceland & 1.58 & 1.18 & -2.29 & 3.23 & 0 \\
\hline$\frac{\text { Icelana }}{\text { Czech Republic }}$ & $\begin{array}{l}1.58 \\
1.52 \\
\end{array}$ & 1.18 & $\frac{-2.29}{2.27}$ & 9.23 & -6.76 \\
\hline Dominican Republic & 1.49 & 1.16 & 5.93 & $\frac{01}{4.87}$ & $\begin{array}{l}-0.10 \\
-0.76\end{array}$ \\
\hline Luxembourg & 1.46 & 1.11 & 9.12 & 0.47 & -5.14 \\
\hline Greece & 1.43 & 1.06 & 1.51 & 7.71 & -3.07 \\
\hline Estonia & 1.42 & 1.06 & 10.57 & -0.71 & 0.98 \\
\hline Spain & 1.4 & 1.02 & -1.22 & 7.62 & -0.13 \\
\hline Chile & 1.39 & 1.07 & 10.88 & -1.11 & -0.66 \\
\hline Peru & 1.37 & 1 & $\mathrm{c}$ & 35.29 & c \\
\hline Thailand & 1.36 & 1.08 & -4.75 & 16.73 & 16.18 \\
\hline Montenegro & 1.34 & 1.03 & -6.09 & 5.95 & 5.18 \\
\hline Turkey & 1.33 & 1.12 & -2.8 & 10.9 & 3.17 \\
\hline $\begin{array}{l}\text { Iureland } \\
\text { Irend }\end{array}$ & $\begin{array}{l}1.33 \\
1.32\end{array}$ & 1.1 & 3.34 & 3.67 & $\begin{array}{l}3.17 \\
-0.5 \\
\end{array}$ \\
\hline Lithuania & 1.3 & 1.02 & 14.23 & 5.45 & 1.5 \\
\hline Switzerland & 1.29 & 1.26 & 4.8 & 6.56 & -5.54 \\
\hline Bulgaria & 1.28 & 0.96 & -3.15 & 14.02 & -3.75 \\
\hline Croatia & 1.27 & 1.13 & -2.21 & $\frac{14.02}{1.08}$ & -1.74 \\
\hline Portugal & 1.25 & 1.14 & 4.35 & 7.23 & -2.93 \\
\hline Latvia & 1.19 & 1.08 & -0.72 & -0.25 & -0.79 \\
\hline Germany & 1.18 & 1.24 & 4.9 & 2.16 & -1.8 \\
\hline France & 1.14 & 1.11 & 8.67 & -5.62 & -10.45 \\
\hline Finland & 1.13 & 1.05 & 18.17 & 5.51 & \\
\hline Cyprus* & 1.12 & 1.07 & -1.27 & 9.07 & -7.62 \\
\hline Slovenia & 1.09 & 1.09 & 6.15 & 4 & -13.46 \\
\hline $\begin{array}{l}\text { Slovenia } \\
\text { Belgium }\end{array}$ & 1.08 & 1.09 & 8.13 & $\begin{array}{r}4 \\
4.43 \\
\end{array}$ & $\frac{-13.46}{-24.42}$ \\
\hline Hungary & 1.05 & 1.04 & -5.29 & 4.16 & -2.14 \\
\hline United Kingdom & 1 & 1.1 & 1.71 & 3.46 & -0.65 \\
\hline Russia & 1 & 0.99 & 0.39 & 1.42 & 4.63 \\
\hline Austria & 1 & 1.26 & 3.47 & 9.68 & -19.23 \\
\hline Sweden & 0.99 & 1.31 & 8.88 & 7.98 & -0.09 \\
\hline Singapore & 0.98 & 0.93 & 7.37 & 8.25 & c \\
\hline Denmark & 0.98 & 1.23 & 6.1 & 3.93 & $c$ \\
\hline United Arab Emirates & 0.96 & 1 & 2.91 & 0.83 & -8.22 \\
\hline Qatar & 0.95 & 0.93 & 4.54 & -1.33 & $\mathrm{c}$ \\
\hline Hong Kong (China) & 0.93 & 1.02 & $\frac{1.47}{-1.44}$ & 9.02 & c \\
\hline Norway & 0.93 & 0.98 & 12.8 & $\mathrm{~m}$ & $c$ \\
\hline Japan & 0.92 & 1.19 & $\begin{array}{l}14.0 \\
14.12\end{array}$ & $\mathrm{~m}$ & $\begin{array}{r}-2 \\
-8.37\end{array}$ \\
\hline Netherlands & 0.9 & 1.41 & 1.39 & 1.63 & -11.04 \\
\hline Canada & 0.84 & $\mathrm{~m}$ & 1.16 & 0.03 & c \\
\hline Costa Rica & 0.83 & 1.02 & 11.35 & 15.32 & -3.87 \\
\hline United States & 0.81 & 1.05 & 4.59 & -1.11 & $c$ \\
\hline Macao (China) & 0.78 & 1 & 6.26 & -5.21 & -0.07 \\
\hline Australia & 0.75 & 0.95 & 3.54 & 2.26 & -3.02 \\
\hline New Zealand & 0.74 & 0.91 & 4.19 & -0.2 & $c$ \\
\hline Albania & $\mathrm{m}$ & $\mathrm{m}$ & -13.66 & -0.33 & 2 \\
\hline Algeria & $\mathrm{m}$ & $\mathrm{m}$ & 6.55 & 2.26 & 3.78 \\
\hline CABA (Argentina) & $\mathrm{m}$ & $\mathrm{m}$ & 7.77 & -1.62 & 10.55 \\
\hline $\begin{array}{l}\text { CABA (Argentma) } \\
\text { FYROM }\end{array}$ & $\frac{m}{m}$ & $\frac{m}{m}$ & -14.62 & $\frac{-1.62}{15.65}$ & $\frac{10.55}{-3.06}$ \\
\hline Georgia & $\mathrm{m}$ & $\mathrm{m}$ & 5.23 & 2.81 & 0.09 \\
\hline Israel & $\mathrm{m}$ & $\mathrm{m}$ & -4.89 & -4.56 & $\frac{\mathrm{c} c \mathrm{c}}{\mathrm{c}}$ \\
\hline Italy & $\mathrm{m}$ & $\mathrm{m}$ & $\begin{aligned}-4.03 \\
4.02 \\
\end{aligned}$ & 10.74 & -2.16 \\
\hline Jordan & $\mathrm{m}$ & $\mathrm{m}$ & -0.74 & 1.34 & $\mathrm{c}$ \\
\hline Kosovo & $\mathrm{m}$ & $\mathrm{m}$ & -1.91 & 2.62 & -21.94 \\
\hline Lebanon & $\mathrm{m}$ & $\mathrm{m}$ & -1 & 12.06 & c \\
\hline Malta & $\mathrm{m}$ & $\mathrm{m}$ & -1.19 & 11.07 & c \\
\hline Moldova & $\mathrm{m}$ & $\mathrm{m}$ & 4.8 & 7.72 & c \\
\hline Trinidad and Tobago & $\mathrm{m}$ & $\mathrm{m}$ & 0.59 & 7.65 & c \\
\hline
\end{tabular}

* See note at the beginning of this Chapter.

Notes: Only countries/economies with valid data for at least one outcome are presented.

Students who reported being frequently bullied are those who answered "a few times a month" "once a week or more" to at least one of the questions about how often, during the previous 12 months: "Other students left me out of things on purpose"; "Other students made fun of me"; "I was threatened by other students"; "Other students took away or destroyed things that belong to me"; "I got hit or pushed around by other students"; and "Other students spread nasty rumours about me".

Students who reported frequent unfair treatment by their teachers are those who answered "a few times a month" or "once a week or more" to at least one of the questions about how often, during the previous 12 months: "Teachers called me less often than they called on other students"; "Teachers graded me harder than they graded other students"; "Teachers gave me the impression that they think I am less smart than I really am"; "Teachers disciplined me more harshly than other students"; "Teachers ridiculed me in front of others"; and "Teachers said something insulting me in front of others".

Students who reported receiving frequent feedback from their science teacher are those who answered "many lessons" or "every lesson or almost every lesson" to at least one of the statements: "The teacher tells me how I am performing in this course"; "The teacher gives me feedback on my strength in this subject"; "The teacher tells me in which areas I can improve"; "The teacher tells me how I can improve my performance"; "The teacher advises me on how to reach my learning goals"

Source: OECD, PISA 2015 Database, Tables 7.22, 7.34 and 7.37.

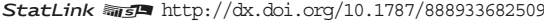


Table 7.2 - Snapshot of school-level risk factors for immigrant students - 2

\begin{tabular}{|c|c|c|c|c|}
\hline & \multicolumn{4}{|c|}{$\begin{array}{l}\text { Countries/economices with values above the OECD average } \\
\text { Countries/economices with values not significantly different from the OECD average } \\
\text { Countries/economices with values below the OECD average }\end{array}$} \\
\hline & $\begin{array}{l}\text { Concentration of students } \\
\text { with an immigrant } \\
\text { background in schools } \\
\text { (difference between observed } \\
\text { and maximal potential } \\
\text { concentration) }\end{array}$ & $\begin{array}{c}\text { Relative risk } \\
\text { for immigrant students } \\
\text { of being in urban schools }\end{array}$ & $\begin{array}{l}\text { Relative risk } \\
\text { for immigrant students } \\
\text { of being in a school with } \\
\text { levels of disciplinary climate } \\
\text { below the OECD average }\end{array}$ & $\begin{array}{l}\text { Number of after-school } \\
\text { activities available in schools } \\
\text { attended by the average } \\
\text { immigrant student compared } \\
\text { to the number available } \\
\text { in schools attended } \\
\text { by the average native student }\end{array}$ \\
\hline OECD average & -26.28 & 1.65 & 1.22 & -0.15 \\
\hline EU average & 25.22 & 1.63 & 1.09 & -0.27 \\
\hline United Kingdom & 40.69 & 2.74 & 0.7 & -0.6 \\
\hline Singapore & 39.26 & 1 & 0.67 & 0.35 \\
\hline Kosovo & 38.17 & 1.1 & 2.3 & 0.58 \\
\hline Italy & 36.1 & 1.24 & 1.25 & -0.18 \\
\hline Ireland & 35.93 & 1.15 & 0.86 & 0.16 \\
\hline Denmark & 34.36 & 2.73 & 1.15 & -0.47 \\
\hline Slovenia & 32.85 & 1.64 & 1.26 & -0.47 \\
\hline Cyprus* & 32.68 & 1.2 & 0.94 & -0.43 \\
\hline Australia & 32.47 & 1.54 & 0.87 & 0.07 \\
\hline Montenegro & 31.83 & 0.95 & 1.38 & 0.66 \\
\hline Jordan & 31.79 & 1.64 & 1.01 & 0.52 \\
\hline Croatia & 31.56 & 1.02 & 1.19 & -0.33 \\
\hline New Zealand & 31.38 & 1.67 & 0.83 & 0.21 \\
\hline Switzerland & 31.27 & 1.65 & 1.13 & -0.04 \\
\hline Canada & 31.17 & 2.06 & 0.82 & 0.71 \\
\hline Israel & 30.82 & 1.58 & 1.06 & 0.3 \\
\hline Portugal & 30.46 & 1.09 & 1.23 & -0.76 \\
\hline Hong Kong (China) & 30.27 & 1 & 1.28 & -0.61 \\
\hline Luxembourg & 28.88 & 1.07 & 1.05 & -0.48 \\
\hline Austria & 28.66 & 2.04 & 1.49 & 0.09 \\
\hline Sweden & 28.62 & 1.77 & 1.06 & -0.25 \\
\hline Belgium & 27.68 & 2.76 & 0.95 & -0.5 \\
\hline CABA (Argentina) & 26.9 & 0.98 & 1.14 & -0.44 \\
\hline Greece & 26.26 & 1.13 & 1.05 & -0.4 \\
\hline Germany & 25.8 & 1.94 & 1.36 & -0.51 \\
\hline United States & 25.17 & 1.56 & 0.98 & -0.06 \\
\hline Norway & 24.98 & 2.32 & 1.16 & 0.2 \\
\hline Malta & 24.67 & 1 & 0.9 & -0.88 \\
\hline Russia & 24.62 & 1.04 & 1.59 & 0.02 \\
\hline France & 23.39 & 1.63 & 1.09 & -0.12 \\
\hline Costa Rica & 23.35 & 1.31 & 1.04 & -0.13 \\
\hline Netherlands & 23.19 & 2.71 & 1.15 & 0.07 \\
\hline Trinidad and Tobago & 22.37 & 1 & 1.19 & 0.3 \\
\hline Spain & 22.12 & 1.17 & 1.18 & -0.23 \\
\hline Qatar & 21.26 & 1.22 & 0.51 & 0.91 \\
\hline Iceland & 21.02 & 1.59 & 1.12 & -0.01 \\
\hline Lebanon & 20.73 & 1.14 & 1.14 & -0.51 \\
\hline Latvia & 19.98 & 1.58 & 0.97 & 0.31 \\
\hline Macao (China) & 18.78 & 1 & 0.61 & -0.09 \\
\hline Estonia & 18.59 & 1.68 & 0.98 & -0.65 \\
\hline Lithuania & 17.66 & 1.65 & 1.03 & -0.03 \\
\hline Czech Republic & 15.41 & 1.95 & 1.13 & -0.23 \\
\hline Finland & 15.11 & 1.9 & 0.93 & 0.35 \\
\hline Chinese Taipei & 13.52 & c & c & c \\
\hline Moldova & 13.29 & 2.46 & 0.92 & -0.14 \\
\hline FYROM & 12.55 & 1.38 & 1.59 & -1.01 \\
\hline United Arab Emirates & 11.23 & 1.52 & 0.73 & 1.24 \\
\hline Slovak Republic & 9.83 & 0.98 & 1.28 & -0.17 \\
\hline Hungary & 9.8 & 1.47 & 0.92 & 0.4 \\
\hline Tunisia & 9.57 & 0.7 & 1.03 & 0.23 \\
\hline Georgia & 7.77 & 1 & 1.7 & -0.24 \\
\hline Chile & $\mathrm{m}$ & 1.1 & 1.26 & -0.11 \\
\hline Japan & $\mathrm{m}$ & 0.91 & 5.86 & -0.99 \\
\hline Mexico & $\mathrm{m}$ & 0.74 & 0.98 & -1.14 \\
\hline Turkey & $\mathrm{m}$ & 1.38 & 1.16 & 0.56 \\
\hline Albania & $\mathrm{m}$ & 0.42 & 1 & -0.34 \\
\hline Algeria & $\mathrm{m}$ & 0.47 & 0.93 & 0.54 \\
\hline Brazil & $\mathrm{m}$ & 1.08 & 1.17 & -0.81 \\
\hline B-S-J-G (China) & $\mathrm{m}$ & c & 1.93 & -0.47 \\
\hline Bulgaria & $\mathrm{m}$ & 1.04 & 1.07 & -0.82 \\
\hline Colombia & $\mathrm{m}$ & 1.37 & 1.28 & -0.21 \\
\hline Dominican Republic & $\mathrm{m}$ & 0.86 & 1.44 & -0.57 \\
\hline Peru & $\mathrm{m}$ & 1.78 & 1.3 & 0.04 \\
\hline Thailand & $\mathrm{m}$ & 0.65 & 1.8 & 0.48 \\
\hline Uruguay & $\mathrm{m}$ & 1.4 & 1.14 & 0.23 \\
\hline
\end{tabular}

Uruguay

* See note at the beginning of this Chapter.

Notes: Only countries/economies with valid data for at least one outcome are presented.

Urban schools are those in communities of more than 100000 people, as reported by school principals.

Disciplinary climate is measured through the PISA index of disciplinary climate. The school value is the average of individual students' reports.

Source: OECD, PISA 2015 Database, Tables 7.7 and 7.29.

StatLink Ants http://dx.doi.org/10.1787/888933682528 
The likelihood that schools serving students with an immigrant background will have adequate material and human resources depend both on the amount invested in the education system and the extent to which education policies target disadvantaged student populations. This means that students with an immigrant background can encounter very different learning environments depending on the overall amount spent on education, how expenditures are allocated, and how well resources are used to create environments that benefit all learners.

Material resources include school infrastructure and equipment; human resources encompass the quantity and quality of education staff, and how staff members behave towards students; time resources indicate the amount of learning time and any extracurricular activities that are available. While education policies can shape the intended learning time, the quality of the teaching staff determines how much of the intended learning time is, in fact, dedicated to learning. The quality of infrastructure and equipment determines the availability of extracurricular activities and the effectiveness of learning time.

Figure 7.1 - How education policies can promote the resilience of students with an immigrant background

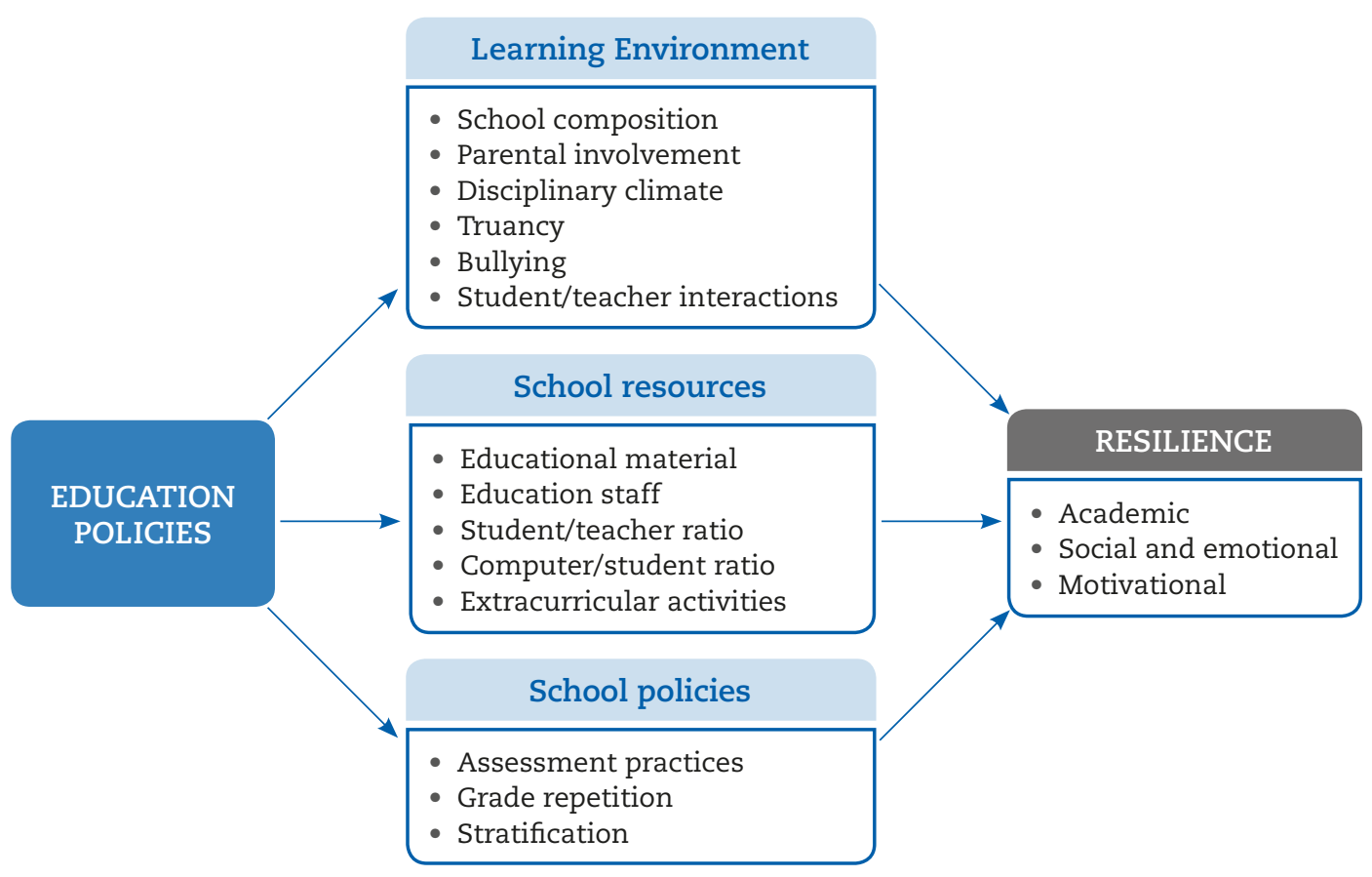

While evidence suggests that lack of material resources can have adverse effects on learning (Schneider, 2002; Uline and Tschannen-Moran, 2008), research shows that after a certain threshold is reached, it is not the quantity of resources, but rather how well resources are spent that determines learning outcomes (Burtless, 1996; Nannyonjo, 2007; Nicoletti and Rabe, 2012; OECD, 2013, 2016a; Suryadarma, 2012; Wei Clifton and Roberts, 2011). These results indicate that the focus of schools and policy makers should be on identifying factors that make a difference to the learning and well-being outcomes of immigrant students, and targeting resources to ensure that more of what helps these students flourish is offered to them. The academic achievement, and social and emotional well-being of immigrant students is inevitably determined by the quality of school resources, how effectively they are used, and how equitably they are distributed across schools, rather than their sheer quantity (Gamoran, Secada and Marrett, 2000; OECD, 2016a).

How resources are allocated can have particularly large effects on the outcomes of first- and secondgeneration immigrant students because these students tend to be more socio-economically disadvantaged than students without an immigrant background, students of mixed heritage and returning foreign-born students (see Chapter 6). They also tend to be concentrated in specific residential areas. In some countries 
and economies, residential segregation based on income, and immigrant and ethnic background translates into differences in the quantity and quality of educational resources (Reardon and Owens, 2014), with significant consequences on students' opportunities to receive high-quality instruction (Roemer, 1998).

The chapter first examines if and to what extent different school environments are associated with a greater likelihood that students with an immigrant background will be academically, socio-emotionally and motivationally resilient. The chapter then identifies the education policies that are associated with the likelihood that students with an immigrant background will be resilient, considering academic, social, emotional and motivational dimensions of resilience.

Figure 7.1 presents a conceptual model of how education policies and practices can promote academic, social, emotional and motivational resilience among students with an immigrant background. The figure suggests that education policies can promote the various dimensions of the resilience of students with an immigrant background by shaping the learning environment in schools and the resources schools have to facilitate immigrant students' integration.

\section{The learning environment and the academic, social, emotional and motivational resilience of immigrant students}

The resources, policies and stakeholders of a school all contribute to shaping the learning environment. The learning environment comprises what happens in the classroom, in the school, in general, and in the wider community (OECD, 2013). The character of the community surrounding the school is shaped by the interactions between students, teachers, parents and school principals. In turn, the nature and quality of these interactions depend on the legislation regulating them and on specific school practices and parents' attitudes.

Learning environments can be described as innovative, dynamic, collaborative, smart or authentic (Engerström, 2009) and they can be labelled as positive or negative. The quality of the learning environment in a school is, first and foremost, measured by the school climate. Several studies highlight the importance of a positive classroom climate for students' academic achievement (Güzel and Berberoğlu, 2005; Shin et al., 2009; OECD, 2004; Ma et al., 2013). Some of the facets of a positive school climate that have been shown to be associated with positive academic performance are: supportive teacher-student interactions, good student-student relationships, and an orderly learning atmosphere with clear disciplinary rules (Creemers and Kyriakides, 2008; Harris and Chrispeels, 2006; Hopkins, 2005; Scheerens and Bosker, 1997). Even more notably, research suggests that supportive teacher-student interactions, good student-student relationships, and the strong focus on student learning that characterises schools with a positive disciplinary climate are particularly beneficial to disadvantaged students (Murray and Malmgren, 2005; Cheema and Kitsantas, 2014).

Meaningful learning is more likely to happen in a disciplined environment, where students can listen to what the teacher says and can concentrate on academic tasks (Ma and Willms, 2004). A school's disciplinary climate is also a strong predictor of sense of belonging at school (Arum and Velez, 2012; Chiu et al., 2016). The learning environment of classrooms is shaped by teachers' attitudes as well as the disciplinary climate (Fraser, 2015). Some classroom dynamics spread to the school level. For example, the effects of truancy may go beyond the single truant student and have consequences for other students, by creating resentment among those who attend class, by indicating that they, too, can skip class or by lowering the quality of instruction because of the disruptions caused by frequent absences (Wilson et al., 2008).

A school's learning environment significantly influences student performance and engagement at school (Engerström, 2009; Thapa et al., 2013). It also has an impact on the overall well-being of students. For example, disciplinary climate is a strong predictor of students' sense of belonging at school (Arum and Velvez, 2012; Chiu et al., 2016; OECD, 2003). Positive relationships between students and teachers are also particularly important for the social and emotional well-being of disadvantaged students (Battistich et al., 1997).

Learning requires an orderly, supportive and positive environment not only within the classroom but also outside (Jennings and Greenberg, 2009). Studies have found that supportive relationships among teachers, students and families can improve the performance of students, especially disadvantaged students 
(Crosnoe, Johnson and Elder, 2004; Hughes and Kwok, 2007). Linguistic or economic barriers can prevent families with an immigrant background from fully integrating into a school's social environment. That, in turn, can influence a child's academic results and broader well-being.

Studies suggest that the likelihood that socio-economically disadvantaged students will be academically resilient is higher when they attend schools that offer more and higher-quality resources and extracurricular activities (Agasisti and Longobardi, 2017; 2014a; 2014b). Since resources invested in education are often found to be weakly associated with education outcomes overall (Hanushek, 1986; 1997; 2003; Burtless, 2011), these results suggest that the availability of high-quality resources may benefit those who are at the greatest risk of falling behind. This could be because a lack of human, material and time resources within the family might be one of the reasons why such students are academically disadvantaged in the first place. The availability of such resources in school acts as a safety net that prevents these students from falling behind their classmates.

There is also evidence that students who are at a particularly high risk of falling behind academically because of their socio-economic status benefit more than other students from attending schools that establish close collaborations among the students, their families and the local community (Bryan, 2005; Ali and Jerald, 2001; Harris, 2007; Kannapel et al., 2005). Bryan (2005) also highlights the importance of having dedicated figures within the school, such as mentors and counsellors, specifically trained and assigned to support these students and build partnerships with families and communities.

\section{School composition}

Immigrant students are often not evenly represented across schools. Evidence indicates that in Canada, the United Kingdom and the United States, $60-65 \%$ of immigrant students would have to move to another school to achieve an even distribution across schools country-wide (Schnepf, 2004). This percentage is slightly lower in Australia, France, Germany, the Netherlands, New Zealand and Sweden (around 50\% would have to move) and lowest in Switzerland (40\%). Moreover, schools are also split along socio-economic lines. Socio-economic segregation in secondary schools (according to parents' background, excluding immigrant background) is particularly pronounced in Belgium, Germany and Hungary, somewhat less so in the United Kingdom and the United States, and the least prevalent in Nordic countries (Jenkins et al., 2008).

In part, the concentration in schools of immigrant students and social disadvantage arises from broader residential segregation and from the tendency, among native families, to avoid schools with large numbers of immigrant students. Some of these families fear that students with an immigrant background will require greater attention from teachers and will slow the pace of instruction because of language barriers or other difficulties associated with their background.

PISA 2015 shows that students with an immigrant background tend to be more concentrated in urban areas than native students, an indication of residential segregation. In school questionnaires, principals were asked about the size of the community where their school was located. Responses were coded so that schools were considered to be in an urban area if they were found in a city of at least 100000 people and in a rural area if they were in less populous communities. Figure 7.2 shows that in the majority of countries and economies, immigrant students were less likely to be enrolled in rural schools. On average across OECD countries, the percentage of students enrolled in rural schools was 17 percentage points lower among immigrant students than native students (15 percentage points lower across EU countries).

Table 7.3 (available on line) shows that, in the majority of countries and economies, second-generation immigrant students were the most likely to be enrolled in urban schools. On average across OECD countries, they were 20 percentage points more likely than native students to be found in urban schools (16 percentage points across EU countries), followed by first-generation immigrant students who were 16 percentage points more likely (15 percentage points across EU countries). Returning foreign-born students and native students of mixed heritage were, respectively, seven and eight percentage points more likely than native students to be enrolled in schools in urban areas (seven and eight percentage points, respectively, across EU countries). 
Figure 7.2 - Enrolment in urban schools, by immigrant background Schools in communities with more than 100000 citizens

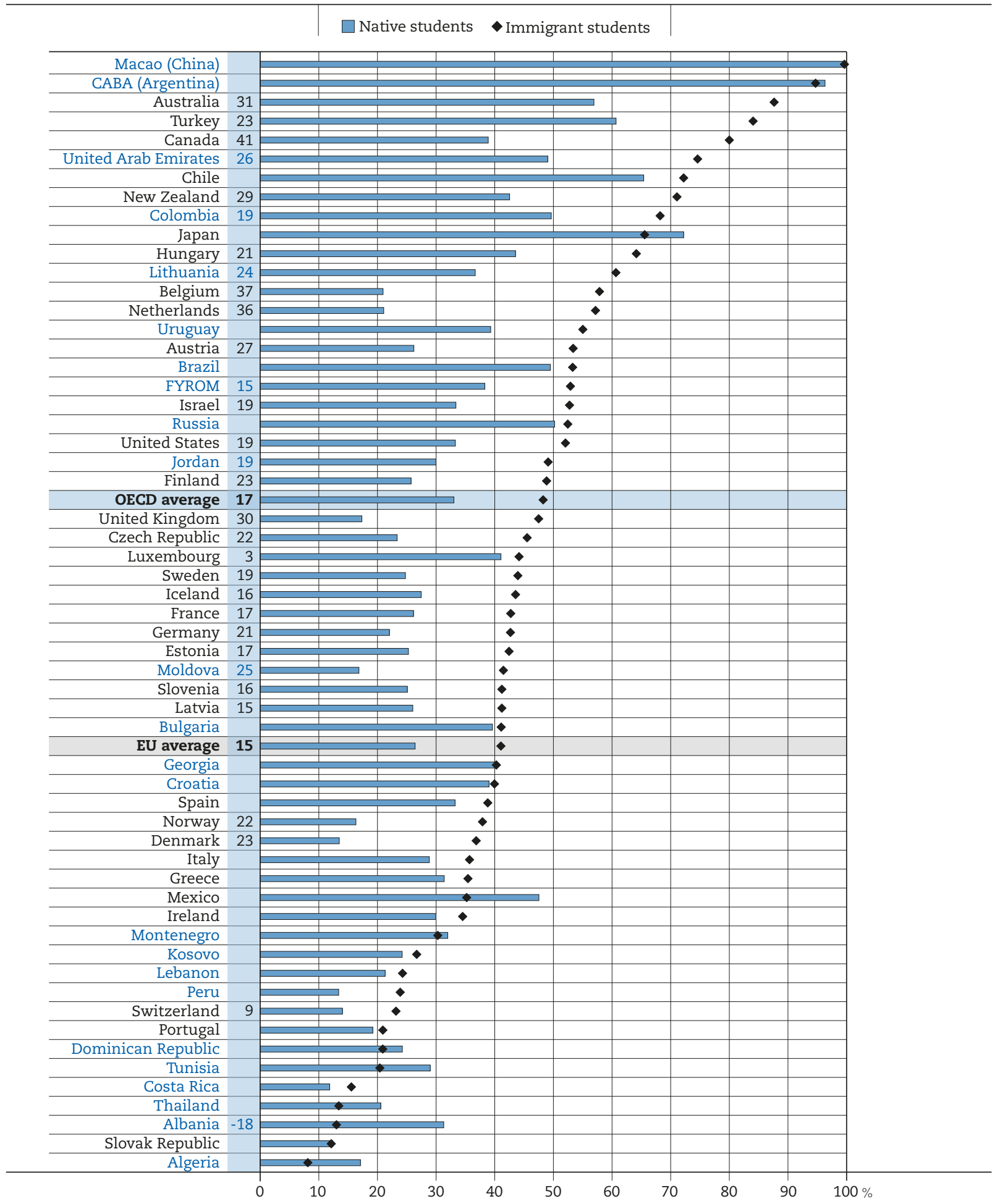

Notes: Only countries with valid data on immigrant students and where not all students are in urban or rural communities are shown. Urban schools are schools located in communities with more than 100000 citizens, as reported by school principals.

Statistically significant differences between immigrant and native students are shown next to country/economy names. For the OECD and EU average, this number refers only to the subset of countries/economies with valid information on both groups of students.

Countries and economies are ranked in descending order of the percentage of immigrant students enrolled in urban schools.

Source: OECD, PISA 2015 Database, Table 7.3.

StatLink नोाडा http://dx.doi.org/10.1787/888933682167 
Another reason why students with an immigrant background could end up concentrated in particular schools stems from the different criteria native and immigrant families apply when choosing a school for their children. While students in some school systems are assigned to their neighbourhood school, in recent decades, reforms in many countries have tended to give greater choice to parents and students, to enable them to choose the schools that meet the child's education needs or preferences (Heyneman, 2009). One reason these policies have been adopted is that the competition created by choice compels institutions to organise programmes and instruction in ways that better meet diverse student requirements and interests, thus reducing the cost of failure and mismatches (Card, Dooley and Payne 2010; Woessmann et al., 2007). This all assumes that students and parents have adequate information and choose schools based on their quality.

But some studies have questioned the validity of the underlying assumptions about parental and student choice, such as equal access to information about schools (Berends and Zottola, 2009; Hess and Loveless, 2005; Jensen et al., 2013; Waslander, Pater and van der Weide, 2010). Previous PISA findings, for instance, clearly show that even if most parents would like their child to attend the best school, disadvantaged parents weigh financial considerations more than advantaged parents do when choosing a school (OECD, 2015). Furthermore, to the extent that immigrants and natives belong to different religious denominations and have different cultural traditions, school choice based on such considerations can lead to a lack of integration in schools. As a result, adopting school-choice practices can lead to greater segregation, which, in turn, can result in differences in teacher quality and student achievement across schools, harming disadvantaged students the most (Behrman et al., 2016; Ladd, 2002; Valenzuela, Bellei and Rios, 2014). And when students are segregated, there are fewer opportunities for them to socialise and learn about each other's cultures and traditions.

In PISA 2015, students in 18 countries and economies took home a questionnaire for their parents to complete. Parents were asked which criteria they consider important when choosing a school for their child. They were asked to report how much importance they give ("not important", "somewhat important", "important" or "very important") to 11 criteria, mainly related to school quality, financial constraints, the school's philosophy or mission, and geographic distance between their home and the school.

Figure 7.3 - Immigrant-native differences in school-choice criteria

Difference in the percentage of immigrant parents and native parents who indicated that the following criteria are important when choosing a school, after accounting for socio-economic status

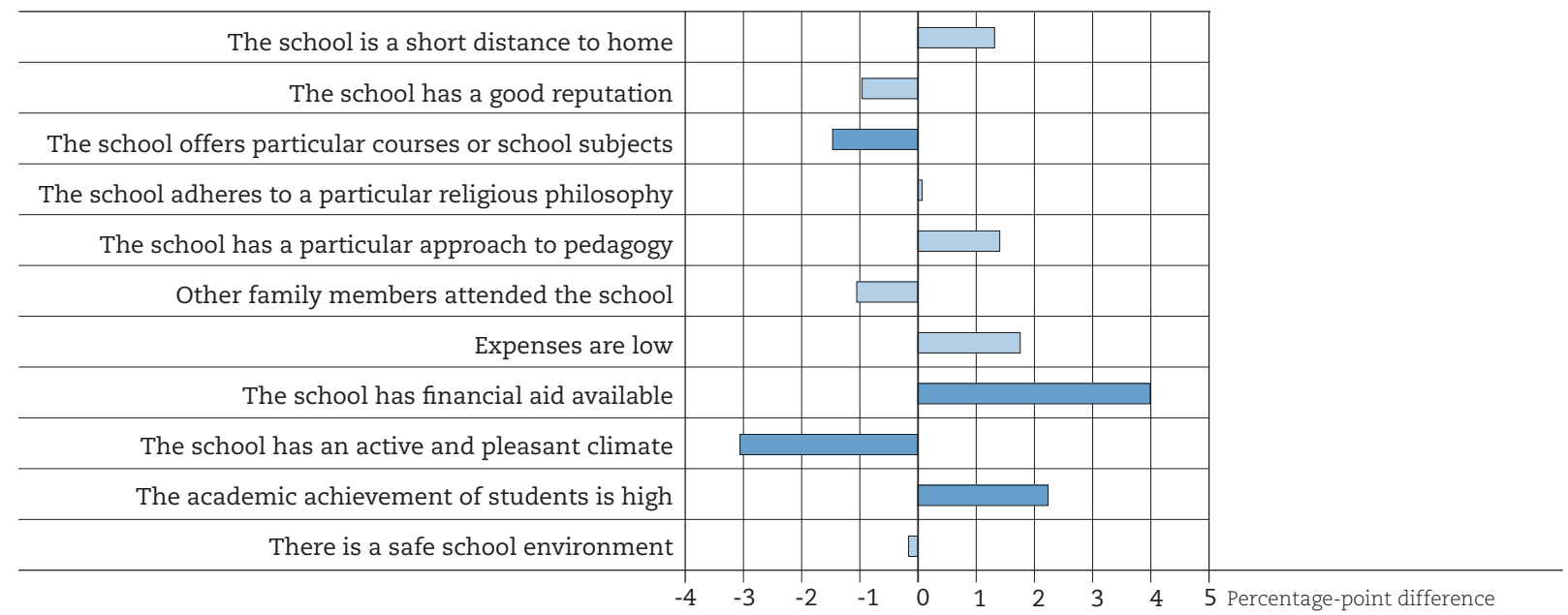

Notes: Results are averages for the countries and economies that distributed the parental questionnaire and have valid estimates. Statistically significant differences in the percentage of immigrant and native parents who reported that they consider a criterion important when choosing a school are marked in a darker tone.

Socio-economic status is measured by the PISA index of economic, social and cultural status (ESCS).

Source: OECD, PISA 2015 and 2003 Database, Table 7.5.

StatLink 司IT http://dx.doi.org/10.1787/888933682186 
Figure 7.3 indicates that, on average across the 17 countries and economies that distributed the parent questionnaire in PISA 2015 and had valid estimates, and after accounting for socio-economic status, there were no differences between immigrant and native parents in the importance they give to how distant the school is from home, the reputation of the school, the pedagogical approach used in the school or its religious philosophy, and the fact that other family members attended the school, that expenses are low, and that the school has a pleasant environment. However, the parents of immigrant students were more likely than the parents of native students to consider the availability of financial aid and the academic achievement of students in the school as important criteria to guide their choice. By contrast, the parents of native students were more likely than the parents of immigrant students to consider important the availability of particular courses and the overall climate in the school.

Table 7.5 (available on line) and Figures 7.4, 7.5 and 7.6, however, indicate that there are considerable differences across countries in the relative importance native and immigrant parents assign to the various criteria. In particular, Figure 7.4 suggests that, in Belgium, Croatia, France, Germany, Hong Kong (China) and Luxembourg, the parents of immigrant students were more likely than the parents of native students to consider the religious philosophy of the school. Conversely, in Italy, Macao (China), Malta and Portugal, the parents of native students were more likely to consider the religious philosophy of the school. Figure 7.5 shows that in Belgium, Germany, Hong Kong (China), Ireland, Luxembourg and the United Kingdom, the parents of immigrant students were more likely than the parents of native students to consider the availability of financial aid in the school, while in Mexico, the parents of native students were more likely to consider the availability of financial aid (financial support given to families to help them cover education expenses). By contrast, Figure 7.6 suggests that in Belgium, France, Germany, Hong Kong (China), Ireland, Luxembourg, Mexico and Spain, the parents of native students were more likely than the parents of immigrant students to consider whether the school has an active and pleasant climate.

Figure 7.4 - Immigrant-native differences in the importance of a school's religious philosophy Difference in the percentage of immigrant parents and native parents who indicated that the religious philosophy the school adheres to is important when choosing a school, after accounting for socio-economic status

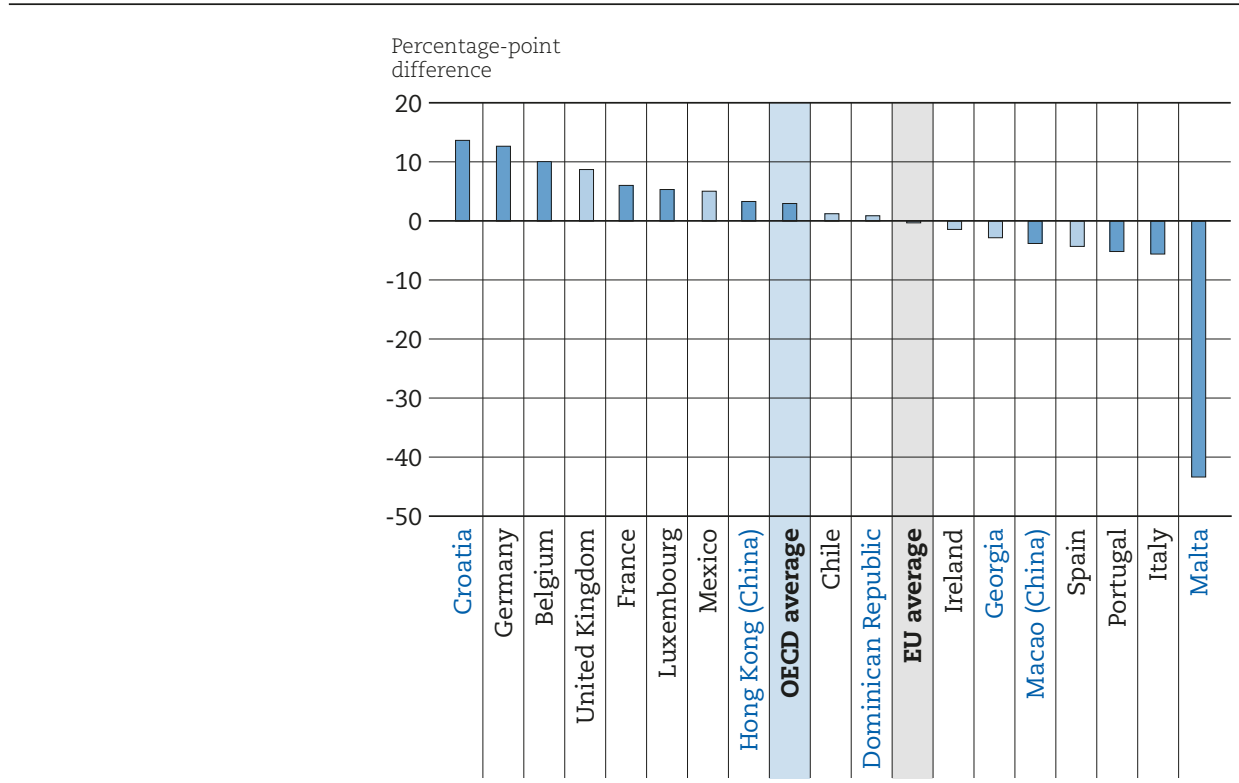

Notes: Results are displayed for the countries and economies that distributed the parent questionnaire and have valid estimates of immigrant-native gaps.

Statistically significant differences in the percentage of immigrant and native parents who reported that they consider the school's religious ideology important when choosing a school after accounting for their socio-economic status are marked in a darker tone.

Socio-economic status is measured by the PISA index of economic, social and cultural status (ESCS).

Countries and economies are ranked in descending order of the difference in the percentage of immigrant and native parents who reported that they consider the school's religious ideology important when choosing a school, after accounting for their socio-economic status.

Source: OECD, PISA 2015 Database, Table 7.5

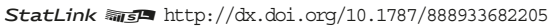


Figure 7.5 - Immigrant-native differences in the importance of financial aid for school Difference in the percentage of immigrant parents and native parents who indicated that the availability of financial aid is important when choosing a school, after accounting for socio-economic status

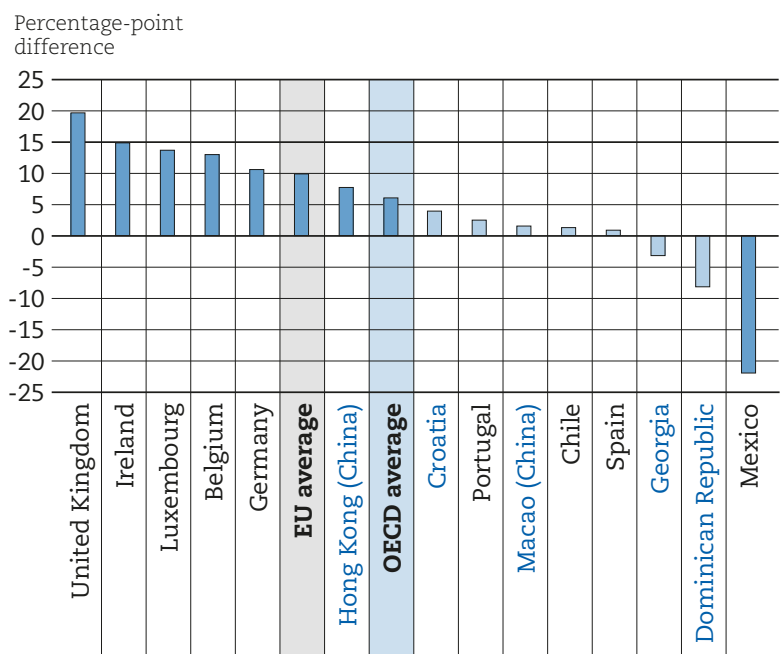

Notes: Results are displayed for the countries and economies that distributed the parent questionnaire and have valid estimates of immigrant-native gaps.

Statistically significant differences in the percentage of immigrant and native parents who reported that they consider the availability of financial aid important when choosing a school after accounting for their socio-economic status are marked in a darker tone.

Socio-economic status is measured by the PISA index of economic, social and cultural status (ESCS).

Countries and economies are ranked in descending order of the difference in the percentage of immigrant and native parents who reported that they consider the availability of financial aid important when choosing a school, after accounting for their socio-economic status.

Source: OECD, PISA 2015 Database, Table 7.5.

StatLink Ails $\mathrm{http}: / / \mathrm{dx} . \mathrm{doi} .0 \mathrm{rg} / 10.1787 / 888933682224$

Figure 7.6 Immigrant-native differences in the importance of school climate Difference in the percentage of immigrant parents and native parents who indicated that knowing that the school has an active and pleasant climate is important when choosing a school, after accounting for socio-economic status

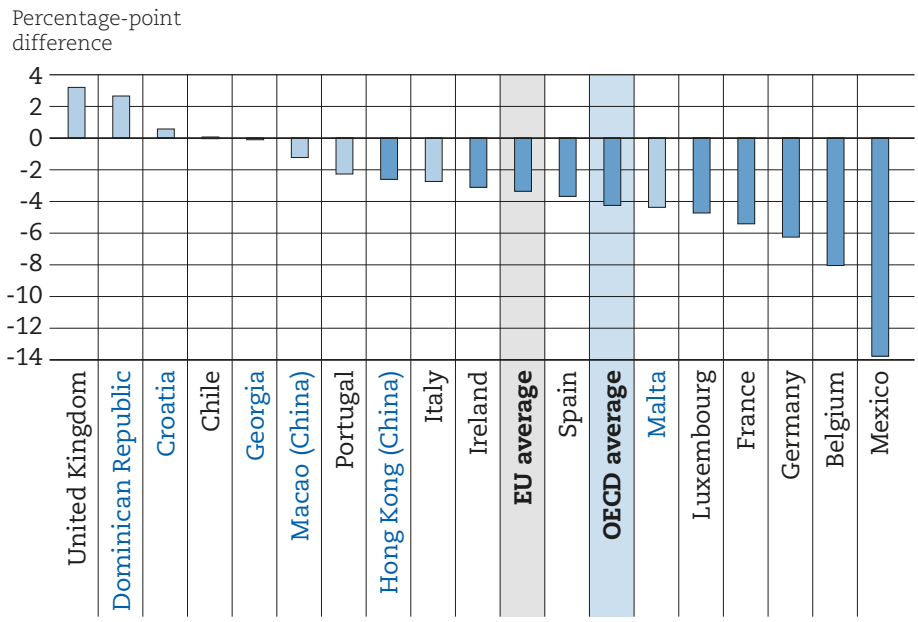

Notes: Results are displayed for the countries and economies that distributed the parent questionnaire and have valid estimates of immigrant-native gaps.

Statistically significant differences in the percentage of immigrant and native parents who reported that knowing that the school has an active and pleasant climate is important when choosing a school after accoutning for their socio-economic status are marked in a darker tone.

Socio-economic status is measured by the PISA index of economic, social and cultural status (ESCS)".

Countries and economies are ranked in descending order of the difference in the percentage of immigrant and native parents who reported that knowing that the school has an active and pleasant climate is important when choosing a school, after accounting for their socio-economic status.

Source: OECD, PISA 2015 Database, Table 7.5.

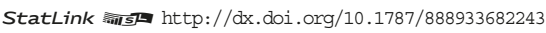


The effect of school composition, and the academic and well-being outcomes of immigrant students might be subject to thresholds or "tipping points" whereby the negative consequences of a high concentration of disadvantaged or students with an immigrant background might be particularly severe (Szulkin and Jonsson, 2007; Andersen and Thomsen, 2011). A number of studies on the impact of a high concentration of students with immigrant parents suggest that it is not immigrant background, per se, but, rather, the concentration of socio-economic disadvantage that has a negative effect on education outcomes (Rumberger and Palardy, 2005; van der Slik et al., 2006; OECD, 2012; OECD, 2016b). However, little is known about the effect of the socio-economic and immigrant composition of a school's student population on the broader well-being outcomes of students with an immigrant background.

Measuring the concentration of students with an immigrant background in schools in a reliable and internationally comparable way is challenging in many respects, mainly because of the variation in the percentage of immigrant students across countries. PISA 2015 relied on two indices to measure the concentration of students with an immigrant background in schools. The first is the index of current concentration, which represents the percentage of students with and without an immigrant background that would have to be relocated from one school to another so that all schools would have an identical percentage of students with an immigrant background. The second measure is the index of maximum potential concentration, which represents the minimum percentage of students that would have to be moved across schools if all students with an immigrant background were allocated to the largest schools.

Figure 7.7 - Avoiding high concentrations of immigrant students in particular schools Distance between current and maximum potential concentration

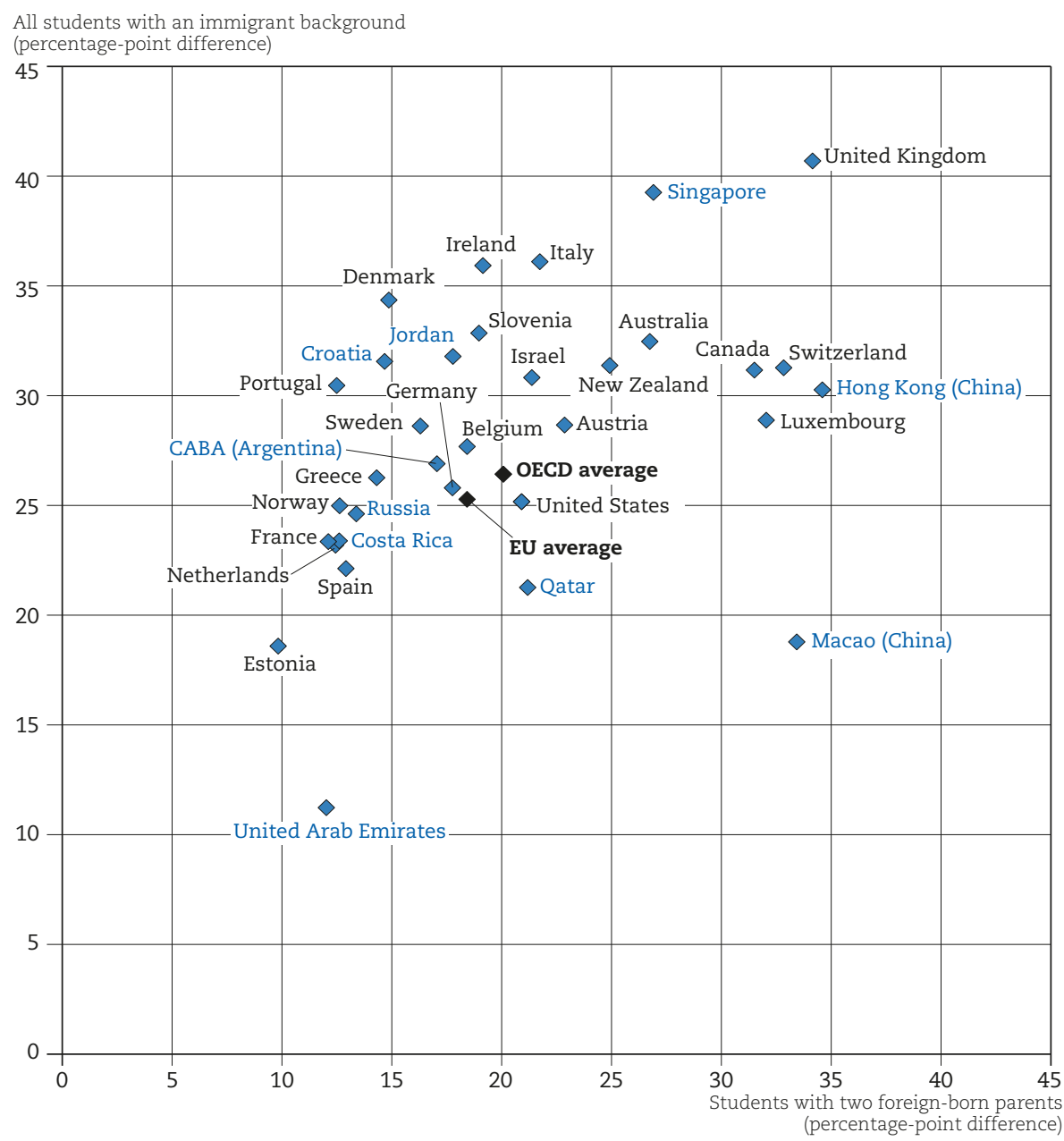

Notes: Only countries where the percentage of immigrant students is higher than $6.25 \%$ are shown.

Source: OECD, PISA 2015 Database, Tables 7.6 and 7.7

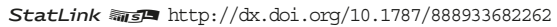


By defining country-specific thresholds for the school-level concentration of students with an immigrant background, these indices address some of the shortcomings of other concentration measures and provide a benchmark that reflects more accurately the relative similarity between the composition of schools and their social context.

The difference between the two indices indicates the distance between the current mix of native students and students with an immigrant background in schools and the highest possible degree of segregation of students with an immigrant background in a country/economy, given the overall percentage of students with an immigrant background and the size of the country's/economy's schools. The maximum potential concentration is a hypothetical scenario in which all immigrant students attend the largest schools in the country, and hence where the largest number of them can be found in the same schools and classrooms. Given this scenario, countries and economies where the difference between the two indices is larger can be seen as having greater success in avoiding segregating students with an immigrant background into particular schools.

Table 7.6 and Table 7.7 (available on line) report current and potential maximum levels of concentration of students with an immigrant background. The difference between the two is related to the fact that while Table 7.6 only considers students with two foreign-born parents (both native-born and foreign-born students), Table 7.7 also considers mixed-heritage students and returning foreign-born students. Table 7.6 reveals that current levels of concentration and the maximum levels of concentration of immigrant students that could occur in a country/economy differed the most - over 30 percentage points - in Canada, Hong Kong (China), Luxembourg, Macao (China), Switzerland and the United Kingdom. They were the most similar - lower than 15 percentage points - in Costa Rica, Croatia, Denmark, Estonia, France, Greece, the Netherlands, Norway, Portugal, the Russian Federation (hereafter "Russia"), Spain and the United Arab Emirates.

The picture changes, however, when considering mixed-heritage students and returning foreign born students. In particular, Table 7.6 shows that the United Kingdom had a very good record of avoiding the concentration of immigrant students in schools, while Estonia and the United Arab Emirates did comparatively poorly on this measure. Denmark did poorly when considering first- and second-generation immigrant students but very well when considering returning foreign-born and mixed-heritage students. Conversely, Macao (China) did very well when considering only first- and second-generation immigrant students, but comparatively poorly when considering mixed-heritage and returning foreign-born students.

Results presented in the left panel of Figure 7.8 indicate that, on average, the likelihood that students of similar socio-economic status will attain baseline levels of academic proficiency is lower when they attend schools with a high concentration of immigrant students. Across OECD countries, attending a school with between one in ten and one in four students with an immigrant background compared to attending a school where fewer than one in ten students has an immigrant background corresponds to a decrease of two percentage points in the probability that such a student will reach baseline levels of academic proficiency (three percentage points across EU countries).

PISA results show that the higher the concentration of immigrant students in a school, the larger the difference in academic outcomes. In 2015, across OECD countries, the difference in likelihood of attaining baseline academic proficiency between students attending schools where up to one in ten students is an immigrant student and those in schools where between one in four and one in two students has an immigrant background was four percentage points. The difference was 13 percentage points when comparing students in schools where up to one in 10 students has an immigrant background and students attending schools where more than one in two students have an immigrant background (across EU countries, these differences were even larger: eight percentage points for the first comparison and 19 percentage points for the second). Figure 7.8 reveals a large degree of heterogeneity across countries. In particular, a gradient effect is observed in Belgium, Denmark, France, Germany, Greece and Slovenia, while in Austria, Italy, Spain and Switzerland, only very high concentrations of immigrant students were associated with a decrease in the likelihood that students will reach baseline levels of academic proficiency. 
Figure 7.8 - Academic proficiency and concentration of immigrant students in school Difference in the percentage of students attaining baseline academic proficiency compared to schools where less than $10 \%$ of students are immigrant students

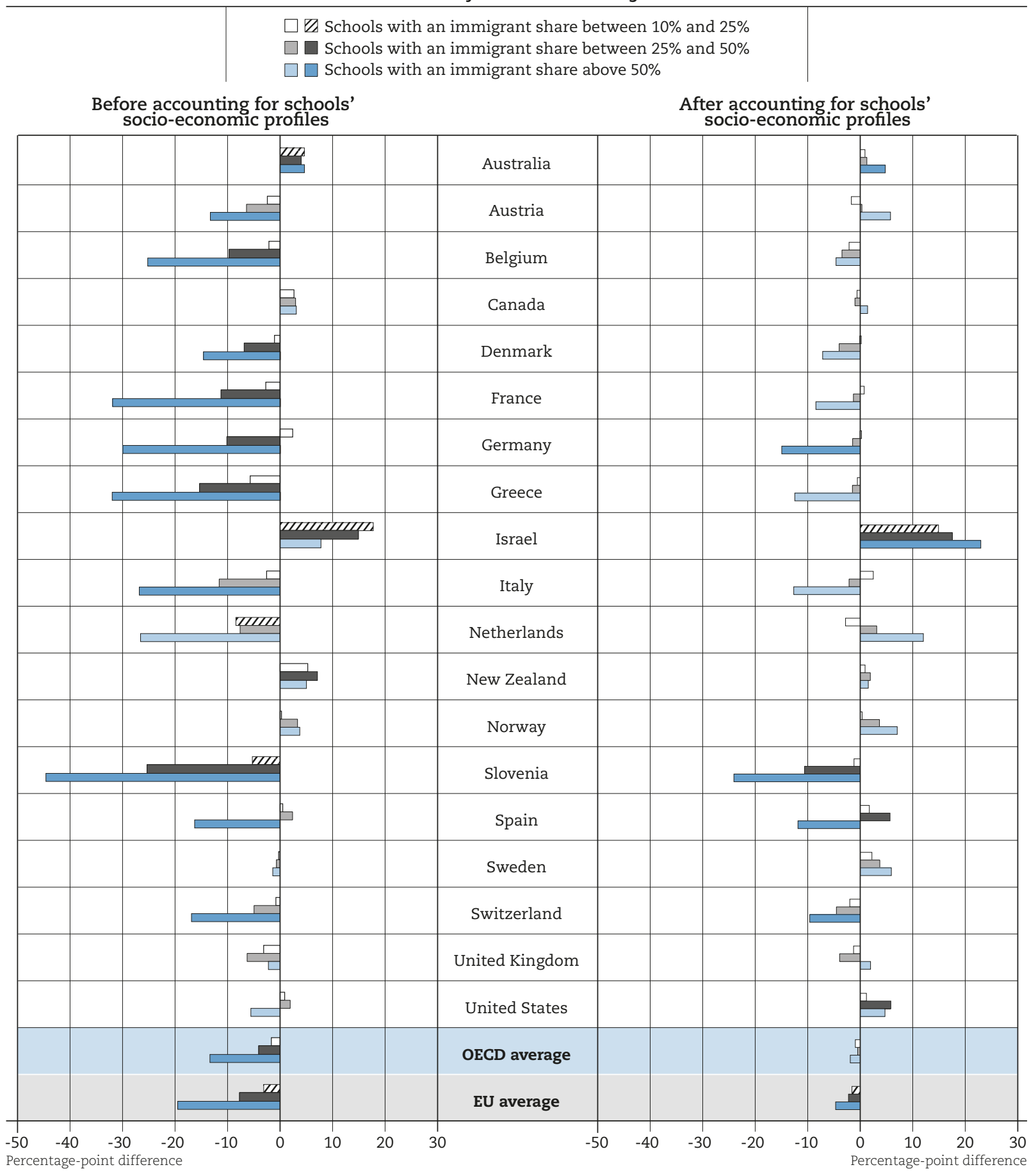

Notes: Only countries with valid estimates for schools with each immigrant share are shown.

Students who attain baseline academic proficiency are those who attain at least proficiency Level 2 in all three core PISA subjects: science, reading and mathematics.

Results in the left panel are obtained from regressions accounting for students' gender, socio-economic status and language spoken at home. The regressions used to obtain estimates for the right panel also accounted for the school's socio-economic profile.

Statistically significant differences are marked in a darker tone or with a striped pattern.

Countries and economies are ranked in alphabetical order.

Source: OECD, PISA 2015 Database, Table 3.7.

StatLink तiाs http://dx.doi.org/10.1787/888933682281 
The right panel of Figure 7.8 suggests that most of the difference is due to the socio-economic composition of schools attended by a large number of immigrant students, and the detrimental effect of socio-economic disadvantage on academic performance. On average across OECD countries, and after accounting for the socio-economic profile of schools, no association can be identified between the percentage of immigrant students attending a school and the likelihood that students attending that school will attain baseline levels of academic proficiency. After accounting for schools' socio-economic profile, a high concentration of immigrant students was associated with poorer performance in Germany, Slovenia, Spain and Switzerland. Slovenia was the only country where students who attend schools where more than one in four students has an immigrant background are less likely to attain baseline levels of proficiency, after accounting for the school's socio-economic profile. Interestingly, the association between the concentration of immigrants in a school and academic performance was similar across students with and without an immigrant background (Table 7.9, available on line).

The concentration of immigrant students in schools appears to be even more weakly associated with students' ability to feel a sense of belonging at their school and their sense of identification with the school. Figure 7.9 suggests that, before accounting for the socio-economic profile of the school, the difference in the sense of belonging among students who attend a school where between one in ten and one in four students has an immigrant background, and students who attend schools where fewer than one in ten students is an immigrant student was significant only in Belgium (where students in the former group were five percentage points less likely to report a strong sense of belonging), the Netherlands (five percentage point less likely) and Slovenia (6 percentage point less likely). In Australia students in the former group were four percentage points more likely to report feeling like they belong at school. The difference was wider when comparing students who attend schools where fewer than one in 10 students has an immigrant background and students who attend schools where more than one in two students is an immigrant student. In Austria, Denmark, France and Switzerland, this difference amounted to more than five percentage points. Interestingly, in Australia, Norway and the United Kingdom, students' sense of belonging at school was stronger among students who attend schools where more than one in two students were immigrants.

Accounting for the socio-economic profile of schools explains most of the negative associations between high concentrations of immigrant students and a sense of belonging (although Switzerland is an important outlier). In Australia, Norway and the United Kingdom, larger concentrations of students with an immigrant background were generally associated with stronger feelings of belonging at school community among both native and immigrant students.

Table 7.11 (available on line) shows the association between the concentration of immigrants in a school and the share of immigrant and native students who report feeling like they belong at school. On average across OECD countries, after accounting for the socio-economic profile of the school, native students who in 2015 attended a school where over one in two students had an immigrant background were four percentage points less likely to report a sense of belonging at school compared to native students who attended schools where fewer than one in ten students was an immigrant student. The difference was as large as 26 percentage points in Switzerland.

\section{Parental involvement in the school community}

Learning requires an orderly, supportive and positive environment not only within the classroom but also outside (Jennings and Greenberg, 2009). A school's learning environment does not uniquely involve school climate; it includes any interactions among members of the school community. Parental involvement can help create a socially connected school where students, teachers, parents and principals work together to create a positive learning environment. Supportive relationships among teachers, students and families can also improve student performance, particularly among disadvantaged students (Crosnoe, Johnson and Elder, 2004; Hughes and Kwok, 2007). Parental involvement can thus improve the academic and social resilience of immigrant students.

In PISA 2015, the involvement of parents in the school community was measured by asking parents how many friends of their child and parents of their child's friends they know. It also asked how many of the school staff parents would feel comfortable talking to if they had a question about their child. Parents are defined as being involved in the school community if their response to all three questions was greater than three. 
Figure 7.9 - Sense of belonging and concentration of immigrant students in school Difference in the percentage of students reporting a sense of belonging at school compared to schools where less than $10 \%$ of students are immigrant students

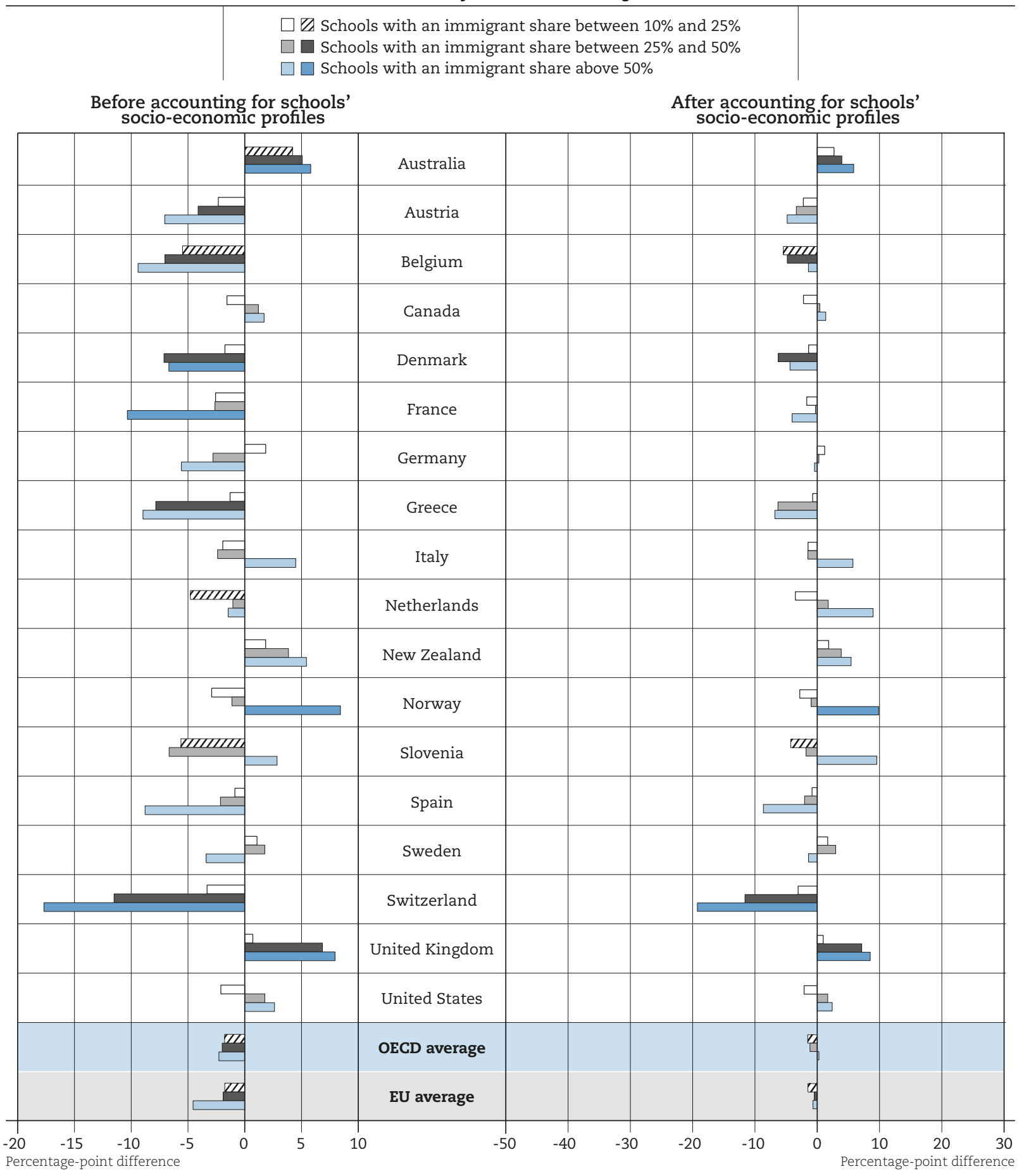

Notes: Only countries with valid estimates for schools with each immigrant share are shown.

Students who reported a sense of belonging at school are those who reported that they "agree" or "strongly agree" with the statement "I feel like I belong at school" and "disagree" or "strongly disagree" with the statement "I feel like an outsider at school".

Results in the left panel are obtained from regressions accounting for students' gender, socio-economic status and language spoken at home. The regressions used to obtain estimates for the right panel also accounted for the school's socio-economic profile.

Statistically significant differences are marked in a darker tone or with a striped pattern.

Source: OECD, PISA 2015 Database, Table 7.10.

StatLink तiाs http://dx.doi.org/10.1787/888933682300 
Figure 7.10 shows that in 11 out of 17 countries and economies where the parental questionnaire was distributed, the parents of immigrant students are less likely than the parents of native students to be involved in the school community. On average across OECD countries with available data, they were 17 percentage points less likely to be connected with the school community; across EU countries they were 19 percentage points less likely. In Germany, Ireland, Italy, Spain and the United Kingdom, the parents of immigrant students were more than 20 percentage points less likely than the parents of native students to be involved in the school community.

Figure 7.10 - Students whose parents are involved in the school community, by immigrant background

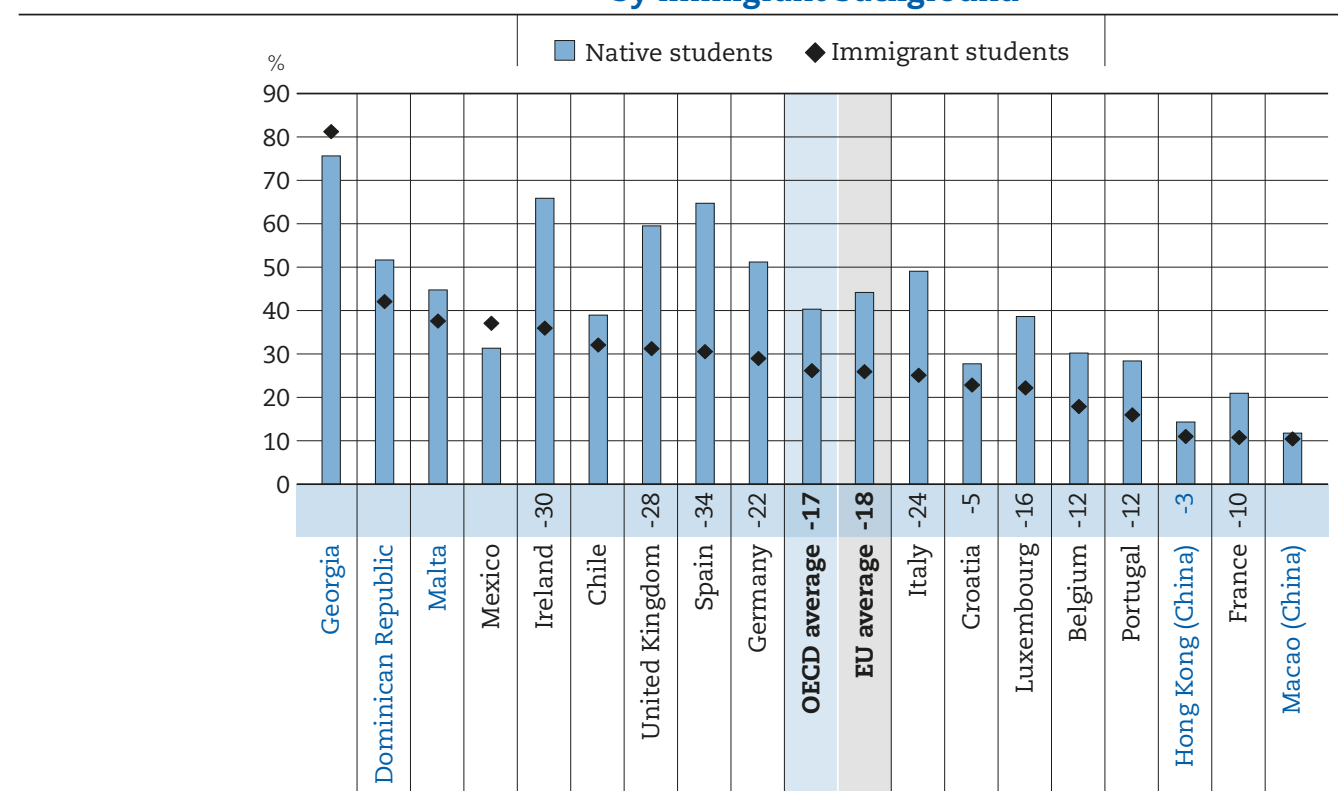

Notes: Only countries that distributed the parental questionnaire and have valid data on immigrant students are shown.

Involvement of parents in the school community is measured by asking parents how many friends of their child and parents of their child's friends they know, and how many of the school staff they would feel comfortable talking to if they had a question about their child. Parents are defined as being involved in the school community if their response to all three questions was greater than three.

Statistically significant differences between immigrant and native students are shown next to country/economy names. For the OECD and EU average, this number refers only to the subset of countries/economies with valid data on both groups of students.

Countries and economies are ranked in descending order of the percentage of immigrant students whose parents are involved in the school community. Source: OECD, PISA 2015 Database, Table 7.12.

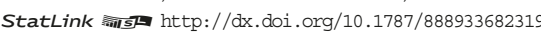

Parents' involvement in the school community has a strong effect on the well-being of their children. Table 7.13 shows the association between having parents involved in the school community and the likelihood that students in those schools will reach baseline levels of academic proficiency ${ }^{1}$, report high levels of sense of belonging at school ${ }^{2}$, report that they are satisfied with their life ${ }^{3}$, report low levels of schoolwork-related anxiety ${ }^{4}$, and have high motivation to achieve ${ }^{5}$. On average across OECD countries, the children of parents involved in the community were six percentage points more likely to report that they feel like they belong at school and that they are satisfied with their life (seven or six percentage points, respectively, across EU countries). The effect is particularly strong in the United Kingdom: students with involved parents were around 12 percentage points more likely to report that they feel like they belong at school and that they are satisfied with their life. In the United Kingdom, the percentage of immigrant students whose parents reported being involved in the community was 28 percentage points lower than of native students. Effects were approximately the same in Luxembourg, but immigrant students were only 16 percentage points less likely than native students to have parents who were involved in the school community. In Ireland and Spain, the percentage of immigrant students whose parents were involved in the community were, respectively, 30 and 34 percentage points lower than that of native students, but the effect of parents' involvement in the school community on a child's sense of belonging at school and life satisfaction was about half as strong as in the United Kingdom. 
In Ireland, Italy, Luxembourg and the United Kingdom, immigrant students were less likely to have parents involved in the school community and parental involvement is associated with an increased likelihood of reaching baseline academic proficiency of around four percentage points, at least. The effect of parental involvement in the school community on students' schoolwork-related anxiety and motivation to achieve are not as pronounced as on the other outcomes considered. In Germany, immigrant students are less likely than native students to have parents who are involved in the school community, and parental involvement increases the likelihood of students reporting low anxiety and high motivation by around five percentage points.

\section{Table 7.13 - Parents' involvement in the school community, and students' academic and well-being outcomes}

\begin{tabular}{|c|c|c|c|c|c|c|}
\hline & \multicolumn{6}{|c|}{$\begin{array}{l}\text { Statistically significant and positive value } \\
\text { Statistically significant and negative value } \\
\text { Missing or invalid estimate }\end{array}$} \\
\hline & \multirow{2}{*}{$\begin{array}{l}\text { Percentage-point } \\
\text { difference between } \\
\text { immigrant and native } \\
\text { students } \\
\text { in the percentage } \\
\text { of students whose } \\
\text { parents are involved } \\
\text { in the school } \\
\text { community }\end{array}$} & \multicolumn{5}{|c|}{ Effect of parents' involvement in the school community (percentage-point change) } \\
\hline & & $\begin{array}{l}\text { On the } \\
\text { likelihood } \\
\text { of attaining } \\
\text { baseline } \\
\text { academic } \\
\text { proficiency }\end{array}$ & $\begin{array}{l}\text { On the } \\
\text { likelihood } \\
\text { of reporting } \\
\text { a sense } \\
\text { of belonging } \\
\text { at school }\end{array}$ & $\begin{array}{l}\text { On the } \\
\text { likelihood } \\
\text { of reporting } \\
\text { being satisfied } \\
\text { with life }\end{array}$ & $\begin{array}{c}\text { On the } \\
\text { likelihood } \\
\text { of reporting } \\
\text { low } \\
\text { schoolwork- } \\
\text { related anxiety }\end{array}$ & $\begin{array}{l}\text { On the } \\
\text { likelihood } \\
\text { of reporting } \\
\text { high } \\
\text { achievement } \\
\text { motivation }\end{array}$ \\
\hline Mexico & 5.73 & -0.52 & 0.70 & 2.64 & 2.16 & 1.60 \\
\hline Georgia & 5.58 & 7.88 & 8.20 & & & \\
\hline Macao (China) & -1.34 & -1.53 & 7.10 & 0.18 & -3.14 & 4.31 \\
\hline Hong Kong (China) & -3.32 & -0.45 & 6.13 & 9.46 & 2.42 & 5.33 \\
\hline Croatia & -4.89 & 3.10 & 3.13 & 3.98 & -1.87 & 0.53 \\
\hline Chile & -6.88 & 5.60 & 3.95 & 5.74 & 2.61 & -0.63 \\
\hline Malta & -7.17 & 5.74 & 13.71 & & & \\
\hline Dominican Republic & -9.59 & 2.13 & 2.05 & 3.68 & 0.56 & -1.64 \\
\hline France & -10.19 & -0.31 & 6.88 & 5.57 & 2.02 & -0.08 \\
\hline Belgium & -12.31 & 1.88 & 3.46 & & 1.99 & 4.32 \\
\hline Portugal & -12.41 & -3.86 & 1.71 & 2.29 & -2.40 & 2.50 \\
\hline Luxembourg & -16.44 & 4.25 & 11.11 & 9.04 & 4.35 & 1.27 \\
\hline OECD average & -17.37 & 1.95 & 5.58 & 5.65 & 1.93 & 1.35 \\
\hline EU average & -18.36 & 2.97 & 6.99 & 6.12 & 1.60 & 1.21 \\
\hline Germany & -22.22 & 1.16 & 5.38 & 5.02 & 5.49 & 4.33 \\
\hline Italy & -23.96 & 3.89 & 7.52 & 5.05 & -1.73 & -1.84 \\
\hline United Kingdom & -28.27 & 8.68 & 11.94 & 12.49 & 1.65 & -0.82 \\
\hline Ireland & -29.91 & 4.38 & 6.79 & 6.05 & 3.85 & 0.00 \\
\hline Spain & -34.17 & 3.74 & 5.25 & 5.57 & 2.63 & 1.90 \\
\hline
\end{tabular}

Notes: Only those countries with a valid estimate for the immigrant-native gap in the percentage of students whose parents are involved in the school community are displayed. The OECD and EU average percentage-point differences are based only on countries with reliable estimates for both native and immigrant students.

Involvement of parents in the school community is measured by asking parents how many friends of their child and parents of their child's friends they know, and how many of the school staff they would feel comfortable talking to if they had a question about their child. Parents are defined as being involved in the school community if their response to all three questions was greater than three.

Results on the effects of parents' involvement in the school community are obtained from regressions that account for students' gender, immigrant background and socio-economic status, as well as the socio-economic profile of schools.

Students who attain baseline academic proficiency are those who reach at least PISA proficiency Level 2 in all three core PISA subjects: science, reading and mathematics.

Students who reported a sense of belonging at school are those who reported that they "agree" or "strongly agree" with the statement "I feel like I belong at school" and "disagree" or "strongly disagree" with the statement "I feel like an outsider at school".

Students who reported being satisfied with life are those who reported a life satisfaction of 7 or above on a scale from 0 to 10.

Students who reported low schoolwork-related anxiety are those who reported that they "disagree" or "strongly disagree" with the statements "I often worry that it will be difficult for me taking a test" and "Even if I am well prepared for a test, I feel very anxious".

Students who reported high motivation to achieve are students who reported that they "agree" or "strongly agree" with the statement "I want to be the best, whatever I do".

Countries and economies are ranked in descending order of the percentage-point difference between immigrant and native students in the percentage of students whose parents are involved in the school community.

Source: OECD, PISA 2015 Database Tables 7.12 and 7.24.

StatLink 제개 http://dx.doi.org/10.1787/888933682547 


\section{Disciplinary climate}

In PISA 2015, disciplinary climate was evaluated by asking students about the frequency with which "students don't listen to what the teacher says", "there is noise and disorder", "the teacher has to wait a long time for students to quiet down", "students cannot work well" and "students don't start working for a long time after the lesson begins" during their science lessons in school. Possible answers were "every lesson", "most lessons", "some lessons" and "never or hardly ever". Responses were combined to create an index of disciplinary climate with an average of zero and standard deviation of one across OECD countries. Since index scores are based on students' subjective perception of the disciplinary climate in their science class, school averages were calculated in order to obtain objective school-level measurements.

Figure 7.11 shows differences across countries and economies in the disciplinary climate of schools attended by native and immigrant students. It suggests that in 26 countries and economies out of the 63 considered, 15-year-old immigrant students in 2015 tended to be enrolled in schools characterised by a worse disciplinary climate. On average, the difference was not large: 0.06 point across OECD countries and 0.05 point across EU countries. However, large differences are observed across countries. For example, in Brazil, the Slovak Republic and Slovenia, immigrant students were more likely be enrolled in schools where the disciplinary climate was considerably worse compared to the disciplinary climate of schools in which native students were enrolled (a mean index difference of about 0.20 point). The difference was largest in Japan (0.62 point). By contrast, in Australia, Canada, Macao (China), New Zealand, Qatar, Singapore, the United Arab Emirates and the United Kingdom, immigrant students tended to be enrolled in schools with a more positive disciplinary climate than native students. Results reported in Table 7.14 (available on line) indicate that first- and second-generation immigrant students were enrolled in schools that had similar disciplinary climates and that, on average across OECD and EU countries, returning foreign-born students and native-born students with an immigrant background attended schools whose disciplinary climate was similar to those attended by native students.

But does disciplinary climate matter for academic performance, and social and emotional well-being? Table 7.15 shows the association between disciplinary climate, at the school level, and the likelihood that students in those schools will reach baseline levels of academic proficiency, report high levels of sense of belonging at school, report that they are satisfied with their life, report low levels of schoolwork-related anxiety, and have high motivation to achieve. Estimated associations control for socio-economic status at the individual and school level, the student's gender, his or her immigration background and the ISCED level of the class he or she is currently enrolled in.

Results suggest that a school's disciplinary climate was a strong predictor of academic achievement and well-being in PISA 2015. A 0.10-point increase in the index was associated with a change of between 0.04 and 3.77 percentage points in the probability of attaining baseline levels of academic proficiency. Since in many countries and economies the mean difference in the index between native and immigrant students was larger than 0.10 point, the findings indicate a strong association between the learning environment to which native and immigrant students are exposed and the likelihood that these students will attain baseline levels of academic proficiency. Schools' disciplinary climate is thus particularly important for the academic resilience of immigrant students.

The association between disciplinary climate and sense of belonging at school was also strong. A change of 0.10 point in the mean index corresponded to a difference of between 0.40 and 2.12 percentage points in the likelihood of students reporting a strong sense of belonging at school. The association between disciplinary climate and students' satisfaction with life was weaker but significant in most countries, while the association between disciplinary climate, on the one hand, and emotional and motivational outcomes (schoolwork-related anxiety and achievement motivation) on the other, was less pronounced.

In Austria, Brazil, Chile, Colombia, the Czech Republic, the Dominican Republic, Germany, Greece, Iceland, Italy, Japan, Kosovo, Russia, the Slovak Republic, Slovenia, and Turkey, on average, immigrant students attended schools whose disciplinary climate was considerably worse than the disciplinary climate in the schools attended by the average native student (mean index difference greater than 0.10 point). In several of these countries, this difference had a large effect on students' academic and well-being outcomes. 
Figure 7.11 - Disciplinary climate in schools attended by the average immigrant and native student

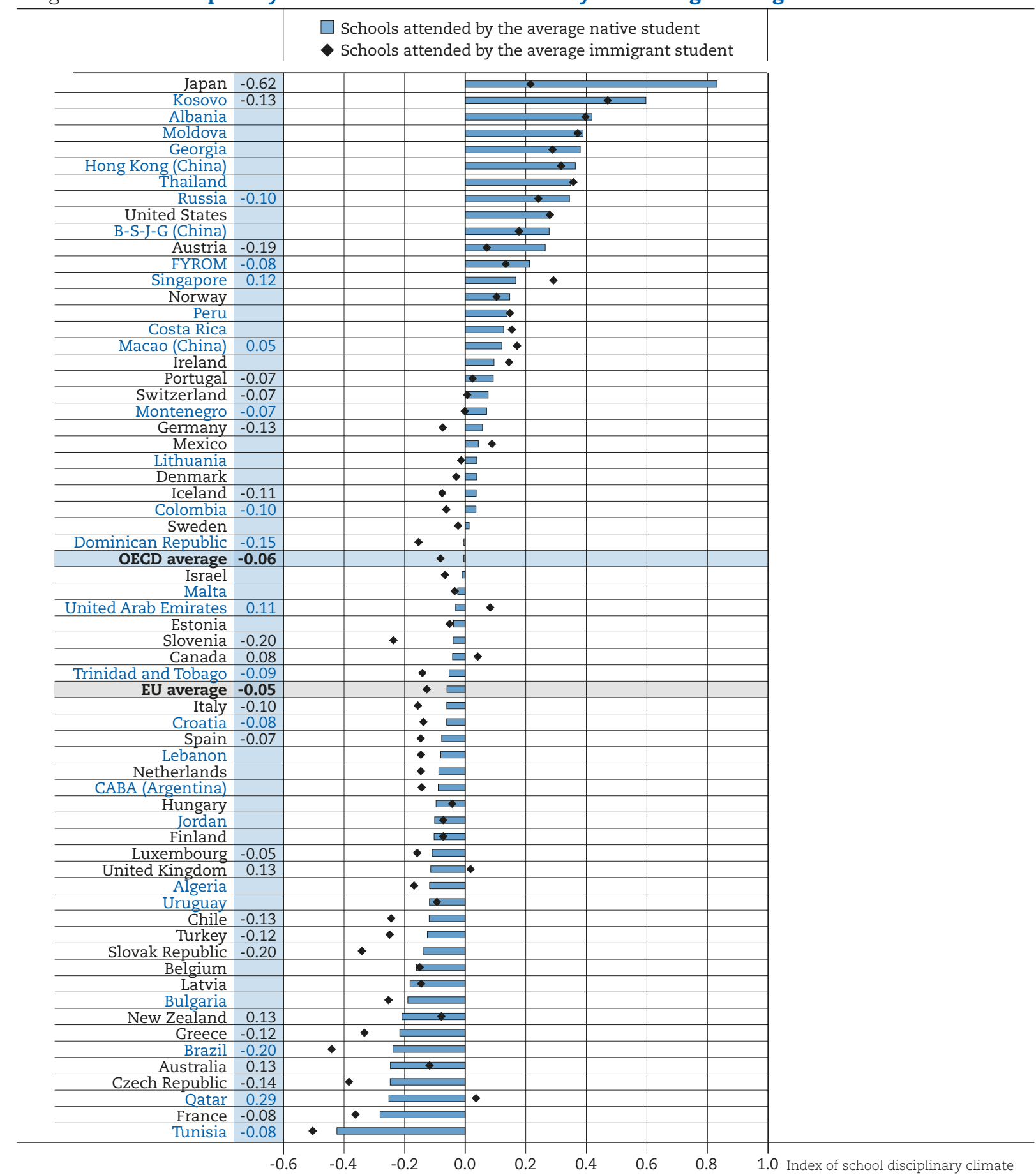

Notes: Only countries with valid data on immigrant students are shown.

The index of disciplinary climate was constructed based on students' responses about the frequency (i.e. "every lesson", "most lessons", "some lessons" and "never or hardly ever") with which "students don't listen to what the teacher says", "there is noise and disorder", "the teacher has to wait a long time for students to quiet down", "students cannot work well" and "students don't start working for a long time after the lesson begins" during their science lessons in school. The school score on the index was calculated as the average of the index values for students in the school.

Statistically significant differences between immigrant and native students are shown next to country/economy names. For the OECD and EU average, this number refers only to the subset of countries/economies with valid data on both groups of students.

Countries and economies are ranked in descending order of the average index of school disciplinary climate in schools attended by the average immigrant student.

Source: OECD, PISA 2015 Database, Table 7.14.

StatLink न्नाजा http://dx.doi.org/10.1787/888933682338 
Table 7.15 - School disciplinary climate, and students' academic and well-being outcomes

\begin{tabular}{|c|c|c|c|c|c|c|}
\hline & \multicolumn{6}{|c|}{$\begin{array}{l}\text { Statistically significant and positive value } \\
\text { Statistically significant and negative value } \\
\text { Missing or invalid estimate }\end{array}$} \\
\hline & \multirow{2}{*}{$\begin{array}{l}\text { Difference in the index } \\
\text { of school disciplinary } \\
\text { climate between schools } \\
\text { attended by the average } \\
\text { immigrant student and } \\
\text { those attended by the } \\
\text { average native student }\end{array}$} & \multicolumn{5}{|c|}{ Effect of a 0.10-point increase in the school climate index (percentage-point change) } \\
\hline & & $\begin{array}{l}\text { On the likelihood } \\
\text { of attaining } \\
\text { baseline } \\
\text { academic } \\
\text { proficiency }\end{array}$ & $\begin{array}{l}\text { On the likelihood } \\
\text { of reporting } \\
\text { a sense } \\
\text { of belonging } \\
\text { at school }\end{array}$ & $\begin{array}{l}\text { On the likelihood } \\
\text { of reporting being } \\
\text { satisfied with life }\end{array}$ & $\begin{array}{l}\text { On the likelihood } \\
\text { of reporting low } \\
\text { schoolwork- } \\
\text { related anxiety }\end{array}$ & $\begin{array}{l}\text { On the likelihood } \\
\text { of reporting high } \\
\text { achievement } \\
\text { motivation }\end{array}$ \\
\hline Qatar & 0.29 & 3.26 & 1.57 & 0.00 & -0.63 & 0.20 \\
\hline United Kingdom & 0.13 & 0.71 & 0.83 & 0.40 & 0.01 & 0.24 \\
\hline New Zealand & 0.13 & 0.37 & 0.58 & & 0.21 & 0.04 \\
\hline Australia & 0.13 & 0.72 & 0.84 & & 0.06 & 0.03 \\
\hline $\begin{array}{l}\text { Singapore } \\
\text { United Arab Emirates }\end{array}$ & 0.12 & 0.31 & 0.59 & 0.65 & 0.40 & -0.32 \\
\hline Canada & 0.11 & $\frac{1.99}{0.40}$ & $\frac{1.46}{0.40}$ & 0.05 & $\frac{-0.15}{0.05}$ & $\begin{array}{l}0.01 \\
0.32\end{array}$ \\
\hline Hungary & 0.05 & 1.72 & 1.08 & 0.49 & -0.11 & 0.12 \\
\hline Macao (China) & 0.05 & 3.58 & 2.12 & 0.81 & -0.39 & -0.91 \\
\hline Ireland & 0.05 & 0.80 & 0.96 & 0.67 & 0.47 & -0.08 \\
\hline Mexico & 0.05 & 1.43 & 0.47 & 0.55 & 0.25 & 0.41 \\
\hline Latvia & 0.04 & 0.72 & 0.20 & 0.49 & 0.17 & -0.06 \\
\hline Finland & 0.03 & 0.48 & 0.18 & 0.51 & 0.31 & 0.44 \\
\hline Jordan & 0.03 & 0.73 & 1.09 & & & \\
\hline Costa Rica & 0.03 & 1.21 & -0.19 & 0.05 & 0.26 & 0.51 \\
\hline Uruguay & 0.02 & 0.04 & 0.32 & 0.66 & 0.08 & -0.07 \\
\hline Belgium & 0.01 & 0.70 & 0.98 & 0.52 & 0.58 & -0.50 \\
\hline Peru & 0.01 & 0.72 & 0.80 & 0.89 & -0.19 & -0.14 \\
\hline $\begin{array}{l}\text { Thailand } \\
\text { Inited Staten }\end{array}$ & 0.01 & 1.38 & 0.88 & 0.92 & 1.31 & 0.17 \\
\hline United States & 0.00 & $\frac{1.26}{2.57}$ & 0.50 & 0.22 & 0.21 & -0.02 \\
\hline$\frac{\text { Malta }}{\text { Estonia }}$ & -0.01 & 2.57 & 0.73 & & & \\
\hline $\begin{array}{l}\text { Estonia } \\
\text { Moldoya }\end{array}$ & -0.01 & 1.23 & 0.74 & 0.08 & -0.04 & -0.27 \\
\hline$\frac{\text { Moldova }}{\text { Albania }}$ & $\begin{array}{l}-0.02 \\
-0.02\end{array}$ & $\frac{0.45}{-0.90}$ & 1.93 & & & \\
\hline Sweden & -0.04 & 0.76 & 0.12 & 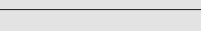 & -0.18 & 0.06 \\
\hline Norway & -0.04 & 1.08 & 0.61 & & 0.34 & -0.19 \\
\hline Hong Kong (China) & -0.05 & 1.30 & 1.02 & 0.59 & -0.01 & 0.12 \\
\hline Luxembourg & -0.05 & 1.73 & 0.82 & 0.03 & 0.41 & -0.19 \\
\hline Algeria & -0.05 & 0.89 & 0.29 & & & \\
\hline Lithuania & -0.05 & 1.51 & 0.68 & 0.55 & 0.03 & 0.31 \\
\hline EU average & -0.05 & 1.34 & 0.85 & 0.50 & 0.19 & -0.10 \\
\hline CABA (Argentina) & -0.05 & 0.82 & 0.68 & & & \\
\hline Israel & -0.06 & 0.44 & $\mathrm{~m}$ & & 0.09 & 0.09 \\
\hline Netherlands & -0.06 & 1.64 & 0.66 & 0.06 & 0.35 & -0.35 \\
\hline OECD average & -0.06 & 1.06 & 0.71 & 0.44 & 0.18 & -0.03 \\
\hline Bulgaria & -0.06 & 2.27 & 1.28 & 0.41 & 0.27 & 0.06 \\
\hline Lebanon & -0.07 & 1.20 & 2.02 & & & \\
\hline Denmark & -0.07 & 0.64 & 0.70 & & 0.32 & -0.43 \\
\hline Portugal & -0.07 & 0.31 & 0.38 & 0.53 & 0.21 & 0.07 \\
\hline Switzerland & -0.07 & 0.73 & 1.53 & 0.23 & 0.72 & 0.12 \\
\hline Spain & -0.07 & 0.43 & 0.20 & 0.80 & 0.24 & 0.02 \\
\hline Montenegro & -0.07 & 2.53 & 0.60 & 0.26 & -0.04 & -0.08 \\
\hline Croatia & -0.08 & 3.77 & 1.61 & 0.61 & -0.05 & -0.60 \\
\hline FYROM & -0.08 & 1.80 & 1.59 & & & \\
\hline Tunisia & -0.08 & 0.86 & 0.87 & 0.60 & 0.68 & 0.18 \\
\hline France & -0.08 & 1.07 & 0.81 & 0.90 & -0.20 & -0.02 \\
\hline Trinidad and Tobago & -0.09 & 2.32 & 0.80 & & & \\
\hline Georgia & -0.09 & 0.94 & 1.67 & & & \\
\hline Italy & -0.10 & 0.77 & 1.12 & 0.56 & -0.02 & 0.11 \\
\hline $\begin{array}{l}\text { Colombia } \\
\text { PS }\end{array}$ & -0.10 & 1.29 & 0.78 & 0.48 & 0.33 & 0.17 \\
\hline B-S-J-G (China) & -0.10 & 1.98 & 1.10 & 1.26 & 0.38 & 0.08 \\
\hline$\frac{\text { Russia }}{\text { Iclang }}$ & -0.10 & 1.38 & 1.05 & 0.63 & -0.29 & 0.38 \\
\hline Iceland & -0.11 & $\frac{0.42}{2.30}$ & 0.37 & 0.06 & 0.27 & -0.18 \\
\hline Greece & -0.12 & 2.38 & 1.28 & 0.67 & 0.14 & -0.48 \\
\hline$\frac{\text { Turkey }}{\text { Chile }}$ & -0.12 & 3.15 & 0.85 & 0.60 & 0.54 & 0.02 \\
\hline$\frac{\text { Chile }}{\text { Kosovo }}$ & $\begin{array}{l}-0.13 \\
-0.13\end{array}$ & 1.92 & 0.77 & 0.06 & 0.11 & 0.10 \\
\hline$\frac{\text { Kosovo }}{\text { Germany }}$ & $\begin{array}{l}-0.13 \\
-0.13\end{array}$ & $\begin{array}{l}1.45 \\
1.03\end{array}$ & $\frac{1.02}{0.82}$ & 0.53 & 070 & 023 \\
\hline Czech Republic & -0.14 & $\frac{1.05}{1.25}$ & 0.82 & 0.27 & & $\begin{array}{l}-0.23 \\
-0.23 \\
y\end{array} \mathrm{x}$ \\
\hline Dominican Republic & -0.15 & 0.73 & 0.58 & 0.44 & 0.03 & $\begin{array}{c}-0.23 \\
0.12 \\
\mathrm{~s}\end{array}$ \\
\hline Austria & -0.19 & 0.68 & 0.50 & 0.36 & 0.05 & $\frac{-12}{-0.27}$ \\
\hline $\begin{array}{l}\text { Mustra } \\
\text { Slovenia }\end{array}$ & $\begin{array}{l}-0.19 \\
-0.20\end{array}$ & 0.68 & 0.57 & 0.38 & 0.42 & $\begin{array}{l}-0.27 \\
-0.07\end{array}$ \\
\hline Slovak Republic & -0.20 & 2.04 & 0.88 & 0.56 & -0.13 & -0.23 \\
\hline Brazil & -0.20 & 1.31 & 1.06 & 0.42 & 0.24 & -0.16 \\
\hline Japan & -0.62 & 1.13 & 0.49 & 0.44 & -0.38 & 0.34 \\
\hline
\end{tabular}

Notes: Only those countries with a valid estimate for the immigrant-native gap in the school disciplinary climate index are displayed. The OECD and EU average percentage-point differences are based only on countries with reliable estimates for both native and immigrant students.

The index of disciplinary climate was constructed based on students responses about the frequency (i.e. "every lesson", "most lessons", "some lessons" and "never or hardly ever") with which "students don't listen to what the teacher says", "there is noise and disorder", "the teacher has to wait a long time for students to quiet down", "students cannot work well" and "students don't start working for a long time after the lesson begins" during their science lessons in school. The school score on the index was calculated as the average of the index values for students in the school.

Results on the effects of school climate are obtained from regressions accounting for students' gender, immigrant background, socio-economic status, the ISCED level of the class where they are enrolled, and the socio-economic profile of schools.

Students who attain baseline academic proficiency are those who reach at least PISA proficiency Level 2 in all three core PISA subjects: science, reading and mathematics.

Students who reported a sense of belonging at school are those who reported that they "agree" or "strongly agree" with the statement "I feel like I belong at school" and "disagree" or "strongly disagree" with the statement "I feel like an outsider at school".

Students who reported being satisfied with life are those who reported a life satisfaction of 7 or above on a scale from 0 to 10.

Students who reported low schoolwork-related anxiety are those who reported that they "disagree" or "strongly disagree" with the statements "I often worry that it will be difficult for me taking a test" and "Even if I am well prepared for a test, I feel very anxious".

Students who reported high motivation to achieve are those who reported that they "agree" or "strongly agree" with the statement "I want to be the best, whatever I do".

Countries and economies are ranked in descending order of the mean difference in the index of school disciplinary climate between schools attended by the average immigrant student and those attended by the average native student.

Source: OECD, PISA 2015 Database Tables 7.14 and 7.24

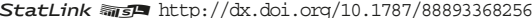


In Brazil, Chile, Colombia, the Czech Republic, Germany, Greece, Japan, Kosovo, Russia, the Slovak Republic and Turkey, a 0.10-point change in the disciplinary climate index reduced the likelihood of students attaining baseline academic proficiency by more than 1 percentage point. In Turkey, the effect amounted to a three percentage-point difference. The effects on the likelihood of students feeling like they belong at school were smaller within this group of countries; it is larger than one percentage point only in Brazil, Greece, Italy, Kosovo and Russia.

\section{Truancy}

Truancy is also a factor shaping the learning environment at school (OECD, 2016b). When truancy is pervasive, not only do many students miss learning opportunities, thus reducing opportunities for peer-to-peer learning, the pace of instruction is disrupted, teacher motivation and self-efficacy decline, and students are exposed to an atmosphere that devalues learning. Furthermore, truant students can generate resentment among students who attend class regularly; they might also tempt other students to skip class as well (Wilson et al., 2008). For immigrant students, truancy can also affect the likelihood of being academically resilient.

PISA 2015 measured truancy by asking students how many school days they had skipped in the two weeks prior the PISA test. In this chapter, truancy reflects the percentage of students in a school who reported that they had skipped at least one day of school in that two-week period.

Figure 7.12 shows that immigrant students in 2015 on average attended schools with higher truancy rates than the schools that native students attended. On average across OECD and EU countries, the average immigrant student attended a school where the rate of truancy was three percentage points higher than the average rate in schools attended by the average native student. The difference in truancy rates between the schools attended by the average immigrant and the schools attended by the average native was larger than five percentage points in Estonia (21 percentage points), France, Lithuania, Mexico, Peru, Tunisia and the United Arab Emirates. In Macao (China) and Qatar, immigrant students, on average, attended schools where the truancy rate was lower than in schools attended by native students.

Table 7.16 (available on line) shows that, on average, foreign-born returning students and native students of mixed heritage also attended schools where truancy was more widespread than in the schools that native students attended, although gaps between these two groups of students with an immigrant background and native students were smaller than those between other groups of immigrant students. On average across OECD countries, returning foreign-born students and native students of mixed heritage attended schools where the percentage of truant students was one percentage point larger than in schools attended by native students (two and one percentage points larger respectively across EU countries). Interestingly, it is often the case that in countries where immigrant students in 2015 were enrolled in schools with higher rates of truancy, the same was true for foreign-born returning students and native students of mixed heritage. This is observed in Austria, Estonia and Switzerland, where the differences between natives and students with an immigrant background were above average across all immigrant backgrounds.

Table 7.17 shows the association between the percentage of students in a school who play truant and the likelihood that students in that school will reach baseline levels of academic proficiency, report a strong sense of belonging, report being satisfied with their life, have low levels of schoolwork-related anxiety, and are highly motivated to achieve.

Table 7.17 indicates that the adverse effects of school level truancy rates were strongest on academic proficiency and sense of belonging in those countries and economies with less truancy. In BeijingShanghai-Jiangsu-Guangdong (China) (hereafter "B-S-J-G [China]") and the Netherlands, in 2015 a 10 percentage-point increase in the rate of truancy in a school was associated with a 14 percentage-point reduction in the likelihood that a student attained baseline levels of academic proficiency. However, since in these two economies the difference in average truancy between the schools that native and immigrant students attended was small (about two percentage points), school-level truancy did not explain much of the difference in academic outcomes between native and immigrant students. 
Figure 7.12 - Truancy rates in schools attended by the average immigrant and native student

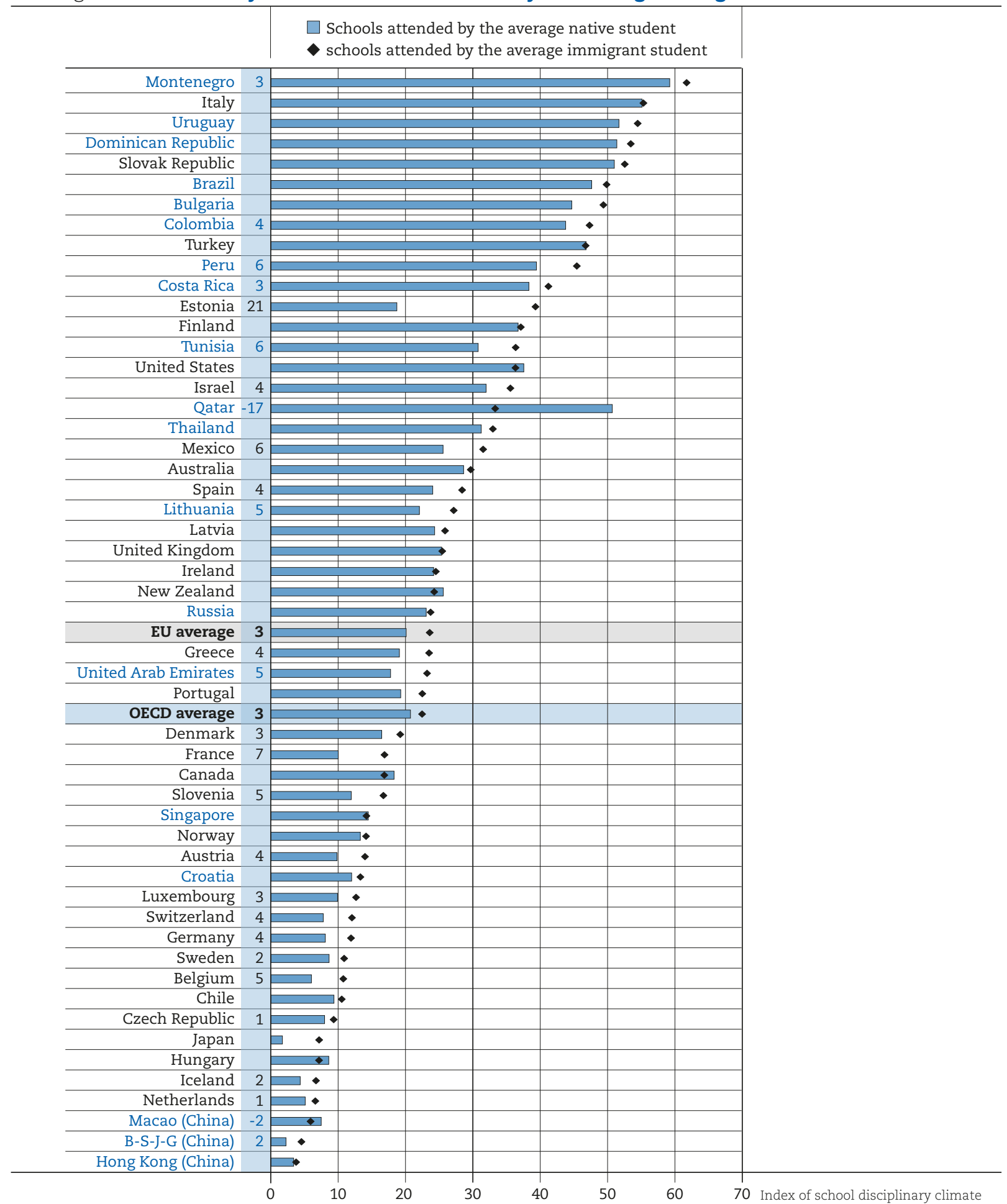

Notes: Only countries with valid data on immigrant students are shown.

The truancy rate is defined as the percentage of students in a school who reported that they had skipped at least one day of school in the two weeks prior to the PISA test.

Statistically significant differences between immigrant and native students are shown next to country/economy names. For the OECD and EU average, this number refers only to the subset of countries/economies with valid data on both groups of students.

Countries and economies are ranked in descending order of the average percentage of truant students in schools attended by the average immigrant student.

Source: OECD, PISA 2015 Database, Table 7.16.

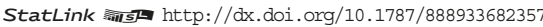


Table 7.17 - School-level truancy, and students' academic and well-being outcomes

\begin{tabular}{|c|c|c|c|c|c|c|}
\hline & \multicolumn{6}{|c|}{$\begin{array}{l}\text { Statistically significant and positive value } \\
\text { Statistically significant and negative value } \\
\text { Missing or invalid estimate }\end{array}$} \\
\hline & \multirow{2}{*}{$\begin{array}{l}\text { Percentage-point difference } \\
\text { in the percentage of } \\
\text { truant students in schools } \\
\text { attended by the average } \\
\text { immigrant student and } \\
\text { those attended by the } \\
\text { average native student }\end{array}$} & \multicolumn{5}{|c|}{$\begin{array}{c}\text { Effect of a } 10 \text { percentage-point increase in the percentage of truant students in a school } \\
\text { (percentage-point change) }\end{array}$} \\
\hline & & $\begin{array}{l}\text { On the likelihood } \\
\text { of attaining } \\
\text { baseline } \\
\text { academic } \\
\text { proficiency }\end{array}$ & $\begin{array}{l}\text { On the likelihood } \\
\text { of reporting } \\
\text { a sense of } \\
\text { belonging at } \\
\text { school }\end{array}$ & $\begin{array}{l}\text { On the likelihood } \\
\text { of reporting } \\
\text { being satisfied } \\
\text { with life }\end{array}$ & $\begin{array}{l}\text { On the likelihood } \\
\text { of reporting low } \\
\text { schoolwork- } \\
\text { related anxiety }\end{array}$ & $\begin{array}{l}\text { On the likelihood } \\
\text { of reporting high } \\
\text { achievement } \\
\text { motivation }\end{array}$ \\
\hline Estonia & 20.59 & -1.92 & -1.83 & -0.39 & -0.05 & 0.91 \\
\hline France & 6.87 & -6.70 & -2.04 & -0.99 & 0.14 & 2.54 \\
\hline Peru & 6.00 & -2.46 & 0.61 & 0.87 & -0.91 & -0.44 \\
\hline Mexico & 5.95 & -4.97 & -1.75 & -0.37 & -2.00 & -1.14 \\
\hline Tunisia & 5.57 & -1.80 & -0.85 & -0.09 & -0.12 & -0.72 \\
\hline Japan & 5.45 & -14.62 & -6.64 & -3.92 & 7.52 & -2.50 \\
\hline United Arab Emirates & 5.42 & 1.53 & -1.83 & -1.80 & -3.16 & -0.94 \\
\hline Lithuania & 5.09 & -6.69 & -2.07 & -1.06 & 0.98 & -0.42 \\
\hline Slovenia & 4.77 & -7.82 & -3.56 & -0.46 & 0.20 & 1.78 \\
\hline Belgium & 4.73 & -6.41 & -5.23 & 1.54 & -2.97 & 3.94 \\
\hline Bulgaria & 4.70 & -4.48 & -2.93 & -0.40 & 0.93 & 1.25 \\
\hline Greece & 4.41 & -8.44 & -2.24 & -1.51 & 0.49 & 0.87 \\
\hline Spain & 4.36 & -2.76 & 0.07 & -1.10 & 0.42 & 1.28 \\
\hline Switzerland & 4.26 & -4.69 & -4.53 & -0.93 & -1.25 & 0.51 \\
\hline Austria & 4.16 & -5.43 & -3.00 & -1.26 & 0.96 & 1.80 \\
\hline Germany & 3.81 & -4.77 & -1.10 & -1.28 & $\begin{array}{l}-1.01 \\
\end{array}$ & 2.08 \\
\hline EU average & 3.61 & -5.18 & -2.57 & -0.88 & -0.22 & 1.13 \\
\hline Israel & 3.60 & -1.45 & & & -3.00 & -0.02 \\
\hline Colombia & 3.55 & -2.70 & -1.36 & -0.14 & -0.67 & -0.46 \\
\hline Costa Rica & 2.90 & -2.30 & -0.34 & -0.08 & 0.08 & 0.37 \\
\hline Uruguay & 2.78 & -0.35 & -0.31 & -0.19 & 0.11 & 0.10 \\
\hline Denmark & 2.75 & -2.53 & -1.58 & & -0.44 & 1.26 \\
\hline Luxembourg & 2.75 & -10.16 & -10.15 & -2.94 & -7.38 & 6.10 \\
\hline OECD average & 2.70 & -5.06 & -2.63 & -1.00 & -0.22 & 0.85 \\
\hline Montenegro & 2.51 & -1.09 & -0.52 & -0.63 & 2.07 & -0.86 \\
\hline Iceland & 2.34 & -4.79 & -2.27 & -2.60 & 0.18 & 2.91 \\
\hline B-S-J-G (China) & 2.29 & -13.66 & -5.90 & -6.28 & -0.03 & 0.79 \\
\hline Sweden & 2.23 & -3.75 & -2.82 & & -0.10 & -0.11 \\
\hline Brazil & 2.21 & -2.35 & -1.21 & -0.68 & -0.06 & 0.49 \\
\hline Dominican Republic & 2.07 & -2.42 & -0.94 & -0.53 & -0.77 & 0.83 \\
\hline Thailand & 1.73 & -4.34 & -1.77 & -1.34 & -1.63 & -0.06 \\
\hline Portugal & 1.73 & -2.14 & -1.01 & -0.64 & -0.35 & 0.65 \\
\hline Slovak Republic & 1.55 & -1.64 & -0.58 & -0.18 & 0.92 & 1.00 \\
\hline Latvia & 1.55 & -4.39 & -2.24 & -1.82 & 0.30 & 0.26 \\
\hline Netherlands & 1.50 & -14.06 & -5.13 & -0.90 & -0.75 & 1.66 \\
\hline Czech Republic & 1.35 & -7.07 & -2.64 & -1.44 & 0.21 & -0.66 \\
\hline Croatia & 1.30 & -12.04 & -4.38 & -2.81 & 1.03 & 1.26 \\
\hline Chile & 1.16 & -6.58 & -1.30 & 1.28 & -2.08 & 0.79 \\
\hline Australia & 1.06 & -0.92 & 0.01 & & -0.11 & -0.29 \\
\hline Norway & 0.84 & -3.36 & -3.42 & & 0.00 & 2.18 \\
\hline Russia & 0.65 & -3.91 & -2.39 & -1.33 & 0.54 & 0.82 \\
\hline Finland & 0.40 & -0.13 & 0.16 & -0.60 & -0.33 & -2.38 \\
\hline Hong Kong (China) & 0.36 & -17.03 & -6.94 & -7.94 & -0.05 & -2.03 \\
\hline Ireland & 0.32 & -1.56 & -1.64 & -0.14 & 0.27 & 0.97 \\
\hline Italy & 0.19 & -4.97 & 0.03 & -0.62 & -0.58 & 2.52 \\
\hline United Kingdom & 0.08 & -1.53 & -0.90 & -0.30 & -0.31 & -0.09 \\
\hline Turkey & -0.07 & 0.26 & -0.65 & -0.81 & 0.21 & -0.22 \\
\hline Singapore & -0.28 & -2.75 & -0.74 & & -0.95 & 0.11 \\
\hline United States & -1.24 & -1.83 & -0.94 & 0.34 & -0.10 & -0.22 \\
\hline New Zealand & -1.35 & -3.59 & -1.21 & & -0.66 & 0.10 \\
\hline Canada & -1.45 & -3.95 & -0.68 & & -2.25 & 4.90 \\
\hline Hungary & -1.45 & -6.08 & -2.37 & 0.40 & 0.95 & 0.73 \\
\hline Macao (China) & -1.58 & -15.80 & -2.89 & -5.39 & 1.87 & 6.23 \\
\hline Qatar & -17.40 & -7.54 & -2.21 & 0.96 & 2.62 & 0.15 \\
\hline
\end{tabular}

Notes: Only those countries with a valid estimate for the difference in the percentage of truant students in schools attended by the average immigrant student and those attended by the average native student are displayed. The OECD and EU average percentage-point differences are based only on countries with reliable estimates for both native and immigrant students.

The percentage of truant students in a school is defined as the percentage of students in a school who reported that they had skipped at least one day of school in the two weeks prior to the PISA test.

Results on the effects of school average truancy are obtained from regressions accounting for students' gender, immigrant background, socio-economic status, the ISCED level of the class where they are enrolled, and the socio-economic profile of schools.

Students who attain baseline academic proficiency are those who reach at least PISA proficiency Level 2 in all three core PISA subjects: science, reading and mathematics.

Students who reported a sense of belonging at school are those who reported that they "agree" or "strongly agree" with the statement "I feel like I belong at school" and "disagree" or "strongly disagree" with the statement "I feel like an outsider at school".

Students who reported being satisfied with life are those who reported a life satisfaction of 7 or above on a scale from 0 to 10 .

Students who reported low schoolwork-related anxiety are those who reported that they "disagree" or "strongly disagree" with the statements "I often worry that it will be difficult for me taking a test" and "Even if I am well prepared for a test, I feel very anxious".

Students who reported high motivation to achieve are those who reported that they "agree" or "strongly agree" with the statement "I want to be the best, whatever I do".

Countries and economies are ranked in descending order of the percentage-point difference in the percentage of truant students in schools attended by the average immigrant student and those attended by the average native student.

Source: OECD, PISA 2015 Database Tables 7.16 and 7.24

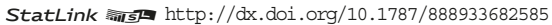


In another set of countries, the effects of truancy were weaker, but the average difference between schools attended by the average native student and those attended by the average immigrant student was larger. In Belgium, France, Greece, Lithuania and Slovenia, where this difference was more than four percentage points, a 10 percentage-point increase in the percentage of students who played truant during the two weeks prior to the PISA test reduced the probability that students attained baseline academic proficiency by at least six percentage points. Truancy's negative effect on students' sense of belonging ranged from 1 to 10 percentage points; its effects on life satisfaction, schoolwork-related anxiety and motivation were small.

\section{Bullying}

Relationships between students also affect school climate and its conduciveness to effective learning and well-being. Bullying is a form of student-on-student interaction that has harmful effects on individual students, their families and the school community. Bullies or victims of bullying perform worse academically and are more likely to show symptoms of depression, feel lonely and have low self-esteem (Konishi et al. 2010; Townsend et al., 2008; Haynie et al., 2001; Kochel et al., 2012; Striegel-Moore et al., 2002). Students who are frequently bullied may feel constantly insecure and have difficulties finding their place at school (Rivara and Le Menestrel, 2016). They are also more likely to experience schoolwork-related anxiety (Berry and Hunt, 2009) and to report low satisfaction with life (OECD, 2017).

Immigrant students are more likely to be victimised because of differences in language, culture, ethnicity and appearance (Qin, Way and Rana, 2008). They can be targeted because of poor language proficiency (Peguero, 2008) or long-standing conflicts between ethnic or national groups (McKenney et al. 2006). Rates of victimisation are higher among recent arrivals (OECD, 2017) because of their unfamiliarity with the language or weaker social networks.

Figure 7.13 - Victims of frequent bullying, by immigrant background Based on students' self-reports

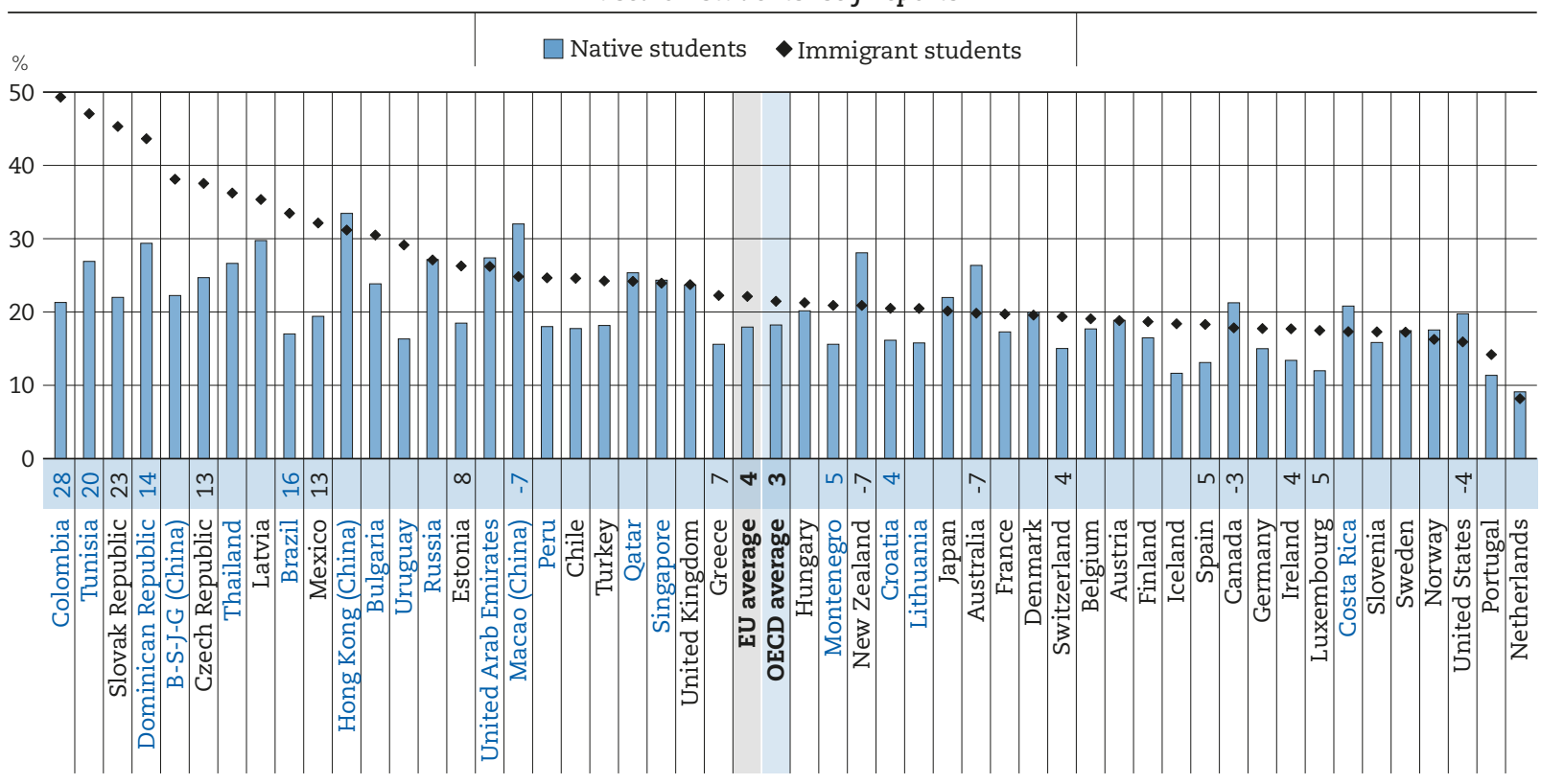

Notes: Only countries with valid data on immigrant students are shown.

Students who reported being frequently bullied are those who answered "a few times a month" or "once a week or more" to at least one of the the questions about how often, during the previous 12 months: "Other students left me out of things on purpose"; "Other students made fun of me"; "I was threatened by other students"; "Other students took away or destroyed things that belong to me"; "I got hit or pushed around by other students"; and "Other students spread nasty rumours about me".

Statistically significant differences between immigrant and native students are shown next to country/economy names. For the OECD and EU average, this number refers only to the subset of countries/economies with valid data on both groups of students.

Countries and economies are ranked in descending order of the percentage of immigrant students who reported being victims of frequent bullying.

Source: OECD, PISA 2015 and 2012 Database, Table 7.18.

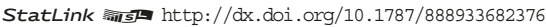


In PISA 2015, bullying was measured by asking students how often they experienced the following in the previous 12 months: "other students left me out of things on purpose"; "other students made fun of me"; "I was threatened by other students"; "other students took away or destroyed things that belong to me"; "I got hit or pushed around by other students"; or "other students spread nasty rumours about me". Possible responses were "never or almost never", "a few times a year", "a few times a month", "once a week or more". Answers were coded into binary responses where the first two answers correspond to "rarely" and the latter two are considered "often". The six items were then summarised into a single binary variable indicating whether a child reported that he or she had frequently experienced at least one form of bullying in the previous 12 months.

Figure 7.13 shows that PISA results are consistent with the finding in the literature that immigrant students are more likely than native students to be victims of bullying. On average across OECD countries, the percentage of immigrant students who reported having been victim of at least one form of bullying in the previous 12 months was three percentage points greater than that of native students (four percentage points greater across EU countries). In Brazil, Colombia, the Czech Republic, the Dominican Republic, Mexico, the Slovak Republic and Tunisia, the difference was greater than 10 percentage points. By contrast, in Australia, Canada, Macao (China), New Zealand and the United States, native students were more likely than immigrant students to be victims of frequent bullying.

Results show that, in 40 out of the 50 countries and economies that included questions on bullying in the student questionnaire and had valid data on immigrant students, victims of frequent bullying were less likely to attain baseline levels of proficiency in the three core PISA subjects. On average across OECD countries, they were six percentage points less likely to do so. In Croatia, the Czech Republic, Greece, Luxembourg, Montenegro, Portugal, the Slovak Republic and Spain, where immigrant students were more likely to be frequent victims of bullying, these students were more than eight percentage points less likely to attain baseline academic proficiency (Table 7.19).

Table 7.19 shows that bullying has strong adverse effects on immigrant students' sense of belonging at school and satisfaction with life. In all countries and economies with available data, students who reported being frequent victims of at least one form of bullying in the previous 12 months were less likely to feel satisfied with their life or feel that they belong at school. On average across OECD and EU countries, the percentages of students who reported feeling like they belong at school and being satisfied with life were 23 and 18 percentage points lower, respectively, among bullied students than among students who reported that they were not frequently bullied during that period (22 and 18 percentage points, respectively, across EU countries). In all countries and economies where immigrant students were more likely to be victims of frequent bullying, the adverse effects of bullying on both immigrant students' likelihood of being satisfied with life and the likelihood of reporting a sense of belonging was more than 11 percentage points. Effects were particularly strong in Ireland, where immigrant students were 4 percentage points more likely than native students to be frequent victims of bullying, and where bullied students were 30 percentage points less likely than native students to feel like they belong at school and 24 percentage points less likely to be satisfied with their life. There bullying played a considerably role in decreasing the social and emotional resilience of immigrant students.

Frequently bullied students were less likely to enjoy low levels of schoolwork-related anxiety in all countries and economies with available data except Japan. On average across OECD and EU countries, frequently bullied students were 10 percentage points less likely to report low levels of such anxiety. In countries where immigrant students were more often frequent victims of bullying, the adverse effects of bullying on the likelihood of having low levels of anxiety ranged from two percentage points (in Brazil) to 17 percentage points in Switzerland. The effects of bullying on achievement motivation were not statistically significant in the majority of countries and economies.

\section{Student-teacher interactions}

The well-paced and orderly instruction that can occur in a positive disciplinary climate where students attend school regularly appears to be a necessary, but not a sufficient, condition to ensure that immigrant students receive the support they need to become academically, socially and emotionally resilient. 
Table 7.19 - Frequent bullying, and students' academic and well-being outcomes

\begin{tabular}{|c|c|c|c|c|c|c|}
\hline & \multicolumn{2}{|c|}{$\begin{array}{l}\text { Statistically significant and positive value } \\
\text { Statistically significant and negative value } \\
\text { Missing or invalid estimate }\end{array}$} & & & & \\
\hline & \multirow[b]{2}{*}{$\begin{array}{l}\text { Percentage-point difference } \\
\text { between immigrant and } \\
\text { native students in the } \\
\text { percentage of students } \\
\text { who reported being victims } \\
\text { of frequent bullying }\end{array}$} & \multicolumn{5}{|c|}{ Effect of being bullied frequently (percentage-point change) } \\
\hline & & $\begin{array}{l}\text { On the likelihood } \\
\text { of attaining } \\
\text { baseline } \\
\text { academic } \\
\text { proficiency }\end{array}$ & $\begin{array}{l}\text { On the likelihood } \\
\text { of reporting } \\
\text { a sense of } \\
\text { belonging at } \\
\text { school }\end{array}$ & $\begin{array}{l}\text { On the likelihood } \\
\text { of reporting } \\
\text { being satisfied } \\
\text { with life }\end{array}$ & $\begin{array}{l}\text { On the likelihood } \\
\text { of reporting low } \\
\text { schoolwork- } \\
\text { related anxiety }\end{array}$ & $\begin{array}{l}\text { On the likelihood } \\
\text { of reporting high } \\
\text { achievement } \\
\text { motivation }\end{array}$ \\
\hline Colombia & 28.01 & -5.41 & -13.13 & -13.84 & -3.58 & -1.18 \\
\hline Slovak Republic & 23.32 & -8.71 & -23.25 & -17.91 & -7.70 & 1.69 \\
\hline Tunisia & 20.14 & -1.86 & -15.55 & -14.31 & -10.14 & -0.23 \\
\hline Brazil & 16.46 & -4.79 & -20.66 & -13.88 & -1.85 & -0.35 \\
\hline B-S-J-G (China) & 15.86 & -3.85 & -18.67 & -17.78 & -6.84 & -0.70 \\
\hline Dominican Republic & 14.26 & -2.47 & -11.69 & -11.98 & -3.43 & -1.24 \\
\hline Czech Republic & 12.85 & -8.04 & -19.14 & -18.12 & -10.56 & -0.04 \\
\hline Uruguay & 12.82 & -4.27 & -21.28 & -18.99 & -2.75 & 3.05 \\
\hline Mexico & 12.73 & -5.88 & -18.66 & -14.37 & -9.70 & -0.57 \\
\hline Thailand & 9.60 & -9.28 & -17.93 & -10.87 & -14.83 & -0.46 \\
\hline Estonia & 7.80 & -0.58 & -19.71 & -13.13 & -7.57 & 0.83 \\
\hline Chile & 6.85 & -6.56 & -21.65 & -15.51 & -13.49 & 0.47 \\
\hline Iceland & 6.75 & -6.99 & -25.92 & -26.79 & -12.21 & -2.53 \\
\hline Greece & 6.66 & -8.87 & -26.23 & -18.42 & -5.47 & 2.88 \\
\hline Bulgaria & 6.65 & -4.31 & -14.40 & -14.19 & -9.87 & 2.03 \\
\hline Peru & 6.65 & -5.52 & -16.67 & -15.44 & -5.13 & -2.24 \\
\hline Turkey & 6.07 & -4.49 & -14.62 & -18.76 & -6.63 & -1.76 \\
\hline Latvia & 5.60 & -6.81 & -19.46 & -13.02 & -11.05 & 1.74 \\
\hline Luxembourg & 5.49 & -11.38 & -24.27 & -18.18 & -8.64 & 4.90 \\
\hline Montenegro & 5.30 & -8.52 & -15.51 & -14.58 & -3.35 & 3.10 \\
\hline Spain & 5.19 & -8.49 & -22.50 & -18.13 & -7.83 & 1.02 \\
\hline Lithuania & 4.70 & -7.47 & -9.64 & -18.58 & -7.37 & -1.59 \\
\hline Croatia & 4.35 & -9.28 & -22.24 & -16.83 & -14.54 & 3.20 \\
\hline Switzerland & 4.33 & -6.26 & -24.37 & -18.91 & -17.15 & 3.58 \\
\hline Ireland & 4.30 & -2.15 & -30.27 & -24.24 & -9.85 & 0.11 \\
\hline EU average & 4.23 & -6.71 & -22.34 & -18.22 & -10.01 & 1.80 \\
\hline OECD average & 3.11 & -5.97 & -23.15 & -18.13 & -9.86 & 1.25 \\
\hline Portugal & 2.83 & -11.06 & -25.55 & -18.08 & -9.53 & -2.56 \\
\hline Germany & 2.75 & -5.25 & -29.48 & -21.29 & -15.97 & -1.22 \\
\hline France & 2.43 & -5.43 & -9.13 & -16.79 & -12.28 & 4.42 \\
\hline Finland & 2.20 & -4.46 & -30.14 & -14.57 & -10.06 & 1.55 \\
\hline Slovenia & 1.46 & -6.89 & -20.99 & -21.23 & -6.65 & 6.79 \\
\hline Belgium & 1.38 & -4.55 & -21.12 & -22.40 & -13.04 & 3.09 \\
\hline Hungary & 1.10 & -6.56 & -26.56 & -18.56 & -11.37 & -1.88 \\
\hline United Kingdom & 0.04 & -6.30 & -31.71 & -24.03 & -8.42 & -1.01 \\
\hline Austria & -0.04 & -2.90 & -20.41 & -16.77 & -11.06 & 2.26 \\
\hline Russia & -0.05 & -3.79 & -22.09 & -14.46 & -6.03 & 2.98 \\
\hline Sweden & -0.20 & -6.46 & -18.01 & & -6.18 & 1.23 \\
\hline Denmark & -0.40 & -7.33 & -20.83 & & -7.07 & 5.02 \\
\hline Singapore & -0.41 & -7.14 & -25.88 & & -6.06 & 0.46 \\
\hline Netherlands & -0.94 & -7.39 & -30.72 & -17.27 & -11.83 & 4.59 \\
\hline Qatar & -1.16 & -8.96 & -23.14 & -17.94 & -10.80 & -2.35 \\
\hline United Arab Emirates & -1.18 & -11.83 & -22.24 & -15.54 & -9.60 & -2.32 \\
\hline Norway & -1.28 & -7.35 & -32.68 & & -8.14 & -0.20 \\
\hline Japan & -1.85 & -1.85 & -14.58 & -13.77 & -1.81 & 1.27 \\
\hline Hong Kong (China) & -2.28 & -1.13 & -12.23 & -11.40 & -6.46 & -2.46 \\
\hline Canada & -3.42 & -6.73 & -26.51 & & -7.88 & 1.31 \\
\hline Costa Rica & -3.49 & 1.10 & -16.01 & -19.59 & -3.07 & -4.57 \\
\hline United States & -3.83 & -7.22 & -28.10 & -19.56 & -8.48 & -0.54 \\
\hline Australia & -6.53 & -8.50 & -34.39 & & -10.46 & -0.99 \\
\hline New Zealand & -7.18 & -7.13 & -30.27 & & -11.84 & -1.23 \\
\hline Macao (China) & -7.18 & -7.35 & -20.07 & -11.55 & -8.95 & 7.41 \\
\hline
\end{tabular}

Notes: Only those countries with a valid estimate for the difference in the percentage of immigrant and native students who reported being victims of frequent bullying are displayed. The OECD and EU average percentage-point differences are based only on countries with reliable estimates for both native and immigrant students.

Students who reported being frequently bullied are those who answered "a few times a month" or "once a week or more" to at least one of the the questions about how often, during the previous 12 months: "Other students left me out of things on purpose"; "Other students made fun of me"; "I was threatened by other students"; "Other students took away or destroyed things that belong to me"; "I got hit or pushed around by other students"; and "Other students spread nasty rumours about me".

Results on the effects of being bullied frequently are obtained from regressions that account for students' gender, immigrant background and socio-economic status, as well as the socio-economic profile of schools.

Students who attain baseline academic proficiency are those who reach at least PISA proficiency Level 2 in all three core PISA subjects: science, reading and mathematics.

Students who reported a sense of belonging at school are those who reported that they "agree" or "strongly agree" with the statement "I feel like I belong at school" and "disagree" or "strongly disagree" with the statement "I feel like an outsider at school".

Students who reported being satisfied with life are those who reported a life satisfaction of 7 or above on a scale from 0 to 10.

Students who reported low schoolwork-related anxiety are those who reported that they "disagree" or "strongly disagree" with the statements "I often worry that it will be difficult for me taking a test" and "Even if I am well prepared for a test, I feel very anxious".

Students who reported high motivation to achieve are those who reported that they "agree" or "strongly agree" with the statement "I want to be the best, whatever I do".

Countries and economies are ranked in descending order of the percentage-point difference between immigrant and native students in the percentage of students who reported being victims of frequent bullying.

Source: OECD, PISA 2015 Database Tables 7.19 and 7.24

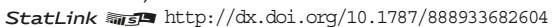


Immigrant students need support from their teachers in order to make the most of the learning opportunities that are available to them (Klem and Connell, 2004). The literature suggests that at-risk students have more positive attitudes and higher academic motivation if teachers care about them and help them when they need it (Pitzer and Skinner, 2016; Ricard and Pelletier, 2016).

One of the ways in which PISA can be used to examine the support teachers give to students with an immigrant background is by asking students to report the frequency with which, over the previous 12 months, "teachers called on [me] less often than they called on other students"; "teachers graded [me] harder than they graded other students"; "teachers gave [me] the impression that they think [I] am less smart than [I] really am"; "teachers disciplined [me] more harshly than other students"; "teachers ridiculed [me] in front of others"; and "teachers said something insulting to [me] in front of others". Possible responses were "never or almost never", "a few times a year", "a few times a month", "once a week or more". Answers were coded into binary responses where the first two answers correspond to "rarely" and the latter two are considered "frequently". The six items were then summarised into a single binary variable indicating whether a student reported having frequently experienced at least one of the situations detailed above in the previous 12 months.

The use of such a variable was preferred over an index, because the latter consists of an average of the responses to the six questions, which could mask important results. For example, a student could report being insulted once a week or more, but respond "never" to all other questions, which would yield a relatively low score on an index, similar to another student answering "a few times a year" to all questions. The proposed binary variable is more effective in signalling frequent mistreatment of any sort. ${ }^{6}$

Figure 7.14 - Students reporting unfair treatment by teachers, by immigrant background

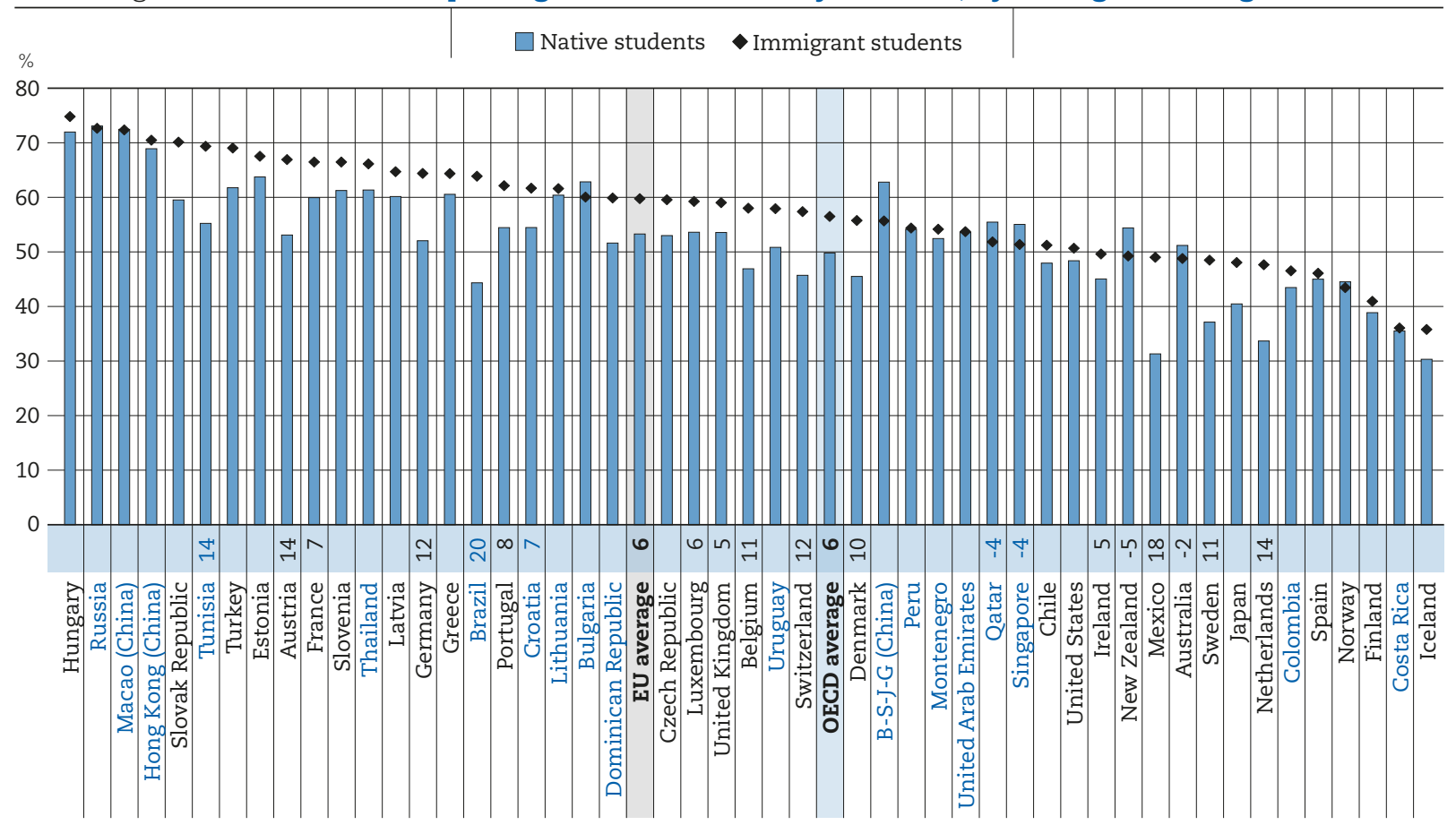

Notes: Only countries with valid data on immigrant students are shown.

Students who reported frequent unfair treatment by their teachers are those who answered "a few times a month" or "once a week or more" to at least one of the questions of how often, during the previous 12 months: "Teachers called me less often than they called on other students"; "Teachers graded me harder than they graded other students"; "Teachers gave me the impression that they think I am less smart than I really am"; "Teachers disciplined me more harshly than other students"; "Teachers ridiculed me in front of others"; and "teachers said something insulting me in front of others".

Statistically significant differences between immigrant and native students are shown next to country/economy names. For the OECD and EU average, this number refers only to the subset of countries/economies with valid data on both groups of students.

Countries and economies are ranked in descending order of the percentage of immigrant students who reported unfair treatment by teachers.

Source: OECD, PISA 2015 Database, Table 7.20.

StatLink 形) http://dx.doi.org/10.1787/888933682395 
Figure 7.14 shows that in 16 countries and economies the percentage of students who reported that they were frequently treated unfairly in the previous 12 months was higher among immigrant students than native students. On average across OECD and EU countries, the difference was approximately six percentage points, but significant differences were observed across countries. In Austria, Belgium, Brazil, Denmark, Germany, Mexico, the Netherlands, Sweden, Switzerland and Tunisia, the difference was greater than 10 percentage points; in Brazil and Mexico, it was more than 15 percentage points.

Table 7.20 (available on line) shows that, in most countries and economies, first- and second-generation immigrant students were equally likely to report frequent unfair treatment from their teachers. However, in Norway, Spain Sweden, the United Kingdom and the United States, second-generation immigrant students were more likely to report so. The table also shows that students with an immigrant background who have at least one native-born parent were also more likely than native students to report being treated unfairly by their teachers. In Mexico and Peru, the percentage of native students of mixed heritage who reported unfair treatment was over 20 percentage points higher than the percentage of native students who so reported. In Colombia, the Dominican Republic and the Netherlands, the difference was between 12 and 14 percentage points. In Belgium, Colombia, Croatia and the Dominican Republic, foreignborn returning students were over 10 percentage points more likely to report frequent unfair treatment from their teachers than their native peers. Unfair treatment by teachers can decrease both the academic and social resilience of immigrant students.

Table 7.21 shows the adverse consequences of enduring at least one form of perceived mistreatment from a teacher on academic and well-being outcomes. In all countries and economies but three, the percentage of students who attained baseline levels of academic proficiency was lower among students who perceived unfairness by their teachers compared to other students. On average across OECD and EU countries the difference was about eight percentage points. In Denmark, Mexico and Sweden, where immigrant students were over 10 percentage points more likely than native students to report having suffered some form of unfair treatment from their teachers in the previous 12 months, students who so reported were more than 10 percentage points less likely to attain baseline levels of academic proficiency than other students. Because these results are obtained while accounting for students' and schools' socio-economic profile, they do not reflect the lower likelihood that immigrant students attain baseline levels of proficiency and the greater likelihood that they perceive unfair treatment by their teachers.

The association between students reporting that they have been treated unfairly by their teachers and students' outcomes are even more pronounced when considering students' social and emotional wellbeing. On average across OECD, students who reported that their teachers frequently treated them unfairly during the previous 12 months were 11 percentage points less likely feel a sense of belonging at school (10 percentage points less likely across EU countries), 10 percentage points less likely to reporting feeling satisfied with their life (10 percentage points less likely across EU countries), and eight percentage points less likely to report low levels of schoolwork-related anxiety (eight percentage points less likely across EU countries). The effects on achievement motivation were smaller and significant only in a small group of countries.

In several countries and economies, the negative effects of perceived teacher unfairness are strong for more than one well-being outcome. In Belgium, Germany, Mexico, Switzerland and Tunisia, where immigrant students were more than 10 percentage points more likely than native students to report frequent unfair treatment from their teachers, students who so reported were at least 9 percentage points less likely to report feeling like they belong at school, feeling satisfied with their life, and that they do not suffer much from schoolwork-related anxiety. In Belgium and Mexico, these students were as much as 14 percentage points less likely to report feeling a sense of belonging. In Ireland and the United Kingdom, they were 16 and 17 percentage points, respectively, less likely to report feeling like they belong at school, and 16 and 14 percentage points, respectively, less likely to report being satisfied with life. Evidence shows that poor teacher-student relations have a strong impact on several aspects of students' well-being as well as on their academic performance. 
Table 7.21 - Perceived frequent unfair treatment by teachers, and students' academic and well-being outcomes

\begin{tabular}{|c|c|c|c|c|c|c|}
\hline & \multicolumn{2}{|c|}{$\begin{array}{l}\text { Statistically significant and positive value } \\
\text { Statistically significant and negative value } \\
\text { Missing or invalid estimate }\end{array}$} & & & & \\
\hline & \multirow[b]{2}{*}{$\begin{array}{l}\text { Percentage-point difference } \\
\text { between immigrant and } \\
\text { native students in the } \\
\text { percentage of students who } \\
\text { reported frequent unfair } \\
\text { treatment by teachers }\end{array}$} & \multicolumn{5}{|c|}{ Effect of perceiving frequent unfair treatment by teachers (percentage-point change) } \\
\hline & & $\begin{array}{l}\text { On the likelihood } \\
\text { of attaining } \\
\text { baseline } \\
\text { academic } \\
\text { proficiency }\end{array}$ & $\begin{array}{l}\text { On the likelihood } \\
\text { of reporting } \\
\text { a sense of } \\
\text { belonging at } \\
\text { school }\end{array}$ & $\begin{array}{l}\text { On the likelihood } \\
\text { of reporting } \\
\text { being satisfied } \\
\text { with life }\end{array}$ & $\begin{array}{l}\text { On the likelihood } \\
\text { of reporting low } \\
\text { schoolwork- } \\
\text { related anxiety }\end{array}$ & $\begin{array}{l}\text { On the likelihood } \\
\text { of reporting high } \\
\text { achievement } \\
\text { motivation }\end{array}$ \\
\hline Brazil & 19.53 & -7.87 & -6.47 & -3.65 & -2.00 & 1.53 \\
\hline Mexico & 17.70 & -12.06 & -14.11 & -9.87 & -12.25 & -1.82 \\
\hline Tunisia & 14.13 & -5.01 & -11.93 & -12.42 & -9.83 & -1.60 \\
\hline Netherlands & 13.97 & -3.48 & -9.89 & -7.85 & -5.91 & 2.65 \\
\hline Austria & 13.83 & -5.15 & -5.25 & -12.55 & -14.44 & -1.16 \\
\hline Germany & 12.34 & -5.81 & -10.51 & -11.15 & -13.31 & 0.72 \\
\hline Switzerland & 11.67 & -8.98 & -11.68 & -10.26 & -9.41 & 2.05 \\
\hline Sweden & 11.35 & -11.70 & -12.23 & & -8.10 & 5.69 \\
\hline Belgium & 11.10 & -6.54 & -13.97 & -10.92 & -11.53 & 2.82 \\
\hline Slovak Republic & 10.60 & -10.81 & -12.44 & -7.45 & -9.63 & -1.71 \\
\hline Denmark & 10.25 & -10.10 & -12.57 & & -4.49 & 3.20 \\
\hline Dominican Republic & 8.26 & -5.69 & -8.94 & -4.98 & -4.40 & 2.10 \\
\hline Portugal & 7.69 & -6.31 & -9.59 & -10.06 & -5.30 & 1.52 \\
\hline Japan & 7.59 & -6.86 & -8.81 & -9.55 & -3.36 & 3.11 \\
\hline Turkey & 7.27 & -6.08 & -1.78 & -10.21 & -8.33 & 0.86 \\
\hline Croatia & 7.21 & -7.87 & -10.48 & -6.47 & -9.61 & 2.69 \\
\hline Uruguay & 7.09 & -6.18 & -7.85 & -5.89 & -2.04 & 3.58 \\
\hline Czech Republic & 6.56 & -10.29 & -10.67 & -8.19 & -7.45 & 3.14 \\
\hline EU average & 6.55 & -7.61 & -10.17 & -9.90 & -8.16 & 1.70 \\
\hline France & 6.53 & -6.68 & -10.27 & -10.20 & -9.33 & 2.33 \\
\hline OECD average & 6.33 & -7.90 & -10.54 & -10.14 & -7.98 & 1.44 \\
\hline Luxembourg & 5.64 & -7.76 & -11.25 & -10.60 & -10.55 & 1.85 \\
\hline Iceland & 5.47 & -10.81 & -10.55 & -13.65 & -10.24 & 3.99 \\
\hline United Kingdom & 5.46 & -7.02 & -16.64 & -13.78 & -4.47 & 1.25 \\
\hline Slovenia & 5.22 & -4.09 & -6.63 & -9.68 & -6.25 & -0.10 \\
\hline Thailand & 4.79 & -6.82 & -4.80 & -4.31 & -9.11 & 0.06 \\
\hline Ireland & 4.58 & -6.22 & -16.36 & -15.83 & -6.66 & -0.40 \\
\hline Latvia & 4.55 & -9.11 & -7.93 & -7.10 & -6.63 & 3.57 \\
\hline Greece & 3.80 & -8.03 & -7.30 & -8.71 & -5.44 & 2.15 \\
\hline Estonia & 3.79 & -5.53 & -9.75 & -10.98 & -7.31 & 2.96 \\
\hline Chile & 3.28 & -6.85 & -10.10 & -6.21 & -10.84 & 0.05 \\
\hline Colombia & 3.06 & -5.02 & -8.93 & -8.52 & -2.15 & 0.15 \\
\hline Hungary & 2.83 & -8.92 & -9.59 & -8.89 & -10.18 & -1.06 \\
\hline United States & 2.29 & -7.92 & -12.11 & -9.98 & -8.76 & 0.00 \\
\hline Finland & 2.08 & -10.33 & -12.22 & -8.13 & -9.49 & 2.39 \\
\hline Montenegro & 1.71 & -5.65 & -3.04 & -9.82 & -5.67 & -0.35 \\
\hline Hong Kong (China) & 1.57 & -1.75 & -4.25 & -6.97 & -6.66 & 2.11 \\
\hline Lithuania & 1.20 & -9.66 & -4.36 & -6.12 & -8.85 & 0.79 \\
\hline Spain & 1.08 & -8.68 & -5.25 & -11.20 & -4.52 & 1.13 \\
\hline Costa Rica & 0.53 & -7.23 & -8.27 & -9.86 & -0.58 & -0.24 \\
\hline Peru & 0.23 & -6.07 & -8.37 & -10.46 & -4.30 & 0.02 \\
\hline United Arab Emirates & 0.16 & -11.55 & -13.47 & -9.97 & -10.64 & -0.89 \\
\hline Macao (China) & -0.10 & -3.75 & -6.98 & -7.43 & -7.61 & 0.00 \\
\hline Russia & -0.42 & -6.17 & -9.48 & -9.61 & -8.76 & 3.48 \\
\hline Norway & -1.07 & -9.75 & -16.71 & & -6.50 & 3.77 \\
\hline Australia & -2.40 & -6.69 & -13.86 & & -6.50 & -0.22 \\
\hline Bulgaria & -2.79 & -0.49 & -6.10 & -5.77 & -6.91 & 4.42 \\
\hline Qatar & -3.62 & -8.55 & -10.21 & -11.15 & -8.38 & 1.94 \\
\hline Singapore & -3.68 & -4.64 & -9.05 & & -5.37 & 0.29 \\
\hline New Zealand & -5.14 & -8.07 & -15.03 & & -6.01 & -0.91 \\
\hline B-S-J-G (China) & -7.11 & -0.23 & -5.17 & -6.37 & -5.29 & 1.06 \\
\hline
\end{tabular}

Notes: Only those countries with a valid estimate for the difference in the percentage of immigrant and native students who reported being treated unfairly by their teachers are displayed. The OECD and EU average percentage-point differences are based only on countries with reliable estimates for both native and immigrant students.

Students who reported frequent unfair treatment by their teachers are those who answered "a few times a month" or "once a week or more" to at least one of the questions of how often, during the previous 12 months: "Teachers called me less often than they called on other students"; "Teachers graded me harder than they graded other students"; "Teachers gave me the impression that they think I am less smart than I really am"; "Teachers disciplined me more harshly than other students"; "Teachers ridiculed me in front of others"; and "teachers said something insulting me in front of others".

Results on the effects of perceiving frequent unfair treatment by teachers are obtained from regressions that account for students' gender, immigrant background and socio-economic status, as well as the socio-economic profile of schools.

Students who attain baseline academic proficiency are those who reach at least PISA proficiency Level 2 in all three core PISA subjects: science, reading and mathematics.

Students who reported a sense of belonging at school are those who reported that they "agree" or "strongly agree" with the statement "I feel like I belong at school" and "disagree" or "strongly disagree" with the statement "I feel like an outsider at school".

Students who reported being satisfied with life are those who reported a life satisfaction of 7 or above on a scale from 0 to 10.

Students who reported low schoolwork-related anxiety are those who reported that they "disagree" or "strongly disagree" with the statements "I often worry that it will be difficult for me taking a test" and "Even if I am well prepared for a test, I feel very anxious".

Students who reported high motivation to achieve are those who reported that they "agree" or "strongly agree" with the statement "I want to be the best, whatever I do".

Countries and economies are ranked in descending order of the percentage-point difference between immigrant and native students in the percentage of students who reported frequent unfair treatment by teachers.

Source: OECD, PISA 2015 Database Table 7.20 and Table 7.24.

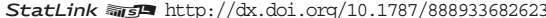


Another aspect of student-teacher relations that PISA 2015 aimed to measure was the amount of academic feedback and guidance that students receive from their teachers. Students were asked to report, with reference to their science class, the frequency with which "the teacher tells me how I am performing in this course"; "the teacher gives me feedback on my strength in this subject"; "the teacher tells me in which areas I can improve"; "the teacher tells me how I can improve my performance"; and "the teacher advises me on how to reach my learning goals". Possible responses were "never or almost never", "some lessons", "many lessons" and "every lesson or almost every lesson". Responses were summarised in a single index signalling whether a student answered "many lessons" or "every lesson or almost every lesson" to at least one of the five questions.

Figure 7.15 shows that immigrant students were more likely than native students to report receiving frequent feedback from their teachers. On average across OECD and EU countries, the percentage of student answering "many lessons" or "every lesson or almost every lesson" to at least one of the questions was six percentage points higher among immigrant students than among native students. To account for the fact that the feedback from science teachers is related to students' science performance and that immigrant students tend to perform worse than native students, Figure 7.15 also shows differences accounting for science performance. Some of the differences are reduced but most remain statistically significant, indicating that immigrant students were not receiving more feedback than native students simply because they performed worse in their science classes. On average across OECD and EU countries, the difference dropped to five and four percentage points respectively, after accounting for science performance.

Table 7.22 (available on line) shows that, on average across OECD countries, first-generation immigrant students were five percentage points more likely than second-generation immigrant students to report receiving frequent teacher feedback. In Canada, Greece, Israel and Spain, the difference was larger than ten percentage points. In the majority of countries and economies, returning foreign-born students and native students of mixed heritage were as likely as native students to report that they receive frequent feedback from their teachers.

Table 7.23 shows the effects of receiving feedback from teachers on well-being outcomes. The effect on academic performance is not calculated because of the risk of reverse causality (students who perform worse are likely to receive more feedback, which could be misinterpreted as more feedback causing poorer academic outcomes). In 37 countries and economies out of 59 with valid estimates of immigrantnative gaps in receiving frequent teacher feedback and its effect on sense of belonging, students were more likely to report that they feel like they belong at school if they received academic feedback from their science teacher. On average across OECD and EU countries, the effect was a two percentage-point increase in the likelihood of feeling a sense of belonging at school. In Macao (China), Qatar and Singapore, where immigrant students were more likely than native students to receive feedback from their teachers, the effect was greater than seven percentage points. In Chile, Estonia, France and Norway, where immigrant students were over 10 percentage points more likely than native students to receive feedback from their teachers, students who reported receiving feedback were over three percentage points more likely to report feeling that they belonged at school. Receiving regular feedback from their teachers can improve the academic and social resilience of immigrant students.

On average across OECD countries, receiving feedback and support from the science teacher increased the likelihood of students being satisfied with life by approximately five percentage points (four percentage points across EU countries). The effect was significant in several countries where immigrant students were more likely to report that they receive feedback from their teachers, namely Chile, Costa Rica, Estonia, Finland, Germany, Lithuania, Luxembourg, Macao, Qatar, Switzerland and the United States. In Chile and Estonia, the percentage of immigrant students who reported receiving frequent feedback from their science teacher was around 11 percentage points larger than the percentage of native students who so reported, even after accounting for their science scores. In both countries, students who reported receiving frequent feedback were around eight percentage points more likely to report being satisfied with their life. Receiving regular feedback from teachers can also improve the emotional resilience of immigrant students. 
Figure 7.15 - Immigrant-native differences in receiving teachers' feedback Differences in the percentage of immigrant and native students who reported that they receive frequent feedback from their science teacher

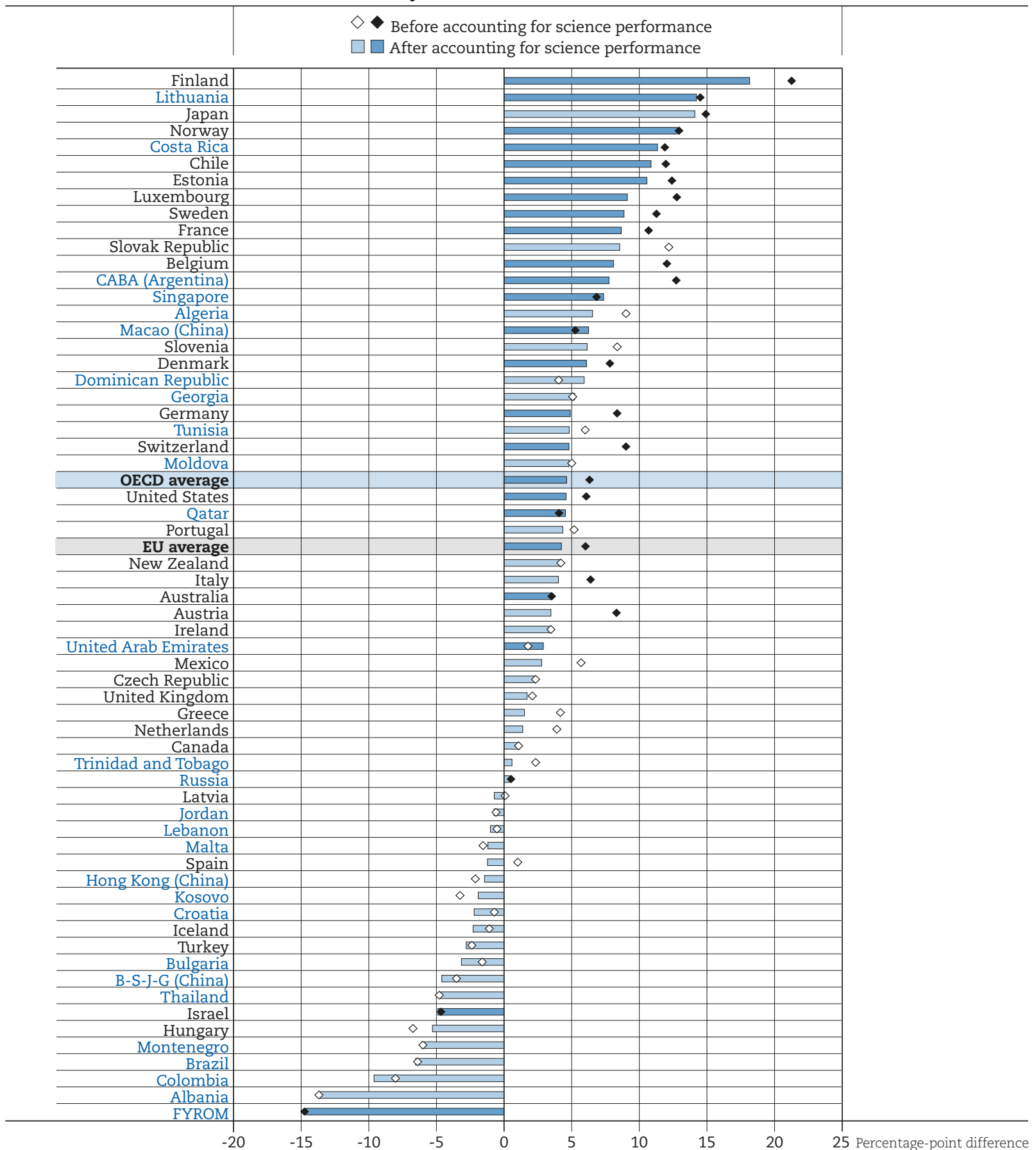

Notes: Only countries with valid estimates of immigrant-native gaps before and after accounting for science performance are displayed. Statistically significant immigrant-native gaps are marked in a darker tone.

Students who reported receiving frequent feedback from their science teacher are those who answered "many lessons" or "every lesson or almost every lesson" to at least one of the statements: "The teacher tells me how I am performing in this course"; "The teacher gives me feedback on my strength in this subject"; "The teacher tells me in which areas I can improve"; "The teacher tells me how I can improve my performance"; and "The teacher advises me on how to reach my learning goals".

Countries and economies are ranked in descending order of the percentage of immigrant students who reported that they receive frequent feedback from their science teacher, after accounting for their science performance.

Source: OECD, PISA 2015 Database, Table 7.22.

StatLink न्ताड़ http://dx.doi.org/10.1787/888933682414 
Table 7.23 - Receiving frequent feedback from the science teacher, and students' well-being

\begin{tabular}{|c|c|c|c|c|c|c|}
\hline & \multicolumn{6}{|c|}{$\begin{array}{l}\text { Statistically significant and positive value } \\
\text { Statistically significant and negative value } \\
\text { Missing or invalid estimate }\end{array}$} \\
\hline & \multicolumn{2}{|c|}{$\begin{array}{c}\text { Percentage-point difference between } \\
\text { immigrant and native students in the } \\
\text { percentage of students who reported } \\
\text { that they received frequent feedback from } \\
\text { their science teacher }\end{array}$} & \multicolumn{4}{|c|}{$\begin{array}{l}\text { Effect of receiving frequent feedback from the science teacher } \\
\text { (percentage-point change) }\end{array}$} \\
\hline & $\begin{array}{l}\text { Before accounting } \\
\text { for science } \\
\text { performance }\end{array}$ & $\begin{array}{l}\text { After accounting } \\
\text { for science } \\
\text { performance }\end{array}$ & $\begin{array}{l}\text { On the likelihood of } \\
\text { reporting a sense of } \\
\text { belonging at school }\end{array}$ & $\begin{array}{l}\text { On the likelihood } \\
\text { of reporting being } \\
\text { satisfied with life }\end{array}$ & $\begin{array}{l}\text { On the likelihood } \\
\text { of reporting low } \\
\text { schoolwork-related } \\
\text { anxiety }\end{array}$ & $\begin{array}{l}\text { On the likelihood } \\
\text { of reporting high } \\
\text { achievement } \\
\text { motivation }\end{array}$ \\
\hline Finland & 21.27 & 18.17 & 1.64 & 3.72 & -1.04 & 2.58 \\
\hline Lithuania & 14.52 & 14.23 & -1.45 & 2.89 & -0.06 & 1.99 \\
\hline Japan & 14.93 & 14.12 & 2.21 & 7.67 & -4.61 & 6.55 \\
\hline Norway & 12.94 & 12.80 & 3.47 & & -0.44 & 2.57 \\
\hline Costa Rica & 11.90 & 11.35 & $\begin{array}{l}0.71 \\
0.29 \\
\end{array}$ & 6.09 & -1.87 & 0.85 \\
\hline Chile & 11.97 & 10.88 & 5.15 & 8.07 & -0.28 & 5.27 \\
\hline Estonia & 12.42 & 10.57 & 3.46 & 7.54 & -3.38 & 5.11 \\
\hline Luxembourg & 12.78 & 9.12 & -2.80 & 4.78 & $\frac{-. .79}{-2.79}$ & 4.64 \\
\hline Sweden & 11.28 & 8.88 & -0.05 & & 2.03 & 1.68 \\
\hline France & 10.70 & 8.67 & 3.01 & 1.36 & -2.62 & 3.56 \\
\hline Slovak Republic & 12.19 & 8.56 & -0.98 & 2.67 & -0.59 & 1.10 \\
\hline Belgium & 12.05 & 8.10 & -3.70 & 2.02 & -4.17 & 6.69 \\
\hline CABA (Argentina) & 12.74 & 7.77 & 2.63 & & & \\
\hline Singapore & 6.84 & 7.37 & 7.28 & & -0.18 & 3.64 \\
\hline Algeria & 9.03 & 6.55 & -3.11 & & & \\
\hline Macao (China) & 5.27 & 6.26 & 8.23 & 4.94 & 1.26 & 6.63 \\
\hline Slovenia & 8.37 & 6.15 & 4.46 & 4.81 & -0.78 & 1.88 \\
\hline Denmark & 7.83 & 6.10 & 2.50 & & 0.51 & 3.60 \\
\hline Dominican Republic & 4.04 & 5.93 & 5.14 & 3.46 & -2.52 & 2.75 \\
\hline Georgia & 5.08 & 5.23 & 12.35 & & & \\
\hline Germany & 8.37 & 4.90 & 0.60 & 4.68 & -0.27 & 4.28 \\
\hline Tunisia & 6.01 & 4.82 & 5.28 & 9.64 & -0.94 & 1.39 \\
\hline Switzerland & 9.02 & 4.80 & -1.33 & 3.69 & -0.70 & 3.99 \\
\hline Moldova & 5.01 & 4.80 & 9.55 & & & \\
\hline OECD average & 6.33 & 4.64 & 2.27 & 4.68 & -1.39 & 3.16 \\
\hline United States & 6.08 & 4.59 & 4.93 & 6.34 & -2.29 & 1.64 \\
\hline Qatar & 4.07 & 4.54 & 9.06 & 5.79 & 0.76 & 2.31 \\
\hline Portugal & 5.19 & 4.35 & 2.61 & 4.33 & -2.40 & 4.73 \\
\hline EU average & 6.03 & 4.25 & 2.17 & 3.87 & -1.43 & 3.52 \\
\hline New Zealand & 4.20 & 4.19 & 7.57 & 3.01 & $\begin{array}{r}1.35 \\
-0.86 \\
\end{array}$ & 2.67 \\
\hline Italy & 6.41 & 4.02 & 3.07 & 2.23 & -0.98 & 5.26 \\
\hline Australia & 3.53 & 3.54 & 4.33 & & -1.44 & 2.12 \\
\hline Austria & 8.32 & 3.47 & 1.05 & 2.30 & -1.48 & 2.04 \\
\hline Ireland & 3.47 & 3.34 & 5.12 & 4.23 & -2.12 & 2.30 \\
\hline United Arab Emirates & 1.78 & 2.91 & 9.21 & 8.80 & 1.19 & 2.50 \\
\hline Mexico & 5.70 & 2.78 & 1.98 & 4.55 & 0.64 & 2.10 \\
\hline Czech Republic & 2.34 & 2.27 & -0.39 & 2.26 & -2.28 & 0.90 \\
\hline United Kingdom & 2.10 & 1.71 & 8.66 & 4.64 & -3.01 & 1.34 \\
\hline Greece & 4.17 & 1.51 & 3.10 & 5.95 & -0.87 & 1.64 \\
\hline Netherlands & 3.91 & 1.39 & 1.36 & 0.85 & -1.53 & 2.08 \\
\hline Canada & 1.08 & 1.16 & 5.72 & (..0s & -0.44 & 2.70 \\
\hline $\begin{array}{l}\text { Trindidad and Tobago } \\
\text { Tridal }\end{array}$ & 2.34 & 0.59 & 7.70 & & -0.44 & 2.10 \\
\hline Russia & 0.52 & 0.39 & 4.80 & 3.07 & -4.45 & 2.05 \\
\hline$\frac{\text { Kussia }}{\text { Latvia }}$ & $\begin{array}{l}0.52 \\
0.08\end{array}$ & $\begin{array}{c}-0.39 \\
-0.72\end{array}$ & $\begin{array}{l}4.80 \\
0.49\end{array}$ & 2.45 & $\begin{array}{r}-4.45 \\
-4.06\end{array}$ & 4.07 \\
\hline$\frac{\text { Latlia }}{\text { Jordan }}$ & $\begin{array}{r}-0.08 \\
-0.59\end{array}$ & $\begin{array}{l}-0.12 \\
-0.74\end{array}$ & 8.49 & 2.45 & -4.06 & 4.07 \\
\hline Lebanon & -0.52 & -1.00 & 9.57 & & & \\
\hline Malta & -1.55 & -1.19 & 10.78 & & & \\
\hline Spain & 1.02 & -1.22 & 2.77 & 7.03 & -3.67 & 0.89 \\
\hline Hong Kong (China) & $\frac{1.02}{-2.12}$ & -1.44 & 9.67 & 10.00 & 0.31 & 3.88 \\
\hline Kosovo & -3.25 & -1.91 & 6.33 & & & \\
\hline Croatia & -0.71 & -2.21 & 0.50 & 3.32 & 0.44 & 2.89 \\
\hline Iceland & -1.09 & -2.29 & -4.01 & 1.18 & -3.21 & 5.07 \\
\hline Turkey & -2.38 & -2.80 & -0.21 & 8.46 & 2.70 & 3.01 \\
\hline Bulgaria & -1.61 & -3.15 & 3.66 & 5.17 & -1.73 & 5.16 \\
\hline B-S-J-G (China) & -3.51 & -4.60 & 12.43 & 11.85 & -3.80 & 2.41 \\
\hline Thailand & -4.78 & -4.75 & 5.37 & 3.25 & 0.56 & 0.24 \\
\hline Israel & -4.66 & -4.89 & & & -3.37 & 2.37 \\
\hline Hungary & -6.73 & -5.29 & 3.22 & 3.99 & 1.62 & 3.22 \\
\hline Montenegro & -6.00 & -6.09 & 8.04 & 4.29 & 0.24 & 1.07 \\
\hline Brazil & -6.39 & -6.54 & $\begin{array}{l}2.07 \\
2.89\end{array}$ & 4.78 & -0.24 & 2.64 \\
\hline Colombia & $\begin{array}{l}-8.02 \\
\end{array}$ & $\begin{array}{l}-0.54 \\
-9.61 \\
\end{array}$ & $\begin{array}{r}-1.05 \\
-1.53 \\
\end{array}$ & 6.01 & $\frac{-3.02}{-1.16}$ & 1.33 \\
\hline Albania & -13.68 & -13.66 & 7.15 & & & \\
\hline FYROM & -14.75 & -14.62 & 2.93 & & & \\
\hline
\end{tabular}

Notes: Only those countries with a valid estimate for the difference in the percentage of immigrant and native students who reported receiving frequent feedback from their science teacher are displayed. The OECD and EU average percentage-point differences are based only on countries with reliable estimates for both native and immigrant students.

Students who reported receiving frequent feedback from their science teacher are those who answered "many lessons" or "every lesson or almost every lesson" to at least one of the questions about how often: "The teacher tells me how I am performing in this course"; "The teacher gives me feedback on my strength in this subject"; "The teacher tells me in which areas I can improve"; "The teacher tells me how I can improve my performance"; and "The teacher advises me on how to reach my learning goals".

Results on the effects of receiving frequent feedback from the science teacher are obtained from regressions that account for students' gender, immigrant background and socio-economic status, as well as the socio-economic profile of schools.

Students who reported a sense of belonging at school are those who reported that they "agree" or "strongly agree" with the statement "I feel like I belong at school" and "disagree" or "strongly disagree" with the statement "I feel like an outsider at school".

Students who reported being satisfied with life are those who reported a life satisfaction of 7 or above on a scale from 0 to 10 .

Students who reported low schoolwork-related anxiety are those who reported that they "disagree" or "strongly disagree" with the statements "I often worry that it will be difficult for me taking a test" and "Even if I am well prepared for a test, I feel very anxious".

Students who reported high motivation to achieve are those who reported that they "agree" or "strongly agree" with the statement "I want to be the best, whatever I do". Countries and economies are ranked in descending order of the percentage-point difference between immigrant and native students in the percentage of students who reported that they received frequent feedback from their science teacher, after accounting for science performance.

Source: OECD, PISA 2015 Database, Tables 7.22 and 7.24.

StatLink त्नाs ht htp://dx.doi.org/10.1787/888933682642 
Teacher feedback also has a strong motivating effect on students. On average across OECD countries, students who reported receiving frequent feedback from their science teachers were three percentage points more likely to report high achievement motivation (four percentage points across EU countries). The effect is above average in Belgium, Chile, Denmark, Estonia, France, Germany, Italy, Luxembourg, Macao (China), Singapore and Switzerland, where immigrant students were more likely than native students to report receiving feedback from their teachers.

Teacher feedback tends to increase the likelihood that students will report high levels of schoolwork-related anxiety, although there was no significant effect in all countries where immigrant were more likely to report receiving frequent feedback from their teachers, except in Belgium, Estonia and France. However, this effect is likely to be the result of low science scores influencing both the feedback variable and the measure of anxiety. Indeed, the positive and strong effects of teacher feedback on all other well-being outcomes should also be interpreted in light of the fact that students who receive more feedback are also more likely to be performing badly in science, and poor academic performance has adverse effects on students' well-being. Evidence shows that greater teacher support for immigrant students can significantly improve their wellbeing outcomes and moderate the effect of poor academic performance on their well-being.

\section{Box 7.1. Teachers' need for professional development in a multicultural setting, evidence from the Teaching and Learning International Survey}

The finding that many immigrant students reported that their teachers provide them with additional feedback, but that many feel victimised by their teachers could reflect the willingness and eagerness of many teachers to support immigrant students, but also that many lack the skills that would enable them to do so effectively. In teaching students from diverse backgrounds, especially when it comes to immigrant students and students who do not speak the language of the assessment, teachers often feel the need for additional systemic support. As Figure 7.16 below shows, on average, around one in ten teachers participating in the 2013 Teaching and Learning International Survey (TALIS) reported the need for additional professional development when teaching in multicultural settings. In some countries, the reported need is significantly higher than the average. For example, in Brazil, Italy and Mexico, over $25 \%$ of teachers reported that they feel they need more assistance in understanding how to address and support their students' needs in muticultural classrooms.

Results presented in this chapter indicate that teachers adapt their behaviours when teaching students with an immigrant background. Such adaptation can occur because teachers understand the specific strengths and weaknesses of immigrant students and try to provide adequate support. It can also result from implicit expectations teachers hold for the student and his or her academic potential and career possibilities (Boser et al., 2014; Lüdemann and Schwerdt, 2013; Klapproth et al., 2013). Moreover, teachers might hold stereotypical notions about different immigrant groups, which can lead them to behave very differently towards members of perceived "model minorities" or "problem groups" (Burgess and Greaves, 2013). In the United Kingdom, teachers' own assessments of the performance of ethnic minority students is lower than that revealed through in standardised assessments (Burgess and Greaves, 2013), whereas in Sweden students with an immigrant background tend to be evaluated more positively than their performance in a standardised test would predict (Lindahl; 2007).

Some studies attempted to evaluate experimentally the extent to which teachers' grading of school work was influenced by the assumed ethnicity of the student, a proxy for immigrant background. Van Ewijk (2011), for example, randomly assigned Dutch-, Turkish- and Moroccan-sounding names to essays in Dutch elementary schools. The essays were then assigned to 100 elementary school teachers for grading. Results did not indicate any bias in grading. However, teachers were found to express lower expectations and more negative attitudes towards students whose essay had been manipulated to have a Turkish- or Moroccan-sounding name. For example, teachers were less likely to expect that such students would continue with upper secondary education. A similar study conducted in Germany suggested that teachers award lower marks to essays of the same quality if the student writing the essay was assigned a Turkish-sounding name (Sprietsma, 2013). 
Moreover, while the effect was small and appeared to be driven by the behaviour of a small number of teachers, as in the Netherlands, teachers were less likely to give a recommendation for upper secondary education to students with a Turkish-sounding name.

Figure 7.16 - Teacher's need for professional development in a multicultural setting

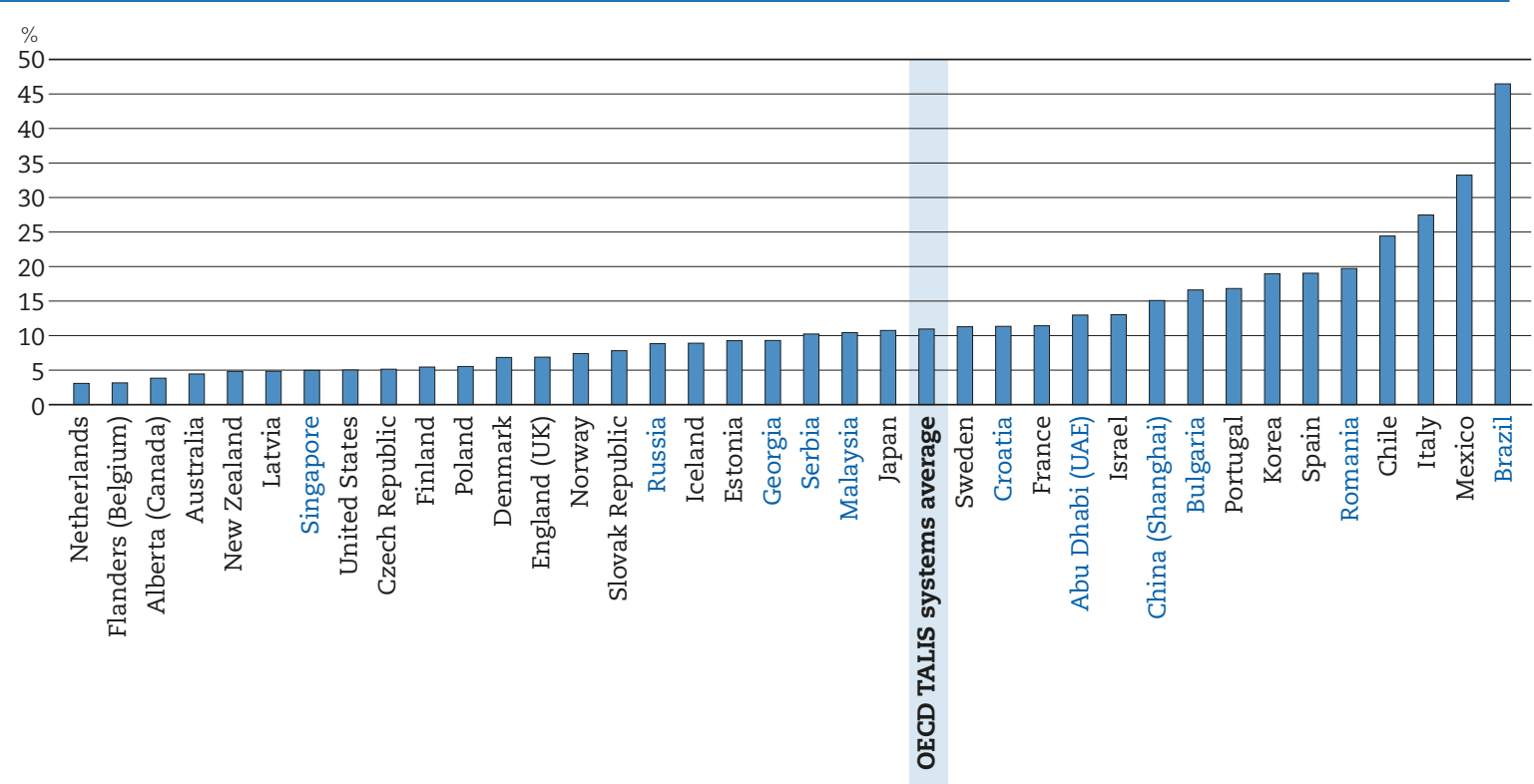

Note: The data from the United States should be interpreted carefully because the United States did not meet the international standards for participation rates.

Source: OECD (2013), Teaching and Learning International Survey (TALIS): 2013 Complete Database, http://stats.oecd.org/index. aspx?

datasetcode=talis_2013\%20.

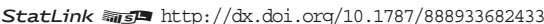

\section{School resources and the academic, social, emotional and motivational resilience of immigrant students}

Resources invested in education are, on average, weakly associated with education outcomes (Hanushek, 1986; Burtless, 2011). Research shows that this is partially because resources matter only up to a certain level, after which additional resources do not necessarily improve learning outcomes (Burtless, 1996; Nannyonjo, 2007; Nicoletti and Rabe, 2012; OECD, 2013, 2016a; Suryadarma, 2012; Wei Clifton and Roberts, 2011). Other studies show that socio-economically disadvantaged students are more likely to be resilient if they attend schools that have more and better resources (Agasisti and Longobardi, 2014a; 2014b; 2017).

In PISA, school principal questionnaires are used to capture information on the material, human and time resources available to schools. Several useful indicators were constructed using principals' responses: student-teacher ratios, computer-to-student ratios, and the number of extracurricular activities offered. ${ }^{7}$ In addition, school principals reported the extent to which their school's capacity to provide instruction is hindered by the following: "a lack of teaching staff"; "inadequate or poorly qualified teaching staff"; "a lack of assisting staff"; "inadequate or poorly qualified assisting staff"; "a lack of educational material"; "inadequate or poor quality educational material"; "a lack of physical infrastructure"; or "inadequate or poor quality physical infrastructure". Possible answers were "not at all", "very little", "to some extent" and "a lot". Responses to these questions were used to construct two binary indices: the index of shortage of educational staff and the index of shortage of educational material. A value of one in the first index indicates schools whose principal answered "to some extent" or "a lot" to at least one of the first four questions listed above. A value of one in the second index indicates that a principal answered "to some extent" or "a lot" to the latter four questions. 
Tables 7.25 to 2.29 (available on line) show average scores on the abovementioned indices for schools attended by students from different immigration backgrounds. Table 7.31 below lists countries where, on average, the resources available in schools attended by the average immigrant student and the resources available in schools attended by the average native student are different. Results show that in 2015 differences in resources between schools attended by the average student with an immigrant background and those attended by the average native student tended to be small and not statistically significant. Student/teacher ratios and computer/student ratios were similar across all groups of students, and on average across OECD and EU countries there were no statistically significant differences. The other three indices vary more across immigrant backgrounds in some countries, especially the availability of extracurricular activities.

\section{Table 7.31 - Immigrant-native differences in school resources}

\begin{tabular}{|c|c|c|}
\hline \multirow[b]{2}{*}{ Index } & \multicolumn{2}{|c|}{$\begin{array}{l}\text { Countries and economies with statistically significant differences between schools } \\
\text { attended by the average immigrant student and the average native student }\end{array}$} \\
\hline & Lower/Less for immigrant students & Higher/More for immigrant students \\
\hline Shortage of educational material & $\begin{array}{l}\text { Costa Rica, Jordan, Lithuania, Qatar, } \\
\text { Singapore, United Arab Emirates, Uruguay }\end{array}$ & $\begin{array}{c}\text { Albania, Brazil, Bulgaria, Ciudad Autónoma } \\
\text { de Buenos Aires (Argentina), } \\
\text { Former Yugoslav Republic of Macedonia, } \\
\text { Iceland, Macao (China), Mexico, Netherlands, } \\
\text { Portugal, United States, Tunisia }\end{array}$ \\
\hline Shortage of educational staff & $\begin{array}{c}\text { Australia, Costa Rica, Luxembourg, Malta, } \\
\text { Montenegro, New Zealand, } \\
\text { United Arab Emirates }\end{array}$ & $\begin{array}{l}\text { Austria, Belgium, Ciudad Autónoma de Buenos } \\
\text { Aires (Argentina), Croatia, Greece, Italy, } \\
\text { Portugal, Slovenia, Tunisia, Turkey }\end{array}$ \\
\hline Student/teacher ratio & $\begin{array}{c}\text { Belgium, Bulgaria, Israel, Lithuania, Peru, } \\
\text { Singapore, Spain, Switzerland, } \\
\text { Trinidad and Tobago }\end{array}$ & $\begin{array}{l}\text { Algeria, Estonia, Iceland, Jordan, Kosovo, } \\
\text { Latvia, Luxembourg, Macao (China), Malta, } \\
\text { New Zealand, Qatar, United Arab Emirates }\end{array}$ \\
\hline Computer/student ratio & $\begin{array}{l}\text { Canada, Estonia, Former Yugoslav Republic } \\
\text { of Macedonia, Macao (China) }\end{array}$ & $\begin{array}{c}\text { Ciudad Autónoma de Buenos Aires (Argentina), } \\
\text { Finland, Hong Kong (China), Iceland, Qatar, } \\
\text { Slovenia }\end{array}$ \\
\hline $\begin{array}{l}\text { Availability of extracurricular } \\
\text { activities }\end{array}$ & $\begin{array}{l}\text { Belgium, Brazil, Bulgaria, Croatia, Denmark, } \\
\text { Estonia, Former Yugoslav Republic of } \\
\text { Macedonia, Greece, Hong Kong (China), } \\
\text { Germany, Luxembourg, Macao (China), Malta, } \\
\text { Mexico, Portugal, Slovenia }\end{array}$ & $\begin{array}{l}\text { Canada, Jordan, Montenegro, } \\
\text { Qatar, Singapore, United Arab Emirates }\end{array}$ \\
\hline
\end{tabular}

Notes: The index of shortage of educational material was constructed based on school principal responses about the extent to which the school's capacity to provide instruction was hindered by: "a lack of educational material", "inadequate or poor quality educational material", "a lack of physical infrastructure", "inadequate or poor quality infrastructure". Possible responses were "not at all", "very little", "to some extent" and "a lot".

The index of shortage of educational staff was constructed based on school principal responses about the extent to which the school's capacity to provide instruction was hindered by: "a lack of teaching staff", "inadequate or poorly qualified teaching staff", "a lack of assisting staff", "inadequate or poorly qualified assisting staff". Possible responses were "not at all", "very little", "to some extent" and "a lot".

The number of extracurricular activities offered at school was calculated as the sum of the yes/no answers to the question of whether the following activities are available at school: band, orchestra or choir; school play or school musical; school yearbook, newspaper or magazine; volunteering or service activities; science club; science competitions; chess club; club with a focus on computers/ICT; art club or art activities; sporting team or sporting activities; and a country-specific item.

Source: OECD, PISA 2015 Database, Tables 7.25, 7.26, 7.28 and 7.29.

StatLink त्तोIs http://dx.doi.org/10.1787/888933682661

Table 7.32 lists countries, out of those listed in Table 7.31, where the school resource indices considered had a statistically significant impact on students' academic and well-being outcomes. Results are consistent with the finding that resources are weakly associated with education outcomes; they also show that there is a weak link between educational resources and the well-being of students. However, some individual countries and economies show large differences between immigrant and native students, and strong effects of certain resource indices on students' outcomes. In Albania, for example, immigrant students were 13 percentage points more likely than native students to be enrolled in a school whose principal reported lack of educational material. In those schools, students were 19 percentage points less likely to attain baseline levels of academic proficiency.

The availability of extracurricular activities was the only resource index for which a considerable number of countries showed significant differences between native and immigrant students and significant effects on outcomes. In 13 of the countries and economies shown in Table 7.31, a greater availability of extracurricular activities was associated with an increase in the likelihood of students attaining baseline 
levels of academic proficiency; in 9 countries and economies it was associated with an increase their likelihood of feeling like they belong at school. In Brazil, Bulgaria, Malta, Mexico and Portugal, schools attended by the average native student offered around one additional extracurricular activity compared to schools attended by the average immigrant student. In Austria, Bulgaria, Chile and Romania, an additional extracurricular activity offered at school was associated with an increase in the likelihood of students attaining baseline levels of academic proficiency by around two percentage points; in Albania, Korea, and Malta, it increased the likelihood by 3 percentage points; and in Macao (China) and Qatar, it increased the likelihood by almost four percentage points.

\section{Table 7.32 - School resources, and academic and well-being outcomes Countries with statistically significant differences in school resource indices between immigrant and native students}

\begin{tabular}{|c|c|c|c|c|c|c|c|c|}
\hline \multirow[b]{3}{*}{ Index } & \multicolumn{8}{|c|}{ Marginal effect } \\
\hline & \multicolumn{2}{|c|}{$\begin{array}{l}\text { On the likelihood } \\
\text { of attaining baseline } \\
\text { academic proficiency }\end{array}$} & \multicolumn{2}{|c|}{$\begin{array}{l}\text { On the likelihood } \\
\text { of reporting a sense } \\
\text { of belonging at school }\end{array}$} & \multicolumn{2}{|c|}{$\begin{array}{l}\text { On the likelihood } \\
\text { of reporting being } \\
\text { satisfied with life }\end{array}$} & \multicolumn{2}{|c|}{$\begin{array}{c}\text { On the likelihood } \\
\text { of reporting low } \\
\text { schoolwork-related anxiety }\end{array}$} \\
\hline & Positive effect & $\begin{array}{l}\text { Negative } \\
\text { effect }\end{array}$ & Positive effect & $\begin{array}{c}\text { Negative } \\
\text { effect }\end{array}$ & $\begin{array}{l}\text { Positive } \\
\text { effect }\end{array}$ & $\begin{array}{l}\text { Negative } \\
\text { effect }\end{array}$ & $\begin{array}{l}\text { Positive } \\
\text { effect }\end{array}$ & $\begin{array}{l}\text { Negative } \\
\text { effect }\end{array}$ \\
\hline $\begin{array}{l}\text { Shortage of } \\
\text { educational } \\
\text { material }\end{array}$ & & $\begin{array}{l}\text { Albania, } \\
\text { Former } \\
\text { Yugoslav } \\
\text { Republic of } \\
\text { Macedonia, } \\
\text { Portugal }\end{array}$ & $\begin{array}{l}\text { Jordan, } \\
\text { United Arab } \\
\text { Emirates }\end{array}$ & $\begin{array}{c}\text { Former } \\
\text { Yugoslav } \\
\text { Republic of } \\
\text { Macedonia }\end{array}$ & $\begin{array}{l}\text { Brazil, } \\
\text { Qatar }\end{array}$ & & $\begin{array}{l}\text { Qatar, } \\
\text { United Arab } \\
\text { Emirates }\end{array}$ & \\
\hline $\begin{array}{l}\text { Shortage } \\
\text { of educational } \\
\text { staff }\end{array}$ & Greece, Luxembourg & $\begin{array}{l}\text { Australia, } \\
\text { United Arab } \\
\text { Emirates }\end{array}$ & Luxembourg & Belgium & & Portugal & \begin{tabular}{|} 
Luxembourg, \\
Slovenia, \\
United Arab \\
Emirates
\end{tabular} & Belgium \\
\hline $\begin{array}{l}\text { Student/ } \\
\text { teacher ratio }\end{array}$ & $\begin{array}{c}\text { Belgium, } \\
\text { Bulgaria, Kosovo, } \\
\text { Macao (China), } \\
\text { Qatar, Singapore, } \\
\text { Switzerland, } \\
\text { Trinidad and Tobago, } \\
\text { United Arab Emirates }\end{array}$ & & $\begin{array}{l}\text { Malta, Spain, } \\
\text { Peru, Qatar }\end{array}$ & Latvia & Belgium & $\begin{array}{l}\text { Bulgaria, } \\
\text { Qatar, } \\
\text { United } \\
\text { Arab } \\
\text { Emirates }\end{array}$ & & $\begin{array}{l}\text { Israel, Latvia, } \\
\text { New Zealand, } \\
\text { Qatar, } \\
\text { United Arab } \\
\text { Emirates }\end{array}$ \\
\hline $\begin{array}{l}\text { Computer/ } \\
\text { student ratio }\end{array}$ & Macao (China), Qatar & $\begin{array}{l}\text { Former } \\
\text { Yugoslav } \\
\text { Republic of } \\
\text { Macedonia, } \\
\text { Hong Kong } \\
\text { (China) }\end{array}$ & $\begin{array}{c}\text { Former } \\
\text { Yugoslav } \\
\text { Republic of } \\
\text { Macedonia, } \\
\text { Macao (China) }\end{array}$ & $\begin{array}{l}\text { Finland, } \\
\text { Hong Kong } \\
\text { (China), } \\
\text { Iceland, } \\
\text { Slovenia }\end{array}$ & & $\begin{array}{l}\text { Finland, } \\
\text { Hong Kong } \\
\text { (China), } \\
\text { Iceland }\end{array}$ & & \\
\hline $\begin{array}{l}\text { Availability of } \\
\text { extracurricular } \\
\text { activities }\end{array}$ & $\begin{array}{c}\text { Belgium, Bulgaria, } \\
\text { Croatia, Estonia, } \\
\text { Jordan, Luxembourg, } \\
\text { Macao (China), Malta, } \\
\text { Portugal, Qatar, } \\
\text { Slovenia, } \\
\text { United Arab Emirates }\end{array}$ & & $\begin{array}{c}\text { Belgium, Brazil, } \\
\text { Estonia, Former } \\
\text { Yugoslav } \\
\text { Republic of } \\
\text { Macedonia, } \\
\text { Luxembourg, } \\
\text { Macao (China), } \\
\text { Slovenia, Qatar, } \\
\text { United Arab } \\
\text { Emirates }\end{array}$ & & $\begin{array}{l}\text { Croatia, } \\
\text { Macao } \\
\text { (China), } \\
\text { United } \\
\text { Arab } \\
\text { Emirates }\end{array}$ & & $\begin{array}{c}\text { Belgium, } \\
\text { Montenegro }\end{array}$ & Qatar \\
\hline
\end{tabular}

Notes: Results on the effects of the indices on academic and well-being outcomes of students are obtained from regressions accounting for students' gender, immigrant background, socio-economic status, the ISCED level of the class where they are enrolled, and the socioeconomic profile of schools.

The index of shortage of educational material was constructed based on school principal responses about the extent to which the school's capacity to provide instruction was hindered by: "a lack of educational material", "inadequate or poor quality educational material", "a lack of physical infrastructure", "inadequate or poor quality infrastructure". Possible responses were "not at all", "very little", "to some extent" and "a lot".

The index of shortage of educational staff was constructed based on school principal responses about the extent to which the school's capacity to provide instruction was hindered by: "a lack of teaching staff", "inadequate or poorly qualified teaching staff", "a lack of assisting staff", "inadequate or poorly qualified assisting staff". Possible responses were "not at all", "very little", "to some extent" and "a lot".

The number of extracurricular activities offered at school was calculated as the sum of the yes/no answers to the question of whether the following activities are available at school: band, orchestra or choir; school play or school musical; school yearbook, newspaper or magazine; volunteering or service activities; science club; science competitions; chess club; club with a focus on computers/ICT; art club or art activities; sporting team or sporting activities; and a country-specific item.

Students who attain baseline academic proficiency are those who reach at least PISA proficiency Level 2 in all three core PISA subjects: science, reading and mathematics.

Students who reported a sense of belonging at school are those who reported that they "agree" or "strongly agree" with the statement "I feel like I belong at school" and "disagree" or "strongly disagree" with the statement "I feel like an outsider at school".

Students who reported being satisfied with life are those who reported a life satisfaction of 7 or above on a scale from 0 to 10.

Students who reported low schoolwork-related anxiety are those who reported that they "disagree" or "strongly disagree" with the statements "I often worry that it will be difficult for me taking a test" and "Even if I am well prepared for a test, I feel very anxious".

Source: OECD, PISA 2015 Database, Tables 7.30 and 7.31.

StatLink न्ना जL http://dx.doi.org/10.1787/888933682680 
Results from PISA 2015 are consistent with the finding that resources are weakly related to education outcomes, or at least that they have an impact on the academic performance of students only to a certain degree, after which they do not make a significant difference. Evidence from the previous section has shown that the school environment has a strong effect on students' academic and well-being outcomes, and that immigrant students tend to be exposed to less-positive learning environments. In terms of school-level factors, differences between immigrant and native students are explained mostly by differences in the school environments to which they are exposed, as opposed to differences in the amount of resources their schools offer. These results imply that, in order to improve the academic, social and emotional resilience of immigrant students, policy makers should focus on the quality and use of resources, rather than the amount of them.

\section{Box 7.2. The role of sports in promoting academic performance and the social well-being of immigrant students}

There is an extensive literature on the health and cognitive benefits of engagement in sports activities. Several sociological studies show that engagement in leisure activities in general, and in sports activities in particular, can contribute to the integration of immigrants. Sporting environments can offer equal opportunities and promote racial equality among those involved, allowing immigrants to maintain their cultural identity alive while integrating in society (Donnelly and Coackley, 2002; Iwasaki and Bartlett, 2006). By participating in leisure activities in the host country with native populations, immigrants can learn about local customs and culture and interact with native peers on a par (Ito et al., 2011, Makarova and Herzog, 2014). This, in turn, can improve the way immigrants relate to native individuals and create positive social bonds. Participation in sports has a dual cultural function: it allows immigrants to maintain their own culture and interact with the local one (Allen et al., 2010).

Research empirical evidence based on PISA data suggests that sports can play an important role in promoting the integration of immigrant students (Garibaldi, 2017). The intuition behind this work is that an immigrant student coming from a country where the main sports that are practiced are very different from the ones practiced in the host country could struggle to take advantage of the sport environment as a way to effectively integrate with his or her native peers. To test this hypothesis, a measure of sports distance between countries was developed, based on Google searches on sports in each set of countries considered. Annex 1 provides a more detailed explanation of how the measure was constructed and table 7.A1.2 (available on line) presents index values for some combinations of host and origin countries in PISA. The index was then used to explain the PISA scores of immigrant students as well as their well-being.

Table 7.A1.1 displays the results from a regression of the PISA science scores of immigrant students on the sport distance between their country of origin and their host country, controlling for a set of background characteristics. Most importantly, the regression accounts for the geographic and cultural distance between the two countries and includes host and origin country fixed effects, so the effect of sport distance is isolated from other potential confounding factors. The results show that for immigrant boys, a 1-point increase in the sports distance index reduces PISA science scores by over 1-point. The negative effect is halved for immigrant girls.

Figure 7.17 below reports, for a selected group of destination countries, the predicted science scores of immigrant boys based on the sports distance between their country of origin and the host country. Science scores change remarkably across countries of origin. The predicted score of South African immigrant students in New Zealand is six points higher than the one of immigrant students from the United Kingdom and 30 points higher than the one of Malaysian immigrant students. According to the OECD, 10 points are equivalent to one semester of school; therefore, the difference is remarkably large. Albanian immigrant students in Switzerland are predicted to score about 30 points less than Austrian immigrant students.

Significant effects of sports distance were also found on reading and math and scores of immigrant students. An increase in one standard deviation of the sport distance index between the host and native country leads to a decrease in reading score of about 14 points for immigrant boys, 
after accounting for individual characteristics and other measures of distance between native and host countries. Results also show that sport distance is negatively associated with the sense of belonging of immigrant students.

Figure 7.17 - The association between sports distance and immigrant boys' science scores in four destination countries

Predicted science scores of immigrant boys based on sports distance between host countries and countries of origin
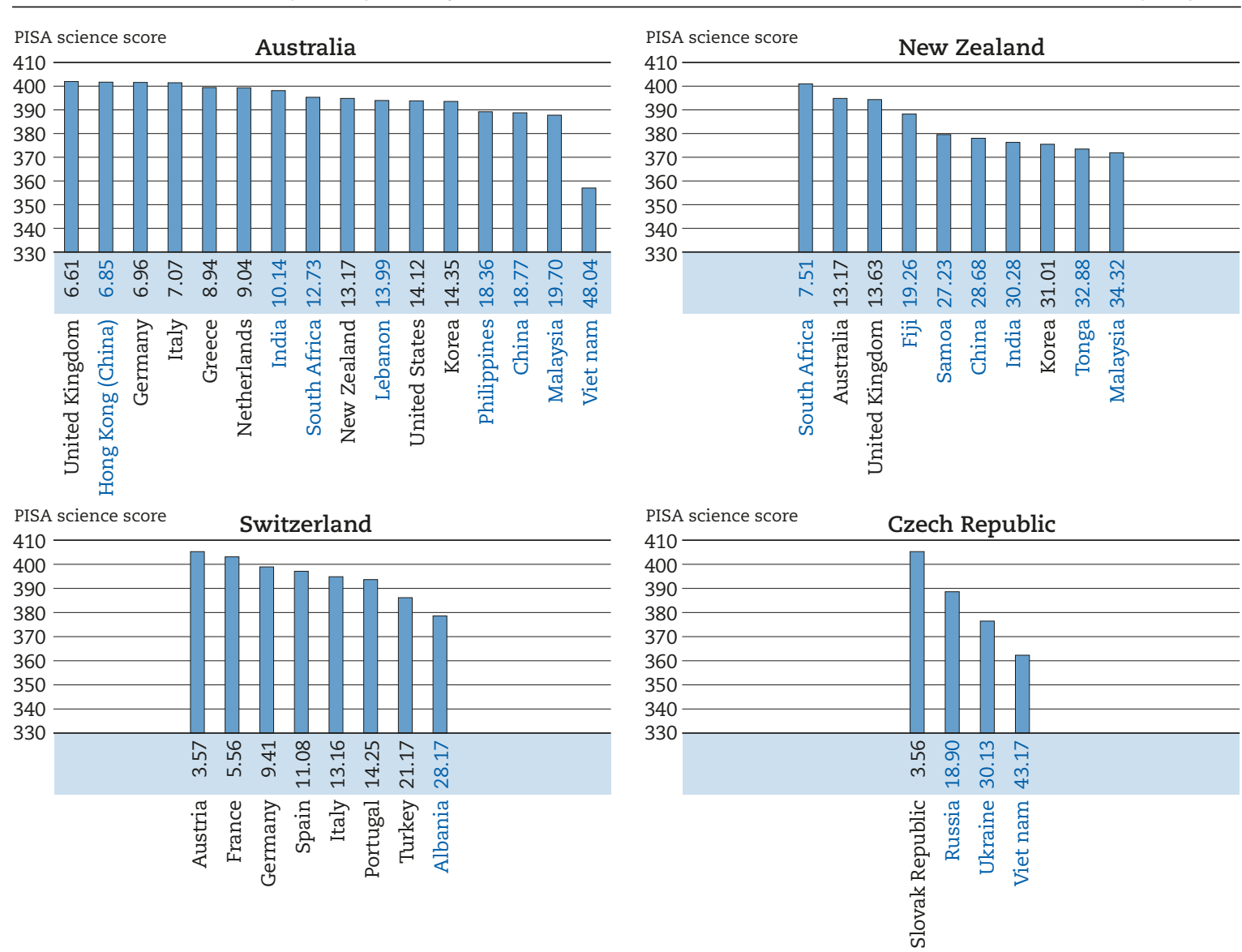

Notes: Host countries are reported on top of the figure and countries of origin are reported on the horizontal axis.

The sport distance between the host and destination countries is reported next to the name of the country of origin of immigrant boys. Results are based on the regression of science scores of immigrant students on students' gender, ISCED level, parental education, the reported number of books in the household, a dummy for first-generation immigrant students, fixed host and origin country effects and indices of sport, linguistic, geographic and cultural distanc between the host and destination country. The sport distance index is also interacted with the gender dummy so that the measured effect is only for male immigrant students. The resulting coefficient is then used to predict the science scores of male imigrant students based on measured sport distance, keeping all other things equal. The results were obtained using pooled data from the PISA rounds of 2003, 2006, 2009, 2012 and 2015.

Source: Adapted from Garibaldi, E. (2017), "The role of sports for the integration of immigrant students", Universitá L. Bocconi Graduate Thesis, Milano (unpublished).

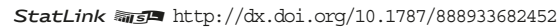

\section{School policies to improve the learning environment}

Disciplinary climate has been identified as one of the factors explaining immigrant students' comparative disadvantage in academic performance and social well-being. Poorer discipline in class is also correlated with higher incidence of truancy and bullying, two other school-level variables that could explain disadvantages for immigrant students (OECD, 2016b; OECD, 2017). Recent evidence suggests that disciplinary climate is better in schools where teacher turnover is low and principals adopt a transformational leadership style (they motivate colleagues to pursuing the strategic goals of the school) (Agasisti et al., 2018). 
To investigate the determinants of a school's disciplinary climate, three models were developed, each having the PISA index of disciplinary climate as the outcome variable. In the first model, the explanatory variables were the school average socio-economic profile and three variables obtained from teacher questionnaires. The first two measured the average amount of years that teachers spent teaching overall and in their current school, the latter being a proxy for teacher turnover. The third variable was the school average score on an index measuring the extent to which the school leader adopted transformational leadership, as measured by teachers' responses to a set of questions. ${ }^{8}$ The second model was identical to the first but also included fixed-country effects. The third model was identical to the second, but it also included the previously mentioned school-resource variables: the ratio of computers to students, the ratio of students to teachers, the index of shortage of educational material, the index of shortage of educational staff, and the number of extracurricular activities provided in school. Results are presented in Annex 2.

Table 7.A2.1 shows that school disciplinary climate was higher in schools where the average number of years spent by teachers in their current school was higher. Results presented in the most comprehensive model in Table 7.A2.1 indicate that a one-year increase in the school average is associated with a 0.01-point improvement in school disciplinary climate. By contrast, the average number of years the staff spent teaching in any school is significant only in the first model, and the index of transformational leadership is significant only in the second. As expected, the former has a negative relationship with disciplinary climate, while the latter is positively associated with a more disciplined school climate.

Results from the third model reveal that certain resource factors can improve school disciplinary climate. A higher student/teacher ratio is associated with a poorer disciplinary climate, although effects are small. A one-point increase in the index of shortage of educational staff is associated with a 0.08-point decrease in a school's disciplinary climate. Offering an additional extracurricular activity leads to a 0.01-point increase in the disciplinary climate of a school. Evidence shows that the quality of a school's disciplinary climate depends on school principals and teachers, as well as on the availability and use of school resources.

Previous discussions have identified perceived frequent unfair treatment by teachers as a major obstacle to students attaining baseline levels of academic achievement and well-being. On average across OECD countries, students with an immigrant background, not just immigrant students, were more likely than native students to report being treated unfairly by their teachers. Four models were developed to investigate some school policies associated with perceived unfair treatment of students. The school-level variables considered are the same as those used in the models to estimate disciplinary climate, but the models are estimated at the individual level.

The first two models only include individual-level variables: the gender and socio-economic status of a student, and a binary variable indicating whether the student has an immigrant background. The second model adds fixed-country effects to the first; the third adds the transformational leadership variable and the measures of teacher turnover and years of experience in teaching in general; the fourth model also includes the school-resource variables used in the model to estimate disciplinary climate. Results are presented in Table 7.A2.2 in Annex 2.

The first two models show that girls and more advantaged students are less likely than boys and disadvantaged students to perceive frequent unfair treatment by their teachers. However, the socioeconomic status variable becomes statistically insignificant in the models with school-level variables (which include average school socio-economic profile). In all models, students with an immigrant background were more likely than their native peers to report frequent unfair treatment by their teachers. In the second model, they were almost four percentage points more likely to report so.

In model 3, all teacher and school principal variables are significant. As expected, in schools whose principals adopt a transformational leadership style, students were less likely to report unfair teacher treatment. A one-point increase in the transformational leadership index reduces the likelihood of unfair treatment by about 1.4 percentage points in model 3. In schools with lower teacher turnover, students are less likely to perceive that their teachers treat students unfairly: a one-year increase in the average years spent by teachers in their current school reduces the likelihood of unfair treatment by 0.5 point. In schools where teachers have had a longer career, students were more likely to report unfair treatment, but the effect disappears in the fourth model. 
In contrast to school disciplinary climate, the incidence of perceived unfair treatment by teachers is not correlated to any of the school-resource factors. Furthermore, the inclusion of such variables does not affect the magnitude of the effects of the variables from the third model, except for the measure of teachers' total experience in teaching. In model 4, the effect of immigrant background is only two percentage points, and is almost not statistically significant. This implies that the greater incidence of perceived unfair treatment by teachers among students with an immigrant background can be explained, in part, by the different types of schools native students and students with an immigrant background attend, and the influence of school factors on the behaviour of teachers.

\section{Assessment practices}

The amount and quality of the feedback immigrant students receive from teachers can affect these students' academic and social resilience (see previous sections in this chapter). Assessment practices are another way in which teachers, educators and school systems can ensure that immigrant students are given the opportunity to reach their potential and overcome the difficulties associated with their immigrant background.

PISA 2015 asked school principals how often ("never", "1-2 times a year", "3-5 times a year", "monthly" or "more than once a month") students in the national modal grade for 15-year-olds are assessed using the following methods: mandatory standardised tests, non-mandatory standardised tests, teacher-developed tests, and teachers' judgemental ratings. On average across OECD countries, about one in four students attends a school whose principal reported that mandatory standardised tests are never used to assess students in the modal grade for 15-year-olds, and six in ten students attend schools where these tests are used once or twice a year (see OECD, 2016b). Non-mandatory standardised tests are used somewhat less frequently than mandatory tests, whereas teacher-developed tests and judgemental ratings are used considerably more frequently. For example, on average across OECD countries, almost two in three students attend schools whose principal reported that teacher-developed tests are used at least once a month, while for more than six in ten students, teachers' judgemental ratings are used at least once a month (see OECD, 2016b).

Results from PISA 2015 indicate that there is no association between the percentage of students who attend schools that use different types of assessments and average science performance, except for teachers' judgemental ratings. Across OECD countries, the percentage of students who attend a school where teachers' judgemental ratings are used at least once a month is positively associated with the country's mean science performance (see OECD, 21b, Figure II.4.23). PISA 2015 also indicates that no matter which assessments are used in school, they are not associated with the degree to which socioeconomic status explains science performance.

Results shown in Table 7.33 (available on line) indicate that there is no association between the different types of assessments used in schools (based on country-level data) and differences between native and immigrant students in the likelihood of achieving baseline levels of proficiency in reading, mathematics and science, feeling like they belong at school, feeling satisfied with life, having low schoolwork-related anxiety, and being motivated to achieve.

\section{Selecting and grouping students: Vertical and horizontal stratification}

Meeting the needs of all learners is not easy. Addressing and accounting for diversity is fundamental if education systems are to be able to promote immigrant students' academic, social and emotional resilience. Many education systems have created homogeneous populations (based on ability) through stratification, tracking policies and ability grouping, and established well-defined and inflexible education pathways from compulsory schooling into further education and training to ensure that instruction is tailored to the specific needs of relatively homogeneous groups (defined by ability, interests and/or preferences). However, selecting and sorting individuals can result in segregation, reinforcing disparities and resulting in differences in opportunities to learn. Many students might then feel they are not being offered equal opportunities to succeed and overcome initial disadvantage (Epple, Newlon and Romano, 2002).

Stratification in education refers to the various ways in which schools and education systems organise instruction for students of varying ability, behaviour, interests and pace of learning (Dupriez et al., 2008). 
In comprehensive systems, all students follow a similar path through education, regardless of their abilities, behaviour and interests. Students of different abilities and aspirations are exposed to similar content, pedagogy and peers. In vertically stratified systems, students of similar age are sometimes enrolled in different grade levels, mainly as a result of grade repetition. In horizontally stratified systems, students of different abilities, behaviour or interests are separated into different schools, classes or groups. In these systems, students of similar abilities, interests and motivation are grouped together so that what is learned (content and difficulty) and how the content is taught (pedagogy) can be tailored to better meet students' needs.

The effect of stratification on student outcomes is the subject of ongoing debate. Research has shown that stratification is not always primarily based on academic criteria. Decisions about sorting students are often influenced by students' background characteristics and not just their academic performance (van de Werfhorst and Mijs, 2010). The more stratified an education system is, the more likely it is that disadvantaged students are placed in the least academically oriented learning environments (Van de Werfhorts and Mijs, 2010). Immigrant students are likely to be more frequently subject to unfavourable stratification outcomes because of their socio-economic status and possibly even their migration history. Experimental studies have shown that teacher-student relationships are shaped by the amount of demographic characteristics they share, through active and passive mechanisms (Dee, 2005; Lavy, 2008). Research on the children of immigrants in Germany have found that they are assigned to academic tracks less often than native students, and this difference cannot be attributed to academic performance (Ludemann and Schwert, 2010). Since teachers and school principals, often in conjunction with parents, decide on grade repetition and the selection of students into different programmes, immigrant students could face disadvantages vis-á-vis their native peers.

\section{Grade repetition}

Grade repetition is the practice of requiring students who have been in a grade level for a full school year to remain in the same grade for an additional school year (Jimerson, 2001; Jackson, 1975). School leaders and teachers, sometimes in consultation with parents, are responsible for deciding who will be promoted or retained, sometimes within guidelines or regulations coming from national or other levels of government (European Commission, 2011). Grade repetition can be a costly policy, as it generally requires greater expenditure on education and delays students' entry into the labour market (OECD, 2013). Grade repetition is used to give students whose teachers believe are not yet ready for more advanced coursework time to "catch up" with their peers. If the curriculum is cumulative and further learning depends on a solid understanding of what had been previously learned, then promoting students regardless of their mastery of the content might put low-performing students in an increasingly difficult position in higher grades.

Irrespective of its intended effect, grade repetition does not appear to promote academic achievement (Jimerson, 2001). It also appears to affect socio-economically disadvantaged students more than advantaged students (even when the two groups perform similarly in standardised tests). And students who repeated a grade are more likely to drop out of school altogether (Jacob and Lefgren, 2004; Manacorda, 2012).

Table 7.34 (available on line) reports the percentage of students with an immigrant background who repeated at least one grade, and the differences in percentages between native students and various groups of immigrant students, before and after accounting for their performance in the three core PISA subjects. On average across OECD and EU countries, and after accounting for academic performance, in 2015 students with an immigrant background were more likely than native students to have repeated a grade. On average across OECD countries, first-generation immigrant students were six percentage points more likely, while second-generation immigrant students were three percentage points more likely than native students to have repeated a grade (eight and four percentage points across EU countries). On average across OECD countries, returning foreign-born students were five percentage points more likely and native-born students of mixed heritage were two percentage points more likely than native students to have repeated a grade (six and three percentage points more likely across EU countries). 
Figure 7.18 - Immigrant-native differences in grade repetition

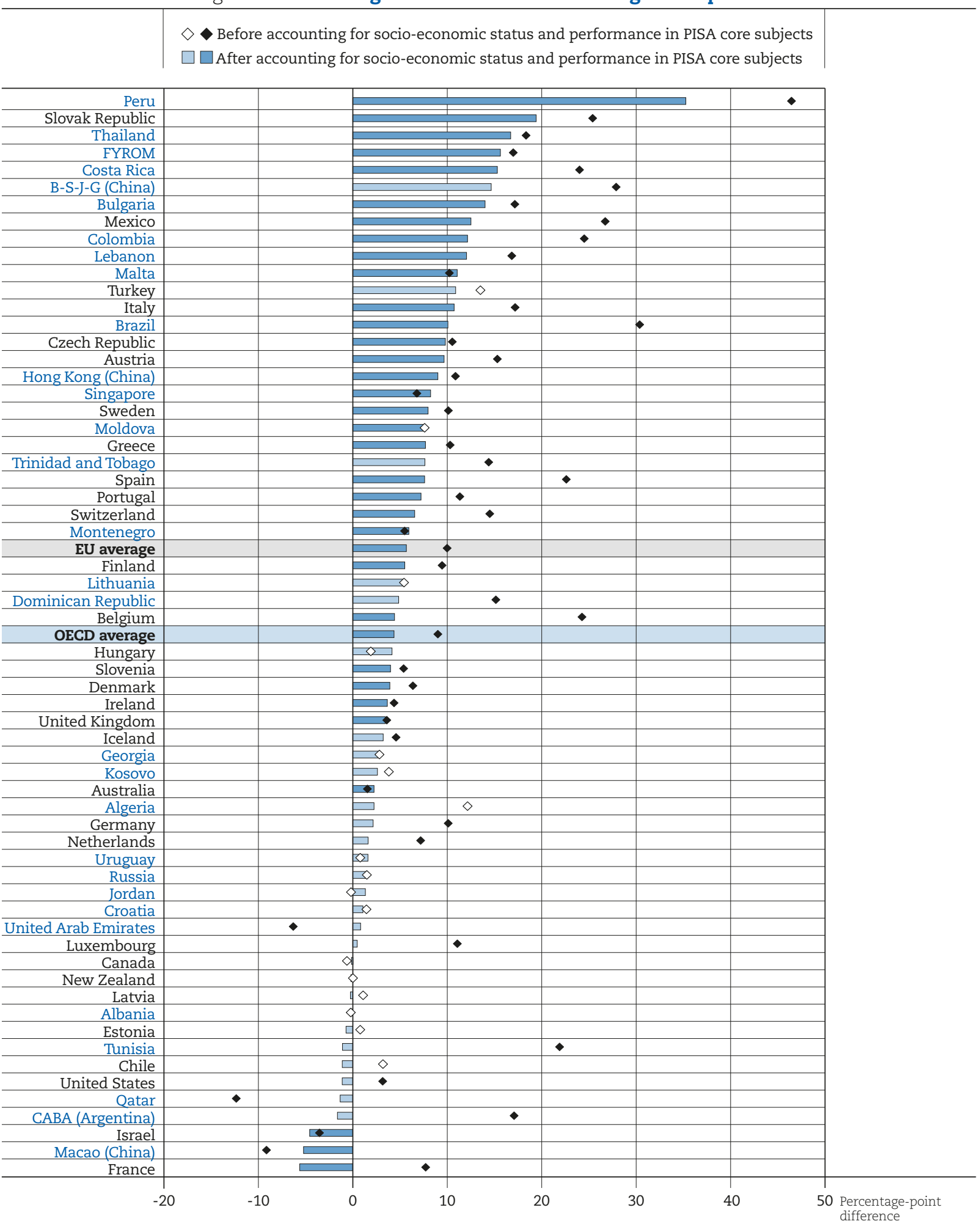

Notes: Only countries with valid estimates of immigrant-native gaps before and after accounting for academic performance and socioeconomic status are displayed.

Statistically significant immigrant-native gaps are marked in a darker tone.

Countries and economies are ranked in descending order of the difference between immigrant and native students in the percentage of students who had repeated a grade at least once, after accounting for socio-economic status and performance in PISA core subjects.

Source: OECD, PISA 2015 Database, Table 7.34.

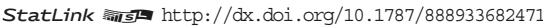


In Austria, Costa Rica, the Former Yugoslav Republic of Macedonia (hereafter "FYROM"), Hong Kong (China), Mexico, the Slovak Republic and Sweden, the percentage of students who had repeated a grade at least once was over 15 percentage points greater among first-generation immigrant students than among native students, after accounting for their academic performance. In Italy and the Slovak Republic, the same was true for second-generation immigrant students compared to native students. In Austria, Costa Rica, Germany, Hong Kong (China), Jordan, Malta, Spain and Switzerland, returning foreign-born students also faced a significant disadvantage, since they were over nine percentage points more likely than native students to have repeated a grade, after accounting for their academic performance. In Bulgaria, Colombia, Costa Rica, the Dominican Republic, FYROM, Peru, Qatar and Spain, the percentage of students who had repeated a grade at least once was over 10 percentage points greater among native-born students of mixed heritage than among native students, after accounting for their academic performance.

Figure 7.18 shows the difference in the percentage of native and immigrant students who had repeated at least one grade, before and after accounting for their performance in the three core PISA domains. In 31 out of 61 countries considered, immigrant students are more likely than native students to have repeated a grade, after accounting for their academic performance. On average across OECD countries, they are four percentage points more likely to have repeated a grade (six percentage points more likely across EU countries); however, values range from a 35 percentage-point disadvantage for immigrant students in Peru, to a four percentage-point advantage in France.

Table 7.35 shows the effects of having repeated at least one grade on students' well-being, after accounting for their academic performance and other control variables. The effect of grade repetition on academic performance was not considered because problems of reverse causality are too great. On average across OECD and EU countries, students who had repeated at least one grade were eight percentage points less likely to report feeling like they belong at school. However, in 17 countries and economies, these students were over 10 percentage points less likely to report a sense of belonging at school. In 11 of these countries, immigrant students were more likely than native students to have repeated at least one grade, after accounting for their academic performance. In FYROM, the Slovak Republic and Thailand, immigrant students are over 15 percentage points more likely than native students to have a repeated a grade. Students in these countries who had repeated at least one grade were 34 percentage points (FYROM), 15 percentage points (the Slovak Republic) and 11 percentage points (Thailand) less likely to report sense of belonging at school than students who had never repeated a grade.

Repeating a grade also negatively affects students' satisfaction with their life, after accounting for their academic performance. On average across OECD countries, students who had repeated a grade were five percentage points less likely to report being satisfied with life (six percentage points less likely across EU countries). The effect was above eight percentage points in Belgium, Costa Rica, the Czech Republic, Montenegro, Spain and Thailand, where immigrant students are more likely to have repeated a grade than native students. Repeating a grade has a negative effect on the likelihood of reporting low levels of schoolwork-related anxiety only in Austria, Finland, France, Israel, Qatar, Israel, Thailand, Tunisia and the United Arab Emirates. Immigrants are more likely to have a repeated a grade in all these countries except Qatar, Tunisia and the United Arab Emirates. On average across OECD countries, students who had repeated a grade were two percentage points less likely to report being motivated to achieve; however, in the majority of countries, effects on motivation are small or not statistically significant.

Results presented in 7.36 (available on line) indicate that there is no association between the percentage of students who had repeated a grade and the difference between native and immigrant students in the likelihood that a student will be academically, socially and emotionally resilient.

\section{Horizontal stratification}

In comprehensive systems, all students follow a similar path through education, regardless of their abilities, behaviour and interests; but in horizontally stratified systems, students are separated into different schools, classes or groups based on their ability, behaviour and/or interests. Stratification can occur between schools or within schools. Between-school sorting occurs when some students attend programmes that are primarily academic, while others attend programmes that are primarily vocational or have a combination of academic and vocational elements (Kerckhoff, 2000; LeTendre et al., 2003). 


\section{Table 7.35 - Grade repetition and students' well-being outcomes}

\begin{tabular}{|c|c|c|c|c|c|c|}
\hline & \multicolumn{6}{|c|}{$\begin{array}{l}\text { Statistically significant and positive value } \\
\text { Statistically significant and negative value } \\
\text { Missing or invalid estimate }\end{array}$} \\
\hline & \multicolumn{2}{|c|}{$\begin{array}{l}\text { Percentage-point difference between } \\
\text { immigrant and native students in the } \\
\text { percentage of students who had repeated } \\
\text { a grade at least once }\end{array}$} & \multicolumn{4}{|c|}{ Effect of having repeated a grade at least once (percentage-point change) } \\
\hline & $\begin{array}{l}\text { Before accounting } \\
\text { for academic } \\
\text { performance and } \\
\text { socio-economic } \\
\text { status }\end{array}$ & $\begin{array}{l}\text { After accounting } \\
\text { for academic } \\
\text { performance and } \\
\text { socio-economic } \\
\text { status }\end{array}$ & $\begin{array}{l}\text { On the likelihood of } \\
\text { reporting a sense of } \\
\text { belonging at school }\end{array}$ & $\begin{array}{l}\text { On the likelihood } \\
\text { of reporting being } \\
\text { satisfied with life }\end{array}$ & $\begin{array}{l}\text { On the likelihood } \\
\text { of reporting low } \\
\text { schoolwork-related } \\
\text { anxiety }\end{array}$ & $\begin{array}{l}\text { On the likelihood } \\
\text { of reporting high } \\
\text { achievement } \\
\text { motivation }\end{array}$ \\
\hline Peru & 46.48 & 35.29 & -4.66 & -4.91 & 0.49 & -0.89 \\
\hline Slovak Republic & 25.42 & 19.44 & -15.04 & -5.77 & 5.47 & -5.59 \\
\hline Thailand & 18.36 & 16.73 & -11.05 & -8.90 & -5.80 & -2.05 \\
\hline FYROM & 17.01 & 15.65 & -33.82 & & & \\
\hline Costa Rica & 24.03 & 15.32 & -4.57 & -10.43 & 0.28 & -0.48 \\
\hline B-S-J-G (China) & 27.91 & 14.67 & -1.81 & -5.40 & -1.98 & 0.76 \\
\hline Bulgaria & 17.17 & 14.02 & -6.10 & -7.87 & -3.12 & 4.97 \\
\hline Mexico & 26.75 & 12.52 & -7.72 & -4.78 & 2.02 & -4.25 \\
\hline Colombia & 24.53 & 12.16 & -5.02 & -4.81 & -0.17 & -0.68 \\
\hline Lebanon & 16.85 & 12.06 & -2.56 & & & \\
\hline Malta & 10.24 & 11.07 & -1.63 & & & \\
\hline Turkey & 13.53 & 10.90 & -3.97 & -4.76 & 2.49 & -3.14 \\
\hline Italy & 17.20 & 10.74 & -8.72 & -4.80 & 3.84 & 0.68 \\
\hline Brazil & 30.40 & 10.08 & -5.28 & -4.26 & 2.15 & 0.70 \\
\hline Czech Republic & 10.55 & 9.81 & -10.23 & -8.71 & 0.34 & -2.12 \\
\hline Austria & 15.32 & 9.68 & -2.38 & -5.57 & -3.99 & 0.09 \\
\hline Hong Kong (China) & 10.89 & 9.02 & -2.03 & -2.93 & 5.46 & -0.59 \\
\hline Singapore & 6.80 & 8.25 & -10.93 & & 7.70 & -5.31 \\
\hline Sweden & 10.13 & 7.98 & -3.82 & & 0.39 & -0.69 \\
\hline Moldova & 7.62 & 7.72 & -14.65 & & & \\
\hline Greece & 10.32 & 7.71 & -18.74 & -1.15 & -4.55 & -1.37 \\
\hline Trinidad and Tobago & 14.41 & 7.65 & -5.93 & & & \\
\hline Spain & 22.63 & 7.62 & -1.91 & -11.66 & 5.90 & -3.22 \\
\hline Portugal & 11.35 & 7.23 & -5.41 & -3.70 & 3.36 & -4.53 \\
\hline Switzerland & 14.52 & 6.56 & -8.07 & -3.80 & -4.19 & 1.10 \\
\hline Montenegro & 5.50 & 5.95 & -17.67 & -8.52 & 5.12 & -9.18 \\
\hline EU average & 10.00 & 5.68 & -7.54 & -5.93 & -0.60 & -1.11 \\
\hline Finland & 9.47 & 5.51 & -10.24 & -6.30 & -10.18 & 7.26 \\
\hline Lithuania & 5.43 & 5.45 & -9.50 & -18.23 & -0.07 & -8.39 \\
\hline Dominican Republic & 15.16 & 4.87 & -6.50 & -4.40 & -1.74 & 3.51 \\
\hline Belgium & 24.29 & 4.43 & -6.44 & -8.12 & -1.41 & 2.69 \\
\hline OECD average & 9.02 & 4.37 & -7.65 & -5.37 & -0.67 & -1.74 \\
\hline Hungary & 1.91 & 4.16 & -6.29 & -1.50 & -3.20 & -3.34 \\
\hline Slovenia & 5.39 & 4.00 & -9.94 & -6.66 & -2.97 & 3.69 \\
\hline Denmark & 6.37 & 3.93 & -18.22 & & -1.96 & 4.84 \\
\hline Ireland & 4.38 & 3.67 & -3.39 & -5.09 & -1.03 & 0.42 \\
\hline United Kingdom & 3.61 & 3.46 & -10.85 & -3.02 & 0.13 & -6.42 \\
\hline Iceland & 4.59 & 3.23 & -19.75 & & 6.58 & -4.80 \\
\hline Georgia & 2.83 & 2.81 & -14.26 & & & \\
\hline Kosovo & 3.83 & 2.62 & -19.32 & & & \\
\hline Australia & 1.55 & 2.26 & -6.71 & & -2.67 & -3.80 \\
\hline Algeria & 12.16 & 2.26 & 21.00 & & & \\
\hline Germany & 10.11 & 2.16 & -3.43 & -4.78 & -2.00 & -4.80 \\
\hline Netherlands & 7.20 & 1.63 & -3.93 & -2.85 & -0.42 & -2.00 \\
\hline Uruguay & 0.79 & 1.61 & -5.36 & -8.18 & 5.91 & 1.01 \\
\hline Russia & 1.50 & 1.42 & -18.21 & -18.34 & 3.45 & 3.27 \\
\hline Jordan & -0.18 & 1.34 & -21.41 & & & \\
\hline Croatia & 1.45 & 1.08 & -5.58 & -2.31 & 5.40 & -4.08 \\
\hline United Arab Emirates & -6.30 & 0.83 & -5.26 & -9.07 & -5.99 & -4.28 \\
\hline Luxembourg & 11.08 & 0.47 & -4.10 & -4.06 & -1.31 & -0.42 \\
\hline Canada & -0.61 & 0.03 & -14.40 & & 1.67 & -9.54 \\
\hline New Zealand & 0.02 & -0.20 & -8.92 & & -3.95 & -10.06 \\
\hline Latvia & 1.10 & -0.25 & -5.81 & -3.43 & 2.28 & -0.43 \\
\hline Albania & -0.21 & -0.33 & -11.76 & & & \\
\hline Estonia & 0.79 & -0.71 & -7.55 & -9.37 & -2.10 & -5.57 \\
\hline Tunisia & 21.91 & -1.09 & -6.18 & -5.51 & -4.29 & -1.43 \\
\hline Chile & 3.20 & -1.11 & -7.42 & -5.70 & 0.85 & 0.07 \\
\hline United States & 3.17 & -1.11 & -7.70 & -6.99 & 0.26 & -2.13 \\
\hline Qatar & -12.34 & -1.33 & -9.15 & -5.00 & -5.09 & -2.93 \\
\hline CABA (Argentina) & 17.09 & -1.62 & -3.49 & & & \\
\hline Israel & -3.52 & -4.56 & & & -5.77 & -0.82 \\
\hline Macao (China) & -9.14 & -5.21 & 0.01 & -2.33 & 2.70 & -3.59 \\
\hline France & 7.73 & -5.62 & -1.95 & -6.01 & -7.04 & 1.90 \\
\hline
\end{tabular}

Notes: Only those countries with a valid estimate for the difference in the percentage native and immigrant students who had repeated a grade are displayed. The OECD and EU average percentage-point differences are based only on countries with reliable estimates for both native and immigrant students.

Results on the effects of having repeated a grade are obtained from regressions that account for students' academic performance in the three PISA core subjects, their gender, immigrant background and socio-economic status, as well as the socio-economic profile of schools.

Students who attain baseline academic proficiency are those who reach at least PISA proficiency Level 2 in all three core PISA subjects: science, reading and mathematics Students who reported a sense of belonging at school are those who reported that they "agree" or "strongly agree" with the statement "I feel like I belong at school" and "disagree" or "strongly disagree" with the statement "I feel like an outsider at school".

Students who reported being satisfied with life are those who reported a life satisfaction of 7 or above on a scale from 0 to 10

Students who reported low schoolwork-related anxiety are those who reported that they "disagree" or "strongly disagree" with the statements "I often worry that it will be difficult for me taking a test" and "Even if I am well prepared for a test, I feel very anxious".

Students who reported high motivation to achieve are those who reported that they "agree" or "strongly agree" with the statement "I want to be the best, whatever I do". Countries and economies are ranked in descending order of the percentage-point difference between immigrant and native students in the percentage of students who had repeated a grade at least once, after accounting for academic performance and socio-economic status.

Source: OECD, PISA 2015 Database Table 7.34 and Table 7.40.

StatLink 部吉 http://dx.doi.org/10.1787/888933682699 
Within-school sorting occurs when students are grouped by ability and placed into different classes or are placed into different study groups within the same class. Most education systems allow a degree of differentiation, but systems differ greatly depending on the age at which students are sorted into different education programmes and the number of programmes that are available. Evidence from PISA 2012 shows that in countries and economies that sort students into different education programmes at an early age, the impact of students' socio-economic status on their performance is stronger than in systems that select and group students later (OECD, 2013).

PISA asked students in what programme they were enrolled; responses were coded to identify vocational tracks. Table 7.37 (available on line) reports the percentage of students with an immigrant background enrolled in vocational tracks and the differences in percentages between native students and students of various immigrant backgrounds, before and after accounting for their performance in the three core PISA subjects. On average in 2015 across OECD countries, and after accounting for students' academic performance, first-generation and second-generation immigrant students were four and three percentage points, respectively, less likely to be enrolled in a vocational track compared to native students of similar ability (across EU countries, five and four percentage points, respectively).

Figure 7.19 - Immigrant-native differences in enrolment in vocational training

\begin{tabular}{l|l|}
\hline$\diamond$ Before accounting for socio-economic status and performance in PISA core subjects \\
$\square \square$ After accounting for socio-economic status and performance in PISA core subjects
\end{tabular} \mid

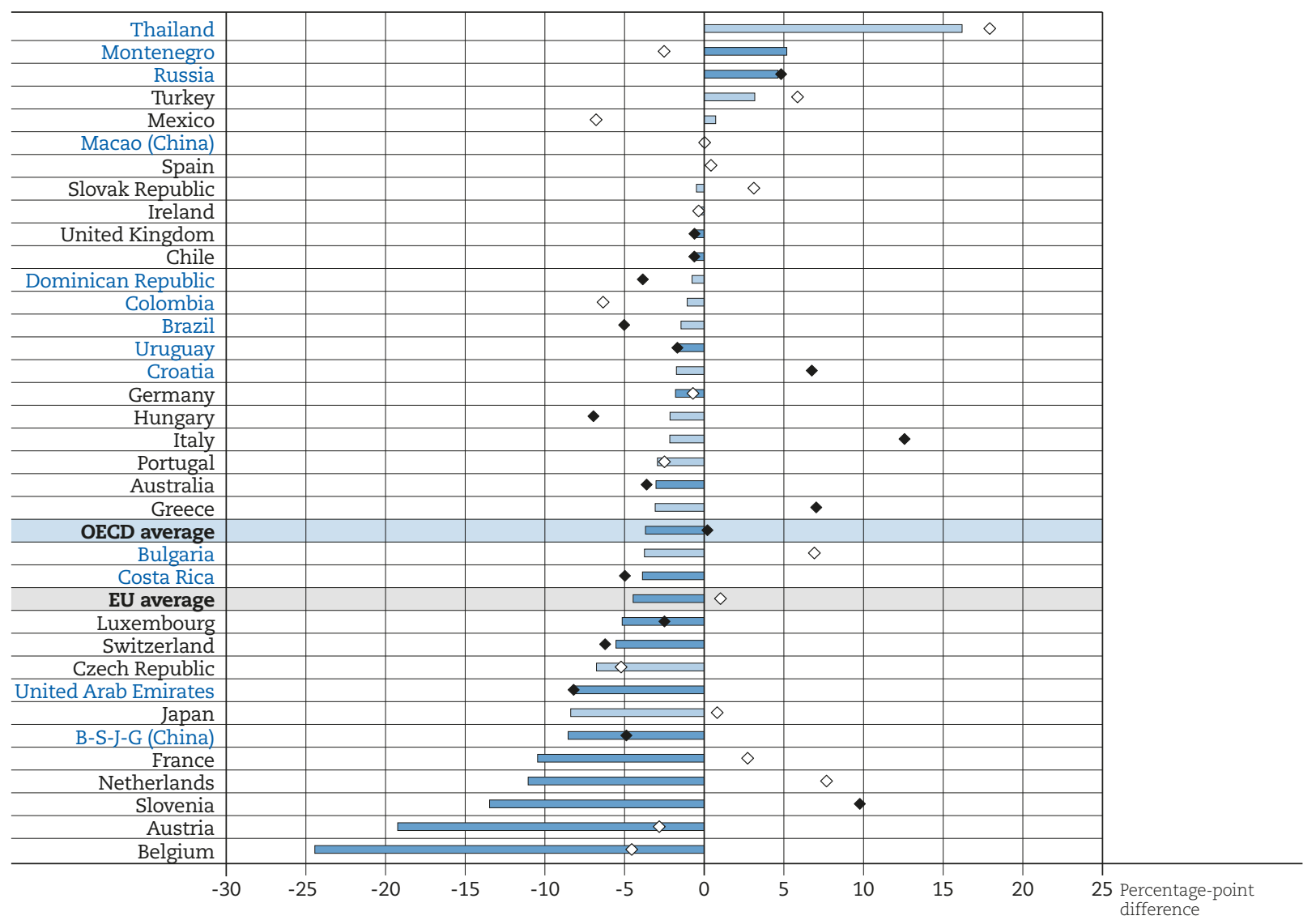

Notes: Only countries in which some students are enrolled in vocational programs and that have valid estimates of immigrant-native gaps before and after accounting for academic performance and socio-economic status are displayed.

Statistically significant immigrant-native gaps are marked in a darker tone.

Countries and economies are ranked in descending order of the difference in the percentage of immigrant and native students enrolled in vocational training, after accounting for socio-economic status and performance in PISA core subjects.

Source: OECD, PISA 2015 Database, Table 7.37.

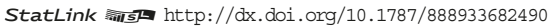


Table 7.38 - Enrolment in vocational programmes and students' well-being outcomes Pre-vocational and vocational programmes

\begin{tabular}{|c|c|c|c|c|c|c|c|}
\hline & \multicolumn{7}{|c|}{$\begin{array}{l}\text { Statistically significant and positive value } \\
\text { Statistically significant and negative value } \\
\text { Missing or invalid estimate }\end{array}$} \\
\hline & \multicolumn{2}{|c|}{$\begin{array}{l}\text { Percentage-point difference } \\
\text { between immigrant } \\
\text { and native students } \\
\text { in the percentage } \\
\text { of students enrolled } \\
\text { in vocational programmes }\end{array}$} & \multicolumn{5}{|c|}{ Effect of being enrolled in vocational programmes (percentage-point change) } \\
\hline & \begin{tabular}{|} 
Before \\
accounting \\
for academic \\
performance and \\
socio-economic \\
status
\end{tabular} & $\begin{array}{l}\text { After accounting } \\
\text { for academic } \\
\text { performance and } \\
\text { socio-economic } \\
\text { status }\end{array}$ & $\begin{array}{l}\text { On the likelihood } \\
\text { of attaining } \\
\text { baseline } \\
\text { academic } \\
\text { proficiency }\end{array}$ & $\begin{array}{l}\text { On the likelihood } \\
\text { of reporting } \\
\text { a sense } \\
\text { of belonging } \\
\text { at school }\end{array}$ & $\begin{array}{c}\text { On the likelihood } \\
\text { of reporting } \\
\text { being satisfied } \\
\text { with life }\end{array}$ & $\begin{array}{l}\text { On the likelihood } \\
\text { of reporting low } \\
\text { schoolwork- } \\
\text { related anxiety }\end{array}$ & $\begin{array}{l}\text { On the likelihood } \\
\text { of reporting high } \\
\text { achievement } \\
\text { motivation }\end{array}$ \\
\hline Thailand & 17.89 & 16.18 & -24.95 & -4.85 & -5.12 & -0.64 & 0.67 \\
\hline CABA (Argentina) & 11.03 & 10.55 & 2.48 & 1.76 & & & \\
\hline Montenegro & -2.54 & 5.18 & -33.42 & 1.99 & 0.53 & 1.41 & 4.04 \\
\hline Russia & 4.80 & 4.63 & -5.92 & 5.89 & 1.04 & 2.23 & -4.81 \\
\hline Turkey & 5.83 & 3.17 & -34.58 & 0.48 & 4.16 & -0.21 & 3.02 \\
\hline Albania & 3.58 & 2.00 & -23.03 & -3.50 & & & \\
\hline Mexico & -6.80 & 0.72 & 12.03 & 0.99 & 0.47 & 0.95 & -0.31 \\
\hline Georgia & 0.24 & 0.09 & -26.27 & -4.25 & & & \\
\hline Macao (China) & 0.01 & -0.07 & -8.79 & -3.03 & -9.83 & 9.84 & 8.75 \\
\hline Spain & 0.41 & -0.13 & -48.99 & -2.95 & 8.21 & 3.77 & 11.61 \\
\hline Slovak Republic & 3.09 & -0.49 & -44.98 & -0.30 & -1.83 & 1.16 & 2.46 \\
\hline Ireland & -0.37 & -0.50 & -60.35 & -13.07 & -18.96 & 20.83 & -1.53 \\
\hline United Kingdom & -0.63 & -0.65 & 0.64 & 3.91 & 3.63 & -2.73 & -1.76 \\
\hline Chile & -0.64 & -0.66 & -7.19 & 12.57 & 7.25 & 5.76 & 8.56 \\
\hline Dominican Republic & -3.87 & -0.76 & 21.52 & 2.69 & 4.18 & 0.78 & -2.83 \\
\hline Colombia & -6.36 & -1.06 & 7.92 & 2.52 & 0.70 & -0.95 & -0.01 \\
\hline Brazil & -5.04 & -1.46 & 30.96 & 2.91 & -0.46 & -1.05 & -1.05 \\
\hline Uruguay & -1.70 & -1.64 & -10.76 & -4.76 & 9.56 & -1.79 & 1.49 \\
\hline Croatia & 6.73 & -1.74 & -40.91 & -0.58 & -2.45 & 7.46 & 0.54 \\
\hline Germany & -0.72 & -1.80 & -14.42 & -2.03 & 7.77 & 2.44 & -0.02 \\
\hline Hungary & -6.97 & -2.14 & -51.57 & -3.55 & 0.19 & 7.82 & -0.45 \\
\hline Italy & 12.54 & -2.16 & -27.03 & -6.57 & 1.51 & 2.97 & -0.16 \\
\hline Portugal & -2.51 & -2.93 & -25.89 & -1.11 & 2.63 & 7.77 & 0.98 \\
\hline Australia & -3.63 & -3.02 & -12.31 & -4.85 & & -1.71 & -1.84 \\
\hline FYROM & -0.65 & -3.06 & -16.01 & -1.24 & & & \\
\hline Greece & 7.01 & -3.07 & -51.90 & -0.52 & -4.24 & 8.82 & 6.51 \\
\hline OECD average & 0.18 & -3.58 & -24.47 & 0.16 & 0.81 & 4.08 & 0.26 \\
\hline Bulgaria & 6.89 & -3.75 & -27.84 & -0.12 & 1.43 & -0.70 & 2.14 \\
\hline Costa Rica & -5.00 & -3.87 & 15.20 & 2.53 & 2.13 & 1.67 & 2.13 \\
\hline EU average & 0.50 & -4.60 & -28.89 & -0.37 & 0.69 & 4.96 & -0.24 \\
\hline Luxembourg & -2.51 & -5.14 & 9.44 & 3.76 & 1.53 & -2.78 & -5.07 \\
\hline Switzerland & -6.23 & -5.54 & 17.83 & 1.92 & -7.02 & -4.14 & 3.47 \\
\hline Czech Republic & -5.23 & -6.76 & -1.75 & 4.19 & -1.11 & -1.20 & -2.35 \\
\hline United Arab Emirates & -8.21 & -8.22 & -13.52 & 0.84 & -6.12 & 9.66 & 1.40 \\
\hline Japan & 0.80 & -8.37 & -9.47 & -0.46 & -0.58 & 1.45 & -1.53 \\
\hline B-S-J-G (China) & -4.90 & -8.54 & 0.81 & -4.29 & -5.15 & 1.92 & 1.88 \\
\hline France & 2.70 & -10.45 & -43.63 & 3.25 & 5.88 & 13.83 & 3.71 \\
\hline Netherlands & 7.65 & -11.04 & -57.80 & 0.88 & -0.36 & 4.21 & -3.06 \\
\hline Slovenia & 9.74 & -13.46 & -24.83 & 0.88 & 0.21 & 2.11 & -5.68 \\
\hline Austria & -2.84 & -19.23 & -25.13 & 3.79 & 1.69 & 0.07 & -3.78 \\
\hline Kosovo & -17.69 & -21.94 & -10.64 & 0.08 & & & \\
\hline Belgium & -4.57 & -24.42 & -30.87 & 7.68 & 3.75 & 12.36 & -6.90 \\
\hline
\end{tabular}

Notes: The table displays only those countries in which some students are enrolled in vocational programmes, with valid estimates of the effect of attending vocational programs on at least two of the five outcomes analysed, and with a valid estimate for the difference between immigrant and native students in the percentage of students enrolled in vocational programs. The OECD and EU average percentage-point differences are based only on countries with reliable estimates for both native and immigrant students.

Results on the effects of being enrolled in vocational programmes are obtained from regressions that account for students' gender, immigrant background and socio-economic status, as well as the socio-economic profile of schools. All regressions but the one for the effect on academic performance also account for the performance of students in the three PISA core subjects.

Students who attain baseline academic proficiency are those who reach at least PISA proficiency Level 2 in all three core PISA subjects: science, reading and mathematics.

Students who reported a sense of belonging at school are those who reported that they "agree" or "strongly agree" with the statement "I feel like I belong at school" and "disagree" or "strongly disagree" with the statement "I feel like an outsider at school".

Students who reported being satisfied with life are those who reported a life satisfaction of 7 or above on a scale from 0 to 10 .

Students who reported low schoolwork-related anxiety are those who reported that they "disagree" or "strongly disagree" with the statements "I often worry that it will be difficult for me taking a test" and "Even if I am well prepared for a test, I feel very anxious".

Students who reported high motivation to achieve are those who reported that they "agree" or "strongly agree" with the statement "I want to be the best, whatever I do".

Countries and economies are ranked in descending order of the percentage-point difference between immigrant and native students in the percentage of students enrolled in vocational training, after acounting for academic performance and socio-economic status.

Source: OECD, PISA 2015 Database, Table 7.37 and Table 7.40.

StatLink +त्ताs http://dx.doi.org/10.1787/888933682718 
In Austria, Belgium, France, Kosovo, the Netherlands and Slovenia, first-generation immigrant students were over 10 percentage points less likely to be enrolled in a vocational track compared to native students. The same was true for second-generation immigrants, except in France. In the majority of countries, differences between native students and returning foreign-born students, and between native students native-born students of mixed heritage were not statistically significant. However, in Austria and Belgium, both groups were at least nine percentage points more likely than native students to be enrolled in a vocational track.

The finding that, in the majority of countries and economies, immigrant students are less likely to be enrolled in vocational tracks than native students, after accounting for their academic performance, is consistent with results showing that immigrant students have greater achievement motivation and that immigrant parents hold more ambitious expectations for their children's education than the parents of native students (OECD, 2015). This could indicate that immigrant students, unlike other socioeconomically disadvantaged students, have not internalised low expectations of social mobility. Chapter 8 examines the education and career expectations of immigrant students, and the educational mobility of immigrants and native students in European countries.

Table 7.38 reports, for countries and economies where some students were enrolled in vocational programs and with valid estimates of immigrant-native gaps in enrolment, the effects of being enrolled in a vocational program on on students' well-being, after accounting for their academic performance and other control variables. In most countries and economies, the effects of being enrolled in a vocational track on students' well-being were small, after accounting for their academic performance. In Austria and Belgium, students enrolled in vocational tracks were, respectively, four and eight percentage points more likely to feel like they belonged at school; in France, they were six percentage points more likely to be satisfied with their life and 14 percentage points more likely to report low levels of schoolwork-related anxiety. In all of these countries, immigrant students were less likely to be enrolled in a vocational track.

Table 7.39 (available on line) shows that there is no association at the country level between the percentage of socio-economically disadvantaged students who attend pre-vocational or vocational programmes and the difference between native and immigrant students in the likelihood of attaining baseline levels of academic proficiency or reporting a sense of belonging at school. Results are the same when considering all students, rather than just disadvantaged students. 


\section{Annex 7.A1}

This section outlines the way in which the index of sports distance was constructed using Google Trend data in Garibaldi (2017). Google Trend provides data on the share of worldwide researches on a topic coming from each country. The actual shares are not available. Instead, normalised values are provided which range between zero and 100, where 100 is the value assigned to the country with the greatest number of researches on the topic. Using Google Trend data from 2004 to 2016, Garibaldi calculates such normalised shares for the set of the most popular sports in the world and for each combination of host and origin country in the PISA rounds of 2003, 2006, 2009, 2012 and 2015. Using such data Garibaldi calculates the so-called "between sports distance" between country A and B for sport S as follows:

$B D_{S}=\mid$ share of searches on sport S from country A - share of searches on sport S from country $B \mid$

The between sports distance represent the absolute value of the difference between the share of worldwide searches of sport S coming from country A and the share coming from country B. For example, taking soccer as a sport and Italy and Germany as countries, the between sport distance is a measure of the difference in the shares of the worldwide Google searches on soccer that were made in Italy and Germany. The measure is computed for all sports and countries considered.

Google Trend also allows calculating the share of the total searches in a given country related to a specific topic. Although, actual shares are not available, Google Trends makes available normalised values which range between 0 and 100, where 100 represents the most searched topic. The author uses this information to calculate the importance of each sport in the Google researches of each country and calculate the "within sports distance" between country A and B for sport S as follows:

$W D_{S}=\mid$ share of searches in country A about sport $S$ - share of searches in country B about sport S |

The within sports distance represents the absolute value of the difference between the share of sport $\mathrm{S}$ in the Google searches of country A and the share of sport S in the Google searches of country B. For example, it could be the difference between the share of total Italian Google searches that were on soccer and the share of total Google in searches in Germany that were on soccer. The measure is computed for all sports and countries considered.

The final measure of sports distance between countries A and B is calculated as follows:

Sport distance $=\sum_{S} B D_{S} * W D_{S}$

Where $\mathrm{S}$ is the set of all sports considered. Table 7.A1.2 (available on line) presents sports index scores for the set of host and origin countries in the pooled sample of PISA rounds from 2003, 2006, 2009, 2012 and 2012. Table 7.A1.1 below reports the results from the regression of the PISA science scores of immigrant students on the index of sports distance, individual control variables and other measures of dissimilarity between host and origin countries.

Table 7.A1.1 - The association between sports distance and immigrant students' science scores

\begin{tabular}{|c|c|c|c|}
\hline Variable & Model 1 & Model 2 & Model 3 \\
\hline Sports Distance & $\begin{array}{l}-0.974^{* * *} \\
(-3.04)\end{array}$ & $\begin{array}{l}-0.812^{* *} \\
(-2.33)\end{array}$ & $\begin{array}{l}-1.085^{* * *} \\
(-3.06)\end{array}$ \\
\hline Female student & $\begin{array}{l}-2.336 \\
(-1.35)\end{array}$ & $\begin{array}{l}-2.547 \\
(-1.46)\end{array}$ & $\begin{array}{l}-4.661^{* * *} \\
(-2.73)\end{array}$ \\
\hline Parents' highest educational attainment & $\begin{array}{l}5.686^{* * *} \\
(7.32)\end{array}$ & $\begin{array}{l}5.541^{* * *} \\
(6.89)\end{array}$ & $\begin{array}{l}5.513^{* * *} \\
(6.86)\end{array}$ \\
\hline Linguistic Distance & & $\begin{array}{l}-0.216^{* * *} \\
(-9.09)\end{array}$ & $\begin{array}{l}-0.215^{* * *} \\
(-9.05)\end{array}$ \\
\hline Sports Distance*Female & & & $\begin{array}{l}0.591^{* * *} \\
(3.00)\end{array}$ \\
\hline Constant & $\begin{array}{l}415.6^{* * *} \\
(50.54)\end{array}$ & $\begin{array}{l}411.1^{* * *} \\
(30.87)\end{array}$ & $\begin{array}{c}409.1^{* * * *} \\
(31.00)\end{array}$ \\
\hline Observations & 40252 & 40252 & 40132 \\
\hline Adjusted R-squared & 0.327 & 0.332 & 0.333 \\
\hline Host and origin country FE & Yes & Yes & Yes \\
\hline
\end{tabular}

Notes: $t$ statistics in parentheses

${ }^{*} \mathrm{p}<0.10,{ }^{* *} \mathrm{p}<0.05,{ }^{* * *} \mathrm{p}<0.01$

Regressions control for the ISCED level of the class where students were enrolled, the ammount of books they reported to have at home and for whether they were first-generation immigrants. Results also account for the geographic and cultural distance between host and origin countries.

The results were obtained using pooled data from the PISA rounds of 2003, 2006, 2009, 2012 and 2015.

Source: Adapted from Garibaldi, E. (2017), "The role of sports for the integration of immigrant students", Universitá L. Bocconi Graduate Thesis, Milano (unpublished).

StatLink त्तारा http://dx.doi.org/10.1787/888933682737 


\section{Annex 7.A2}

This section presents the results from the regression of school disciplinary climate and unfair treatment by teachers on school level factors.

Table 7.A2.1 - Change in school level disciplinary climate associated with school level inputs, regression-based coefficients

\begin{tabular}{|c|c|c|c|}
\hline Variable & Model 1 & Model 2 & Model 3 \\
\hline $\begin{array}{l}\text { Average number of years that teachers spent teaching } \\
\text { in current school }\end{array}$ & $\begin{array}{l}1.76^{* * *} \\
(0.33)\end{array}$ & $\begin{array}{l}0.93^{* * *} \\
(0.34)\end{array}$ & $\begin{array}{l}0.95^{* * *} \\
(0.33)\end{array}$ \\
\hline $\begin{array}{l}\text { Average number of years that the teachers spent } \\
\text { teaching overall }\end{array}$ & $\begin{array}{l}-1.25^{* * *} \\
(0.24)\end{array}$ & $\begin{array}{r}-0.1 \\
(0.29)\end{array}$ & $\begin{array}{l}-0.24 \\
(0.30)\end{array}$ \\
\hline Transformational school leader & $\begin{array}{r}-0.47 \\
(1.87)\end{array}$ & $\begin{array}{c}4.2^{* *} \\
(1.85)\end{array}$ & $\begin{array}{r}2.38 \\
(2.10)\end{array}$ \\
\hline School socio-economic profile (school average ESCS) & $\begin{array}{l}15.92^{* * *} \\
(1.07)\end{array}$ & $\begin{array}{l}15.73^{* * *} \\
(1.19)\end{array}$ & $\begin{array}{l}14.51^{* * *} \\
(1.38)\end{array}$ \\
\hline Computer/student ratio & & & $\begin{array}{l}-2.89 \\
(2.30)\end{array}$ \\
\hline Student/teacher ratio & & & $\begin{array}{l}-0.28^{* * *} \\
(0.10)\end{array}$ \\
\hline Index of shortage of educational material & & & $\begin{array}{r}2.21 \\
(2.16)\end{array}$ \\
\hline Index of shortage of educational staff & & & $\begin{array}{l}-8.7^{* * *} \\
(2.03)\end{array}$ \\
\hline Number of afterschool activities & & & $\left(1.00^{* *}\right.$ \\
\hline Constant & $\begin{array}{l}21.2^{* * * *} \\
(3.54)\end{array}$ & $\begin{array}{l}10.16^{* * *} \\
(3.60)\end{array}$ & $\begin{array}{l}17.75^{* * *} \\
(5.73)\end{array}$ \\
\hline Observations & 157229 & 157229 & 133353 \\
\hline Adjusted R-squared & 0.109 & 0.369 & 0.406 \\
\hline Country FE & No & Yes & Yes \\
\hline
\end{tabular}

Notes: Standard error in parentheses.

${ }^{*} p<0.10,{ }^{* *} p<0.05,{ }^{* * *} p<0.01$

ESCS refers to the PISA index of economic, social and cultural status.

Source: OECD, PISA 2015 Database.

StatLink 解四 http://dx.doi.org/10.1787/888933682756

Table 7.A2.2 - Change in the likelihood that students will report having frequently experienced being unfairly treated by their teachers, regression-based coefficients

\begin{tabular}{|c|c|c|c|c|}
\hline Variable & Model 1 & Model 2 & Model 3 & Model 4 \\
\hline Socio-economic status (ESCS) & $\begin{array}{l}-0.51^{* * *} \\
(0.18)\end{array}$ & $\begin{array}{l}-0.87^{* * *} \\
(0.17)\end{array}$ & $\begin{array}{l}-0.15 \\
(0.31)\end{array}$ & $\begin{array}{l}-0.34 \\
(0.33)\end{array}$ \\
\hline Female student & $\begin{array}{l}-7.76^{* * *} \\
(0.36)\end{array}$ & $\begin{array}{l}-7.88^{* * *} \\
(0.36)\end{array}$ & $\begin{array}{l}-8.04^{* * *} \\
(0.55)\end{array}$ & $(0.57)$ \\
\hline Immigrant background & $\begin{array}{l}4.84^{* * * *} \\
(0.69)\end{array}$ & $\begin{array}{l}3.82^{* * *} \\
(0.62)\end{array}$ & $\begin{array}{l}2.64^{* *} \\
(1.09)\end{array}$ & $\begin{array}{c}1.99^{*} \\
(1.17)\end{array}$ \\
\hline $\begin{array}{l}\text { Average number of years that teachers } \\
\text { spent teaching } \\
\text { in current school }\end{array}$ & & & $\begin{array}{l}-0.51^{* * *} \\
(0.11)\end{array}$ & $\begin{array}{l}-0.46^{* * *} \\
(0.11)\end{array}$ \\
\hline $\begin{array}{l}\text { Average number of years that the } \\
\text { teachers spent teaching overall }\end{array}$ & & & $\begin{array}{c}0.24^{* *} \\
(0.09)\end{array}$ & $\begin{array}{r}0.15 \\
(0.10)\end{array}$ \\
\hline Transformational school leader & & & $\begin{array}{l}-1.44^{* *} \\
(0.71)\end{array}$ & $(0.73)$ \\
\hline $\begin{array}{l}\text { School socio-economic profile (school } \\
\text { average ESCS) }\end{array}$ & & & $\begin{array}{l}-2.76^{* * *} \\
(0.67)\end{array}$ & $\begin{array}{l}-2.31^{* * *} \\
(0.70)\end{array}$ \\
\hline Computer/student ratio & & & & $\begin{array}{l}-0.62 \\
(0.62)\end{array}$ \\
\hline Student/teacher ratio & & & & $\begin{array}{r}0.01 \\
(0.03)\end{array}$ \\
\hline $\begin{array}{l}\text { Index of shortage of educational } \\
\text { material }\end{array}$ & & & & $\begin{array}{r}-0.53 \\
(0.89)\end{array}$ \\
\hline Index of shortage of educational staff & & & & $\begin{array}{r}0.8 \\
(0.96)\end{array}$ \\
\hline Number of afterschool activities & & & & $\begin{array}{r}-0.23 \\
(0.18)\end{array}$ \\
\hline Constant & $\begin{array}{l}54.3^{* * *} \\
(0.33)\end{array}$ & $\begin{array}{l}54.34^{* * *} \\
(0.32)\end{array}$ & $\begin{array}{l}54.71^{* * *} \\
(1.40)\end{array}$ & $\begin{array}{l}57.69^{* * *} \\
(2.05)\end{array}$ \\
\hline Observations & 388058 & 388058 & 136970 & 118773 \\
\hline Adjusted R-squared & 0.007 & 0.055 & 0.038 & 0.041 \\
\hline Country FE & No & Yes & Yes & Yes \\
\hline
\end{tabular}

Notes: Standard error in parentheses.

${ }^{*} \mathrm{p}<0.10,{ }^{* *} \mathrm{p}<0.05,{ }^{* * *} \mathrm{p}<0.01$

ESCS refers to the PISA index of economic, social and cultural status.

Source: OECD, PISA 2015 Database.

StatLink 䣓四 http://dx.doi.org/10.1787/888933682775 


\section{Notes}

1. Students who reach proficiency level 2 in PISA core subjects.

2. Students who report that they "agree" or "strongly agree" with the statement "I feel like I belong at school" and "disagree" or "strongly disagree" with the statement "I feel like an outsider at school".

3. Students who report a life satisfaction of 7 or above on a scale from 1 to 10.

4. Students who reported that they "disagree" or "strongly disagree" with the statements "I often worry that it will be difficult for me taking a test" and "Even if I am well prepared for a test, I feel very anxious".

5. Students to "agree" or "strongly agree" with the statement "I want to be the best, whatever I do".

6. Results obtained with the use of the index are similar to those reported in the chapter.

7. School principals are asked whether their school offers any of the following: band, orchestra or choir; school play or school musical; school yearbook, newspaper or magazine; volunteering or service activities; science club; science competitions; chess club; club with a focus on computers/ICT; art club or art activities; sporting team or sporting activities and a country-specific item. The number of afterschool activities offered was calculated as the sum of positive answers to these questions.

8. The index of transformational leadership is obtained from teacher responses to the following questions: "the principal tries to achieve consensus with all staff when defining priorities and goals in school"; "the principal is aware of my needs"; "the principal inspires new ideas for my professional learning"; "the principal treats teaching staff as professionals"; "the principal ensures our involvement in decision making". Possible responses were "strongly disagree", "disagree", "agree" and "strongly agree".

\section{References}

Agasisti, T. and Longobardi, S. (2014a), "Inequality in education: Can Italian disadvantaged students close the gap?", Journal of Behavioral and Experimental Economics, Vol. 52, pp. 8-20.

Agasisti, T. and Longobardi, S. (2014b), "Educational institutions, resources, and students' resiliency: an empirical study about OECD countries”, Economics Bulletin, Vol. 34/2, pp. 1055-1067.

Agasisti, T. and Longobardi, S. (2017), "Equality of educational opportunities, schools' characteristics and resilient students: An empirical study of EU-15 countries using OECD-PISA 2009 data", Social Indicators Research, 134(3), pp. 917-953.

Agasisti, T. et al. (2018), "Academic resilience: What schools and countries do to help disadvantaged students succeed in PISA”, OECD Education Working Papers, No. 167, OECD Publishing, Paris.

Ali, R. and Jerald, C.D. (2001), "Dispelling the myth in California: Preliminary findings from a state and nationwide analysis of "high-flying' schools", Education Trust West, Oakland, CA.

Allen, J.T. et al. (2010), "Sport as a vehicle for socialization and maintenance of cultural identity: international students attending American universities", Sport Management Review, Vol. 13/4, pp.421-434.

Andersen, S.C. and M.K. Thomsen (2011), "Policy implications of limiting immigrant concentration in Danish public schools", Scandinavian Political Studies, Vol. 34/1, pp. 27-52.

Arum, R. and M. Velez (eds.) (2012), Improving Learning Environments: School Discipline and Student Achievement in Comparative Perspective, Stanford University Press, Stanford, CA.

Battistich, V. et al. (1997), "Caring school communities", Educational Psychologist, Vol. 32/3, pp. 137-151, http://dx.doi. org/10.1207/s15326985ep3203_1.

Behrman, J.R. et al. (2016), "Teacher quality in public and private schools under a voucher system: The case of Chile", Journal of Labor Economics, Vol. 34/2, pp. 319-362, http://dx.doi.org/10.1086/683642.

Berends, M. and G. Zottola (2009), "Social perspectives on school choice”, in M. Berends (ed.), Handbook of Research on School Choice, Taylor and Francis, New York, pp. 35-54.

Bernard, B. (1995), Fostering Resiliency in Kids: Protective Factors in the Family, School and Community, West Ed Regional Educational Laboratory, San Francisco.

Berry, K. and C.J. Hunt (2009), "Evaluation of an intervention program for anxious adolescent boys who are bullied at school", Journal of Adolescent Health, Vol. 45/4, pp. 376-382, http://dx.doi.org/10.1016/j.jadohealth.2009.04.023.

Boser, B.U., M. Wilhelm and R. Hanna (2014), "The Power of the Pygmalion Effect. Teachers Expectations Strongly Predict College Completion", The Center for American Progress, Washington, DC. 
Bryan, J. (2005), "Fostering educational resilience and achievement in urban schools through school-family-community partnerships”, Professional School Counseling, Vol. 8/3, pp. 219-227.

Burgess, S. and E. Greaves (2013), "Test scores, subjective assessment, and stereotyping of ethnic minorities", Journal of Labor Economics, Vol. 31/3, pp. 535-576.

Burtless, G. (1996), Does Money Matter? The Effect of School Resources on Student Achievement and Adult Success, Brookings Institution Press, Washington, DC.

Burtless, G. (ed.) (2011), Does Money Matter?: The Effect of School Resources on Student Achievement and Adult Success, Brookings Institution Press, Washington, DC.

Card, D., M.D. Dooley and A.A. Payne (2010), "School competition and efficiency with publicly funded Catholic schools", American Economic Journal: Applied Economics, Vol. 2/4, pp. 150-176, www.jstor.org/stable/25760236.

Cheema, J.R. and A. Kitsantas (2014), "Influences of disciplinary classroom climate on high school student self-efficacy and mathematics: A look at gender and racial-ethnic differences", International Journal of Science and Mathematics Education, Vol. 12/5, pp. 1261-1279.

Chiu, M.M. et al. (2016), "Students' sense of belonging at school in 41 countries cross-cultural variability”, Journal of CrossCultural Psychology, Vol. 47/2, pp. 175-196, http://dx.doi.org/10.1177/0022022115617031.

Creemers, B.P.M. and L. Kyriakides (2008), "Using a multidimensional approach to measure the impact of classroomlevel factors upon student achievement: a study testing the validity of the dynamic model”, School Effectiveness and School Improvement, Vol. 19/2, pp. 183-205.

Crosnoe, R., M.K. Johnson and G.H. Elder (2004), "Intergenerational bonding in school: The behavioral and contextual correlates of student-teacher relationships", Sociology of Education, Vol. 77/1, pp. 60-81, https://doi.org/10.1177/003804070 407700103.

Dee, T.S. (2005), "A teacher like me: Does race, ethnicity or gender matter?”, American Economic Review, Vol. 95/2, pp. 158-165.

Donnelly, P. and J. Coackley (2002), "The role of recreation in promoting social inclusion”, Laidlaw Foundation Working Paper Series, Toronto.

Engeström, Y. (2009), "From learning environments and implementation to activity systems and expansive learning", Actio: An International Journal of Human Activity Theory, Vol. 2, pp. 17-33.

Epple, D., E. Newlon and R. Romano (2002), "Ability tracking, school competition, and the distribution of educational benefits,” Journal of Public Economics, Vol. 83/1, pp. 1-48, http://dx.doi.org/10.1016/s0047-2727(00)00175-4.

European Commission (2011), Grade Retention during Compulsory Education in Europe: Regulations and Statistics, Education, Audiovisual and Culture Executive Agency, EURYDICE.

Fraser, B. (2015), "Classroom learning environments", in R. Gunstone (ed.), Encyclopedia of Science Education, Springer, Netherlands, pp. 154-157.

Gamoran, A., W.G. Secada and C.B. Marrett (2000), "The organizational context of teaching and learning”, in M. Hallinan (ed.), Handbook of the Sociology of Education, Springer, United States, pp. 37-63, http://dx.doi.org/10.1007/0-387-36424-2_3.

Garibaldi, E. (2017), “The role of sports for the integration of immigrant students”, Universitá L. Bocconi Graduate Thesis, Milano (unpublished).

Güzel, Ç.I. and Berberoğlu, G. (2005), "An analysis of the Programme for International Student Assessment 2000 (PISA 2000) mathematical literacy data for Brazilian, Japanese, and Norwegian students”, Studies in Educational Evaluation, Vol. 31, pp. 283-314.

Hanushek, E.A. (2003), "The failure of input-based schooling policies", The Economic Journal, Vol. 113/485, pp. F64-F98, www.jstor.org/stable/3590139.

Hanushek, E.A. (1987), "Assessing the effects of school resources on student performance: an update", Educational Evaluation and Policy Analysis, Vol 19/2, pp.141-164.

Hanushek, E.A. (1986), "The economics of schooling: Production and efficiency in public schools", Journal of Economic Literature, Vol. 24/3, pp. 1141-1177.

Harris, D.N. (2007), "High-flying schools, student disadvantage, and the logic of NCLB", American Journal of Education, Vol. 113/3, pp. 367-394.

Harris, A. and J.H. Chrispeels (eds.) (2006), Improving Schools and Educational Systems: International Perspectives, Routledge, Abingdon. 
Haynie, D.L. et al. (2001), "Bullies, victims, and bully/victims: Distinct groups of at-risk youth", The Journal of Early Adolescence, Vol. 21/1, pp. 29-49, http://dx.doi.org/10.1177/0272431601021001002.

Hess, F.M. and T. Loveless (2005), "How school choice affects student achievement”, in Getting Choice Right: Ensuring Equity and Efficiency in Education Policy, Brookings Institution Press, Washington, DC, pp. 85-100, www.jstor.org/stable/10.7864/j. ctt12879sq.7.

Heyneman, S.P. (2009), "International perspectives on school choice", in M. Berends et al. (eds.), Handbook of Research on School Choice, Routledge, New York, NY.

Hopkins, D. (ed.) (2005), The Practice and Theory of School Improvement: International Handbook of Educational Change (Vol. 4), Springer Science and Business Media.

Hughes, J. and O.M. Kwok (2007), "Influence of student-teacher and parent-teacher relationships on lower achieving readers' engagement and achievement in the primary grades”, Journal of Educational Psychology, Vol. 99/1, p. 39-51, http:// dx.doi.org/10.1037/0022-0663.99.1.39.

Ito E. et al (2011), "The role of leisure in the assimilation of Brazilian immigrants into Japanese society: Acculturation and structural assimilation, through judo participation”, International Journal of Sport Health Science, Vol. 9, pp. 8-14.

Iwasaki, Y. and J. Bartlett (2006), "Culturally meaningful leisure as a way of coping with stress among Aboriginal individuals with diabetes", Journal of Leisure Research, Vol. 38/3, pp.321-338.

Jackson, G.B. (1975), "The research evidence on the effects of grade retention”, Review of Educational Research, Vol. 45/4, pp. 613-635, http://dx.doi.org/10.2307/1170067.

Jacob, B.A. and L. Lefgren (2004), "Remedial education and student achievement: A regression-discontinuity analysis", Review of Economics and Statistics, Vol. 86/1, pp. 226-244, http://dx.doi.org/10.1162/003465304323023778.

Jenkins, S.P., J. Micklewright and S.V. Schnepf (2008), "Social segregation in secondary schools: how does England compare with other countries?” Oxford Review of Education, 34/1, pp. 21-27.

Jennings, P.A. and M.T. Greenberg (2009), “The prosocial classroom: Teacher social and emotional competence in relation to student and classroom outcomes”, Review of Educational Research, Vol. 79/1, pp. 491-525, https://doi.org/10.3102/00346 54308325693.

Jensen, B., B. Weidmann and J. Farmer (2013), The Myth of Markets in School Education, Grattan Institute, Carlton.

Jimerson, S.R. (2001), "Meta-analysis of grade retention research: Implications for practice in the 21st century", School Psychology Review, Vol. 30/3, pp. 420-437.

Kannapel, P. J. et al. (2005), Inside the Black Box of High-performing High-poverty Schools, Report, Prichard Committee for Academic Excellence, Lexington, KY.

Kerckhoff, A.C. (2000), "Transition from school to work in comparative perspective", in M. Hallinan (ed.), Handbook of the Sociology of Education, Springer, United States, pp. 453-474, http://dx.doi.org/10.1007/0-387-36424-2_21.

Kirby, L. and M. Fraser (1997), "Risk and resilience in childhood”, in M. Fraser (ed.), Risk and Resilience in Childhood, NASW Press, Washington DC, pp. 10-33.

Klapproth, F., S. Glock and R. Martin (2013), "Prädiktoren der Sekundarstufenempfehlungen in Luxemburg", Zeitschrift Für Erziehungswissenschaften, Vol. 16/2, pp. 355-379.

Klem, A.M. and J.P. Connell (2004), "Relationships matter: Linking teacher support to student engagement and achievement”, Journal of School Health, Vol. 74/7, pp. 262-273, http://dx.doi.org/10.1111/j.1746-1561.2004.tb08283.x.

Kochel, K.P., G.W. Ladd and K.D. Rudolph (2012), “Longitudinal associations among youths' depressive symptoms, peer victimization, and low peer acceptance: An interpersonal process perspective”, Child Development, Vol. 83/2, pp. 637-650, http://dx.doi.org/10.1111/j.1467-8624.2011.01722.x.

Konishi et al. (2010), "Do school bullying and student-teacher relationships matter for academic achievement? A multilevel analysis", Canadian Journal of School Psychology, Vol. 25/1, pp. 19-39, https://doi.org/10.1177/0829573509357550.

Jenkins, S.P., J. Micklewright and S.V. Schnepf (2008), "Social segregation in secondary schools: how does England compare with other countries?” Oxford Review of Education, Vol. 34/1, pp. 20-37.

Ladd, H.F. (2002), "School vouchers: A critical view", The Journal of Economic Perspectives, Vol. 16/4, pp. 3-24, http://dx.doi. org/10.1257/089533002320950957.

Lavy, V. (2008) "Do gender stereotypes reduce girls' or boys' human capital outcomes? Evidence from a natural experiment", Journal of Public Economics, Vol. 92/10, pp. 2083-2105. 
LeTendre, G.K., B.K. Hofer and H. Shimizu (2003), "What is tracking? Cultural expectations in the United States, Germany, and Japan", American Educational Research Journal, Vol. 40/1, pp. 43-89, http://dx.doi.org/10.3102/00028312040001043.

Lindahl, E. (2007), “Comparing teachers' assessments and national test results - evidence from Sweden”, IFAU - Institute for Labour Market Policy Evaluation Working Paper, No. 24, Institute for Labour Market Policy Evaluation, Uppsala.

Lüdemann, E. and G. Schwerdt (2013), "Migration background and educational tracking. Is there a double disadvantage for second-generation immigrants?”, Journal of Population Economics, Vol. 26, pp. 455-481.

Ma, X., Jong, C. and Yuan, J. (2013), "Exploring reasons for the East Asian success in PISA", in H.-D. Meyer and A. Benavot (eds.), PISA, Power, and Policy: The Emergence of Global Educational Governance, Symposium Books, Oxford, pp. $225-246$.

Ma, X. and J.D. Willms (2004), "School disciplinary climate: Characteristics and effects on eight grade achievement", The Alberta Journal of Education Research, Vol. 50, pp. 169-188.

Makarova, E. and W. Herzog (2014), "Sport as a means of immigrant youth integration: an empirical study of sports, intercultural relations, and immigrant youth integration in Switzerland”, Sportwissenschaft, Vol. 44/1, pp.1-9.

Manacorda, M. (2012), "The cost of grade retention”, Review of Economics and Statistics, Vol. 94/2, pp. 596-606, https://doi. org/10.1162/REST_a_00165.

Masten, A.S. (1994), "Resilience in individual development: Successful adaptation despite risk and adversity", in M.C. Wang and E.W. Gordon (eds.), Educational Resilience in Inner-city America: Challenges and Prospects, Lawrence Erlbaum, Hillsdale, NJ, pp. 3-25.

McKenney, K.S. et al. (2006), "Peer victimization and psychosocial adjustment: The experiences of canadian immigrant youth", Electronic Journal of Research in Educational Psychology, Vol. 4/2, pp. 239-264.

Murray, C. and K. Malmgren (2005), "Implementing a teacher-student relationship program in a high-poverty urban school: Effects on social, emotional, and academic adjustment and lessons learned”, Journal of School Psychology, Vol. 43, pp. 137-152.

Nannyonjo, H. (2007), "Education inputs in Uganda: An analysis of factors influencing learning achievement in grade six", World Bank Working Papers, No. 98, World Bank Publications, Washington, DC, http://dx.doi.org/10.1596/978-0-8213-7056-8.

Nicoletti, C. and B. Rabe (2012), "The effect of school resources on test scores in England”, ISER Working Paper Series, Institute for Social and Economic Research, Colchester, www.iser.essex.ac.uk/publications/working-papers/iser/2012-13. pdf.

OECD (2017), PISA 2015 Results (Volume III): Students' Well-Being, OECD Publishing, Paris. http://dx.doi.org/10.1787/9789264 273856-en.

OECD (2016a), PISA 2015 Results (Volume I) - Excellence and Equity in Education, OECD Publishing, Paris, http://dx.doi. org/10.1787/9789264266490-en.

OECD (2016b), PISA 2015 Results (Volume II) - Policies and Practices for Successful Schools, OECD Publishing, Paris, http://dx.doi. org/10.1787/9789264267510-en.

OECD (2015), Immigrant Students at School: Easing the Journey towards Integration, OECD Publishing, Paris, http://dx.doi. org/10.1787/9789264249509-en.

OECD (2013), PISA 2012 Results (Volume IV): What Makes Schools Successful? Resources, Policies and Practices, OECD Publishing, Paris, http://dx.doi.org/10.1787/9789264201156-en.

OECD (2012), Untapped Skills - Realising the Potential of Immigrant Students, OECD Publishing, Paris, http://dx.doi. org/10.1787/9789264172470-en

OECD (2004), Learning for Tomorrow's World - First Results from PISA 2003, OECD Publishing, Paris, http://dx.doi.org/10.1787/ 9789264006416-en.

OECD (2003), Student Engagement at School: A Sense of Belonging and Participation: Results from PISA 2000, OECD Publishing, Paris, http://dx.doi.org/10.1787/9789264018938-en.

Peguero, A.A. (2008), "Is immigrant status relevant in school violence research? An analysis with Latino students", Journal of School Health, Vol. 78/7, pp. 397-404, http://dx.doi.org/10.1111/j.1746-1561.2008.00320.x.

Pitzer, J. and E. Skinner (2016), "Predictors of changes in students' motivational resilience over the school year: The roles of teacher support, self-appraisals, and emotional reactivity”, International Journal of Behavioral Development, Vol. 41/1, pp. 15-29, https://doi.org/10.1177/0165025416642051. 
Qin, D.B., N. Way and M. Rana (2008), “The 'model minority' and their discontent: Examining peer discrimination and harassment of Chinese American immigrant youth”, New Directions for Child and Adolescent Development, Vol. 2008/121, pp. 27-42, http://dx.doi.org/10.1002/cd.221.

Reardon, S. and A. Owens (2014), "60 years after Brown: Trends and consequences of school segregation", Annual Review of Sociology, Vol. 40/1, pp. 199-218, https://doi.org/10.1146/annurev-soc-071913-043152.

Ricard, N.C. and L.G. Pelletier (2016), "Dropping out of high school: The role of parent and teacher self-determination support, reciprocal friendships and academic motivation”, Contemporary Educational Psychology, Vol. 44-45, pp. 32-40, http://dx.doi.org/10.1016/j.cedpsych.2015.12.003.

Rivara, F. and S. Le Menestrel (eds.) (2016), Preventing Bullying Through Science, Policy, and Practice, National Academies Press, Washington, D.C.

Roemer, J. (1998), Equality of Opportunity, Harvard University Press, Cambridge, MA.

Rumberger, R. W. and G. J. Palardy (2005), "Does segregation still matter? The impact of student composition on academic achievement in high school”, Teachers College Record, Vol. 107/9, pp. 1999-2045.

Scheerens, J. and R. Bosker (1997), The Foundations of Educational Effectiveness, Emerald Group Publishing, Bingley.

Schneider, M. (2002), “Do School Facilities Affect Academic Outcomes?”, National Clearinghouse for Educational Facilities, National Institute of Building Sciences, Washington, DC.

Schnepf, S.V. (2004), "How different are immigrants? A cross-country and cross-survey analysis of educational achievement”, IZA Discussion Paper Series, No. 1398, Institute of Labour Economics (ILO), Bonn.

Shin, J., H. Lee and Y. Kim (2009), "Student and school factors affecting mathematics achievement: International comparisons between Korea, Japan, and the USA", School Psychology International, Vol. 30, pp. 520-537.

Sprietsma, M. (2013), "Discrimination in grading: experimental evidence from primary school teachers", Empirical Economics, Vol. 45, pp. 523-538.

Striegel-Moore, R.H. et al. (2002), "Abuse, bullying, and discrimination as risk factors for binge eating disorder", The American Journal of Psychiatry, Vol. 159/11, pp. 1902-1907, http://dx.doi.org/10.1176/appi.ajp.159.11.1902.

Suryadarma, D. (2012), "How corruption diminishes the effectiveness of public spending on education in Indonesia", Bulletin of Indonesian Economic Studies, Vol. 48/1, pp. 85-100, https://doi.org/10.1080/00074918.2012.654485.

Szulkin, R. and J.O. Jonsson (2007), "Ethnic segregation and educational outcomes in Swedish comprehensive schools", The Stockholm University Linnaeus Center for Integration Studies Working Paper Series, No. 2.

Thapa, A. et al. (2013), "A review of school climate research", Review of Educational Research, Vol. 83/3, pp. 357-385, https:// doi.org/10.3102/0034654313483907.

Townsend, L. et al. (2008), "The relationship between bullying behaviours and high school dropout in Cape Town, South Africa", South African Journal of Psychology, Vol. 38/1, pp. 21-32, https://doi.org/10.1177/008124630803800102.

Uline, C. and M. Tschannen-Moran (2008), “The walls speak: The interplay of quality facilities, school climate, and student achievement", Journal of Educational Administration, Vol. 46/1, pp. 55-73, http://dx.doi.org/10.1108/09578230810849817.

Valenzuela, J.P., C. Bellei and D.D.L. Ríos (2014), "Socioeconomic school segregation in a market-oriented educational system: The case of Chile”, Journal of Education Policy, Vol. 29/2, pp. 217-241, https://doi.org/10.1080/02680939.2013.806995.

van Ewijk, R. (2011), "Same work, lower grade? Student ethnicity and teachers' subjective assessments", Economics of Education Review, Vol. 30, pp. 1045-1058.

van der Slik, F., G. Driessen and K. de Bot (2006), "Ethnic and socioeconomic class composition and language proficiency: A longitudinal multilevel examination in Dutch elementary schools", European Sociological Review, Vol. 22/3, pp. 293-308.

Van de Werfhorst, H.G. and J.J. Mijs (2010), "Achievement inequality and the institutional structure of educational systems: A comparative perspective”, Annual Review of Sociology, Vol. 36, pp. 407-428, http://dx.doi.org/10.1146/annurev. soc.012809.102538.

Waslander, S., C. Pater and M. Van Der Weide (2010), "Markets in education: An analytical review of empirical research on market mechanisms in education", OECD Education Working Paper, No. 52, OECD Publishing, Paris, http://dx.doi. org/10.1787/5km4pskmkr27-en

Wei, Y., R.A. Clifton and L.W. Roberts (2011), "School resources and the academic achievement of Canadian students", Alberta Journal of Educational Research, Vol. 57/4, pp. 460-478, http://hdl.handle.net/10515/sy5nz8130. 
Werner, E.E. and R.S. Smith (1992), Overcoming the Odds: High-risk Children from Birth to Adulthood, Cornell University Pres, New York.

Wilson, V. et al. (2008), "Bunking off: The impact of truancy on pupils and teachers", British Educational Research Journal, Vol. 34/1, pp. 1-17, http://dx.doi.org/10.1080/01411920701492191.

Woessmann, L. et al. (2007), "School accountability, autonomy, choice, and the level of student achievement: International evidence from PISA 2003”, OECD Education Working Papers, No. 13, OECD Publishing, Paris, http://dx.doi. org/10.1787/246402531617. 


\title{
Chapter 8 \\ What students with an immigrant background expect in their future
}

\begin{abstract}
This chapter examines differences between immigrant and native students in their expectations for further education and a career. In many countries immigrant students are more likely to expect to attend university and to work in managerial and professional occupations. However, many of the immigrant students who hold ambitious expectations for themselves have not acquired the level of skills that would enable them to make a smooth transition into tertiary education and succeed in the labour market.
\end{abstract}

\section{Notes regarding Cyprus}

Note by Turkey: The information in this document with reference to "Cyprus" relates to the southern part of the Island. There is no single authority representing both Turkish and Greek Cypriot people on the Island. Turkey recognises the Turkish Republic of Northern Cyprus (TRNC). Until a lasting and equitable solution is found within the context of the United Nations, Turkey shall preserve its position concerning the "Cyprus issue".

Note by all the European Union Member States of the OECD and the European Union: The Republic of Cyprus is recognised by all members of the United Nations with the exception of Turkey. The information in this document relates to the area under the effective control of the Government of the Republic of Cyprus.

\section{Note regarding data from Israel}

The statistical data for Israel are supplied by and under the responsibility of the relevant Israeli authorities. The use of such data by the OECD is without prejudice to the status of the Golan Heights, East Jerusalem and Israeli settlements in the West Bank under the terms of international law. 


\section{What the data tell us}

- On average across OECD and EU countries, immigrant students are eight percentage points more likely to expect to complete tertiary education than native students of similar socio-economic status and academic performance.

- Immigrant students are less likely than native students to hold ambitious but realistic expectations for future education. On average across OECD countries, the percentage of students who expect to complete tertiary education and who also attain baseline academic proficiency is four percentage points lower among immigrant students than among native students (five percentage points lower across EU countries).

- On average across OECD countries, immigrant students are 11 percentage points more likely than native students of similar socio-economic status and academic performance to expect to have a high-status career, such as manager, professional or associate professional (9 percentage points more likely across EU countries). However, they are ten percentage points less likely to expect so and also attain baseline academic proficiency (ten percentage points less likely across EU countries). In Mexico, for every immigrant student who holds ambitious and realistic career expectations, there are approximately nine native students with similar expectations; in CABA (Argentina), Bulgaria, Brazil, FYROM and Tunisia, the ratio is also above one to two.

$\mathrm{M}$ any migrants decide to leave their country as a way to improve their and, particularly, their children's economic condition and well-being. Notwithstanding hardships and difficulties faced, most have an ambition to succeed that often surpasses the aspirations of families in their host country (OECD, 2015).

Previous chapters in this report show how the likelihood that students with an immigrant background will be academically, socially, emotionally and motivationally resilient depends on the specific background of individual students, as well as the characteristics of the schools these children attend and the principles guiding the organisation of schooling in different countries. Although it is crucial to identify if and how different education systems support students with an immigrant background in their daily lives as teenagers, it is also important to examine if and how education systems support and promote these students' aspirations and equip them with the skills and mindset that will help them reach their life goals.

Chapter 7 in this report describes how immigrant students are less likely than their native peers to attend pre-vocational and vocational school, and Chapter 3 shows that immigrant students tend to have greater achievement motivation, measured by the extent to which immigrant students report strongly agreeing or agreeing with the statement "I want to be the best, whatever I do", than their native peers. Immigrant students' achievement motivation and their preference for academically oriented studies that require time and resources to complete, is noteworthy, even more so given widespread concerns over lack of engagement and motivation to learn among secondary school students, especially socio-economically disadvantaged students, in many countries (OECD, 2013).

Immigrant students' achievement motivation and willingness to pursue tertiary level education signals their desire to improve their socio-economic status. However, as previous chapters in this report show, too many immigrant children lack the foundation skills that are necessary to succeed in school. Without solid foundation skills, they will be unlikely to realise their ambitions.

Although PISA data do not allow to identify the longer term outcomes of the group of students with an immigrant background who was surveyed in 2015 , it is possible to describe the educational and career expectations of these students and of their families. This chapter discusses the proportion of immigrant students who hold ambitious education and career expectations who reach baseline levels of proficiency in reading, mathematics and science and compares this to the proportion of students with an immigrant background who do not reach baseline levels of proficiency and to the proportion of native students with similar background characteristics who do. These students are most likely to fulfil their ambitions. 
Table 8.1 - Snapshot of the expectations of immigrant students for the future

\begin{tabular}{|c|c|c|c|c|c|c|}
\hline & \multicolumn{6}{|c|}{$\begin{array}{l}\text { Countries/economices with values above the OECD average } \\
\text { Countries/economices with values not significantly different from the OECD average } \\
\text { Countries/economices with values below the OECD average }\end{array}$} \\
\hline & 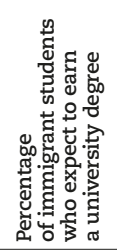 & 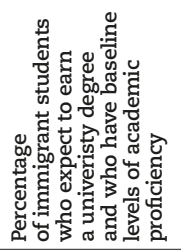 & 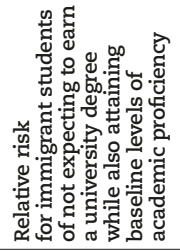 & 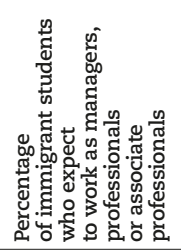 & 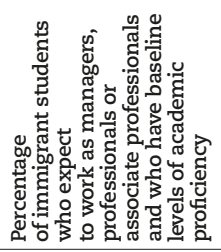 & 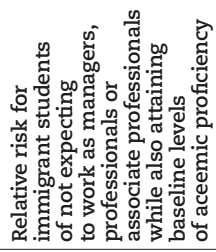 \\
\hline OECD average & 41.37 & 29.9 & 1.08 & 79.05 & 48.61 & 1.23 \\
\hline EU average & 36.95 & 27.55 & 1.08 & 75.16 & 48.38 & 1.25 \\
\hline Qatar & 81.32 & 47.4 & 0.61 & 93.97 & 52.09 & 0.57 \\
\hline United Arab Emirates & 77.58 & 50.72 & 0.62 & 97.05 & 59.19 & 0.53 \\
\hline Canada & 77.5 & 67.76 & 0.67 & 92.19 & 78.16 & 0.66 \\
\hline Singapore & 77 & 72.84 & 0.59 & 96.55 & 87.79 & 0.55 \\
\hline United States & 74.53 & 50.8 & 1.22 & 86.95 & 54.28 & 1.24 \\
\hline Colombia & 73.04 & 16.17 & 1.19 & 89.44 & 19.25 & 1.16 \\
\hline Turkey & 71.69 & 32.65 & 1.05 & 78.32 & 31.35 & 1.12 \\
\hline Australia & 67.84 & 57.79 & 0.73 & 84.69 & 66.97 & 0.8 \\
\hline Montenegro & 67.34 & 34.07 & 0.95 & 85.28 & 42.86 & 0.87 \\
\hline Dominican Republic & 60.56 & 6.42 & 1 & 94.58 & 6.46 & 1.01 \\
\hline Czech Republic & 60.54 & 48.31 & 1.03 & 77.32 & 54.44 & 0.99 \\
\hline United Kingdom & 60.22 & 47.72 & 0.78 & 90.9 & 64.39 & 0.98 \\
\hline Chile & 60.03 & 26.77 & 1.22 & 91.59 & 28.96 & 1.32 \\
\hline Uruguay & 59.18 & 37.89 & 0.86 & 81.31 & 44.14 & 0.92 \\
\hline New Zealand & 57.14 & 47.89 & 0.8 & 86.31 & 66.31 & 0.83 \\
\hline Lithuania & 56.06 & 44.27 & 1.03 & 68.61 & 51.4 & 1.12 \\
\hline Israel & 55.27 & 41.06 & 1.06 & 90.84 & 56.15 & 0.98 \\
\hline Ireland & 54.42 & 45.78 & 0.92 & 88.47 & 71.32 & 0.93 \\
\hline Hungary & 52.44 & 47.13 & 0.77 & 76.05 & 64.23 & 0.68 \\
\hline Hong Kong (China) & 51.84 & 47.36 & 1.21 & 81.07 & 70.8 & 1.23 \\
\hline Costa Rica & 50.72 & 12.48 & 1.11 & 90.15 & 19.82 & 1.21 \\
\hline Sweden & 50.21 & 32.25 & 1.01 & 83.73 & 45.27 & 1.36 \\
\hline Greece & 49.66 & 28.61 & 1.49 & 71.17 & 32.99 & 1.4 \\
\hline Macao (China) & 47.45 & 44.93 & 0.9 & 77.4 & 69.68 & 0.87 \\
\hline Mexico & 43.8 & 2.57 & 1.33 & 88.03 & 4.11 & 1.48 \\
\hline Japan & 40.99 & 31.16 & 1.51 & c & c & c \\
\hline Spain & 40.87 & 31.97 & 1.31 & 81.63 & 48.44 & 1.43 \\
\hline Portugal & 39.9 & 31.84 & 1.06 & 85.15 & 53.83 & 1.26 \\
\hline Luxembourg & 38.83 & 31.82 & 1.17 & 68.05 & 47.5 & 1.51 \\
\hline Tunisia & 37.49 & 3.82 & 1.12 & 76.09 & 3.83 & 1.16 \\
\hline Cyprus* & 36.78 & 37.71 & 1.1 & 80.5 & 41.47 & 1.04 \\
\hline Bulgaria & 36.75 & 13.57 & 1.2 & 52.77 & 23.96 & 1.47 \\
\hline Belgium & 36.1 & 27.58 & 1.04 & 77.52 & 48.4 & 1.32 \\
\hline Thailand & 35.54 & 16.63 & 1.22 & 51.91 & 25.55 & 1.07 \\
\hline Denmark & 35.29 & 25.83 & 1.12 & 84.57 & 52.27 & 1.4 \\
\hline Norway & 34.6 & 24.26 & 0.94 & 84.31 & 53.62 & 1.25 \\
\hline Peru & 32.74 & 12.42 & 1.15 & c & c & c \\
\hline Croatia & 30.72 & 25.37 & 1.09 & 64.02 & 43.66 & 1.2 \\
\hline France & 29.13 & 24.27 & 1.09 & 77.95 & 46.01 & 1.3 \\
\hline Brazil & 27.83 & 5.08 & 1.15 & 74.74 & 7.41 & 1.24 \\
\hline Latvia & 26.62 & 20.74 & 1.02 & 74.11 & 52.52 & 1.2 \\
\hline Switzerland & 26.41 & 23.46 & 1.02 & 61.61 & 43.04 & 1.35 \\
\hline Estonia & 25.73 & 23.54 & 1.39 & 75 & 60.83 & 1.33 \\
\hline Italy & 25.42 & 17.9 & 1.23 & 68.37 & 38.93 & 1.37 \\
\hline Iceland & 24.61 & 12.78 & 1.3 & 82.92 & 32.69 & 1.65 \\
\hline Austria & 22.6 & 17.94 & 1.11 & 67.57 & 38.92 & 1.41 \\
\hline Russia & 22.57 & 18.47 & 0.95 & 83 & 59.88 & 1.02 \\
\hline Slovak Republic & 22.16 & 13.17 & 0.93 & 62.31 & 31.14 & 1.43 \\
\hline Netherlands & 19.15 & 16.88 & 0.99 & 82.61 & 54.53 & 1.2 \\
\hline Slovenia & 17.25 & 13.74 & 1.15 & 74.69 & 48.06 & 1.62 \\
\hline Germany & 16.27 & 14.14 & 1.04 & 65.23 & 45.11 & 1.26 \\
\hline B-S-J-G (China) & 8.83 & 7.06 & 1.47 & c & c & c \\
\hline Finland & 7.87 & 6.7 & 0.97 & 69.41 & 40.72 & 1.36 \\
\hline Algeria & $\mathrm{m}$ & $\mathrm{m}$ & $\mathrm{m}$ & 81.81 & 4.99 & 1.04 \\
\hline CABA (Argentina) & $\mathrm{m}$ & $\mathrm{m}$ & $\mathrm{m}$ & 90.4 & 31.61 & 1.87 \\
\hline FYROM & $\mathrm{m}$ & $\mathrm{m}$ & $\mathrm{m}$ & 79.19 & 4.31 & 1.16 \\
\hline Georgia & $\mathrm{m}$ & $\mathrm{m}$ & $\mathrm{m}$ & 80.33 & 31.02 & 1.01 \\
\hline Jordan & $\mathrm{m}$ & $\mathrm{m}$ & $\mathrm{m}$ & 85.81 & 30.02 & 0.93 \\
\hline Kosovo & $\mathrm{m}$ & $\mathrm{m}$ & $\mathrm{m}$ & 74.06 & 6.17 & 1.07 \\
\hline Lebanon & $\mathrm{m}$ & $\mathrm{m}$ & $\mathrm{m}$ & 91.92 & 19.3 & 1.05 \\
\hline Malta & $\mathrm{m}$ & $\mathrm{m}$ & $\mathrm{m}$ & 86.46 & 57.43 & 0.92 \\
\hline Moldova & $\mathrm{m}$ & $\mathrm{m}$ & $\mathrm{m}$ & 76.27 & 37.86 & 0.94 \\
\hline Trinidad and Tobago & $\mathrm{m}$ & $\mathrm{m}$ & $\mathrm{m}$ & 75.96 & 28.38 & 1.17 \\
\hline Viet Nam & $\mathrm{m}$ & $\mathrm{m}$ & $\mathrm{m}$ & 75.96 & 28.38 & 1.17 \\
\hline
\end{tabular}

${ }^{*}$ See note at the beginning of this Chapter.

Note: Only countries/economies with valid data for at least one outcome are shown.

Students who attain baseline academic proficiency are students who reach at least PISA proficiency level two in all three PISA core subjects - math, reading and science.

Source: OECD, PISA 2015 Database, Tables 8.2, 8.4, 8.9 and 8.11

StatLink aits http://dx.doi.org/10.1787/888933682984 
The chapter also examines the persistence of education gaps between immigrant and native students across generations, and whether such differences have been reduced among more recent cohorts.

\section{Expectations of further education}

Students who hold ambitious expectations about their educational prospects are more likely to put effort into their learning and make better use of the education opportunities available to them to achieve their goals (OECD, 2012; Borgonovi and Pal, 2016; OECD, 2017; Nurmi, 2004; Beal and Crockett, 2010; Morgan, 2005; Perna, 2000). Therefore, expectations of further education, in part, become selffulfilling prophecies. When comparing students with similar levels of skills and similar attitudes towards school, those who expect to graduate from university are more likely than those who do not hold such expectations to eventually earn a university degree (OECD, 2012). Countries and economies vary widely in the extent to which their students expect to graduate from university. Such differences reflect historical differences in levels of participation in tertiary level education, the availability and quality of vocational education and training, in the relative returns associated with attending tertiary studies, in the structure of the local labour markets, as well as the incentives available to students to pursue tertiary level education.

\section{Figure 8.1 Expectation to complete tertiary education, by immigrant background}

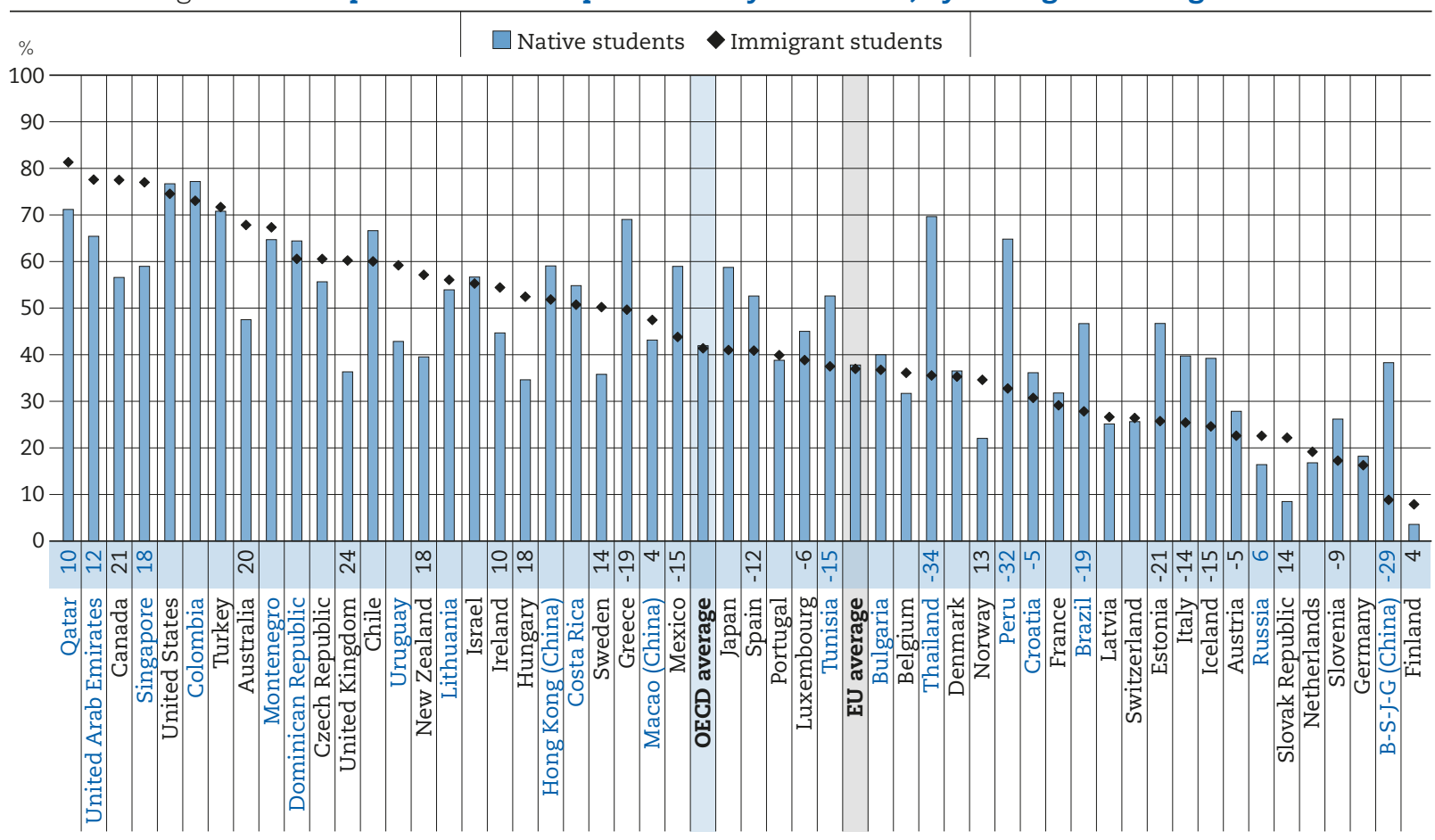

Notes: Only countries with valid data for immigrant students are shown.

Statistically significant differences between immigrant and native students are shown next to country/economy names. For the OECD and EU average, this number refers only to the subset of countries/economies with valid information on both groups of students. Countries and economies are ranked in descending order of the percentage of immigrant students who expect to complete tertiary education. Source: OECD, PISA 2015 Databases, Table 8.2.

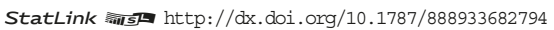

Figure 8.1 shows that in 24 of the 57 countries and economies with available data in PISA 2015, more than one in two 15-year-old students expected to complete a university degree (ISCED level 5a or 6); in Korea, as many as three out of four students expected to do so. Between 2003 and 2015, many of the countries and economies with available data saw a substantial increase in the percentage of 15-year-olds who expect to earn a university degree (OECD, 2016). However, countries vary widely in whether students' skills match their expectations, and whether other factors, such as their immigrant background, are related to students' expectations of further education. 
Despite the considerable challenges they often face, many immigrant students hold high educational expectations. In 15 countries and economies out of 52 with available data, immigrant students who participated in PISA 2015 were more likely to expect to complete tertiary education compared to native students (Figure 8.1) (results for other groups of students with an immigrant background can be found in Table 8.2 available on line); in 11 countries they were over 10 percentage points more likely. In 16 countries and economies, native students held more ambitious expectations for their education. These results are particularly remarkable because they do not account for the socio-economic status and academic performance of students - two of the factors that influence the probability of expecting to complete tertiary education, and that differ between immigrant and native students.

Figure 8.2 reveals that, when comparing students of similar socio-economic status and, even more so, when comparing students of similar socio-economic status and academic performance, immigrant students are more likely than native students to hold ambitious expectations for their education. In 27 out of 52 countries and economies with available data, immigrant students were more likely to expect to complete tertiary education; the opposite was true in only 7 countries and economies. On average across OECD and EU countries, the percentage of immigrant students who expected to earn a university degree was eight percentage points greater than the percentage of native students who expected to do so. The difference between immigrant students and native students of similar socio-economic status and academic performance was greater than 15 percentage points in Australia, Belgium, Canada, New Zealand, Norway, the Slovak Republic, Sweden and the United Kingdom. In Norway and Sweden, the unadjusted gap already stood at 13 and 14 percentage points respectively, but accounting for academic performance and socio-economic status increased it by a significant degree.

Figure 8.2 - Difference in the expectation to complete tertiary education Difference between immigrant and native students

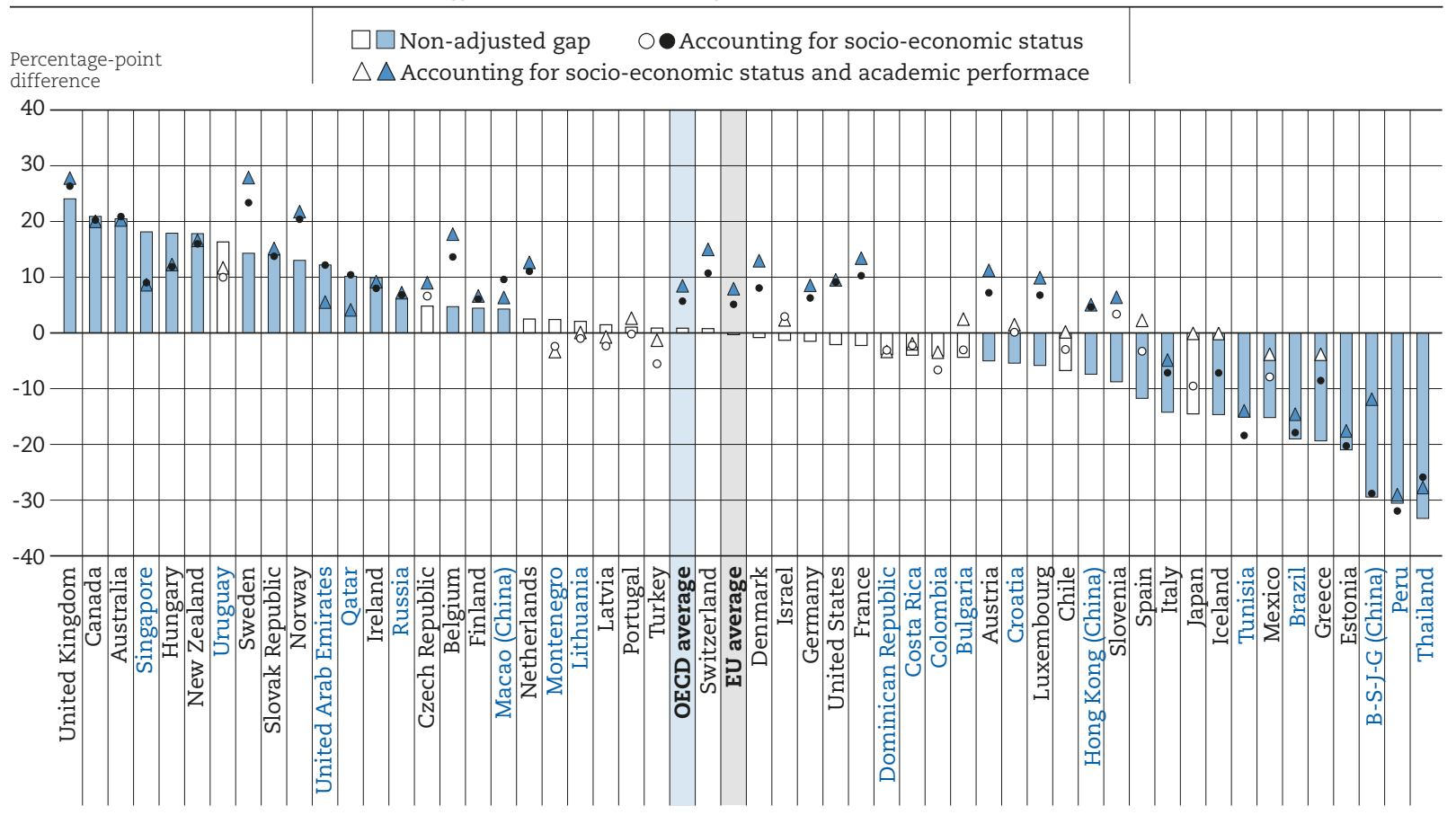

Notes: Only countries/economies with valid estimates of the immigrant-native gap are shown.

Statistically significant differences are marked in a darker tone.

Socio-economic status is measured by the PISA index of economic, social and cultural status (ESCS). Only students with non-missing values for the index are considered.

Academic performance is measured by whether a student achieved at least PISA proficiency Level 2 in all three core PISA subjects science, reading and mathematics.

Countries and economies are ranked in descending order of the difference in the percentage of immigrant and native students who expect to complete tertiary education, before accounting for socio-economic status and academic performance.

Source: OECD, PISA 2015 Database, Table 8.3.

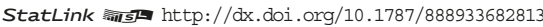


Immigrant students who hold high educational expectations often lack the academic skills to fulfil them. Students who do not reach baseline levels of proficiency in the core PISA subjects - science, reading and mathematics - are unlikely to be able to realise ambitious academic goals and unlock their full potential. On average across OECD countries, only $74 \%$ of immigrant students who held ambitious expectations for their education reached baseline levels of academic performance in reading, mathematics and science ( $78 \%$ across EU countries). By contrast, $87 \%$ of native students $(89 \%$ of native students across EU countries) who held ambitious educational expectations attained baseline academic proficiency, about 15 percentage points more than the percentage of immigrant students who fit this profile (Table 8.4 available on line).

When students who expect to complete tertiary education also have foundation skills, they are more likely to be able to achieve their goals. Immigrant students whose academic skills match their educational ambitions are more likely to be successful beyond their secondary education. Figure 8.3 shows the percentage of immigrant and native students who expect to complete tertiary education and who reach baseline levels of proficiency in reading, mathematics and science. In 24 out of 52 countries and economies with available data, the percentage of students who held ambitious but realistic expectations of further education was lower among immigrant students than among native students. The opposite was true only in Australia, Canada, Hungary, Ireland, Macao (China), New Zealand, Norway, Qatar, Singapore, the United Arab Emirates and the United Kingdom. On average across OECD countries, immigrant students were four percentage points less likely than native students to hold ambitious educational expectations and attain baseline academic proficiency (five percentage points less likely across EU countries). The difference was greater than 15 percentage points in Beijing-Shanghai-JiangsuGuangdong (China) (hereafter "B-S-J-G [China]"), Estonia, Greece, Iceland, Italy, Japan, Mexico, Spain and Thailand.

Figure 8.3 - Students with ambitious but realistic educational expectations, by immigrant background Percentage of students who expect to complete tertiary education and who attain baseline academic proficiency

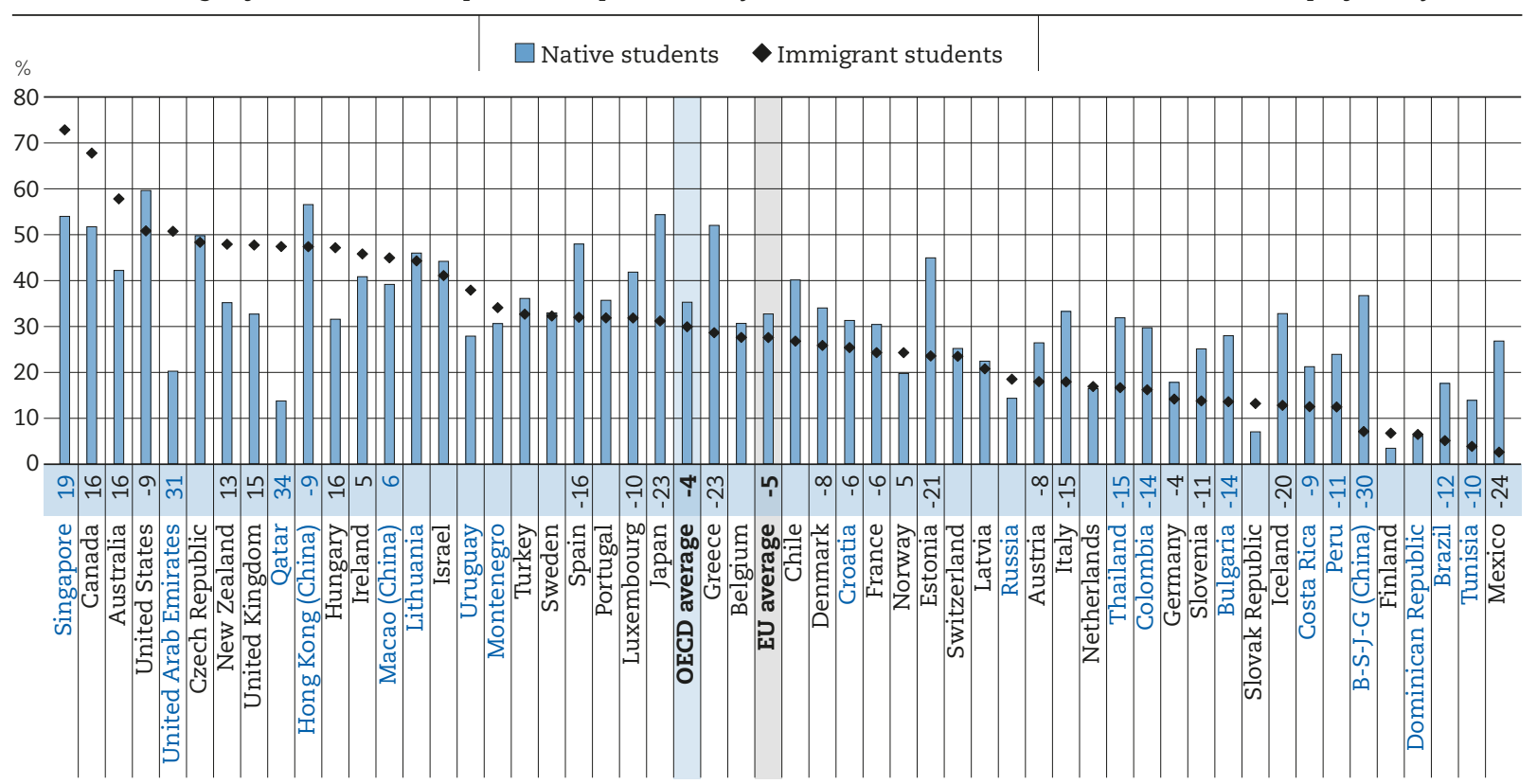

Notes: Only countries with valid data for immigrant students are shown.

Statistically significant differences between immigrant and native students are shown next to country/economy names. For the OECD and EU average, this number refers only to the subset of countries/economies with valid information on both groups of students.

Students with ambitious but realistic educational expectations are those who expect to complete tertiary education (ISCED levels 5 a and 6) and also attain at least PISA proficiency Level 2 in all three core PISA subjects - science, reading and mathematics.

Countries and economies are ranked in descending order of the percentage of immigrant students who expect to complete tertiary education and who attain baseline levels of academic proficiency.

Source: OECD, PISA 2015 Database, Table 8.4.

StatLink तोI http://dx.doi.org/10.1787/888933682832 
Educational expectations can become self-fulfilling prophecies not only for ambitious students, but also for those with low - or no - ambition. Students who are socio-economically disadvantaged and struggling academically are more likely to be discouraged and generally hold low expectations about their academic career. This can lead to even less motivation and effort in their schoolwork, resulting in lower academic achievement and a greater likelihood that they will not complete their studies. Figure 8.4 reveals that in 16 out of 52 countries and economies with available data, immigrant students were more likely than native students to expect to complete only lower secondary education (ISCED level 2). The difference was remarkably large in B-S-J-G (China) (42 percentage points) and the Slovak Republic (21 percentage points) (results for all groups of students with an immigrant background can be found in Table 8.5 available on line).

Figure 8.4 - Expectation to complete only lower secondary education, by immigrant background

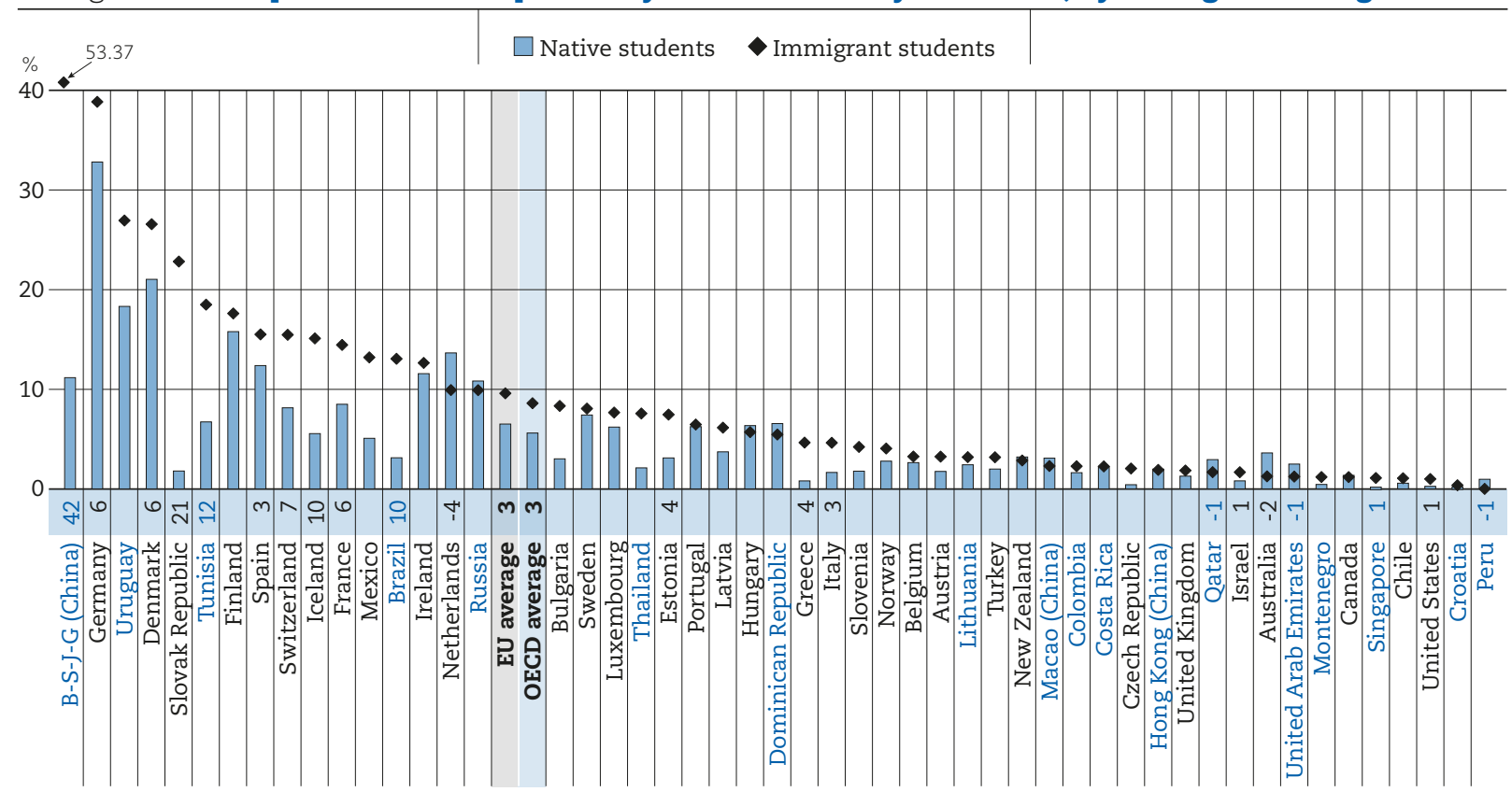

Notes: Only countries with valid data for immigrant students are shown.

Statistically significant differences between immigrant and native students are shown next to country/economy names. For the OECD and EU average, this number refers only to the subset of countries/economies with valid information on both groups of students.

Countries and economies are ranked in descending order of the percentage of immigrant students who expect to complete only lower secondary education.

Source: OECD, PISA 2015 Database, Table 8.5.

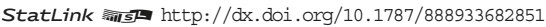

Immigrant students' socio-economic status and academic performance explain part of this difference. Table 8.6 shows that accounting for these factors greatly reduces the difference in expectations between the two groups of students. Indeed, it remains significant only in nine countries and economies, while in eight others immigrant students are less likely than their native peers to expect to finish only lower secondary education.

PISA 2012 distributed a questionnaire to the parents of students who participated in the assessment. The questionnaire was distributed in a small number of countries because it was optional and asked parents about the expectations they hold for their child's education and career. Inevitably, an element of aspiration is contained in parents' responses.

Figure 8.5 reveals that the parents of immigrant students who sat the PISA test in 2012 in Belgium, Germany and Hungary were more likely than the parents of native children to expect that their children will earn a tertiary degree. This is remarkable, given that immigrant students in these countries do not perform as well as, and their families are more disadvantaged than, non-immigrant students. When comparing students of similar socio-economic status, the difference between immigrant and nonimmigrant students in their parents' educational expectations for them grows considerably larger. 
In Belgium, Germany, Hong Kong (China) and Hungary, the parents of immigrant students held much higher educational expectations for their children than the parents of similarly disadvantaged non-immigrant students (results for other groups of students with an immigrant background can be found in Table 8.7 available on line). And this result holds even when comparing students of similar socio-economic status and similar academic performance (results for other groups of students with an immigrant background can be found in Table 8.8 available on line).

Figure 8.5 - Difference in parents' expectation that their child will complete tertiary education Difference between immigrant and native students

\begin{tabular}{|c|c|c|c|c|c|c|c|c|c|c|c|}
\hline $\begin{array}{l}\text { Percentage-point } \\
\text { difference }\end{array}$ & \multicolumn{10}{|c|}{$\begin{array}{l}\square \square \text { Non-adjusted gap } \quad \text { Accounting for socio-economic status } \\
\triangle \triangle \text { Accounting for socio-economic status and academic performace }\end{array}$} & \\
\hline $30-$ & $\Delta$ & & & & & & & & & & \\
\hline 20 & $\bullet$ & 0 & & & & & & & & & \\
\hline 10 & & & 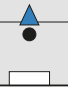 & $\Delta$ & $\triangle$ & & & 8 & & & \\
\hline-10 & & & & & & $d$ & 8 & & A & $\Delta$ & $\begin{array}{ll} \\
\bullet\end{array}$ \\
\hline$-20-$ & & & & & & & & & & & \\
\hline 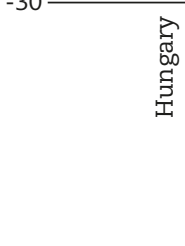 & 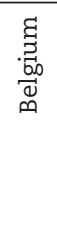 & 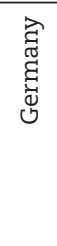 & 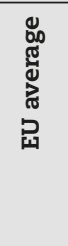 & 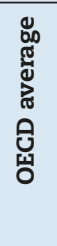 & 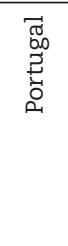 & 䒕 & 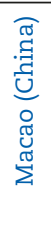 & 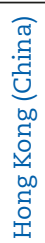 & 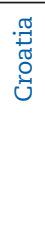 & 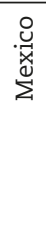 & 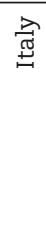 \\
\hline
\end{tabular}

Notes: Only countries that distributed the parental questionnaire are shown.

Statistically significant differences are marked in a darker tone.

Socio-economic status is measured by the PISA index of economic, social and cultural status (ESCS). Only students with non-missing values for the index are considered.

Academic performance is measured by whether a student achieved at least PISA proficiency Level 2 in all three core PISA subjects science, reading and mathematics.

Countries and economies are ranked in descending order of the difference in the percentage of immigrant and native students whose parents expect them to complete tertiary education, before accounting for socio-economic status and academic performance.

Source: OECD, PISA 2012 Database, Table 8.8.

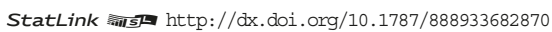

The figure also shows that, when considering families of similar socio-economic status, parents of immigrant students in Italy and Mexico in 2012 generally held lower expectations for their children's education than parents of students who did not have an immigrant background. These disparities might be due to differences among the immigrant groups settling in various countries, and the value different cultures ascribe to education qualifications. However, and more unsettling, these disparities might reflect the different barriers immigrant students face during their progress through education and the opportunities available to highly skilled immigrants in different countries. If, for example, immigrant students struggle at school and the returns to education are lower for immigrants, then parents might be less likely to expect their children to pursue a tertiary education.

The association between parents' expectations and students' academic achievement might reflect both that parents whose children attain baseline academic proficiency tend to hold more ambitious expectations for them, but also that parents' expectations and, presumably, their encouragement and support, have a positive impact on students' achievement. Results presented in Figure 8.5 therefore might suggest that immigrant students in some countries find - at home - the emotional support they need to deal with the many difficulties arising from their immigrant background. 


\section{Career expectations}

In PISA 2015, students were asked to report what job they expected to hold at the age of 30. Students' responses to this open-ended question were manually coded and classified using a standardised classification (the four-digit classification numbers of the International Standard Classification of Occupations 08 ISCO-08).

Figure 8.6 reports the percentage of native and immigrant students who expect to work as managers, professionals or associated professionals (some of the occupations that are highest in social status, earnings and that typically require university-level education) (results for other groups of students with an immigrant background can be found in Table 8.9 available on line). In 21 countries and economies, students with an immigrant background were more likely than native students to hold ambitious career expectations and in 32 countries and economies, immigrant students held career expectations that were similar to those held by native students. Only in Brazil, Bulgaria, Ciudad Autónoma de Buenos Aires (Argentina) (hereafter "CABA [Argentina]"), Croatia, Greece and Luxembourg did immigrant students hold less ambitious career expectations than their non-immigrant peers.

These differences are remarkable given that immigrant students generally come from less socioeconomically advantaged households and that they tend to perform worse academically than native students - two factors that are negatively associated with the probability that students will hold ambitious career expectations. When comparing students of similar socio-economic status and accounting for whether they attained baseline academic proficiency, the gap in the percentages of immigrant and native students who expect to work in managerial, professional or associated professional occupation is wide. In 2015 it was significant in around half of the countries and economies with available data (Figure 8.7, results for all groups of students with an immigrant background can be found in Table 8.10 available on line). On average across OECD countries, immigrant students were 11 percentage points more likely to hold ambitious career expectations than native students, after accounting for their socio-economic status and academic performance (a difference of 9 percentage points across EU countries).

Table 8.10 (available on line) shows that in 2015, in most countries and economies, first- and secondgeneration immigrant students were equally likely to expect to work as managers, professionals or associate professionals, after accounting for their socio-economic status and academic performance. Immigrant students with at least one native-born parent tended to have more ambitious career expectations than native students, although not as ambitious as immigrant students with two foreignborn parents. In 14 out of 43 countries and economies with available data, returning foreign-born students held more ambitious expectations than native students. In Austria, the Czech Republic, Denmark, Germany and Switzerland, they were 10 percentage points more likely than native students to expect to work as managers, professionals or associate professionals. In 17 countries and economies, native students of mixed heritage had more ambitious career expectations than native students.

Although immigrant students tend to have more ambitious career expectations than native students, Table 8.11 (available on line) shows that their skills are less likely to match their ambitions. On average across OECD countries in 2015, only 62\% of immigrant students with ambitious career expectations attained baseline academic proficiency (65\% across EU countries), while $79 \%$ of native students with ambitious career expectations attained baseline academic proficiency ( $80 \%$ across EU countries). Students who lack basic proficiency in core PISA subjects are unlikely to realise their ambitious career plans. Figure 8.8 shows the percentage of immigrant and native students with ambitious career expectations and who attain baseline academic proficiency. In 29 out of 59 countries and economies with available data, immigrant students in 2015 were less likely to fall into this category. On average across OECD countries, immigrant students were 10 percentage points less likely than native students to have ambitious career expectations and attain baseline academic proficiency.

PISA shows that not only are immigrant students more likely than native students to expect to work as managers or professionals, they also tend to hold more ambitious career expectations across the whole distribution of occupations. Responses to the question about expected occupation were assigned a score on the International Socio-economic Index of Occupational Status (ISEI), which ranks occupations based on social prestige. Table 8.12 (available on line) reports the expected ISEI ranking of students with different immigrant backgrounds; Table 8.13 (available on line) reports group differences controlling for the socio-economic status and academic performance of students. 
Figure 8.6 - Ambitious career expectations, by immigrant background

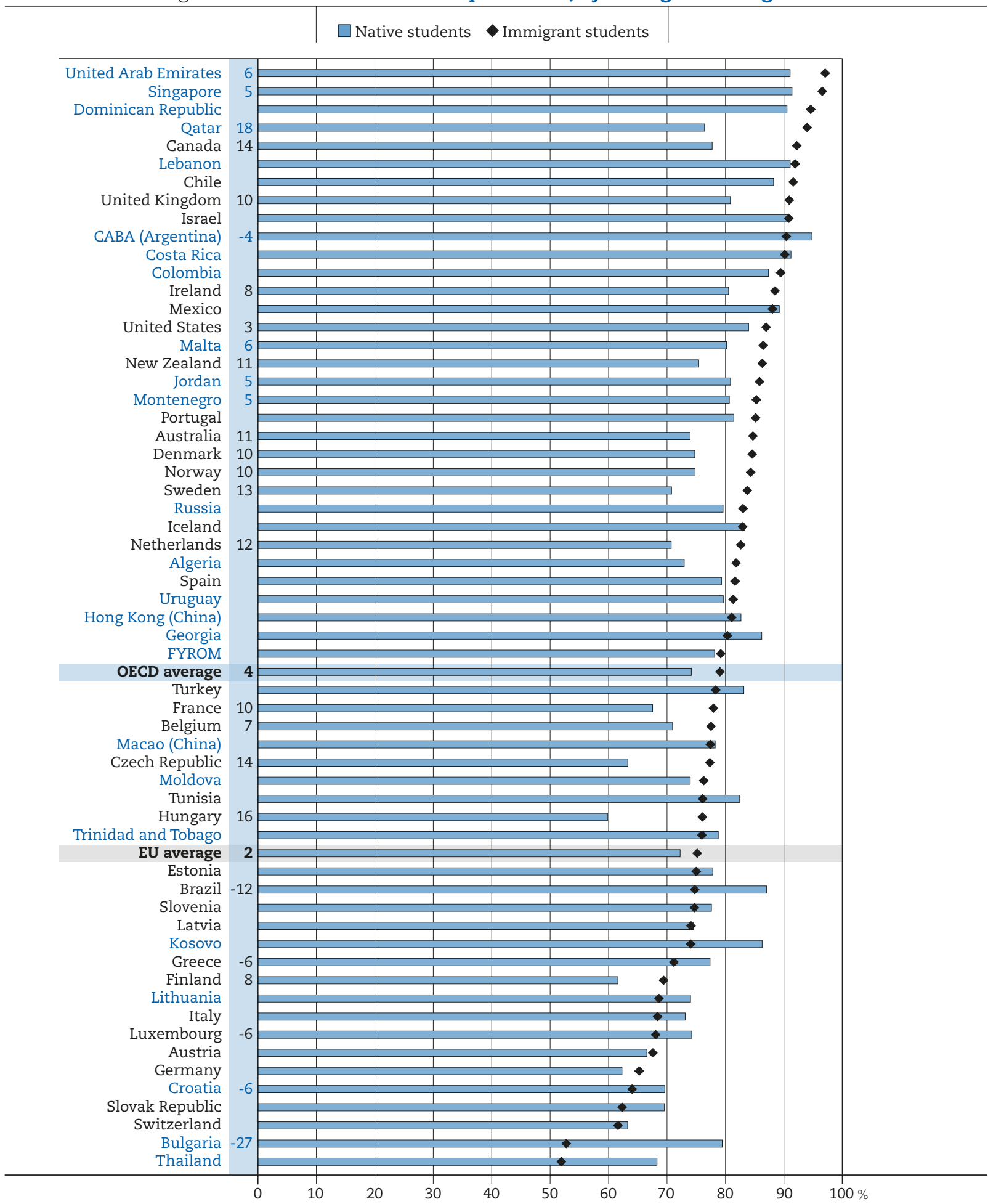

Notes: Only countries with valid data for immigrant students are shown.

Statistically significant differences between immigrant and native students are shown next to country/economy names. For the OECD and EU average, this number refers only to the subset of countries/economies with valid information on both groups of students.

Students with ambitious career expectations are those who expect to become managers, professionals or associate professionals and technicians by the age of 30 .

Countries and economies are ranked in descending order of the percentage of immigrant students with ambitious career expectations.

Source: OECD, PISA 2015 Database, Table 8.9

StatLink Ailst $\mathrm{http}: / / \mathrm{dx} . \mathrm{doi}$. org/10.1787/888933682889 
Figure 8.7 - Difference in holding ambitious career expectations Difference between immigrant and native students

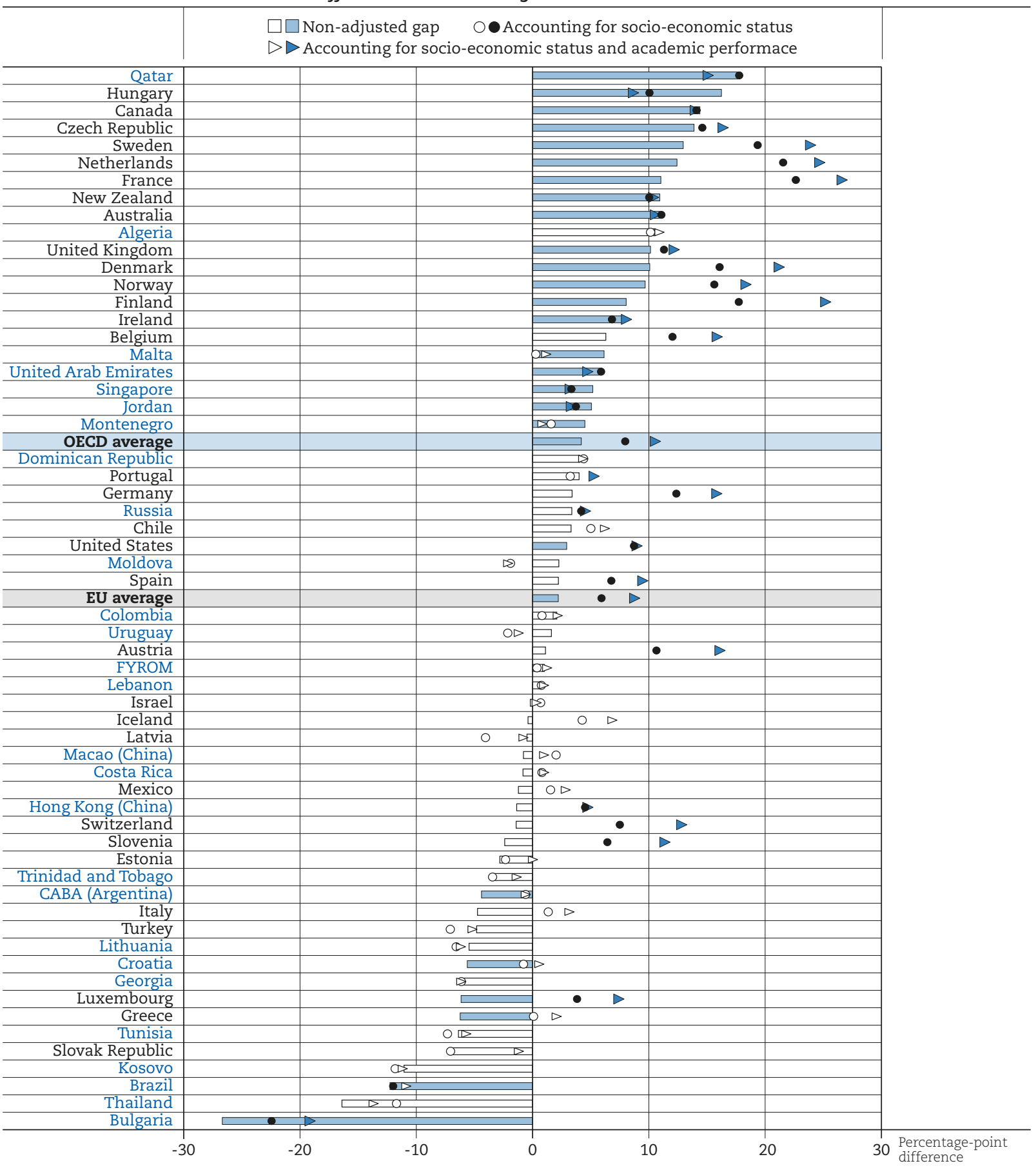

Notes: Only countries/economies with valid estimates of the immigrant-native gap are shown.

Statistically significant differences are marked in a darker tone.

Students with ambitious career expectations are those who expect to become managers, professionals or associate professionals and technicians by the age of 30 .

Socio-economic status is measured by the PISA index of economic, social and cultural status (ESCS). Only students with non-missing values for the index are considered.

Academic performance is measured by whether a student achieved at least PISA proficiency Level 2 in all three core PISA subjects science, reading and mathematics.

Countries and economies are ranked in descending order of the difference in the percentage of immigrant students and native students who hold ambitious career expectations.

Source: OECD, PISA 2015 Database, Table 8.10.

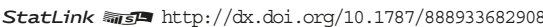


Figure 8.8 - Students with ambitious but realistic career expectations, by immigrant background Percentage of students who hold ambitious career expectations and who attain baseline academic proficiency

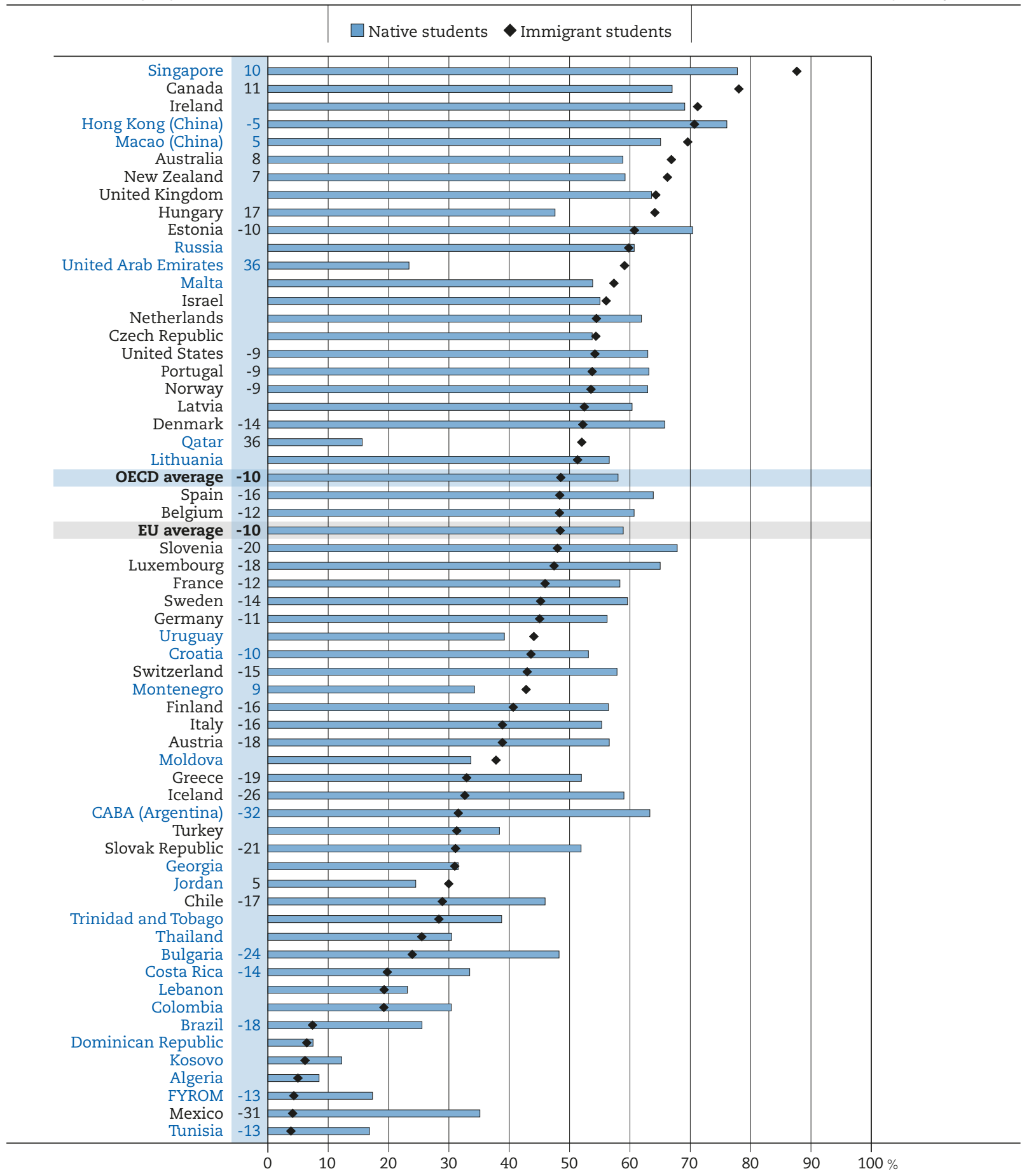

Notes: Only countries with valid data for immigrant students are shown.

Statistically significant differences between immigrant and native students are shown next to country/economy names. For the OECD and EU average, this number refers only to the subset of countries/economies with valid information on both groups of students.

Students with ambitious but realistic career expectations are those who expect to become managers, professionals or associate professionals and technicians by the age of 30 and who achieved at least PISA proficiency Level 2 in all three core PISA subjects - science, reading and mathematics.

Countries and economies are ranked in descending order of the percentage of immigrant students who hold ambitious career expectations and who attain baseline academic proficiency.

Source: OECD, PISA 2015 Database, Table 8.11.

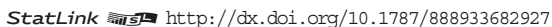


Figure 8.9 - Difference in the prestige of expected careers Difference between immigrant and native students in the ISEI score of their expected career

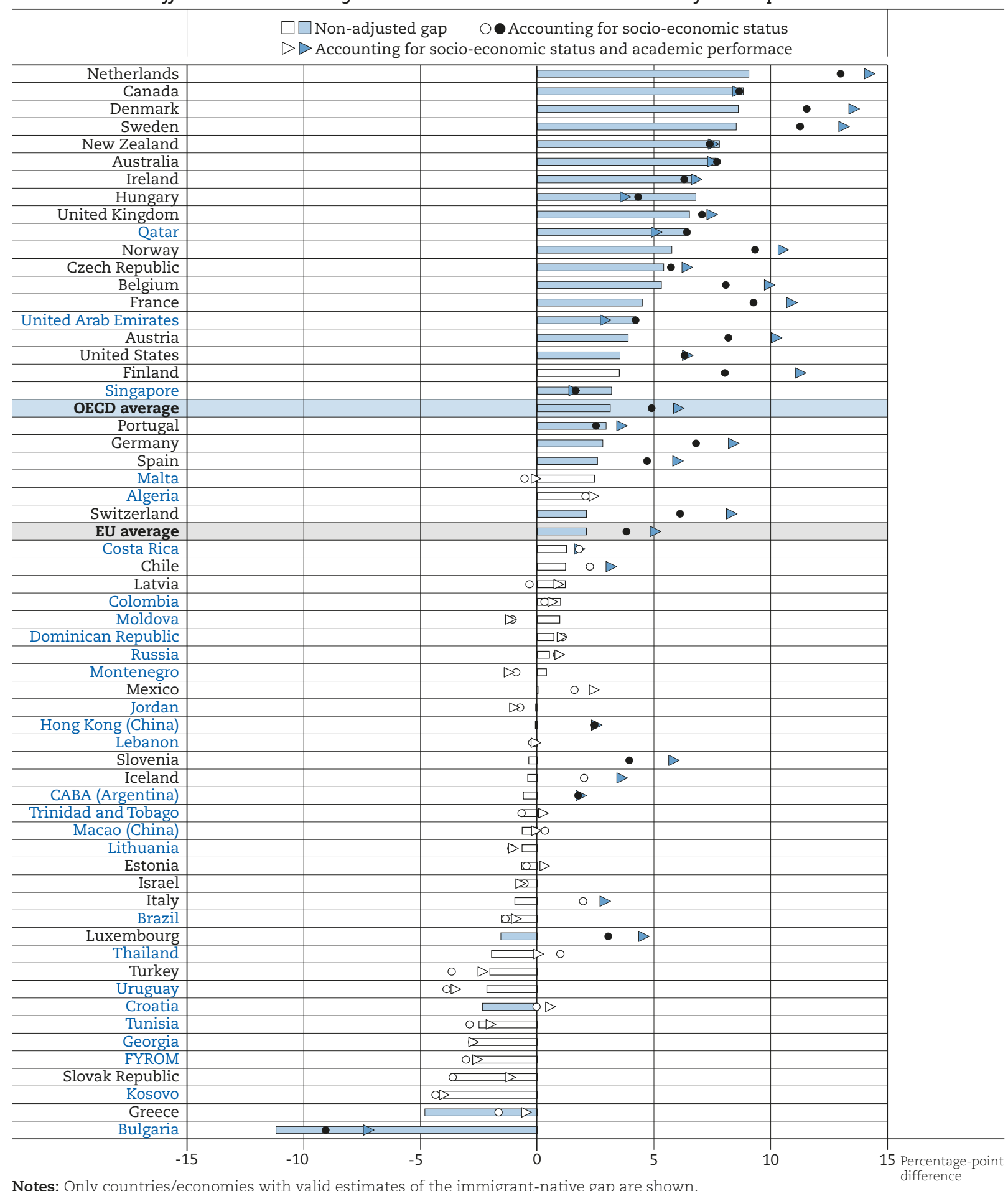

Statistically significant differences are marked in a darker tone.

Socio-economic status is measured by the PISA index of economic, social and cultural status (ESCS). Only students with non-missing values for the index are considered.

Academic performance is measured by whether a student achieved at least PISA proficiency Level 2 in all three core PISA subjects science, reading and mathematics.

Countries and economies are ranked in descending order of the difference between immigrant and native students in the ISEI score of their expected occupation.

Source: OECD, PISA 2015 Database, Table 8.12.

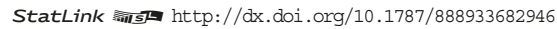


Results show that in 2015 in 22 out of 62 countries and economies with available data, immigrant students expected to work in a job that was more prestigious than the one expected by native students. Once socio-economic status and academic performance are accounted for, the gap was statistically significant in as many as 32 countries. In Austria, Denmark, Finland, France, the Netherlands, Norway and Sweden, the adjusted gap was larger than 10 index points, which corresponds roughly to the difference between the occupational status of the average parent in Sweden and a parent in the Dominican Republic in the PISA 2015 sample.

The PISA 2006 student questionnaire also included the question about career expectations. Responses were coded using ISCO-88, an earlier version of ISCO-08, the classification used for PISA 2015 responses. Results are still comparable at the level of the first ISCO digit because no significant changes have occurred for ISCO major groups. Therefore, the percentage of students expecting to work as managers, professionals or associate professionals by the age of 30 is comparable across PISA 2015 and PISA 2006 cycles.

\section{Figure 8.10 - Change between 2006 and 2015 in ambitious career expectations, by immigrant background \\ Change in the percentage of students who hold ambitious career expectations}

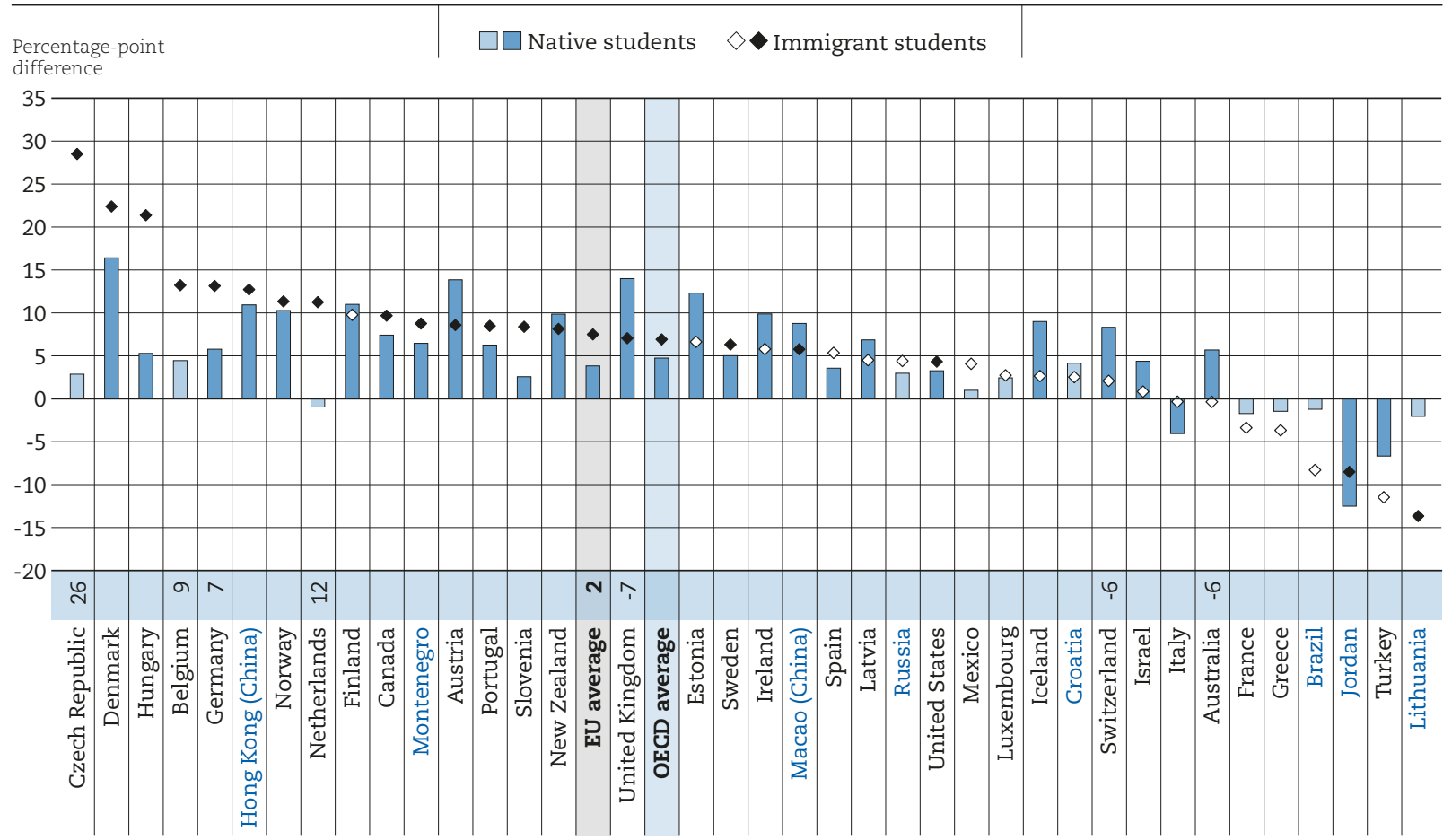

Notes: Only countries that participated in PISA 2006 and PISA 2015 and have valid data on immigrant students in both rounds are shown. Statistically significant differences between PISA 2015 and 2006 are marked in a darker tone.

Students with ambitious career expectations are those who expect to become managers, professionals or associate professionals and technicians by the age of 30 .

Countries and economies are ranked in descending order of the change between 2006 and 2015 in the percentage of immigrant students who have ambitious career expectations.

Source: OECD, PISA 2015 and 2006 Database, Table 8.9.

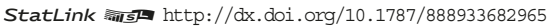

Figure 8.10 shows that in the majority of countries and economies, the percentage of immigrant students with ambitious career expectations grew between 2006 and 2015 (results for other groups of students with an immigrant background can be found in Table 8.9 available on line). On average across OECD and EU countries, it grew by approximately 7 percentage points; it grew more than 20 percentage points in the Czech Republic, Denmark and Hungary. In most countries, the percentage of native students holding ambitious career expectations also grew. Indeed, on average across OECD countries, the difference between immigrant and native students remained unchanged between 2006 and 2015. 
However, on average across EU countries, the percentage of immigrant students with ambitious career expectations grew by two percentage points more than did the percentage of native students with similar expectations. In Belgium, the Czech Republic, Germany and the Netherlands, the difference between the two groups grew by at least seven percentage points. In Belgium, the Czech Republic and the Netherlands, the expectations of native students remained unchanged, while more immigrant students held ambitious career expectations in 2015 than they did in 2006. In Australia and Switzerland, the difference between native and immigrant students in the percentage of students holding ambitious career shrank by six percentage points. 


\section{Spotlight on intergenerational educational mobility: Evidence from the European Social Survey}

Evidence from PISA suggests that, in many countries, immigrant students are less likely than native students with similar background characteristics to reach baseline levels of proficiency but that they tend to report greater achievement motivation and to have more ambitious educational and career expectations. However, because PISA focuses on the outcomes of 15 year old students, it does not allow identifying the educational careers of immigrant students and the educational qualifications they will obtain. Moreover, while PISA clearly indicates that parental educational qualifications and broader socio-economic status play an important role in shaping their skill acquisition, it cannot illustrate differences between immigrant and native students in the overall intergenerational transmission of educational attainment, which is shaped not only by skill accumulation but also by the broader set of opportunities and barriers that students encounter beyond age 15.

This section complements analyses based on PISA data with analyses from the European Social Survey (ESS) to illustrate differences in educational attainment between immigrants and natives as well as differences across the two groups in the extent to which parental educational attainment plays a role in determining educational attainment. In order to look at changes over time while using a cross-sectional study, two age groups are considered: 25-45 year-olds and 45-65 year-olds ${ }^{1}$.

Analyses were conducted using participants' responses to questions about the highest education level attained by themselves and by their father and mother. Due to differences between ESS rounds in the way these questions were formulated, variables representing respondents' answers were harmonised and the following categories were derived: "less than lower secondary education"; "lower secondary education"; "upper secondary education"; "advanced vocational education"; and "tertiary education". The highest between the mother and father's educational level successfully completed was used to identify parental educational attainment.

Immigrant individuals are defined as those who are either foreign-born or are native-born but have two foreign-born parents. The 27 countries considered are: Austria, Belgium, Croatia, the Czech Republic, Denmark, Estonia, Finland, France, Germany, Greece, Hungary, Ireland, Israel, Latvia, Lithuania, Luxembourg, the Netherlands, Norway, Poland, Portugal, the Russian Federation (hereafter "Russia"), the Slovak Republic, Slovenia, Spain, Sweden, Switzerland and the United Kingdom.

Tables 8.a (available on line) indicates that levels of educational attainment increased markedly in recent decades. On average across the 27 countries analysed, respondents' education level was higher than the education level of their parents both among natives and immigrants for both age groups considered. On average across the countries considered, among those aged 45 to 65 , the percentages of natives and immigrants whose highest education level was less than lower secondary education were $11 \%$ and $12 \%$ respectively. Among parents of individuals in this age group as many as $37 \%$ and $38 \%$ respectively had not achieved a lower secondary degree. In this age group, $22 \%$ of natives but $25 \%$ of immigrants had obtained a tertiary degree, compared to only $9 \%$ and $14 \%$ respectively among the parents of individuals in this age group.

Among individual aged 25 to 45, the percentage of natives and immigrants whose highest education level was less than lower secondary education was considerably lower and stood at $4 \%$ and $6 \%$ respectively. Among their parents this percentage was higher, corresponding to $18 \%$ and $25 \%$. By contrast, among individuals aged 25 to 45 as many as 32\% of natives and 30\% of immigrant individuals obtained a tertiary degree while only $19 \%$ of the parents of natives observed in the sample and $23 \%$ of the parents of immigrants had obtained tertiary qualifications.

Table 8.b shows that in many countries the correlation between the education level attained by the respondent and the highest education level successfully completed by his or her parents was stronger among immigrants than among individuals without an immigrant background for both age groups analysed. However, whereas among natives the strength of the correlation was somewhat weaker among younger cohorts, it was broadly similar among the two age groups among immigrants. 
Table 8.b - Correlation between respondent's level of education and the highest level of education of their parents, by immigrant background

\begin{tabular}{|c|c|c|c|c|c|c|c|c|}
\hline & \multicolumn{3}{|c|}{$45-65$ year-olds } & \multicolumn{3}{|c|}{$25-45$ year-olds } & \multicolumn{2}{|c|}{$\begin{array}{l}\text { Difference between } \\
25-45 \text { and } 45-65 \text { year-olds }\end{array}$} \\
\hline & Natives & Immigrants & $\begin{array}{c}\text { Difference } \\
\text { (immigrants - } \\
\text { natives) }\end{array}$ & Natives & Immigrants & $\begin{array}{c}\text { Difference } \\
\text { (immigrants - } \\
\text { natives) }\end{array}$ & Natives & Immigrants \\
\hline Austria & 0.38 & 0.50 & 0.12 & 0.36 & 0.59 & 0.23 & -0.02 & 0.09 \\
\hline Belgium & 0.45 & 0.50 & 0.05 & 0.44 & 0.51 & 0.07 & -0.01 & 0.02 \\
\hline Croatia & 0.47 & 0.48 & 0.01 & 0.37 & 0.52 & 0.15 & -0.09 & 0.04 \\
\hline Czech Republic & 0.39 & 0.54 & 0.15 & 0.39 & 0.57 & 0.18 & 0.00 & 0.03 \\
\hline Denmark & 0.35 & 0.43 & 0.07 & 0.30 & 0.36 & 0.06 & -0.05 & -0.06 \\
\hline Estonia & 0.34 & 0.38 & 0.04 & 0.33 & 0.30 & -0.03 & -0.01 & -0.08 \\
\hline Finland & 0.36 & 0.39 & 0.03 & 0.29 & 0.33 & 0.04 & -0.07 & -0.06 \\
\hline France & 0.40 & 0.38 & -0.03 & 0.39 & 0.39 & 0.00 & -0.01 & 0.01 \\
\hline Germany & 0.32 & 0.45 & 0.13 & 0.34 & 0.43 & 0.10 & 0.02 & -0.01 \\
\hline Greece & 0.39 & 0.44 & 0.05 & 0.42 & 0.50 & 0.08 & 0.03 & 0.06 \\
\hline Hungary & 0.48 & 0.45 & -0.03 & 0.49 & 0.33 & -0.16 & 0.01 & -0.12 \\
\hline Ireland & 0.42 & 0.43 & 0.00 & 0.42 & 0.44 & 0.03 & 0.00 & 0.02 \\
\hline Israel & 0.47 & 0.42 & -0.05 & 0.46 & 0.41 & -0.05 & -0.01 & -0.01 \\
\hline Latvia & 0.34 & 0.46 & 0.12 & 0.29 & 0.54 & 0.25 & -0.05 & 0.08 \\
\hline Lithuania & 0.29 & 0.29 & 0.00 & 0.38 & 0.47 & 0.09 & 0.09 & 0.18 \\
\hline Luxembourg & 0.42 & 0.52 & 0.10 & 0.39 & 0.52 & 0.13 & -0.03 & 0.00 \\
\hline Netherlands & 0.41 & 0.47 & 0.06 & 0.39 & 0.47 & 0.07 & -0.01 & 0.00 \\
\hline Norway & 0.38 & 0.33 & -0.05 & 0.34 & 0.40 & 0.06 & -0.04 & 0.07 \\
\hline Poland & 0.43 & 0.44 & 0.01 & 0.40 & 0.46 & 0.06 & -0.03 & 0.02 \\
\hline Portugal & 0.43 & 0.44 & 0.01 & 0.44 & 0.44 & 0.00 & 0.01 & 0.00 \\
\hline Russia & 0.36 & 0.33 & -0.03 & 0.33 & 0.17 & -0.16 & -0.03 & -0.16 \\
\hline Slovak Republic & 0.39 & 0.40 & 0.01 & 0.41 & 0.14 & -0.27 & 0.03 & -0.25 \\
\hline Slovenia & 0.42 & 0.52 & 0.10 & 0.36 & 0.44 & 0.08 & -0.06 & -0.08 \\
\hline Spain & 0.45 & 0.50 & 0.04 & 0.39 & 0.52 & 0.13 & -0.06 & 0.02 \\
\hline Sweden & 0.35 & 0.38 & 0.04 & 0.26 & 0.39 & 0.13 & -0.08 & 0.01 \\
\hline Switzerland & 0.36 & 0.55 & 0.19 & 0.32 & 0.52 & 0.20 & -0.04 & -0.03 \\
\hline United Kingdom & 0.34 & 0.44 & 0.10 & 0.36 & 0.42 & 0.06 & 0.02 & -0.02 \\
\hline Average & 0.39 & 0.44 & 0.05 & 0.37 & 0.43 & 0.06 & -0.02 & -0.01 \\
\hline
\end{tabular}

Notes: Analysis based on simple correlation coefficients.

Immigrants are defined as those who are either foreign-born or are native-born but have two foreign-born parents.

Differences between immigrants and natives are highlighted in gray. A ligher tone is applied to positive differences (i.e. correlation is stronger among immigrants) and a darker tone is applied to negative differences (i.e. correlation is stronger among natives).

Differences between age groups are highlighted in blue. A ligher tone is applied to positive differences (i.e. correlation is stronger among people aged 25 to 45) and a darker tone is applied to negative differences (i.e. correlation is stronger among people aged 45 to 65 ).

Only countries that participated in at least two rounds and with a sample of at least 30 immigrant individuals are included in the analysis. Countries and economies are ranked in alphabetical order.

Source: European Social Survey rounds 1-8 (pooled data).

StatLink त्ता St http://dx.doi.org/10.1787/888933683003

Among 45 to 65 year-olds, parental educational attainment appears to play a more important role in shaping the educational attainment of immigrants than native individuals. In this age group the difference between immigrants and natives in the correlation between parental educational attainment and the respondent's own educational attainment was particularly pronounced in the Czech Republic, Germany and Switzerland. By contrast, parental educational attainment was less strongly associated with the educational attainment of 45 to 65 year-old immigrants than among 45 to 65 year-old natives in France, Hungary, Israel, Norway and Russia. Among 25 to 45 year-olds, parental educational attainment also played a more important role in shaping the educational attainment of immigrants than native individuals and the difference was particularly pronounced in Austria, Latvia and Switzerland. By contrast, parental educational attainment was less strongly associated with the educational attainment of 25 to 45 year-old immigrants than among 25 to 45 year-old natives in Estonia, Hungary, Israel, Russia and the Slovak Republic.

Another measure of the importance family circumstances play in shaping the educational trajectory of individuals is intergenerational education mobility. This can be operationalised as the percentage of individuals in the two groups who reported having attained educational qualifications that are higher than the highest educational qualifications that were successfully completed by their parents.

Table 8.c shows that, on average across all countries analysed, the intergenerational education mobility of natives and of immigrant individuals was similar. On average across the 27 countries examined, among 45 to 65 year-olds, $50 \%$ of natives and $48 \%$ of immigrants had obtained greater educational qualifications than their parents. Similarly, among 25 to 45 year olds, $44 \%$ of natives and $43 \%$ of immigrants had obtained more advanced qualifications than their parents. 
Table 8.c - Educational mobility, by age group and immigrant background Percentage of respondents who report having attained an education level that is higher than the highest education level successfully completed by their parents

\begin{tabular}{|c|c|c|c|c|c|c|}
\hline & \multicolumn{3}{|c|}{ 45-65 year-olds } & \multicolumn{3}{|c|}{ 25-45 year-olds } \\
\hline & Natives & Immigrants & $\begin{array}{c}\text { Difference } \\
\text { (immigrants - } \\
\text { natives) }\end{array}$ & Natives & Immigrants & $\begin{array}{c}\text { Difference } \\
\text { (immigrants - } \\
\text { natives) }\end{array}$ \\
\hline Austria & 37.72 & 36.80 & -0.92 & 34.26 & 39.61 & 5.35 \\
\hline Belgium & 55.69 & 53.31 & -2.38 & 47.32 & 54.53 & 7.22 \\
\hline Croatia & 60.92 & 62.86 & 1.93 & 46.66 & 54.12 & 7.46 \\
\hline Czech Republic & 25.51 & 38.30 & 12.79 & 20.07 & 30.89 & 10.82 \\
\hline Denmark & 51.84 & 44.50 & -7.34 & 38.87 & 47.98 & 9.11 \\
\hline Estonia & 62.96 & 61.73 & -1.22 & 39.82 & 36.93 & -2.89 \\
\hline Finland & 65.03 & 59.38 & -5.66 & 52.98 & 43.96 & -9.02 \\
\hline France & 54.54 & 53.13 & -1.42 & 54.24 & 56.38 & 2.14 \\
\hline Germany & 32.30 & 40.45 & 8.16 & 27.27 & 37.14 & 9.87 \\
\hline Greece & 52.50 & 44.72 & -7.78 & 72.94 & 47.86 & -25.09 \\
\hline Hungary & 45.86 & 41.46 & -4.40 & 30.51 & 42.19 & 11.68 \\
\hline Ireland & 60.98 & 49.72 & -11.26 & 63.26 & 46.32 & -16.93 \\
\hline Israel & 58.61 & 52.33 & -6.28 & 50.36 & 41.72 & -8.64 \\
\hline Latvia & 50.56 & 52.38 & 1.82 & 30.16 & 27.27 & -2.89 \\
\hline Lithuania & 67.05 & 48.60 & -18.45 & 51.45 & 33.33 & -18.12 \\
\hline Luxembourg & 42.23 & 33.45 & -8.78 & 45.20 & 44.81 & -0.39 \\
\hline Netherlands & 56.68 & 44.03 & -12.65 & 51.36 & 49.46 & -1.89 \\
\hline Norway & 57.95 & 52.38 & -5.57 & 41.43 & 43.01 & 1.58 \\
\hline Poland & 57.76 & 61.96 & 4.20 & 49.98 & 51.35 & 1.37 \\
\hline Portugal & 29.07 & 43.33 & 14.26 & 55.64 & 50.32 & -5.32 \\
\hline Russia & 60.39 & 58.62 & -1.76 & 40.30 & 32.95 & -7.36 \\
\hline Slovak Republic & 47.46 & 40.70 & -6.77 & 29.82 & 34.38 & 4.56 \\
\hline Slovenia & 44.51 & 49.60 & 5.09 & 42.93 & 42.27 & -0.66 \\
\hline Spain & 48.06 & 48.09 & 0.03 & 66.86 & 50.49 & -16.36 \\
\hline Sweden & 48.87 & 39.94 & -8.93 & 33.27 & 29.41 & -3.85 \\
\hline Switzerland & 42.13 & 45.77 & 3.64 & 35.79 & 44.83 & 9.04 \\
\hline United Kingdom & 42.30 & 41.08 & -1.22 & 36.42 & 43.06 & 6.64 \\
\hline Average & 50.35 & 48.10 & -2.26 & 44.04 & 42.84 & -1.21 \\
\hline
\end{tabular}

Notes: Statistically significant differences are indicated in bold.

Immigrants are defined as those who are either foreign-born or are native-born but have two foreign-born parents.

Statistically significant differences between immigrants and natives for each age group are highlighted in blue. A ligher tone is applied to negative differences (i.e. the percentage of immigrants who reported having attained an education level that is higher than the highest education level successfully completed by their parents is smaller) and a darker tone is applied to positive differences (i.e. the immigrants who reported having attained an education level that is higher than the highest education level successfully completed by their parents is greater).

Only countries that participated in at least two rounds and with a sample of at least 30 immigrant individuals are included in the analysis. Countries and economies are ranked in alphabetical order.

Source: European Social Survey rounds 1-8 (pooled data).

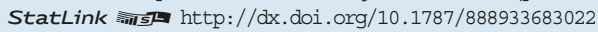

Countries differ greatly in the extent to which natives and immigrants experienced upward educational mobility. In the Czech Republic, Germany, Portugal and Switzerland, in the older cohort, the percentage of individuals who obtained greater educational qualifications than their parents was greater among immigrants than natives. By contrast, in the same age group, natives experienced greater educational mobility in Denmark, Greece, Ireland, Israel, Lithuania, Luxembourg, the Netherlands and Sweden. Among 25 to 45 year olds immigrants were more likely than natives to obtain higher educational qualifications in Austria, Belgium, the Czech Republic, Denmark, Germany, Hungary, Switzerland and the United Kingdom. By contrast, in Finland, Greece, Israel, Ireland, Lithuania, Spain and Sweden natives experienced greater educational mobility than immigrants.

\section{Note}

1. Due to the small number of observations at the country level, data from the first eight ESS rounds was pooled. The most recent ESS study is round eight, which contains information collected in 2016. However, at the time this analysis was conducted (December 2017), data from round eight was not yet available for Portugal and Spain. In these cases, the analysis is based on data from rounds one through seven. More information about the ESS is provided in the introductory chapter of this report. Only countries that participated in at least two rounds and with a sample of at least 30 immigrants in the pooled sample are included in the analysis. Overall, analyses are based on a sample of $23300025-65$ year-olds in Europe, $12 \%$ of whom are immigrants. 


\section{References}

Beal, S.J. and L.J. Crockett (2010), "Adolescents' occupational and educational aspirations and expectations: Links to high school activities and adult educational attainment”, Developmental Psychology, Vol. 46/1, pp. 258-265, http://dx.doi.org/10.1037/a0017416.

Borgonovi, F. and J. Pál (2016), "A Framework for the Analysis of Student Well-Being in the PISA 2015 Study: Being 15 In 2015”, OECD Education Working Papers, No. 140, OECD Publishing, Paris, http://dx.doi.org/10.1787/5jlpszwghvvb-en.

Morgan, S. (2005), On the Edge of Commitment: Educational Attainment and Race in the United States, Studies in Social Inequality, Stanford University Press, Stanford, CA.

Nurmi, J.E. (2004), “Socialization and self-development: Channeling, selection, adjustment, and reflection”, in R.M. Lerner and L. Steinberg (eds.), Handbook of Adolescent Psychology, John Wiley \& Sons, Hoboken, NJ, pp. 85-124.

OECD (2012), Grade Expectations: How Marks and Education Policies Shape Students' Ambitions, PISA, OECD Publishing, http:// dx.doi.org/10.1787/9789264187528-en.

OECD (2013), PISA 2012 Results: Ready to Learn: Students' Engagement, Drive and Self-Beliefs (Volume III), PISA, OECD Publishing. http://dx.doi.org/10.1787/9789264201170-en.

OECD (2015), Immigrant Students at School: Easing the Journey towards Integration, OECD Publishing, http://dx.doi. org/10.1787/9789264249509-en.

OECD (2017), PISA 2015 Results (Volume III): Students' Well-Being, PISA, OECD Publishing, Paris, http://dx.doi.org/10.1787/ 9789264273856-en.

Perna, L.W. (2000), "Differences in the decision to attend college among African Americans, Hispanics, and Whites", The Journal of Higher Education, Vol. 71/2, pp. 117-141. 



\section{Chapter 9 \\ Policies and practices to support the resilience of students with an immigrant background}

This chapter discusses the policy implications and provides further evidence on examples of countries' approaches to integrate, and promote the well-being of, students with an immigrant background. It also details a comprehensive set of education policies and practices. Some of these policies and practices are designed to address the specific challenges immigrants face upon arriving in a new country; others are designed to foster the long-term integration of immigrants and their children. 
$\mathrm{T}$ his report provides ample evidence that international migration flows have reshaped the composition of classrooms in most education systems, with a marked increase in the heterogeneity of student populations. Students with an immigrant background in many education systems are at an increased risk of academic underperformance, of reporting feelings of alienation, high anxiety related to schoolwork and low satisfaction with life. Yet, many express high levels of motivation to achieve at their best in school and beyond.

A key contribution of the report is that it identifies the possible long-term effects of having an immigrant background on individuals' academic performance and broader well-being. Some of these consequences span more than one generation (as in the case of increased risk of academic underperformance that is associated with being native-born but having at least one foreign-born parent). Others are more complex and play out over time in non-linear ways, interacting with individuals' life circumstances (such as the increased risk of reporting low satisfaction with life among native-born children of mixed heritage).

In order to address the risks associated with having an immigrant background and support the resilience of students with such background, teachers and educators need to know the personal histories of their students, develop the tact that is necessary to discuss their past experiences, and be aware of how migration can affect academic performance, social integration, and emotional and psychological well-being. Students with an immigrant background should receive support to help them achieve their potential, but care should be taken to avoid stigmatising such students because of their background if and when targeted initiatives are implemented. Supporting students with an immigrant background can help education systems develop adequate responses to tackle underachievement and poor student well-being more generally and help classrooms become inclusive and responsive to individual needs.

The report identifies the key barriers to the academic, social, emotional and motivational well-being of students with an immigrant background, and has shown how they might affect the different groups of students with an immigrant background.

Language barriers and a relatively disadvantaged socio-economic status are key risk factors for students with an immigrant background, particularly first-generation immigrant students who had settled in a new country at or after the age of 12 . Teachers are crucial in helping these students adjust in their classrooms and in the broader society. Teachers in many education systems appear keen to offer additional assistance to students with an immigrant background. But many students with an immigrant background reported feeling that they are unfairly treated by their teachers, suggesting that teachers might not know how to support their students. In fact, teachers in many education systems reported that they need to develop further their ability to handle multicultural classrooms. Just as countries invest in developing language programmes and initiatives aimed at supporting socio-economically disadvantaged students, so they should invest in widening the availability of programmes designed to help teachers teach in diverse classrooms and upgrade the quality of existing training modules.

This chapter draws on the evidence detailed in the report, the research literature and policies developed in OECD and EU countries to provide concrete examples of education policies and practices that could help students with an immigrant background reach their academic potential, become better socially integrated, emotionally adjusted and motivated to achieve. The examples highlighted do not constitute an exhaustive list of policies and practices towards these ends; however they are exemplary in that they represent a wide selection of approaches taken to tackle the problem and illustrate commonalities and differences in approaches.

In some cases policies and practices attempt to reduce the vulnerability of students with an immigrant background by limiting the factors that could undermine performance and prevent social, emotional and motivational adjustment. At other times, policies and practices try to strengthen the factors that protect these students from the adverse effects of migration. While many policies and practices are designed explicitly for students with an immigrant background, others benefit these students indirectly by targeting broader groups in which students with an immigrant background are over-represented, such as socio-economically disadvantaged students. 


\section{The overall well-being of students}

The report highlights major differences in the academic, social, emotional and motivational outcomes of students without an immigrant background (students who were born in the country in which they sat the PISA test in 2015 of parents who were also born in that country) and different groups of students with an immigrant background. The report shows a large degree of variation in the vulnerability of different groups of students and that such variation differs systematically, depending on the country in which they (or their parents) had settled, and the characteristics of the schools they attend and of their families.

By defining resilience using multiple indicators that reflect academic, social, emotional and motivational well-being, the report identifies a clear role for education systems in promoting the full development of children with an immigrant background. The report recognises the different sets of vulnerabilities that accompany direct and indirect displacement (being foreign-born or having foreign-born parents) and the fact that they might affect students' sense of themselves (e.g. when native-born students of mixed heritage have to negotiate among multiple identities). While education systems clearly can and should play a role in promoting the well-being of students with an immigrant background, their role should be seen in light of a broad and co-ordinated effort encompassing the education, health, social and welfare systems, and potentially involving partnerships among schools, hospitals, universities and community organisations.

\section{Policies and practices aimed at promoting overall well-being}

In Ontario, Canada, "Developing child and student well-being means supporting the whole child - not only the child's academic achievement but also his or her cognitive, emotional, social and physical well-being" (Ontario Ministry of Education, 2014: 14). Promoting the well-being of children helps ensure that students can be better learners and excel in school. The guidelines provided by the ministry are followed by district school boards. For example, the Ottawa-Carleton District School Board (OCDSB) aims to enhance the use of resources to improve the well-being of all learners by 2019 (OCDSB, 2015). The board has developed a well-being framework as a guide for schools and the district to ensure the socio-emotional, cognitive and physical well-being of students (Bilgili, 2017).

An effective project targeting the well-being of immigrant students is the Boston Hospital SHIFA project. Since 1992, more than 5000 Somali refugees and immigrants have settled in Boston, Massachusetts (United States). While many Somali youth suffer from mental health problems related to trauma and stress, few receive the help they need because of cultural or other barriers. Project SHIFA was founded to address this concern. It grew out of a partnership between the Somali community, and education and mental health systems in the Boston area. Based at the Lilla G. Frederick Pilot Middle School in Boston, the project provides culturally appropriate services, from prevention to full intervention, including parent workshops, home visits and phone calls, teacher training, student groups and direct intervention for students. The programme works with schools for one to two years to develop skills among the school staff to address mental health and cultural issues relevant to the Somali refugee experience. An evaluation of Project SHIFA suggests that community-wide acceptance of the programme led to high rates of engagement by children and families and a significant decrease in post-traumatic stress disorder (PTSD) symptoms over eight months. Alongside the positive mental-health outcomes for Somali youth, involvement in Project SHIFA is also associated with greater parental involvement with the school, increased sense of belonging at school, and a reduction in immigrant students' rejection of school (Ellis et al., 2012). The programme has been expanded to the Bhutanese community. ${ }^{1}$

The Bridges programme, based at New York University (NYU) in New York City (United States), also aims to build immigrant parents' resilience by strengthening their cultural identity. ${ }^{2}$ The prevention programme seeks to enhance the well-being of young children attending New York public schools by providing consultation to teachers and a workshop series to parents of students in first grade. Consultation includes education on cultural competence, ethnic socialisation, and common mental health problems among young children. Consultation and training is provided in five schools in Brooklyn, New York, a community where the majority of residents are immigrants from Afro-Caribbean countries. Consultants, a team made up of NYU Child Study Centre clinicians and community representatives, help teachers use behaviour-management techniques, incorporate cultural activities in the classroom, and engage families. 
Parent workshops focus on ethnic and racial socialisation by encouraging the use of strategies that teach children about the unique values and behaviours of their culture of origin and instil pride in their cultural background.

Another promising project is World Relief Chicago, a youth mental-health project in Albany Park. The community of Albany Park has the highest percentage of foreign-born residents in the Chicago area and is one of the most diverse communities in the United States. Refugees from all over the world settle in the community, often with little time for the school and community to prepare for them. To help families see the importance of school and parents working together, Horizons Clinic of World Relief Chicago placed culturally competent mental-health clinicians in an elementary and high school in Albany Park. Through home visits and family meetings, the programme educates families about the school, helps them become more involved in supporting their children's education, and ultimately helps them become integrated into the life of the school. ${ }^{3}$

\section{The importance of access to education for all children with an immigrant background}

By relying primarily on data from PISA, this report inevitably focused on individual-, school- and systemlevel factors that foster the academic, social, emotional and motivational resilience of children with an immigrant background who are enrolled in and attend lower or upper secondary schools at the age of 15 , and have the basic language skills that are necessary to be able to complete a test. As a result, the report contains very little pointers on factors that support access to education, or on the academic and broader well-being outcomes of the most recent wave of migrants, which, in Europe, includes a considerable number of refugees and asylum-seekers. Ensuring that students with an immigrant background, and, in particular, first-generation immigrant students, have access to schools requires co-ordination between the education sector, housing, social welfare and migration services. A vibrant civil society that supports national, regional and local institutions can further facilitate access to, and ensure the continuity of, schooling among students with an immigrant background, particularly among the most disadvantaged children.

In about half of OECD countries with available data, the enrolment rate in pre-primary education in 2015 exceeded $90 \%$ for 3- and 4-year-olds. Enrolment at even earlier ages is relatively common in some countries, with Denmark, Iceland and Norway achieving full enrolment for two-year-olds. In other countries, full enrolment is achieved for children between the ages of 5 and 6, except in Russian Federation (hereafter Russia) (full enrolment for 7-year-olds) and Estonia (full enrolment for 8-year-olds) (OECD, 2017a). Several countries have policies in place that encourage students with an immigrant background in general, and newly arrived children in particular, to attend schools and other education services.

\section{Examples of policies to promote access to quality early education}

In most OECD countries, access to pre-primary education has been expanded to include children with an immigrant background. Most of these programmes are part of policies designed to offer access to preprimary education to disadvantaged students. Germany, for example, set a strategic goal in its National Action Plan on Integration (2011) to facilitate access to early learning, care and education in day-care facilities and day nurseries for children (OECD, 2015b).

In Estonia, the Pre-school Child Care Institutions Act states that local governments are to provide the opportunity to attend childcare institutions to all children between the ages of 1 and 7 if requested by their parents. In France, every child living in the country has the right to education in a state school, including pre-primary education. Free pre-primary education starts from the age of 2 and extends to the age of 6 . Most children of immigrant families attend pre-primary school at the age of 3 (MIPEX, 2015). In Finland, participation in pre-primary education is voluntary but municipalities are obliged to provide pre-primary education if parents ask for it. Furthermore, the backgrounds of immigrant children are taken into account, even if the instruction follows the general objectives of education and learning (MIPEX, 2015).

In the United States, several states have tried to increase immigrant enrolment in early childhood development programmes as part of wider efforts to expand pre-school options among disadvantaged communities. To improve access, some states have created or expanded public pre-school systems that supplement and complement the federal Head Start and Early Head Start programmes (Crosnoe, 2013). 
Both national and municipal governments in Norway have made special efforts to support equality of participation, particularly for low-income and minority-language families. Initiatives include fee reductions or exemptions, as well as pilot programmes providing up to four hours per day of kindergarten free for children aged 3 to 5 . This scheme is expected to be extended to all 4- and 5-year-olds from lowincome families across Norway (OECD, 2015c).

\section{Access to compulsory education}

Having access to compulsory education is also key for children with an immigrant background. Across most OECD countries, full enrolment ends when students are around 17 or 18 years old, but it ends earlier in Mexico (at the age of 14) and Turkey (14). In most OECD countries, compulsory education starts at the age of 6 and ends at the age of 16 or 17. The typical starting age for compulsory education ranges from 4 in Brazil, Luxembourg and Mexico to 7 in Estonia, Finland, Indonesia, Russia, South Africa and Sweden. In the United Kingdom, the starting age ranges between 4 and 5, and in the United States between 4 and 6 (OECD, 2017a). However, many students with an immigrant background do not participate in compulsory education. In particular, children who entered a country illegally might not have a right to enrol or might be afraid of enrolling in education for fear of deportation. In other cases, children might miss time in school because they had migrated during the school year. In other cases, children might not have stable accommodation or might not have the language skills to be able to take part in regular classes, and they might not be able to access classes in their mother tongue.

Several countries offer compulsory education to immigrants, refugees and sometimes even undocumented individuals as a legal right (including the Czech Republic, Italy, Korea, Latvia and Portugal). However, this does not mean that children are obliged to attend school (e.g. in the Czech Republic) (MIPEX, 2015). For example, in Portugal, the Education Law specifies that basic education is universal, compulsory and free: for children between the ages of 6 and 18, schooling is compulsory. The Support for Multicultural Families Act in Korea specifies that neither the state nor local governments shall discriminate against children of any multicultural family in providing care and education to children. Children of multicultural families can be provided with care and education before entering elementary school and given assistance to improve their language skills (MIPEX, 2015).

Some countries actively promote the integration of immigrant students in schools. For instance, in Portugal, the General Directorate of Education and the High Commission for Migration, in collaboration with the Aga Khan Foundation Portugal, have awarded an intercultural school seal since 2012, and disseminate good practices in welcoming and integrating students who are descendants of immigrants. The Intercultural School Seal distinguishes public, private or co-operative schools that, through educational programmes and practices, promote the recognition and enhancement of cultural and linguistic diversity as an opportunity and a source of learning for all (European Commission, 2018).4

\section{Examples of policies to promote access to vocational education and training, and higher education}

Matching the aspirations and skills of students with an immigrant background to potential vocational pathways is difficult. Many recently arrived immigrants are unfamiliar with vocational education and training systems, the occupations covered, and the labour market outcomes associated with participation in vocational education. In many of the countries of origin of immigrants who had settled in OECD countries, vocational education and training is often poorly developed. Therefore many immigrants may view tertiary-level education as the only pathway that will enable them to attain a good job. For others, financial constraints mean that they cannot afford to pursue lengthy vocational education and training programmes and earn only apprentice wages for several years, even though future returns would make such choices a worthwhile investment.

In some countries (such as Austria, Belgium and France) being enrolled in a vocational track is associated with a stronger sense of belonging and greater satisfaction with life, but students with an immigrant background are less likely to be involved in vocational education than native students. A number of countries offer access to education and training to immigrant and refugee students beyond the compulsory school age, such as vocational training or higher education. This is the case, for example, in Australia, Canada, Estonia, Finland, Germany, Greece, the Netherlands and the United States. 
The German National Integration Pact underlines the importance of measures to increase the participation of students with an immigrant background in vocational education and training, and of employers who will be willing to host such students in work-study programmes or apprenticeships. These include programmes like KAUSA, ${ }^{5}$ which encourages entrepreneurs with an immigrant background to provide vocational training to students with an immigrant background, or Netzwerk IQ. ${ }^{6}$

In Australia, both the federal and state governments have such policies. At the federal level, they include the Trade Training Centres in Schools Programme, which enables all students attending secondary schools to access vocational education through Trade Training Centres; the Productivity Places Programme, which provides targeted training to develop skills in the country to meet existing and future industry demands; and the Language, Literacy and Numeracy Programme, which improves participants' language, literacy and/or numeracy, with the expectation that such improvements will enable immigrant students to participate more effectively in training or in the labour force, and lead to greater gains for them and society in the long term (MIPEX, 2015). ${ }^{7}$

To facilitate access to and participation of students with an immigrant background in higher education, the Finnish government has implemented targeted measures to develop student-selection processes, allocate sufficient resources for student guidance, increase and focus instruction in the Finnish language and culture, and develop open higher education studies. The institutions of higher education may apply for state support (study vouchers) to assist their students' Finnish/Swedish language studies (MIPEX, 2015). In Australia, the state government of Victoria has targeted measures to increase acceptance and participation of immigrant students at the tertiary level. For example, the Victorian Tertiary Admissions Centre provides a Special Entry Access Scheme for eligible migrant students who come from a non-English speaking or refugee background to be granted extra consideration for entry into programmes at the university level (MIPEX, 2015).

\section{Evidence on ability grouping, grade repetition and early tracking}

Policies that support access to and participation in education programmes among students with an immigrant background are a crucial first step to ensure the long-term integration of these students and their broader well-being. However, such policies have to be complemented by others that sustain the quality of the education received by these students, and that ensure that they have access to these programmes, and the same opportunities to succeed as other students.

Ability grouping, early tracking and grade repetition might have adverse effects on student achievement and well-being, and might disproportionally affect students with an immigrant background. Many studies have shown the negative effect of early selection for children from disadvantaged backgrounds (Ammermüller, 2005; Bauern and Riphahn, 2006; Breen and Jonsson 2005; Brunello and Checchi, 2007; Horn, 2009; van der Werfhorst and Mijs, 2010) and a few studies have examined the effect of early selection and tracking on children with an immigrant background (Crul and Vermeulen, 2006; Entorf and Lauk, 2008; Heckmann et al., 2001; Penn and Lampert, 2009; Shavit, 1990). Entorf and Lauk (2008), Shavit (1990) and Schnell (2014), in particular, suggest that ethnic minority groups suffer most when students are tracked at an early age. There is also some evidence that early tracking might be especially problematic for students with an immigrant background if these students do not have access to high-quality early childhood education (Crul, 2015; Crul et al, 2016).

While there is great variation in children's cognitive and personal development, this variation is likely to be even more pronounced among children with an immigrant background, given the wide variety of their experiences. For example, students with an immigrant background might have difficulties with language because of their multilingualism, they might have been exposed to different curricula and education systems, and might have had their schooling interrupted, possibly for extensive periods of time. All of these factors make the identification of underlying ability, potential and aspirations even more difficult than is the case for students without an immigrant background.

The increased likelihood of developing certain skills at an older age could make students with an immigrant background more likely to be asked to repeat grades, when countries use grade repetition to create relatively homogeneous classrooms. However, evidence presented in this report suggests that 
students with an immigrant background are at a greater risk of repeating grades even when they perform similarly to other students in a standardised test. Teachers and educators might be more likely to require students with an immigrant background to repeat a grade not because of their academic proficiency, but because these students might have behavioural or disciplinary problems that might be related to their background or because these children are relatively less knowledgeable about the set of behaviours that are considered acceptable and/or are encouraged in their host country. In addition, students with an immigrant background might not be fully informed about the availability of different education pathways. Their parents might have fewer resources (cognitive, time, social, cultural) than other parents to advocate on behalf of their children and negotiate decisions with teachers and school staff that could maximise their children' academic and broader well-being.

If students with an immigrant background are separated too early from other children and are grouped with other academically weak students, they will fall behind in the development of linguistic and culturally relevant skills that are needed to perform well at school (Entorf and Lauk, 2008; Sirin and Rogers-Sirin, 2015).

Given that studies suggest that early tracking could increase the vulnerability of students with an immigrant background if these students had not attended pre-primary education, Table 9.1 groups countries on the basis of two characteristics: presence of early tracking and attendance rates in pre-primary education. In the top right quadrant (Belgium, Italy and Luxembourg), students are tracked at an early age, but many students attend pre-primary education. To the extent that students with an immigrant background are encouraged to take part in pre-primary education, the potentially negative effects of early tracking could be relatively easily reduced in these countries. In the bottom left quadrant (the Dominican Republic), few students attend pre-primary education, but students are tracked in later years, which can compensate for the low attendance rates in pre-primary education. However, in the bottom right quadrant (Croatia and Germany), the combination of a small share of students in pre-primary education and the early age at which children are first tracked could greatly increase the vulnerability of students with an immigrant background to poor performance in school.

Table 9.1 - Interaction between tracking and attendance at pre-primary education

\begin{tabular}{l|c|c|c}
\hline & Late age at first tracking & Average & Early age at first tracking \\
\hline $\begin{array}{l}\text { High percentage of students who } \\
\text { had attended pre-primary education }\end{array}$ & Chile, Spain & Belgium, Italy, Luxembourg \\
\hline Average & Malta, United Kingdom & $\begin{array}{c}\text { France, Hong Kong (China), } \\
\text { Ireland, Macao (China), Mexico, }\end{array}$ & \\
\hline $\begin{array}{l}\text { Low percentage of students who } \\
\text { had attended pre-primary education }\end{array}$ & Dominican Republic & Georgia, Korea & Croatia, Germany \\
\hline
\end{tabular}

Notes: Dimension 1 (rows) sorts countries based on the percentage of students who reported to have attended pre-primary education in their responses to the PISA student questionnaire.

Dimension 2 (columns) sorts countries based on the age at first tracking in school.

Source: OECD, PISA 2015 Database.

\section{Examples of policies to reduce grade repetition and early tracking}

Policies to reduce the use of grade repetition have been introduced in a few countries. For example, France reduced repetition rates by 11.1 percentage points between 2003 and 2012. Since then, the country has used grade repetition only in exceptional cases (OECD, 2013). In the French Community of Belgium, the Take-off project (Projet décolage, 2012) was developed to reduce the use of grade repetition by providing pedagogical tools for schools (OECD, 2015a).

While in some countries tracking takes place at a later age and provides opportunities for all students to access higher education, in Germany students are selected into tracks already at the age of 10 or 12 thus limiting students' options later on (Crul et al, 2017). The new school education system in Berlin (Germany) introduces an integrated secondary school (ISS) to provide more individualised support and learning. It also provides heterogeneous learning groups, all-day schools and work-based learning. These measures are aimed at mitigating against early tracking. The ISS combines elements of academically oriented learning with vocational training and offers a range of vocational qualifications, as well as the possibility of completing the Abitur as offered in the Gymnasium (European Commission, 2013b: 37). 


\section{Access to quality education and career guidance}

While students with an immigrant background are often highly motivated, it is important that they are able to capitalise on their motivation and have realistic expectations to achieve their goals. Information on education and career opportunities and on the requirements of different pathways should be made available so that students with an immigrant background can fully benefit from education and training services (OECD, 2012a). Guidance is crucial in countries with differentiated schooling and education sectors, where students and their families are expected to make important decisions on which school a student will attend and/or where there are few second-chance opportunities for students. Education and career guidance is particularly important for students with an immigrant background, given the limited knowledge students and their parents might have about career opportunities, and how best to prepare for them.

Career guidance can include providing information about careers, using assessment and self-assessment tools, interviews, career-education programmes, taster programmes, work-search programmes and transition services. But young people in all levels of education often face obstacles to obtaining the guidance they need, because of a lack of access, poor quality of services, or limited resources that are not always dedicated to career guidance (OECD/European Commission, 2004).

\section{Examples of policies to reduce grade repetition}

In Sweden, newly arrived students receive career guidance on the same terms as other students. The quantity and quality of the services depend upon local regulations and allocation of resources (Hertzberg, 2017). Career guidance in lower secondary education mainly involves choosing upper secondary education. Studies on career guidance of ethnic minorities in Sweden (Sawyer, 2006) and in other countries (Yogev and Rdoditi, 1987; Resh and Erhard, 2002) suggest that immigrant and/or ethnic minority students might be advised to temper their career aspirations, implicitly or explicitly, based on low and unfair expectations for immigrant and/or minority students.

Quality career guidance goes hand in hand with education guidance for students with an immigrant background and their families. In Sweden, municipal authorities have a responsibility to inform newly arrived families of their rights with regard to pre-school and school education. Interpreting services must be made available, when required, at the welcome meetings for recently arrived families. These families are also entitled to an interpreter to enable them to participate in the "personal development discussion" held with all parents twice a year. Schools are obliged to communicate with all parents and must therefore adopt the measures necessary (MIPEX, 2015).

In Flanders, Belgium, every school co-operates with a Pupil Guidance Centre (CLB). ${ }^{8}$ The CLB guides students as they develop into independent adults and monitors students' health and well-being, either systematically or if requested to do so. Parents, teachers, school-management teams and the young people themselves may turn to the CLB for information, help and guidance. Various professionals, including doctors, nurses, social workers, psychologists and educators work together within a CLB. Working with the school, this team ensures that every child and young person can develop his or her knowledge, talents and skills at school. The CLB operates in four guidance domains: learning and studying, educational career, psychological and social behaviour, and preventative health care.

In Australia, the New South Wales Education and Training website and Victoria's Department of Education and Training website provide advice at all levels of education about the education system, in immigrants' languages of origin. They also have centres students can consult for orientation as well as interpretation services for families of students with an immigrant background for advice and guidance on education (MIPEX, 2015). ${ }^{9}$

\section{Early assessment of language and other skills}

It is important to assess the language and other skills of students with an immigrant background, not only those of foreign-born children who had arrived after the start of schooling, but also of native-born children of foreign-born parents, in order to identify the needs of each individual child and to target training. Language support requires an accurate assessment of children's language skills (in both the 
mother tongue and the language of instruction) and other competencies at the time of entry into the education system (European Commission, 2013a; Nusche, 2009; Sirova and Essomba, 2014) and also during their education, since some children with an immigrant background may not exhibit difficulties at the start of their schooling, but might progressively fall behind due to a lack of language practice and support at home. Poor measures of assessment on entering the school system can have a detrimental impact on immigrant children because these children are more likely to be allocated to special education and lowerability tracks (European Commission, 2015).

Screening for language proficiency not only informs teachers about individual students' needs, but also informs education authorities at the district or system level, and can be used as a basis for distributing additional funding to schools (Mengering, 2005).

Policies that support early language assessment can target language-minority students or students with an immigrant background, or be part of non-targeted initiatives aimed at diagnosing children with language difficulties and meeting their individual needs.

\section{Examples of policies to promote early language assessment of all children}

Denmark, for example, introduced a mandatory assessment of language development for all 3-year-olds that aims to diagnose possible language problems before children start school (MIPEX, 2015; OECD, 2015a). If identified as necessary, additional language training of at least 15 hours per week can take place as an integrated part of normal kindergarten activities or in separate groups.

In Germany, the majority of Länder introduced screening processes to identify pre-school children in need of additional language support. These assessments are usually conducted 12 to 24 months before children's transition to school. Support for other mother tongues besides German is only provided within individual projects or on the initiative of early childhood and education staff/centres/ providers. The most common practice to improve children's skills in German is the child-oriented approach Alltagsintegrierte Sprachliche Bildung (i.e. language education embedded into daily routines). This approach was spread nationwide through the federal programme Frühe Chancen: SchwerpunktKitas Sprache und Integration (Early Chances: Childcare centres with special focus on language and integration), and continued through the follow-up programme Sprach-Kitas: Weil Sprache der Schlüssel zur Welt ist (Language day nurseries: Because language is the key to the world) ${ }^{10}$ (OECD, 2017b).

In the Netherlands, young children, especially those from disadvantaged backgrounds, are entitled to receive language-development support. These children can participate in early childhood and education targeted programmes (vooren vroegschoolse educaties) that provide support before and during the first years of school. All toddlers (2.5 to 4 years old) who are part of this programme receive 10 hours of language development per week. For the rest of the day, targeted toddlers attend the same early childhood and education programme as their non-targeted peers. Findings from the Pre-COOL national cohort study show that this approach is effective (Akgunduz and Heijnen, 2016; Leseman et al., 2017). Participating in day care centres and preschools reduces the difference in language and executive-function skills (measured by a selective-sustained attention test) between advantaged and disadvantaged children. Disadvantaged children who attend day care centres and preschools implementing these programmes show even more enhanced language and executive-function development than disadvantaged children who participated in other centres and preschools (OECD, 2017b).

\section{Examples of policies to promote rapid language assessments of newly arrived immigrant children}

In Canada, welcome centres assess English language and mathematics skills of newcomers, connect students and families with a settlement worker, and offer advice on entry into school. Newly arrived immigrants are particularly targeted and receive additional support for transitioning to school as soon as possible (Bilgili, 2017).

Ireland developed guidelines for language assessment, with assessment tool kits and intercultural education guidelines for pedagogy to integrate language learning with content learning (OECD, 2010). ${ }^{11}$ Standardised tests are only used at the end of a student's participation in a language programme when a school wants to extend language support beyond two years (MIPEX, 2015). 
In New Zealand, the Ministry of Education requires schools to identify and assess students with high English-language needs. All students from immigrant and refugee backgrounds are entitled to funding for English-as-a-second language programmes for up to 5 years (20 terms) if they score below the benchmark (MIPEX, 2015). ${ }^{12}$

In Oslo, Norway, an assessment tool with levels equivalent to those in the Common European Framework of Reference for Languages was developed to enable more tailored and systematic second-language training and a better assessment of children's language skills (European Commission, 2015).

Since 2016, Sweden has implemented a policy whereby diagnostic tests on students' previous schooling and their level of academic knowledge are conducted within two months of the student's arrival at school. Subsequently, additional tests are conducted in different school subjects. No more than two months after the student is enrolled in a school, the principal makes a decision regarding his or her grade and placement in either introductory (separate) or regular class. The decision is based on the student's accumulated academic knowledge and relevant social reasons, such as his or her age and network in the community (Bunar, 2017).

When schools in Portugal identify at least 10 students as having beginning or intermediate proficiency in Portuguese, these students are enrolled in a Portuguese-as-a-second-language course. Additional teachers are allocated based on the needs of each school and with the defined criteria. When schools fail to meet the necessary conditions for the formation of these groups, students attend regular Portuguese courses, but follow a special curriculum and benefit from support language classes. In addition, the Ministry of Education, in partnership with the Portuguese Language Cyberschool and with some schools, has developed a project distance courses in Portuguese-as-a-second-language offered by the Cyberschool. ${ }^{13}$

\section{Targeted language training}

As Chapter 5 has noted, language skills are not only important for academic achievement, but are essential if students with an immigrant background are to develop a sense of belonging at school. That is why it might be beneficial for newly arrived immigrant children who are not proficient in the hostcountry language to be moved quickly to targeted language support provided in mainstream classrooms (immersion) rather than in separate classes (European Commission, 2015).

Age at arrival explains much of the outcome gap between immigrant and native students, as does mastery of the assessment language. Late-arrival penalties vary across countries, but they are more pronounced for immigrant students who do not speak the assessment language at home (OECD, 2012b; 2015a). As Chapter 5 has reported, linguistic differences explain a large part of the disadvantage for late arrivals Austria, Germany and Slovenia.

While most countries provide language training to first-generation immigrants and new arrivals, it is also important to offer targeted language training to returning students and students from mixed-heritage households (i.e. with at least one native-born parent) when proficiency in the host language is markedly lower than that among native students (see Chapter 5).

\section{Examples of policies to promote language training}

Several countries offer targeted language training to immigrant students. For example, classes in the Estonian language are provided to any student in pre-primary school who does not speak Estonian at home (MIPEX, 2015). In Finland, the National Core Curriculum for Instruction Preparing Immigrants for Basic Education was introduced in 2009 to support students with an immigrant background who are not proficient in the Finnish or Swedish language. The curriculum is differentiated according to age, learning abilities and background. Austria developed a national curriculum framework for language learning in kindergarten and standards for second-language learning (OECD, 2010; 2015a).

In keeping with Norway's Curriculum in Basic Norwegian for Language Minorities in compulsory primary education, support for lessons in Norwegian-as-a-second-language can be provided as long as local authorities deem it necessary. The national strategy plan, “Equal Education in Practice!", strongly recommends language support in both the mother tongue and Norwegian in pre-primary education, 
primary, secondary and higher education, as well as adult training. About 150 different projects were implemented between 2004 and 2009, some of which are ongoing (MIPEX, 2015). ${ }^{14}$

In Luxembourg, native students speak Luxembourgish at home, start to learn French and German during primary education, and then later usually learn English. The government provides two years of compulsory pre-school education for children aged 4 to 6 which introduces language learning. At the end of compulsory education, $43 \%$ of total teaching time is devoted to teaching languages. Students - including immigrant students - are expected to achieve high levels of competency in at least two foreign languages (European Commission, 2015).

\section{Multilingualism and exposure to more than one language}

This report could only examine the language spoken at home versus the language of the assessment due to limited questions in PISA; but it recognises that being exposed to more than one language can be beneficial to immigrant children. Multilingualism is associated with cognitive, social, personal, academic and professional benefits (Herzog-Punzenberger, Le Pichon-Vorstman and Siarova, 2017). Studies indicate that children exposed to more than one language tend to perform better than their monolingual counterparts (Collier and Thomas, 2007; Cummins, 2000; see also discussion in Mehmedbegovic and Bak, 2017). Learning multiple languages requires the support of families, communities, school leaders and teachers, and also involves relevant training and professional-development activities for teachers.

\section{Examples of policies and practices to promote multilingualism}

The Bundeszentrum für Interkulturalität, Migration und Mehrsprachigkeit (BIMM) ${ }^{15}$ in Austria (Federal Center for Interculturalism, Migration and Multilingualism) is a resource centre for the professionalisation of teachers in the field of interculturalism, migration and multilingualism. BIMM organises network meetings among the relevant staff of the teacher-training institutions, and convenes workshops and conferences (Herzog-Punzengerger, Le Pichon-Vorstman and Siarova, 2017).

Most surveys only allow respondents to mention one "home language"; but a few surveys include questions about "exposure to more than one language". The broad and inclusive definition of exposure to more than one language (Hall et al. 2012) is much more suitable to contexts where many languages are spoken and where proficiency in the languages used varies considerably (Mehmedbegovic and Bak, 2017). This definition was used in London schools to collect data on languages spoken at home during the Ethnic Minority Achievement Grant (1999-2010), which funded specialist teachers who provide language support to children new to English (Mehmedbegovic and Bak, 2017). In future rounds of the assessment, PISA could also include a question about "exposure to more than one language" in order to collect data on multilingualism among 15-year-old students.

\section{The role of socio-economic disadvantage}

Socio-economic status is a strong determinant of students' academic performance and general well-being (OECD, 2016a; 2017c) and the relevance of socio-economic status in shaping the outcomes of students with an immigrant background has been widely examined (Marks, 2006; Martin, 1998; Portes and MacLeod, 1996). It affects student outcomes in a variety of ways, at the individual, school and system levels.

Sorting and selecting policies used by schools and education systems, such as early tracking or grade repetition, can lead to differences in academic and well-being outcomes across students from different socio-economic backgrounds. While the selection of students for certain grades or programmes should be based primarily on performance, research shows that students' background characteristics also influence those decisions (Agasisti and Cordero, 2017; van de Werfhorst and Mijs, 2010). Other characteristics of education systems, such as the level of resources available to public or private schools, or to urban and rural schools, can strengthen or weaken the relationship between socio-economic status and academic performance (Greenwald, Hedges and Laine, 1996; OECD, 2016b; Rivkin, Hanushek and Kain, 2005).

As Chapter 6 on socio-economic status has shown, immigrant students (both first- and second-generation immigrant students) tend to be more disadvantaged than native students. By contrast, in the majority of countries, returning foreign-born students and native students of mixed heritage are more advantaged than their native peers. 
Differences between native and immigrant students in academic proficiency are at least partly explained by greater socio-economic disadvantage among immigrant students. Yet, disadvantage is not the same across the distribution, and also differs by country. Performance gaps between native and immigrant students are largest at the middle of the socio-economic distribution, where student performance is most varied and the relationship with socio-economic status is weaker. Chapter 6 has shown that while socio-economic status accounts for a remarkably large share of the differences in academic achievement between immigrant and native students, the largest portion of the disparities is unexplained in most countries and economies.

\section{Additional support to disadvantaged students and schools}

Disadvantaged students and schools need additional support, which is most often provided in the form of greater resources. Immigrant students are a key focus of resource allocations both because of migrationrelated needs (such as language difficulties) and socio-economic disadvantage (immigrant students tend to be socio-economically disadvantaged and live in disadvantaged communities). Countries typically use one of the following two approaches to promote equity: provide additional resources through targeted programmes (external to the main allocation mechanism) or include additional funding in the main allocation mechanism (e.g. through weightings in a funding formula) (OECD, 2017d).

Programmes might direct additional funding to certain geographical areas or to the actual population in each school. Area-based funding aims to address the additional negative impact of a concentration of disadvantage; student-based funding aims to adapt funding levels to the needs of the actual population in each school. Providing additional resources to students or areas that have greater need to promote equity in outcomes assumes that data on students' level of needs is both available and accurate. Designing funding formulas to account for individual or area-based need also involves a trade-off between simplicity and accuracy (OECD, 2017d).

\section{Examples of policies aimed at providing greater support}

Many countries provide additional resources to schools to overcome language difficulties among newly arrived students, with funding provided to promote second-language teaching and learning and to support the creation of innovative teaching modules. For example, in Estonia, the Multicultural School project covering 2017-20 aims to reform the structure of financial support available to schools with a diverse student population and change school-level approaches to multiculturalism.

In the Flemish Community of Belgium, schools receive additional funding to target socio-economic disadvantage and have discretion over how to use this funding. The funding is mostly used to provide necessary material for teachers, and to cover expenditures to address the needs of disadvantaged students, such as specific teaching materials, in-service training or community-school activities (OECD, 2017d).

Extra funding can also be targeted to immigrant students facing a transition into a new education system. In Canada, for example, the Department of Education and Early Childhood Development in the province of Newfoundland and Labrador has a funding programme for before- and after-school activities for "new Canadians". This immigration strategy funding can support initiatives such as the provision of additional English Second Language (ESL) ${ }^{16}$ materials to school districts, funding to community groups such as the Association for New Canadians ${ }^{17}$ to support after school activities and funding to the organisation Sharing Our Cultures for the publication of Cultural Context, ${ }^{18}$ a grade 6 complementary resource for English, Francophone and Aboriginal communities which features local students with diverse backgrounds and cultures.

\section{Evidence on the concentration of students with an immigrant background in disadvantaged schools}

Concentration of disadvantage in schools is another risk factor that can affect the resilience of immigrant students. Schools that struggle to do well for native students might struggle even more with a large population of children who cannot speak or understand the language of instruction. Countries that distribute immigrant students across a mix of schools and classrooms achieve better outcomes for these students. A more even distribution also relieves the pressure on schools and teachers when large numbers of immigrant students arrive over a short period of time (OECD, 2015a). 
As the previous chapters have shown, most of the differences in student outcomes that appear to be associated with the concentration of students with an immigrant background in specific schools reflect the fact that these schools are socio-economically disadvantaged, rather than that these schools are disadvantaged because of a concentration of students with an immigration background.

\section{Examples of policies aimed at limiting the concentration of disadvantaged students}

Some countries have measures designed to counter the concentration of students with an immigrant background and promote integration. Countries have used three main ways to address the concentration of immigrant and other disadvantaged students in particular schools. The first is to attract and retain other students, including more advantaged students. The second is to better equip immigrant parents with information on how to select the best school for their child. The third is to limit the extent to which advantaged schools can select students on the basis of their family background (OECD, 2015a). Brunello and De Paola (2017) suggest that desegregation policies are not only equitable - they provide better opportunities to individuals from relatively disadvantaged backgrounds - but also efficient.

Language barriers, resource constraints, lower levels of education or lack of knowledge of the host country's school system could hinder immigrant parents' capacity to enrol their children in the most appropriate schools (OECD, 2015a). To overcome these barriers, the municipality of Rotterdam in the Netherlands runs bus tours to take parents around to visit local schools. The purpose of the tour is to allow parents to discuss enrolment options and encourage them to use their local schools. There are also student-exchange projects run by schools with very different profiles. These projects, which include team sports, after-school child care and excursions, attempt to bring together students from diverse cultural backgrounds (Brunello and De Paola, 2017).

In the Flemish Community of Belgium, in regions with many immigrant communities, a platform of local organisations linked with education has been established to design regulations that aim to avoid high concentrations of immigrants or natives in particular schools. The project School in zicht ${ }^{19}$ encourages parents of native children to enrol their child in local schools that have many students with an immigrant background (MIPEX, 2015).

In Denmark, the 2006 school act permits municipalities to refer students with an immigrant background to other schools. Different measures to promote integration are developed at municipality level. Some municipalities, such as Aarhus, practice forced desegregation; others, including Copenhagen, encourage ethnic-minority parents to choose a school with fewer ethnic minorities, and majority parents to choose schools with a large number of ethnic-minority students. A report from the municipality of Copenhagen concluded that such measures seem to improve societal integration to a certain extent, but they can create new problems for the targeted minority students (MIPEX, 2015).

The Education Territories of Priority Intervention Programme for clustered and non-clustered schools in Portugal is largely implemented in disadvantaged contexts, where the risk of school failure and dropout is high. The programme involves 137 school clusters, representing 17\% of all Portuguese school clusters. These schools are invited to develop specific improvement plans based on an agreement, between the school and school authorities, on measures, targets, evaluation and additional resources. The specific improvement plan covers four areas: support to improve learning; management and organisation of the cluster's programmes; prevention of dropout, absenteeism and indiscipline; and relations among the school, families and community. ${ }^{20}$

Studies have shown that it is mostly advantaged, non-immigrant families who exercise school choice. Therefore, it is important to make schools attractive to students from these families. One example is Qualität in multikulturellen Schulen (Quality in multicultural schools-QUIMS) ${ }^{21}$ in Switzerland, which is an obligatory programme if more than $40 \%$ of a school's student population are multilingual. The school administration supports QUIMS-schools with extra financial resources and professional help, so that the school can adapt the programme as required in the areas of language, attainment and integration. Language support includes promoting literacy for all students using language-competence assessments, and creative work for oral and written proficiency, and supporting integrated "native language and culture lessons". Attainment support includes a variety of learning methods to encourage co-operative learning 
and problem solving, and to increase the involvement of parents and mentors. Integration support is based on building a shared culture of appreciation, respect and understanding by using intercultural mediators to develop connections between parents and teachers, including the establishment of parent councils (Gomolla, 2006; Herzog-Punzenberger, Le Pichon-Vorstman and Siarova, 2017).

As school places are limited, the schools that are perceived to be of the highest quality are likely to attract more applicants than they have places available. Several studies suggest that school-choice plans should use simple lotteries to select among the applicants for oversubscribed schools in order to promote more diverse student populations (Godwin et al, 2006). Education systems can also consider providing financial incentives for oversubscribed schools to enrol immigrant students (Field, Kuczera and Pont, 2007). For example, in the French Community of Belgium, differentiated funding is provided to schools based on the socio-economic background of students. The 2004 Contract for School and the 2007 Enrolment Decree seek to fight against segregated schools. The 2005 Report on Intercultural Dialogue identified the problem of concentration of disadvantage in ghetto schools and recommended using funds to increase socio-cultural diversity (MIPEX, 2015).

\section{Links between language and socio-economic background}

Prioritising language training or reducing socio-economic disadvantage might not be equally beneficial in all countries: there might be a trade-off between language policies and policies targeting socio-economic disadvantage for promoting the academic and social resilience of students with an immigrant background. Tables 9.2 and 9.3 show that in some countries, language is a relatively important factor in explaining the disparities in academic performance and sense of belonging between native and immigrant students. In these countries, offering language-specific training for immigrant students is a crucial ingredient of policies aimed at fostering their academic and social resilience. In other countries, socio-economic background plays a more important role than language in promoting academic proficiency and sense of belonging.

In Table 9.2, for countries and economies in the top left quadrant of the table (Croatia, Hong Kong [China] and Luxembourg), policy might promote immigrant students' academic resilience by targeting both socio-economic and linguistic differences. For countries and economies in the top right quadrant (Ciudad Autónoma de Buenos Aires [Argentina], France and the United States), policies to reduce socio-economic disadvantage might be more beneficial to reduce the academic gap between immigrant and native students. In the bottom left quadrant (Estonia, Latvia and the Slovak Republic), policies that target language training might be more effective. In the bottom right quadrant (the Czech Republic, Portugal and the United Kingdom), policies might instead target issues other than language and socio-economic background.

Table 9.2 - Targeting efforts on key risk factors for the academic resilience of immigrant students: The relative importance of language and socio-economic background

\begin{tabular}{|c|c|c|c|}
\hline & $\begin{array}{l}\text { Language } \\
\text { relatively important }\end{array}$ & Average & $\begin{array}{l}\text { Language relatively } \\
\text { not important }\end{array}$ \\
\hline $\begin{array}{l}\text { Socio-economic status relatively } \\
\text { important }\end{array}$ & $\begin{array}{l}\text { Croatia, Hong Kong (China), } \\
\text { Luxembourg }\end{array}$ & Greece, Netherlands & $\begin{array}{c}\text { Ciudad Autónoma de Buenos } \\
\text { Aires (Argentina), France, } \\
\text { United States, }\end{array}$ \\
\hline Average & Jordan, Switzerland & $\begin{array}{l}\text { Austria, Belgium, Germany, } \\
\text { Slovenia, Sweden }\end{array}$ & Italy, Spain \\
\hline $\begin{array}{l}\text { Socio-economic status relatively } \\
\text { not important }\end{array}$ & Estonia, Latvia, Slovak Republic & Denmark, Finland & $\begin{array}{l}\text { Czech Republic, Portugal, } \\
\text { United Kingdom }\end{array}$ \\
\hline
\end{tabular}

Notes: Dimension 1 (rows) sorts countries based on the share of the difference between native and immigrant students (first- and second-generation) in the likelihood of attaining baseline academic proficiency that is explained by differences in socio-economic status. The share is larger for countries in the top row and smaller for those in the one below.

Dimension 2 (columns) sorts countries based on the difference between native-speaking and non-native speaking immigrant students in the likelihood of attaining baseline academic proficiency. The positive gap is larger for countries in the left column and smaller for those in the right one.

Students who attain baseline academic proficiency are those who reach at least PISA proficiency Level 2 in all three core PISA subjects: science, reading and mathematics.

Socio-economic status is measured through the PISA index of economic, social and cultural status (ESCS).

Native-speaking students are students who speak most frequently at home the language of the PISA assessment. Non-native-speaking students are those who reported that the language they most frequently speak at home is different from the language of the PISA assessment.

Source: OECD, PISA 2015 Database. 
Table 9.3 - Targeting efforts on key risk factors for the social resilience of immigrant students: The relative importance of language and socio-economic background

\begin{tabular}{|c|c|c|c|}
\hline & $\begin{array}{l}\text { Language } \\
\text { relatively important }\end{array}$ & Average & $\begin{array}{l}\text { Language relatively } \\
\text { not important }\end{array}$ \\
\hline $\begin{array}{l}\text { Socio-economic status } \\
\text { relatively important }\end{array}$ & & $\begin{array}{c}\text { Austria, Ciudad Autónoma } \\
\text { de Buenos Aires (Argentina), } \\
\text { Denmark, Netherlands }\end{array}$ & $\begin{array}{c}\text { Belgium, France, Germany, } \\
\text { Luxembourg }\end{array}$ \\
\hline Average & Greece, Italy, Spain, Sweden & New Zealand & Slovenia, Switzerland \\
\hline $\begin{array}{l}\text { Socio-economic status } \\
\text { relatively not important }\end{array}$ & $\begin{array}{c}\text { Estonia, Jordan, Latvia, } \\
\text { Montenegro }\end{array}$ & Czech Republic, Portugal & Ireland, Malta \\
\hline
\end{tabular}

Notes: Dimension 1 (rows) sorts countries based on the share of the difference between native and immigrant students (first- and second-generation) in the likelihood of reporting a sense of belonging at school that is explained by differences in socio-economic status. The share is larger for countries in the top row and smaller for those in the one below.

Dimension 2 (columns) sorts countries based on the difference between native-speaking and non-native speaking immigrant students in the likelihood of attaining baseline academic proficiency. The positive gap is larger for countries in the left column and smaller for those in the right one.

Students who reported a sense of belonging at school are those who reported that they "agree" or "strongly agree" with the statement "I feel like I belong at school" and "disagree" or "strongly disagree" with the statement "I feel like an outsider at school".

Socio-economic status is measured through the PISA index of economic, social and cultural status (ESCS).

Native-speaking students are students who speak most frequently at home the language of the PISA assessment. Non-native-speaking students are those who reported that the language they most frequently speak at home is different from the language of the PISA assessment.

Source: OECD, PISA 2015 Database.

In countries in the top right quadrant of Table 9.3 (Belgium, France, Germany and Luxembourg), policies that target socio-economic differences are likely to be particularly beneficial in supporting the social resilience of immigrant students. By contrast, among the set of countries that are in the bottom left quadrant of Table 9.3 (Estonia, Jordan, Latvia and Montenegro), policies that target language are likely to be particularly beneficial in reducing the gap between immigrant and native students in sense of belonging at school.

\section{Achieving a supportive climate at school through positive relationships}

As Chapter 7 has shown, a positive classroom climate is key for students' academic and well-being. Some of the facets of a positive school climate that have been shown to be associated with positive academic performance are supportive teacher-student interactions, good student-student relationships, and an orderly learning atmosphere with clear disciplinary rules (Creemers and Kyriakides, 2008; Harris and Chrispeels, 2006; Hopkins, 2005; Scheerens and Bosker, 1997). Even more notably, research suggests that supportive teacher-student interactions, good student-student relationships, and the strong focus on student learning that characterises schools with a positive disciplinary climate are particularly beneficial to disadvantaged students (Cheema and Kitsantas, 2014; Murray and Malmgren, 2005).

Good student-student relationships are an important factor in creating a positive school climate. However, many vulnerable children and adolescents, including those who are poor or from ethnic, linguistic or cultural minorities, or are from migrant or refugee communities, or have disabilities, are at higher risk of school violence and bullying (UNESCO, 2017). The social costs of bullying are high: bullied children face a greater risk of poor health, internalised stress, and suicidal thoughts (United Nations, 2016). Bullying of immigrant children is particularly problematic as immigrants often experience several layers of disadvantage (Caulfield et al, 2005; Elame, 2013; Mühlenweg, 2010; Ponzo, 2013). "Immigrant bullying" has been defined as "bullying that targets another's immigrant status or family history of immigration in the form of taunts and slurs, derogatory references to the immigration process, physical aggression, social manipulation or exclusion because of immigration status" (UNESCO, 2017). A number of countries have introduced policies to combat bullying of all children, though some countries have specific immigrant-related strategies.

\section{Examples of policies that promote a bully-free environment}

In Ireland, the National Action Plan on Bullying (2013) promotes the development of school policies, including strategies to combat bullying. The plan was informed by consultations with children and young people, who emphasised prevention, including the need for: all members of the school community to understand the various manifestations and consequences of bullying; schools to tackle the underlying causes of bullying by promoting a culture of respect for the dignity of every person; and children and young people to learn about and value diversity. The plan also called for new national anti-bullying procedures for schools, support for training of school administrators and parents, and the creation of a positive school culture to tackle bullying22 (United Nations, 2016). 
In Ontario, Canada, the Comprehensive Action Plan for Accepting Schools includes legislation and resources on bullying prevention and intervention, while the Equity and Inclusive Education Strategy identifies discriminatory biases and systemic barriers to student achievement, promotes the participation of parents in their children's education and in supporting safe and inclusive schools, and provides counselling and guidance on Internet safety. ${ }^{23}$

In Mexico, in 2014, the Convivencia sin violencia campaign was introduced to bring attention to bullying in schools and to promote peaceful social interaction. The campaign included an anti-bullying initiative, Proyecto a favor de la convivencia escolar, through which the education community, including parents, students and civil society actors, were given access to resources and recommendations on how to support and protect children both within and outside of school. The initiative advances the peaceful resolution of conflict, self-control and the development of coping abilities (UNESCO, 2017).

In France, bullying prevention has been a priority for the Ministry of National Education. Students are offered training and support and are informed of available services, while the responsibilities of school administration are clearly identified. An Internet site sets out national policies and programmes for the general public (Agir contre le harcèlement à l'École"24).

In Sweden, the Education Act (2010) identifies measures that schools must take to prevent bullying and highlights their responsibility to investigate and take appropriate measures against degrading treatment. It also requires that schools report and investigate all alleged incidents of bullying and have an annual plan to prevent and address it (United Nations, 2016).

In Portugal, the Directorate General for Schools is partnering with Public Security Police and the PINProgressive Children's Clinic in a pilot project to analyse the phenomenon of bullying through innovative management of cases of young people with at-risk behaviour or who seriously violate students' rights. Although bullying is used to define aggressions, physical or psychological, with characteristics of increasing continuity and intensity, it also often includes cases of racism and intolerance (Ministry of Education, Portugal).

\section{Evidence on the availability of and participation in extracurricular activities}

Chapter 7 has highlighted that allocating resources to after-school activities can make a difference in helping immigrant students integrate better. Extracurricular activities include any organised social, artistic or physical activities for school-aged youth that occur during out-of-school time, usually before or after school or during the summer. But schools are not the only venues where after-school activities take place; these activities are also often provided by communities or religious organisations.

There is strong evidence that extracurricular activities increase students' self-esteem and positive social behaviours (Durlak et al., 2010). They can also be a vehicle for strengthening social support systems, developing social skills and relationships, and enhancing neighbourhood cohesion (Macomber and Moore, 1999). There are a variety of these types of activities and programmes, and some are more effective than others (Farb and Matjasko, 2012). Creative extracurricular activities, such as music, dance, drama and the visual arts can increase participants' self-confidence, self-esteem and positive behaviours (Bungay and Vella-Burrows, 2013). After-school activities appear to improve immigrant high school students' sense of belonging, motivation and academic achievement (Camacho, 2015).

Extracurricular activities with academic components can also help students modestly improve their grades, test scores and academic proficiency (Bodilly and Beckett, 2005; Durlak et al.; Farb and Matjasko, 2012; Grogan, Henrich and Malikina, 2014; Leos-Urbel, 2015; Vandell, 2013).

While extracurricular activities have mainly positive benefits for every student, they can be particularly beneficial for students with learning disabilities and from disadvantaged backgrounds. Through such activities, these students might assume leadership roles and demonstrate talents in ways that that might not be available to them in traditional classroom settings. Extracurricular activities might also allow students to meet and make friends with peers from different cultural and socio-economic backgrounds (Moody, 2001). 
One after-school activity that can be particularly beneficial for immigrant students is sports. There is a growing literature on the benefits of sports for individuals, including better health and social skills (see Heckman, Stixrud and Urzua, 2006; Keogh, 2002; Morgan, 2008; UNHCR, 2008). Sporting environments can offer equal opportunities and promote racial equality among those involved, allowing immigrants to maintain their cultural identity while integrating into the host-country society (Iwasaki and Bartlett, 2006). By participating in leisure activities with native populations, immigrants can learn about local customs and culture, and interact with native peers (Makarova and Herzog, 2014, Garibaldi, 2017). This, in turn, can improve the way immigrants relate to natives and create positive social bonds (Toyoda, 2012). Sports can also provide "a sense of purpose and direction for young people recovering from the traumas of the refugee experience or the impact of racism" (Dykes and Olliff, 2007: 1). Sport also offers an opportunity for social interaction, and a way for non-English speakers to learn and practise English; and it can promote ethnic and cultural harmony and strengthen communities (Allen et al., 2010; Olliff, 2007).

\section{Examples of practices to encourage participation in sports and extracurricular activities}

Communities have developed a variety of ways to promote sporting activities among immigrants. For example, the German Football League (DFL) started a "Willkommen im Fußball" (Welcome to Football) initiative in 2015, leading to 24 of the country's professional clubs launching similar schemes (e.g. Werder Bremen's "Bleib am Ball" (Stay on the Ball) project and Bayer Leverkusen's "Bayer 04 macht Schule" (Bayer 04 does school project). Around 65 training sessions involving about 800 refugees aged between 4 and 30 take place in Germany every week, and around 600 of these participants have begun playing in amateur leagues. In conjunction with the local amateur side TSC Eintracht Dortmund, and with funding from the DFL and the German Children and Youth Foundation, the Bundesliga club's BVB Foundation has helped to create a project that allows a group of refugees aged between 18 and 20 to attend a weekly training session at the stadium, where they also receive a free meal before training and a German lesson afterwards. Students from refugee communities attending local schools are rewarded for good behaviour with a year-long place in the course, and organisers also help find them jobs and university places afterwards. In addition to providing coaching and equipment, Dortmund gives away free tickets for their matches (Aarons, 2017).

At the EU level, the "European Sport Inclusion Network (ESPIN): Promoting Equal Opportunities of Migrants and Minorities through Volunteering in Sport" involves those who are at risk of social exclusion. Equal access to organised sport is promoted among disadvantaged groups. ${ }^{25}$ Another example is the "MATCH MigrAtion and SporTs - a CHallenge for Sports Associations and Trainers". ${ }^{26}$ This is a partnership among five countries, targeting sports associations and focused on the theme of integrating migrants through sports. The project collects and disseminates good practice examples. One of them is the multicultural sports festival "Let's play", in Alto Adige, a region in northern Italy. This festival, a sporting competition in which local and migrants participate together, is organised every year by the non-profit association OEWOrganizzazione per Un mondo solidale in Bressanone.

\section{The role of parent engagement}

As Chapter 7 has shown, parents' engagement is crucial for good academic, and social and emotional outcomes of students with an immigrant background. Numerous other studies indicate that students are better learners when their parents are involved in their education (Desforges and Abouchaar, 2003; Fan and Chen, 2001; Jeynes, 2007; OECD, 2012a; Schofield, 2006). Therefore it is important that parents can communicate with teachers, and get to know their children's teachers and friends. Several studies examine factors that can promote or hinder immigrant parents' engagement with the education of their children (Bouakaz, 2007; Bouakaz and Persson, 2007; Crul et al., 2017, Fibbi and Truong, 2015). Whatever the parents' educational background, parents who are able to provide strategic direction, show support for their children's education, and value education can help their children's integration into the host-country school system and promote a climate at school and at home that supports their academic, social and emotional development. Schools and teachers that offer information to parents, meet with them regularly and seek to understand students' backgrounds can also encourage parents' engagement. 
Visiting homes, recruiting culturally appropriate and trained specialists, providing learning resources and information to families, launching awareness campaigns, and training teachers and staff to work with culturally and linguistically diverse children are all ways that education systems can support immigrant parents in their efforts to help their children succeed (OECD, 2014).

\section{Examples of policies and practices that promote parent engagement}

Many countries have developed policies to support parents as their children move from pre-primary to primary school. For example, Australia, Austria, New Zealand, Norway and Wales have implemented a number of strategies to encourage parents from disadvantaged households to support their children as they transition from early childhood education into primary schools (OECD, 2017b).

The Parent-Child Home Programme ${ }^{27}$ in the United States is an early-childhood literacy, parenting and school-readiness programme. It provides two years of twice-weekly visits to families with children between the ages of 16 months and 4 years who are living in poverty or isolation, have limited opportunities for education and poor language and literacy skills, and/or are confronted with other obstacles to healthy development and success in education. The programme employs early literacy specialists from the community they serve, sharing both the language and culture of the families with whom they work. In addition to leading weekly activities to stimulate parent-child interactions and help the child learn English, the specialist also connects the families to other community resources, such as health and medical facilities, and other education programmes. On completion of the programme, families are assisted in enrolling their child in a centre-based, pre-school programme (OECD, 2015a).

Another example of an effective way to engage marginalised parents in early childhood education is the HIPPY 28 (Home Instruction for Parents of Preschool Youngsters) programme, which operates in 10 countries spanning 5 continents. The programme is designed especially for those parents who may not feel comfortable in their own abilities to support their children's (pre-primary) education. Similar initiatives are found in Germany, the Netherlands and Switzerland. HIPPY has gained recognition as an efficient method for raising families' awareness of their potential as educators. Once a week the family is visited by trained peers from the same socio-cultural background who provide first-language assistance and learning activities for children. The visitor acquaints parents with games and learning materials in their mother tongue. Parents are also encouraged to create learning situations for their own child. Several research studies have shown positive results both for children and families alike (Gomby, 2005).

Some programmes aim specifically to involve immigrant parents in their children's education. One of them is Berlin's (Germany) "Neighbourhood mothers" programme, through which immigrant mothers are trained to act as contact and resource persons for families and particularly other women in the neighbourhood (for instance by working in schools or by visiting families in their homes). ${ }^{29}$ It resembles similar programmes in Denmark and the Netherlands (Herzog-Punzenberger, Le Pichon-Vorstman and Siarova, 2017).

In Norway, the Multicultural Initiative and Resource Network, a volunteer organisation, recognises parents as resources for student learning. This network works for bilingual parents who wish to co-operate with the school and who will and can take responsibility for their child's learning. The agency also works to make parents more aware of their role in relation to the Norwegian school system, to society and to their own children (National Centre for Multicultural Education, 2010). ${ }^{30}$

Australia also implements measures to support immigrant parents and communities. For instance, in Queensland, intensive English-language courses are offered in consultation with parents ${ }^{31}$ as the government has committed to improving the engagement of migrant and refugee communities in education. The New South Wales Department of Education offers Community Information Officers to help schools strengthen links with parents and community members from diverse cultural and linguistic backgrounds. The department also offers a specific programme for Youth Partnerships with Pacific Communities that includes parent/school partnerships and homework support ${ }^{32}$ (MIPEX, 2015). 


\section{The role of diversity-aware teachers for supporting all learners}

All efforts to integrate children with an immigrant background depend on well-skilled and well-supported teachers who take into account the diversity of their student populations in their instructional approaches and who can help all students to achieve. Teachers are often ill-prepared in pedagogical approaches for second-language learning or in recognising and helping children overcome the effects of trauma that many immigrant children endure (OECD, 2015a).

Table 9.4 shows the difference between native and immigrant students in the extent to which immigrant students are more likely to receive feedback from their science teachers (after accounting for their PISA science score) and the extent to which immigrant students are more likely than native students to perceive that their teachers treat them unfairly. In countries and economies in the top left quadrant (Costa Rica, Finland, Lithuania, Macao [China], Norway and Singapore), immigrant students appear to be relatively well-supported by their teachers: they reported receiving additional feedback compared to native students and reported being treated fairly by their teachers. Immigrant students in countries and economies in the bottom right quadrant (Brazil, Croatia, the Netherlands and Turkey) reported receiving little additional feedback from their teachers compared to native students, and reported feeling that they are treated unfairly by their teachers. These countries might consider implementing policies that support teacher-training initiatives designed to improve teachers' ability to support and assist immigrant students. In countries listed in the top right quadrant (Belgium, Denmark, the Slovak Republic and Sweden), teachers appear to be aware of the importance of supporting immigrant students, since immigrant students in these countries reported receiving more feedback than native students. But teachers in these countries appear to need additional training in how to provide assistance to these students without stigmatising them.

\section{Table 9.4 - Interaction between feedback and perceived unfair treatment by teachers}

\begin{tabular}{l|c|c|c}
\hline & $\begin{array}{c}\text { Small gap in perceived unfair } \\
\text { treatment (immigrant - native) }\end{array}$ & Average & $\begin{array}{c}\text { Large gap in perceived unfair } \\
\text { treatment (immigrant - native) }\end{array}$ \\
\hline $\begin{array}{l}\text { Large gap in feedback } \\
\text { (immigrant - native) }\end{array}$ & $\begin{array}{c}\text { Costa Rica, Finland, Lithuania, } \\
\text { Macao (China), Norway, } \\
\text { Singapore }\end{array}$ & $\begin{array}{c}\text { Chile, Estonia, Luxembourg, } \\
\text { Slovenia }\end{array}$ & $\begin{array}{c}\text { Belgium, Denmark, } \\
\text { Slovak Republic, Sweden }\end{array}$ \\
\hline Average & Austria, Mexico, Portugal & $\begin{array}{c}\text { Czech Republic, Ireland, } \\
\text { United Kingdom, United States }\end{array}$ & $\begin{array}{c}\text { Austria, Dominican Republic, } \\
\text { Germany, Mexico, Portugal, } \\
\text { Switzerland, Tunisia }\end{array}$ \\
\hline $\begin{array}{l}\text { Small gap in feedback } \\
\text { (immigrant - native) }\end{array}$ & $\begin{array}{c}\text { Beijing-Shanghai-Jiangsu- } \\
\text { Guangdong (China), Bulgaria, } \\
\text { Hong Kong (China), Montenegro, } \\
\text { Russia, Spain }\end{array}$ & $\begin{array}{c}\text { Colombia, Greece, Hungary, } \\
\text { Iceland, Latvia, Thailand }\end{array}$ & $\begin{array}{c}\text { Brazil, Croatia, Netherlands, } \\
\text { Turkey }\end{array}$ \\
\hline
\end{tabular}

Notes: Dimension 1 (rows) sorts countries based on the difference in the percentage of immigrant and native students who reported receiving frequent feedback from their science teacher, after accounting for their science performance. Immigrant students tended to report more frequent feedback, so a large gap favours immigrant students.

Dimension 2 (columns) sorts countries based on the difference in the percentage of immigrant and native students who reported frequent unfair treatment by their teachers. Immigrant students were more likely to report unfair treatment, which is a "negative" outcome.

Students who reported frequent unfair treatment by their teachers are those who answered "a few times a month" or "once a week or more" to at least one of the question of how often, during the previous 12 months: "Teachers called me less often than they called on other students"; "Teachers graded me harder than they graded other students"; "Teachers gave me the impression that they think I am less smart than I really am"; "Teachers disciplined me more harshly than other students"; "Teachers ridiculed me in front of others"; and "Teachers said something insulting me in front of others".

Students who reported receiving frequent feedback from their science teacher are those who answered "many lessons" or "every lesson or almost every lesson" to at least one of the questions about how often: "The teacher tells me how I am performing in this course"; "The teacher gives me feedback on my strength in this subject"; "The teacher tells me in which areas I can improve"; "The teacher tells me how I can improve my performance"; and "The teacher advises me on how to reach my learning goals".

Source: OECD, PISA 2015 Database.

\section{Examples of policies and practices for building a diversity-aware teaching force}

All teachers could benefit from training to teach children who do not speak the language of instruction and to address cultural diversity within their teaching. This could include intercultural training and training for different learner needs (European Commission, 2015). For example, in the French Community of Belgium, intercultural education has been part of teacher training since 2000, and includes pre-service training for teaching in culturally diverse classrooms and awareness of ethnic/social discrimination for all teacher candidates. Professional-development training on diversity is also offered for all teachers (MIPEX, 2015). 
In New Zealand, pre-service training is required in order to qualify as a teacher. The standards make specific reference to the need for teachers to develop intercultural competence. They also require graduating teachers to have knowledge of the Maori culture and language so they can work effectively in the bicultural contexts of Aotearoa New Zealand. In-service training is provided through teachers' centres and/or through postgraduate courses at universities across the country (MIPEX, 2015).

In the Netherlands, an understanding of cultural diversity is also a prerequisite for qualification as a teacher. The Requirements for Teaching Staff Act also specifies and requires ongoing development of all competencies, including cultural understanding (MIPEX, 2015).

Teachers might also benefit from learning about the needs specific to immigrants. For example, in Norway, the government introduced a five-year plan in 2013 to improve multicultural competence among teachers and kindergarten staff. The efforts are focused on multicultural pedagogy, multilingualism, second-language teaching and adult education. The programme aims to cover 600 schools during the five-year period (MIPEX, 2015).

All teachers in Victoria, Australia, are required to register with the Victorian Institute of Teaching (VIT). To qualify for registration, an applicant must have completed an appropriate four years of tertiary education in primary or secondary school teaching, or relevant industrial experience, and have completed an approved course of teacher education. For English-as-a-second language teachers, an additional requirement is needed (the ISLPR Test, which is a language test to measure a person's proficiency in English and other languages). Teachers could be encouraged to participate in professional development activities in order to maintain their registration, which is renewed every five years. This is also required to renew their certificate and to acquire knowledge and practice with the relevant VIT standards. Standards at the Proficient Teacher level expressly require skills to work with students from diverse linguistic, cultural, religious and socio-economic backgrounds. This standard is also evident in the Australian Professional Standards for Teachers (MIPEX, 2015).

Initial teacher education in the United Kingdom focuses on standards including those on equality and diversity. There is an expectation that trainee teachers will understand issues of diversity and be able to work with those students for whom English is not their mother tongue. Standards for serving teachers also address diversity, and if teachers wish to progress in their career they must excel in these areas. However, there is a variety of constraints on standards for existing teachers to the extent that these specific standards might not be targeted as explicitly as they are in initial teacher education (MIPEX, 2015). ${ }^{33}$

To understand and teach immigrant students effectively, it is helpful for teachers to learn how to teach students with different mother tongues. Various methods are taught in teacher training (for an overview, see European Commission, 2017), including language-sensitive teaching. In this approach, teachers learn to become aware of the language dimension of teaching and learning content in their subject, and to acquire teaching strategies and techniques which link language to curriculum content and academic standards (Beacco et al., 2015: 99).

One example is the "Step Together" project in Hungary, which developed content-based language-teaching material to assist primary school teachers in teaching children who do not speak the host-country language. The material covers four areas of the national core curriculum with the aim of building language skills by learning content related to topics covered in the wider curriculum throughout the school year (European Commission, 2015).

\section{Evidence on mentoring schemes}

While not explicitly discussed in the previous chapters, mentoring can provide additional, nonprofessional support to students with an immigrant background and thus improve their well-being. Mentors can be teachers, other school personnel or peers. Evidence indicates that mentoring relationships, especially those characterised by closeness and continuity, promote resilience and enhance psychological well-being among youth (DuBois and Silverthorn, 2005). There is evidence that young people from disadvantaged backgrounds, among which students with an immigrant background are over-represented, benefit the most from participating in mentoring programmes (DuBois et al, 2002; Rotich, 2011). 
Mentoring can be especially beneficial for newly arrived immigrant students. Mentors can help facilitate the integration of these students into the host community, as they can offer opportunities to acquire or improve local language skills, and can help connect youth to resources, such as public transportation, the local library, and other programmes (Birman and Morland, 2014, Suárez-Orozco and Suárez-Orozco, 2001). Through such programmes, immigrant youth can build connections with caring adults who can encourage them in their studies and provide information about the school and higher-education system (Oberoi, 2016). Peer mentors can also help immigrant students feel welcomed and "learn the ropes" in the school they attend. Mentoring can also play an important role in developing the types of positive social relations with teachers and peers that research suggests can nurture students' engagement and sense of belonging at school (Oberoi, 2016).

According to the Network of Experts in Social Sciences of Education and Training (NESSE, 2008) and Crul and Kraal (2004), the success of mentoring rests on how well mentors have been trained, the extent of schools' co-operation, and the engagement of parents and children. Mentors are often from the same cultural background as the mentee, so they can use their mother tongue to communicate knowledge about the school and the education system, as well as help immigrant students learn the host-country language.

\section{Examples of practices aimed to promote mentoring}

Most mentoring initiatives aim to help children from minority groups "catch up" with their peers, but they can also promote linguistic diversity (Herzog-Punzenberger, Le Pichon-Vorstman and Siarova, 2017). For example, the (peer) mentoring initiative in Hamburg, Germany, Junge Vorbilder (Young Role Models), targets students in grades 8 to 11 (lower secondary school) with an immigrant background. Mentors are university students who come from immigrant backgrounds and often share similar cultural and linguistic heritage and school experience as their mentees (European Commission, 2015). Mentoring is conducted at the homes of the mentees so that mentors can learn about their mentee's family environment and develop a good relationship with their parents. Mentoring consists of tutoring, social and emotional support, and educational and vocational orientation. ${ }^{34}$

Another example is Nightingale Mentoring, ${ }^{35}$ which operates in Austria, Finland, Germany, Iceland, Norway, Spain, Sweden, Switzerland and Uganda. Begun in Malmö, Sweden, in 1997, it seeks to recruit students from cultures and societies where there is little or no tradition of children being involved in higher education. The mentor gives the child a positive role model by establishing a personal relationship with the mentee child. This in turn helps strengthen the child's personal and social confidence. The goal is that the child will perform better in school and will be more likely to apply for university when the time comes. The concept is based on the idea of "mutual benefit" for the child and student (HerzogPunzengerger, Le Pichon-Vorstman and Siarova, 2017).

\section{Monitoring progress}

Information on students' background characteristics, sources of vulnerability and well-being outcomes is crucial if education systems are to be able to help these students develop academically, socially and emotionally and overcome the adversities related to their immigrant background. Collecting relevant data is key to ensure that schools support these students; monitoring their progress through schooling helps to build a body of good practices and avoid repeating mistakes. Because of sensitivities associated with collecting highly personal information, many countries do not collect relevant data, or if they collect such data, they do not publish aggregated findings which makes it difficult to monitor progress and learn from experience. While identifying different groups of students with an immigrant background and evaluating their academic, social, emotional and motivational well-being is important for targeting initiatives to strengthen these students' resilience, monitoring strategies could be perceived as stigmatising by some students and families if they are not implemented with sensitivity (OECD, 2015a).

\section{Examples of monitoring policies}

Monitoring the quality and impact of pre-primary education is not a well-developed practice across OECD countries. Monitoring processes tend to focus more on compliance with regulations than on the quality of service or assessing how well children's needs are being identified and met (OECD, 2015d). However, a few OECD countries have developed systems to benchmark and monitor children's progress, including 
children from different socio-economic and ethnic groups. Some countries use school-entry tests as a means to focus on child development and to provide information on how young children are progressing. Australia, for example, uses a national adaptation of the Early Development Instrument (EDI). The EDI, originally developed in Ontario, Canada, is a measure of children's development as they enter school. Teachers complete a checklist measuring children's physical health and well-being, social competence, emotional maturity, language and cognitive skills, and communication skills and general knowledge. The results are aggregated to the group level (school, neighbourhood and city) to provide a populationbased measure of children's development (OECD, 2015d). Another example is the Estonian Education Information System (EHIS), which records data of students' mother tongue and tracks progress through education. This data can be integrated with the census to track years of residence and generations (MIPEX, 2015).

The Finnish system disaggregates immigrants into a sub-group, "foreign-language students", and foreignlanguage students by age (statistics that are publicly available). For upper secondary education, vocational education, polytechnics and universities, the system disaggregates students into subgroups by mother tongue, nationality and country of origin (statistics are public although covered by privacy protection) (MIPEX, 2015).

The Primary School Information System (GSI) in Norway provides statistics about students, including language minorities. The data includes gender, age and language (not country of origin). Publicly available statistics on upper secondary students do not separate out language minorities, but the directorate does publish annual reports including statistics that are related to minority education issues (MIPEX, 2015).

In the United States, the No Child Left Behind (NCLB) act mandates disaggregated assessment results for protected groups: limited English proficiency, black, Hispanic, Asian, low income, and special education. States can define the number that constitutes a group for reporting purposes. However, no information on country of birth is provided. This monitoring is conducted within the NCLB Waiver programme that applies to the vast majority of US states (MIPEX, 2015). ${ }^{36}$

In Italy, a national observatory for the integration of foreign students and intercultural education was created in 2006. Since 2005, an annual statistical study on the presence of migrant students, based on reports from regional education authorities, is published by the ministry of education. The system disaggregates immigrant students by country of origin (MIPEX, 2015). 


\section{Notes}

1. See www.healthinschools.org/caring-across-communities/childrens-hospital-boston/.

2. See www.healthinschools.org/Immigrant-and-Refugee-Children/Caring-Across-Communities/NYU.

3. See www.healthinschools.org/Immigrant-and-Refugee-Children/Caring-Across-Communities/World-Relief-Chicago.

4. See www.dge.mec.pt/selo-escola-intercultural.

5. See www.jobstarter.de/de/kausa-21.php.

6. See www.netzwerk-iq.de/.

7. See www.deewr.gov.au/Pages/DepartmentSites.aspx.

8. See www.komposyt.sk/pre-odbornikov/ziak-so-svvp/integracia-ziaka-so-svvp/dokumnetacia/preview-file/het-centrumvoor-leerlingenbegeleiding-docx_nl-nl_en-gb-3-767.pdf.

9. See www.det.nsw.edu.au/home; www.education.vic.gov.au/default.htm.

10. See https:// sprach-kitas.fruehe-chancen.de/programm/ueber-das-programm.

11. See www.curriculumonline.ie/Primary/Curriculum-Areas/Language-New-Junior-infants-2nd-class/Language-Home/ Introduction/(ii)-Using-the-Curriculum-and-Toolkit.

12. See http://nzcurriculum.tki.org.nz/System-of-support-incl.-PLD/Leamer-initiated-supports/ESOL-funding-and-MoE-support.

13. See http://dge.mec.pt/portugues-lingua-nao-materna.

14. See www.regjeringen.no/globalassets/upload/KD/Vedlegg/Grunnskole/Strategiplaner/Likeverdig_ENG_nett.pdf.

15. See https://bimm.at/.

16. See www.ed.gov.nl.ca/edu/k12/curriculum/guides/esl/index.html.

17. See www.ancnl.ca/?Content=SWIS/Homework_Club.

18. See www.sharingourcultures.com/cultural-contxt/.

19. See www.schoolinzicht.be.

20. See www.dge.mec.pt/teip.

21. See www.quims.ch/.

22. See www.education.ie/en/Publications/Education-Reports/Action-Plan-On-Bullying-2013.pdf.

23. See www.edu.gov.on.ca/eng/safeschools/SafeAccepSchools.pdf.

24. See www.education.gouv.fr/cid86060/agir-contre-le-harcelement-a-l-ecole.html.

25. See www.sportinclusion.net/.

26. See www.match-eu.at.

27. See www.parent-child.org/.

28. See http://hippy-international.org/.

29. See http://policytransfer.metropolis.org/case-studies/neighbourhood-mothers.

30. See www.mimett.org/pub/.

31. See http://education.qld.gov.au/multicultural/pdfs/qld-multicultural-action-plan-08-11.pdf.

32. See www.schools.nsw.edu.au/learning/yrk12focusareas/ccbuilding/clresources.php.

33. See www.rbkc.gov.uk/pdf/standards_core.pdf.

34. See www.verikom.de/bildung/junge_vorbilder/.

35. See http://nightingalementoring.org/.

36. See www2.ed.gov/policy/eseaflex/secretary-letters/cssorenewalltr.html.

\section{References}

Aarons, E. (2017), "Welcome to football: how Borussia Dortmund help give refugees hope", The Guardian, www.theguardian. com/football/2017/dec/05/borussia-dortmund-refugees-bundesliga-german-football-league.

Agasisti, T. and J.M. Cordero (2017), “The determinants of repetition rates in Europe: Early skills or subsequent parents' help?", Journal of Policy Modeling, Vol. 39/1, pp. 129-146, https://doi.org/10.1016/j.jpolmod.2016.07.002.

Akgunduz, Y. and S.M.M. Heijnen (2016), "Impact of funding targeted preschool interventions on school readiness: evidence from the Netherlands", CPB Discussion Paper 328. 
Allen, et al. (2010), "Sport as a vehicle for socialisation and maintenance of cultural identity: international students attending American universities”, Sport Management Review, Vol. 13/4, pp. 421-434, https://doi.org/10.1016/j.smr.2010.01.004.

Ammermüller, A. (2005), "Educational Opportunities and the Role of Institutions", Zentrum fur Europäische Wirtschaftsforschung Discussion Paper No. 5-44, Mannheim.

Bauern, P. and R. Riphahn (2006), "Timing of school tracking as a determinant of intergenerational transmission of education", Economics Letters, Vol. 91/1, pp. 90-97.

Beacco, J. et al. (2015), "The Language Dimension in All Subjects”, in A Handbook for Curriculum Development and Teacher Training, Council of Europe Publishing, Strasbourg.

Bilgili, Ö. (2017), “The “CHARM” Policy Analysis Framework: Evaluation of Policies to Promote Immigrant Students' Resilience”, OECD Education Working Papers, No. 158, OECD Publishing, Paris, http://dx.doi.org/10.1787/164a7643-en.

Birman, D. and L. Morland (2014), "Immigrant and refugee children", in D.L. DuBois and M.J. Karcher (eds.), Handbook of Youth Mentoring (2nd ed.), pp. 355-368, SAGE, Thousand Oaks, CA.

Bodilly, S. and M. Beckett (2005), Making Out-of-School-Time Matter: Evidence for an Action Agenda, Prepared for the Wallace Foundation, RAND Corporation, Santa Monica.

Bouakaz, L. (2007), Parental involvement in school: What promotes and what hinders parental involvement in an urban school, Doctoral dissertation, Malmö Studies in Educational Sciences.

Bouakaz, L. and S. Persson (2007), "What hinders and what motivates parents' engagement in school?", International Journal about Parents in Education Vol.1, pp. 97-107.

Breen, R. and J. Jonsson (2005), "Explaining change in social fluidity: educational equalization and educational explanation in twentieth-century Sweden”, American Journal of Sociology, Vol. 112/6, pp. 1775-1810.

Brunello, G. and D. Checchi (2007), "Does school tracking affect equality of opportunity? New international evidence", Economic Policy, Vol. 22/52, pp. 781-861.

Brunello, G. and M. De Paola (2017), "School segregation of immigrants and its effects on educational outcomes in Europe”, EENEE Analytical Report No. 30, prepared for the European Commission.

Bunar, N. (2017), "Migration and education in Sweden: integration of migrants in the Swedish school education and higher education systems", NESET II ad hoc question No. 3/2017.

Bungay, H. and T. Vella-Burrows (2013), "The effects of participating in creative activities on the health and well-being of children and young people: a rapid review of the literature", Perspectives on Public Health, Vol. 133/1, pp. 44-52.

Camacho D.E. and A.J. Fuligni (2015), "Extracurricular participation among adolescents from immigrant families", Empirical Research, Vol. 44/6, pp. 1251-1262.

Caulfield, C., M. Hill and A.S. Shelton (2005), The Transition to Secondary School: The Experiences of Black and Minority Ethnic Young People, Glasgow Anti Racist Alliance, Glasgow.

Cheema, J. R. and A. Kitsantas (2014), "Influences of disciplinary classroom climate on high school student self-efficacy and mathematics: A look at gender and racial-ethnic differences", International Journal of Science and Mathematics Education, Vol. 12, pp. 1261-1279.

Collier, V. and W. Thomas (2007), "Predicting second language academic success in English using the prism model", in J. Cummins and C. Davison (eds.), International Handbook of English Language Teaching, Springer, pp. 333-348.

Council of Europe, Language Policy Unit (2015), The Language Dimension in all Subjects - A Handbook for Curriculum Development and Teacher Training, Council of Europe, Strasbourg.

Creemers, B.P.M. and L. Kyriakides (2008), "Using a multidimensional approach to measure the impact of classroomlevel factors upon student achievement: a study testing the validity of the dynamic model", School Effectiveness and School Improvement, Vol. 19/2, pp. 183-205.

Crosnoe, R. (2013), Preparing the Children of Immigrants for Early Academic Success, Migration Policy Institute, Washington, DC.

Crul, M. (2015), "Is education the pathway to success? A comparison of second generation Turkish professionals in Sweden, France, Germany and The Netherlands", European Journal of Education, Vol. 50/3, pp. 325-339.

Crul, M. and K. Kraal (2004), Evaluatie Landelijk Ondersteuningsprogramma Mentoring, University of Amsterdam Report, https://pure.uva.nl/ws/files/3596443/56846_228380.pdf.

Crul, M. and H. Vermeulen (2006), "Immigration and education. The second generation in Europe", in T. Smeeding and C. Parsons (eds.), Immigration and the Transformation of Europe, Cambridge University Press, Cambridge. 
Crul, M. et al. (2017), "The multiplier effect: how the accumulation of cultural and social capital explains steep upward social mobility of children of low-educated immigrants", Ethnic and Racial Studies, Vol. 40/2, pp. 321-338.

Crul, M. et al. (2016), "No lost generation: education for refugee children, a comparison between Sweden, Germany, the Netherlands and Turkey”, European University Institute Paper.

Cummins, J. (2000), Language, Power and Pedagogy: Bilingual Children in the Crossfire, Multilingual Matters, Clevedon.

Desforges, C. and A. Abouchaar. (2003), "The Impact of Parental Involvement, Parental Support and Family Education on Pupil Achievements and Adjustment: A Literature Review”, Research Report No. 433, Department for Education and Skills, London.

DuBois, D.L. and N. Silverthorn (2005), "Characteristics of natural mentoring relationships and adolescent adjustment: Evidence from a national study", The Journal of Primary Prevention, Vol. 26/2, pp. 69-92, http://dx.doi.org/10.1007/s10935005-1832-4.

DuBois, D.L. et al. (2002), "Effectiveness of mentoring programs for youth: A meta-analytic review", American Journal of Community Psychology, Vol. 30/2, pp. 157-197, https://doi.org/10.1023/A:1014628810714.

Durlak, J., R. Weissbergand and M. Pachan (2010), "A meta-analysis of after-school programmes that seek to promote personal and social skills in children and adolescents" American Journal of Community Psychology, Vol. 45, pp. 294-309.

Dykes, J. and L. Olliff (2007), "Sport and Recreation as a Tool for Social Inclusion: The Experiences of Refugee and Migrant Young People”, Centre for Multicultural Youth Issues, Melbourne.

Elame, E. (2013), Discriminatory Bullying: A New Intercultural Challenge, Springer, Milan.

Ellis, B.H. et al. (2012), "Multi-tier mental health program for refugee youth", Journal of Consulting and Clinical Psychology, Vol. 81/1, pp. 129-140, http://dx.doi.org/10.1037/a0029844.

Entorf, H. and M. Lauk (2008), "Peer effects, social multipliers and migrants at school: an international comparison", Journal of Ethnic and Migration Studies, Vol. 34, pp. 633-654.

European Commission (2018), "Initiatives promoting social inclusion and raising awareness: Portugal", EACEA National Policies Platform, https://eacea.ec.europa.eu/national-policies/en/content/youthwiki/45-initiatives-promoting-social-inclusionand-raising-awareness-portugal.

European Commission (2017), Migrants in European Schools: Thematic Report from a Programme of Expert Workshops and Peer Learning Activities, Publication office of the European Union, Luxembourg.

European Commission (2015), Language Teaching and Learning in Multilingual Classrooms, Publications office of the European Union, Luxembourg, http://ec.europa.eu/dgs/education_culture/repository/languages/library/studies/multilingual-classroom _en.pdf.

European Commission (2013a), Study on Educational Support for Newly Arrived Migrant Children. Final Report, Publication Office of the European Union, Luxembourg, http://dx.doi.org/10.2766/41204.

European Commission (2013b), Reducing Early School Leaving: Key Messages and Policy Support, Final Report of the Thematic Working Group on Early School Leaving, Publication Office of the European Union, Luxembourg.

Fan, X. and M. Chen (2001), "Parental involvement and students' academic achievement: A meta-analysis", Educational Psychology Review, Vol. 13/1, pp. 1-22.

Farb, A. and J. Matjasko (2012), "Recent advances in research on school-based extracurricular activities and adolescent development”, Developmental Review, Vol. 32/1, pp. 1-48.

Fibbi, R. and J. Truong (2015), "Parental involvement and educational success in Kosovar families in Switzerland”, Journal of Comparative Migration Studies, Vol. 3/1, pp. 1-17.

Field, S., M. Kuczera and B. Pont (2007), No More Failures: Ten Steps to Equity in Education, Education and Training Policy, OECD Publishing, Paris, http://dx.doi.org/10.1787/9789264032606-en.

Garibaldi, E. (2017), The role of sports for the integration of immigrant students, Master's thesis, Bocconi University, unpublished.

Gomby, D. (2005), "Home visitation in 2005: outcomes for children and parents", Invest in Kids Working Paper No. 7, Committee for Economic Development, Washington, DC.

Gomolla, M. (2006), "Tackling the underachievement of learners from ethnic minorities: A comparison of recent policies of school improvement in Germany, England and Switzerland”, Current Issues in Comparative Education, Vol. 9/1, pp. 46-59.

Godwin, R.K. et al. (2006), "Sinking Swann: Public school choice and the resegregation of Charlotte's public schools", Review of Policy Research, Vol. 23/5, pp. 983-997. 
Greenwald, R., L.V. Hedges and R.D. Laine (1996), "The effect of school resources on student achievement”, Review of Educational Research, Vol. 66/3, pp. 361-396, http://dx.doi.org/10.3102/00346543066003361.

Grogan, K., C. Henrich and M. Malikina (2014), "Student engagement in after-school programmes, academic skills and social competence among elementary school students", Child Development Research, Article ID 498506, http://dx.doi. org/10.1155/2014/498506.

Hall, D. et al. (2012), Assessing the Needs of Bilingual Pupils: Living in Two Languages, Routledge, Abingdon.

Harris, A. and J.H. Chrispeels (eds.) (2006), Improving Schools and Educational Systems: International Perspectives, Routledge, Abingdon.

Heckmann, F., H. Lederere and S. Worbs (2001), Effectiveness of National Integration Strategies towards Second Generation Migrant Youth in a Comparative European Perspective, Final Report to the European Commission, EFMS, Bamberg.

Heckman J., J. Stixrud and S. Urzua (2006), "The effects of cognitive and non-cognitive abilities on labor market outcomes and social behaviour”, Journal of Labour Economics, Vol. 24/3, pp. 411-482.

Hertzberg, F. (2017), "Swedish career guidance counsellors' recognition of newly arrived migrant students' knowledge and educational strategies", Nordisk tidsskrift i veiledningspedagogikk, Vol. 2/1, pp. 45-61.

Herzog-Punzenberger, B., E. Le Pichon-Vorstman and H. Siarova (2017), Multilingual Education in the Light of Diversity: Lessons Learned, NESET II report, Publications Office of the European Union, Luxembourg, http://dx.doi.org/10.2766/71255.

Hopkins, D. (ed.) (2005), The Practice and Theory of School Improvement: International Handbook of Educational Change (Vol. 4), Springer, Berlin.

Horn, D. (2009), "Age of selection counts: cross-country analysis of educational institutions", Educational Research and Evaluation, Vol. 15/4, pp. 343-366.

Iwasaki, Y. and J. Bartlett (2006), "Stress-coping among aboriginal individuals with diabetes in an urban Canadian city: from woundedness to resilience”, Journal of Aboriginal Health, pp. 15-25.

Jeynes, W.H. (2007), “The relationship between parental involvement and urban secondary school pupil academic achievement: A meta-analysis", Urban Education, Vol. 42/1, pp. 82-110.

Keogh, V. (2002), Multicultural Sport: Sustaining a Level Playing Field, Centre for Multicultural Youth Issues, Melbourne.

Leos-Urbell, J. (2015), "What works after school? The relationship between after-school programme quality, programme attendance and academic outcomes", Youth and Society, Vol. 47/5, pp. 684-706.

Leseman, P. et al. (2017), "Effectiveness of Dutch targeted preschool education policy for disadvantaged children: Evidence from the pre-COOL study", in H.-P. Blossfeld et al. (eds.), Childcare, Early Education and Social Inequality: An International Perspective, Edwar Elgar, Cheltenham.

Macomber, J. and K. Anderson (1999), “Children's environment and behaviour: participation in extracurricular activities", Urban Institute Brief, www.urban.org/research/publication/childrens-environment-and-behavior-participationextracurricular-activities.

Makarova, E. and W. Herzog (2014), "Sport as a means of immigrant youth integration: an empirical study of sports, intercultural relations and immigrant youth integration in Switzerland”, Sportwissenschaft, Vol. 44/1, pp. 1-9.

Marks, G. (2006), "Accounting for immigrant non-immigrant differences in reading and mathematics in twenty countries", Ethnic and Racial Studies, Vol. 28/5, pp. 925-946.

Martin, J. (1978), The Migrant Presence, George Allen and Unwin, Sydney.

Mehmedbegovic, D. and T. Bak (2017), “Towards an interdisciplinary lifetime approach to multilingualism”, European Journal of Language Policy, Vol. 9/2, pp. 149-167.

Mengering, F. (2005), "Bärenstark - Empirische Ergebnisse der Berliner Sprachstandserhebung an Kindern im Vorschulalter", Zeitschrift für Erziehungswissenschaft, Vol. 8/2, pp. 241-262.

MIPEX (2015), "Policy indicators scores 2007-2014”, Migration Integration Policy Index, www.mipex.eu/download-pdf.

Moody, J. (2001), "Race, school integration, and friendship segregation in America”, American Journal of Sociology, Vol. 107/3, pp. 679-716, http://dx.doi.org/10.1086/338954.

Morgan, L. (2008), The Role of Sport in Assisting Refugee Settlement, Refugee Council of Australia, www.uts.edu.au/sites/ default/files/com-student-work-morgan.pdf. 
Mühlenweg, A. (2010), "Young and innocent: International evidence on age effects within grades on victimization in elementary school”, Economics Letters, Vol. 109/3, pp. 157-160, https://doi.org/10.1016/j.econlet.2010.08.032.

Murray, C. and K. Malmgren (2005), "Implementing a teacher-student relationship program in a high-poverty urban school: Effects on social, emotional, and academic adjustment and lessons learned”, Journal of School Psychology, Vol. 43/2, pp. 137-152, https://doi.org/10.1016/j.jsp.2005.01.003.

National Centre for Multicultural Education (2010), The Road Ahead: The Final Report, Equal Education in Practice, National Centre for Multicultural Education, Oslo, http://nafo.hioa.no/wp-content/uploads/2013/10/NAFO_Sluttrapport_ENG_korr4.pdf.

NESSE (2008), "Education and migration: strategies for integrating migrant children in European schools and societies A synthesis of research findings for policy-makers", an independent report submitted to the European Commission by the NESSE network of experts, DG EAC.

Nusche, D. (2009), "What Works in Migrant Education? A Review of Evidence and Policy Options”, OECD Education Working Papers, No. 22, OECD Publishing, Paris, http://dx.doi.org/10.1787/227131784531.

Oberoi, A. (2016), "Mentoring for first-generation immigrant and refugee youth", National Mentoring Resource Center Population Review, National Mentoring Resource Center, Washington, DC.

OCDSB (2015), Framework for Student Well-being, OCDSB Communications and Information Services and Inclusive, Safe and Caring Programs, Ottawa.

OECD (2017a), Education at a Glance 2017: OECD Indicators, OECD Publishing, Paris, http://dx.doi.org/10.1787/eag-2017-en.

OECD (2017b), Starting Strong V: Transitions from Early Childhood Education and Care to Primary Education, OECD Publishing, Paris, http://dx.doi.org/10.1787/9789264276253-en.

OECD (2017c), PISA 2015 Results: Students' Well-being, OECD Publishing, Paris, http://dx.doi.org/10.1787/9789264273856-en.

OECD (2017d), The Funding of School Education: Connecting Resources and Learning, OECD Publishing, Paris, http://dx.doi. org/10.1787/9789264276147-en.

OECD (2016a), Skills Matter: Further Results from the Survey of Adult Skills, OECD Publishing, Paris, http://dx.doi.org/ 10.1787/9789264258051-en.

OECD (2016b), Equations and Inequalities: Making Mathematics Accessible to All, OECD Publishing, Paris, http://dx.doi. org/10.1787/9789264258495-en.

OECD (2015a), Immigrant Students at School: Easing the Journey towards Integration, OECD Publishing, Paris, http://dx.doi. org/10.1787/9789264249509-en.

OECD (2015b), Education Policy Outlook 2015: Making Reforms Happen, OECD Publishing, Paris, http://dx.doi. org/10.1787/9789264225442-en.

OECD (2015c), Early Childhood Education and Care Policy Review: Norway, OECD Publishing, Paris, www.oecd.org/norway/ Early-Childhood-Education-and-Care-Policy-Review-Norway.pdf.

OECD (2015d), Starting Strong IV: Monitoring Quality in Early Childhood Education and Care, OECD Publishing, Paris, http:// dx.doi.org/10.1787/9789264233515-en.

OECD (2014), International Migration Outlook 2014, OECD Publishing, Paris, http://dx.doi.org/10.1787/migr_outlook-2014-en.

OECD (2013), PISA 2012 Results: What Makes Schools Successful (Volume IV)? Resources, Policies and Practices, PISA, OECD Publishing, Paris, http://dx.doi.org/10.1787/9789264201156-en.

OECD (2012a), Equity and Quality in Education: Supporting Disadvantaged Students and Schools, OECD Publishing, Paris, http://dx.doi.org/10.1787/9789264130852-en.

OECD (2012b), Untapped Skills: Realising the Potential of Immigrant Students, OECD Publishing, Paris, http://dx.doi.org/ 10.1787/9789264172470-en.

OECD (2010), Closing the Gap for Immigrant Students: Policies, Practice and Performance, OECD Reviews of Migrant Education, OECD Publishing, Paris, http://dx.doi.org/10.1787/9789264075788-en.

OECD and European Commission (2004), Career Guidance: A Handbook for Policy-Makers, OECD Publishing, Paris, http:// dx.doi.org/10.1787/9789264015210-en.

Olliff, L. (2007), Playing for the Future: the Role of Sport and Recreation in Supporting Refugee Young People to "Settle Well" in Australia, Centre for Multicultural Youth Issues, Melbourne.

Ontario Ministry of Education (2014), "Achieving Excellence: A Renewed Vision for Education in Ontario", Ontario Ministry of 
Education Publications.

Penn, R. and P. Lampert (2009), Children of International Migrants in Europe. Comparative Perspectives, Palgrave MacMillan, New York.

Ponzo, M. (2013), "Does bullying reduce educational achievement? An evaluation using matching estimators", Journal of Policy Modeling, Vol. 35/6, pp. 1057-1078.

Portes, A. and D. MacLeod (1996), "Educational progress of children of immigrants: the roles of class, ethnicity and school context”, Sociology of Education, Vol. 69/4, pp. 255-275.

Resh, N. and R. Erhard (2002), "'Pushing up' or 'cooling out'? Israeli counsellors' guidance on track placement”, Interchange, Vol. 33/4, pp. 325-349.

Rivkin, S.G., E.A. Hanushek and J.F. Kain (2005), "Teachers, schools, and academic achievement”, Econometrica, Vol. 73/2, pp. 417-458, http://dx.doi.org/10.1111/j.1468-0262.2005.00584.X.

Rotich, J. (2011), "Mentoring as a springboard to acculturation of immigrant students into American schools", Journal of Case Studies in Education, pp. 1-8.

Sawyer, L. (2006), "Att koppla drömmar till verkligheten. SYO-konsulenters syn på etnicitet i övergången från grundskolan till gymnasiet" [Connecting dreams to reality. The views of career counsellors on the significance of ethnicity in the transition from primary to secondary education], in L. Sawyer and M. Kamali (eds.), Utbildningens dilemma. Demokratiska ideal och andrafierande praxis, pp. 187-249, [The dilemma of education. Democratic ideals and othering practices], SOU 2006:40. Fritzes, Stockholm.

Scheerens, J. and R. Bosker (1997), The Foundations of Educational Effectiveness, Emerald Group Publishing, Bingley.

Schnell, P. (2014), Educational Mobility of Second Generation Turks. Cross-national Perspectives, Amsterdam University Press, Amsterdam.

Schofield, J.W. (2006), "Migration Background, Minority-Group Membership and Academic Achievement Research Evidence from Social, Educational, and Developmental Psychology", AKI Research Review 5, Programme on Intercultural Conflicts and Societal Integration (AKI), Social Science Research Center Berlin.

Shavit, Y. (1990), "Segregation, tracking and the educational attainment of minorities: Arabs and Oriental Jews in Israel", American Sociological Review, Vol. 55, pp. 115-126.

Siarova, H. and M.A. Essomba (2014), "Language support for youth with a migrant background: policies that effectively promote inclusion", SIRIUS Network Policy Brief Series, Issue No. 4. SIRIUS.

Sirin, S.R. and L. Rogers-Sirin (2015), The Educational and Mental Health Needs of Syrian Refugee Children, Migration Policy Institute, Washington, DC

Suárez-Orozco, C. and M. Suárez-Orozco (2001), Children of Immigration, Harvard University Press, Cambridge, MA.

Toyoda, E. (2012), "Acculturation through a leisure activity: the Argentine tango in Japan", Asian Journal of Latin American Studies, Vol. 25/2, pp. 1-26.

UNESCO (2017), School Violence and Bullying: Global Status Report, UNESCO, Paris.

United Nations (2016), Protecting Children from Bullying: Report of the Secretary General, United Nations General Assembly Report A/71/213

UNHCR (2008), Sport for Refugees - Let's Play!, United Nations High Commissioner for Refugees.

Vandell, D.L. (2013), "Afterschool programme quality and student outcomes: reflections on positive key findings on learning and development from recent research", www.expandinglearning.org/sites/default/files/expandingminds section 3 0.pdf\#page $=12$.

Van der Werfhorst, H.G. and J. Mijs (2010) "Achievement inequality and the institutional structure of educational systems: a comparative perspective”, Annual Review of Sociology, Vol. 36, pp. 407-428.

Yogev, A. and H. Roditi (1987), "School counsellors as gatekeepers: guidance in poor versus affluent neighbourhoods", Adolescence, Vol. 22/87, pp. 625-639. 


\section{ANNEX A \\ LIST OF TABLES AVAILABLE ON LINE \\ The following tables are available in electronic form only (see StatLinks below)}

Chapter 1 Overview - The resilience of students with an immigrant background: Factors that shape well-being

\begin{tabular}{|c|c|}
\hline \multicolumn{2}{|c|}{ StatLink न्माज्ञा http://dx.doi.org/10.1787/888933683041 } \\
\hline \begin{tabular}{|l|l} 
WEB & Table 1.1
\end{tabular} & Well-being risks for students, by immigrant background \\
\hline WEB Table 1.2 & Relative risk for immigrant students of not being resilient, by resilience outcome \\
\hline WEB Table 1.3 & The overlap of immigrant students' resilience \\
\hline
\end{tabular}

Chapter 3 Adversity and adjustment: The resilience of students with an immigrant background

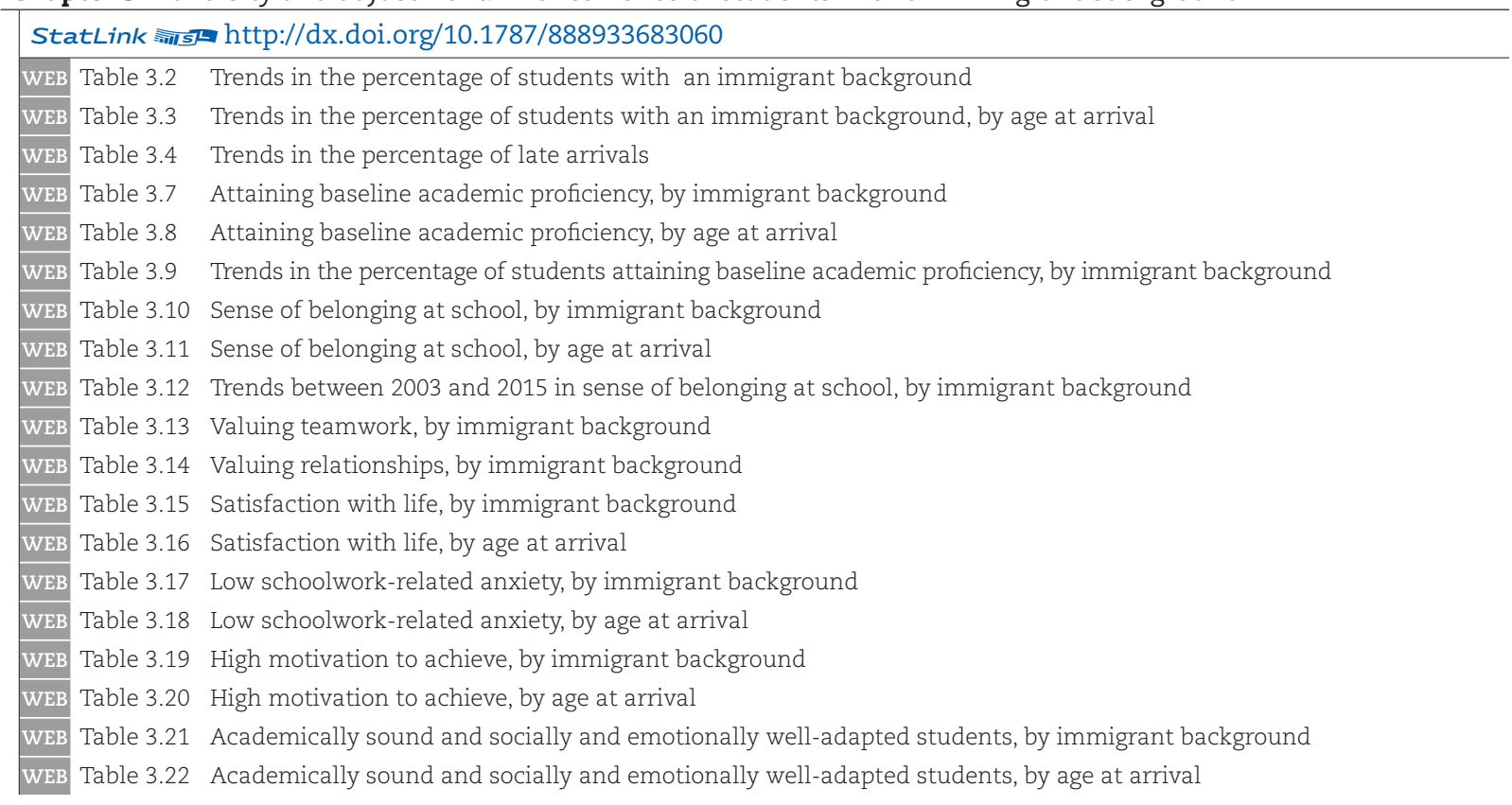

Chapter 4 Individual characteristics and the resilience of students with an immigrant background

\begin{tabular}{|c|c|c|}
\hline \multicolumn{3}{|c|}{ StatLink त्माज्ञा http://dx.doi.org/10.1787/888933683079 } \\
\hline WEB & Table 4.1 & Students who work for pay, by immigrant background \\
\hline WEB & Table 4.2 & Students who do unpaid work in the household, by immigrant background \\
\hline WEB & Table 4.3 & Change in the likelihood of attaining baseline academic proficiency related to working for pay/unpaid \\
\hline WEB & Table 4.4 & Participation in pre-primary education, by immigrant background \\
\hline WEB & Table 4.5 & Change in the likelihood of attaining baseline academic proficiency related to attendance at pre-primary education \\
\hline WEB & Table 4.6 & Percentage of female students, by immigrant background \\
\hline WEB & Table 4.7 & $\begin{array}{l}\text { The interaction between gender and immigrant background in students' likelihood of attaining baseline levels } \\
\text { of academic proficiency }\end{array}$ \\
\hline WEB & $\mathrm{Tab}$ & $\begin{array}{l}\text { The interaction between gender and immigrant background in students' likelihood of reporting a sense of belonging } \\
\text { at school }\end{array}$ \\
\hline WEB & Table 4.9 & The interaction between gender and immigrant background in students' likelihood of reporting being satisfied with life \\
\hline WEB & Table 4.10 & $\begin{array}{l}\text { The interaction between gender and immigrant background in students' likelihood of reporting } \\
\text { low schoolwork-related anxiety }\end{array}$ \\
\hline & Table 4.11 & $\begin{array}{l}\text { The interaction between gender and immigrant background in students' likelihood of reporting high achievement } \\
\text { motivation }\end{array}$ \\
\hline
\end{tabular}


Chapter 5 Language barriers and the resilience of students with an immigrant background

\begin{tabular}{|c|c|}
\hline WEB Table 5.3 & Students with an immigrant background and non-native speakers \\
\hline WEB Table 5.4 & Non-native speakers, by immigrant background \\
\hline WEB Table 5.5 & Percentage of non-native speakers in each immigrant group \\
\hline WEB Table 5.6 & Non-native speakers, by age at arrival \\
\hline WEB Table 5.7 & PISA reading scores, by immigrant background and language spoken at home \\
\hline WEB Table 5.8 & PISA mathematics scores, by immigrant background and language spoken at home \\
\hline WEB Table 5.9 & Attaining baseline academic proficiency, by immigrant background and language spoken at home \\
\hline WEB Table 5.10 & Attaining baseline academic proficiency, by immigrant group and language spoken at home \\
\hline WEB Table 5.11 & Baseline academic proficiency and sense of belonging, by age at arrival \\
\hline WEB Table 5.12 & Sense of belonging at school, by immigrant background and language spoken at home \\
\hline WEB Table 5.13 & Sense of belonging at school, by immigrant group and language spoken at home \\
\hline WEB Table 5.14 & Life satisfaction and low schoolwork-related anxiety, by language spoken at home \\
\hline
\end{tabular}

Chapter 6 Resilience and the socio-economic status of students with an immigrant background

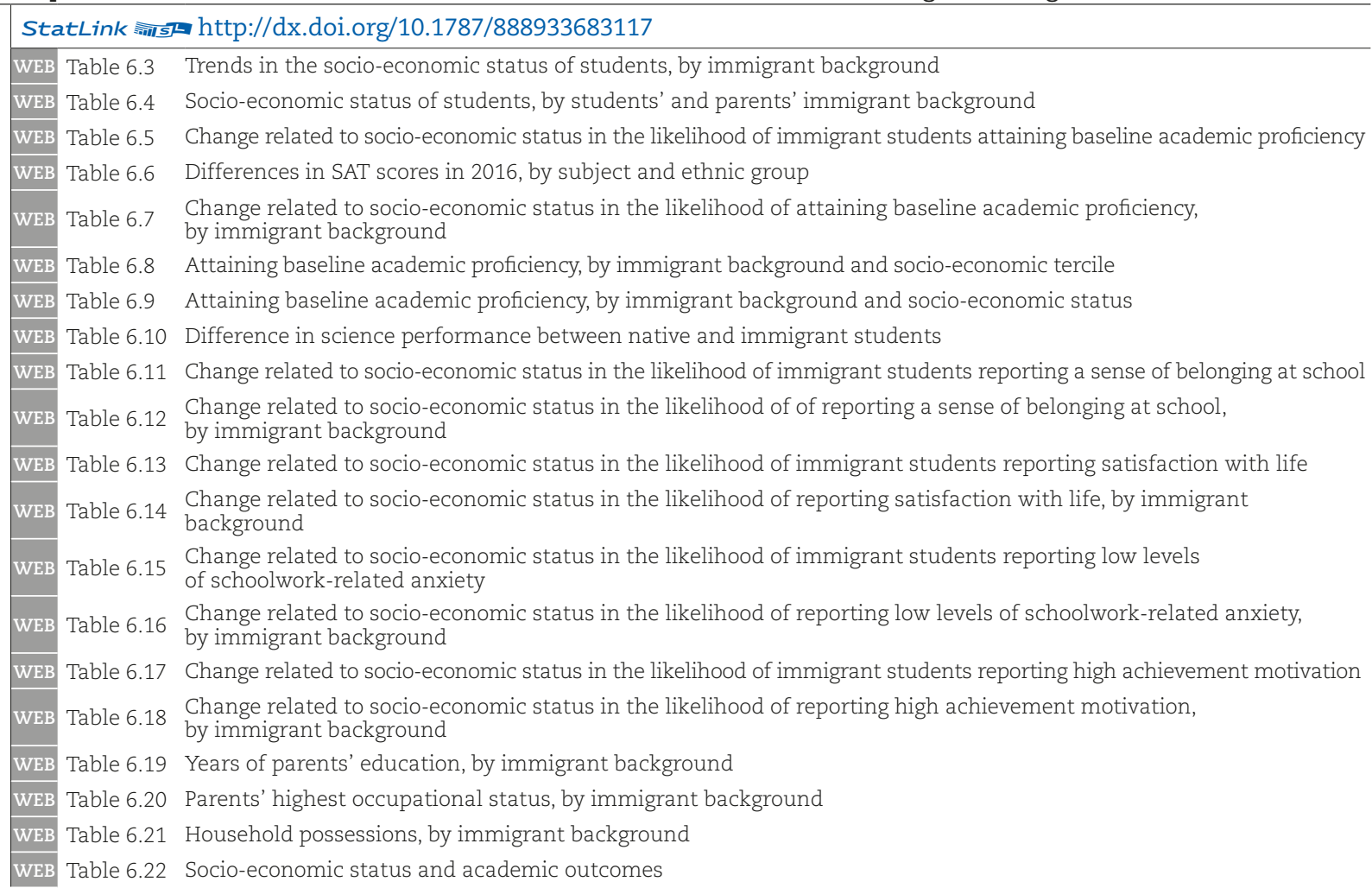

Chapter 7 How schools and education policy support or undermine student resilience

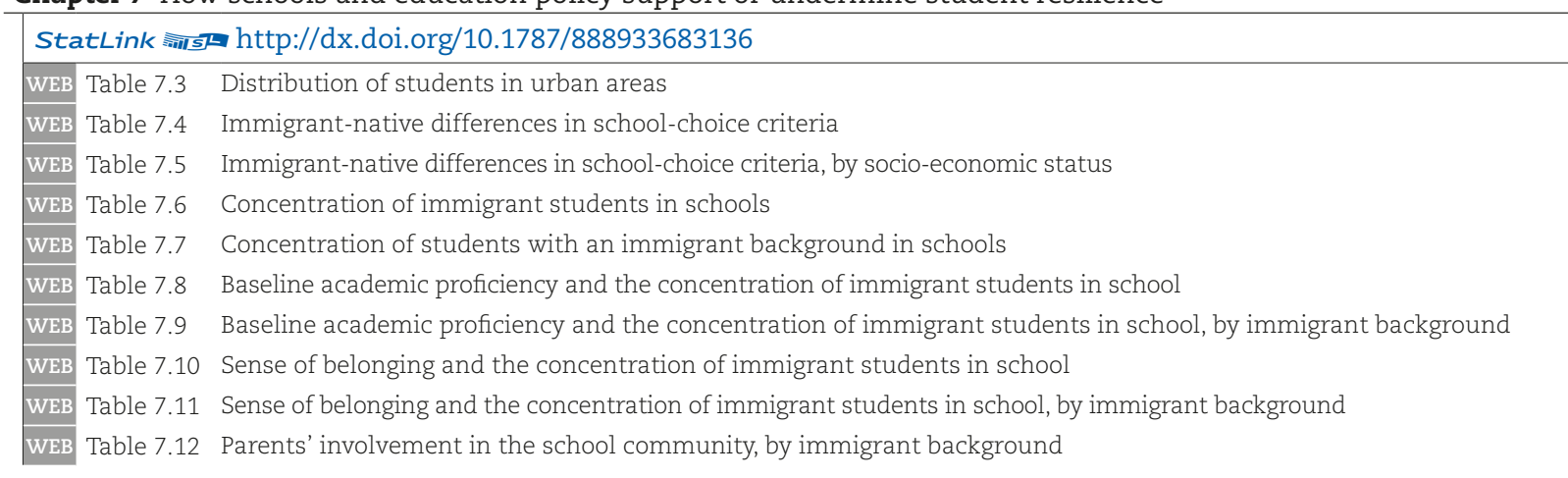


Chapter 8 What students with an immigrant background expect in their future
School disciplinary climate, by immigrant background

Student truancy, by immigrant background

Victims of frequent bullying, by immigrant background

Frequent perceived unfair treatment by teachers, by immigrant background

Frequent feedback from science teacher, by immigrant background

Effect of school climate factors on academic and well-being outcomes

Shortage of educational material at school, by immigrant background

Shortage of educational staff at school, by immigrant background

Student/teacher ratio, by immigrant background

Computer/student ratio, by immigrant background

Number of extracurricular activities, by immigrant background

Effect of school resource factors on academic and well-being outcomes

Academic proficiency and types of assessment at school

Grade repetition, by immigrant background

Academic and well-being outcomes, and grade repetition

Enrolment in a vocational or pre-vocational programmes, by immigrant background

Enrolment in vocational programmes, and academic and well-being outcomes

Effect of vertical and horizontal stratification on academic and well-being outcomes

2 Index of sports distance for selected destination and origin countries
WEB Table 8.3

WEB Table 8.4

WEB Table 8.5

WEB Table 8.6

WEB Table 8.7

WEB Table 8.8

WEB Table 8.9

WEB Table 8.10

WEB Table 8.11

WEB Table 8.12

WEB Table 8.13

WEB Table 8.a
Expectation to complete tertiary education, by immigrant background

Difference in the expectation to complete tertiary education

Students with ambitious but realistic educational expectations, by immigrant background

Expectation to complete only lower secondary education, by immigrant background

Difference in the expectation to complete only secondary education

Parents' expectation for their child to compelte tertiary education, by immigrant background

Difference in parents' expectations for their child's education

Trends between 2006 and 2015 in holding ambitious career expectations, by immigrant background

Difference in the expectation to work as a manager, professional or associate professional

Students with ambitious but realistic career expectations, by immigrant background

Prestige of expected occupation, by immigrant background

Difference in the prestige of expected occupation

Educational attainment of respondents and their parents, by age group and immigrant background 



\section{ORGANISATION FOR ECONOMIC CO-OPERATION AND DEVELOPMENT}

The OECD is a unique forum where governments work together to address the economic, social and environmental challenges of globalisation. The OECD is also at the forefront of efforts to understand and to help governments respond to new developments and concerns, such as corporate governance, the information economy and the challenges of an ageing population. The Organisation provides a setting where governments can compare policy experiences, seek answers to common problems, identify good practice and work to co-ordinate domestic and international policies.

The OECD member countries are: Australia, Austria, Belgium, Canada, Chile, the Czech Republic, Denmark, Estonia, Finland, France, Germany, Greece, Hungary, Iceland, Ireland, Israel, Italy, Japan, Korea, Latvia, Luxembourg, Mexico, the Netherlands, New Zealand, Norway, Poland, Portugal, the Slovak Republic, Slovenia, Spain, Sweden, Switzerland, Turkey, the United Kingdom and the United States. The European Union takes part in the work of the OECD.

OECD Publishing disseminates widely the results of the Organisation's statistics gathering and research on economic, social and environmental issues, as well as the conventions, guidelines and standards agreed by its members. 


\section{OECD Reviews of Migrant Education}

\section{The Resilience of Students}

\section{with an Immigrant Background}

\section{FACTORS THAT SHAPE WELL-BEING}

Migration flows are profoundly changing the composition of classrooms. Results from the OECD Programme for International Student Assessment (PISA) reveal that in 2015, almost one in four 15-year-old students in OECD countries reported that they were either foreign-born or had at least one foreign-born parent.

Between 2003 and 2015, the share of students who had either migrated or who had a parent who had migrated across international borders grew by six percentage points, on average across OECD countries.

The Resilience of Students with an Immigrant Background: Factors that Shape Well-being reveals some of the difficulties students with an immigrant background encounter and where they receive the support they need. The report provides an in-depth analysis of the risk and protective factors that can undermine or promote the resilience of immigrant students. It explores the role that education systems, schools and teachers can play in helping these students integrate into their communities, overcome adversity, and build their academic, social, emotional and motivational resilience.

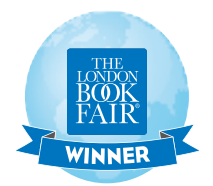

INTERNATIONAL EXCELLENCE Awards 2017

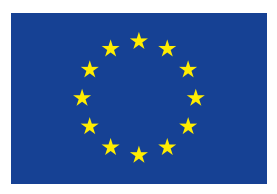

Co-funded by the European Union

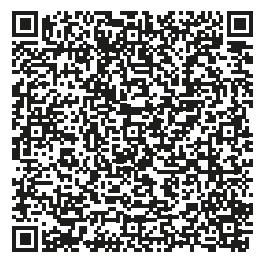

ISBN 978-92-64-20090-6 $912018011 \mathrm{P}$

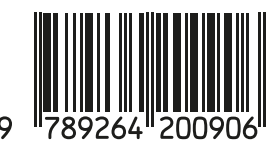

